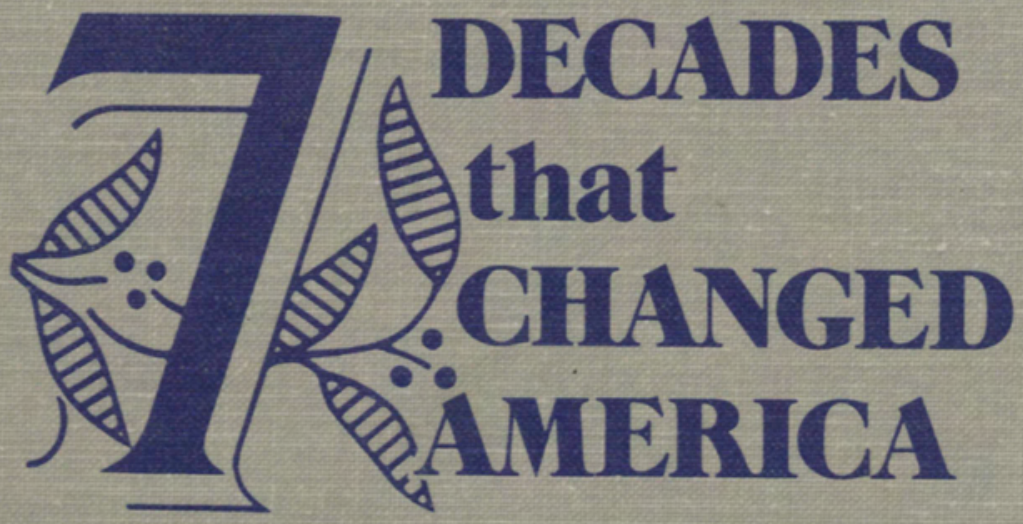

A History of the

American Society of Agricultural Engineers 1907-1977

by

Robert E. Stewart 


\title{
SEVEN DECADES THAT CHANGED AMERICA A History of the American Society of Agricultural Engineers 1907-1977
}

\author{
by \\ Robert E. Stewart, P.E. \\ Past-President and Fellow, ASAE \\ Distinguished Professor \\ Agricultural Engineering \\ Texas A\&M University
}

Copyright $\odot$ 1979, By the American Society of Agricultural Engineers

Library of Congress Catalog Card Number 79-56 485 International Standard Book Number: 0-916-150-17-18

The American Society of Agricultural Engineers

2950 Niles Road, St. Joseph, Michigan 49085 USA

Online distribution with permission of

Donna Hull, ASAE

\section{Distributed by \\ The Internet-First University Press}

This manuscript is among the initial offerings being published as part of a new approach to scholarly publishing. The manuscript is freely available for personal usage from the Internet-First University Press repository within DSpace at Cornell University

\section{http:/ / dspace.library.cornell.edu/handle/1813/62}

The online version of this work is available on an open access basis, without fees or restrictions on personal use. A professionally printed version may be available from digital@cornell.edu Cornell University, Ithaca, NY 14853

All mass reproduction, even for educational or not-for-profit use, requires permission and license. For more information, please contact dcaps@cornell.edu or ASAE.

Cornell University, Ithaca, NY, March, 2006 


\title{
SEVEN DECADES THAT CHANGED AMERICA
}

\author{
A History of the \\ American Society of Agricultural Engineers \\ $1907-1977$
}

by

Robert E. Stewart, P.E.

Past-President and Fellow, ASAE

Distinguished Professor

Agricultural Engineering

Texas A\&M University 
Copyright (c) 1979, By the American Society of Agricultural Engineers Library of Congress Catalog Card Number 79-56 485

International Standard Book Number: 0-916-150-17-18

The American Society of Agricultural Engineers 2950 Niles Road, St. Joseph, Michigan 49085 USA 


\section{Table of Contents}

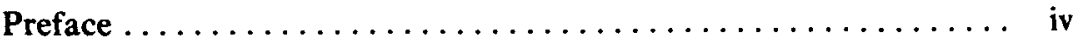

Introduction $\ldots \ldots \ldots \ldots \ldots \ldots \ldots \ldots \ldots \ldots \ldots \ldots \ldots \ldots \ldots \ldots \ldots$

1st Decade, 1908-1917

"Let us devote ourselves" ..................... 5

2nd Decade, 1918-1927

"A good foundation has been laid" $\ldots \ldots \ldots \ldots \ldots \ldots \ldots \ldots, 30$

3rd Decade, 1928-1937

"The engineer must accept responsibility" $\ldots \ldots \ldots \ldots \ldots \ldots, \quad 82$

4th Decade, 1938-1947

"We builded well during peacetime" ............... 129

5th Decade, 1948-1957

"Anniversaries call for inventories" ............... 175

6th Decade, 1958-1967

"Agricultural engineering is unique" $\ldots \ldots \ldots \ldots \ldots \ldots \ldots 241$

7th Decade, 1968-1977

"For the benefit of man" .................... 330

\section{Appendices}

Charter Members .......................... 410

ASAE Presidents ......................... 410

Honarary Members ........................ 411

Recipients of ASAE Awards and Medals .............. 412

Sources of Historical Information $\ldots \ldots \ldots \ldots \ldots \ldots \ldots \ldots .419$

Acknowledgements ........................ 429 



\section{Preface}

From the time of J. B. Davidson, our first ASAE president, the desire for a history of ASAE can be found in the records. No one explained why ASAE should have a book of history. That seemed self-evident: to honor the past; to inspire the present; to guide the future; and to give pleasure and prestige to the Society. History committees rose and fell over many years. But although committees may design camels they write few volumes of history. When I was ASAE president in 1970-71 the question arose again: "When will ASAE have a history?" Being a lover of history, and also foolhardy, I persuaded the Executive Committee to allow me to write one. This book is a result of that moment of madness. The most undiscriminating reader will perceive that it was written by an amateur. My years of teaching and research did not prepare me to write history in the adroit and sparkling fashion of a Bruce Catton. However, one will at least find very few errors of fact in my drab account of our "Roots."

The book examines many aspects of ASAE's history from its founding in 1907 to its 70th year in 1977. The record outlined and discussed here is not, however, complete. For example, it lacks detail pertaining to the geographic units of ASAE, the rise of agricultural engineering influence in industry and government, and the development of departments of agricultural engineering in the universities. Also, detailed histories of ASAE's technical divisions are regretfully omitted. Instead, the book is centered mainly upon how the Society grew and organized its services; how it became the world focus for agricultural engineering technology; how it achieved recognition as a group of professional engineers; and how it interacted with American agriculture and society. In the process, of course, it was necessary to allude many times to the ASAE geographic units and to industry and government, the universities, and to the ASAE Technical Divisions.

Writing the book gave me enormous appreciation of the quality of agricultural engineers and their achievements. Hard workers all, with inventiveness second to none, they created ASAE and made it their instrument through which the power revolution was wrought in this country's agriculture. By their work the land was totally changed, the social patterns were changed, and the foundations of America's greatness immeasurably strengthened.

In this time of reassessment may today's members enjoy reading about their technical and professional heritage.

Robert E. Stewart

College Station, Texas

June, 1979 



\section{INTRODUCTION}

Widespread use of agricultural machinery was common in the United States by the latter half of the 19th century. Although the motive power was largely horses and mules, in 1890 about 3000 steam tractors and 2661 steam threshers were built. By 1900 more than 30 firms were manufacturing some 5000 large steam-traction engines per year. In fact, the word "tractor" originated in the year 1890 .

By 1906 a rival to steam had appeared: there were about 600 gasoline tractors in the United States. The first tractor school was held that year at the University of Minnesota by William Boss and Philip Rose, both destined to be ASAE presidents. At that time horses, mules and oxen provided $21,000,000$ horsepower to United States agriculture-75 percent of the total power input. The remainder came from wind, steam, and stationary gasoline engines.

A power revolution was quietly being born. The age of the horse, the mule, and the ox was beginning to wane. New industries making new kinds of prime movers were springing up and farmers fed these movers only when they worked. Engineers and blacksmiths were replacing the animal breeders. Agriculture and engineering were on a collision course.

Since the 1850s engineers and engineering had done much for agriculture. Roads, railroads, bridges, and a variety of machines had helped farming to enter the stream of industrialization. The era was also the age of founding of engineering societies:

American Society of Civil Engineers .................. 1852

American Institute of Mining Engineers . . . . . . . . . . . 1871

American Society of Mechanical Engineers .............1880

American Institute of Electrical Engineers . . . . . . . . . . . 1884

ASCE lapsed and was revived in 1867. Thus between 1867 and 1884 the major branches of engineering founded their technical societies. But 
still new societies emerged with new technologies:

Society of Naval Architects and Marine Engineers............1893

American Society of Heating and Ventilating Engineers . . . . . . . 1894

American Railroad Engineers' Association . . . . . . . . . . . . 1897

Society of Automobile Engineers . . . . . . . . . . . . . . . . 1904

Illuminating Engineering Society . ................. 1906

American Institute of Chemical Engineers . . . . . . . . . . . 1908

"Engineering of agriculture" even in 1906 or 1907 involved several kinds of engineering. Rural roads and bridges constituted civil engineering. Machinery, both animal-powered and mechanized, was mechanical engineering. Irrigation, drainage, and surveying was civil engineering. Layout, design, and construction of farmstead buildings was not only civil engineering but architecture, with mechanical engineering for heating and ventilation. In 1905, 0.3 percent of farm power was electric, which required electrical engineering. Problems of water supply and sewage disposal involved either civil or sanitary engineering.

If you were an "agricultural" engineer in 1906, what engineering society would you join? Technically speaking, you would feel constrained to join ASCE, ASME, AIEE, ASHVE, and SAE! And, since many farm houses were illuminated by acetylene gas, perhaps IES also.

Was ASAE born because the "Founder" Societies failed to perceive the potential of "engineering in agriculture"? There is truth in this tradition, but probably the diversity of agriculture's engineering requirements could be met only by a new society that could put it all together. Many of ASAE's founders held engineering degrees, predominantly mechanical; many of them belonged to societies such as ASME and ASCE. They understood that such societies can help the engineers develop their professional specialty, aid their own professional life, better serve an industry, and benefit the public. Such a one was J. Brownlee Davidson.

Davidson was professor and head of the Agricultural Engineering Department at Iowa State College in 1906 . He went there from the University of Nebraska, where Dean of Engineering O. V. P. Stout had long preached that agriculture was a great field for engineers to work in.

Davidson keenly felt the need for an exchange of views and techniques among those interested in teaching "farm mechanics." During 1906 and 1907 he corresponded and held small meetings with counterparts at other colleges. These efforts culminated in a meeting at the University of Wisconsin (Madison) in December 1907. Eighteen charter members formed an association they called the American Society of Agricultural Engineers 


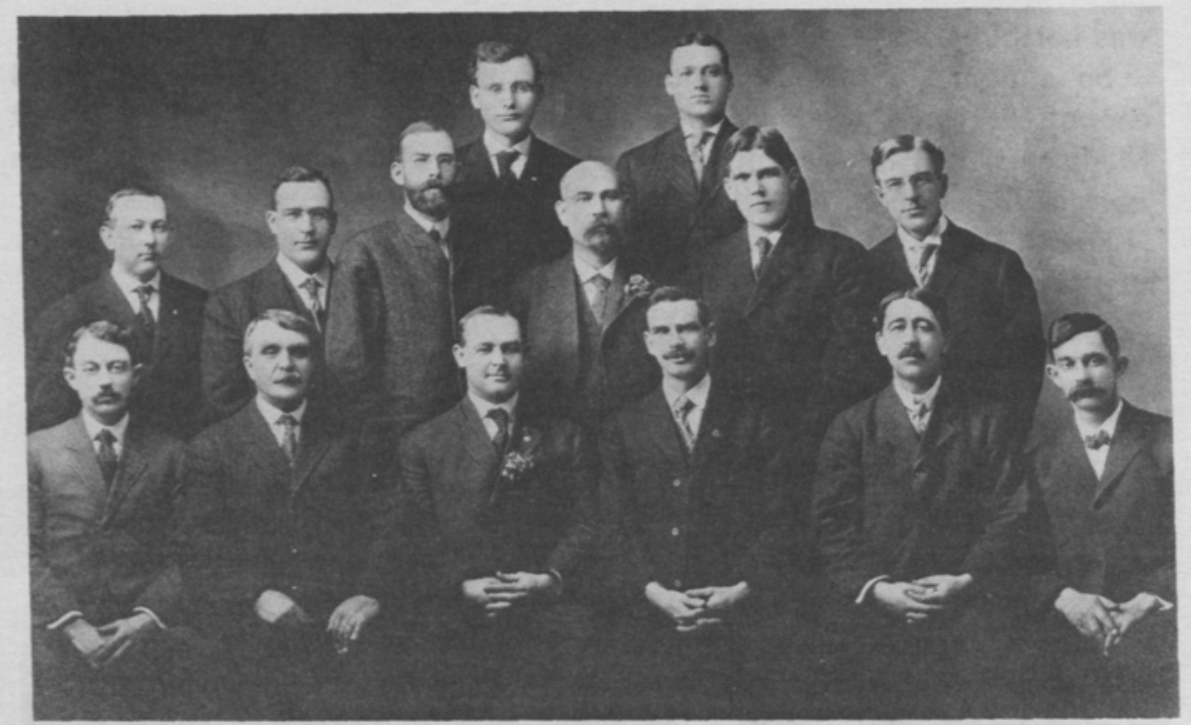

This picture was taken at the organization meeting of the American Society of Agricultural Engineers, at Madison, Wisconsin, December 27 and 28, 1907. (Left to right, front row) J. W. Criswell, J. B. Parker, F. R. Crane, J. B. Davidson, P. S. Rose, H. M. Bainer; (second row) W. M. Nye, C. A. Ocock, H. W. Riley, John Evans, E. A. White, M. L. King; (third row) Everett W. Hamilton, Walter R. Block. Present at the meeting but not in the picture were L. W. Chase, B. B. Clarke, R. M. Dolve, J. M. Drew, A. O. Fox, Elmer W. Hamilton, Mr. Mallet, E. E. Parkinson, H. L. Russell, R. P. Teele, J. G. Wynn

(Davidson later stated he copied the name from ASME) and elected Davidson president (he was 27 years old). The name was questionable because several charter members were Canadians. The constitution read: "The object of this Society shall be to promote the art and science of engineering as applied to agriculture."

Eventually a 102-page "Transactions" of the 1907 meeting was prepared. It was complete with records of the business meetings, papers presented and discussions on them. Committees were appointed and plans made. While this small group came prepared to do a great work, social life was not neglected. The original constitution provided specifically for "social intercourse."

A banquet for the hard-working charter members was given by Bascom B. Clarke, editor and publisher of the "American Thresherman" and "Gas Review" - whose pages were first to announce the birth of the infant society. (Writing many years later to Raymond Olney at ASAE Headquarters, Clarke recalled that the banquet was quite convivial - in fact some members were not as dignified as he had expected professors to be!) Thus 
was born another tradition, the annual banquet.

So a name, a purpose, standards of membership, a leadership and committee structure, an archives, and a champagne supper came to pass at Madison. All these, except perhaps the last, are necessary elements of an engineering society.

They agreed to meet at Champaign, Illinois the next year. Perhaps memories of Clarke's hospitality influenced the choice.

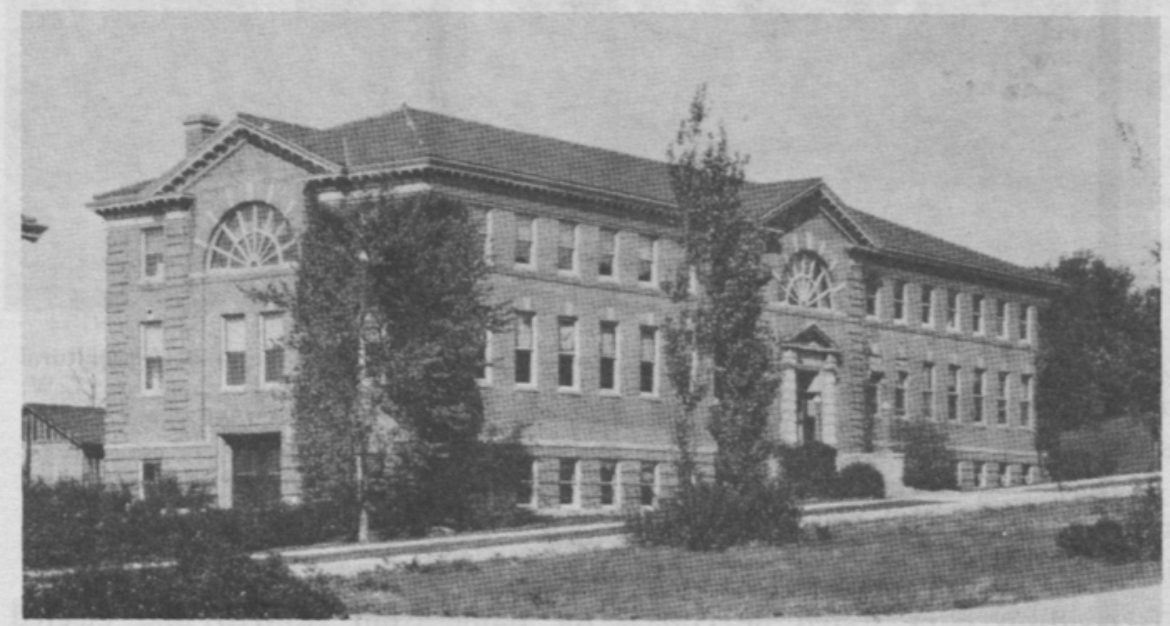

The agricultural engineering building at the University of Wisconsin, where the American Society of Agricultural Engineers was founded in 1907 


\section{"LET US DEVOTE OURSELVES:..}

\section{J. B. Davidson}

\section{A \\ General Progress}

Charter Member Earl White had probably invited them to Champaign. He would in time become president, but at the Madison meeting the year before he was an undergraduate at the University of Illinois. Apparently being a student among the professors at Madison didn't inhibit him. He was an outstanding center for the Illini football team and in time his record became legendary.

White called the second ASAE meeting to order on December 29, 1908. After a welcoming address by the dean of agriculture there, White introduced President Davidson, who appointed a committee on Resolutions. Finally, as the members settled in for the morning, Davidson commenced his address, the first of 70 annual presidential ruminations.

That address accurately outlines many of the problems, needs, and achievements which ASAE would fall heir to. It even hints at future Society structure.

Davidson said that last year he was concerned whether "...enough dignity could be given to the organization to induce men well up in their respective lines of work to become members." Now he was sure that "...practical engineers working along agricultural lines were quite ready to join...as soon as there were indications that the Society would be able to offer benefits in return."

He reviewed the rising importance of engineering to all phases of agriculture, pointing out that most of the agricultural colleges had established courses and even departments for agricultural engineering instruction. The "sudden" expansion of agricultural engineering had created a tremendous demand for technical literature. He thought a first task for ASAE should be to obtain a "complete" bibliography of agricultural engineering literature, with abstracts, in book form. "Nothing else will be such a power 
in giving dignity and character to the work of the agricultural engineer." Unfortunately the project was never completed.

The Society must play a major role in "...establishing the science, theory, and practice of agricultural engineering" in the colleges. The agricultural college curriculum must have its agricultural engineering components strengthened. This would lead to better trained agricultural workers and advance the prosperity of the nation. Davidson at this point referred to agricultural engineering as a "branch of agriculture." Two paragraphs later he said "Agricultural engineering is as truly an engineering branch and I defy anyone to construe any true definition of engineering to prove the contrary." He then asked for a committee to prepare resolutions stating why "Agricultural Engineering" was preferable to all other titles. Some colleges were calling it "Farm Mechanics," "Rural Engineering," and such titles, which to him were either not broad enough or misleading.

Davidson appeared convinced that ASCE, ASME and the others offered little that applied to agriculture; this gave ASAE every prospect of a good future. And those older societies had started very small also. He thought that by renting an office, hiring a secretary, and using "judicious methods of advertising," ASAE could have " 1000 members within a year." This set of procedures was not implemented for many years; a paid secretary did not appear until the 1920s and his hiring did not produce the predicted quantum jump in membership. Davidson seemed to assume that phenomenal growth of ASAE was inevitable when its existence became known. The sad failures of many frantically advertising business concerns of the time should have tempered his optimism. However, ten new members were elected at this meeting; two of them were honorary.

President Davidson called for the establishment of "groups or divisions" of ASAE so that there could be specialty sessions as well as general sessions at the meetings. He added: "This would be looking into the far-distant future."

The question of agricultural engineering being a "profession" received his attention. He claimed that drainage, irrigation, and highway engineers were agricultural engineers. His college (Iowa State) was starting up a degree course in agricultural engineering, so he was carefully studying possible professional employment for the graduates. The prospects looked good; requests were coming in for men qualified to operate "motor farms." He quoted Elwood Mead (a civil engineer), who said that skilled engineers might earn up to $\$ 20,000$ a year managing the irrigation pumps and showing farmers how to use water on large California ranches. Some were saying that agricultural engineers would earn only "mediocre sums," but Davidson disagreed strongly; he expressed faith in the "future of the profession." 


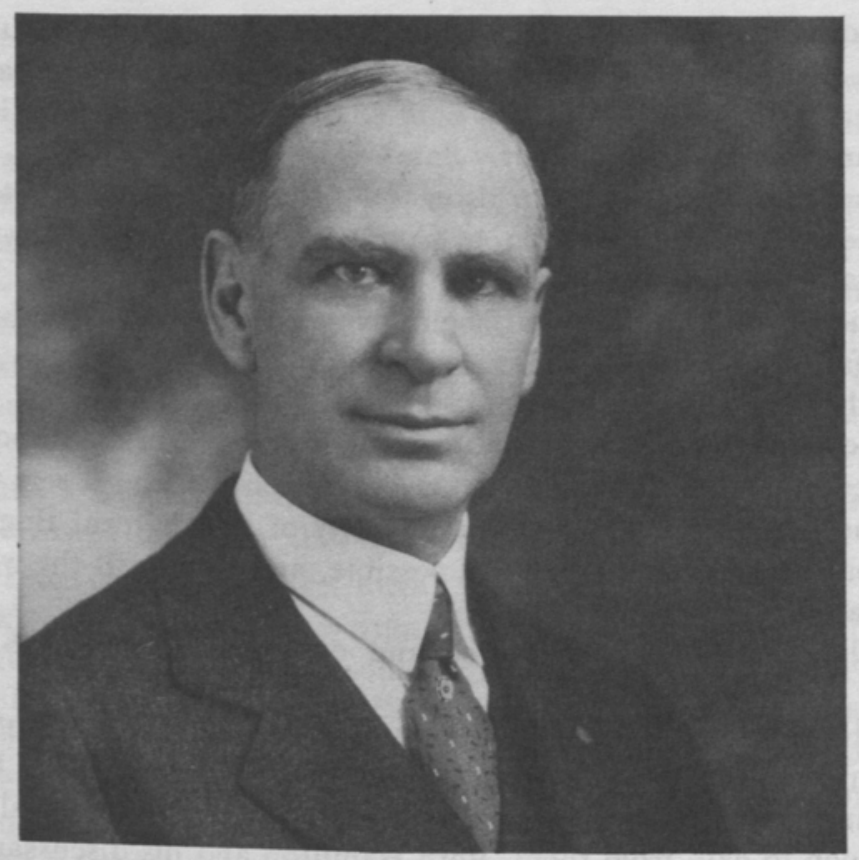

J. Brownlee Davidson 1st president, ASAE, 1908

In addition to an appeal for cooperation with the research committee, these committees were recommended:

- A committee on membership, on which each member should act

- A committee on publications

- A farm machinery committee, to report the development of new machines and their success

- A patent committee, to learn how the patent law might be used to promote further development

- A foreign committee, to investigate agricultural engineering in foreign countries

- A highway committee

- A drainage committee

- An irrigation committee

- A committee on farm building

- A college committee to monitor courses and to prepare recommendations on course content. 
The address printed in the 1908 "Transactions" includes a subheading titled "A Committee on Standards," but nothing further is said about standards. Possibly some text was omitted. Was Davidson thinking of industry standards even at that early date?

A committee, headed by Davidson, had already been appointed to investigate establishing a Bureau of Agricultural Engineering within the United States Department of Agriculture (USDA).

Thus the vision of agricultural engineering as a profession with interests reaching far beyond those of "farm mechanics" is clear. Davidson's address ended with this challenge:

"In conclusion, let me say that I am firmly convinced of the importance and need of our work; then let us devote ourselves with all zeal to promote the interests of the American Society of Agricultural Engineers, to aid our profession in every way possible, and to benefit the world to the greatest degree."

What did those papers presented and discussed at the 1908 meeting cover?

E. W. Hamilton of Winnipeg spoke on the educational value of traction motor contests. The first Canadian contest had just been held. Hamilton was convinced that farmer, manufacturer, and the agricultural colleges all had much to gain from them. Both Hamilton and his discussant, C. A. Ocock, brought out the emerging advantages of internal combustion.

E. W. Hamilton of Ames (that first Hamilton was Elmer W; this one was Everett $W$. These men were confused at the 1907 meeting and the Canadian Hamilton was omitted from the charter member list for many years) discoursed on farm buildings. He pleaded for good location of the home in particular, with elevation, and noted that "A water course at the foot of a slope is also ideal for the disposal of drainage and sewerage."

The members heard an industrial titan discuss relations between academic agricultural engineering departments and manufacturers of farm equipment. J. B. Bartholomew, president of the Avery Company, steam tractor builders, was elected a member of ASAE at this meeting. He complained that the colleges borrow machines from the companies, run tests on them and publish the results without notifying the companies. This was an "unfair" practice, in his opinion.

Young Earl A. White gave a paper on "The Plowing Match." He highly favored such events as conducive to good husbandry and machine development. He called for ASAE to set up uniform standards for these events, particularly since traction engines were now entering the contests.

The proper aims of instruction in farm machinery (in the colleges) formed the subject of a lengthy paper by J. F. Steward of the International Harvester 
Company. Apparently, the college instruction of the time was lacking in "hands-on" experience of depth and diversity. Moreover, the new graduate then, as now, tended to come across to some as a know-it-all, because Steward ended his paper thus:

"I think it proper to mention the apparent lack of effort in our colleges to check the development of conceit in the pupil. The selfassertiveness of some graduates is immense. The conceit is taken out of them when they find themselves working beside those who have grown into the special lines by hard knocks. If I were a teacher I should endeavor to make them understand that their college course but fitted them to use the faculties nature had given them, as tools enable a mechanic to accomplish ends, and that their natural qualifications can only be tested out after they are thrown upon the business world."

R. P. Teele of the USDA set forth "The Need of Agricultural Engineering Work by the National Government." Taking a broad view of agricultural engineering, he told that some work so defined was then being done by several separate agencies of USDA, and other work so defined needed to be done. This included expansion of significant investigations in the field. Teele outlined in a masterly fashion the difficulty to be encountered in spreading responsibility for machines, engines, structures, irrigation works, etc., among practically all the present agencies and divisions of the Department of Agriculture. He argued that the only solution was to create a separate Bureau of Agricultural Engineering (a committee to promote this was previously noted). He encouraged the members to work for the Bureau and "...to see that we do not shade the light that is in us so that the rays shall not illumine the halls of Congress."

H. M. Bainer, professor of farm mechanics at Colorado Agricultural College, gave a paper on pumping machinery for irrigation. According to him, the power used at the time for driving the pumps was gasoline engines, steam engines, electric motors, horses, windmills, and the hot air engine. The gasoline engine was more popular than any other type, due to low cost. The pumps were mostly of the centrifugal type.

The 1908 "Transactions" contains a "Report on the Committee on Instruction in Agriculture," read by one R. P. Nile, apparently not a member. The Committee was one of an un-named association; the report was actually that of the subcommittee on rural engineering. This subcommittee defined rural, or farm, engineering instruction as having two ends in view:

a. To provide a practical working knowledge of the ordinary mechanical operations of the farm.

b. To prepare the student for a professional career in some field of engineering applied to agriculture. 
The report outlined the syllabus for a 64-hour course which met the requirements of (a) above and noted that such instruction was a "proper part of a course in agriculture." The report also pointed out that (b) above constituted "special engineering training." This is interesting because it offers an early distinction between "service" and "professional" teaching in agricultural engineering. The distinction became blurred in many colleges as years passed, if, indeed, it ever existed. The thrust of accreditation as engineering curricula was probably a decisive factor in enforcing the distinction but this did not occur generally until the close of World War II.

The nominating committee brought in a slate which included demotion of Davidson to the office of "Third Councilman." Dues were set at $\$ 10.00$ per year. It was voted that papers must be in the hands of discussants 30 days prior to the annual meeting. After a vote of thanks to Mr. E. A. White, the members went home.

The ensuing years witnessed a struggle - a struggle at times just to survive, at times to create an identity sufficient to capture the loyalty of men whose vision of agricultural engineering differed from each other. And even as today, there was disagreement on issues which have broken up engineering societies. Membership standards was one of these.

In 1909 President John G. Wynn proposed the organization of local ASAE branches at the agricultural colleges. This innocent suggestion was followed with the notion that ".... a student membership should be established so that the student will be able to associate with the Society and in time become a member." Today, we would praise Wynn for a farsighted proposal. Not so with his successor, President Philip S. Rose. Rose thundered in December 1910:

"In the first place we all want to see this Society placed on a high professional plane. In order to obtain this we must adhere closely to the qualifications that were laid down in the beginning for membership

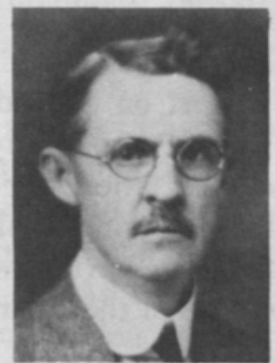

John G. Wynn 2nd president, ASAE, 1909

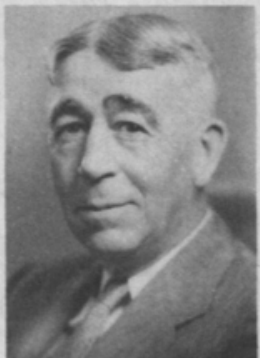

Philip S. Rose 3rd president, ASAE, 1910 


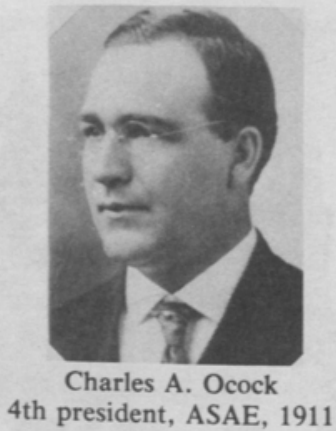

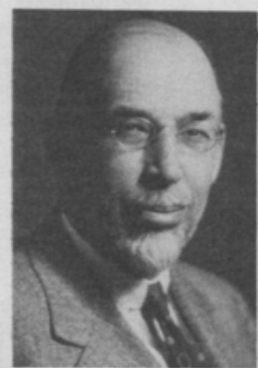

Howard W. Riley

Sth president, ASAE, 1912

in the Society. If anything, the qualifications should be raised rather than lowered. I am in favor of any policy that will interest students...in the Society...but I do not want to make admission to the Society so easy that it will in any way impair its professional standing. I do not want to see any man admitted to membership who is not a qualified engineer. I have given some thought to this subject and it seems to me that it would be a dangerous thing to admit students...even to partial membership in the Society."

We can be sure that Rose was aware of the strong student branch which J. B. Davidson had just organized at Iowa State College. The constitution contained no provision as yet, however, for student members and perhaps Rose hoped to forestall such a change. One view of student organizations held at the time was expressed by President Ocock in 1911. He was chairman of the Committee on Student Organizations. His view of them was as "feeders for ASAE" and as instruments to "bridge the gap between our Society and the farmer." The latter was to be accomplished by "writing articles for publication in the home papers."

By the time President H. W. Riley gave his benediction in 1912, the membership problem had evidently become acute. He announced proposed constitutional changes brought about because "Our first need is for more members." The 1907 constitution had called for three grades: Honorary member, member, and associate member. The revision would add two new grades, junior and affiliate, "...the former being members in the making, the latter including that great class of persons who are really interested in our work but because of their lack of training in any agricultural lines are not eligible for any other class of membership." The rank of associate was raised in stature and requirements revised. Only honorary members and members could both vote and hold office. Associate members could vote but not hold office. Juniors and affiliates could neither vote nor hold office. This constitution was adopted August 1, 1913. 


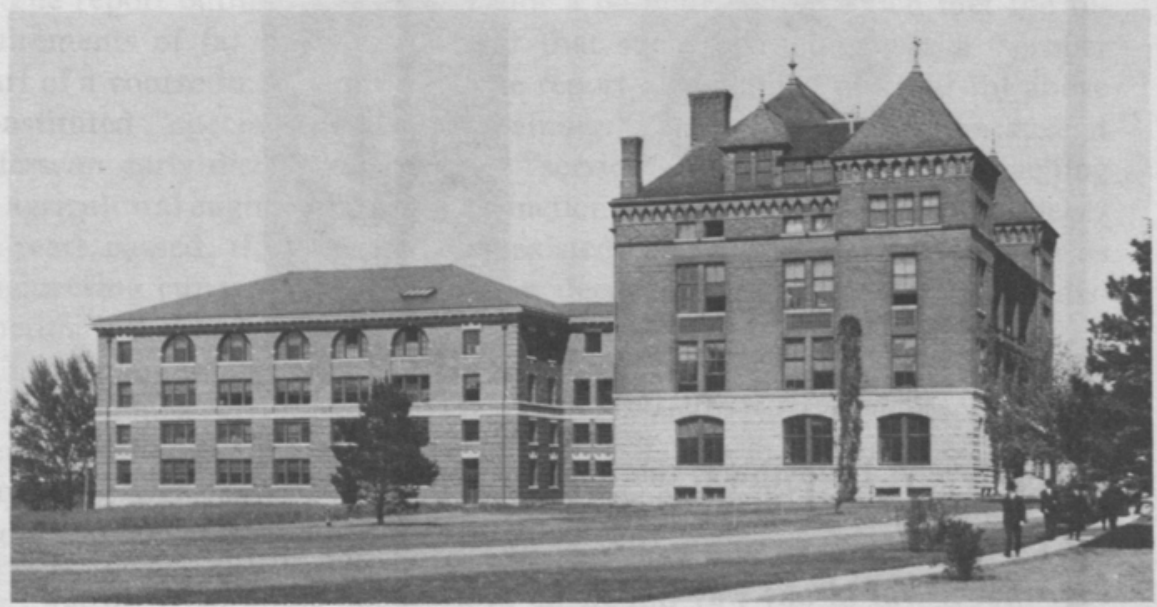

This building, started in 1903 and completed in 1904, as an annex to the Agricultural Hall at the Iowa State College, is believed to have been the first building in the United States for use in teaching agricultural engineering subjects and for research in engineering problems related to agriculture. It cost about $\$ 70,000$

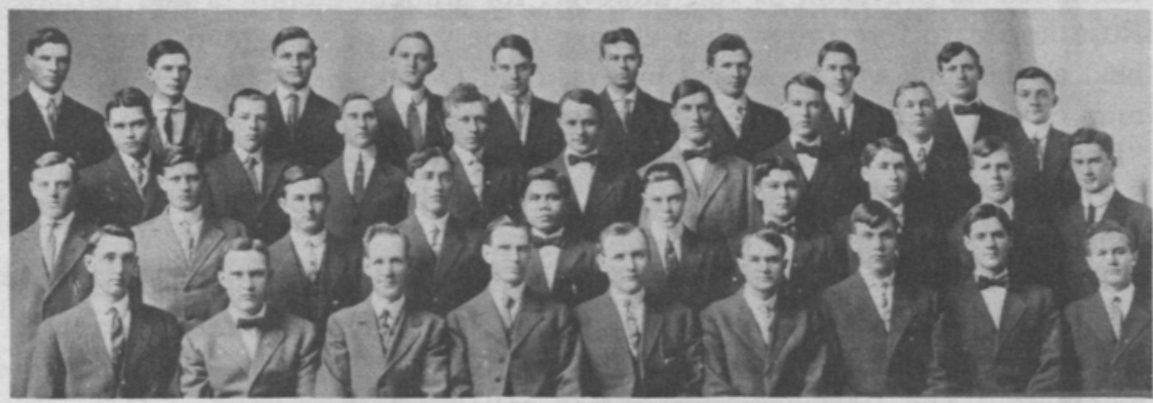

The first Student Branch, organized in the Fall of 1910 at the Iowa State College and authorized by the ASAE in December of that year. ( $f$ ) after a name indicates faculty member. (Left to right, front row) C. A. Norman, C. O. Alexander (f), D. W. Sylvester (f), J. B. Davidson (f), Everett W. Hamilton (f), E. Y. Cable (f), Martin, Feay, S. D. Snyder; (second row) G. W. Iverson, Wallace Ashby, M. A. R. Kelley, J. B. Kelley, Justion Valdez, G. I. McDermott, Filson, Daley, A. D. Longnecker, C. R. Hoff; (third row) G. L. Costigan, Cahow, B. R. Mullen, J. E. Waggoner, D. S. Wormley, Brooks, Clark, W. G. Kaiser, Hampe; (top row) H. B. Bliss, E. G. Welch, James Arentson, E. J. Van Meerten, S. Steigerwalt, Severson, F. G. Hodson, C. W. Stafford, Charles Cathcart 


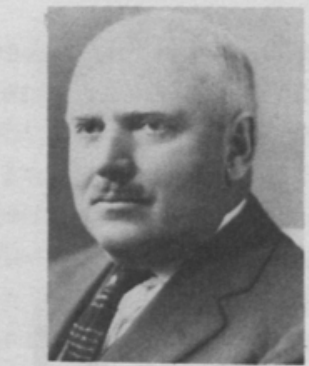

Leon W. Chase 6th president, ASAE, 1913

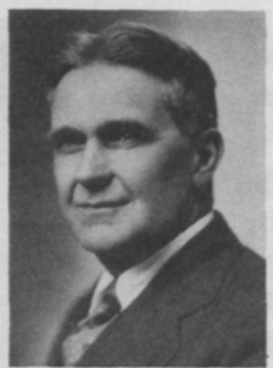

Wallace F. MacGregor

7th president, ASAE, 1914

Establishment of the affiliates opened a can of worms for many future generations of ASAE leadership. Counting them as members for some purposes and not for others made complicated the meaning of the word "Engineers" in the Society's name. The affiliates themselves were sometimes restive under their "second class" status and periodically set off rebellions against it, though largely unsuccessful. And some affiliates had proved their worth by ably filling specific positions within the Society.

One can imagine the rage of such men as Philip Rose at this lowering of standards of membership. By contrast, Howard Riley hoped that state organizations of farmers and others could become affiliates of ASAE en masse. In fact, he helped organize such a group in his home state of New York in 1911 (the New York State Rural Engineering Society) and wanted it to be a part of ASAE.

Since the new grades of membership were adopted, regardless of the Rose philosophy, we must conclude that it was more important to build the numbers of ASAE than it was to keep it "pure." Leadership must meet and solve current problems as best it can.

Something happened to improve the numbers, anyway, for President L. W. Chase announced in 1913 a 39 percent increase in membership during the past year. That convinced him the Society was "showing a permanent, steady growth.” Wallace MacGregor, president in 1914, noted an increasing attendance at the annual meetings; possibly because they started meeting in Chicago in 1912.

The increasing membership was gratifying; indeed, it may have staved off a stiff dues increase or even dissolution. What qualifications were possessed by those who joined about this time? Did the move to affiliate grade prove successful? Evidently it did because MacGregor said in his 1914 address that "we now include among our members a number of men actually engaged in farming." (It is assumed that these men were not professional engineers, and would therefore have been affiliates.) He seemed quite 


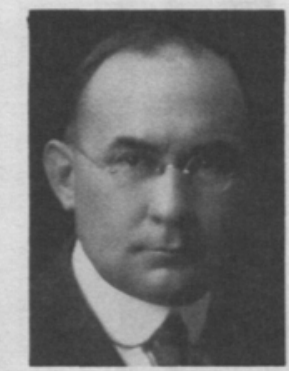

Harry H. Musselman 8th president, ASAE, 1915

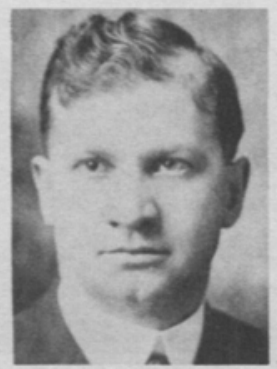

Frank M. White 9th president, ASAE, 1916

pleased with this development. He said, "We need the wisdom and experience of the farmers and our society will be greatly benefited if we are fortunate enough to interest them in our work."

MacGregor was a highly qualified engineer. He held the master's degree in mechanical engineering from the University of Wisconsin. In 1914, at age 40 , he was superintendent, experimental department, of the J. I. Case Threshing Machine Company at Racine. He was also a prominent member of ASME.

The membership ball kept rolling sufficiently well that President Musselman commented on it in 1915. Although he cited no figures, ASAE gained 24 new members that year, pushing the total to 132 . Yet the problem of insufficient money still persisted. President Frank M. White, speaking in 1916, said that money was needed to do "committee work." There were two ways to raise money: tax the members or get new members. All should try to get at least one new member signed up each year. However, White believed that some members would give " $\$ 25$ or $\$ 50$ for one or two years to assist the Society in getting on a good financial basis." He proposed a committee to "interview certain men" who might be likely prospects. Presentday members may wonder what they did with the money, having no headquarters building or staff and all the rest as we know it now. They spent it on printing and mailing the "Transactions," correspondence, and the secretary's "honorarium," among others.

By December 1917 America's entry into World War I was uppermost. President Edmund B. McCormick made no allusions to membership or financial issues; he concentrated on the potential contributions of agricultural engineering to winning the war. However, at that time the membership included 118 members, 36 associates, 11 juniors, 4 affiliates (not many after all) -171 total. There were 14 student branch members; 5 were at Iowa State and 9 at Nebraska.

The growth of ASAE was not, in a way, anything to brag about. From 18 
to 171 in 11 years! But it was better than a ninefold increase.

For many years (to 1920) the presidents were greatly concerned about the work of administration which devolved upon a secretary who held a fulltime job elsewhere. Davidson in a moment of uncharacteristic euphoria had predicted 1000 new members within a year if ASAE would hire a secretary. Philip Rose called for a permanent secretary in 1910, pointing out that sometimes it took an applicant 13 or 14 months to be admitted to the membership. As he put it: "We are all too busy to attend to the Society business." Worse was yet to come.

President Riley disclosed that during the summer of $1912 \mathrm{Mr}$. C. O. Reed had had a "serious physical breakdown" caused by his duties as secretary. Riley went on to say that "it is absolutely essential that we secure at the earliest possible moment the services of a paid secretary." The problem of delay in admitting new members was to be solved. Furthermore, the requirement that an applicant must be known personally to a member was to be abandoned.

L. W. Chase said of the secretary in 1913 that "He has been the mainspring of the clock and I have been the hand which indicates his bidding."

President MacGregor expressed the hope in 1914 that "the day is not far distant when we may reward our secretary with something more substantial than vocal bouquets." He also suggested a two-year term for the president. Nothing more was heard of this proposal.

F. M. White moved up to president in 1916. An ASAE "handbook" was a popular need; a committee had been appointed to get it started. White suggested that the secretary's honorarium be raised and that he assume the task of compiling the data. Apparently this idea didn't click.

The 1907 constitution provided for a Council made up of the two vicepresidents and three elected members, one of whom retired each year. The president, the vice-presidents, the secretary and the treasurer held office for one year. That constitution also provided for a three-man committee on research.

The 1913 constitution eliminated the two vice-presidents from the Council

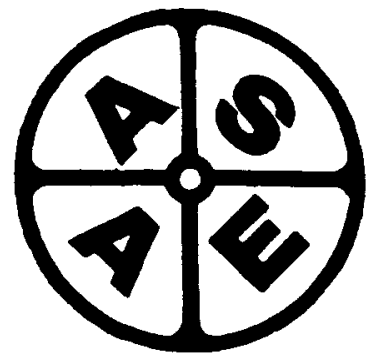

ASAE emblem provided for in 1913 constitution of ASAE Council 
and substituted the two immediate past-presidents. The offices of secretary and treasurer were combined. The standing committees were increased to 13. This constitution both opened the way for the student branches and contained the design of an ASAE emblem (not the one used today).

The Council chairman was simply the "elective member next retiring." He did, at least, bring two years of Council membership to the task. This policy prevailed until the June 1921 revision of the constitution, which made the president chairman of the Council and the two vice-presidents were added again.

\section{B}

\section{Technical Developments}

The technical influence and accomplishments of the period 1908-1917 can be examined under three categories: the "Transactions," the motor contests, and the standards.

Eleven volumes of "Transactions" had been printed by June 1918. Materials included were presidential addresses, technical papers and discussions of them, committee reports, secretary's and treasurer's reports, and reports of the business sessions. One or two pages were also devoted to the list of officers and committees.

The 1907 "Transactions" had a total of 102 pages. It contained the original constitution plus six technical papers and three "addresses." The 1917 "Transactions" (Volume 11) contained 261 pages, 15 technical papers, 10 committee reports, and a roundtable on extension work, plus the usual Society materials.

The character and quality of the technical papers was perhaps uneven, since the concept of referral was unknown. On the other hand, a number of other competent, recognized engineers and others published in the "Transactions," along with the members. Some of these were...

Anson Marston, dean of engineering, Iowa State College. "Sewage Disposal Plants for Private Houses." Volume 3, 1909.

Samuel Fortier, chief of irrigation investigation, USDA. "Agricultural Engineering and the Demand for Agricultural Engineers." Volume 4, 1910.

F. H. King, agricultural physicist, University of Wisconsin. "Principles of Ventilation Applied to Farm Buildings." Volume 4, 1910.

C. F. Hirshfeld, mechanical engineer, Cornell University. "The Principles of Fuel Oil Engines." Volume 6, 1912.

Because the founding group were mostly college instructors, many were devoted to issues related to instruction...

P. S. Rose (North Dakota Agricultural College). "Teaching a Course in 
Farm Motors." Volume 1, 1907.

C. K. Shedd (University of Nebraska). "Draft Apparatus for the Lecture Room." Volume 4, 1910.

J. B. Davidson (Iowa State College). "Laboratory Efficiency." Volume 7, 1913.

H. C. Ramsower (Ohio State University). "Some Phases of Teaching Agricultural Engineering." Volume 8, 1914.

J. B. Davidson (University of California). "Recommendations Concerning Agricultural Engineering Instruction for Agricultural Students." Volume 9, 1915. (He was in California from 1915 to 1919 as department head at Davis.)

F. A. Wirt (Kansas State Agricultural College). "Instruction in Farm Machinery." Volume 10, 1916.

F. W. Ives (Ohio State University). "Teaching Drawing to Agricultural Students." Volume 11, 1917.

One notable characteristic of the Society, however, was the rising number of members affiliated with industry. They evidently found the meetings to be a congenial place to present papers on products and processes from their companies...

P. T. Libberton (Portland Cement Co.). "Concrete in Drainage and Irrigation." Volume 7, 1913.

L. W. Eggleston (American Radiator Co.). "Farm Residence Heating." Volume 9, 1915.

O. E. Bransky (Standard Oil Co.). "Fuels for Internal Combustion Engines." Volume 10, 1916.

M. L. King (Permanent Buildings Society). "Hollow Clay Blocks for Farm Buildings." Volume 10, 1916.

H. E. Horton (American Steel and Wire Co.). "Wire Bale Ties." Volume 11, 1917.

F. N. G. Kranich (Hyatt Roller Bearing Co.). "Anti-Friction Bearings in Farm Machinery." Volume 11, 1917.

As a repository of research results, these "Transactions" were not richly endowed. While little work of lasting value was reported, it reflected the needs of the times. Some of it was concerned with technology that rapidly died a natural death. The college men apparently had little time or money for elaborate experiments. The USDA men reported excellent research, but there were very few of these men. Engineers from industry reported few investigative results; perhaps what little was carried on was not revealed for proprietary reasons. Research papers included...

H. W. Riley, "A Sprayograph.” Volume 3, 1909.

C. O. Reed, "Corn Planter Tests - Value and Methods." Volume 5, 
1911.

O. W. Sjogren, "Conditions Affecting the Accuracy of Drop in Corn Planters." Volume 6, 1912.

E. B. McCormick, "Draft of Farm Wagons." Volume 8, 1914.

G. W. Iverson, "Stresses in a Shawver Barn Truss." Volume 10, 1916.

J. B. Davidson, "Some Experiments in the Use of Electric Power for Field Work." Volume 11, 1917.

L. J. Smith, "Experiments in Sewage Disposal." Volume 11, 1917.

Another type of paper was read at the meetings with some regularity. These were non-experimental and descriptive in nature, organizing knowledge and ideas on a single subject. While some revealed a surprising depth of historical background, no papers of the period contained listed references. These papers usually were on some phase of machinery and therefore can be regarded as contributory to machine development through assembly of information. Examples include...

M. L. King, "A New Six Stroke Cycle for Internal Combustion Engines." Volume 3, 1909.

W. J. Brandon, "The Small Farm Tractor." Volume 5, 1911.

F. H. Demaree, "Larger Farm Implements and the Cost of Crop Production." Volume 5, 1911.

Max Patitz, "The Rotary Tiller or Soil Milling Machine." Volume 8, 1914.

E. P. Wiggins, "Economics of Farm Tractors." Volume 9, 1915.

C. M. Eason, "Tendency of Farm Tractor Design." Volume 9, 1915.

Howard W. Riley made this comment in his presidential address (1912):

"...the agricultural engineer is not the exotic product of a college greenhouse bred and developed by the efforts of a group of college professors. The agricultural engineer has not been brought into existence by the formation of this society but rather is this society the result of the existence of the agricultural engineer. If the college professor gave to him his name and proclaimed for him his independence, give the professor credit if you please, but do not let the date of the christening or the personality of the god-father blind you to the age and robustness of him who thus tardily receives his proper name before the world."

Riley was speaking of a subject dear to all engineers: professional identity - a subject especially dear to agricultural engineers. The presidential addresses contain many defensive statements along this line, commencing with Davidson. Thus it is surprising that the only permanent records now widely available, the "Transactions," contain little on professional identity. It appears that our predecessors did not formally examine their qualifi- 


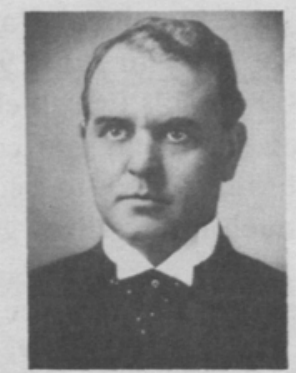

Edmund B. McCormick

10th president, ASAE, 1917

cations as agricultural engineers and then relate themselves to the general profession of enginering. With respect to agriculture, they seemed to assume that it was panting to be transformed by agricultural engineers, an assumption fostered by presidential rhetoric, no doubt, but not much else.

One paper clearly qualifies as an exploration of professional identity. In Volume 8, 1914, under the title "The Place and Field of the Agricultural Engineer," is a panel discussion; the speakers were: R. S. Shaw, dean of agriculture at Michigan Agricultural College; Anson Marston, dean of engineering at Iowa State College; and E. Davenport, dean of agriculture at University of Illinois.

The ag deans were not quite sure what profession was involved. They felt more at home in discussing the contributions of agricultural engineers to the field of farm mechanics, a state of mind which unfortunately prevailed for many decades in many ag deans. By contrast, Marston (no doubt under J. B. Davidson's influence) could envision a strong professional identity under development and was enthusiastic regarding its potential engineering contributions.

Other deans of engineering also left their mark on the infant profession during the period. O. V. P. Stout of the University of Nebraska has already been mentioned; his name will occur again. E. B. McCormick, ASAE president in 1917, was dean of engineering at Kansas State Agricultural College in 1910. He is credited with originating the first program in Kansas designed to bring engineering expertise directly to solution of agricultural problems. McCormick was followed as dean in 1914 by A. A. Potter, who organized a division of farm engineering for farmers; resident instruction in agricultural engineering was already under way. Potter later became dean of engineering at Purdue, where he helped agricultural engineering develop professionally.

The motor contests gave ASAE an opportunity to exert beneficial technical influence in a much needed sector. In the 1908 "Transactions" Elmer 
W. Hamilton discussed "The Educational Value of the Motor Contest." He described a contest at Winnipeg in July 1908 between traction engines weighing no more than 14,000 pounds (which eliminated steam engines and resulted in contention among seven internal combustion engines, burning oil, or kerosene). The contestants had to plow, among other activities. Medals were awarded and much interest was generated in the new "light" motors.

Hamilton's report also generated the desire to see such a contest performed in the United States. The initial move was the appointment of a Committee to Investigate Plowing Contests; its report consisted of Hamilton's paper.

The minutes of the 1910 meeting show that a Committee on Farm Machine and Farm Motor Standardization and Competitions existed; the chairman was J. B. Davidson. A motion authorized the secretary to "make a proposal to the Minnesota Board of Agriculture for a motor competition to be held under the auspices of the Society at their next annual fair." The secretary was further authorized to "make proposals for competitive tests and trials of farm machines and motors to the authorities of the next World's Fair." This was shooting pretty high.

The following year Davidson (now serving as Society secretary) reported results of correspondence with the Minnesota State Board of Agriculture. After some haggling over money it was decided that "time was too short" so the Minnesota proposal was dropped. However, the committee was approached by the National Implement and Vehicle Association (a respectable body) to "put on a contest" at an exposition in Peoria. On checking this out it proved to be no more than a demonstration. After trying to get several members to go, Davidson went himself and conducted the demonstration.

Another prospect which arose in 1911 was the Panama-Pacific Exposition scheduled at San Francisco in 1915. Davidson had contacted them, proposing that ASAE "put on an elaborate series of tests covering all lines of farm machinery on which it is possible to run satisfactory tests." He thought it would take six months to complete the tests and cost $\$ 100,000$. This was shooting even higher. The minutes reflect no action except to wait on some kind of decision from San Francisco.

L. W. Chase (University of Nebraska) delivered a lengthy paper on motor contests at the 1912 meeting. Starting with the virtues and defects of the Winnipeg contests, he analyzed the total rationale of such activities. In his opinion they were a "good thing," good for farmers, good for manufacturers, and delightful entertainment for the public. He believed it was time for a contest to be run in the United States and that ASAE should be in charge of the "technical part of the work." 
Chase devoted much attention to the technicalities of a contest; matters such as selecting the judges, classifying the machines, instrumentation, design of the testing shed, and reproduction of the Winnipeg score cards received full measure. He ended with a careful cost analysis. His paper was discussed by J. B. Bartholomew, president that year of the National Implement and Vehicle Association.

Bartholomew felt compelled to view the contest issue from his position as president of Avery Company; as a member of ASAE; and as president of NIVA, which sponsored exhibitions at Peoria. As a company president he favored contests held anywhere, including Winnipeg, and would send tractors to them because "we think these things promote the use of the tractor and consequently help sales." As an ASAE member, he thought that "this motor contest proposition" ought to be the "central feature of the organization." (Here one can imagine some dissent from those members committed to facets of agricultural engineering other than power and machinery.) Finally, as NIVA official in charge of the Peoria National Implement Show, he frankly stated that Chase's idea of a motor contest was too "comprehensive." He would like to invite ASAE to put on a contest but it would have to be "within the bounds of reason." (This is evidently what happened the year before; at first it was to be a contest, but finally Davidson went there and conducted a demonstration.)

L. W. Chase was a competent engineer and capable of conducting excellent tractor tests. He thought the Winnipeg tests were not well conducted (for one thing they used an old-fashioned form of prony brake) and did not yield full educational and engineering benefits. Thus, his score cards seemed unnecessarily complicated and intricate to Bartholomew. Also, the latter may have believed that Chase's methods eliminated some of the more crowdpleasing aspects.

To keep the peace, President Riley appointed a committee with a number of industry men on it (but Chase was chairman) to formulate contest score card and regulations acceptable to all. The committee reported later in the day. A classification of tractor and truck size and combustion type was decided upon. A Canadian score card was accepted, with an American card to be worked out. The agricultural engineers would handle no contest funds, but would only estimate costs; their job would be to manage the "technical side." The report was accepted as recommended practice.

Next, Riley queried the meeting as to the readiness of the Society to manage a motor contest if invited by an acceptable organization. The meeting voted that ASAE was "ready to consider and accept an invitation to manage the technical end of a motor contest."

So in December 1912, after much talking, they were ready to act. 
But invitations did not pour in. The report of the Committee on Motor Contest presented in December 1914 showed that the only work finished was involvement in some power farming demonstrations. As to new work, the Committee formulated some rules for a "competition being considered in the West."

The Committee, now entitled Tractor Demonstrations Committee, reported in 1916 a set of rules for demonstrations which were adopted by the tractor manufacturers. The rules offered an orderly mode of conducting demonstrations, with no suggestion of engineering measurements (such as horsepower, etc.). No doubt the demonstrations were very competitive, and no doubt they served a purpose in allowing farmers to see the machines in action, but a demonstration was not a contest. A contest yielded quantitative results for comparison, while a demonstration did not. One must conclude that the manufacturers didn't desire contests because those events had not only winners but losers - and who wants to be a loser? But demonstrations were another story.

Hence, the zeal of ASAE to become the grand arbiter of tractordom in the United States was watered down to regulating some of the activities at the county fair. There it would have remained, except for one man-L. W. Chase.

Recall that Chase developed a complete method for tractor contests which he thought was much better than the Winnipeg procedures. By 1917 he found the right handle: to conduct engineering tests, publish the results, and award no prizes. The collection of reliable comparative data was the important thing, as he pointed out in his 1913 presidential address.

For several years Chase and his colleagues in Nebraska were involved in what they called the Fremont Demonstration. With many tractors (they called them traction engines then) assembled for the demonstration, Chase and company conducted tests on them, tests of the most rigorous kind. The 1917 "Transactions" reports the results of 90 such tests under the title "Nebraska Tractor Tests, 1917." (These were not the same as today's "Nebraska Tests.") Chase was aided significantly in this pioneering work by the J. I. Case Threshing Machine Co., the International Harvester Co., the Advance-Rumely Co., the Wallis Tractor Co., the John Deere Plow Co., the American Seeding Co., the Grand Detour Plow Co., the J. I. Case Plow Works, and the Parlin \& Orendorff Plow Works. His paper would probably rank among the ten most important of ASAE history because it helped the manufacturers obtain crucially important performance data of their competition. This eliminated unreliable and inefficient machines 
and provided stimulus for many design improvements. No doubt this work led directly to the present-day "Nebraska Tractor Tests."

While ASAE's involvement in motor contests contained more promise than substance, when the gaudy references to World's Fairs and PanamaPacific Expositions are pushed under the rug, a solid remnant remains the work of $\mathrm{L}$. W. Chase and his assistants. They achieved a lasting influence upon the design and performance of the agricultural tractor.

From all that to involvement with standards is an easy step. Standards for engineering design and practice is a universal concern of engineering societies. Such concerns tend to unite the interests of all classes of members. Standards make easier the instructor's task. Standards simplify manufacturing processes, lower product costs, and lead to wider consumer acceptance. In the area of safety alone, the discussion and promulgation of standards is a definite public service. Moreover, working with standards usually causes an engineering society sooner or later to come in cooperative contact with other societies, manufacturers, universities, and certain governmental agencies. Such contacts can be of benefit, particularly to a struggling-youngster like ASAE. So it is not surprising to find the agricultural engineers involved with standards from the beginning.

A. O. Fox (honorary member, 1908) wrote a paper for the 1909 meeting on "Standardization of Farm Machinery." The lack of standards in the farm equipment industry and their advantages were considered. Fox called for a concerted effort between ASAE, the USDA, the State Experiment Stations and the industry to remedy the situation.

As the result of Fox's paper and ensuing discussion, President Wynn appointed a Committee on Standardization with seven members: three to handle tractors, three to handle farm machinery, and a general chairman. The chairman appointed was (who else?) J. B. Davidson.

By the following year (1910) this Committee had the word "Competition" added to it and thus they were simultaneously concerned with motor contests. Davidson "made a verbal report of progress" at the 1910 meeting whose gist has long since been lost.

Things were not much better at the 1911 meeting. President Ocock called for reports from the subcommittees. The tractor subcommittee reported that no progress had been made. The farm machinery subcommittee (L. W. Chase, chairman) stated that they had outlined some standard specifications for manure spreaders and corn planters. (Was the enormity of the task beginning to dawn upon them?) Member L. W. Ellis called for standardizing both brake and tractive ratings for tractors and for standardizing bolts, nuts, and other small parts.

However, at the 1912 meeting Edwin Ehrman of the Chicago Screw Co. 
presented a discussion on "The Standardization Work of the Society of Automobile Engineers." This excellent paper outlined the procedures employed by SAE in developing standards.

This was followed by J. B. Davidson's paper on "Standardization in Agricultural Engineering," a thorough review of the topic. He observed that ASME had established a central bureau on standardization activity, and that ASAE had been invited to cooperate with the bureau. This was an early example of cooperation with another engineering society.

James A. King of the Hart-Parr Co. then reported for the Committee on Standards for Farm Machinery. He had little to recommend for adoption but pointed out a number of machines and components which needed standardization. He indicated that the National Vehicle and Implement Association (sic) had adopted some wheel standards.

In the discussion of King's report, H. J. Podlesak of the International Harvester Co. warned that it would "take four or five years to...discuss and adopt some standards." D. M. Weeks of the Studebaker Corp. sounded a more cheerful note, however, by saying "when...vehicles are standardized the user will pay less money for a better vehicle, and the maker will receive a greater return upon his investment."

Next appeared W. J. Brandon of the Avery Co., who reported for his committee on "Standards in Gas Tractor Construction." The touchy problem of developing standard methods for measuring belt and traction horsepower was brought out, along with the critical need for such methods. Other parts needing similar attention were the magneto, the sparkplugs, screw threads, tap and die tolerances, bolt and nut heads, wheel tire stock, carburetor fittings, plow hitches, and wagon drawbars. Brandon ended by saying that the agricultural engineers "will soon have to wake up. If you don't look out, the American Society of Mechanical Engineers will break into the agricultural machinery problem and take up work that belongs to the agricultural engineers."

A long discussion followed Brandon's report. It can be characterized as "What shall we do next?" The session ended with a comment from W. F. MacGregor. MacGregor offered a partial rebuttal to the "If we don't do it someone else will" ploy by noting that many of the items mentioned in the Brandon report were already in the jurisdiction of SAE, ASME, and other groups. It would be better to cooperate with them than to attempt the impossible.

Thus the 1912 meeting brought many of the real issues of standardization before the members. The complexity of the problems was evident. However, these men were thinking only of power and machinery at that stage; structures, electricity, etc., still lay in the future. 
At the same meeting, a committee headed by L. W. Chase worked up a set of "Conventional Symbols for Agricultural Engineering Drafting." These were apparently sent to several members in a bulletin to allow time for examination prior to the meeting. The symbols were discussed in depth at the meeting, with a great amount of quibbling over the width of lines, etc. Finally, they had an argument as to whether ASAE should adopt the symbols as "standards" or as "recommended practice." (Davidson remarked that he believed the meaning was the same.) But it seemed that, confronted with a chance to adopt a standard, the members shrank from the dread word, preferring recommended practice as something easier to revise later. So the work of Chase's committee was adopted as "Conventional Signs for Agricultural Engineers." There were 202 signs in the final booklet ranging in grandeur from "national boundary" to "out house." The 1000 copies of the booklet were printed in 1913 , but sales were slow.

The 1913 meeting brought forth one paper, "Standardization of Farm Wagons," which aroused discussion of the value of good roads, but not much else. However, the incoming president, MacGregor, asked for special emphasis on standards during his term of office.

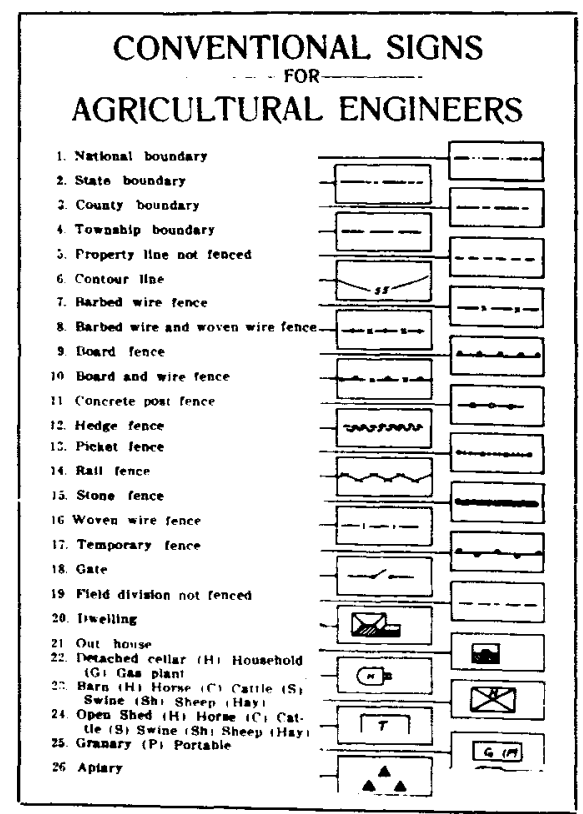


MacGregor's interest in standards was probably aroused by his membership in ASME and involvement with the efforts of that society to formulate a steam boiler code. In his presidential address (1914) he called detailed attention to the importance of a uniform code of boiler construction; to the fact that legislatures reject codes offered by commercial interests; and to the assumption that an "influential body" such as ASME, "uninfluenced by commercial interests," is therefore professionally obligated and qualified to draw up such codes in the public interest. Proceeding on this line, MacGregor voiced the opinion that formulation of codes and standards should be the main effort of ASAE.

J. B. Davidson submitted a report for the Committee on Standards at the 1914 meeting. The Committee had been "active" on wagons, gas engine rating and testing, and screw threads. They had finished standardizing sizes of catalogs, bulletins, drawings, and specifications. Cooperation with two trade associations was developing; these were the National Implement and Vehicle Manufacturers Association and the Gas Engine Association.

President Musselman spoke in 1915 of "An opening of great promise... with the Division of Rural Engineering of the USDA in establishing standard methods of rating and testing tractors." (On December 6, W. F. MacGregor was appointed to act for ASAE in this connection. The problem was to standardize the drawbar rating of gas tractors.)

The 1915 report of the Standards Committee recommended approval of the standards for wagons adopted by the National Implement and Vehicle Manufacturers Association. The Committee then proposed to break new ground by developing standards for methods of rating farm electric lighting plants. The Committee on Farm Power Machinery also made a new proposal. The members were somewhat disheartened by the lack of information contained in the manufacturers' catalogs, to say nothing of the misinformation purveyed by over-zealous salesmen. They therefore proposed to test power machinery (grain separators, corn shellers, feed grinders, silage cutters, etc.) and provide the manufacturer with an impartial analysis of capacity, horsepower rating, and all the rest. The Committee (F. N. G. Kranich was the chairman) expected to be paid for conducting the tests. They thought the idea so good that they recommended another committee should be formed to handle draft machines in a similar manner. Nothing came of this; probably when they got down to figuring out how to do it the idea lost its charm!

The following year, 1916, brought further doses of disillusionment (but perhaps a growing wisdom also). W. F. MacGregor reported on the "opening of great promise" to which he had been assigned in 1915. USDA had asked a number of tractor manufacturers if they wanted the government to 
test tractors. It appeared that they did. So a committee was formed to work out the details. Organizations represented were ASAE, the National Gas Engine Association (H. R. Brate, an ASAE member), National Association of Thresher and Tractor Manufacturers, USDA Office of Public Roads and Rural Engineering (E. B. McCormick, an ASAE member), and the United States War Department.

The committee held several meetings in Washington. They formulated a standard type of brake and drawbar horsepower test, along with a set of administrative procedures. One member, McCormick, proposed a new dynamometer design for the tests. All was apparently going well when, in August, Director Page of the USDA bureau announced that the appropriations bill just signed by the President contained "such a meager appropriation for rural engineering that it would be impossible to proceed...".

MacGregor ended the report by stating his belief that the government ought to test tractors and that he wanted ASAE to pass a resolution to that effect.

With President F. M. White in the chair, and after some discussion, Philip $S$. Rose moved that the government ought to test tractors in cooperation with the manufacturers. There was an argument about where the government should do the testing, but the resolution passed unanimously.

Just before MacGregor reported on his frustrating experience, Raymond "lney (editor of "Power Farming") presented a thoughtful discussion of "The Standardization of Gas Tractor Ratings." A mechanical engineer, his affiliation with the publicity world probably focused his outlook on the realities of commerce. He stated plainly that he was not in favor of allowing the government to test tractors. He believed that ASAE and similar organizations should work with manufacturers in developing a standard rating. Specifically, the National Association of Tractor and Thresher Manufacturers should establish the official rating and ASAE should simply adopt that rating as the universal standard. (The reader may wonder where Olney was when the resolution on government testing was passed unanimously. He was not there; his paper was read by a gentleman named Wiggins who disclaimed responsibility for everything in it.)

The 1916 Report of the Committee on Standards contained a set of recommendations for low-voltage electric lighting plants. These were put together after a canvass of manufacturers indicated a need for standard specifications and had furnished suggestions for these. This report was accepted after minor changes. The convention also considered a proposal from the national Gas Engine
Association that the standard belt speed be adopted as 1500 feet per minute. The proposal was referred to a special "committee of technical engineers." 
Perhaps Philip S. Rose had the last word in 1916 in a discussion on the "handbook" issue. Rose gave them a blast which was vitally linked to the problems of standardization. He said:

"It seems to me there is considerable chasing after strange gods. I don't know how you are going to standardize tractors when the manufacturers themselves do not know what a tractor is. I don't know how you are going to standardize a lot of things when the manufacturers themselves do not know exactly what they are doing or where they are headed. You can't do it.

"I think we had better consider for a moment what the Society is for. This Association, if it is anything at all, is an engineering association. This is a professional association. It is not a manufacturers' club. You people are here primarily to better yourselves and your knowledge of your profession... Your mission is not to reform the world. It is not your purpose to go out and tell all the manufacturers what they ought to do..."

The United States entry into World War I in April 1917 probably reduced the pace of activity on standards. The 1917 meeting yielded one committee report. The low-voltage lighting plant standards were discussed but no definite action taken. J. F. Max Patitz (Allis-Chalmers Co., Milwaukee) reported for the sub-committee on tractor standards.

Patitz stated that the Society of Automobile Engineers had combined with the Society of Aeronaut Engineers and the Society of Tractor Engineers, thus forming the Society of Automotive Engineers, (SAE). The ASAE sub-committee had offered cooperation to the SAE Tractor Standards Committee. The latter had arrived at a set of recommended ratings for drawbar and belt horsepower and for belt speed. The ASAE Committee on Standards moved that these SAE standards be adopted by ASAE; the motion carried unanimously.

The end of the period brought no great achievements in the standards area. The feverish activity, however, was extremely valuable. In the beginning grandiose dreams found print and half-baked plans were made. These came to naught because ASAE was just too new and too small to exert influence in an arena which included not only the manufacturers and the trade associations but also the larger and older engineering societies. There was hardly a machine or a device of any kind over which ASAE could claim sole jurisdiction. Wisdom arrived also, particularly with the object lesson of how ASME worked out the standard boiler code in 1914; they did it by working with the trade associations, even though the resultant code was something less than ideal.

Having learned these lessons (disregarding that temporary aberration 
of favoring testing by government) ASAE swallowed its pride and started endorsing the standards worked out by the manufacturers and other engineering societies. Whether Philip Rose liked it or not, to exert any influence at all ASAE had to recognize commercial realities: standards that tend to decrease sales are not likely to be voted on favorably. Was this behaving like a professional society? Probably not, but aside from Rose there is no public record of objections. If ASAE was "influenced by commercial interests," and it certainly was in order to survive, few members seemed to
mind. 


\section{nd decade, ${ }_{1918-1927}$}

\section{"A GOOD FOUNDATION HAS BEEN LAID:..}

Raymond Olney

\section{A \\ General Progress}

Notwithstanding a flowery invitation from a representative of the St. Louis Chamber of Commerce, the Society convened again in Chicago on December 30, 1918. President Daniels Scoates of Mississippi A. \& M. College spoke with feeling of the contributions of ASAE toward the war effort just concluded. ASAE had 27 members in the services. The university people had trained thousands of men to drive trucks and tractors and to repair them. The industry people had not only trained men but had manufactured "instruments of warfare."

But the demands were not yet ended. Disabled soldiers must be retrained and some would require agricultural engineering training. Professor Davidson delivered a paper on this topic, pointing out the experiences of France and Canada in training mutilated veterans to operate tractors and farm machinery.

The group passed a resolution which was also concerned with the disposition of the discharged soldier. The resolution favored expenditure of federal funds for settlement of such persons on wet, arid, and cut-over lands. The money would not be given to the settlers but rather loaned at low interest for purchase of land previously improved by the government.

The war must have caused the death of some members, although no record exists of who they were. A resolution was adopted which stated (in part):

"WHEREAS some of our members who answered our country's call have answered their last roll call here on earth and have given their lives to the great cause; Therefore be it

"RESOLVED: THAT the American Society of Agricultural Engineers in Twelfth Annual Convention assembled record its lasting appreciation of those of its members who fought so nobly." 
The 1918 meeting adopted another resolution which called for the employment of an "assistant secretary to aid....in carrying out a wide publicity to increase the membership and extend the usefulness of the Society." Granted to the incoming secretary was authorization to hire a stenographer at $\$ 65$ or $\$ 70$ a month. Outgoing Secretary H. C. Ramsower commented that his successor would have to pay bills amounting to $\$ 700$ or $\$ 800$, "with the total in the treasury of \$138." Ramsowner was convinced that only a big membership drive would save ASAE from financial collapse. A doubling of membership was essential, and a stenographer would be a real help. Moreover, he believed that hiring a stenographer would be a step toward a permanent secretary.

The 1919 president, Raymond Olney, editor of "Power Farming," admitted that the membership drive didn't quite come up to the hopes of one year ago. He also commented that a permanent secretary "is absolutely essential to the progress that the Society should henceforth make." His secretary, F. W. Ives of Ohio State University, did hire a stenographer during the year for the sum of $\$ 386.37$. The net increase for the year was 122 members. As of December 31, 1919, the membership stood at 189 members, 97 associates, 21 juniors, and 8 affiliates for a total of 315 . Student branch members were: Iowa 5, Nebraska 5, Mississippi 15, Ohio State 21. The year 1919 showed a definite upturn (70 percent). As Olney said, "A good foundation has been laid."

By August 18, 1920, membership had reached 537. A linear projection to January 1, 1921, suggested 639 members. That was from Frank P. Hanson, who had plotted ASAE growth from 1908 to August 18, 1920. The plot shows that January 1, 1919, was the point of critical upturn.

Since Society income was almost totally based on membership dues, the unprecedented increase in members stimulated President Kranich, Secretary-Treasurer Davidson and the Council to embark on two projects of exceptional importance: (a) Hiring of the long-needed "paid secretary," and

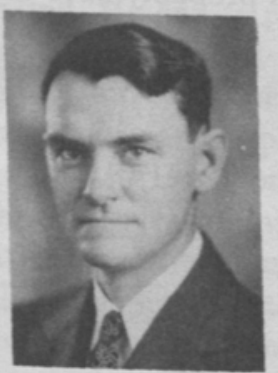

Daniels Scoates 11 th president, ASAE, 1918

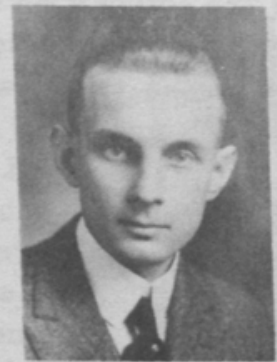

Raymond Olney 12th president, ASAE, 1919

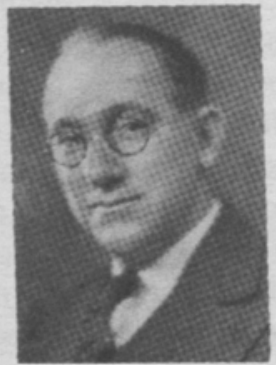

Frank N. G. Kranick 13th president, ASAE, 1920 
(b) establishing a monthly publication.

Since J. B. Davidson was the elected secretary, he was authorized to hire an assistant secretary. He hired Frank P. Hanson, a new agricultural engineering graduate of Iowa State College, at a salary of $\$ 1600.00$ per year. Hanson was given a desk in the ag engineering building at Ames from which to operate Society business. Although his appointment was to take effect on July 1 , Hanson eagerly went to work on June $28,1920$.

With Hanson on deck the leadership felt prepared to tackle the publication problem. Starting in July 1914, a news sheet called the "Bulletin" was published several times a year. As the "News Letter" this was expanded in January 1916 and published at more frequent intervals up to September 1920. Now these crude items were to be replaced by a monthly journal complete with technical papers (but not replacing the "Transactions"), detailed accounts of Society affairs, and (very important) advertising.

After some deliberation it was decided to name the new publication AGRICULTURAL ENGINEERING, The Journal of the American Society of Agricultural Engineers. Over the years it was customarily referred to as the "Journal." Hanson had quite a job in registering the titles with the United States Patent Office without hiring an attorney.

Shooting for publication of Volume 1, Number 1 in September, Hanson, with three courses in agricultural journalism under his belt, had to do everything. He obtained copy, made the layouts, sold a little advertising, and found a printer (Torch Press of Cedar Rapids, Iowa). Apparently they ran 1500 copies per issue.

By exerting himself to the utmost, Hanson got out the September, October, November, and December issues of the Journal. Then, upon taking stock, he found that the 1920 Journal deficit amounted to $\$ 833.68$; for the four issues he had managed to sell advertising worth $\$ 293.10$. At any rate, the Journal was launched.

Had they waited a few months, the launching would probably have been

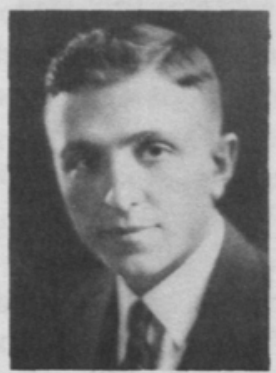

Frank P. Hanson 


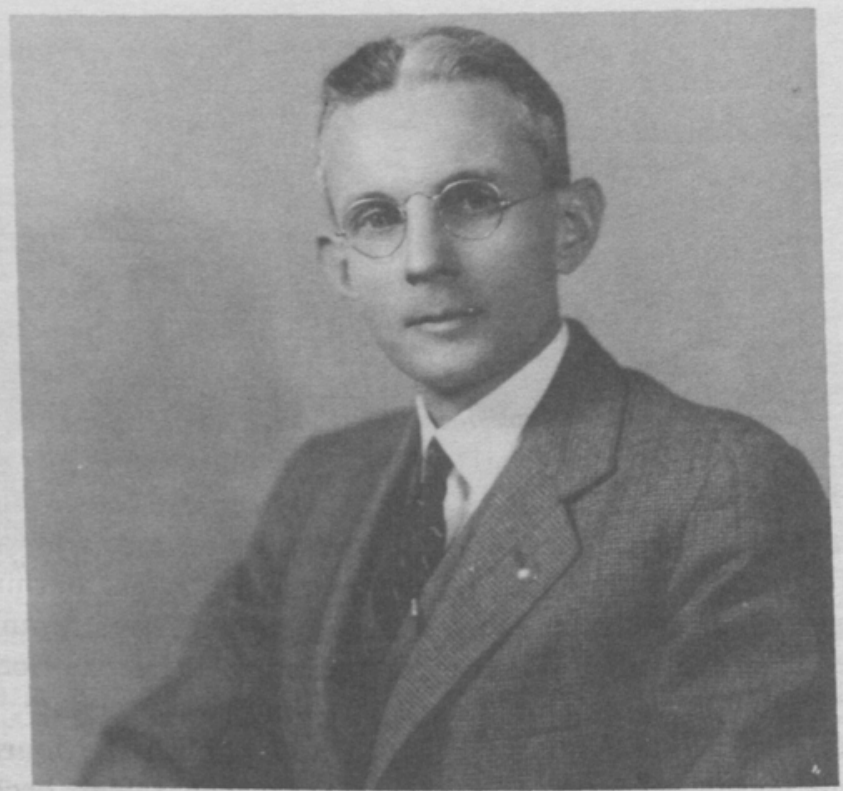

In 1921 Raymond Olney, editor of "Power Farming" and former president of ASAE became editor and publisher of AGRICULTURAL ENGINEERING. He became fulltime secretarytreasurer-publisher, etc. in 1925

delayed for years. By the end of 1920 the post-war depression had set in, especially in the agricultural sector. Hanson recalled that shortly after the dues statements went out in January 1921 the "roof began to fall in." Resignations came in thick and fast. Without financial reserves, this was a very shaky time for Hanson (who became secretary on January 1, 1921) and for the Journal. He was promised a raise if he sold enough advertising to pay for the 1921 Journal, but that didn't pan out (the Journal did not become solvent until 1924). In fact, by June, Hanson's salary payments began to fall behind. He had to postpone his wedding day to September.

Hanson resigned as secretary on November 1 with ASAE still in debt to him for $\$ 172.66$, which was later paid. His vicissitudes embraced more than the financial problem. For example in June 1921, he was responsible for an ASAE exhibit at the Fargo, North Dakota National Plowing Match. One horsedrawn unit was worked too hard and a horse became overheated. After its harness was removed it got to its feet and took off. Afflicted with the "blind staggers," the horse charged directly through the ASAE exhibit, moved on a short distance, and went down and stayed down. The exhibit was wrecked. As Hanson wrote later, “...the Society was not only struggling to outlive the post-war depression but was receiving no help from horses." 


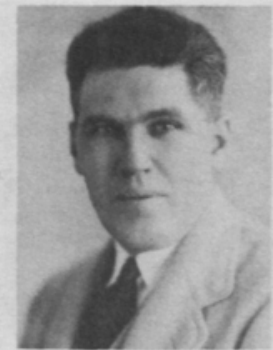

Earl A. White

14th president, ASAE, 1921

Meanwhile, the administration of President Earl A. White had commenced with a very significant change. In January 1921, Raymond Olney was appointed editor and publisher of the Journal. He was located at St. Joseph, Michigan, and employed by the magazine "Power Farming." The Journal would be printed by the Power Farming Press. Thus, Frank Hanson was released from the duties of editing and printing. When Hanson resigned as secretary, Olney was appointed as a part-time paid secretary, and later as treasurer also, while continuing to edit and publish the Journal. This arrangement continued until August 1, 1925, when Olney became fulltime paid secretary-treasurer-publisher, etc. He retired from ASAE employment in July 1959. The influence of his character and deeds upon the development of ASAE deserves a book in itself. One point can be made immediately. Because Olney resided in St. Joseph, that was where ASAE headquarters were established (except for two years in Mt. Clemens, Michigan in 1923 and 1924) and where it is today.

Frank Hanson had extrapolated the growth curve to indicate that 639 members might be expected on January 1, 1921. The end of 1920 showed the figure to be 569 , with new student branches at Missouri, Wisconsin, and Kansas State.

The membership problem received attention at a Council meeting held at Fargo during the plowing match. A constitutional amendment was proposed to authorize a special grade of affiliate membership for county extension workers. The amendment was printed in the July Journal and the members were promised a letter ballot on the topic. The grade of membership did not carry the privilege of voting or of holding office, nor would the "Transactions" be included. Apparently nothing came of this. Olney's report on the year 1922 is filled with gloomy comments on membership but contains no reference to the extension affiliate grade. Perhaps the idea was dropped because the affiliate grade was already adequate for such purposes. New student branches, however, were organized in 1922 at Illinois and North Carolina. The deepening agricultural depression was 


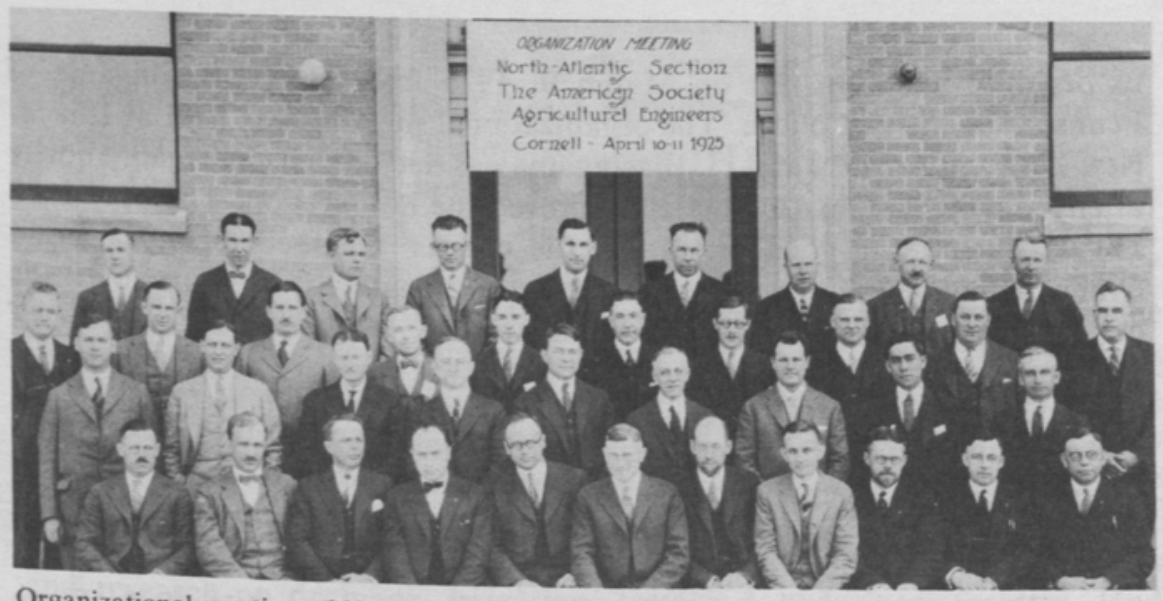

Organizational meeting of North Atlantic Section of ASAE held at Cornell University, April 1925. (left to right, front row) J. L. Strahan, G. L. Wendt, Kurt Grunwald, R. W. Trullinger, W. C. Harrington, R. U. Blasingame, H. W. Riley, Raymond Olney, F. L. Fairbanks, C. E. Ladd, B. B. Robb. (second row) R. T. Wagner, C. L. Andrews, A. M. Goodman, M. A. R. W. B. F. Knipe, E. W. Pilgrim, F. E. Hand, Alexander Gordo, J. C. McCurdy. (third row) Gross, F. G. Beh, W. T. Ackerman, C. H. Churchill, Jr., O. B. Stichter, D. B. Lucas, E. R. Lantz, G. N. Allen, N. D. J. Bullock, C. I. Cohee, F. Ransom. (fourth row) N. S. Grubbs, E. G. Ray Carpenter.

being reflected more and more on the membership.

One bright membership event occurred during 1921: ASAE acquired its first female member. Mrs. Mary A. Ives was elected an associate member. She held a degree in home economics and specialized in designing mechanical household equipment for her husband's consulting firm, the Agricultural Engineering Company of Columbus, Ohio. Her husband was Frederick W. Ives of Ohio State University, a prominent member soon to become president, but for a tragically short time. ASAE has had a few women members over the years, most of them home economists like Mrs. Ives. Judging by the small number of girls presently attracted to the professional curriculum in the universities, ASAE may remain a male-dominated group.

The desire of members to meet on a geographical or regional basis was first implemented by the Southern Section. This group first met and organized at Auburn, Alabama, in June 1917. They met at Memphis in August 1920 for two days and enjoyed a banquet courtesy of the Memphis Engineers Club. After a meeting in 1921 the Southern Section apparently was dormant until 1926. The Pacific Coast Section was organized in December 1924; it has since been reorganized into smaller geographic units.

The palm for the geographic unit longest in existence under the same name should go to the North Atlantic Section (now Region). The call for 
its organization went out on March 9, 1925 from R. U. Blasingame of Pennsylvania State College. The organizational meeting was held at Ithaca, New York, on April 10 and 11. Blasingame was elected first chairman. Shortly after the meeting, ASAE Council approved the new section. The May 1925 Journal includes a good picture of the charter members plus Raymond Olney. Although the Journal announcement is lengthy, it contains no details on the geographical boundaries of the section. The Secretary's Letter of October 8, 1925, states vaguely that it is "in the eastern part of the United States and Canada."

Two more sections were organized during this period - the Southwest late in 1925 and North Central in May 1927.

Meanwhile, increasing specialization within agricultural engineering, both of a technical and a professional-objective nature, was stimulating the formal breakup into divisions that Davidson had predicted in 1908. These were called "Sections" at the time. To avoid confusion with geographic units let us call them "Divisions," a term which was to come into use after a few years.

At the Annual Meeting of 1920 , tentative organization of a College Division of ASAE was authorized. The need for it lay in the "...desire to further the interests of agricultural engineering in land grant colleges, experiment stations and extension service and to promote research and better teaching methods and more largely to correlate these activities with those of the United States Department of Agriculture." F. W. Ives was appointed chairman of a temporary advisory committee with responsibility to get the division started.

The committee met in Washington in May 1921, at the Division of Agricultural Engineering, Bureau of Public Roads, USDA, by courtesy of Samuel H. McCrory, engineer in charge and member of the committee. The group effected a permanent organization and discussed future plans. Cooperation between USDA, state agencies, and ASAE was considered essential. Development of standard methods in education was a desirable goal. Problems needing research were outlined and plans made to circulate them to the colleges. In turn, the colleges were to be solicited for work in progress and suggestions for new projects.

The committee wrote to Secretary of Agriculture Henry C. Wallace to request that the Division of Agricultural Engineering be retained in the Department of Agriculture. A reorganization was proposed in which all engineering work would be placed under one head.

The meeting ended with discussion of program material for the Annual Meeting in December. It was decided that the general topic of "Better 
Methods of Instruction" would be the theme for the College Division program. In the June Journal it was announced that one evening of the December meeting would be devoted to the Division.

The College Division enjoyed a strong organizational structure and a private newspaper. The former was provided by an executive committee, while the latter was provided by a mimeographed "confidential news sheet" entitled "The Confessor." "The Confessor" apparently first came out in the fall of 1923. Copies of it are now scarce, but the October 1925 issue is identified as Volume 4, No. 1, and comprises five pages. It circulated among the agricultural engineering departments and was written by the members of those units. Daniels Scoates was the editor of this "journal of the College Division."

Many ASAE members had long been interested in technical activities and research on drainage, irrigation, terracing, hydrology, forestry, land clearing, and similar issues. In February 1921, Professor D. P. Weeks of Iowa State College was authorized to work with the Sections (Divisions) Committee to take the steps necessary to organize a Reclamation Division which would focus on these technical interests.

Comment in the March Journal set the stage for Reclamation.

"This step taken to increase the Society's activities in the field of reclamation engineering, which includes principally drainage, irrigation, reforestation and land clearing, is a most significant one. In the years to come, due largely to the fact that new lands in this country have practically all been acquired by private owners, the reclamation of land to increase the production of foodstuff through drainage, irrigation and clearing will become increasingly important and essential, as will also the reforestation to provide for the timber supply for future generations.

"Reclamation is second to none in importance compared with other branches of agricultural engineering, and the far-sightedness of the Society in giving recognition to the needs in this direction through the organization of a reclamation section will give encouragement to engineers in this line of work and impetus to the development of this phase of agricultural engineering."

In June it was announced that Weeks, who was chairman of the Drainage Committee, would welcome suggestions for the Reclamation Division program at the Annual Meeting in December; one half-day was to be devoted to the group. It turned out that a whole day was devoted to the Division, with papers on land clearing, financing of drainage districts, planned rural development, flood control, and committee reports. 
The Reclamation Division was organized with David Weeks as chairman. Its committees and their chairmen were: Irrigation (Samuel Fortier); Drainage (E. R. Jones); Land Clearing (John Swenehart); Soil Erosion (Q. C. Ayres); Colonization (O. V. P. Stout). Chairman Weeks wrote in March 1922 on Division objectives:

1. The presentation of untried material before the members of the Section (Division) through AGRICULTURAL ENGINEERING and at the Annual Meeting, as well as professional meetings of the Division, for the purpose of determining its importance, proper application, and reliability.

2. The dissemination of technical information throughout the membership of the Society:

(a) By beginning the preparation of a bibliography on reclamation engineering.

(b) By presentation of technical papers before the members of the Society at the Annual Meeting and also other professional meetings of the Reclamation Division.

(c) By the publication of technical articles in AGRICULTURAL ENGINEERING.

(d) By the presentation of technical papers before the members of the Society at the Annual Meeting and other professional sessions of the Division.

3. The collection of fragmentary material through the cooperation of the several members for the purpose of combining into a completed whole.

President Earl A. White noted in his address of December 27, 1921 that "At present there are four distinct groups represented in the Society, viz., reclamation, college, farm buildings and farm operating equipment. The organization of two of these groups into sections logically brings up the question of the desirability of organizing the two remaining groups into sections. It is my opinion that such action would be desirable..."

The 1922 Council, held its first meeting on December 29, 1921. With President A. J. R. Curtis of the Portland Cement Association presiding, the discussion turned to further structuring of ASAE into technical divisions. It was reported later:

"The organization of the Reclamation Section (Division) of the Society has proven so satisfactory that the Council has decided that it is desirable at this time to organize the other groups into sections. There was some discussion as to whether or not farm sanitation should be separated from farm structures. It was finally decided that for the present sanitation should be included with the farm structures section. A farm power 
operating equipment section will also be organized, to which farm lighting will go, while all other phases of farm sanitation will come within the farm structures section. The purpose is to appoint a strong man as chairman of these sections who will be responsible for the section's activities and results."

Thus the stage was set for formation of two more professional divisions. In the area of farm structures, a high degree of technical interest had been evident since 1907. Members taught courses, did research, and worked with business enterprises involved with design, layout, and construction of farm service buildings, farm housing, and ancillary structures such as fences. Early techniques for maintaining proper environments in animal shelters were discussed at the meetings. In fact, F. H. King, one of ASAE's first two honorary members, was the inventor of the King system of gravity barn ventilation. The early 1920 s witnessed publication of several basic papers on animal heat production and energy metabolism as related to environmental control. Concurrently the arts of framework analysis and mechanics of materials were being applied to the barn arches of the time. Water supply and sewage disposal for the farmstead were also receiving attention. The acquisition of Mary Ives as a member turned attention to the engineering needs of household equipment. Committees active in most of those specialties existed or had existed for some time.

The Farm Buildings Division came into being under the chairmanship of W. G. Kaiser of the Portland Cement Association. These committees and chairmen were appointed: Ventilation (M. A. R. Kelley); Sanitation (E. W. Lehmann); Farm Building Design (W. A. Foster).

Farm power and equipment hardly needs a review. The early struggles with motor contests and standards, which represented ASAE's principal interaction with the public in the first decade, indicated the strong affiliation of many members toward the machinery and prime movers of agriculture. Of course the problems these pose to the agricultural engineer are

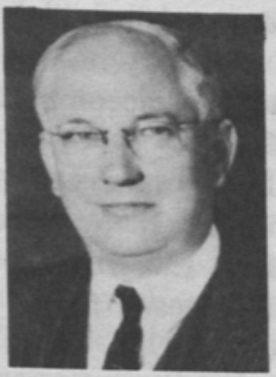

Arthur J. R. Curtis 15th president, ASAE, 1922

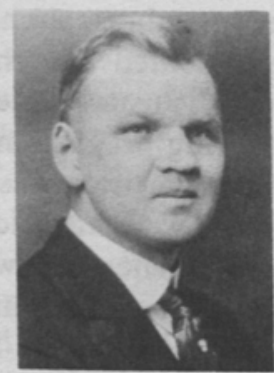

Emil W. Lehmann 16th president, ASAE, 1923 
always close to the human heart, muscle, and pocketbook. Machinery draws together the college man, the industrialist, the USDA man, and the farmer. Machinery problems are usually acute and immediate; industrial competition and farm labor shortages leave little time for engineers to philosophize. And a new tractor might keep a farm boy from going to the city while a new barn or a newly terraced field probably would not.

The Farm Power and Equipment Section (Division) was organized with J. B. Davidson as chairman. These committees and their chairmen were set: Animal Motors (Wayne Dinsmore); Stationary Gas Engines (E. R. Wiggins); Tractor Testing and Rating (O. W. Sjogren); Motor Fuels (A. H. Gilbert); Horse Drawn Field Machinery (L. W. Chase); Left Hand Plow Investigation (G. W. McCuen); Tractor Field Machinery (Theo. Brown); Disc Harrow Investigation (E. V. Collins); Belt Machinery (G. B. Gunlogson); Grain Handling Equipment (R. H. Black); Farm Lighting (I. W. Dickerson); Power Farming (O. W. Sjogren).

With the birth of technical divisions, members started talking about separate division meetings during the year, leaving the Annual Meeting for more general topics and for "promoting agricultural engineering science in a big broad way." A start in this direction was made when 20 of the Reclamation members met in September 1922 at Kansas City during the National Drainage Congress. After lunch in the Convention Hall they listened to a talk by Walter W. Weir of the University of California on drainage of irrigated lands. It would probably be incorrect to term this a divisional meeting. Olney's writings indicate that the first technical divisional meeting separate from the Annual Meeting was in December 1924, when the Farm Power and Equipment Section (Division) met in Chicago. Later the other divisions joined the machinery group in December, usually in Chicago, at a conclave which became known as the Fall or Winter Meeting.

Meanwhile the growing degree of specialization created an innovation at the Annual Meeting in December 1922-the concurrent session. One afternoon offered the members a choice between four divisional programs. In 1931 Olney commented that this was necessary in order not to prolong the meeting beyond the usual three days and still accommodate all who were presenting and hearing program material.

One more technical division was born during the decade-Rural Electric. Some early members were electrical engineers (H. W. Riley was one) and interest in small farm generators was evident. Electricity for household and farmstead work was recognized in the first decade for its great potential. An electric tractor was tested by Davidson in 1917. With the 1920s came the real start of the electric age. USDA, American Farm Bureau Federation, the National Electric Light Association (NELA), and ASAE organized 


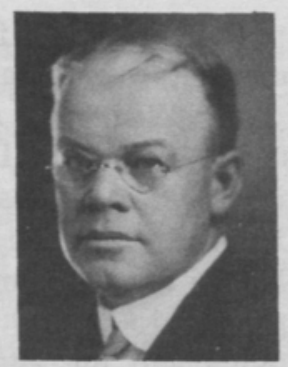

Samuel H. McCrory

17th president, ASAE, 1923-24

a national Committee on the Relation of Electricity to Agriculture (CREA) in September 1923. Dr. Earl A. White was appointed director of CREA; Davidson represented ASAE. (White earned the first Ph.D. in agricultural engineering at Cornell in 1917.)

CREA was to carry out an extensive survey of rural and farm use of electricity in the U.S. and abroad and to stimulate research and development in the field. Officials of the Farm Bureau Federation were certain that a major thrust in this direction would come from ASAE. CREA committees were rapidly organized in 28 states; the first was in Minnesota, with its experimental electric line at Red Wing. In almost every state the CREA committee chairman and other engineers were connected with the agricultural engineering departments of the local universities and were ASAE members. According to Truman E. Hienton, former chief, Farm Electrification Branch of USDA-ARS, four of these men were ASAE past-presidents and 10 others were later elected to that office, indicating that the state organizations were handled by members of high standing. So the expectation of the Farm Bureau was gratified.

President S. H. McCrory, speaking in June 1924, commented on the "increasing interest in the application of electricity to agriculture." $\mathrm{He}$ called it a new field for the profession and suggested that ASAE should organize new committees to "study the various phases of this work." He also suggested that since "radio has captured the world" a radio committee might be formed to study how to take advantage of it.

The following year President H. B. Walker recommended the formation of a "rural electric division," even though "rural electrification is very closely related to farm power and machinery."

It seemed, therefore, that electricity in agriculture deserved ASAE divisional status. The new division (the word "section" was no longer used for this purpose) was organized in late 1925 under the chairmanship of Arthur Huntington of the Iowa Electric Light \& Power Company. The Division com- 
mittees and their chairman were listed as follows: Correlation of State Projects (L. J. Fletcher); Nomenclature and Standard Practice (F. D. Paine); Rate Forms (B. D. Moses); Farm Wiring (E. A. Stewart); Portable Motors (E. W. Pilgrim); Methods of Motor Drive (D. L. Renner); Household Appliances (Eloise Davison); Individual Electric Plants (P. C. Cosgrove); Windmill Power (F. C. Fenton). The Rural Electric Division did not hold a midyear technical meeting in Chicago until December 1928.

The second decade, then, produced a divisional structure similar to today's except for some name-changing and the addition of Food Engineering. The College Division evolved into Education and Research; its divisional status was abolished in the 1968 reorganization. There is little doubt, however, that the central technical directions of ASAE jelled in the 1920s. There is an additional point of interest regarding Rural Electric. It played a role not only in farm production but also in the quality of rural living. In concert with the Farm Structures Division, the farm home became an object of research and development for agricultural engineers.

Discontent with the December Annual Meeting came to a head in 1922. Olney was instructed to canvass the membership on when that meeting should be held. Wives and children resented the absence of ASAE members from home during Christmas holidays. That poll resulted in a Council decision to hold the 1923 Annual Meeting in November in Chicago but, starting in 1924, the Annual Meeting would be in the latter part of June. Also this meeting would be held in various parts of the country. The decision was probably influenced strongly by the many college members whose school year would be closed by the end of June. Perhaps the desire of spouses to accompany their husbands on a family vacation affected this decision also.

Thus the new officers would assume office at the end of the Annual Meeting. The first president so affected was Samuel McCrory, who assumed office from E. W. Lehmann at the November 1923 meeting and relinquished the presidency to Frederick W. Ives at the June 1924 meeting at Lincoln, Nebraska. McCrory, therefore, served only seven months as president.

Ives, of Ohio State University, was 18th president of ASAE and his term was to extend through the 1925 Annual Meeting. However, after leaving the Lincoln ASAE meeting he attended a meeting of the Society for Promotion of Engineering Education at Chicago. He was fatally injured in a railroad accident as he returned to Columbus. The secretary of the American Society of Civil Engineers lost his life in the same accident.

Ives was an able and active member. His loss was keenly felt. The Council brought out a resolution of regret immediately for forwarding to his family and his associates at Ohio State. The National Association of Farm Equip- 
ment Manufacturers sent similar resolutions, including one to ASAE.

The accident had implications. Investigation proved that the fatal injuries were confined to the occupants (a number of prominent engineers) of a wooden pullman sleeping car placed between two steel cars. On discovering this, the ASAE Council sent a vigorous resolution of protest to the American Engineering Council (AEC) asking it to protest unsafe railroad practices to the Interstate Commerce Commission on behalf of "engineers of all classes." The Commission replied to Secretary Olney that there was no law prohibiting use of wooden sleeping cars but it had recommended to Congress that "the use in passenger trains of wooden sleeping cars between or in front of steel cars be prohibited." Meanwhile, the AEC authorized its secretary, L. W. Wallace (who had attended the November 1923 , ASAE meeting and praised the agricultural engineers) to "take up the matter" with the Commission. That was about the end of it. Ives' name was given to the agricultural engineering building at Ohio State.

Harry B. Walker of Kansas State Agricultural College was first vicepresident and became president with the passing of F. W. Ives. Years later (1942-43) Walker was elected president in his own right. The case of the wooden sleeping car created two unique events of ASAE history: Ives is the only president to date to die in office; Walker is the only member to have served twice as president.

It was natural for ASAE to turn to the American Engineering Council when it wished a platform representing the total profession. AEC didn't represent all American engineers but it was closer than anything else in existence.

AEC was the governing body of the Federated American Engineering Societies which was formed in 1920 with Herbert Hoover as its first president. Hoover, a mining engineer who was about to become Secretary of Commerce, stood strongly for engineering leadership and responsibility. He wanted FAES to be dedicated to the "public interest" and to this end 71 engineer-

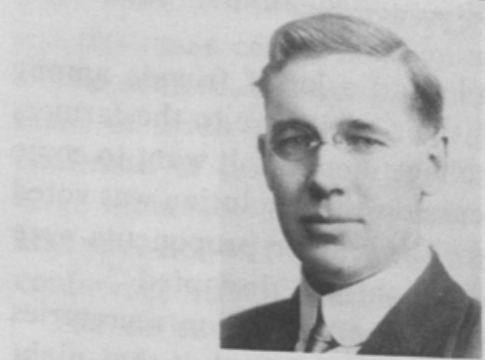

Frederick W. Ives Inducted president, ASAE, 1924

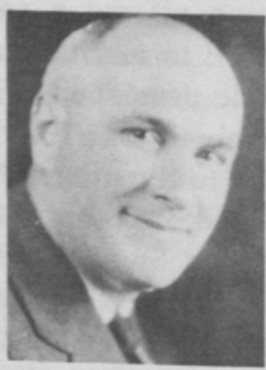

Harry B. Walker 18th president, ASAE, 1924-25 
ing societies participated in the formation of FAES. But when time came to pay dues only 29 of them stayed with the organization; ASAE was one of them.

When the ASAE Council met October 11, 1921 with President E. A. White presiding, it was voted unanimously to disaffiliate with FAES because of the financial crisis. It was agreed that membership would be resumed when the Society's financial posture would justify the move. Normally this would have disposed of any further association with FAES. However, Mortimer E. Cooley, a prominent engineering dean who had succeeded Herbert Hoover as FAES president, was the ASAE annual meeting banquet speaker. Cooley evidently "sold" the members and the leadership on returning to the FAES fold. ASAE stayed with the organization (AEC) until its demise in 1940.

Apparently in the 1920 s. B. Davidson was impressed by a study of industrial waste performed early by FAES. He and Arthur Huntington, Oscar W. Sjogren, Harry B. Walker, and F. A. Wirt prepared an elaborate proposal to AEC for $\$ 30,000$ to study waste in agriculture. The proposal was submitted on September 10, 1926, but nothing came of it.

The difficulties experienced by FAES (and later AEC) in trying to serve the engineering profession were by no means unique. The engineering society members themselves had different employment affiliations, which led them to occasional disagreement on where professional loyalty is due to the profession or to the employer. ASAE argued this at the Lincoln meeting in 1924; this was remembered by Olney many years later as "one of the most vivid events in my memory...the like of which I had never seen before... nor since."

Recall the Animal Motors Committee of the Farm Power and Machinery Division. Its chairman, Dinsmore of the Horse Association, spearheaded a drive in the news media in favor of animal power which was quite effective. Certain ASAE members affiliated with the tractor industry at the 1924 business meeting offered a resolution which opposed animal power and committed ASAE to mechanical power.

An epic battle developed. The horse people had a lot of friends among the college members, who felt that they owed their jobs more to the farmers back home than to the manufacturers. The college men didn't want to come out for either kind of power. After much discussion the resolution was voted upon and defeated by only one or two votes. The tractor proponents were so enraged that Olney was fearful that ASAE might be "disrupted."

Having the usual large corner room allotted to organization secretaries at the Hotel Lincoln, Olney brought the key dissidents together that night to seek a compromise. He wanted "a resolution that would satisfy every- 
one." With President McCrory moderating, about 15 members went after it. A compromise was worked out about 2 am. They created what Olney called a "straddle," which performed "a great service to the Society in that it kept peace in the family."

Next day it was voted that ASAE impartially favored use of any kind of power but because an economic trend toward mechanical power was underway, more research on this was recommended.

Olney published an editorial titled "Horseless Farming" in the February 1925 Journal. It is written carefully enough to recognize that horses were still around, but he firmly stated that "mechanical power is destined to displace much power in agriculture." It should not be done, however, by publicity and promotion but by engineering studies.

With the advent of Annual Meetings in June, the Farm Power and Machinery Division broke new ground with its "Winter Meeting" on December 3, 1924, at Chicago. Eighty-nine registered, most of them from the ind ustrial sector. The presiding officers were ASAE Vice-President O. B. Zimmerman (International Harvester Company) and F. A. Wirt (J. I. Case Company), chairman of the Division. Among the papers presented was one by Past-President W. F. MacGregor (J. I. Case Company) on the revolutionary combined harvester-thresher, or combine, which was moving in from the West. The discussions departed at one point from the technical when it was voted to ask ASAE to recommend to President Coolidge that a qualified agricultural engineer be added to an agricultural commission he had recently appointed. The meeting was considered a success! It was agreed the problems of farm power and machinery were so multitudinous that this kind of midyear meeting was justified.

The Farm Structures Division helped to put on a National Farm Homes Conference at Chicago for two days in February 1926. Although cooperating with other groups, the agricultural engineers played a predominant role. Addresses and papers were given by President F. A. Wirt, D. G. Carter (University of Arkansas), and K. J. T. Ekblaw, a private consultant. Carter was chairman of the Division and conference chairman.

The conference issued a number of resolutions. One called for appointment of seven committees, the chairmen of which to be named by the chairman of ASAE's Farm Structures Division. Another recognized the large monetary loss from fire which annually occurred in farm dwellings and appealed to Herbert Hoover, Secretary of Commerce, to call a national conference on elimination of fire waste.

The entire proceedings of the National Farm Homes Conference were printed in the April Journal, a unique development, although as examples of technical literature their value seems minimal. The papers run largely to 
overblown statements of the obvious and photos of farm houses which only rich people could afford. A member named Walter B. Jones wrote Olney complaining that the conference had nothing to say about heating the farm home; according to Jones, who also lived in St. Joseph, this topic deserved more engineering attention than any other facet of the structure.

Even so, this activity of the Farm Structures Division was a landmark.

After the 20th meeting, at Lake Tahoe, California, (June 1926) was over, an editorial appeared in "The National Stockman and Farmer" which pleased Olney and the others very much. The writer said: "It will surprise even most engineers to know that this continent's greatest engineering achievement, the Panama Canal, is of less magnitude, less cost and less importance to our national prosperity than one of the oldest agricultural engineering achievements, the drainage of land... After 20 years the agricultural engineer and his profession are beginning to receive the recognition they deserve." Another editorial appeared in the "Engineering NewsRecord" about the same time, stating that "The science of agricultural engineering is growing up, and that science is slowly making its impress on the struggling industry toward which it is directed."

President Wirt handed the gavel to President O. W. Sjogren (University of Nebraska) at the close of the 20th meeting. Sjogren probably was applauded for representing a new generation - he was the first ASAE president to start at the bottom as a student of ag engineering and a student branch member.

Membership was gradually growing. A new student branch had been organized at the University of Saskatchewan, the first in Canada. The Tahoe meeting was managed by the Pacific Coast Section, the start of a traditional practice, and was the first held in a resort. The meeting was graced by the presence of Honorary Member Elwood Mead. Now United States Commissioner of Reclamation, Mead had promoted agricultural engineering for many years; his great work of Boulder Dam was yet before him.

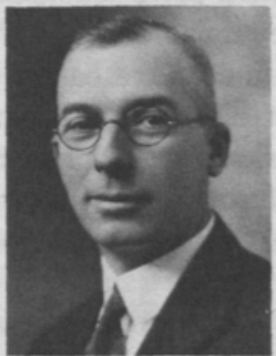

Frederick A. Wirt 19th president, ASAE $1925-26$

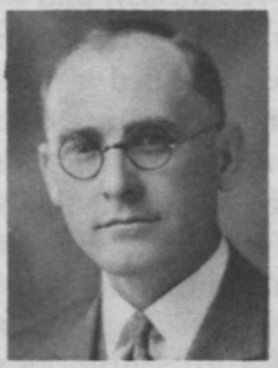

Oscar W. Sjogren 20th president, ASAE, 1926-27 
Competent Ray Olney was firmly in charge of the national office; he could be depended upon to handle all the details that increasing services to members, increasing size, and increasing complexity of structure were bringing. In such agreeable surroundings, with the 20th year of ASAE ahead and a special ASAE train waiting to take the Midwestern members back home in solid comfort, Sjogren could have speculated that things were looking good.

The Council met in Chicago on December 1, although Sjogren was not present. They approved a petition for a new professional Division, the "Consulting Engineers Division." The president appointed Wendell P. Miller, a consultant of Columbus, Ohio, as acting chairman until the June 1927 meeting when formal organization would take place. This Division did not survive long, possibly due to the scarcity of full-time consultants in ASAE.

The Council also authorized the employment of an assistant secretary, a decision which indicated the growing importance of Olney's office. Ralph A. Palmer, a 1926 agricultural engineering graduate of Ohio State University, took the job in March 1927.

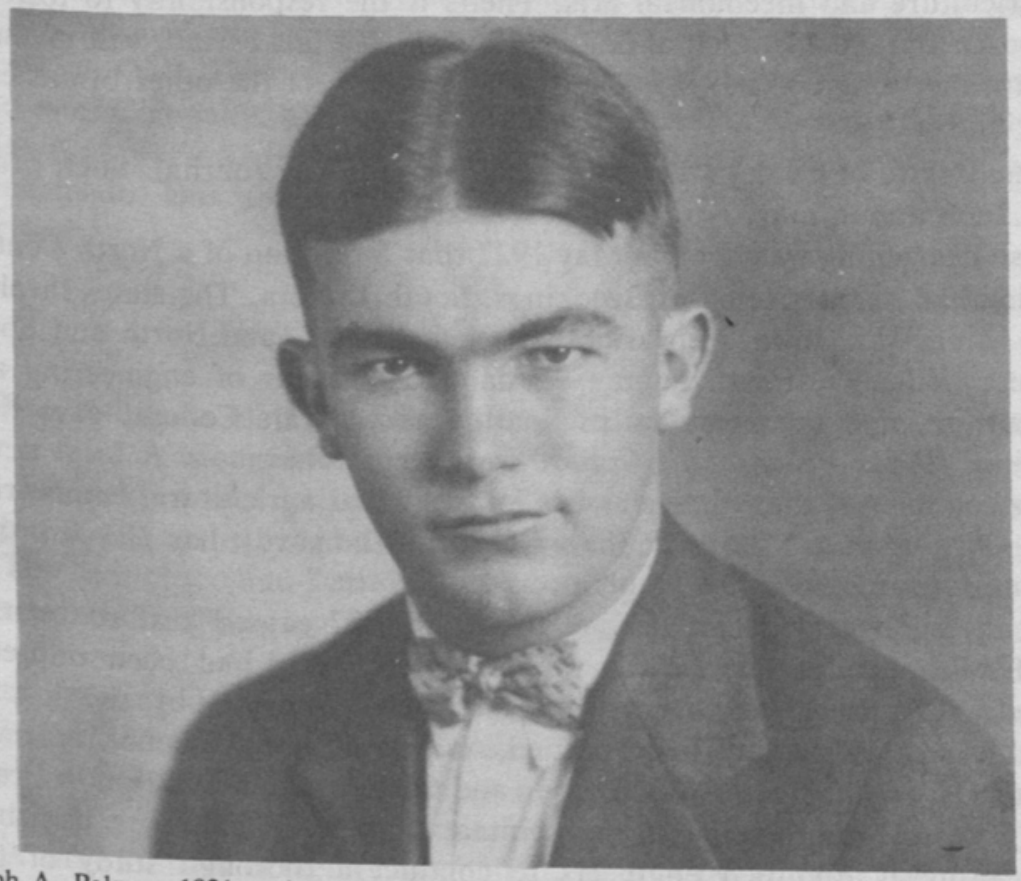

Ralph A. Palmer, 1926 agricultural engineering graduate of Ohio State University, became assistant secretary of ASAE March 1927. 
During these early years recognition of any kind was precious, but most precious was recognition from outstanding engineering leaders. We have already met Dean Mortimer Cooley, past-president of American Engineering Council; he was also past-president of ASME. Cooley wrote to ASAE Past-President Daniels Scoates, head of the Dept. of Agricultural Engineering of the A. \& M. College of Texas, of the significance of this new engineering profession, now nearly 20 years old. He wrote:

"Looking backward half a century I have often thought that had I my life to live over again and could choose I would have gone to teach in an agricultural and mechanical college instead of in a university. Notwithstanding the field of engineering in which $I$ have wrought is very great and the results have been commensurately great, the field in agriculture, as I see it, is even greater. It has afforded opportunities in engineering which in their bearing on the welfare of the nation must stand first in importance. Nothing could be more important than feeding and clothing a people...

"...a great and important field is agricultural engineering, and so closely tied to agriculture that it belongs primarily to our colleges of agriculture and mechanical arts. Theirs is the responsibility to foster and encourage a branch of engineering which I feel certain will in the future outweigh some, if not most, or even all, of the other branches in importance."

Much more of Cooley's letter was published in the Journal. Such praise from such a man must have been very heartening.

Also heartening was news in May 1927 that formation of a North Central Section had been effected at Brookings, South Dakota. The states involved were Minnesota, Iowa, Nebraska, Missouri, Kansas, and North and South Dakota. With President Sjogren on hand, the deans of engineering and agriculture, and the president of South Dakota State College, gave their blessings. R. L. Patty of the College was elected chairman. A local newspaper commented that "It was not so long ago that agricultural engineering was looked upon as little more than a fad, but the part it has played in improving farm methods has amply proved its worth."

Meanwhile, the vast Mississippi floods of 1927 caused real concern to ASAE's leadership. Destruction of life and property had been unprecedented; agricultural engineers were extremely disturbed by the loss of valuable soil. Measures were needed to prevent a recurrence of these disasters. On behalf of ASAE, Sjogren and Olney sent a resolution to President Coolidge, urging him to "appoint at once an engineering board of seven properly qualified engineers to conduct a thorough study of the Mississippi River problem and make a report to the next Congress for its 
guidance in adopting a proper and effective method of river control..." The fate of the resolution is unknown, but the responsible expression of such concern can be applauded. Of course, our heroes may possibly have hoped for the appointment of an ASAE member to such an important board of engineers! It does seem somewhat strange that American Engineering Council was ignored in the process. Although by 1927 AEC was definitely opposed to government usurpation of private enterprise, the control of the Mississippi River looked unquestionably like a job for government.

The Annual Meeting at University Farm, St. Paul, Minnesota, drew onethird of the membership. A farm machinery publication reported later that "The meeting was characterized by a spirit of good fellowship, optimism, progress, and enthusiasm, for which agricultural engineers are noted..." Olney editorialized that the profession was "on the verge of a tremendous development..." after attending the meeting. Certainly, the various addresses, papers, and committee reports are impressive evidence that "the time is at hand when the agricultural engineer will need to spend less time in selling himself and the service he can render..."

At the end of 20 years of sometimes precarious existence ASAE was well-established and its members had much to be proud of. The incoming president, $\mathbf{O}$. B. Zimmerman, an experimental engineer of the International Harvester Company, had recently told the American Society of Mechanical Engineers that ASAE was in charge of agricultural mechanization, a bold thing to do. But now boldness and achievement were outweighing mere survival.

\section{B}

\section{Educational Development}

The influence of ASAE on agricultural engineering education during the second decade gained strength. The report delivered by the Committee on Education to the 1919 convention was unusually complete and detailed; it provides a springboard for examination of the educational phase.

The committee had surveyed the country and discovered that only eight agricultural engineering students had graduated in the past year and that 36 colleges did not offer courses in agricultural engineering. Five colleges were granting degrees in the field; University of Nebraska, University of Missouri, Utah Agricultural College, Kansas State Agricultural College, and Iowa State College. A number of other colleges permitted students to "major" in agricultural engineering as they did in animal husbandry, etc.

A large number of faculty vacancies existed in the colleges, although some of them would have been filled if funds had been available. 
The committee found that many (14) colleges did not require agricultural students to take a farm machinery subject.

After concluding that the "situation is deplorable," the committee made some recommendations: (1) ASAE should approve the "six essentials for good farm machinery courses"; (2) the Society should sponsor post-graduate courses for instructors; (3) the Research Committee should write to the directors of the experiment stations "about the importance of research in agricultural engineering." The committee also called for a Bureau of Agricultural Engineering.

We have seen that the College Section, or Division, was organized at the 1920 meeting. For the first time, this offered a definite focus for the "fullest cooperation of all members...who are teachers or investigators either at land grant colleges or experiment stations."

The prime educational difficulties which confronted the struggling departments of agricultural engineering at the time were discussed in a 1921 Southern Section paper by E. R. Gross of Mississippi A. \& M. College. First he added his own college to the list of those granting degrees in agricultural engineering. Then he asked "Is agricultural engineering an engineering or an agricultural course, or is it to be supervised by both of these colleges?" (Perennial question which has led to much controversy and trouble for the whole profession, but for which there is still today no perfect answer.) The course can be under agriculture, under engineering, or jointly supervised; of those six degree courses, three were under engineering, one under agriculture, and two jointly supervised. Mississippi was about to pass under the wing of engineering. Where the course was entirely under engineering, it was difficult to obtain the "necessary agricultural information."

But, according to Gross, a greater difficulty lay in what to call those who "majored" in agricultural engineering in the ag colleges. They should not be called "engineer." He felt that the term "farm mechanic" was a proper title for them.

It is apparent that Gross, and probably a number of his colleagues, believed that the four-year course in agricultural engineering should meet the criteria of an engineering curriculum. If this was to be done at the expense of training in agricultural topics, then so be it because traditionally the agricultural engineer was farm-raised. Therefore he was supposed to know about agriculture from early boyhood (even if the "family farm" was a 60 -acre patch of mismanagement and desolation).

The professional curriculum developed by Davidson at lowa State College was held to be not only the first but one of the best with regard to meeting the difficult problem of subject matter distribution. According to Gross. Iowa followed this curriculum: 
Agricultural engineering $\ldots \ldots \ldots \ldots \ldots \ldots \ldots \ldots \ldots \ldots \ldots \ldots \ldots \ldots$

General engineering . . . . . . . .

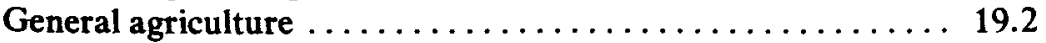

Science $\ldots \ldots \ldots \ldots \ldots \ldots \ldots \ldots \ldots \ldots \ldots \ldots \ldots . \ldots \ldots . .28 .4$

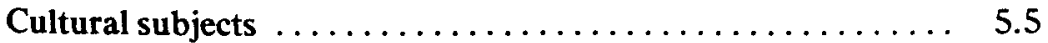

Elective ......................... 8.2

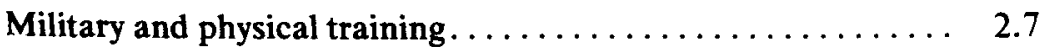

The work in general agriculture consisted of courses in soils and crops and in horticulture. There is no doubt that the Iowa requirements tended to set a pattern which others used for many years.

Gross did not exactly sweep the problem of the "ag engineering major" under the rug. But to expect a college graduate to be contented with the title of "farm mechanic" seems unreasonable. And they weren't contented with the title. This, of course, promoted or allowed use of the term "engineer" for these graduates, which led to decades of misunderstanding. That misunderstanding cast a shadow on the educational development of the profession by causing other branches of engineering to downgrade agricultural engineering. A really good name for graduates of "mech ag" curricula is yet to be discovered.

Later in 1921 the A. \& M. College of Texas announced establishment of a degree course in agricultural engineering "which will be in the engineering school." Agricultural, civil, mechanical, and electrical engineering comprised 78 hours of the course; agriculture required 31 hours. This brought the number of professional curricula up to seven.

A department of agricultural engineering was established at the University of Montana (College of Agriculture and Mechanic Arts) in 1921. It was preceded by a similar department established earlier in the agricultural experiment station. Courses in agricultural engineering had been taught as "agronomy" during the interim. In charge was H. E. Murdock, who stated that the new department was "in response to a demand by the citizens of Montana for more instruction dealing with tractors, farm buildings, irrigation, drainage, etc." In October of 1922 Murdock announced that his department had become "full-fledged."

The early days were not easy for some college men. In 1922 Olney asked Leslie E. Hazen of the Oklahoma Agricultural and Mechanical College for news of himself. Hazen replied: "I have neither been hired nor fired, discouraged nor encouraged, abused nor misused, browbeaten nor frightened. I am so terribly busy I could not blow a horn if I had one. I am instituting about three new subjects, rooting for a new building, trying to fix up an old one, seeking for funds, and attempting to put agricultural engineering on the first page of the annals of this school." 
The Virginia Agricultural and Mechanical College and Polytechnic Institute (VPI) started a department of agricultural engineering in 1921, headed by Charles E. Seitz. Their program of instruction changed in 1923 from "the major course in agriculture" to a professional course leading to the degree B.S. in Agricultural Engineering. This brought the total to eight.

The College Division showed interest in standardizing courses, or at least in a thorough investigation of how courses were taught at the various colleges. Their initial effort was applied to farm motors. W. J. Gilmore (Oregon Agricultural College) reported on some survey findings to the 1922 convention -17 institutions replied to his questionnaire. Most of the students taking the farm motors course were collegiate students in agriculture. It was implied that students in professional degree curricula took the same motors course as any one else, a practice which persisted beyond the end of World War II and which aroused suspicion of the quality of instruction in professional agricultural engineering.

Gilmore found wide variation in topics covered, division of time between lecture and practical work, and the types- of engines employed in the laboratory. Some used a manual, some did not. No less than 10 different books were used as texts. Some schools borrowed 95 percent of their equipment from manufacturers. Some borrowed none. Little use was made of slides and films.

Gilmore suggested that a committee of agricultural engineers write a text. In a similar way, a laboratory manual could also be furnished to instructors. Another committee could work out exactly the topics to be covered and the length of time for each one.

However, Chauncey W. Smith (University of Nebraska) discussed Gilmore's paper with some distaste. Smith made two points: (1) Farm motors and farm machinery should not be taught as separate units but should be integrated as they are in real life; (2) most of the agricultural engineering courses were not of college caliber. He presented his ideas of a course which embraced the mechanical, electrical, and thermal principles underlying motors and machinery. He ended his discussion by suggesting that ASAE appoint an inspection committee "whose duty it was to visit each college trying for an accredited standing by following the plan worked out by a standardization committee." Truly a man ahead of his time.

The same meeting brought forth a paper by E. A. Stewart of the University of Minnesota. His institution was about to start up a professional degree course and he wanted the members to understand its requirements. The Minnesota course was compared to Iowa State, Kansas State and University of Nebraska. The principal difference was a lesser amount of general engineering and a greater amount of agricultural engineering at 
Minnesota. Because the Division of Agricultural Engineering was separated from the main campus, physics, steam boilers, surveying, and some other engineering subjects were taught by the agricultural engineering faculty. Minnesota's course brought the professional courses up to nine.

Stewart had some interesting statistics in his paper. As of 1921 the professional courses had produced 157 B.S. Agricultural Engineering graduates and 14 "post-graduate degrees." One-hundred seventy-three students were enrolled. They were instructed by about 140 teachers. In 1922 some 7600 students had taken an agricultural engineering course in "ten of the largest colleges."

Those agricultural students who majored or minored in agricultural engineering, Stewart said, ".... are not qualified as experts along engineering lines, but they are filling a very useful field in educating the people to the value of engineering training in agriculture, and they are also building up many positions which will soon be occupied by professional engineers."

So the colleges were trying to meet several problems at once. The aid of ASAE as a focus for interchange of methods and ideas was only the beginning. Another service was to interact with other organizations on behalf of the college members. For example, in March 1924 the Committee on Cooperative Relations met with a similar committee of the National Association of Farm Equipment Manufacturers (NAFEM). Davidson, Sjogren, and H. B. Walker represented ASAE. It was first agreed that "the educational institutions desired to be of...service to the farm-equipment industry since the advancement of agriculture depends to a great extent upon the intelligent use of farm labor-saving machines."

The principal discussion centered on the work in vocational agriculture created by the Smith-Hughes Act and the preparation of teachers of such work. It was agreed that the agricultural engineering departments would have major responsibility for preparing men to teach farm mechanics in rural high schools. The colleges would also be expected to hold tractor and farm equipment schools for dealers and users.

The same committees met again in July. They worked out a general plan for conducting tractor schools and gave consideration to a procedure for "inducting graduates in agricultural engineering into the farmequipment industry." Because the ASAE committee was part of the College Division and because they were finding openings for graduates, much interest was given these activities.

At the NAFEM convention in October ASAE President Walker gave an address on cooperation between the college agricultural engineers and the farm equipment industry. The convention adopted a resolution of commendation for ASAE. And the joint committees on cooperation met again 
to further the cooperative movement. They discussed the issues pertaining to the Smith-Hughes teachers and the problems connected with trainee courses for agricultural engineering graduates. ASAE members were happy to learn that Deere \& Co. would take 10 graduates each year and provide summer employment for 20 undergraduates. Also, a training course had been started by J. I. Case Threshing Machine Co.

Late in 1924 President Pugsley of South Dakota State College announced the establishment of a department of agricultural engineering at that institution. Ralph L. Patty, extension specialist, would head the department. Patty was a 1916 agricultural engineering graduate of lowa State.

Not so happy was the news in April 1925 from South Carolina. A fire at Clemson Agricultural College had destroyed everything used in the agricultural engineering work at the institution. Professor J. T. McAlister notified the Journal that he would appreciate copies of bulletins, texts, notebooks, laboratory guides, or anything that would help to put him back in business.

Q. C. Ayres (Iowa State College) wrote in May 1925, that the Society for the Promotion of Engineering Education (SPEE) had evidenced convincing proof of the educational importance of agricultural engineering. He said: "The attitude of these engineering grandfathers toward agricultural engineering has passed through successive stages of open hostility and concealed skepticism to good-natured tolerance, and finally to that kind of interest which presages enthusiastic support." SPEE had recently asked ASAE for information on the profession; an ASAE committee was organized to provide this. As Ayres put it, "No profession that is represented in more than 30 of our leading educational institutions and that serves annually 13,000 students can be lightly brushed aside by any thinking person." Of course. this kind of interest does not arise by accident. Members belonging to the colleges had been involved with SPEE for some time. One year before, President Ives had lost his life after attending a SPEE meeting at Chicago.

Interaction between college and industry was beneficial to both segments of ASAE. However, another class of "industry" member, the private consultant, found certain college practices somewhat unpalatable - the employment of extension agricultural engineers. Member S. F. Morse, a well-known and successful consultant, in the July 1925 Journal chastised the colleges thus: "The function of the agricultural colleges should be to train agricultural engineers but not to compete with their own graduates by offering free consulting service. In fact, the U.S. Department of Agriculture and the agricultural colleges should respond to inquiries for service by sending out lists of properly qualified agricultural engineers." Morse 
went on to argue that "Scarcely a more valuable work can be done by the ASAE than to help competent agricultural engineers to efficiently serve farmers...etc." We can be sure he didn't refer to extension engineers. The controversy went on during the decades and is still in existence. If ASAE had had a greater number of full-time consultants (most of them are usually moon-lighting professors) the battle might have become downright vicious. But the consultants never had enough manpower to make a real fight of it. For example, when Morse wrote of the problem there were six advertisements of private consultants (since the death of Ives apparently none of the professors were advertising), and only four of them were ASAE members.

When President H. B. Walker gave his annual address at Madison, Wisconsin, in June 1925, he called particular attention to educational progress and needs. He stated that 40 percent of the membership (there were $\mathbf{4 0 0}$ members) was engaged in education and research. The Committee on Cooperative Relations of the College Division came in for praise. He said that "Education must always occupy an important place in our development. The introduction of mechanical equipment, the building of efficient farm structures, and the economical reclamation of land all carry an educational responsibility for final success." Walker gave much notice to a resolution adopted at a recent meeting of the National Electric Light Association. NELA resolved that colleges engaged in training agricultural engineers should include a component of electrical engineering in such training and that power companies and electric equipment companies should offer summer employment to agricultural engineering students.

Speaking of students, by 1925 the student branches had gained considerable strength and esprit de corps on a number of campuses. Some of their fairs and frolics were reported in the Journal. D. C. Heitshu of Virginia Polytechnic Institute claimed "the largest group of agricultural engineers to be graduated from any college in the country in 1925." They published an article on soybean harvesting in the "Journal of Agronomy," and conducted a number of other investigations. Some war-surplus vehicles were rebuilt by the students and one of them bought a Holt "Caterpillar" for his "horseless farm in Kentucky." Meetings, smokers, and a grand exhibit took time and energy but informed the campus that agricultural engineering was around. Heitshu foresaw a great 1926 because the agricultural engineering seniors were in dominant positions: class president, editor of the campus weekly, and high in the cadet corps.

At about the same time 53 members of the Nebraska student branch took over the Chase Plow Company and operated it for half a day. L. W. Chase (charter member and past-president) admitted it was a bit risky to allow the boys such a free hand, but as a former teacher he hoped it would prove 
educational. And it was! The students were astounded at how complex it was to manufacture such a simple machine as a two-row cultivator. (Apparently the company survived the ordeal!)

Following a recommendation of President McCrory, ASAE apparently sponsored some radio broadcasts in the Chicago area sometime in 1925, as an educational effort. The results were not satisfactory according to President Sjogren. He advised the departments of agricultural engineering to prepare their own radio talks and broadcast them from local stations wherever possible. He acknowledged the efforts of K. J. T. Ekblaw, who had delivered the ASAE radio talks. The members of the Agricultural Engineering Dept. at the University of Missouri gave a series of lectures over the local station in April and May of 1926. Topics on land clearing, drainage, planning farm buildings, selection of machinery, and water supply were discussed by A. J. McAdams, J. C. Wooley, and M. M. Jones. They were given on what is now called "prime time," 7:15 p.m.

On the Pacific coast, the University of California announced a professional course in May 1926. The student would spend the first three years studying engineering at Berkeley, the final year at Davis. A close relationship was claimed between the Agricultural Engineering Division of the College of Agriculture and the "College of Mechanics." The distribution of subjects was science, 24 percent; general engineering, 25 percent; general agriculture, 13 percent; agricultural engineering, 14 percent; cultural, military and physical education, and electives, 24 percent. A summer practice course was required which involved study of engineering problems on typical farms. L. J. Fletcher, head of the Agricultural Engineering Division at Davis, announced that a new building was under construction for his department.

Even as it is today, the college teacher of the 1920 s had a limited choice of textbooks for the agricultural engineering student. Among his manifold contributions, J. B. Davidson worked hard to meet this need. He was co-author with L. W. Chase of "Farm Machinery and Farm Motors" and author of "Agricultural Engineering." In 1925 John Wiley \& Sons announced its Agricultural Engineering Series, with Davidson as editor. That series contained these titles: "Farm Buildings" by Foster and Carter; "Farm Mechanics" by Robb and Behrends; "Land Drainage" by Powers and Teeter; and "Dairy Engineering" by Bowen. About a year later McGrawHill Book Company announced a series under the title of "Agricultural Engineering Texts." Dan Scoates was the series editor. It was proposed that two kinds of texts be developed - one for agricultural students taking work in agricultural enginering, the other for engineering students in the professional degree course. Scoates was the author, among others, of a 


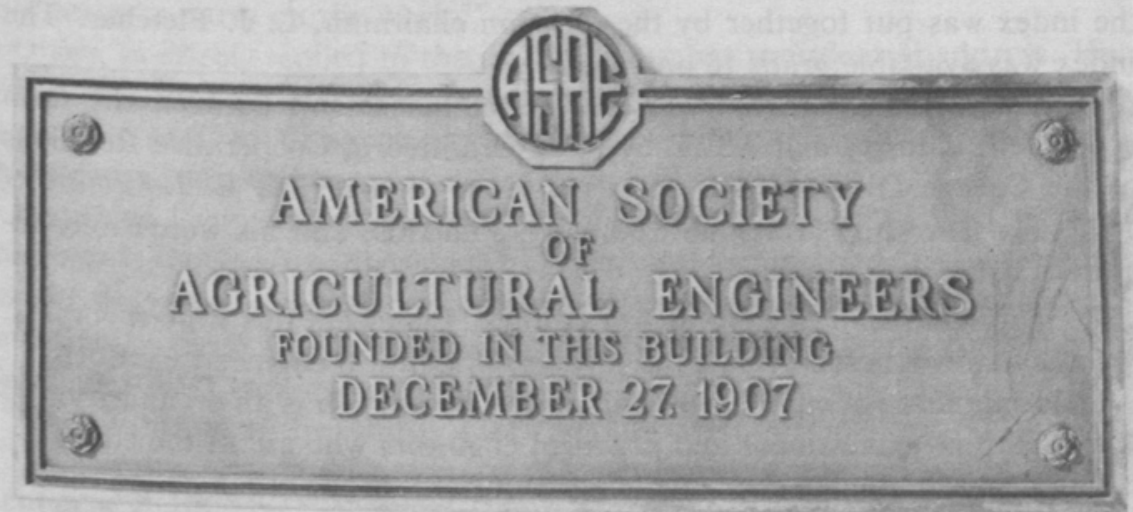

This bronze tablet appears in the agricultural engineering building at University of Wisconsin, Madison.

manual for use in machinery lab.

The Advisory Committee of the College Division met in Washington, D.C., March 7 to 9, 1927. Progress and action of 1926 were reviewed. It was determined that the aims and objectives of the Division were not clear and that action would be taken at the June meeting to straighten things out. It was decided to recommend to Council that a bronze tablet be placed at the University of Wisconsin to commemorate the founding there of the Society. Membership qualifications were creating trouble; the matter was referred to the Council. The educational institutions were called upon to provide only "good men" for employment by the implement industries. A campaign was planned to establish a national exhibit of agricultural equipment.

At its 1926 meeting the Advisory Committee attempted to standardize the conditions under which manufacturers loaned equipment to the colleges. They adopted a resolution covered most contingencies. One part of the resolution states that when such equipment is used for "regular operation on the college farm it shall be purchased by the college..." Evidently some of the colleges had been using the "loaner" machines for more than display and instruction, possibly arguing that they were "testing" or "demonstrating." 
ASAE's influence in education was growing. Creation of the College Division did much to strengthen this. Among its lesser-known accomplishments was completion in 1926 of an index of the first 19 volumes of "Transactions" and all volumes of AGRICULTURAL ENGINEERING. Actually, the index was put together by the Division chairman, L. J. Fletcher. The index was available gratis to any member.

Perhaps more significant was the interaction set up between the farm equipment industry and ASAE by the Committee in Cooperative Relations of the College Division. The 1926 president of NAFEM, E. J. Gittins of J. I. Case Threshing Machine Company, said this, and his words were inspired by the committee:

"The American Society of Agricultural Engineers fills a need for a force that can best correlate the various agricultural engineering efforts, including those of our colleges and of our industry. It is an organization made up of professional and practical engineers who are in the educational and producing branches of agriculture. It is one organization that can intelligently blend the engineering talent in the agricultural field. It is and will be a strong factor in securing support, financial and otherwise, for the agricultural engineering departments of our colleges. It can foster movements, make recommendations, and otherwise effectively exert influence in a way which cannot be duplicated."

The end of the decade, June 1927, saw degree courses in agricultural engineering established at these colleges: California, Iowa, Kansas, Michigan, Minnesota, Missouri, Nebraska, Saskatchewan, South Dakota, Tennessee, Texas, Utah, Virginia, and Washington.

\section{C \\ The Federal Government}

Interaction of ASAE with the federal government, mainly the Department of Agriculture, was marked from the beginning. Agricultural engineering work was started by USDA before ASAE was founded. Honorary member Elwood Mead took charge of its first irrigation research in 1898. Samuel Fortier, another honorary member, took over from Mead in 1907. R. P. Teele of USDA had presented a paper at the 1908 meeting in which he called for a bureau of agricultural engineering - and a committee was appointed. E. B. McCormick, tenth president, was chief of the Division of Rural Engineering in the Office of Public Roads and Rural Engineering at the time.

The second decade witnessed a quickening pace. President Olney, on October 1, 1919, sent a memorial to Secretary of Agriculture David Houston. It covered "the need and scope of a bureau of agricultural engineering" 
in USDA. Houston replied on November 21. His letter was basically sympathetic to the desires of ASAE and the profession; however, he said "I do not see the necessity at this time...for creating a new and independent organization to carry on the work."

Olney, in effect, replied to this in his December presidential address. He stated that through good member contacts in Washington a bill had just been presented to Congress for a separate bureau. Evidently Secretary Houston had his way because nothing came of the bill.

President Frank Kranich spoke in December 1920, of how glad he was that the USDA had a division of agricultural engineering within one of its bureaus; that its advisory committee was composed of ASAE members; and that its head was a "very active member." Kranich was referring to Samuel H. McCrory.

The problems of the cutover lands were a concern following World War I. Attempting to stimulate shaping of a national reclamation policy, ASAE sent a memorial to Secretary Henry C. Wallace over the signatures of President Lehmann and Secretary Olney on June 30, 1923. ASAE recommended establishing a land clearing section in the division of agricultural engineering of the Bureau of Public Roads. Proper care and development of these lands, regarded as a "heritage of enormous potential value," would be enhanced by focussing engineering talent upon them.

Wallace was not in town. His acting secretary replied that "it is desirable to enlarge the scope of this work...provided the necessary funds can be obtained from Congress." He went on to say that the economic aspects were under study by one bureau, the crop aspects by another, forest aspects by another, and grazing by yet another. So the cutover lands were receiving attention, but ASAE wanted this attention integrated and unified into a total policy. And got nowhere.

The members in Washington in 1924 raised the profession several notches by influencing the Civil Service Commission to conduct competitive examinations for "an agricultural engineer at a salary of $\$ 3000$ to $\$ 4500$ a year." The position called for research on agricultural machinery; design of machinery; and giving of advice on engineering and economic questions related to machinery. In addition the applicants had to be similarly qualified in the field of structures. They were to receive preference if they possessed a degree in agricultural engineering.

That same year, Dr. Earl White, director of the CREA, asked the USDA Office of Experiment Stations (OES) for assistance in developing a national research program on the relation of electricity to agriculture. OES designated member R. W. Trullinger to take charge of the project, because it involved agricultural engineering more than any other discipline. The 
Journal said of this: "Success in outlining a comprehensive investigational program will go a long way toward establishing a recognition of agricultural engineering as one of the most potent forces in agricultural development. It goes without saying that agricultural engineers of this country are entirely competent to formulate a comprehensive and fundamental investigation program."

McCrory, ASAE president in 1923-24, had been in charge of engineering work in the Public Roads organization. In 1925 he was made chief of the Division of Agricultural Engineering. The Division embraced irrigation, drainage, structures, mechanical equipment, and war surplus explosives. Upon adding a plans and services group, the Division received over $\$ 222,000$ for its first year's work. This administrative arrangement was beginning to look like the bureau ASAE wanted so badly.

McCrory's fine Division had barely been created when it was threatened by the American Engineering Council. AEC was sponsoring a government reorganization in 1925 which would put the Bureau of Public Roads under the Department of the Interior, including the Division of Agricultural Engineering. ASAE was horrified that McCrory and company should pass from the jurisdiction of Agriculture to the unsympathetic hands of Interior. A resolution was passed at the June 1925 meeting which instructed ASAE's representative to AEC to "use his efforts" to retain the Division of Agricultural Engineering within USDA. AEC responded sympathetically.

An editorial appeared in the November 1925 Journal announcing that the USDA was to undertake a "survey of the status of research in mechanical farm equipment." The survey was requested jointly by ASAE and NAFEM. In fact, at NAFEM's October convention a resolution of thanks for the survey to Secretary of Agriculture W. M. Jardine was passed. The importance of the survey lay partly in the need to reduce farm production costs. and partly to put the implement industry in a better economic position.

J. B. Davidson agreed to head the survey by taking leave from Iowa State and becoming a USDA employee. He and McCrory mapped out the preliminary procedure. Secretary Jardine appointed a 19-man advisory council, of whom 13 were ASAE members. Further involvement included the departments of agricultural engineering and the ASAE Research Committee. M. L. Nichols, head of the Department of Agricultural Engineering at Alabama Polytechnic Institute, was chairman of the Research Committee. He had a long editorial in the January 1926 Journal on the survey. He stressed that the departments at the colleges should do all in their power to advance the survey, since they would carry out the major part of the research to be planned. Unfortunately the experiment station administrators had little faith in the ability of agricultural engineers to plan and carry out good re- 
search; therefore they would not get much money. But the survey would give them a new chance to plan and carry out fundamental work of real distinction. The need was for "fundamental" research: determination of specific agricultural requirements for a given class of machine. Projects should be limited to a feasible scope. The national program of research in farm equipment could be a great step forward, Nichols said, but it would also involve serious individual responsibility.

Davidson went to work on the project January 1, 1926. He delivered a report to the members at the June meeting at Lake Tahoe. It was a comprehensive statement of background and inspiration for a quantum jump in quality and quantity of agricultural engineering research. It contained some excellent sources of data. It also contained some basic truths such as the statement that "there is a general lack of appreciation of the services of the engineer." Davidson had to quit the project shortly after. It was to be continued by McCrory's Division, with the help of the advisory council. Once again Davidson gave the profession a good shove forward.

In 1927 the Bureau of Agricultural Engineering question became hot again. Olney, in his January 10 Secretary's Letter, asked the members: "Do you want a separate Bureau of Agricultural Engineering....at Washington? Do you want it badly enough to fight for it?" He urged every member to write Secretary Jardine. The Department of Agriculture had to be convinced first, then Congress.

The following month a resolution went to Jardine recommending a separate bureau. It stressed that McCrory's Division should be divorced from Public Roads and elevated to Bureau status. Signed by Olney and President Oscar Sjogren, the resolution was dated Februrary 2. It gave rise to an editorial by Sjogren in the February Journal. He said: "Every member has an opportunity to assist in one of the biggest jobs we have ever undertaken."

Arnold P. Yerkes was editor of International Harvester Co.'s "Tractor Farming." For many years previously he had worked (and very successfully) as an agricultural engineer for USDA. In a later issue of the Journal he plucked all the familiar strings as to why a Bureau should be created plus another one worth quoting:

\footnotetext{
"From the standpoint of the amount of money invested by American farmers in equipment falling within the scope of the agricultural engineer and their annual expenditures in this field, as compared with the amounts of money invested and expended along other lines, a Bureau of Agricultural Engineering is more than justified. The fact that such a bureau has not already been created in the Department of Agriculture undoubtedly accounts to a considerable extent for the failure of our
} 
state colleges, as a whole, to appropriate adequate funds for carrying on sadly needed research and extension work in agricultural engineering, which would have been of immense financial benefit to American agriculture if carried on."

Olney's February 5 Newsletter begged those members who hadn't written Secretary Jardine to do so. Attached were excerpts from some letters. These are worth examination:

"The farmer today needs help, not by the temporary means of legislation but by the permanent method of learning to produce at less cost."

"If agriculture is to prosper, the same engineering principles which are increasingly applied to other industries must be applied to it."

"We are not unmindful... of what the USDA, through $R$. W. Trullinger, has been able to do to strengthen our research... If the creation of a bureau of agricultural engineering would do no more than multiply his activities by fifty, it would seem a thing highly to be desired."

By March 21, Olney had to report a discouraging word from Jardine (who was probably tired of opening his mail). As with Secretary Houston back in 1919, Jardine did not feel the time was opportune for McCrory's crew to be elevated. The story was similar: provision must be made for "adequate financing." Heavy demands on his budget (the European corn borer, for example) left him in a bad position for such a major move. So Olney acknowledged another defeat on the Bureau issue. He believed he had lost only a skirmish, however, not the war. He advised the members to "keep it continually agitated." Sjogren appointed a special committee with a mandate to do just that and everybody would talk it over at the June meeting at St. Paul.

Were the members as concerned about the public welfare as they claimed? Many were honest enough to want the Bureau because it would confer prestige on the profession and raise its stature in the USDA, if not elsewhere. This interaction stretched across the whole decade and created a consistent harmony of purpose, a goal, for ASAE. While the activity had its self-serving aspects, it was not a mean or contemptible goal. When the Bureau was created in 1931 it did not last very long; this suggests that such a configuration was not well suited to solving the real-life problems of the Department.

\section{D \\ Research}

The first 10 volumes of "Transactions" contain little or no original research. The papers embalmed therein are sometimes valuable today for other reasons, but rarely for scientific merit. 


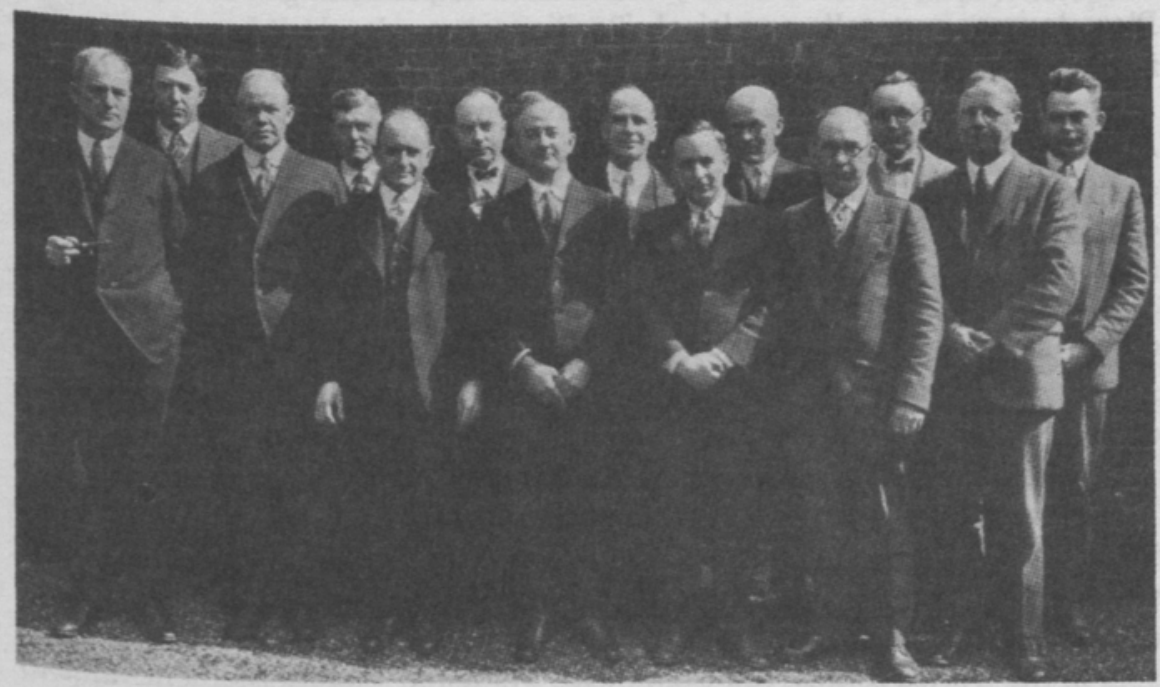

This picture was taken during a meeting of the Advisory Committee of the College Division of ASAE at Washington, D.C., March 1926. (Left to right, back row) R. B. Gray, R. U. Blasingame, R. W. Trullinger, J. B. Davidson, William Boss, L. J. Fletcher, C. D. Kinsman. (Front row) H. H. Barrows, S. H. McCrory, L. A. Jones, M. A. R. Kelley, C. E. Seitz, H. H. Musselman, and M. C. Betts.

The Research Committee was number one in the list of standing committees in the constitution. While this indicated respect for research by the founding fathers, it was many years before respectable research began to become a regular feature of the meetings.

The second decade opened with a slow start. No report of the Research Committee was offered at the 1918, 1919, or 1920 conventions. Examination of papers entitled "Tests" or "Investigations" or "Influence of..." delivered at those meetings is disappointing. Few contained actual data derived from controlled experiments.

However, 1920 witnessed the first research review by R. W. Trullinger. $\mathrm{He}$ analyzed agricultural engineering research, American and foreign, in all the recognized subdivisions. He classified an enormous (11-page) bibliography. Sparing no one, he charged that the members were working mostly to meet "immediate needs in the solution of a specific problem." Also, they were making little effort "to increase the basic knowledge of agricultural engineering."

As an example, Trullinger noted that aside from work done by Dr. Earl A. White no real research had been done on plows since Thomas Jefferson, "although there has been a lot of costly experimentation." That this led 
to nowhere was proven by the myriad number of plow designs on the market. Plow design was totally empirical; Trullinger was clearly opposed to empiricism and favored the scientific method.

Thus was launched ASAE's research arbiter and persistent gadfly. Although he probably never personally conducted an experiment, Trullinger could recognize good research; it was his job. As a specialist in the Office of Experiment Stations he spent much time visiting the agricultural engineering departments, so he knew what was going on. He was well read and quite articulate. He was accustomed to the society of scientists serving various sectors of agriculture; therefore, he possessed standards of comparison. His attempts to raise ASAE's standards created enemies but he never ceased pleading the cause of good research.

In 1921 Trullinger emerged as chairman of the Research Committee. The committee report was another roundup of "Research in Agricultural Engineering." The report noted that seven experiment stations had been working on tractor economics, usually in departments other than agricultural engineering. Because over 300 different types of tractors were being sold in the United States, the Committee wondered what permanent value to agricultural engineering might arise from the mass of statistics being produced by the economists.

In 1921 the custom had commenced of submitting research projects to the Research Committee for comment and criticism. The practice could not fail to have good effects. The Committee included, besides Trullinger, men like E. V. Collins, O. B. Zimmerman, L. J. Fletcher, and O. W. Sjogren.

That year also brought a few more papers of potential long-term value. For example, M. A. R. Kelley of USDA started publishing his work on farm building ventilation systems. Although he reported only results of field tests, he introduced basic data on animal heat and moisture production into his papers and related that data to environmental conditions.

Some may be surprised to learn that ASAE used to directly sponsor "research," although apparently no money changed hands. The 1921 meeting heard reports from the "Disk Harrow Investigation" and the "Left Hand Plow Investigation." Both these investigations concerned implements whose manufacture had been stopped as a World War I measure (the cutaway disk in the first instance) of industrial economy. The companies were making them again and ASAE was asked to decide whether their continued manufacture was justified. E. V. Collins' report on the disk harrow indicated that the cutaway disk was of low value, but the committee was not ready to entirely condemn it. G. W. McCuen (Ohio State University) reported a tremendous amount of fact-finding with respect to the 
left-hand plow which boiled down, as he said, to "a question of psychology."

Trullinger published an article on "Research in Agricultural Engineering" in the December 1921 Journal. He acknowledged that the profession originated as a teaching subject and had only gradually become a field of investigation. Because of this, much of its subject matter was badly in need of "inquiry along advanced lines." He found that the station projects were "rather elementary," with "very few projects of actual research grade." He disclosed that the ASAE Research Committee had conducted a survey which revealed 50 promising lines of investigation. The important role of ASAE in helping to establish cooperative relations between state and federal agencies and between institutions in the states was emphasized. And finally "if this specialty is to grow it must be through research which is searching and severe and the department must not be exclusively a teaching and service department or restricted wholly to practical affairs."

The 1922 report of the Research Committee was another Trullinger compendium. These reports are confusingly titled "Research in Agricultural Engineering," suggesting that the work reported was done by members of the profession. Trullinger, however, included all work which he thought had application to agricultural engineering no matter who performed it. He ended the report with these words: "The growth of the research spirit has been so marked during the year that it would not be practical at this time to draw conclusions as to the most important lines of future endeavor."

The 1923 report also was prepared by Trullinger, who concluded that "while there is a marked growth in the research attitude, much is yet to be learned about the best methods of approach to problems for study." In his nagging way, he pointed out that every subdivision of the profession needed physical and biological requirements established before machinery, farm structures, or irrigation and drainage methods could be designed. (Surely he must have known that farmers and implement manufactures couldn't wait around while the college men spent time and non-existent money doing all that!) And he concluded with another idealistic broadside that "agricultural engineers must...strengthen their cooperative relations with the other branches of agriculture if they expect to maintain a position of equal scientific and professional standing." Good advice, but it's hard to "maintain" something you don't have to start with!

More work was reported in 1923. F. W. Duffee at the University of Wisconsin had started to research the silage cutter. A. W. Clyde and Henry Giese at lowa State reported work on barn roofs, which for Giese was the outset of a long and distinguished career in farm structures (Clyde switched to machinery later). H. B. Walker contributed to the technology of household sewage disposal, and O.V.P. Stout, now with USDA, reviewed seepage 
loss measurement in canals. One of the interesting researches of 1923 was done for Wayne Dinsmore's Committee on Animal Motors. E. V. Collins built a special dynamometer at Ames for testing the power of horses; he found that over a short time and distance horses could develop quite a lot of horsepower, about 6 to 15. The work was done during the horsepulling contests at the state fair.

CREA national of course had asked OES in 1924 for assistance in developing their national program of research; Trullinger was put in charge. Evidently he worked fast because he presented a report at the June 1924 Annual Meeting on "Some Research Features of the Application of Electricity to Agriculture." A typical Trullinger job, it comprised 28 printed pages in the "Transactions" plus 111 references at the end. It is astounding that he could turn out such volumes of work. Less than a year later he wrote Olney that the Department had pared office expenses to the point that it was difficult to get typing done; the letter was in his handwriting. In fact, he complained that "Everything I am doing for the Society now is being done in my own time at considerable personal expense..." However, within a few days his letters were again being typewritten.

Something was stimulating interest in research methods that year. A non-member, W. L. DeBaufre, discussed "The Fundamentals of Research" at the 1924 Annual Meeting. His viewpoint was the need for research by business concerns; that is, the fundamentals of industrial research. He said that "research in engineering...must be carried to fruition by the installation of a new...process or machine or the production of a new article of manufacture or an improvement thereon..." His views may have left some of the college people unsatisfied.

Earlier, Trullinger had started a new feature in the January Journal. Entitled "Research Methods in Agricultural Engineering," it was sponsored by the Research Committee. The initial contribution, described by Trullinger as a "masterpiece," was written by member Earl S. Patch of the General Motors Research Corp. Its title was "The Place of Research in the Agricultural Engineering Field." It was an excellent plea for more and better research, with emphasis on scientific methods that would create findings of lasting value. Patch looked at all sectors of the profession and found them deficient. As he said:

"In spite of the evident need therefore, the organization for research in the field of agricultural engineering is pitifully inadequate. Very few of the larger companies... have what can be truthfully called research departments. Usually these organizations have little more than experimental departments... [They] do not feel that is is necessary to incorporate...research procedure in their experimental departments in order to 
develop and improve their products. In this state of mind...the advancement of manufactured products on the basis of hit-or-miss experimentation has always been doubtful.

"Some of the agricultural experiment stations are equipped to do a certain amount of this work, but...it is questionable whether the advances possible can be made to any very practical extent with the limited funds and personnel usually available. The attitude of most manufacturers of implements toward the work of public institutions is usually not very favorable."

Furthermore, Patch stated that since manufacturers were "too lethargic" to improve their own equipment, the resources of the public agencies should not be devoted to such work. He called attention to strides made in the electrical and automotive industries through scientific research and saw no reason why farm equipment should not follow suit instead of taking pride in their old designs. The experiment stations should be encouraged to establish "broad, general fundamental principles in agricultural engineering which may be used by the different farm equipment industries as foundations for development..." All this was, of course, flying in the face of reality, but its idealism so matched that of Trullinger it is easy to see why he thought the paper was a "masterpiece." Some of these goals did come to pass eventually.

Patch outlined an expanded mandate of the Research Committee which bore Trullinger's imprint. The committee had gone beyond merely "reviewing" and "stimulating" research. It had commenced giving "both specific and general advice on the research phases of problems in agricultural engineering." Members were encouraged to submit projects to the Research Committee for private review and advice. Also, the new Journal feature "Research Methods..." would become a medium for public analysis and discussion of problems of "timely importance" in which all members might receive guidance and inspiration.

Prosecution of such a program would have demanded from Trullinger mostly that which he did professionally anyway; review of research projects in the state experiment stations was his business! This work was necessary (and still is) to assure that the federal funds were spent properly. A good reviewer had influence in broadening the minds and improving the talents of the researchers. A bad reviewer was merely obnoxious and officious - something to be tolerated. Trullinger was undoubtedly an excellent reviewer; his position as chairman of a Research Committee that was growing in stature gave his capacity an enlarged stage.

M. L. Nichols of Alabama, a member of the Research Committee, came along in February with a paper on "Agricultural Engineering Research in 
Farm Field Equipment." He pleaded for strengthening of the ties with agronomy and soil mechanics so that the needed fundamental facts could finally emerge and be used by industry.

Trullinger himself handled the March "Research Methods..." paper, this time on fence posts of wood. He analyzed the problems thoroughly and included a voluminous and up-to-date bibliography.

W. H. McPheters of Oklahoma A. \& M. gave a detailed appraisal of "Soil Erosion as a Research Problem" in July. A method of measuring loss of organic matter was discussed by quoting a long Trullinger letter. The phases of soil erosion that required research were, according to McPheeters:

1. Value of humus in soil to retard soil erosion.

2. The grade to give a terrace for the different types of soil and slope of land.

3. The comparative efficiencies of the variable and constant grade of terrace.

4. The fall between terraces for different slopes.

5. Amount of soil leaving an acre of land with each acre-inch of water on various types of soil and slope of land.

6. The value of terracing on the conservation of moisture.

The October "Research Methods..." was written by R. H. Driftmier of Kansas State. His topic was "Investigation of Farm Sewage Disposal Systems." He asked for close cooperation between biologist and engineer because such investigations have the "most sound fundamental results."

Trullinger published another "Research Methods..." in the November Journal on "Fundamentals of Ventilation of Animal Shelters." His masterly review suggested that field studies of animal shelters ventilation had left the art in a state of some confusion and contradiction. His solution was in agreement with the ASAE Committee on Farm Building Ventilation: do the research under controlled conditions, if necessary in respiration calorimeters.

Research reported in 1924 in the Journal did not reach the quality demanded by the "Methods" theorists, but it was improving. Duffee at Wisconsin was still testing silage cutters. M.A.R. Kelley of USDA tested barn ventilation while his brother J. B. at the University of Kentucky discussed tobacco barn research. G. W. McCuen at Ohio State reported on a new dynamometer. C. D. Kinsman released voluminous results of the USDA national survey of farm power showing that cost of tractor power was much less than that of horse power. And L. J. Fletcher editorialized that "Research is in the air."

To Fletcher it didn't matter whether the subject was "love, lubrication, or lockjaw," the thing to do was start. "If you are still shivering on the bank 
of the research pond, kick off the ball and chain and jump in."

The 1925 year opened with repetition of an announcement that General Motors Research Corporation would lend three pieces of testing apparatus to state or federal institutions engaged in agricultural engineering research by application to ASAE's Research Committee. The items were a Watson dynamometer arranged for recording draft up to 6000 pounds, a Hyatt recording hydraulic dynamometer, and a small dynamometer car for the Hyatt instrument. This would relieve impoverished departments from the necessity of building dynamometers and plunge them faster into Fletcher's research pond.

Deane G. Carter, University of Arkansas, published a "Research Methods..." in February on "Major Problems in a Study of the Irrigation of Rice by Pumping." The article had 71 references; Carter explained in a footnote these were prepared by Trullinger.

The indefatigable Trullinger waded into the March and April Journals with a long disseration on "Soil Colloids and Tillage." He told Olney it took him three years to write the article. He had hoped that "some of our tillage experts would hit onto this matter before but...they play all around it like a sunfish around a worm but they refuse to bite." Trullinger believed that colloids and an understanding of them were essential to understanding the physical phenomena of tillage and soil dynamics.

M. L. Nichols published "The Sliding of Metals Over Soil" in April, which fitted well with Trullinger's colloid analysis. Nichol's paper was a contribution to the "Research Methods...," now just called "Research..." When Trullinger sent the manuscript to Olney his covering letter stated that "...this work is one of the most fundamental and important pieces of agricultural engineering research with a truly practical objective which has ever been reported by any member of the Society." It had application to design of tillage and traction machinery and explained empirical findings of others. To quote him further:

"While not any too well presented, ...this is a masterly example of what should comprise fundamental research in agricultural engineering. Not a single case of comparative tests of things we already know is included."

Trullinger was convinced that this was the kind of work which would lead to "permanent friendly relations with the implement industry." However, the Nichols paper reported research done with a piece of plow iron pulled through five kinds of synthetic soil; moisture and temperature of the soil were varied. The industrial people probably found it difficult to see how the results were going to affect plow design. It would demand patience from both sides. 
Nichols and J. W. Randolph returned to the "Research..." section in the June Journal. The paper was titled "A Method of Studying Soil Stresses." The method involved use of thin paper layers followed by plaster casts, after distortion of the soil, to allow study at leisure. The excellent concurrent measurements described by the authors suggest why the USDA National Tillage Machinery Laboratory was ultimately established at Alabama Polytechnic Institute (now Auburn University) in 1935.

Speaking at Madison on June 24, 1925, President H. B. Walker noted that "Our Society has been fortunate in having its Research Committee headed by a man who devoted his entire time to the experimental and research fields." He added "It is apparent...that agricultural engineering is hampered in its growth by a dearth of organized and properly digested facts, and a lack of many undiscovered truths."

The Director of Research at Cornell, $R$. W. Thatcher, delivered an address at the 1925 North Atlantic Section meeting on "Fundamental Research in Agricultural Engineering and the Purnell Bill." It was printed in the August Journal as "Research in Agricultural Engineering." The Purnell Act would provide increased funds to the agricultural experiment stations. Thatcher reviewed the chances of agricultural engineers for obtaining some of this money. He stated that he felt engineering was in the "job" or "service" category, with little or no research involved. He suggested that engineers should organize research to ask what engineering problems are involved in the different phases of agriculture; that is, what are the engineering features of tillage, land drainage, etc? He warned against research organized into problems of various "engineering sciences," such as application of mechanics to agriculture, etc. In other words, the program should be worked up in terms of the needs of agriculture, and should yield principles of a general nature. After Thatcher finished, Trullinger rose to say that Thatcher had expressed in a few words the ideas which the Research Committee had been trying to impress upon the Society: to be real research, a particular problem must deal with the fundamentals.

In the September Journal Trullinger aired his views on "The Problem of Research in Farm Equipment," which was originally presented to the Power and Machinery Division in December 1924. As usual, he was painfully blunt, saying that neither the profession nor the manufacturers had kept pace with agricultural science and practices, leaving the farmer as the "goat." He thought it was high time for the "agricultural engineer to crawl out of his shell of professional...reserve and for the manufacturer to melt his armor of business disregard for scientific facts, and for the two to get together..." Such a move would be only in the best interests of the farmer and the consumer. And the best way to accomplish such cooperation, said 
Trullinger, "is by undertaking active membership in the American Society of Agricultural Engineers."

The 1924-25 report of the Research Committee was again the product of Trullinger's pen and experience. It was an analysis of "Agricultural Engineering at the Experiment Stations." Its somewhat gloomy conclusion was that there was "a still too frequent tendency to limit agricultural engineering work to comparative tests of...different...apparatus and methods to meet agricultural requirements for engineering manipulation when the development of new principles or the fundamental modification of old ones are really necessary." He also called for cooperative effort by groups of stations on common problems to reduce duplication and cause different work phases to be allocated where they could best be handled. This, of course, was the "regional research" concept which came into sharp focus and efficiency after World War II.

The last "Research..." article of 1925 was written by H. B. Josephson of Pennsylvania State College, where it was discovered that 65 percent of the cost of producing corn was due to power and labor. The agricultural engineers drew up a research project designed to create machines and management systems which would reduce power and labor. The project was submitted to the OES, where evidently $R$. W. Trullinger gave it a blessing, because the Penn State engineers recieved some of the Purnell Bill money. Although Josephson used the word "fundamental" several times, the "plan of attack" reads suspiciously like just another set of comparative tests with emphasis on "immediate, practical value."

M. L. Nichols took over the Research Committee during the 1925-26 year. His editorial in the January 1926 Journal about Davidson's survey of mechanical farm equipment has been alluded to already. The editorial was important because it expressed "official" Committee doctrine and because Nichols himself was vice-director of the Alabama Agricultural Experiment Station. Nichols plainly stated that no station director would approve projects consisting merely of variety tests. Then he wrote:

"In the farm machinery field there is now even less reason for simple comparative testing than there is with live materials. The manufacturer should, and does, do this himself. The trouble lies mainly in the fact that most of our machines, due to the lack of fundamental information, have been designed by the cut-and-try method. As the Research Committee sees it, the manufacturers are interested in the experiment stations, mainly in the hope that they can secure the information to improve the design of farm machinery without the necessity for following the expensive cut-and-try method."

This was a large order to place with the agricultural engineering de- 
partments. Many of them were staffed by two or three men. These men had to meet their classes and do the extension work as well as the research. They had to compete with the entrenched agricultural disciplines, many of which regarded agricultural engineering as little better than blacksmithing.

President F. A. Wirt, in his address to the NAFEM convention in 1925 , gave some revealing figures on the posture of agricultural engineering research. He said that in fiscal 1924-25 the experiment station projects totalled 6594. Of those, agricultural engineering accounted for 189, less than 2.9 percent. Field crops, horticulture, animal sciences, soils, etc., took care of all the rest. Why such a dismal showing? Wirt claimed it was because the engineers had no farm organization to speak for them at Washington and the state capital. Wirt didn't say that many station directors, as Nichols had the nerve to state in the Journal, had no faith in the engineers' ability to do acceptable research, but the latter was more likely the problem. Earl White was probably the single Ph.D. in ASAE. The members at the experiment stations probably found this a disadvantage, also.

Trullinger counted projects late in 1925 on a different basis. He counted as agricultural engineering those projects in other departments on topics such as drainage, soil erosion, irrigation, etc. When counted that way he found 404 "agricultural engineering" projects underway at the 48 experiment stations. Trullinger's count was much more encouraging than Wirt's in terms of results applicable to agriculture but not in terms of professional prestige, since his figures were padded.

In March 1926 E. G. McKibben of the University of California published "A Study of the Dynamics of the Disk Harrow." The author used considerable theoretical analysis to predict optimum hitch points of multiple-gang harrows so that they might be drawn without side draft. The Research Committee considered the paper an excellent example of how engineering knowledge and analytical methods could solve problems easily and quickly in contrast to the cut-and-try method which was wasteful and often ineffective.

McKibben made the "Research in Agricultural Engineering" feature again in 1926 with his analysis of "The Soil Dynamics Problem." The paper called attention to the multiple variables underlying the soil dynamics field and to the need for strong cooperative research in tackling the problems. "There is not one scientist or farmer who is able to state in definite terms the optimum state of tilth for any one type of soil for any one variety of plant," he asserted.

The Research Committee presented J. W. Randolph's study of tractor lugs on sandy soil in May 1926. The study was done under laboratory con- 
ditions but was sufficiently detailed to yield adequate design information. Unfortunately the days of the lug were numbered because the rubber tire was soon to replace it.

Speaking before the 20th Annual Meeting at Lake Tahoe, Trullinger this time needled the irrigation and drainage specialists. He argued that much fundamental data on soil properties and behavior were available but that the engineers failed to use it. The most important data concerned the moisture behavior of soil. Without using such information, "the design of an underdrainage system for a certain soil can be based on speculative knowledge only." And 97 current references were appended to the paper. Few authors listed any references during the first and second decades, but Trullinger tended to make up for all of them! In reviewing the entire research picture for 1925 , Trullinger said at the same meeting that "substantial" progress had been made during the year.

The December 1926 meeting of the Farm Power and Machinery Division revealed what the machinery men were then researching. The combine harvester was spreading into the humid areas of the U.S. and reports of testing these machines emanated from Wisconsin, Illinois, Pennsylvania, Ohio, North Dakota, Indiana, Saskatchewan, and Alberta. C. D. Kinsman gave a preliminary report on an ambitious USDA study of combines. The corn borer control problem was growing; reports of research on this came from the USDA and Ohio State University. G. W. McCuen of the latter institution discussed his progress toward motorization of corn production. Frank N. G. Kranich of Timken Roller Bearings said that no progress had been made with the power take-off because of lack of standards between manufacturers of tractors and of driven machines. A member named Thomas D. Campbell had leased 100,000 acres of Indian reservation in Montana and had developed a highly engineered system of producing wheat. A film showing the latest form of the Farmall tractor was sent to the meeting by $B$. R. Benjamin, experimental engineer of the International Harvester Company. J. B. Davidson indulged in some visions of tractor research; changes in fuels and radical reduction in draft seemed well within reach to him.

The Research Committee sponsored in January 1927 the landmark series of seven papers on "The Kinematics and Dynamics of the Wheel Type Farm Tractor" by E. G. McKibben. The author applied the laws of mechanics to an idealized tractor to obtain insight into stability, external forces, soil reactions at the wheels, drawbar pull, and similar items. The theoretical values obtained were checked by laboratory studies. McKibben shared one attribute with Trullinger and Nichols: he didn't mince words. In his brief introduction to the now classical set of papers he said "If the agricultural 
engineer... is to earn and hold a recognized place among other engineers, he must have more than the garage mechanic's conception of the tractor. He must visualize the tractor as a unit and have a clear conception of all forces acting upon it. He must be informed concerning the fundamental laws of mathematics and physics which govern its... responses to these forces. In no other way will he be able to make the tractor perform its maximum service."

There were 43 conclusions to McKibben's papers. These are impressive even today because of their basic knowledge of tractor design; indeed. their application to safety alone would have justified ASAE's printing of his work. In addition, he presented some "crude apparatus" (his words) for use in lecture demonstrations. It is to be hoped that Trullinger's efforts over the previous years had their effect upon this "junior agricultural engineer" from California.

Perhaps Trullinger's 1926 paper on soil moisture encouraged deeper study. He published a two-part series on "Factors Influencing Soil Moisture Regulation" in June and July of 1927. These articles were "intended to lay a foundation for a program of research in the regulation of soil moisture" because the subject had influence upon drainage and irrigation practice and upon cultivating and tillage machinery design.

Other areas received research attention near the end of the decade. The Research Committee sponsored a long article by Henry Giese on methods of investigating air requirements of poultry. Randolph continued his work on tractor lugs. F. W. Duffee began working on the grain drying problems introduced by the combine. George W. Kable (Oregon Agricultural College) reported on feed grinding research, just one of the farmstead engineering processes made possible by rural electrification. E. G. Lantz was invited by Trullinger to present his work on farm fires. A. W. Farrall (University of California) commenced his research on dairy equipment sterilizers, the beginning of a career which undoubtedly helped to create food engineering as an ASAE branch.

The second decade witnessed the real start of agricultural engineering research. Without ASAE's coordination it never would have occurred. Robert $\mathbf{W}$. Trullinger was a key figure in this process. The Journal provided him the crucial platform, the Research Committee gave him standing, and the meetings afforded personal contacts. He used the Journal for more than articles and analytical reports. In 1921 he started a monthly abstract list of literature titled "Agricultural Engineering Development.". Under other titles such as "Survey of Agricultural Engineering Progress" and "Agricultural Engineering Digest" this valuable feature was continued on into the third decade. The literature abstracted originated worldwide and covered 
every possible technical area of interest; Trullinger was not parochial in his outlook.

Also, of course, the Journal and the "Transactions" provided an outlet for the increasing volume of research papers considered worthy of print. Thanks to the untiring efforts of Raymond Olney and his office, by 1927 the Journal had grown from a feeble start to a volume comprising 358 pages, including an index; much of this growth was due to research.

Most of the research work reported was not of the kind so ardently desired by Trullinger. He himself was well aware of the need for immediate answers to pressing problems, problems whose urgency could disappear quite soon. The industry men and public service men alike had to cope with such problems. Yet Trullinger's constant demands for "fundamental" research probably reacted sometimes on those with time and capacity to do it. The results nearly always proved to be of lasting value, which raised the stature of agricultural engineering and the persons involved. Trullinger helped to change agricultural engineering research, to start it on the path away from "cut-and-try" and toward the scientific method. He told them how to do it!

\section{$\mathbf{E}$ \\ Technical}

The Nebraska Legislature contained farmers with unhappy tractor experience; it passed a tractor testing law in 1919 without a dissenting vote. Each make and model of tractor sold in the state had to be tested by a board of three engineers at the state university.

The Nebraska Tractor Tests were firmly established in 1920. ASAE's attempts to standardize motor contests and tractors themselves also created background, incentive, and need for the Nebraska Tests. Many ASAE committees contributed to this development in many ways, including vital interaction with manufacturers, trade associations and other technical societies. The original Test Board was composed of members L. W. Chase, O. W. Sjogren, E. E. Brackett, and J. W. Haney. C. K. Shedd was engineerin-charge.

Sjogren in 1920 was head of the Department of Agricultural Engineering, University of Nebraska, which had full charge of the tests. He published a paper in 1920 "Transactions" which summarized the current situation. In that year, he wrote:

"One-hundred and three applications for testing tractors were received for the season. Of these sixty-eight appeared for test and thirtyfive had their applications cancelled and temporary permits withdrawn. Of the sixty-eight which appeared for tests thirty-nine went through 
without any changes while twenty-nine made changes as follows: four changed the rated engine speed, eleven changed some item of equipment, and three withdrew after being on the preliminary test. Of the eleven which changed equipment, two also changed their rating. One of those which withdrew later made a re-application and appeared and finished the test. These results in themselves I believe speak very loudly for the necessity of a method of testing and rating of tractors as has been carried out under the provisions of this law. These tractors have all been tested under conditions as nearly uniform as it is possible to obtain them by a competent force of men who have been unbiased and unprejudiced."

It must be noted that the Nebraska engineers had to draw up the rules of the game. Although ASAE's Standards Committee was working on a tractor testing code it was not yet available; however, much preliminary thinking had been done. Sjogren commented that the performance of a large number of tractors conformed to the "recommended standards of the [ASAE] and the Society of Automotive Engineers." This referred, of course, to the "unofficial" standards.

The Nebraska Tests were quickly accepted by ASAE, not surprisingly. The Subcommittee on Tractor Ratings proposed a "Standard Code for Testing Tractors" at the 1921 convention. The code contained the phrase "Nebraska Results May be Accepted" in lieu of certain tests. Also, the maker was given a choice of two drawbar rating tests, one of which was the test "conducted by and under the rules of the Nebraska tractor tests." In the discussion, Subcommittee chairman G. W. Iverson mentioned University of Nebraska as the "standard" testing place. One member of the subcommittee was $\mathrm{O}$. W. Sjogren.

The worldwide importance of the Nebraska Tests today indicates that this may be one of ASAE's greatest achievements. It would be pleasant to add that the two legislators who introduced the bill were influenced to do so by, say, L. W. Chase. Unfortunately, no evidence exists to suggest such an event. Wilmot F. Crozier, who wrote the bill, was a farmer and educator as well as legislator. He told Professor Chauncey Smith that the idea of the bill occurred to him while reading an editorial in a farm paper which commented on the undependability of many tractors. In 1916 and 1917 Crozier himself purchased two tractors that were satisfactory. These men could have been acquainted with Chase's testing work at Fremont, Nebraska, by 1917, for example, and thus been inspired to turn the testing over to Chase's department. But that is speculation. It is a fact that the test codes of ASAE (and SAE) strongly influenced Nebraska testing procedures over the years. 
The development of a standard is rarely easy. In ASAE's youth, the Tractor Testing and Rating Code underwent years of argument and debate (even though some provisions were useful) before final endorsement by the Standards Committee in early 1923. It was then ready for submission to each member of the Society to vote upon, believe it or not!

The Code's test provisions were very similar to those used at Nebraska. The Testing Board was to be composed of at least three and no more than five "disinterested" engineers. These were to be selected from ASAE, SAE, ASME, or state college staff, with approval of ASAE. The board was responsible to the chairman of the Farm Power and Equipment "Section." An elaborate mode of choosing the board was adopted, presumably to minimize possibility of bias.

The Secretary's Letter of April 2, 1923, had the standards letter ballot attached to it. Members were asked to approve adoption of a standard dairy barn manger and a standard set of litter carrier sizes as well as the tractor code. They could also write in exceptions if they wished. The tractor exceptions were to be turned over to Sjogren at Nebraska in preparation for a conference with SAE and NAFEM. The conference was intended to approve the tractor test code.

This set of events finally created a testing and rating code standard after many years of hesitation and debate. NAFEM adopted the code in April 1925 and recommended it to the tractor industry. SAE approved the code as a standard in June 1925.

Recognition followed. Olney sent the members in October 1926 a clipping from a Peoria newspaper. It was an advertisement for the Twin City tractor built by the Minneapolis Steel and Machinery Co. and contained this statement: "The Twin City tractor is now rated in accordance with the formula of the American Society of Agricultural Engineers from results of tests made at the University of Nebraska in May, 1926." As Olney said, "it was gratifying."

Interest in the general-purpose tractor was already in evidence-one such tractor (the Farmall) appeared during the second decade. Was Bert Benjamin of the International Harvester Co., principal developer of the Farmall, inspired by ASAE meetings and literature? In 1943 he was presented ASAE's Cyrus Hall McCormick Medal primarily for his achievements in developing a tractor which not only functioned accurately in row-crop culture but also provided adequate power at the drawbar. The Farmall extended full mechanization to the growers of corn, cotton, potatoes, vegetables, fruits, and many other crops.

William C. Zelle, president of the Zelle Tractor Company, authored an article in the 1920 Journal titled "What Form Will the Tractor Ultimately Take?". Zelle was sure that the tractor would become attractive to farmers 
when it could replace work animals and portable engines entirely. The demand for capacity to cultivate row crops was, he felt, bound to become significant. Motor cultivators could not do this nor could they draw plows, etc. At least two rows should be cultivated at a time, without undue soil compaction; to do this, a four-wheel tractor would be required, with gauge and clearance as currently adopted for corn and cotton implements. He recommended attaching a harvesting cutterbar at the rear of the tractor and then operating in reverse when harvesting. Four speeds forward and at least two in reverse were desirable. Large wheels were considered essential, along with a belt pulley. With drive at the rear wheels, for safety enough weight should be on the front wheels to keep them down. The tractor should be designed as a complete machine with all its attachments, including a power lift for them, and a power take-off to replace the bull wheel of mowers, binders, etc. Finally, its design should allow safe and effective operation by "unskilled and even ignorant labor."

The general-purpose tractor was set back by World War I. As L. J. Fletcher noted in 1921, the manufacturers were thinking "small tractor" but there was such a demand for tractors they could sell anything. When the depression set in, farmers were overstocked with poorly designed tractors. Then the first small tractors were sold with the idea that horse-drawn tools could be attached to them, and this created further disrespect.

George W. Iverson analyzed the "Possibilities of the All Purpose Tractor" at the 1922 meeting. He made some good points about the Corn Belt, which had one-third of all the tractors in the United States, but only six percent of the Corn Belt farms had tractors. The rest of them had to have horses to cultivate the corn so they did all the other work with horses. Now, the logical solution was to "design a tractor that will do cultivating as well as plowing, disking, dragging, and other drawbar work." To Iverson, that was not so simple. The power requirements of plowing and cultivating were quite different, unless one settled for a compromise design slightly heavy for the latter and somewhat underpowered for the former. The Iverson compromise design had six to seven drawbar horsepower and weighed less than 3000 pounds. He thought this tractor would "displace about 50 percent or more of the horses used on the Corn Belt farms." Unfortunately, it was supposed "to hitch to any standard horse-drawn tool with only minor changes in the tool itself." As L. J. Fletcher said in 1921: "The tractor has suffered because it has been considered a substitute for the horse." Still, Iverson outlined the problem very well:

At the November 1923 meeting F. A. Wirt predicted that "the next big development in the tractor industry is expected to be a general-purpose tractor..." The analysis he presented moved further technologically than 
did Iverson. A main justification for such a tractor was that row crops occupied far more acreage than grain and were worth over a billion dollars more. Yet row crop farming was inefficient because "suitable mechanical power" was not available. Wirt's ideal general-purpose farm tractor should pull two 14-inch plow bottoms, operate a 20-22 inch thresher, mow a 6-8 foot swath, and plant or cultivate two or three rows. Also, the attached equipment should be designed for it.

Were Benjamin and his group at IHC influenced by these published papers of Zelle, Fletcher, Iverson, and Wirt (which were the only relevant papers on the small tractor published between 1918 and 1925)? It is doubtful, because the company began selling the Farmall in 1924. Thus a potentially successful all-purpose tractor was already in existence when Wirt outlined its design characteristics. This suggests that Benjamin played his cards close to the vest; the process of designing, testing, and patenting the machine was done very discreetly. It was not until December 1926 that Benjamin sent a movie of the "latest" Farmall tractor to the Farm Power and Machinery Division meeting. One must conclude that the influence of ASAE on this important advancement may have been limited, except for personal contacts made possible by the meetings.

Other technical developments of great importance had their genesis in the second decade; some other ideas never caught hold. An example of the latter was a "manless plow" designed and tested by Davidson and his students at Iowa State. An example of the former was rural electrification.

The January 1925 Journal contained an enormous two-page advertisement by the National Electric Light Association with the headline: "THE GREAT EXPERIMENT IN AGRICULTURAL ENGINEERING." It referred to the formation of the National CREA (Committee on Relation of Electricity to Agriculture). The basic problem was that "application of city electrical practice to farms is impossible." That is, farm electric load per mile of line must be developed sufficiently to secure reasonable costs. CREA was to determine how to do this under a multitude of different conditions so that farmers and power companies alike might profit. The ad gave full credit to agricultural engineering leadership in this national effort. The Rural Electric Division was started a few months later. The details of ASAE's achievements, however, must be left to the third decade, for that was when the electrification thrust gathered real momentum.

The importance of reclamation as a distinct field of agricultural engineering endeavors was solidified in the second decade. The formation of the Reclamation Division was a genuine impetus for those activities. Reclamation involved all operations that made land more productive: land clearing, irrigation, drainage, erosion control, hydraulics of canals, water- 
shed management, flood control, and many others. Such a spectrum of technical interests seems incredibly broad yet undeniably necessary to best solve interrelated problems. Difficulties kept arising, however, from jurisdictional jealousies, mainly among civil engineers, but including others also. One can be sure that by the mid-1920s ASAE had gained some degree of stature in these technical areas in order to even be noticed by the civils. Such difficulties are interesting because in increasing measure they marked the struggle for recognition; as ASAE and agricultural engineering gained strength, the more toes in other branches of engineering were thought to be trod upon.

In the case of reclamation, a technical philosopher was needed to apportion the work among the branches. O.V.P. Stout, chairman of the Division, did this in fine style at a meeting of the Pacific Coast Section at Davis, California, late in 1925. Stout, now with McCrory's Division of Agricultural Engineering, started with a review of the whole history of engineering. Then he compared agricultural to mining engineering as a branch serving a particular industry. He commented that agricultural engineering was not a new concept either, that it was "foreshadowed" in an 1847 speech to the Institution of Civil Engineers of Great Britain. Furthermore, Alexander Holley, an outstanding American civil, mechanical, and mining engineer of the 19th century, told ASME years ago that agriculture was "a world-wide arena for the operation of machines."

So much for background. Stout then noted that the economic purpose of reclamation was agricultural production, which brought in ASAE and agricultural engineering. But the delivery of irrigation water to agriculture had been the province of civil engineering and should remain so. This applied also to other "large works" such as drainage and flood control. Except for consultation on capacity requirements, agricultural engineers should have no part in the design and construction of the "largest ways and structures."

What is then left for the agricultural engineer? According to Stout, construction of the irrigation delivery systems would be to no avail until the land had been prepared to receive the water, roads laid out, farmsteads established, etc., all of which had rarely received engineering attention in the past. That opened up a tremendous opportunity for agricultural engineers, with ASAE to take the lead. Drainage and flood control work could be considered in an analogous way, while the engineering of cut-over lands could also be assigned to agricultural engineering. In addition, the operation and maintenance of irrigation systems presented problems which "may with propriety be considered by the American Society of Agricultural Engineers...without danger of meeting resentment... of another society..." 
Thus Stout believed he had "partitioned" the civil engineering phase of reclamation between civil and agricultural engineering. But this still left the mechanical and electrical engineering phases. On the mechanical side, large pumps were the key machines. Stout asserted that their design was not agricultural engineering but that their testing was. The same applied to the farm tractor. Ditch construction and maintenance called for special machines whose design was mechanical engineering but whose performance affected agricultural engineering. Thus ASAE should "keep open its proceedings to the treatment and discussion of mechanical engineering subjects such as these enumerated."

As to electrical engineering, the agricultural engineer would serve "chiefly as consultant to the consumer of electricity" to aid him in securing performance efficiency and economic rates. ASAE should study farm plants and all "but the largest plants using electric power for reclamation purposes."

Stout concluded by pointing out that the guiding principle of the agricultural engineer should be that of serving as advisor to the individual farmer. With this principle uppermost, ASAE activities in reclamation would not in any way infringe upon those of the "fundamental branches of engineering" and their national societies would find nothing objectionable in ASAE's growing involvement in reclamation.

In studying the technical development of ASAE, Stout's paper should be considered important. As a respected civil engineer and former dean of engineering who was known to be friendly toward ASAE's aspirations, he could say things most members could not. His analysis probably helped ASCE to view the agricultural engineer more kindly. Such kindly views were needed. The struggling college departments needed a philosophy in order to gain cooperation in the engineering college. The federal men needed it also, to strengthen their position in research.

Unfortunately, no such philosopher as Stout appeared in the case of farm machinery, a philosopher who could soothe the mechanical engineers. This was unfortunate because much writing and talking in the ASAE publications and meetings suggest that all farm machinery, even the tractor, was designed by agricultural engineers. This was not true, of course. ASAE had its friends among high-ranking mechanical engineers (Mortimer Cooley was one) but they were not active members as Stout was; they did not carry their vision down to interaction with the soil and apply philosophy to it. ASAE had many mechanical engineers as members, but once they became members they seemed to neglect the opportunity to carve out "spheres of influence." One exception was O. B. Zimmerman, who told ASME that the mechanization of agriculture was a task for the agricultural engineer; Zimmerman held two degrees in mechanical engineering from the University of Wisconsin. 


\section{rd decade, ${ }_{1928-1937}$}

\section{"THE ENGINEER MUST ACCEPT RESPONSIBILITY.:.}

L. J. Fletcher

A

\section{General Progress}

O. B. Zimmerman had barely settled into the presidential chair when he found himself talking to President Coolidge at Rapid City, South Dakota. As one trout fisherman visiting another, it was probably pleasant for Zimmerman, particularly since the President was noted for listening and saying nothing.

Zimmerman headed an official ASAE delegation composed of First Vice-President Arthur Huntington and Past-Presidents J. B. Davidson, F. A. Wirt, and O. W. Sjogren. H. B. Walker was invited but was unable to join. The visit was arranged through Huntington's friendship with former Governor S. R. McKelvie of Nebraska, whose guests they were while at Rapid City. They met with Coolidge on August 30, 1927.

The engineers ostensibly wanted to support the farm measure urged by Secretary of Agriculture Jardine. However, going beyond some of the gospel of the day, they laid a 5000-word statement in front of Coolidge which embraced total ASAE beliefs. He was obviously impressed - he talked with the delegation three times longer than the time allotted for the interview!

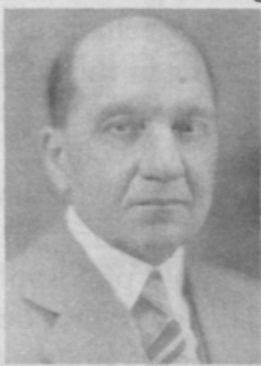

Oliver B. Zimmerman 21st president, ASAE, 1927-28

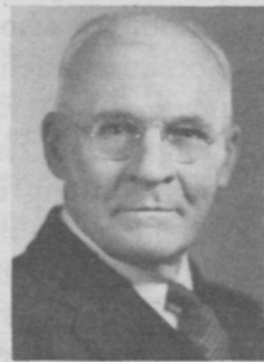

William Boss 22nd president, ASAE, 1928-29 
After considerable background on agricultural engineering and engineering in agriculture, the ASAE delegation made several definite recommendations:

1. Methods were needed to increase production per worker and to lower costs. Less attention should be given to price-fixing and marketing.

2. Earnings of agriculture were more important than speculative land values.

3. Industrial uses should be developed for farm crops.

4. Surplus farm people should be transferred to industrial activities.

5. A study of losses in agriculture should be made by ASAE and the American Engineering Council.

6. In flood control, upstream retardation methods practiced by agricultural engineers should be considered.

7. More and better research programs in the state experiment stations and federal agencies should be developed.

8. A Bureau of Agricultural Engineering should be organized within USDA.

These recommendations made eminent good sense, although the one related to "surplus people" has a callous sound to our squeamish presentday ears, a totalitarian flavor which Zimmerman and friends probably never intended. Engineers sometimes use inhuman phrases when proposing solutions to human problems.

Next day, August 31, the New York Times gave full details on these ideas for farm relief. Better yet, on the day after, the Times commented editorially that the ASAE "visit to the President, it may be hoped, marks the beginning of saner and sounder discussions of the whole vexed question" of farm relief.

Over the next two weeks the farm press, especially in Iowa and Nebraska picked up the Rapid City story. In general they gave it full and sympathetic coverage, even the "surplus farm people" clause. An exception was a gentleman named Stengle, a former member of Congress who wrote a column in the "National Farm News." Stengle hooted at the notion that a delegation of engineers felt competent to "tell the President what the farmers want and how they should be managed." As he said, there was not a "single dirt farmer among them." Stengle fairly brayed as he examined the ASAE recommendations. The idea that some farmers didn't know how to farm and should therefore be removed! And to be judged by "machine manufacturers and railway operators!" (Huntington's company was then named the "Iowa Railway and Light Company"-an interurban with generating capacity used partly to supply electricity for urban and farm use.) 
His parting shot was that "the queerest fellows I meet these days are those who think they can solve the great farm problem without knowing a thing in the world about farming." It probably did not occur to Stengle that when he was a member of Congress he voted on legislative and other matters about which he had little or no special knowledge. Actually, to accuse the Zimmerman delegation of having no knowledge of farming betrayed the journalism hack at his worst. But there were other critics as well, although better informed. One, an editorial writer, commented that the ASAE proposals were "sound suggestions." But, he said, "some of them will affect our chronic relievers about the same as a red flannel shirt affects a bull. At least two more plans for farm relief are promised us in the near future." And that was probably why Stengle didn't like the agricultural engineers; their cool and rational proposals meant no votes for congressmen.

The affair with President Coolidge put Olney in a state of ecstasy. His October 7 Secretary's Letter commented at length on how the favorable reaction "far exceeded anything that had been anticipated." The recognition was so widespread that Olney felt compelled to caution the members about becoming self-enamored. "What has happened should tend to make us very humble, for all of a sudden our responsibilities have been tremendously increased." As he put it, "The big job is to make good."

Further effects of the interview were relayed to the members by Olney in his November 15 Secretary's Letter. "Collier's," a national magazine, had an editorial which was inspired by the ASAE delegation and its recommendations. The October issue of "Scribner's" magazine contained a long article written by Professor H. B. Roe of the Department of Agricultural Engineering at Minnesota University; it described the activities of ASAE. "The Country Gentlemen" was throwing bouquets at the agricultural engineers. By December 20, Olney reported a 20 percent increase in membership and a good increase in Journal advertising. He stated that the recognition stimulated by the Coolidge interview was the "most significant feature" of the year, and that ASAE had received $\$ 100,000$ worth of "white space" from the newspapers as result of it. Finally, it was learned that member J. de la Fuente of Torreon, Mexico, had translated the recommendations into Spanish for publication by two Mexican engineering societies.

Examination of the ASAE proposals reveals nothing that would not benefit American agriculture. Reviving the "waste in agriculture" issue could have done much to improve agricultural efficiency. Creating a Bureau of Agricultural Engineering could hardly have been detrimental. The remainder of the recommendations were well-conceived; vigorous implementation of them could have spelled major improvements in the one industry that was still suffering from World War I. The difficulty was, of course, 
that ASAE had no political power unless backed by large groups of farmers. These preferred other roads to salvation, mainly in the direction of price supports and cooperatives. And they were probably a bit skeptical of a program which proposed that part of their numbers (each one with a vote) be shunted off the farm into urban industries.

Never again would ASAE leadership go to the summit as they did in August 1927. If their solutions to the "farm problem" were rejected, at least they made the name of ASAE a household word for a time.

The burden of stimulating the federal government to create a Bureau of Agricultural Engineering was shared by the California Associated Concrete Pipe Manufacturers. On July 15, 1927, this group sent a wordy resolution to Secretary Jardine requesting establishment of the Bureau. Olney commented in the November Journal that the squeaky wheel gets the grease; more seriously, he stated that the stimulus should have "political influence back of it." Therefore, the members should work on their "political friends" in Washington, also the deans and directors at the colleges. However, in December he stated that it was unlikely that anything would be done about the BAE until disposition of the Wyant Bill. This bill was the reorganization bill which would transfer the Bureau of Public Roads to the Department of the Interior.

Meanwhile there was talk that the next occupant of the White House would be an engineer. Arthur Huntington wrote Olney early in 1928 to say that he had been in correspondence with Herbert Hoover. Hoover told Huntington that "agricultural engineering will be a big factor in his agricultural policy." Olney urged the members to favor Hoover, regardless of their party affiliations. Hoover had a committee set up to study "The Engineering Aspects of Agriculture," with ASAE represented, but nothing came of it.

At the 22nd Annual Meeting in Washington, D.C., the members went to the Department of Commerce to hear an address by Hoover, while Mrs. Hoover entertained the ladies. Those events promoted an optimistic feeling about the BAE.

There it rested until December 1929. A delegation consisting of President W. G. Kaiser, Arthur Huntington, F. A. Wirt, O. B. Zimmerman, and G. W. Kable then went to Secretary Arthur Hyde to urge upon him once again the BAE. Hyde was unable to meet with them; however, they met for two hours with Dr. A. F. Woods, director of scientific work for USDA. The delegation came away convinced the BAE would soon be in existence. A provision for the bureau would need to be incorporated in the next agricultural appropriations bill, whose drafting was soon to commence. Then, with a friend in the White House...things were looking up. 


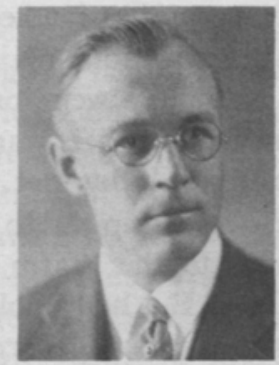

William G. Kaiser

23rd president, ASAE, 1929-30

And so it came to pass. President Hoover signed the bill funding the BAE in April 1931, thus establishing it as of July 1. The Secretary of Agriculture signed a memorandum on June 1 which designated Samuel H. McCrory as chief of the new bureau. In its 25th year ASAE had accomplished a major triumph in the federal government.

Secretary Hyde released a statement when McCrory's appointment was announced which explained the attitude of USDA toward agricultural engineering:

"The importance of sound engineering practice as a factor in modern agriculture has made the creation of a new bureau necessary.

"Agricultural engineering is one of the younger professions and its importance is steadily increasing. The engineering work of the Department has dealt with irrigation, drainage, soil erosion control, farm mechanical equipment, and farm structures. The high efficiency of American agriculture has been in a great measure the result of the rapid development of farm machinery, and agricultural engineering has been instrumental in this development.

"The growing problem of the prevention and control of soil erosion has opened an important field for the agricultural engineer...

"With all these activities expanding, it has been deemed highly desirable that the Department of Agriculture include in its organization a strong agricultural engineering bureau.

"It is hoped to make the new bureau serve the needs of the family farm, rather than the more spectacular mass-production farm."

This announcement probably launched BAE on an awkward politically based mandate to serve the family farm. But the Great Depression had started and the idea of the small farm was gaining acceptance as an economic storm shelter, even though ASAE members were sure it was not very effective as a food producer.

O. V.P. Stout, the former dean of engineering at University of Nebraska, 


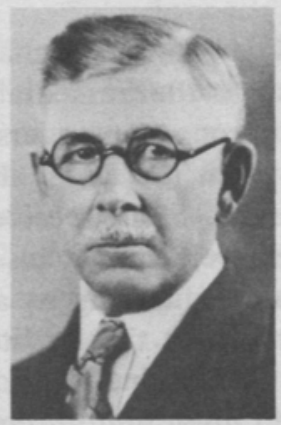

O.V.P. Stout, dean of engineering, University of Nebraska, was first recipient of Cyrus Hall McCormick Medal

was elected honorary member in May 1928. As head of civil engineering, he was ex officio irrigation and drainage engineer of the Nebraska Agricultural Experiment Station years before ASAE was organized. He consistently recognized the potential value of engineering in agriculture. Thus he influenced young engineers like J. B. Davidson, L. W. Chase, F. A. Wirt, and O. W. Sjogren to put their talents to work for agriculture. Stout was titled "Agricultural Engineer" in 1895, possibly the first in the Land Grant college system. He was widely recognized as a successful dam builder and constructor of large irrigation works.

Stout was held in very high regard by ASAE. At the July 1931, Annual Meeting (ASAE's 25th anniversary) it was announced that the children of Cyrus Hall McCormick (inventor of the reaper) had given $\$ 10,000$ to ASAE, the income to be used for an award to "the individual...who has rendered the most outstanding service...in the field of agricultural engineering." This development, undoubtedly stimulated by O. B. Zimmerman,

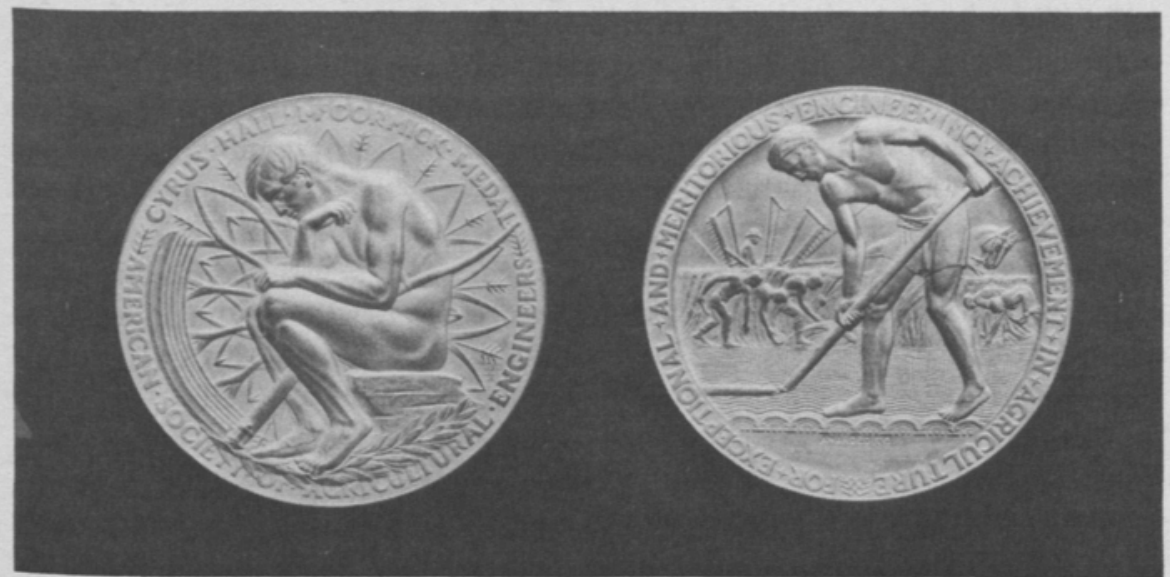

Cyrus Hall McCormick Gold Medal was first presented in 1932 "For Exceptional and Meritorious Engineering Achievement in Agriculture" 
resulted in the McCormick Gold Medal. The committee charged with determining the recipient each year was set up as the immediate seven living past-presidents. Stout and Davidson were strong contenders for the first medal, but it was decided that Stout, now with the BAE, should have it.

On June 22, 1932, at Ohio State University, Stout received the medal. The citation said of him that his greatest achievement was his "...successful sponsoring of the principles of agricultural engineering as a field worthy of special academic and professional attention. In this he literally became the father of the agricultural engineering profession." Just a month previously University of Nebraska had conferred upon him an honorary degree of doctor of engineering.

Some partisans of Davidson at Iowa State may have been disgruntled by the committee's choice of Stout as first McCormick medalist. Their dissatisfaction did not linger, however, because J. Brownlee Davidson received the second McCormick Medal at the June 1933 Annual Meeting. He was himself probably content to have been preceded by his respected preceptor from college days.

Herbert Hoover was elected president of the United States by a landslide in November 1928 . He promised the country a minimum of central government, professing faith in "rugged individualism." About a year later the stock market collapse marked the beginning of ten years of depression. The hard times familiar to agriculture since 1920 would now be visited upon all. At first Hoover thought individualism would restore prosperity, but later he signed measures which established the Reconstruction Finance Corporation and released United States gold to industry and business, pumping millions into the economy. But the deepening, tragic rate of unemployment in 1933 brought Franklin Delano Roosevelt into office with his promises of a "New Deal." And what of ASAE in these difficult times?

Olney, the optimist, issued statements periodically that things were getting better, but things didn't. A bright spot was the 25th Annual Meeting in 1931 at Ames. Members were proud to learn that J. B. Davidson had just been granted an honorary doctor of engineering degree from University of Nebraska. It was the largest ASAE meeting yet, with 450 men, women and children in attendance ( 342 members, about 25 percent of ASAE). That was good. But by December Olney had a sad bank story to tell.

In June 1930, the ASAE bank had failed and been absorbed by another bank. In September that second bank closed and "caught us plenty." Fortunately Olney had some money in a Benton Harbor bank and could scrape by. Then a week later the third ASAE bank folded-but it had only $\$ 75.00$ of ASAE's money; Olney had started putting the excess funds into postal savings. As of December 1931, only one bank out of six was left in St. 
Joseph-Benton Harbor and it had a run going on it. The second bank that had folded with ASAE's money in it was still in receivership.

Olney liked to write "there is no depression in agricultural engineering" but he was whistling in the dark. The year 1931 closed with a net operating loss of money and membership.

During 1932 not one "Position Open" announcement appeared in the Journal. Olney announced that members could pay their dues on the installment plan. Most drastic, the Headquarters staff was cut in half; Assistant Secretary Ralph Palmer and a stenographer were "let go" on August 1 because they were unmarried. Then, without consulting the officers or the Council, Olney cut his own salary about ten percent. Palmer, a reserve officer from ROTC days at Ohio State, made out with tours of active duty at Fort Benning and as a Civilian Conservation Corps camp commander. $\mathrm{He}$ wrote in later years that Olney's wedding present to him in January 1936 was a telegram telling him to come back to the office when ready.

Those were lean years indeed. Without Olney's faith in the profession and his superb business ability the office could have been wiped out. And the troubles visited upon ASAE were not only monetary.

The rising unemployment created a deep distrust and suspicion of engineering, of science, of machines, of corporations, of industrial society. As high priests, so to speak, of the machine age, the engineers received much criticism for "putting people out of work." Because ASAE had in 1927 openly admitted that rising farm mechanization created "surplus people," the leadership became defensive when the breadlines grew longer in the thirties. For the first time agricultural engineers began to wonder about the social impact of their machines and whether they had any responsibility for that impact.

A profession's social responsibility implies the obligation to use its special knowledge and privileged position mainly for the betterment of the society that protects its special standing. Some of the older societies had toyed

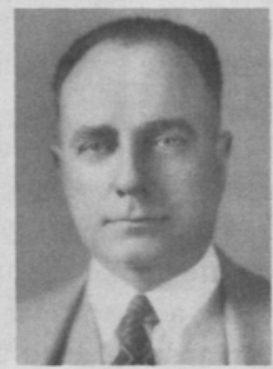

Robert W. Trullinger 24th president, ASAE, 1930-31

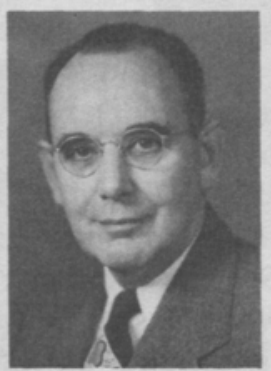

Leonard J. Fletcher 25th president, ASAE, 1931-32 
with the idea in former years, partially as a springboard to power, but ASAE had been too deeply engaged in the struggle to survive. Now it appeared that something must be said for the agricultural machine as an instrument of social progress.

R. W. Trullinger was president in 1931 when he said that "Engineers have been accused of being magnificent creators of unemployment" at both factory and farm. However, Trullinger asserted that agricultural engineers were "contributing indirectly to the prosperity and higher standard of living of the country as a whole." But this was merely a reflex action which could have been said by any engineer of the time, hardly worthy of Trullinger's keen mind.

The next president was Leonard J. Fletcher of the Caterpillar Tractor Company. Fletcher's presidential address was delivered in June 1932, when not even the faint hope of a New Deal was perceptible. He should probably be rated as one of ASAE's outstanding philosopher-presidents because at a time of trial he attempted to relate agricultural engineering to the crisis.

Fletcher scorned the notion that unemployed city people should go and farm areas that had defeated experienced farmers. Agricultural engineers should offer constructive solutions to these problems "instead of laughing at the political scheme..."

What role did machinery play in agriculture? Pest control and soil conservation were impossible without it; certain lands could not produce without it; production per unit of labor was enormously increased by it. Fletcher compared the combine to the sickle and flail in harvesting and threshing grain; the gain per unit of labor was 4700 percent, with a labor displacement of 98 percent. And that was the ticklish problem of 1932. Although "America is committed to mechanized agriculture," he said, "the engineer must accept a large responsibility for the solving of problems arising from the machine's displacement of muscular energy." So Fletcher said it clearly, but he didn't say how to do it. He basically hoped that "free enterprise" would take care of the problems, not the government. Unfortunately the people had lost faith in "free enterprise"; their fear of "socialism" was eclipsed by fear of starvation.

And so Roosevelt took office on March 4, 1933. The unprecedented social legislation of the "Hundred Days" followed. It created a new climate of hope and even a temporary alliance of business and government. President Charles E. Seitz of Virginia Polytechnic Institute spoke the unspeakable in June 1933, when he said "We are now...entering a new social and economic era. The "laissez faire' attitude will no longer answer." He advocated that ASAE turn to social questions and asked for a "section on human relations." However he attempted to duck the blame for unemployment by 
pointing out that "political and social programs have not kept pace with the application of physical science to the work of the world."

Arthur Huntington (Iowa Electric Light and Power Company) followed Seitz into the presidency with a record of eloquent speeches in favor of engineering leadership. Unlike his predecessors, Huntington thought the attacks upon engineers were justified, mainly because the engineers had failed to seize leadership. They had abrogated leadership to politicians, businessmen, and socialists and thus had shrunk from responsibility to society.

Huntington's concern for unemployed people was real. As he put it: "Displaced workers, until located, have no buying power."

As president, Huntington addressed the Southern Section in January 1934. The address was titled "The Engineer as Counsel for the People," a title worthy of the finest tradition of social responsibility. In it he condemned engineers who endorsed public works programs whose engineering was faulty and without regard for the public welfare. Again he pleaded for engineering leadership, especially by agricultural engineers who had contributed so much "to the general good and...made so little effort to assume leadership."

President Huntington, in his annual address, warned the members that the public considered engineering largely responsible for the current economic distress. He claimed that ASAE was, however, unlike the others because it believed in "The necessity of relocating those workers which are displaced by a machine before a new machine is introduced." Huntington was stretching the truth on this; there is no evidence of such belief. Still, his pleas for involvement in economic and social problems were inspiring. They may have been partially rooted in the distaste many business-oriented engineers were beginning to feel for the New Deal; he spoke often of "politicians...trying to regiment free men and to destroy us into prosperity." But there was an idealism in his proposals for social action which was reminiscent of the turn of the century, when engineers dreamed of national leadership.

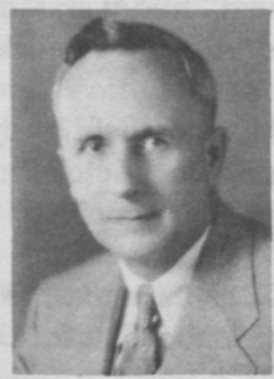

Charles E. Seitz

26th president, ASAE, 1932-33
Arthur Huntington

27th president, ASAE, 1933-34

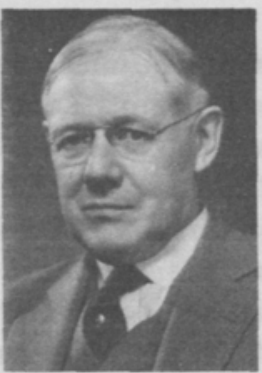

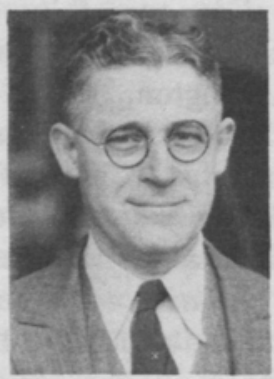

Glen W. McCuen 28th president, ASAE, 1934-35 
By the 1930 s only a renegade group of pseudo-engineers calling themselves "technocrats" was serously working for political and economic domination of the U.S.

But ASAE's depression coin had another side. No doubt some members thought private enterprise should get the country going, but many other members were employed by New Deal agencies. And if these latter spent a lot of money they also did much good. Consider the Soil Conservation Service (still around today), the Civilian Conservation Corps, the Emergency Relief Administration, the Works Progress Administration, the Rural Electrification Administration (still functioning), the Tennessee Valley Authority (still going), and many others. These agencies contained strong contingents of ASAE members. In a way not perhaps envisioned by Huntington they were serving as "counsel for the people" by conquering the Dust Bowl, taming the floods, draining the swamps, and training a generation of needy, impoverished youth to self-respecting labor.

Past-President Harry B. Walker of Kansas State Agricultural College in 1936 disagreed with the idea of social responsibility. His address at the June 1936 meeting was important because of his reputation and prestige. He said that it would be futile for engineers to "claim responsibility for laborsaving equipment and then try to convince the public that labor-saving machines create labor."

After commenting that ASAE had spent too much time telling of its own importance, Walker said, "Our professional future appears brightest if we hold ourselves rather rigidly to the technical and...tangible phases of engineering as related to agriculture. While we should be concerned with social progress the same as any good citizen should be, we invite disaster to good professional service when we try to design social justice into production machinery."

Walker's argument had its compelling aspects. It relieved the more tender-minded members from an uneasy feeling that somehow they should be doing something about "technological unemployment" and it was much easier to understand and comply with than the utopian appeals of Huntington.

But Walker did not summon the members to transcend their everyday concerns in favor of a wider arena of services; Huntington, Fletcher, and others did so summon them. Walker reduced them to the technician level with the implicit message: "Idealism doesn't pay."

The issue remained as an ethical and professional dilemma until World War II brought full employment; then the dilemma's root cause disappeared.

Another dilemma for ASAE during the period was the "corporation" or 
"mass-production" farm. The Secretary of Agriculture had expected the new Bureau of Agricultural Engineering to ignore such farms, concentrating instead upon the "family" farm. This, of course, was not based on economic or engineering reality. It was based partly on votes, partly on hazy nostalgia, partly on the assumption that country life produced a better class of citizen. In addition, the city welfare lists were reduced by the movement to subsistence farms, even though such farms did little for national production. And then the New Deal came along and paid farmers to reduce production!

All this was repugnant to agricultural engineers. Their basic approach was to increase per capita production through mechanization of large, efficient farms, thus reducing cost of production per unit produced, just as in any American industry. This philosophy committed them to the "massproduction" farm, even though American society thought such farms were socially detrimental.

The corporation farm had gained sustained favorable attention by ASAE starting in 1928. A 1928 Journal writer noted two distinct farm trends: one, the smaller unit operated entirely by the owner; the other, larger units with large increments of machinery. Because all people who wanted to live on a farm could not own one, these "may find the greatest success by working on a corporation farm managed by an agricultural engineer." This type of farm was called "...one of the most important developments in American agriculture at the present time."

But even as competent an engineer as Herbert Hoover had come out flatly against corporation farming, saying that farming is more than just a business. This statement occurred in his speech accepting the Republican nomination for the presidency of the U.S. The Journal carried a "digest" of editorial reaction to Hoover's stand, with a pussyfooting disclaimer at the end saying that ASAE neither agreed nor disagreed with Hoover. The cream of that jest was that Hoover owned a 1280-acre farm in California run strictly on corporation lines. It was exactly the kind of heavily mechanized farm ASAE members believed in. But the influential farm press "Wallace's Farmer," "Prairie Farmer," and "Capper's Weekly" - praised Hoover's attitude; the farm vote was powerful then.

Shortly after, an editorial appeared in the Journal entitled "Large Scale Farming." The writer concluded that money, not sentiment, would decide the issue. If the one-family farm could pay a good return on investment and permit a good standard of living, it was a success. The same applied to the corporation farm. The writer predicted growing numbers of the latter. As Fletcher said in dedicating the new agricultural engineering building at Davis, California, in 1918: "Large-scale farming is in the air. The question is not whether we want the large farm but rather, what are we going 
to do with it? How will we direct its development?" And symptomatic of wide interest, Olney wrote in September 1928 that the United States Chamber of Commerce was investigating large-scale farming. They sent a questionnaire to owners and operators of large-scale farms, some of them ASAE members. Olney suggested full cooperation because the results would be kept "strictly confidential."

In December the Power and Machinery Division held an all-day symposium on "Present Status and Trend of Large-Scale Farming." Those papers and discussions were published in the January 1929 Journal. Editorial comment in that issue emphasized that ASAE was neither "for or against," but that the large-scale operation would inevitably set the trend, whether it be a corporate or a family enterprise.

The 1929 Winter Meeting of the Power and Machinery Division yielded some more papers on large-scale farming. Some of these authors were farmers and also ASAE members. One operated 30,000 acres of dry-land wheat farms near Amarillo, Texas. He owned a fleet of 60 -horsepower tractors. Wheeler McMillen, editor of a farm magazine and also a member, wrote that this man was the forerunner of farms utilizing "1000-hp tractors and hired men paid $\$ 10,000$ per year."

Such euphoria couldn't last. The deepening depression, men out of work, surplus commodities, lack of capital, and the Dust Bowl all conspired to put the brakes on ASAE's espousal of the "big farm." One of the victims of the times was Tom Campbell, an ASAE member who farmed 100,000 acres in Montana. He was accused in the "Fortune" magazine of November 1935 of being a major contributor to the dust that was wafting out of the West those days. This called forth a defensive editorial in the Journal; Campbell was praised for "efficiency." But nothing was said about dryfarming an Indian reservation which was probably better suited for grassland. This, of course, was part of the dilemma for ASAE members then. Some could not honestly advocate destroying the sod in order to practice dry-farming. Others, in their hearts, would have still seen farming as Hoover claimed he saw it: more than just a business.

In any event, the surplus commodities, and the New Deal modes of coping with them, did not tend to promote large-scale farming. On the other hand, these problems and policies did promote the Ever-Normal Granary, conservation of the soil, and other activities in which agricultural engineers could engage whole-heartedly without apologies. The interest in largescale farming fell by the wayside in the process; the members took up other burdens. But that itch to defend the machine persisted. Leonard J. Fletcher, who seldom minced words, was quoted in January 1936, as having said: 
"We have developed the machine. It is possible to have a better existence through its displacement of human toil. Our civilization is built upon it. If anyone just cannot stand it here with our machines, he can find places in the world where there are none. I prescribe therefore for such cases a one-way ticket. There will not be much demand."

The machine and the large-scale farm were, of course, highly related. When the combine, for example, came out of California and the other West Coast areas in the twenties it took hold fast. Its mechanisms were quickly adapted to handle not only small grain but also corn and soybeans. Efficient use of such a machine called for large farms, among other needs.

The combine, etc., stimulated production to the point where something had to be done with the surplus. Utilization of agricultural products as industrial raw materials seemed to offer hope. Distillation of power alcohol from surplus crops was an example. Henry Ford had proposed doing this during World War I when gasoline was scarce. Another example of chemurgy was Ford's use of soybean plastics for parts of automobiles.

Chemurgy had seized the imagination of certain ASAE members. But of the experimentation reported, most involved power alcohol as a fuel additive. Interest in power alcohol persisted through the decade. Several good papers were published (the first in 1921) which showed that alcohol-gasoline blends were highly practical. The problem was that alcohol cost more than gasoline.

The general aspects of chemurgy were looked at through participation in conferences of the Farm Chemurgic Council and the Chemical Foundation. The 1936 conference of these groups was addressed by ASAE President L. F. Livingston of E. I. du Pont de Nemours and Company. His talk was titled "Chemurgic Progress in the Land-Grant Colleges." The conference considered a number of agricultural products, including tung oil, cork oak trees, perilla (an oil seed), cotton, pyrethrum, and Jerusalem artichokes.

Another chemurgic product of interest in the 1930s (and 1940s) was the

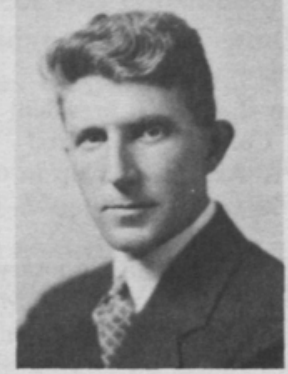

Lawrence F. Livingston

29th president, ASAE, 1935-36 
humble cornstalk. As a source of industrial cellulose, the cornstalk received some attention at ASAE meetings. But as with power alcohol, cornstalk cellulose was costly.

The chemurgy movement was good for ASAE in at least one respect: it led to interaction with, and recognition by, broadened associations of scientists and businessmen. ASAE President Arnold P. Yerkes (International Harvester Company) was an indefatigable supporter of chemurgy. His presidential address of June 1938 was largely devoted to the marvels of chemurgy and how agricultural engineers should be challenged by such marvels. At that time Yerkes was a member of the Farm Chemurgic Council's board of governors; in 1949 he was elected a vice-president of that group.

Passage of time wrought its inevitable toll on three honorary members of note during the decade.

Bascom B. Clarke died in March 1929. The first ASAE honorary member, he was credited by J. B. Davidson with delivering the oration at the first meeting which caused the charter members to decide to name the Society what they did. Clarke was not noted for his technical contributions but he enjoyed the banquets at those early meetings. But because he failed to attend the affair of December 1921, President Earl White requested Olney to write him that he was missed. Clarke wrote promptly back with a florid recollection of the 1907 banquet, which of course he had paid for:

"How well I remember that first meeting, for it opened to me a vision of the educated man...I sounded Prof. O'Cock as to whether 'These pot-hounds' would be human enough to lick up a few if, perchance they were invited to poke their legs under the mahogany at a diet of crackers and cheese, and on being assured that they were exceedingly human, we gave them the most enjoyable time I ever experienced with such a herd of highbrows. And Old White was on the job every minute of the time. I think it was Chase, or 'Case' or some such person who presided.

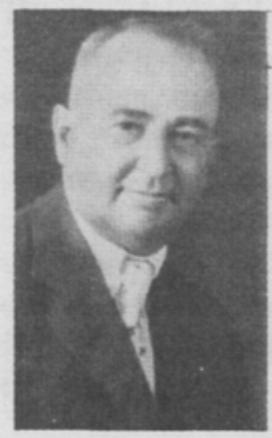

Left: Bascom B. Clarke, president of Clarke Publishing Co., became first Honorary Member of ASAE for his help in organizing the Society

Right: Elwood Mead, an Honorary Member of ASAE, received the Cyrus Hall McCormick Medal in 1936. As United States Commissioner of Reclamation his accomplishments in completing Boulder (Hoover) Dam were acknowledged by the naming of Lake Mead

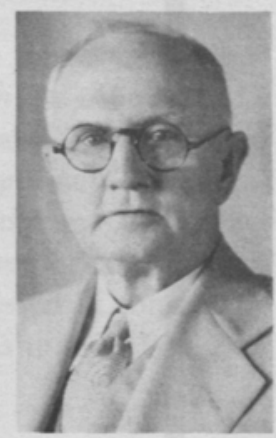


"And did we grow gracious and get happy? We did, Raymond, we fairly effervessed (sic)..."

In August 1935 the BAE lost an eminent employee, Oscar Van Pelt Stout. Since leaving University of Nebraska in 1920 he had pursued his specialty, irrigation engineering.

Honorary Member Elwood Mead died January 26, 1936. His culminating effort as United States Commissioner of Reclamation, Boulder (Hoover) Dam, was dedicated on September 30, 1935; he was in the hospital when President Roosevelt led the dedication ceremonies. Ten days after Mead died, Secretary of Interior Harold Ickes announced that the reservoir created by Boulder Dam would be named Lake Mead. Dr. Mead had been selected by the Jury of Awards to receive the 1936 ASAE McCormick Medal; he was aware of this honor at the time of his passing. It was presented to his widow at the June meeting, the only posthumous award of this medal.

Mead's life should be required reading for ambitious engineers. He was a brilliant, innovative, tireless administrative genius whose greatest desire (as a civil engineer) was "to do something for farmers." Though not all of his great irrigation schemes were successful, many were. In 1902 he lost his right arm under a trolley car, but he learned to live easily with this problem (in fact, he married the nurse who assisted at the subsequent surgery). He was 77 when he finished Boulder Dam. The flowering of California's Imperial Valley and the lights of Las Vegas, each in its way, form his monuments.

Members of ASAE became globetrotters during the third decade. J. B. Davidson spent the summer of 1929 in Siberia along with the president of Brigham Young University and other scholars. They were investigating a plan of the Soviet Government to colonize the Russian Jews. The commission was sponsored by a United States group called "ICOR" whose interests were related to Jewish welfare in Russia. After examining the Siberian area proposed for colonization, the commission was to discuss its findings with the government. If the project was considered practical by the commission, presumably modern "American methods" would be employed to open up the area. Because Davidson was working for "ICOR," ASAE records do not reveal that decision on colonization. He had written Olney in August from Obloochy in the Far East Soviet Republic about the 25th meeting in Ames. He said he saw Fletcher in Moscow and also in Rostov, and that he was leaving "by pack train" the next day. But he gave no hint as to whether the place was fit to be a Jewish colony. The commission returned in late October and reported at a dinner in New York City; nothing appeared about this in ASAE literature.

H. B. Walker represented ASAE at the World Engineering Congress 
in Tokyo in October 1929. There he presented a paper titled "Engineering Applied to Agriculture." As a contribution to an international gathering of engineers, Walker's paper deserves much praise for its thoroughness and accuracy. It was a state-of-the-art review. At that time it was the best available analysis of the background, development, and future outlook of the subject. It assembles a unique set of statistics. Historians of the subject would find this paper indispensable. An interesting attempt was made to forecast the limit of mechanical power in reducing the percent of total population engaged in agriculture. Walker estimated that by 1975 about 15 percent would be so engaged. He underestimated the capacity of mechanical power to produce; the year 1975 saw less than 5 percent of Americans living on farms, with each worker feeding 50 to 60 persons.

The First International Congress of Agricultural Engineering was held in Liege, Belgium, in August of 1930. The Congress was organized by the Commission Internationale du Genie Rural (CIGR). On invitation, President W. G. Kaiser named H. B. Josephson of Pennsylvania State College as ASAE delegate. The report of the meeting indicates that Josephson, E. R. Gross of Rutgers, and W. C. Harrington of the Portland Cement Association presented papers. Others who contributed papers but did not attend were H. E. Murdock, H. T. Barr, E. G. McKibben, A. H. Hoffman, and Hobart Beresford.

ASAE's membership in CIGR was called at this time a "Gift Member" (Membre Donateur), according to McKibben. This was probably a temporary kind of membership, because ASAE did not become a regular member of CIGR until 1961.

Following the Congress a tragic event occurred. Josephson stayed in Europe on six-month's sabbatical leave, to study artificial dehydration of forage crops. In October he was scheduled to meet his wife in Berlin. She waited for him in that city for two weeks. And then his body was found in the harbor at Hamburg, apparently the victim of accidental drowning. His obituary called him "...one of the Society's most valued and able members."

CIGR held a second International Congress at Madrid in late September of 1935. The official ASAE delegation was composed of Past-President G. W. McCuen, J. B. Davidson, and the United States agricultural attaché at Paris, a Mr. Neilson. Other members who attended were E. R. Gross, J. Q. McDonald, and J. Sabetier; the latter two were European representatives of the Caterpillar Tractor Company. Eleven American papers were included in the proceedings. McCuen and Davidson, prior to the meeting, visited farm equipment research and testing stations in Germany, France, England, and Spain. They were glad to discover that German tractor-testing techniques 
were "quite similar to that used at the University of Nebraska and approved by the American Society of Agricultural Engineers."

The educational scene did not look good in 1930. A survey had shown that only Kansas, Virginia, and Iowa were graduating agricultural engineers in "significant" numbers; these three expected to produce 31 bachelors of science that year. The other 18 professional schools expected to graduate a total of 16 . This dismal picture was not related to demand; colleges and companies were "gasping" for graduates. The problem, according to Olney, was that the departments were not recruiting the farm boys. This group, from which the profession must recruit, was graduating from high school with no knowledge that agricultural engineering even existed. For the first time, ASAE was beginning to develop recruiting literature for the colleges in an effort to solve the problem.

Meanwhile, Penn State's Ralph U. Blasingame announced a new curriculum. As part of the change, his department's name was changed from "farm machinery" to "agricultural engineering." Others would follow.

In 1934 the University of Illinois installed a professional degree program, to be administered by the college of engineering. Options in power and machinery and in drainage and farm structures were provided. Department head E. W. Lehmann pointed out that the "recent increased activity in soil erosion and flood control work has created a demand for agricultural engineers that has greatly exceeded the supply."

Ohio State had its professional curriculum approved during the summer of 1935. It was a five-year program with joint administration between agri-

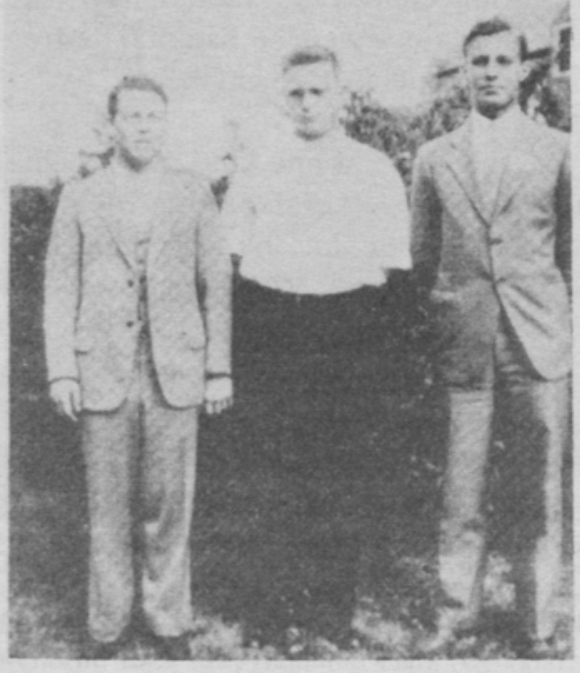

The Agricultural Engineering Students Conference was organized at ASAE Annual Meeting at Purdue University, 1933. Officers elected were (left to right): President, Henry Collin (Oregon); Vice-President, Stanley E. Hill (Ohio) and Secretary-Treasurer, Shafer Meeks (Pennsylvania) 
culture and engineering. The first four years resulted in award of a B.S. in agriculture. The fifth year was taken in the college of engineering; the student then received the Bachelor of Agricultural Engineering degree.

The 27th Annual Meeting at Purdue University (1933) witnessed the organization of the group which became the National Council of Student Branches. The registration of students at that meeting was larger than at any previous meeting, a circumstance which stimulated a desire for their own program and officers. For some reason the largest number of students present were from the Oregon Student Branch. This may explain why the first national student president was Henry Collin of Oregon State College.

The rising "student power" gave birth to a new Journal feature called "Student Activities" which flourished fitfully during the thirties. Some of the contributions to this feature were remarkably interesting. An example was an article written by James B. Stere when a student at Penn State and published in October 1934. Stere analysed ASAE's historical objectives, organization, and development. The remarkable part, however, was a study of 504 students who had graduated with the agricultural engineering degree. He found that 21 percent were in college and experiment station work; 25 percent in commercial work; 19 percent in federal service; 12 percent in farming; 5 percent in public schools; and 16 percent miscellaneous (the numbers are rounded off). Those in public schools had found positions which combined teaching of farm mechanics (Smith-Hughes) with "athletic coaching." The miscellaneous category included "bankers, contractors, insurance men, missionaries, ministers, sanitary engineers, and consulting engineers." Stere thought that "consulting engineers" should have been a leading vocation; however, only three graduates were so listed. The trend was toward increasing employment of agricultural engineers by the federal government.

Young Jim Stere tried to lift the profession out of one kind of parochialism. He noted that a large amount of technical literature existed in languages other than English. To take advantage of this, he urged the study of foreign languages. He ended his excellent paper with the observation that "The future of our profession offers a challenge to young men of ability." (He had a long and productive career in the electric area and was honored with the rank of Fellow.)

The Farm Equipment Institute* of Chicago announced early in 1935 that a "large silver trophy" would be awarded each year to the student branch "showing the greatest activity during the year." If a branch should win the

*The National Association of Farm Equipment Manufacturers (NAFEM) became FEI on December 4, 1933. 
cup three years in succession, it then would become a permanent possession. The first winner of the cup (and perennial winner thereafter) was the Georgia Student Branch. The cup was awarded at the 1935 Annual Meeting, which was at the University of Georgia that year, giving rise to much crude humor in connection with the FEI cup.

The group organized by the students in 1933 was called Agricultural Engineering Students' Conference. This unofficial scheme rocked along until the 1936 meeting at Estes Park, which was attended by 35 to 40 students, a record number. At this meeting the National Council of Student Branches was formally organized and approved by the ASAE Council. A constitution was hammered out and officers elected:

Lawrence Skromme, Iowa State College, President

Clayton Lyle, Texas A. \& M. College, First Vice-President

Howard Fujii, Oregon State College, Second Vice-president

Hamilton Clark, University of Georgia, Secretary

Skromme received the gavel from Paul Doll of the University of Missouri; Doll was the last president of the unofficial organization. Skromme established two records: he was the first president of the official NCSB and he was the first national student president to become ASAE president. The

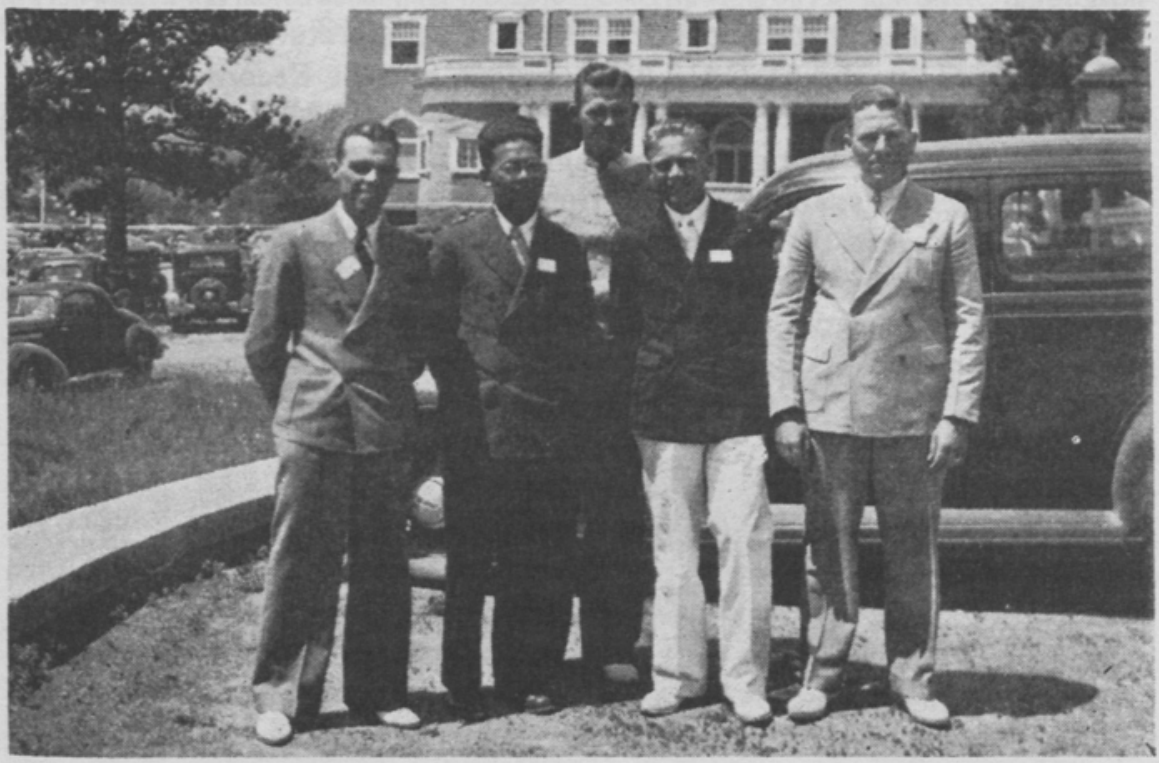

Officers of ASAE National Council of Student Branches at 1936 ASAE Annual Meeting at Estes Park. Front row, left to right, Clayton Lyle (Texas), first vice-president; Howard Fujii (Oregon), second vice-president; Lawrence Skromme (Iowa), president; Paul Doll (Missouri), pastpresident. Back row, Hamilton Clark (Georgia), secretary 
mechanism for making students of agricultural engineering part of ASAE through the student branches was thus perfected.

James Stere's plea for recognition of foreign technical contributions was promptly answered. The Committee on Soil Preparation and Tillage, chaired by I. F. Reed, had a Russian paper translated and published in a 1935 "AGRICULTURAL ENGINEERING." The paper was on methods of studying soil deformations.

This stimulated Walter B. Jones to editorialize on the information flow problem. He wrote that whatever "opinions we may have regarding political, social, and economic practices prevailing in that country" Russia was making remarkable progress in science and engineering. This applied also to certain other countries in Europe. Full advantage should be taken of useful knowledge developed abroad.

But did foreign countries use the material generated by ASAE? Jones surveyed the foreign mailings of "AGRICULTURAL ENGINEERING." These revealed that Russia received more copies of the Journal than all other foreign nations combined. Canada was taking only a quarter as many subscriptions as Russia, a strange circumstance considering its nearness and common language.

Where did the most agricultural engineering literature originate? This was answered by the USDA's "Experiment Station Record," which attempted to cover the world output. Analyzing one issue, Jones found four percent was of foreign origin, 28 percent from United States state or federal official publications, and 68 percent from "AGRICULTURAL ENGINEERING." This suggests that, despite the quality of the Russian work, there was not much of it. It further suggests that by the thirties the U.S. dominated the agricultural engineering profession and the dominant organization was ASAE. The profession existed outside North America only in disconnected fragments. The challenge to ASAE was obvious. But in December 1936 ASAE membership totalled only 841.

"AGRICULTURAL ENGINEERING" was doing more than serve as an outlet for technical papers. Olney observed in 1936 that Journal advertising revenues constituted 70 percent of ASAE income. There was a definite upturn in such revenue for 1936 compared to 1935. Non-member subscriptions (such as those from Russia) were increasing. In fact, Olney the optimist was sure that things had "turned the corner." Palmer had rejoined the staff in March and another steno had been put on. Membership was on the increase and the number of unpaid dues was less than it had been in years. And the Council, as a wise economy move, authorized discontinuance of the old "Transactions," ending with the 1935 volume. These volumes were only duplicating papers printed in the AE Journal. They probably survived through 


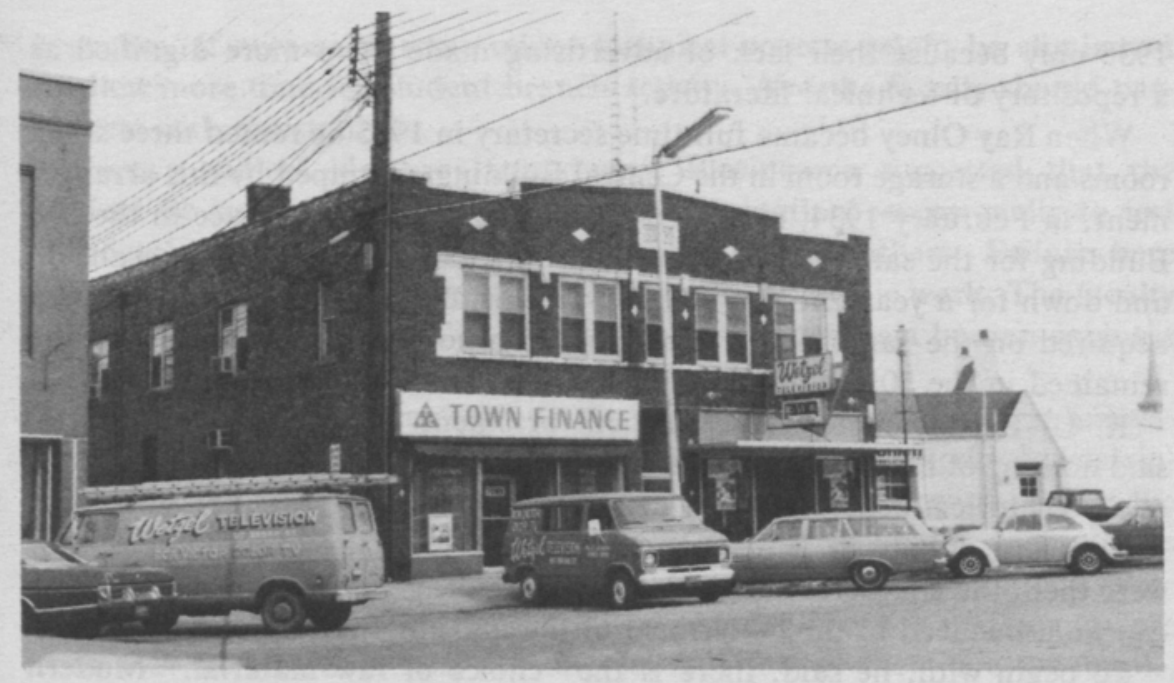

ASAE's first rented office space, occupied when Ray Olney became full-time Secretary in 1925, was in the Central Building (above) directly across the street from the City Hall in St. Joseph. Society Headquarters was located here (except for a short period in Mt. Clemens, Michigan) until 1936 when it was moved about three blocks to the 505 Building on Pleasant Street. In 1955 the first floor of the Masonic Temple at 420 Main Street was Headquarters

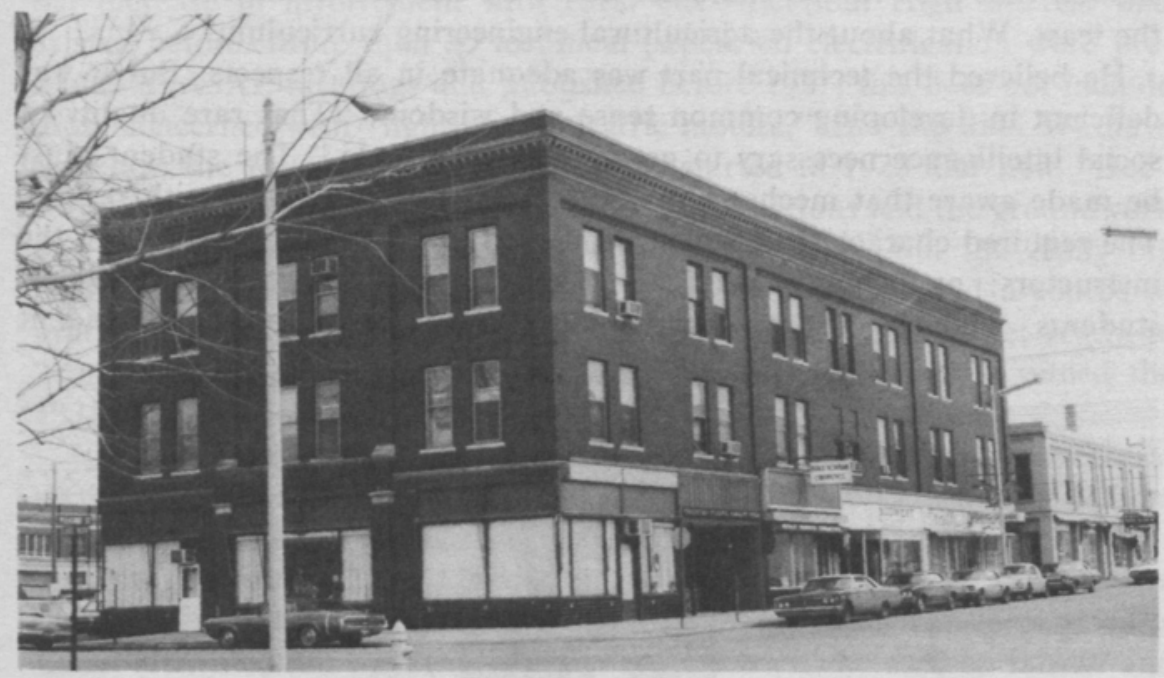


1935 only because their lack of advertising made them more dignified as a repository of technical literature.

When Ray Olney became full-time secretary in 1925 he rented three small rooms and a storage room in the Central Building. Cramped by this arrangement, in February 1934, he rented "three times" as much space in the 505 Building for the same money. On the third floor, the staff had to walk up and down for a year until an elevator was installed. Later, more space was acquired on the same floor from a tenant who moved out. Headquarters remained in the 505 Building until the summer of 1955.

R. U. Blasingame was the thirtieth president. His presidential address said nothing of the depression or social responsibility; it also contained none of the rhetorical boasting which disfigures so many presidential addresses. $\mathrm{He}$ concerned himself with issues which are today as important as they were then: the character and abilities of the young engineer, and how those can be influenced to the betterment of the individual and society.

To begin with, he said, there is the "choice of raw material." Modern methods of psychological testing should be used to select those with the greatest promise. After graduation, psychology should be used to put the engineer into work best suited to his capacity.

Blasingame cited a study of 1500 practicing engineers who were asked: "What are the essential qualities of a successful engineer?" The replies showed that they valued character above all else and technical knowledge the least. What about the agricultural engineering curriculum?

$\mathrm{He}$ believed the technical part was adequate in all respects. But it was deficient in developing common sense and wisdom, "That rare quality of social intelligence necessary to get along with people." The student must be made aware that mechanical skills do not fit him to deal with people. The required characteristics must be elicited in private conference with the instructors; opportunity must arise for cooperative action with fellow students. The best means for the latter is through the ASAE student

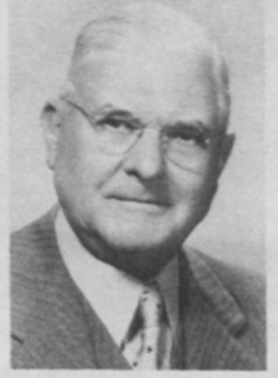

Ralph U. Blasingame 30th president, ASAE, 1936-37 
branches. If necessary, some minor technical courses might be eliminated to allow more time for student branch activity. And the faculty should participate with the students.

Here a radical idea was introduced. Blasingame suggested that the student be subjected to a "private oral examination" occasionally to test the development of his capacity to cooperate with others. Failure here should be viewed in the same way as a failure in academic work. The faculty advisor would be required "to exercise his best efforts as a human engineer to overcome this handicap."

Adoption of Blasingame's proposals would have indeed been an innovation. There is no record of any school formally examining the "social intelligence" of its students. Perhaps many instructors who heard or read the speech were influenced by it, however, and were stimulated to exemplify to their students the kind of man a high-class engineer ought to be.

The problem of "social intelligence" exists today in much greater measure than ever before. Solutions are offered, but few of them are as simple, direct, and of such potential value as Blasingame's.

\section{B}

\section{Rural Electrification}

In many respects the third decade was distinctive for the nearly exponential increase in involvement with rural electrification. High interest had existed before. More than 30 technical papers on electrification were presented at ASAE meetings and published before 1927; this does not include those concerned with "lighting," "electric motors," and the like. We have seen how the Rural Electric Division was started in 1925 and how "Doc" White helped to start the CREA in 1923. These actions laid the groundwork and brought the men into contact with the problems, but the really big push still lay ahead. Until the rural load could be considered a source of profits, utilities moved slowly. And the government was not yet ready to "compete with its citizens," as President Hoover said when he vetoed the 1931 Muscle Shoals Bill.

However, from 1923 through 1926 the number of farmers receiving central station service increased about 87 percent. In 1926 these ranged from 62,000 in California to 325 in Wyoming. For agricultural engineers the load problems by 1927 had, according to White, boiled down to extension programs and research projects. These composed the two prongs of a thrust identified this way: (a) How best can electricity be used on farms? and (b) How do you get this information to the customer? One difficulty was that these two prongs had to function simultaneously. But progress was being made; White was convinced that American agriculture would be 
completely changed by the arrival of electric power.

At this time (1927-28) the Muscle Shoals issue was hot. The power dam at Muscle Shoals on the Tennessee River was a World War I project intended to provide nitrate for wartime explosives and fertilizer for agriculture in peacetime. The problem was that farmers wanted the power used to provide cheap fertilizer while others thought it should be used for industrial development of the region. However nitrogen could be obtained in other, cheaper ways, so the controversy was practically academic. Use of the dam's power for nitrogen fertilizer was against logic. There were many proponents of the idea that the dam should be leased by the government to a private company which would sell power and make fertilizer by the best methods, unhampered by politics. Unfortunately this violated the legislation that established the project back in 1916. Hence the impasse, which was holding up power development in the Tennessee River Basin. In 1928 President Coolidge vetoed a bill - as did Hoover in 1931 - which would have solved all these problems and started electric power toward those rural areas much sooner.

Minnesota established one of the earliest CREA committees. E. A. Stewart and William Boss of the University were the leaders. It is claimed that they set up the first experimental CREA electric line, at Red Wing. A report covering four years of their work appeared in 1928 in an "NELA Bulletin." On the question of whether farms could become an acceptable load for power companies, the Red Wing project returned an "emphatic affirmative." With each year of increased use of electricity the farmers gained increases in net income and decreases in operating expenses. The gains were registered along with profits to the power company. There were five farms on the Red Wing line, which were ranked a "little below" the Minnesota average. One other important point was made: the electricity paid overhead charges on equipment which raised the farm standard of living "up to or higher than that of the city resident." As a social phenomenon electricity was going to be a winner.

In fact, the idea drew forth a Journal editorial in November of 1928. It quoted the words spoken by a farmer: "Everyone interested in agriculture should encourage and aid the development of electric power and the building of high-tension lines into farming communities, because this makes possible the use of labor-saving and automatic devices to lighten farm chores and to give home comforts." Thus the exodus of many of the "best" farm families to the city might be arrested by the availability of electric service. Presumably the movement of the other kind to the cities could proceed unabated because their marginal farms were not worth electrifying.

USDA, the national CREA, NELA, the University of Maryland, and 
the Maryland power companies got together late in 1928 to sponsor the National Rural Electrification Project. Its purpose was to "demonstrate more completely and extensively the possibilities in the application of electricity to agriculture than ever attempted before." George W. Kable, director of the Oregon CREA, was picked as the leader of the project, which was located at College Park, Maryland. It lasted about five years, during which time the work consisted mainly of study of economic and social benefits. During that time Kable was also director of research for the national CREA.

E. C. Easter of the Alabama Power Company reported on the southeastern picture in June 1929. The NELA figures for 1928 showed a 123 percent increase in number of rural lines, 113 percent increase in miles of lines, and 82 percent increase in number of customers within the past year. Average energy consumption by rural customers of one company had doubled in three years due to efforts of extension and research workers in concert with the company. An example of effective load-building was dairy refrigeration; these machines resulted in net savings of over $\$ 500.00$ per year to the customer because he no longer needed to buy ice. Easter was convinced that the rural load could be increased with advantage to all concerned, but the assistance of college extension workers was an important element.

Not all electric utilities wanted rural load, except perhaps for industries in rural areas. Initially, at least, many companies were reluctant to build lines to farm customers. The agricultural engineers of the state CREA committees did much to change this attitude. One way they did it was to point out the potential value of the farmer as a customer for equipment (pumps, heaters, stoves, motors, refrigerators, lighting fixtures, electric irons, etc.) as well as power. Another way was to urge the companies to hire agricultural engineers; by solving electrical problems for farmers, these men could build load rapidly. Finally, of course, was involvement of the state experiment stations and Land-Grant colleges in mutual efforts with the companies. These sometimes resulted in "councils" paid for by the companies which performed research and extension work tailor-made to the changing needs.

Kable reported on the status of research in November 1930. The old "demonstration" lines were now gone. The colleges had accepted rural electrification as an important work area. Many new ways of using electricity in agriculture were being tried: electric plows, sterilizers, effect of light on biological reactions, killing insects with radio waves, electric house heating, and X-ray soil analysis. Future developments would include adequate wiring, better economic farm units, pest and disease control, and something called "electroculture." Kable commented that the benefits 
of electricity, however great, "mean little if they do not bring happiness," and called for research attention to this end of the spectrum.

A tribute to the state and national CREA's came from an electric utility executive in 1931. He compared the progress in rural electrification with electrical progress in other directions. He found that extension of service to the farm was moving forward more rapidly than any other power development in the history of the industry. Supplying power to farms was not significantly different technically from other industry problems. The reason rural electrification was moving so fast was the availability of information on how to properly use electrical devices in farm service. During other periods of development an analogous fund of knowledge was not available. It was the combined efforts of many agricultural engineers and the coordinating effect of ASAE that made much of the difference.

In the following year (1932) Earl White reported on his ten years of experience with the national CREA. In that time the number of farms served by "high-lines" had increased from about 166,000 to more than 647,000 . He regarded this as "substantial" but not "phenomenal." One problem with electricity was that it had to "compete with other forms of energy for its share of the farm power load." But the measurement of efficiency was easier in using electrical equipment, thus leading to some important new developments. White acknowledged the crucial partnership between electrical engineering and agricultural engineering which made rural electrification possible, even though the two groups had worked somewhat independently of each other.

In June of 1931 White addressed the 25th Annual Meeting on "Electricity and the Agriculture of the Next Ten Years." His paper is an interesting blend of socio-economic analysis and estimates of scientific developments. As to electricity on the farm, White's prediction was cautiously stated as follows:

"Due to the still unrealized possibilities for cooking, water heating, irrigation in humid regions, hotbed and soil heating, ultra-violet light...together with such developments as forage drying and fiber processing appearing on the horizon...we can look forward to a remarkable increase in the total amount of electrical energy used in agriculture. Just where 10 years will bring us in this development it is difficult to say, but ultimately I look for an average energy consumption per farm of between 500 and 1000 kilowatt-hours per month.

White's CREA published a landmark book later in 1931 entitled "Electricity on the Farm." It comprised 332 pages, 570 illustrations, 87 charts, 160 tables, and a bibliography. It sold for $\$ 1.00$. A brief review of it in the ASAE Journal said "It summarizes in non-technical language the latest 
information available on more than 100 proven or experimental rural uses of electricity, covering jobs ranging from hair curling to bull taming..."

The death of Thomas Edison in October 1931 caused some uninformed persons to suggest that as a tribute all electric generating plants in the country cut off power for one minute at a prearranged signal. This absurd proposal gave rise to a Journal editorial which stated that "Any threat mechanical, political, or sentimental - to the continuous availability of electric power is a menace to our civilization, and, on an increasing scale, to our agriculture."

In mid-1933 G. W. Kable had some unhappy developments to report. Over-all, only 11 percent of United States farms were receiving central station service and those were using it for less than 2 percent of their power needs. Clearly, the electrification movement still had a lot of territory to be conquered. Worse yet, the Great Depression had caused the National Electric Light Association (NELA) to be replaced by the Edison Electric Institute (EEI), "a new organization with a somewhat different program and a considerably flattened purse." CREA activities would be reduced and there would be other bad effects. In addition, many colleges were cutting down their research and extension work. Some utilities had ceased rural line construction. Kable spoke of rural electrification specialists (presumably agricultural engineers) who were out of work and looking for jobs.

Perhaps the New Deal would step in and provide. Kable evidently thought so. He outlined the essential aspects of the new Norris Act which would give the government "almost unlimited authority" to develop the Tennessee Valley. The Act provided for "study and experiments in rural electrification," a fact of intense interest to ASAE. Kable also mentioned that the National Industrial Recovery Act, which contained more than $\$ 3$ billion for public works, provided for the construction of electric transmission lines. He hoped this might stimulate rural service.

Kable joined the Tennessee Valley Authority soon after its authorization as a senior designing engineer. He was instrumental in organizing an important conference between TVA and ASAE in September 1934. L. J. Fletcher chaired an ASAE group which included President G. W. McCuen, Kable, L. A. Jones of USDA, C. E. Seitz, J. B. Kelley, R. C. Miller of Ohio State University, and I. P. Blauser, vice-chairman of the Rural Electric Division. The TVA group included a number of highly placed individuals. The conference, a three-day affair, was to promote cooperation between ASAE and TVA, to aid TVA in effectively using the information, judgment, and personnel of ASAE to further TVA's objectives. To this end, a permanent contact committee was set up. Kable, representing both organizations, was named general chairman. For ASAE, Fletcher, M. L. Nichols, 
R. C. Miller, and L. A. Jones were appointed by McCuen.

The TVA-ASAE liaison received much favorable attention. It accorded to ASAE a stature for which the members hungered - recognition by a large and important government agency that agricultural engineering would play a key role in developing the Tennessee Valley. But perhaps more realistically in those times of depression, jobs could result from what Kable and the others had started. As was said editorially in the Journal: "While the contact committee is not in purpose an employment agency, it seems obvious that if and when specially qualified talent may be needed by the TVA, the organization of the ASAE and the acquaintance among its membership will be most helpful in locating such talent if available in the Society." The writer added that this was the latest in a series of such relationships with "Federal departments" and others. Such relationships had proved to have "advantage to all concerned," and he hoped for more. In other words, the New Deal was putting the members to work.

Late in 1934, White, evidently undaunted by the diminishing importance of the CREA, spoke briefly to the North Atlantic Section. He spoke of a movement which rural electrification could make possible - the decentralization of American industry. Such a movement would maintain the rural communities, slow the rate of urbanization, and "bring the consuming public to the farmer's door." The social value of these results were, to White, unquestionable. We can say the same today.

On May 11, 1935, the Rural Electrification Administration was established. President Roosevelt named Morris L. Cooke as the first administrator. Cooke, a mechanical engineer, had gained public notice for his interest in cheap electric power. He favored public ownership of power generating plants. Shortly after he took office, the ASAE Committee on Relations with the Federal Power Commission visited Cooke to offer cooperation. That committee had been formed, according to Hienton, in response to a request from Secretary of Agriculture Henry A. Wallace to the American Engineering Council, asking for a proposed program on rural electrification.

It might be conjectured that Cooke's appointment was unpleasant news for ASAE. The agricultural engineers had been working on rural electrification for quite a few years. The value of their expertise was exemplified by the interaction with TVA. Among the long-time leaders in the field, Dr. Earl White was outstanding. Some members must have hoped for White to receive consideration as head of the new REA. Cooke not only was relatively uninformed of agricultural applications, he was not held in high regard as a mechanical engineer. But the Journal breathed nothing of this; indeed, the creation-of REA was not even mentioned for several 
months. It is perhaps significant, however, that an editorial appeared in September which called for "restoring to full strength the CREA, both the national body and its state subsidiaries." Which, of course, would have strengthened White's position. Of course, CREA was supported by private power interests which may have rendered White objectionable as head of a New Deal agency.

The Rural Electric Division acknowledged REA's existence at the 1935 Winter Meeting by inviting W. E. Herring to give an address. He was Cooke's special assistant.

Herring disclosed that REA could lend money to power districts, municipalities, private utilities, or cooperatives. It could also make loans for construction of generating plants. All of these loans were for the sole purpose of extending electric lines into rural areas without such service. Consideration was being given to lending money for wiring of farm houses and buildings. An agency already in existence, the Electric Farm and Home Authority, was making loans for purchase of electric appliances. (This Authority was under fire in Congress and about to be abolished.)

According to Herring, "We hope to have closer contact with you through an engineer who will be available about January 1 and whose sole duty will be to act as liaison engineer between the extension service and the REA." He was probably referring to D. S. Weaver of North Carolina State College. It was announced in March 1936 that Weaver was on a year's ieave of absence "to do special work in rural electrification for the USDA Extension Service in the capacity of extension specialist in rural electrification and liaison for the Rural Electrification Administration."

The attitude of Administrator Cooke toward ASAE and agricultural engineering is somewhat baffling. In spite of the ASAE committee that offered help to him and in spite of Weaver's appointment, Cooke sometimes behaved as if agricultural engineering did not exist. The AEC "Washington News-Letter" of July 1936 quoted him in a discussion of REA engineering needs as saying "it requires a new type of engineer - a rural engineer who is intimately acquainted with the practical problems that the farmer has to face and can make practical suggestions which will stand the test of experience." Yet he wrote to President Blasingame thanking him for the offer of assistance and pointing out how agricultural engineers could assist REA. Perhaps he thought agricultural engineers were "new."

Cooke's resignation was reported the following March, "to seek a rest from the burden of responsibility."

Another problem for the agricultural engineer was the meaning of that word "rural" in "rural electrification." Earl White discussed this at the 
1935 Annual Meeting. He first pointed out how rural consumers of electricity were classified differently in Wisconsin, Illinois, and Indiana, but that this was done for setting rates. Then he noted the United States Census Bureau definition: if you live in a town or city of 2500 population or over, you are an urban dweller. Otherwise, you are a rural dweller. This was the definition to use, White said, because "we are concerned with the building of rural America as contrasted to urban America." He quoted some EEI statistics which indicated that less than three percent of United States electrical energy was used by agriculture, while ten percent was used in rural areas if the Census Bureau definition was the criterion of "rural."

At the same meeting, Kable analyzed the development of that new phenomenon, the electricity consumers' cooperative. This one was the first organized in the TVA system; it was located in Alcorn County, Mississippi. Authorized to purchase energy wholesale from TVA, it had been functioning as a power distributor since June 1,1934; the energy was furnished to members at cost. Kable thought the association would be "free of debt in from six to eight years."

Wisconsin Power and Light Company President Grover Neff praised the long years of effort expended by the agricultural engineers when he spoke to the Rural Electric Division at the 1936 Winter Meeting. He also praised, but faintly, the developing work of REA and the farmer cooperatives. Neff challenged ASAE members to continue their leadership in the field. Specifically, he wanted them to develop safe wiring standards and electric farm machines, to coordinate the expertise of agricultural leaders, to help develop courses in the colleges, and to support CREA.

REA's Oscar Meier spoke also at that meeting. He aimed no insults at the private electric utilities. He offered a plea to the agricultural engineers to work with REA and all others concerned in order to move rural electrification along as fast as possible.

White came along again with a report to the 1937 Annual Meeting. The one-millionth farm was electrified in 1936. Fifteen percent of American farms were using electricity in that year, over two billion kilowatt-hours. The average use per farm was 2050 kilowatt-hours, which was two to four times the amount White predicted in 1931 would be used within ten years. Perhaps he was happy to have been such a bad prophet!

White reiterated his insistence upon the social transformations to be wrought by rural electrification. He quoted some philosopher who stated, "The automobile made it possible for the farmer to get away from home; now electricity makes that home a desirable place to stay." Then he said, "This single fact may have a most important bearing on our national development. It is an engineering achievement of the first magnitude." 
C

\section{Soil Conservation}

Soil conservation was another aspect of agricultural engineering technology which came to flower during the third decade. As a technology it was broad and integrative, embracing engineering problems of wind and water erosion, irrigation and drainage, land utilization and flood control plus politico-socio-economic issues of extreme complexity. The hard times, the climate, and the powers of the federal government conspired to draw large segments of ASAE into a heroic battle for the American soil.

However in 1927 the public was not much aware of any problem. Concern for soil erosion, for example, was restricted to a few engineers such as L. A. Jones of the USDA. Jones thought soil erosion demanded the "most serious attention" of the profession. Olney agreed; he pointed out that "agricultural engineers have the key to the situation" through their previous research.

One of the keys was the technique called terracing, where land surfaces were built up in a series of level areas. Terraced land absorbed rainfall and thus reduced run-off and soil erosion. The technique was known

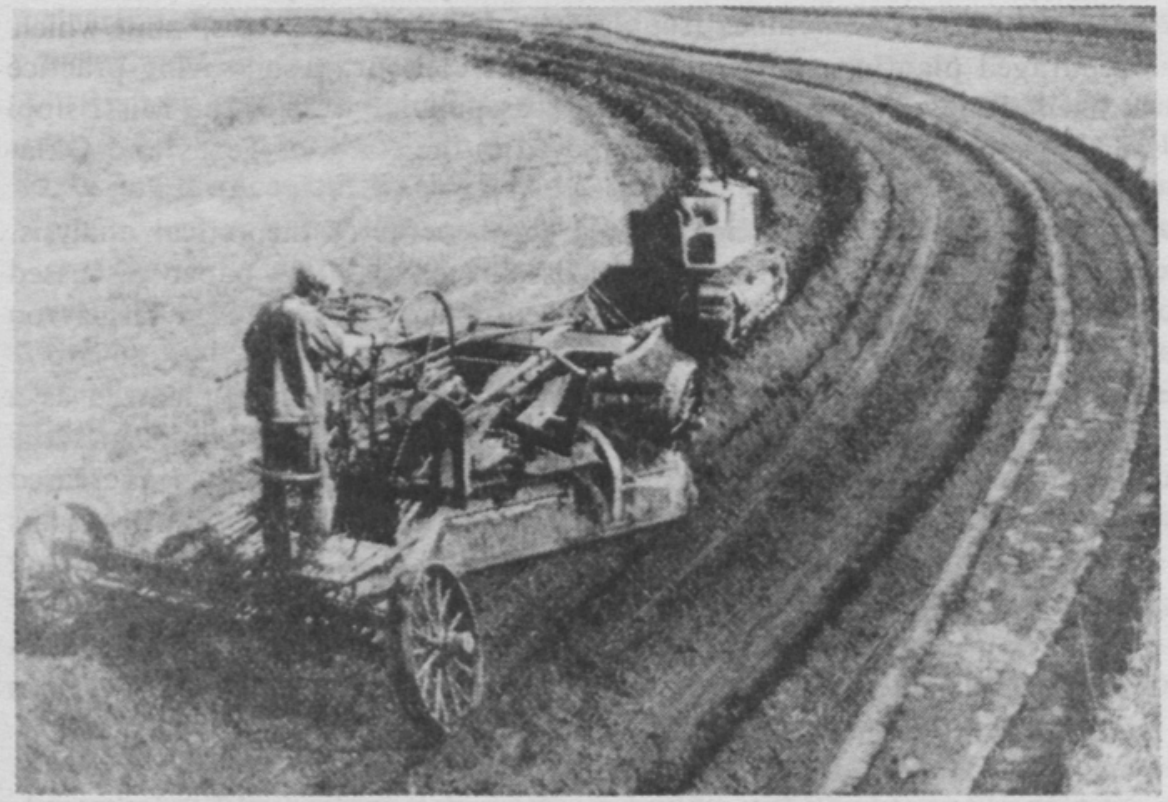

From February 1936 AGRICULTURAL ENGINEERING "Increase in the amount of terracing work being done has resulted in an increase in the size of the equipment used for building terraces, together with a decrease in the amount of labor required and a greater number of complete outfits purchased primarily for terracing work" 
to ancient man, who had terraced steep land in "benches" not practical for modern farming. The broad-base, or Mangum, terraces displaced the bench system because they could be cultivated, leaving no waste land in the field. These terraces were built from 20 to 25 feet broad at the base and from 15 to 24 inches high. They usually were built with fall along the terrace to carry off the runoff water in a broad, shallow channel at a noneroding velocity, although sometimes they were laid out level, depending on the soil type.

The Mangum terrace originated in North Carolina in the 1880s. Its properties were known to agricultural engineers since at least 1917, when E. W. Lehmann published the first of several technical papers on the subject which appeared prior to the third decade. C. E. Ramser of USDA wrote on how to design these terraces in December 1928. Assuming rainfall probability tables were available, Ramser gave data on the fall of the channel in relation to terrace length and slope of the land surface. Protection of the outlets and the design of drop inlets were discussed. Tools for building terraces were portrayed. These were horse-drawn V-shaped contraptions, but they worked. Terraced fields were usually farmed parallel to the terraces, which was sometimes troublesome due to "point rows," but which encouraged planting and cultivating on the contour, a soil-saving practice in itself. Ramser stated that terracing was popular west of the Mississippi and that the best methods "are employed in the states of Texas and Oklahoma."

Terrace design at that time lacked the benefits of theoretical analysis. C. K. Shedd of the University of Missouri in his 1929 paper discussed guiding principles for terracing in the cornbelt. He had relied largely on designs which had proved successful.

At the 1929 Annual Meeting in Dallas, soil erosion was "pictured as a national menace." This problem dominated the meeting. At its end the Resolutions Committee issued a statement which encouraged increased support of state and federal agencies for research and extension programs in erosion control; this was sent to Secretary of Agriculture Hyde. Acting Secretary Dunlap replied that "prevention of destructive erosion [constitutes] one of our outstanding national problems." He added that the USDA was "organizing a comprehensive research program in which the various state agencies will participate."

At the Dallas meeting Ramser described the new federal appropriations which would enable USDA to set up soil erosion projects either independently or in cooperation with the states. Eighteen experimental stations had been authorized, some were already in operation. R. E. Dickson described how erosion and runoff had been measured for several years from plots 
at the Spur substation of the Texas Agricultural Experiment Station. F. O. Bartel did the same for some North Carolina experiments. H. H. Bennett of USDA delivered a long paper on the economics of soil erosion prevention. He stated that the annual loss of phosphoric acid, nitrogen, and potash through soil erosion amounted to $\$ 2$ billion. R. Bentley of Texas A. \& M. College estimated that three million acres had been terraced in Texas, with 18 million cultivated acres yet to be done. He observed that terracing had been taught at Texas A. \& M. since 1911, and also by county agents. G. E. Martin of Oklahoma A. \& M. said that farmers would not terrace their lands until they see a successful demonstration.

The Land Reclamation Division met in December. Among other speakers they heard Elwood Mead "outline some of the triumphs of the agricultural engineer in the conquest of the arid regions," and President W. G. Kaiser say that "Soil erosion control is an engineering problem of the greatest importance."

Papers collected in honor of the 25th anniversary in 1931 examined the soil conservation state of the art. In general, those papers reflect an attitude of cautious optimism. Most reclamation fields, irrigation, drainage, landclearing and erosion control projects seemed well-established but most lacked certain data.

Ramser, in December 1931, discussed the problems of farming terraced land at a Land Reclamation Division meeting. Wheel tractors had trouble crossing terraces but tracklayers did not. Depending on slope, two-bottom plows worked better than single-bottom. Planters and drills, unless singlerow, gave difficulty in operation at any angle to the terrace. Cultivation with the general-purpose tractor would have been improved by power lift of the equipment. Some combines had no troubles while others did. Ramser concluded that many farmers were resisting terracing because they feared difficulty in operating machines on terraced land.

L. A. Jones, now with the Bureau of Agricultural Engineering, told the 1932 Annual Meeting how USDA distributed its soil erosion control research responsibilities:

The Bureau of Chemistry and Soils was working on physical and chemical properties of soil as they relate to erosion.

The Forest Service was studying the effect of forests on runoff and erosion control.

The BAE was investigating the engineering problems of projects such as terraces and soil-saving dams, terrace-building machines, and requirements of machinery for operation over terraced land.

Jones closed his remarks with a poem of "unknown origin" called "Hordes of Gullies": 
"Hordes of gullies now remind us

We should build our lands to stay;

And departing leave behind us

Fields that have not washed away.

When our boys assume the mortgage

On the Land that's had our toil,

They'll not have to ask the question

'Here's the farm, but where's the soil?'”

Terrible poetry but excellent sentiment!

Early in the New Deal legislation came the Agricultural Adjustment Administration. AAA agreed with ASAE that the country had surplus crop acres and moved to put some of them into storage. This gave rise to editorial concern in June of 1933 on the erosion status of such lands. The writer believed that under "a fallow condition" erosion would probably be worse than under normal cropping. Cover crops would offer only temporary protection. But idle acres offered opportunity for terracing, "for the welfare of all America."

It should be added that about this time the Civilian Conservation Corps was formed.

By mid-1933 USDA, in cooperation with the states, had set up ten soil erosion experiment farms. They were near these cities: Guthrie, Oklahoma; Temple, Texas; Hays, Kansas; Tyler, Texas; Bethany, Missouri; Statesville, North Carolina; Pullman, Washington; Clarinda, Iowa; LaCrosse, Wisconsin; and Zanesville, Ohio. These were all concerned with terracing and ancillary problems and were managed by BAE's Division of Drainage and Soil Erosion Control.

Meanwhile, at Auburn, Alabama, M. L. Nichols had redesigned the crosssection of the Mangum terrace. The Nichols terrace was a broad, shallow ditch with only a slight mound on the lower side; it was more easily crossed by machinery than other types. This station also was working successfully with strip-cropping, alternating soybeans, with cotton.

Ivan D. Wood of the University of Nebraska, described a machine which could dig 10,000 holes per acre, each with a capacity of three gallons. Land worked with this machine could hold one inch of rainfall without loss if it fell in one minute. He called for development of the lister to create a dam of earth in the trench at intervals of 15 to 20 feet or less. With partial contouring of the rows, a two- or three-inch rain could be retained. This idea became embodied in the basin lister, a machine which played a major part in taming the Dust Bowl.

By the end of 1933 the New Deal had become a national program. Opportunists were flocking to Washington eager for office. The Journal asked the 
members "to give the New Deal the benefit of our training and judgment. It is a job for engineers, not for opportunists." Through ASAE, these benefits could be extended to the federal government but "It is not a time for too much modesty."

The next year saw a definite trend of members into New Dealish operations involving soil conservation. Principal agencies involved were the Soil Erosion Service of the Interior Department, the CCC drainage camps and the Emergency Conservation Work (ECW) camps. In many cases the agricultural engineers were superintendents of the camps or in charge of groups of camps or district offices.

The year 1934 was the year the Dust Bowl added its outrage to the national troubles. Here is a brief quotation from Stuart Chase's book "Rich Land, Poor Land":

"In the spring of 1934, the farms of the Dust Bowl - which includes western Oklahoma, western Kansas, eastern Colorado, the panhandle of Texas, and parts of Wyoming - blew clear out to the Atlantic Ocean, 2000 miles away. On a single day 300 million tons of rich top soil was lifted from the Great Plains, never to return, and planted in places it would spread the maximum of damage and discomfort."

Dramatic but true - and illustrating a drouth cycle that put a premium on measures of moisture conservation. Those dust storms changed the approach to dry-farming considerably. One would expect an immediate surge of interest in wind erosion, but only one paper was published on that topic between 1934 and 1949.

And the technology of terracing moved on. Ramser reported that terraces conserved soil and fertility and increased yields. They were effective on land slopes as small as 2 percent. The vertical intervals, grades, lengths, and construction methods were being established under a variety of conditions. Concurrently, methods of healing the gullies were being perfected.

The problem of terrace building attracted the attention of the Power and Machinery Division at the 1934 December meeting. Terraces could be built with regular or modified farm implements (the plow, for example) or with road machinery. But these had their disadvantages. Motion pictures were shown of special machines developed by E. V. Collins at Iowa State and J. C. Wooley at University of Missouri. Both used a plow bottom to lift the soil. The Iowa machine then threw the soil sidewise by a helicoid conveyor; the Missouri machine conveyed it on a belt. The Iowa machine could build 700 feet of finished terrace per hour. Both were pulled by $15-30$ horsepower tractors.

These unique machines caused a sensation. For the first time, private industry began to take an interest in soil conservation; here were machines 
which offered hope of commercial advantage. The Journal editorialized that "we have reached the production phase in the soil erosion control program." Not only that, despite input from other disciplines, "there is no denying that the technology of terracing is distinctly an achievement of agricultural engineering." The policy of using erosion control to "employ a maximum of labor with a minimum of equipment and materials" could well be overthrown by the Wooley and Collins terracers. These could provide needed erosion control and contribute to general prosperity through commercial sales. And general prosperity was the only real "farm relief" according to ASAE.

The various agencies of the federal government involved in soil erosion control were unified in March and April of 1935. The base of the new organization was the Soil Erosion Service of the USDI, which was transferred to USDA. Also transferred to USDA were ECW camps and AAA soil erosion activities. In addition, the soil erosion activities of the Bureaus of Chemistry and Soils, Agricultural Engineering, and Plant Industry, and the supervision of CCC erosion-control work which had been under the Forest Service, were transferred to the new unit. On April 27 the unit was designated the Soil Conservation Service, with H. H. Bennett in charge.

Figures quoted in May from the American Engineering Council indicated how much of a stake agricultural engineering had in the New Deal. A breakdown of the new work-relief bill contained these provisions:

Rural rehabilitation, water conservation, irrigation, reclamation .......................\$\$500 million

Rural electrification .................... 100

Civilian Conservation Corps ................ 600

Soil erosion, stream pollution, etc. ............. $350 \quad "$

The terracing work of C. E. Ramser and others from BAE received an editorial boost at this time. Ramser had discovered that the terraces at the LaCrosse, Wisconsin, experiment station had reduced runoff by 45 percent. This undoubtedly affected the volume of water delivered to Louisiana - but how much? National policy was needed to establish the economic value of such relationships.

Although the big dust storms were spectacular, they were infrequent. This perhaps explained why the members did not attack wind erosion as vigorously as they did water erosion; the latter took place constantly. Yet the two were related. Surface roughness and moisture retention could combat both wind and water erosion; the basin lister desired by Wood was the machine that could do this. C. K. Shedd (now with BAE), E. V. Collins and J. B. Davidson announced an experimental basin lister in 1935 
which was used as a corn planter. They concluded that moisture retention and reduction of wind erosion were good.

At the Annual Meeting the Land Reclamation Division voted to change its name to the Soil and Water Conservation Division. The change was termed "Iong overdue" and would have occurred sooner if a better phrase had been available. The new name was criticized for its length but the words "soil conservation" held much "recognition in national concept and policy."

Bennett (a non-member), the new SCS chief, described at the Annual Meeting that year his agency program. And he called for "earnest, creative cooperation from organizations such as the American Society of Agricultural Engineers."

Soil conservation provided a stimulus to membership in ASAE. Olney's Secretary's Letter of August 20, 1935 called attention to the "long list of applicants" in the August Journal (there were 31). Most of them were SCS engineers; they were recent graduates or had immigrated into ASAE from civil engineering.

The Agricultural Adjustment Act of 1933 was invalidated by the Supreme Court in January 1936. On February 29 Congress passed the Soil Conservation and Domestic Allotment Act. This Act continued policies of restricting surplus crops and compensating for cutting acreage of soildepleting crops and planting crops intended to improve and conserve the soil. During the debate on the new bill, the Journal stated in an editorial that "Conservation is too vital to the future of America... to be kicked around as an appendage of employment, of farm relief, or of anything else. It should be the dog, not the tail."

All this fermenting activity caused the members to move around as never before. Not only new members were stirring up ASAE. The federal agencies were drawing heavily from the state institutions; many did not return. Private industry was now hiring young engineers from the colleges. The situation drew the comment that "the profession of agricultural engineering is playing an ever larger part in both public and private enterprise."

The spring of 1936 brought heavy floods to the Ohio river watershed; this was a great industrial area and of less relative importance agriculturally. The Journal called attention to the stake that city people had in soil and water conservation - if they cared to look beyond their immediate troubles. They must be educated to the concept that floods can be controlled "at the source" to some degree, and that coordinated measures for both soil conservation and flood control would serve both city and country, with the best relation of costs to benefits.

Some 46 CCC camps were under the BAE's Division of Drainage. Thirty- 
six of these were directed by member John G. Sutton, a civil engineer located in the central states. The Ohio floods claimed some of their attention during the spring; blasting river ice jams, rescuing people and livestock, and repairing levees were part of the services rendered.

These storm and flood disasters caused AEC to observe that Congress had no hope of balancing the national budget that year; emergency spending for the stricken areas had become a necessity. But with such spending, increases for the regular departments involved in conservation works, etc., were suggested in view of the disasters.

It is unfortunate that human progress often is made only after terrible events occur. Secretary of Agriculture Henry A. Wallace personally observed good farm land dumped into the streets of Washington and of Ithaca, New York, that spring. The experience prompted him to recognize the contributions of agricultural engineering in a speech delivered in April. He wanted "flood control at the grass roots" and he quoted, among others, some findings of Ramser's terracing projects, as examples of the required system. He said "What we need...is a coordinated and interdependent approach which will treat the whole water system, from the crest of the hills right down to the month of the rivers." Which was what ASAE had been saying for years, but perhaps not loudly enough.

In contrast to problems faced by members in the east, BAE's Division of Irrigation under W. W. McLaughlin was engaged in bringing water to arid western lands. They did mainly research, with some extension and service work. And because irrigation water was usually a community or cooperative endeavor, the engineers had to deal with laws, customs, and financing; this was tricky business when it came to using underground water. Another task performed by this wide-ranging group was measuring snow cover and forecasting water supply. Technical achievements of the Division were legion. One of them was the Parshall flume designed by $R$. $L$. Parshall, which every undergraduate learned about in later years.

Later in 1936, President Roosevelt appointed H. H. Bennett, Morris L. Cooke, and F. A. Silcox (chief of the Forest Service) to organize a conference on "Upstream Engineering" to be held in September. The conference would pull together all branches of engineering. ASAE was invited to cooperate. Now would come the great opportunity for technical leadership.

An editorial published in August set the record straight as to what ASAE could contribute to such a conference:

"That an unobtrusive body of agricultural engineers have a head start of twenty to thirty years in working on certain phases of the now popular problem of upstream engineering, is significant. It should 
enable them to render an important contribution to the proposed consolidation of information.

"That the humanitarian inspiration for the conference may not have been fully aware of the valuable foundation for upstream engineering which agricultural engineers have established; that it may not name them specifically for major participation in the conference, is not too significant. It does not mean that agricultural engineers are or can be left out of any well-rounded conference on the subject. It means that they must make known their place in the field.

"The agricultural engineering position in upstream engineering is sound, solid and time-tested. In its seventeen years AGRICULTURAL ENGINEERING has published 140 articles on various phases of the subject by 90 authors, over half of whom are agricultural engineers active in the ASAE, and in a position to bring these articles fully up to date..."

The writer made clear that agricultural engineering stood between civil engineering and agricultural science, and that it offered no competition or duplication to the work of other engineers. It required too much special training and was too well established to be "seriously questioned in its field." Agricultural engineers should respond to the invitation to the Upstream Engineering Conference "with assurance of the inherent integrity of their position..."

Twenty-two members attended. Papers were presented by R. U. Blasingame and W. H. McPheters, E. R. Jones and S. H. McCrory discussed papers presented by others. Blasingame's paper emphasized that the solution of upstream engineering problems depended on cooperation of scientists, engineers, government at all levels, and "intelligent farmers."

Was the ASAE delegation overawed if not submerged by the total forces marshalled at the conference? The federal government alone brought forward not only USDA, but the Army, Forestry, Geological Bureau, TVA, the Weather Bureau, and REA. Add to that the older and more powerful engineering societies. Still, the long-term research and experience coordinated by ASAE must have had impact, to say nothing of the dignified common sense expressed by President Blasingame and other agricultural engineers. A November editorial stated that "The first thing to remember in considering any general program to put upstream engineering into effect is that is must win the approval of millions of land owners." This philosophy alone was an excellent contribution.

AEC commented in November that the Conference had had an "impossible task" set for it and that its "failure" was unavoidable because "all 
information" concerning soil and water conservation was not consolidated. However the need was stressed for "sound engineering based upon complete hydrological data" and for legislation applied to regional river basins rather than political subdivisions. American Engineering Council favored the regional interstate approach in dealing with water resources and problems, even though it deplored public power generation by TVA.

That month President Roosevelt was returned to office by an overwhelming margin, an endorsement of the New Deal. The AEC wondered if this meant a move toward "further socialization of natural resources and more centralization under federal auspices..."

There was no doubt of it. Yet the work done under the emergency soil conservation programs, much of it directed by agricultural engineers, had done much good for the country both in terms of social and economic values and in preservation of the land. The CCC alone had by early 1936 completed 1.9 million soil erosion check dams and planted 558 million forest trees over denuded areas. Establishing the permanent SCS was perhaps a more important development, along with strengthening the water-resource divisions of BAE, for these gave the nation both research and action agencies to attack the problems. It is difficult to visualize any private industry or combination of such that could do what needed to be done. "Socialization" and "centralization" were solving the problems, or at least trying. One enormous hindrance was lack of fundamental data, particularly hydrologic, and emergency agencies were not set up to provide this kind of knowledge. Of course, the agricultural engineers were witnessing (and participating in) the birth of a new American habit: let the government take care of things.

Be that as it may, they helped to make soil conservation an honored term. If the battle for America's soil was not won, at least the battle lines were drawn, the techniques of warfare developed, and leaders were trained. In a day when the term "environment" was not yet a battle cry, agricultural enginers fought for a better environment.

\section{D \\ Rubber Tires for the Tractor}

Arnold B. Skromme of Deere and Company studied the interaction of ASAE and the farm equipment industry during the period 1907-1970. He noted that the topic of rubber tractor tires was first introduced at the November 1932 meeting of the Power and Machinery Division. This was followed by a "flood" of papers on the subject in 1933 and 1934 and by widespread adoption of rubber tires. In complete contrast was the case of the three-point hitch (a remarkable advance) which Harry Ferguson 
introduced in 1939. Skromme found that ASAE completely ignored this valuable mechanism for 13 years and speculated that this strange unwillingness to discuss the innovation may have retarded its adoption.

The October program announcement of the meeting that kicked off rubber tires hardly mentioned them. The speakers must have been secured at the last minute.

J. W. Shields of Firestone Tire and Rubber Company stated that a new lowpressure pneumatic tire had just been developed which could replace the steel wheel and lugs. Its 12-pound pressure allowed the tire to flatten into a large ground contact area. This gave traction qualities adequate for most farming uses. Increasing the weight on the tires increased the drawbar pull. With these tires front and rear and with engines providing higher speeds, the tractor would no longer be barred from the highways; it could haul rubber-equipped trailers and wagons. Such tractors could replace trucks and deal the final death blow to the horse.

McCuen of Ohio State gave a paper on some field tests comparing steel and rubber. He found that rolling resistance was less with rubber, drawbar pull and fuel economy were much better with rubber, plowing was faster with rubber and resulted in better soil structure, and the rubber-equipped tractor was more comfortable for the operator.

Other speakers brought out details of tire and rim design and noted that

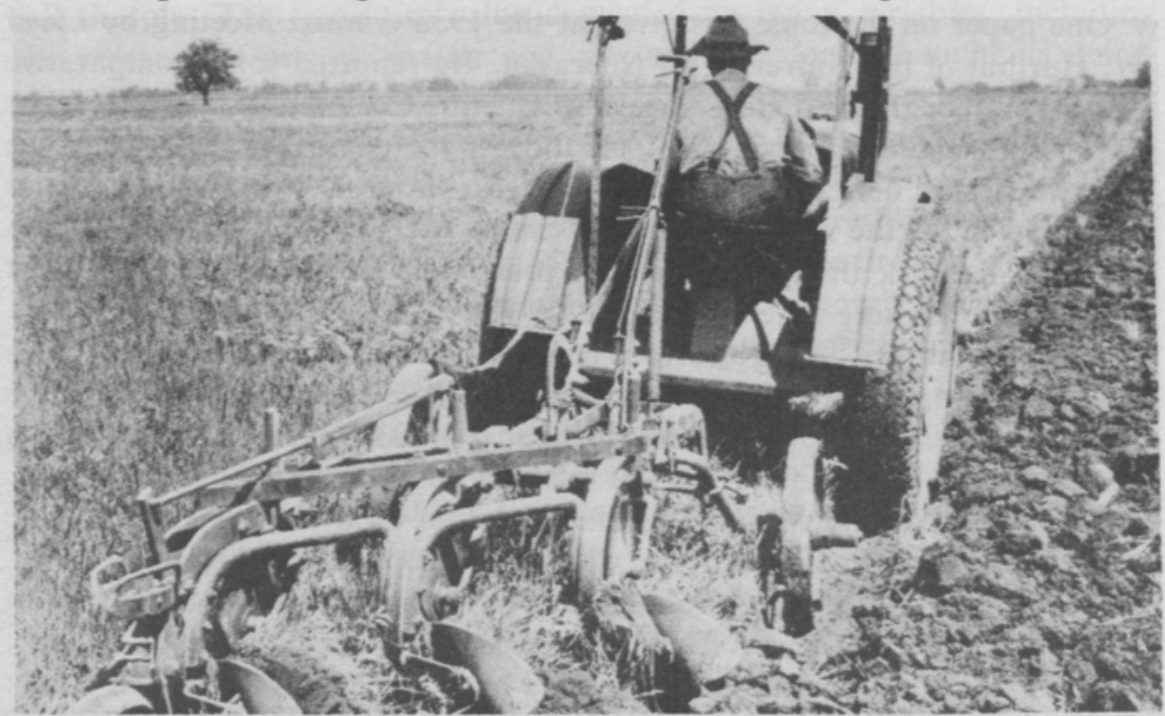

Topic of rubber tractor tires was first introduced at November 1932 meeting of ASAE Power and Machinery Division. Above photo appeared in December 1932 advertisement by the New Departure Manufacturing Company 
the low-pressure tire reduced seedbed packing to a minimum.

Walter B. Jones probably attended the meeting. He wrote a Journal editorial in February 1933 which bubbled with optimism over the "spectacular performance of pneumatic-tired tractors," but which called also for "that critical skepticism which makes engineering advance sound and sure." He was happy that this development had arrived at a time when production of farm machinery was at "low ebb," with the inference that if sound research proved out the tire, tractor sales would pick up.

The skepticism Jones wanted appeared in the form of a long letter to the Journal editior in April. ASAE Past-President Frank N. G. Kranick (he formerly spelled his name Kranich) of J. I. Case Company heard those rubber tire papers. To Kranick, the agricultural engineers were going overboard for an untried technology; some of them were motivated by commercial considerations. In addition, the "college men have accepted...low-pressure tires...hook, line, and sinker..." He pointed out that on wet soil the tire lost traction completely; in low gear its traction was inferior; and its nonsoil-packing attributes were illusory. As to highway advantages, this was not what tractors were designed for. These and other disadvantages were realities. The farmer would suffer if unsound and unproven devices were to be sold him just "to increase our sales." Kranick preferred to wait for some reliable data.

One paper on the topic was given at the 1933 Annual Meeting by Lloyd W. Hurlbut of the University of Nebraska. He reported some comparative tests of rubber tire and steel wheels on an Allis-Chalmers Model " $U$ ". The advantages claimed previously for rubber were confirmed. However, the steel wheels did better in low and second gear in terms of drawbar pull and speed. In mud, the rubber tires with chains did better than steel. Unfortunately, Kranick thought it was bad practice to require extra equipment such as chains every time it rained.

A symposium on "Agricultural Wheel Equipment" was held by the Farm Power and Machinery Division in December 1933. Fourteen papers were presented; these were published in the February 1934 Journal together with a summary by Walter Jones. This was the high point of the rubber tire mania.

The papers mostly reported results of tractor field tests at various state agricultural experiment stations, with one exception; one paper was delivered by a farmer-member from Iowa. Tests were reported from: Nebraska by C. W. Smith and L. W. Hurlbut; Kansas by F. J. Zink, E. L. Barger, J. Roberts, and T. E. Martin; California by B. D. Moses and K. R. Frost; Illinois by R. I. Shawl; Wisconsin by F. W. Duffee; Ohio by E. A. Silver (tires for wagons and trailers); Iowa by F. W. Hawthorn; Indiana by R. H. Wileman; Louisiana by H. T. Barr; Idaho by H. Beresford; Minnesota 
by A. J. Schwantes; Pennsylvania by A. W. Clyde; Saskatchewan by E. A. Hardy; Texas by F. R. Jones; New York by F. L. Fairbanks. Geographic coverage that broad should have yielded definitive results, if such was possible.

The Jones summary, although masterly, is sometimes a little short of thoroughgoing. He said that almost any brief statement about rubber tires "is challenged by exceptions," but he regarded exceptions as "superficially contradictory findings" and ignored many of them.

Jones concluded that "the outstanding characteristics of the low-pressure pneumatic tire is its low rolling resistance." The draft reduction ranged up to 60 percent in comparison to steel equipment. Rolling resistance was less for free-wheeling applications than on drive wheels. Experience on guiding wheels of tractors was generally favorable. However tread alteration sometimes caused poor performance with rubber tires.

The limitations of rubber tire for traction were caused by its dependence on friction for adhesion to the soil. To obtain high friction, considerable weight should be applied. With low rolling resistance and on level ground, this was not objectionable. The low resistance permitted striking increases in capacity and economy at higher speeds with light to medium pulls under favorable moisture conditions.

The critical moisture value, when reached, caused tractive effort to fall sharply. That moisture value depended on many variables, including the presence of organic matter and clay colloids. Jones thought its determination was the main problem to be solved. In fact, in Wisconsin the whole idea of the rubber tire was on trial because of the moisture problem.

For operating in hayfields and for harvesting small grains there was no question of the rubber tire's superiority. But in freshly tilled soil the advantages were not as clear. In seeding small grain the tire had worked well if the soil was dry. In corn cultivation rubber was marginally satisfactory. Harvesting corn with the picker-husker gave the rubber-tired tractor its most publicized defeat because of deep, soft, icy, wet soils.

Adding chains could conquer these difficulties but their installation was time-consuming and maddening to the farmer. They also gave him a bad ride. While the rubber tire sometimes caused hazardous bouncing motions, it usually gave a smooth ride.

Jones stressed also that the tractor was designed neither for road surfaces nor for field use with rubber tires. All the applications had been "makeshifts of steel-wheel jobs."

Where rubber tires were employed on wagons and trailers there appeared to be no impediment to general adoption. The same applied to the ground wheels of implements. But where ground adhesion for tractors was required, 
Jones wondered if rubber tires and steel wheels might not share the load, each used where best adapted. At any rate, he believed the field for rubber tractor tires was large enough "to warrant continued and intensive engineering study, and to justify vigorous, though discriminating, commercial exploitation." Frank Kranick probably thought the latter statement put ASAE out on a limb, since Jones was an ASAE staff member.

Not necessarily, however, since editorial comment in the Journal followed up the Jones analysis chapter and verse, except for the "commercial exploitation" part. The need for a tractor designed for rubber tires was emphasized. This job demanded some "pure" research regarding soil-tire reactions. Fortunately, the new federal tillage machinery laboratory at Auburn, Alabama, had just been announced. "Probably no other single task which might be assigned this laboratory would have so much immediate economic significance to American agriculture." This was assuming that the findings would "pave the way for the true rubber-tired tractor."

Nothing came of that request for research; the October Journal carried an editorial to that effect. It called for a study of the rubber tire similar to that which J. W. Randolph had done of the steel wheel and lug. "It should not be necessary for rubber to repeat the history of the steel plow, going through a century of empiricism before its proportions were defined or its action understood."

Another editorial in November anticipated the Winter Meeting by commenting on the experience of farmers with rubber-tired tractors, as gathered by the Committee on Wheel Equipment. It appeared that relatively few farmers used rubber-equipped tractors for road hauling. But they were using them in increasing numbers for various kinds of field work. They recognized the shortcomings and hoped for future improvements. One thing they liked was the easier ride. This opened up the whole idea of "comfort engineering," which until then was neglected by designers.

The 1934 Power and Machinery Division meeting in December had another symposium on the application of rubber tires to tractors and other farm equipment.

C. W. Smith reported on the 1933-34 survey of farmer experience with rubber-tired tractors. Of 3000 questionnaires sent out, 686 replies were received. Those had been exceptionally dry years; in fact, 1934 was the driest season on United States record. Because rubber tires were quite new on the farm, the experiences reported were gained during those two dry seasons. These owners turned in a preponderance of replies that indicated a rosy future for rubber tires. There were exceptions, of course, particularly in the case of muddy conditions, but the overall evaluation gave the preference to rubber. While the responses came from most parts of the 
United States, the majority were from the Corn Belt.

Workers at Purdue University attached rubber tires to a combine harvester. Their tests showed reduced vibration with rubber, reduced drawbar pull with rubber, and reduced fuel consumption by the tractor when pulling the rubber-tired combine. Highway operation was much easier with rubber. The only disadvantages found with rubber were its increased cost and the puncture hazard in using low-pressure pneumatic tires.

A. W. Clyde addressed the meeting on the possible pitfalls of comparative tests of tractors equipped with steel wheels and rubber tires. True comparisons were not obtained because the wheel diameters were usually different, giving a change in effective gear ratio. This together with a change in rolling resistance tested an "accidental" combination of engine and wheel rather than the wheel alone. Clyde outlined a method of obtaining more accurate comparative data.

The use of pneumatic tractor tires on listed crop ridges was considered a serious problem. Frank J. Zink of Kansas State College cooperated with the Firestone people in some attempts to solve the problem. His December paper pointed out that the basic issues were lack of steering control and inability to keep both front and rear wheels on the ridge top; thus the problem was confined to crops planted in the furrow. Several possible remedies were tested. The most effective was to have the rows spaced consistently 42 inches apart, with tractor tread width set to twice the row spacing. Also lug-type chains could be used under difficult conditions, although this offset the advantage of rubber to a degree.

Meanwhile, the increasing numbers of tractors on roads raised the question of taxing them for the privilege. A Journal editorial of March 1935 pointed out that motor truck taxation had been grossly unfair to farmers. By basing the license fee solely on weight or power rating, regardless of mileage, the farmer's tax per ton-mile was much higher than that of commercial truckers. All indications were that annual tractor mileage would average very low. Therefore, perhaps they should be taxed on their speed capacity as an index to mileage usage of public roads, rather than weight. The practice of tax-free tractor fuel should be continued, as it would be impracticable to "record every passage of the farm gate." The agricultural engineers should be ready with some kind of rational basis for such taxation, to stimulate uniform provisions among the states in advance of legislation. "By offering technical data and counsel, engineers may contribute to the civilization of taxes."

Only one paper on rubber tractor tires was presented at the 1935 December meeting of the Power and Machinery Division. It came from the Nebraska Station and was concerned with the effect of tire size on draw- 
bar pull and travel reduction. It was found that drawbar pull was increased on plowed ground with a reduction in tire pressure, but the opposite occurred on the tractor testing course. Drawbar pull was largely independent of tire size and effective wheel diameter. The latter conclusion was criticized by $A$. W. Clyde in a letter to the Journal of June 1936. His letter ended with the now-familiar statement that "we really know little about the fundamentals of traction of a rubber fire on soil."

Strange-sounding today, but logical in those penny-pinching days was a call by Walter Jones in April 1936 for interchangeability of tire equipment among various classes of farm machinery. He noted that the Farm Equipment Institute was apparently working to that end. In that same editorial, Jones wrote that "the rubber tire has survived its probation and has become just one more item for routine engineering."

That just about ended the initial rubber tire craze. No papers on the subject were given at the 1936 Winter Meeting, although Randolph presented one on steel wheels and lugs. The 1937 Journal had some more Nebraska data on tire size versus drawbar pull plus a suggestion from $E$. V. Collins on how to whip the lister ridge problem. The Auburn laboratory apparently did not commence scientific studies of tires until about 1949.

It seems likely that ASAE's Power and Machinery Division programs, committee work, and interaction with SAE and FEI helped the rubber tire to move into general use very rapidly. These activities served to focus the problem-solving efforts of the state experiment stations (USDA was seemingly not involved) and the tire manufacturers. New information was uncovered and disseminated with a speed that would be difficult to match today. However, the crucial factor must have been farmer acceptance of the pneumatic tire. Its easier ride and diminished tendency to throw dust and dirt over him marked the beginning of attention to human comfort. The increased speed of operations finally divorced him from the pace of a plodding horse. He was no longer barred from the public roads. And the fuel saved by changing to rubber tires quickly paid for them. While he may never have heard of ASAE, these were attractive considerations to him. 


\section{th decade, $1938-1947$}

\section{"WE BUILDED WELL DURING PEACETIME:.}

A. W. Turner

$\mathbf{A}$

\section{General Progress}

When Dr. C. W. Warburton, USDA Director of Extension, addressed the 1937 Annual Meeting at Urbana, he contended that machinery did not displace farm labor; machinery was forced upon the farmer by scarcity of labor. This was probably pleasant to hear, but member Harold E. Pinches of Connecticut State College said in print that mechanized agriculture caused "unemployment . . . labor displacement . . . economic unbalance, social unrest, political upheaval . . ." However, Pinches believed that the benefits outweighed the costs. Was the truth somewhere in between?

The novel "Grapes of Wrath" by John Steinbeck appeared in 1939; later it was made into a popular film. Its theme was that the "Okies" were "tractored-off" their land. L. J. Fletcher wrote of it that "Facts, of course, mean nothing to the writer of fiction, but most people accepted this picture as at least based on truth." He then quoted an Oklahoma A. \& M. College study which showed that of thousands of emigrants from that state, less than 2 percent said they were replaced by machines.

It was truly a difficult time in which to evolve adequate philosophy. It was said in a Journal editorial that "the appraisal of engineering contributions to social and economic values has assumed the proportions of a major problem." And all branches of engineering felt the burden; American Engineering Council called for more attention to "public affairs." It held a forum in May 1938 on "Employment and the Engineers Relation to It." There speakers concluded that "social legislation" and "interference with business investment" were the real enemies rather than technological progress.

Fletcher was chairman of the AEC Committee on Conservation and Utilization of National Resources at that time. To him, one form of social legislation was "national planning," and this was considered as fatal to 
restoration of employment because it tended to destroy free competition in the industrial sphere. Simultaneously, another AEC spokesman praised the government's proposal for a national public works department because this would prevent "thousands" of construction engineers from being thrown out of work should a business collapse occur. So, some planning was bad and some was not.

At any rate, many people thought that machines had created their problems (perhaps overlooking the possibility that people create both machines and problems). A novel idea proposed at the AEC forum by member Arnold P. Yerkes was to relieve the average man of the illusion that machines cause unemployment. The idea was to advertise the hours of labor contained in a product. For example, the 1938 automobile contained 25 percent more man-hours than the 1913 automobile. Therefore, the greater use of labor-saving equipment, with its resulting greater output, tends to increase employment rather than reduce it. There is no indication that the Yerkes proposal was considered seriously.

To agricultural engineers the farm tractor was the key to mechanization. How did it fare during the Great Depression? Was it scorned for "creating unemployment"? Some writers may have condemned it, but those who needed it did not. Between 1930 and 1938 there was a 100 percent increase in the number of farms having tractors. In the process, horses and mules lost their jobs but land formerly devoted to their sustenance was released for human nourishment. But for farm workers this became a complex equation. Less people could now cultivate more acres, so some were rendered "surplus." But many of them were delighted to be liberated from the harsh demands of "following a mule's tail for a compass" and headed for the city with joy. Others were retained on the farm by the new machines, their lives made physically easier and socially more dignified. Many a son took over the family farm because the father finally mechanized. The social and economic impact of mechanization was held by many to be generally beneficial. For example,

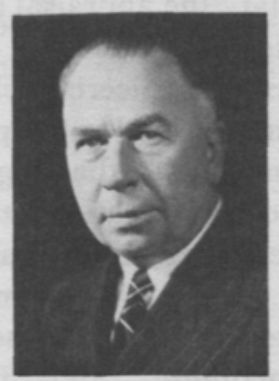

Arnold P. Yerkes

31st president, ASAE, 1937-38 
the cotton gin did not create depression nor throw labor out of work; quite the contrary. And engineers looked toward mechanical picking as a means of making cotton more competitive. They knew the picker (when it came) would probably create a social upheaval. Yet the machine had to come because hand labor was so costly; either that, or the growers must plant other crops more easily mechanized. In either case, the hand labor would be declared loser.

Which is a central question in the sociology of agricultural mechanization. To retard it or to prevent it to "provide jobs" is to condemn humans to brutalizing toil. In no other American industry would this practice be condoned.

Late in 1937 the "Big Problems for Agricultural Engineers" were analyzed editorially by ASAE Headquarters. These were:

- The critical need for an engineering analysis of agriculture; this was proposed by E. A. White.

- Development of farm production economics involving agricultural engineering as an organization, equipment, and operations factor.

- The chemurgy movement.

- The concept of agricultural engineering as the "engineering of agricultural biology."

The last item had its origin in C. O. Reed's address on receiving the 1937 Cyrus Hall McCormick Medal. Reed, a professor at Ohio State University (he is the one whose health was damaged in 1912 by the burdens of being ASAE secretary), was unhappy with the current philosophy. He regarded it as inaccurate and misleading. It seemed to suggest that "agricultural engineering simply is the service of mechanical, civil, electrical, architectural, and industrial engineering taken to the industry of agriculture, as if we were

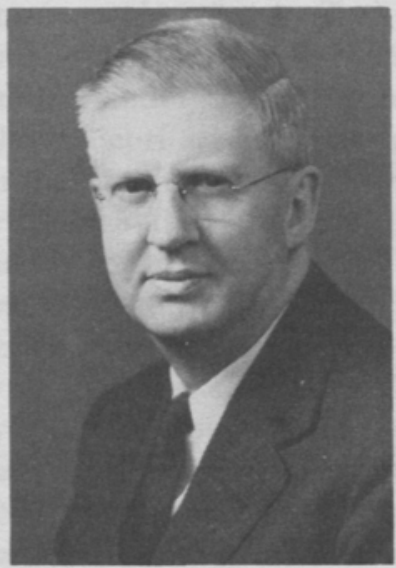

"Engineering of agricultural biology" had its origin in an address by C. O. Reed on receiving the 1937 Cyrus Hall McCormick Medal 
condescending to carry to agriculture something from outside it." This was a disservice to both engineering and agriculture. He argued that agriculture itself $i$ engineering. The factor that conferred distinction upon agricultural engineering was that "it is the engineering of biology." This unique kind of engineering should be based on the energy transformations and transfers conducted by living cells; a methodology and efficiency concept so based would open a new world to the agricultural engineer.

Headquarters, at least, found much merit in Reed's ideas. Among other advantages, the concept would not "step on the toes of older branches of engineering." Also, "every agricultural engineer may be able to see new light and new opportunity in his particular job and abilities by looking at them in relation to the engineering of agricultural biology."

Apparently very few agreed with these views. For example, Reed criticized the Divisional nomenclature, but nothing was done to change it. The colleges badly needed a unique organizing principle for their professional curricula, but there is no evidence that Reed's concept was adopted, even at Ohio State. Design of machines, structures, and processes (and the undergirding research) would likely have profited from the concept, after careful development.

Perhaps lack of development was the roadblock. Early in 1938 a move was made in that direction. A three-man committee was formed, the "ASAE Committee on the Energetics of the Biology in Agriculture." (It also called itself the Horse Feathers Club.) G. D. Jones of the Cleveland Tractor Co. was chairman; C. O. Reed and J. O. Slipher were the other members. They prepared a prospectus which analyzed life, matter, and energy, and proposed the preparation of "charts" in which agricultural engineering responsibilities were to be related to those fundamental entities. The Committee was given official status by President S. P. Lyle in September. Jones wrote to Olney that "The subject upon which this Committee is working is undoubtedly one presenting many difficulties..."

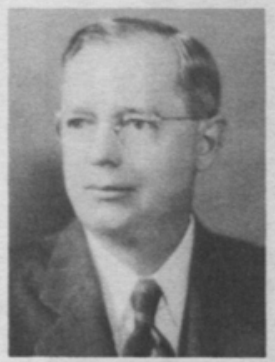

Samuel P. Lyle 32nd president, ASAE, 1938-39 


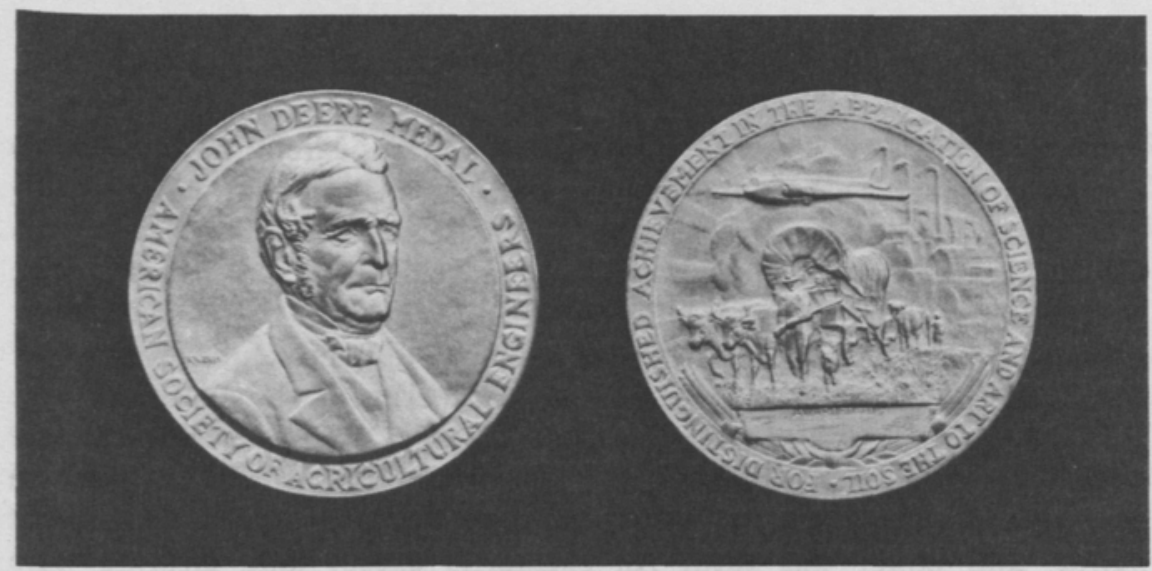

In 1937 Deere \& Company established the John Deere Memorial Medal Trust Fund to present a gold medal "For Distinguished Achievement in the application of Science and Art to the Soil". S. H. McCrory was first recipient

Perhaps the difficulties slowed progress, but Reed was the mainspring. Unfortunately, he fell into ill health and died in June of 1940 . Nothing really concrete emerged from his "engineering of biology" concept. The committee perished with him.

Had the concept been adequately matured and widely accepted, certain troubles lying in wait for agricultural engineering could possibly have been avoided or minimized. Accreditation of professional curricula and recruitment of students into them might have been made easier by a philosophy which clearly differentiated the education and goals of the agricultural engineer from those of other branches of engineering. The role and structure of ASAE itself might also have been clarified in relation to other technical societies. But that is hindsight.

As chairman of the Committee on Awards and Medals, O. B. Zimmerman soon became convinced that another gold medal was needed, in addition to the McCormick. Theo Brown of the John Deere Plow Works was a member of his committee and agreed with him. Some years of quiet effort by these men brought, in February 1937, a grant of $\$ 5000$ to ASAE from Deere \& Co. to establish the "John Deere Memorial Medal Trust Fund." ASAE was to suggest the design and lettering of the medal, which was to be comparable in size and quality to the McCormick.

After some false starts, the committee determined that the medal should bear the words "For Distinguished Achievement in the application of Science and Art to the Soil." A sculptor was employed to render the final design.

The jury of awards picked Samuel H. McCrory, chief of the Bureau of Agricultural Engineering, as the first recipient of the Deere Medal. A civil engineer, McCrory's achievements in drainage, soil erosion, flow in open channels, and administration of research were very impressive. 
The BAE meanwhile was extremely active and was careful to publicize its activities in the Journal. Late in 1937 it published an agricultural engineering bibliography which covered eight general divisions and 52 subdivisions of the field; it listed work done in the public service area only. ASAE Headquarters analyzed the character and number of public service items published, starting with 14 in the year 1900 and building to a peak of 280 in 1932. Most were published by state agricultural experiment stations; next were the state extension services; items from USDA were third. In subject matter, most were concerned with land utilization and development; buildings were a close second; machinery and equipment third; structural equipment fourth; and power was fifth. All categories except land clearing were increasing in interest.

The analysis suggested subject matter trends "toward applying engineering concepts on a broader scale; away from the superficial, toward the fundamental; from the strictly technical toward the practically possible and the economically and socially desirable; and toward a closer, more fruitful cooperation between agricultural engineering and other fields of technology." Unfortunately, less than ten percent of authors of state and federal agricultural engineering publications were ASAE members.

Organized in 1931, in a way the BAE "belonged" to ASAE. It had a relatively short life, however. The first wound occurred in 1935 when its research in soil-erosion control was transferred to the Soil Conservation Service. Then, in 1938, the construction and hydrological work of the BAE Divisions of Drainage and Irrigation were also transferred to the SCS; the other functions of these Divisions were turned over to the Bureau of Plant Industry.

Final dissolution came in 1939 when United States Secretary of Agriculture Henry A. Wallace abolished the BAE and combined the engineering work with chemistry research in the Bureau of Agricultural Chemistry and Engineering. The Journal claimed that this development "provides increased opportunity for agricultural engineering service to agriculture, and is definitely favorable." Not many agreed with this viewpoint. For years afterward the presidents called mournfully for return of the BAE, but USDA wasn't listening.

The queer combination of agricultural engineering and chemistry (which probably pleased the chemurgists but few others) came to an end in 1943 when the engineers were brigaded with the Bureau of Plant Industry and Soils, thus creating the BPISAE.

Of course, Samuel McCrory lost his job when the BAE was dissolved. He became an assistant chief; later he was put in charge of a wartime project intended to produce hemp. And there he ended his working days.

Mark L. Nichols, SCS chief of research, commented in a 1943 speech that 
the BAE failed to play a major part because agricultural engineering was isolated within it. This judgment may be overdrawn, although partially true. The BAE made an important impact in many vital areas of need, but administrative disadvantages probably caused its demise.

By 1940 there was also evidence that the American Engineering Council was in trouble. A Committee on Reorganization was formed. No budget for 1940 was approved-L. J. Fletcher was elected AEC treasurer on January 1, as luck would have it. Later in the year, it was publicly admitted that American Society of Civil Engineers intended to withdraw from the Council at year's end. These events, coupled with the resignation of AEC Executive Secretary Frederick $M$. Feiker suggested that AEC was to drastically change or become extinct.

As a charter member, ASAE had supported AEC since 1920. The cooperation of ASAE with the Council was generous and unselfish even though their interests did not always coincide. ASAE supported the Council with words as well as money. In 1937 a lengthy editorial on "AEC Effectiveness" appeared in AGRICULTURAL ENGINEERING. It was reprinted by Feiker and sent to all member societies (50-odd) as an example for their interaction with the Council. Olney rarely failed to invite Feiker to the Annual Meetings. In response to one of these invitations, Feiker wrote Olney" . . . it is pleasant to know that we have the moral support and understanding of our friends." When in 1938 AEC proposed a series of public forums on the "relation of the engineer to public questions," Olney and Palmer suggested that the contributions of agricultural mechanization to civilized progress form a part of it.

The disenchantment of ASCE with AEC had surfaced early in 1938. A special committee met with representatives of the other "founder" societies-ASME and AIEE. All agreed that "there was a general feeling of disappointment . . . in the apparent failure of Council to fully realize the admittedly high aims and objectives which had led to its creation." A thorough review and reappraisal of the Council was called for. To effect this, a joint committee was created which included the founder societies and also ASAE, SPEE, and two other member societies. Appointed to act for ASAE were L. F. Livingston, G. W. Kable, and J. B. Davidson. But before that committee could meet, ASCE in October 1938 advised AEC President McClellan that it was considering "curtailing or withdrawing its financial support."

The committee did report on January 9, 1939, although it must have been a futile exercise. A survey of $\mathbf{5 2}$ member societies revealed that the majority favored Council continuance but with closer control by the members. Most members expected the Council to monitor engineering matters arising from 
the federal government, for the benefit of the engineering profession. Apparently none of the members expected AEC to speak for engineers as professionals rather than as technical persons. The importance of an agency located in Washington was paramount, but its function was that of an "embassy," as if the government were some kind of foreign power (perhaps that was the idea), but with no hint of any need for a unity organization. Of course, ASCE promptly buried the report.

Few understood the need of American engineering societies for a unity organization as well as Vannevar Bush, president of the Carnegie Institution at Washington. He addressed the AEC annual dinner January 13,1939, on "The Qualities of a Profession." With the end of AEC in sight, Bush pleaded for engineers to lift their vision, to support AEC "adequately," to help it make the vital step toward belief in "ministration to the people," without which hope for professional spirit and status could have no genuine foundation. It was a good speech; in fact, it stimulated Olney's office to produce two Journal editorials measuring agricultural engineering claims to professionalism. But the cause of AEC was doomed.

Led by ASCE, the other founders, ASME and AIEE, withdrew support as of December 31, 1940. Although many other member societies remained, they were unable to sustain AEC financially without the big three. The founders formed a "conference committee" which functioned during the war and later became the nucleus of the Engineers Joint Council.

ASAE's long membership in AEC was probably of considerable value. Being small and somewhat hybridized (the agricultural part), recognition by older and larger engineering groups was beneficial; AEC membership promoted such recognition. Personal contacts with influential engineers were made through AEC by many ASAE presidents and others (L. J. Fletcher and R. W. Trullinger devoted much time to AEC affairs). Occasionally, AEC management helped promote agricultural engineering in Congressional deliberations, such as budget hearings. Although AEC opposed certain New Deal developments important to ASAE such as rural electrification and public power generation, probably that opposition was not too effective. With all of AEC's defects and shortcomings, ASAE was much better off in it than out of it. Sixteen years would elapse before ASAE would join the Engineers Joint Council.

The understanding of the ASAE rank and file members of the AEC and its potential value to the engineering profession was probably minimal. Supportive Journal editorials were printed from time to time. The AEC "Washington News Letter" appeared each month in the Journal (or at least abstracts of it) but much of the subject matter was probably dull to the average member. At the 1939 ASAE annual business meeting Fletcher told of 
AEC's precarious posture and it was voted to endorse the idea of a strong federation of engineering societies. But when the end came AEC disappeared from notice very quietly.

Perhaps one explanation for that apparent indifference was the momentous events taking place in Europe. The first week of September 1939 brought the invasion of Poland by Nazi Germany and the British and French declarations of war. The memories of $1917-18$ and of $\$ 2$ wheat followed by agonizing losses still lingered. An editorial warned that "Reasons might arise which would justify the U.S. in participating in the war, but the hope of thus restoring farm prosperity could not be one of them." Of more immediate interest, the conflict would probably cause food shortages in the world; these would release American farmers from the current low-gear production pace.

In May 1940 the Nazis swept through Belgium and The Netherlands while the British army fled from Dunkirk. The Nazis reached Paris on June 14 and the Battle of France was practically over. Americans awakened to the existence of a hostile Europe and the term "national defense" entered the language. ASAE President K. J. T. Ekblaw called a special session at the June Annual Meeting to consider how the Society might give assistance to the national defense program. The consensus was that ASAE had certain abilities to offer the defense program and that contact be made with Chester C. Davis, the agricultural representative on the National Defense Commission. ASAE's incoming president E. E. Brackett wrote Davis to ask how the members "may be most effectively mobilized for quick and effective action."

Lest anyone should fail to get the message, Olney wrote under date of July 10:

"The world-all of us-has been asleep. It's time to WAKE up! Yes, it is time to wake up and resolutely face and overcome the legions of evil forces battering at our gates-even within our gates.

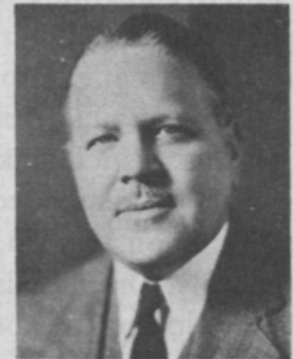

Karl J. T. Ekblaw 33rd president, ASAE, 1939-40

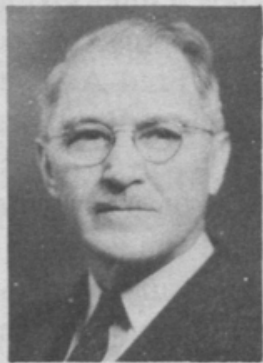

Elmer E. Brackett 34th president, ASAE, 1940-41 
"As a profession, as a Society, as individuals, we shall not fail if we go forward and not backward; if we look up and not down; if we stand firm in the face of any eventuality, and not weaken; if we hold steadfastly to the great truth the ages have proved, that only RIGHT MAKES MIGHT."

It was noted editorially that agricultural engineering must plan for swift farm production changes, notably more food production with less manpower and loss of strategic materials used in farm machines. Prophetic words.

Then came the Battle of Britain; Lend-Lease, price controls, the unlimited national emergency of May 27, 1941, and the June invasion of the Soviet Union by Nazi Germany. An editorial in the Journal that month stated that “. . . it seems certain that we will share substantially in the "blood, sweat, and tears" incidental to the destruction involved and subsequently reconstruction."

The June meeting at Knoxville, Tennessee, prompted resolutions pledging ASAE to support national defense and democracy and calling attention to the importance of food production as an element of defense. (It was at this meeting that E. E. Brackett presented ASAE with a gavel made of Nebraska osage orange wood; this has been the presidential gavel ever since.) PastPresident S. P. Lyle of the USDA Extension Service addressed the meeting on "Agricultural Engineering in National Defense." He mentioned that USDA had established the Office of Agricultural Defense Relations. Farm labor shortages were already severe, spotlighting the need for requiring labor-saving machinery. Employment was rapidly rising in the farm equipment industry. However, metal supplies were becoming tight and priorities for agriculture were not high.

Meanwhile, the military started laying hands on the members. The September 15 "Secretary's Letter" reported that most members who possessed commissions as reserve officers had been called to active duty. This included Assistant Secretary Ralph Palmer, who wrote many of the Journal editorials. Olney invited the membership to contribute their thoughts and comments, hoping thus to make up for the loss of Palmer's able pen.

Past-President Fred A. Wirt responded to Olney's invitation with some comment on "Farm Equipment as a Factor in National Defense." Wirt found that the farm operating equipment was just such a key factor as machine tools in industry; adequate food production depended upon these machines, as did the national defense. The obligation to ship food abroad was eroding the "surpluses" very fast. Fortunately, the metals required to produce the needed equipment were a small fraction of the total industrial requirement.

All this suggests that the defense sector was receiving major attention, but 
the activity was only a small effort compared to that which was coming. Most Americans still regarded the European, and Asian, events as somewhat unreal and unlikely to touch them intimately. The Asian picture was particularly remote. On November 19, 1941, the U.S. Ambassador to Japan warned President Roosevelt that Japan might attack the United States. On November 27, commanders of United States Pacific forces were informed that a carrier force had left Japan and an attack was possible. The public had no knowledge of these events; therefore, the news of the attack by Japanese carrierbased planes on Pearl Harbor early on Sunday morning, December 7 was a sickening surprise. War was declared upon Japan the next day. On December 11 Germany and Italy declared war on the United States.

ASAE Headquarters was hit by the attack. Staff writer Walter B. Jones had a son killed at Pearl Harbor. The "Secretary's Letter" of January 10, 1942 , lacked Olney's usual purple prose in dealing with war. He counselled optimism and hard work, and ended with a quote from Longfellow:

Let us then be up and doing

With a heart for any fate,

Still achieving, still pursuing,

Learn to labor and to wait.

(Tragedy awaited Olney also; he was to lose his son in the war.)

ASAE did not have a "war plan" ready. A member asked: "Has anything been done about the responsibilities of the organization during the present emergency?" Olney could only reply that " . . . a lot of thinking is being done, surely, by a lot of members, because we are all interested in seeing the Society make any contribution it can to the Nation's war effort. So if any member has evolved in his thinking any suggestions . . . the Secretary's office will be glad to have him send them in ... " The January Journal stated that the big problem was to increase production with diminishing manpower, machinery, and materials.

One thing changed quickly; J. B. Davidson remarked, "The lid is off." $\mathrm{He}$ meant that engineering need no longer fear blame for unemployment. Now engineers could advance labor efficiency in unstinted measure because of the seriously increasing labor shortage. In fact, efficiency (plus economy) could be the focus of agricultural engineering's war effort. Efficient utilization of farm labor not only would involve all ASAE divisions, but would harmonize conceptually with USDA's food-for-freedom program. President Kable called upon each member to realize his importance to the war effort. As an analogy he used the contact points and valve springs of the tractor. Those units are small but the machine is useless without them.

Kable went on a speaking tour to the West Coast in February, 1942. While in Yakima, Washington, he made a radio broadcast to farmers in his role as 
ASAE president. His main topic was concerned with methods of "blacking out" dairy barns and poultry houses. There was genuine expectation of Japanese invasion at the time, an expectation that was not completely relieved until the Midway Islands victory in June 1942.

The 1942 Annual Meeting in Milwaukee gave evidence of much concern with the developing conflict. Some said "It is dangerous to assume a short war with no replacement of farm machinery." Some argued that concern for soil losses should now take second place; this provoked a sharp clash. Kable's presidential address looked forward to a post-war government willing to be guided by engineering counsel, a time when fundamental freedoms would be restored. All were concerned by the looming problems of machine rationing directed by "hastily recruited amateurs." Incoming President Harry B. Walker pledged ASAE to help keep farm production "at as high a level of efficiency as possible" without sacrifice of land resources, physical plant, or standard of living. Almost casually, a farm implement company reported that its dealers had collected $1,357,000$ tons of scrap metal, about 75 percent of annual steel tonnage used by the entire industry. This suggested that when farm machine rationing arrived, the dealers ought to be the local managers of it.

The Farm Equipment Institute estimated that the increasing demand for farm products would require 605,000 more men in 1942 than there were on farms during the average of the past five years. Frank Zink of FEI said that 109,000 tractors were needed each year just to replace the declining work animals and that 85,000 tractors were needed as annual replacements. But the materials available in 1942 could not even provide tractors to replace the wornout units.

This picture was duplicated in other areas. For example, the War Production Board (WPB) had virtually stopped construction of new buildings for civilian use and this hit farm buildings very hard. A lack of metal and equipment slowed farm electrification.

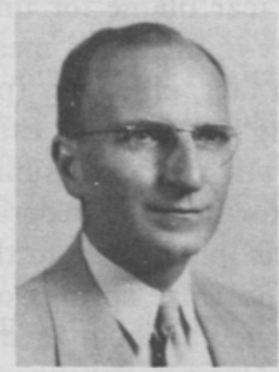

George W. Kable 35th president, ASAE, 1941-42

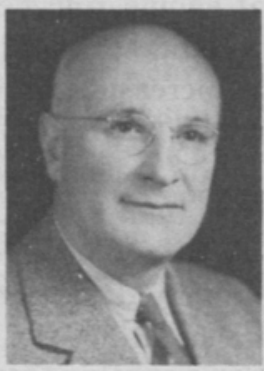

Harry B. Walker 36th president, ASAE, 1942-43 
It is exasperating to realize how little metal went into that all-important farm machinery, which was placed under quota by Washington. In terms of 1940 production, the 1942 new machine quota was 23 percent, and would consume about 0.5 percent of the United States steel supply. These quotas would allow one new two-row horse-drawn planter for each 18,500 acres of corn, a new mower for each 4700 acres of hay, and a new tractor for each 160 farms. Under the repair quotas, tractors would need to have a useful life of 40 years.

But that was only a beginning. To obtain a tire for his farm truck, a farmer had to fill out a form requiring data impossible to provide. But that form stated that any error could lead to a ten-year prison term!

Everybody seemed to hate what the government was doing. However, many ASAE members were in Washington helping the government do it. WPB alone had a half-dozen ASAE members on it by the end of 1942 . Presumably they were doing a better job than the "hastily recruited amateurs" complained of by agricultural engineers. Oleny's year-end message was the cheerful statement that "the future of agricultural engineering is indeed radiant with promise of grand new achievements . . .

Not so radiant was the news from the War Manpower Commission (WMC). Draft boards had been advised that deferments would be given to students who had completed one year of study in an approved engineering curriculum. But agricultural engineering was omitted from the approved list. President Walker felt compelled to state that "the food production plant has fallen into disarray," neglected in favor of building the military. Inefficient farmers were permitted to wear out equipment which others could use more effectively. And the problem of training agricultural workers was acute in the face of competition from the war industries. S. P. Lyle said that 1.5 million new farm workers must be recruited by October 1, 1943. Most of the new workers would be women, children, and non-farm persons; most of these workers would need training in use of farm machinery and equipment.

An ASAE Committee on Wartime Allocation of Farm Machines had been formed in July 1942 under Arthur W. Turner, educational adviser for International Harvester Co. Logically, the committee assumed that high producers ought to have high priority in purchase of machinery. A first problem was determining a production efficiency rating for farmers. The Committee decided on a time-input and product-output system, with the output converted to time units. They assumed that on a national average each person working in agriculture should produce food for 16 others. A set of time units based on national averages was devised so that outputs and inputs could be obtained. The ratio was then the production rating. Farmers with high ratings would be first to receive equipment. However, the 
Committee prepared a complete rationing procedure in addition to the production rating.

On August 17, the entire scheme for distribution of critical farm machines was sent to William R. Tracy, Chief of Farm Machinery and Equipment Branch, War Production Board. Tracy replied with thanks on August 20, saying that the scheme was "being investigated." Nothing much happened except that USDA came out with a farm machinery rationing program somewhat similar to ASAE's. A Journal editorial in early 1945 claimed that the report was "completely and ostentatiously ignored" and accused the government of still using a policy in which "production has nothing to do with who shall go and who shall stay."

Meanwhile, A. W. Turner, although nominated as 1943-44 ASAE president, gave the Allocation Committee to Frank J. Zink and organized the War Activities Committee (WAC), patterned after a similar group in the Society of Automotive Engineers. With President Walker's concurrence, Turner called together R. W. Carpenter, L. J. Fletcher, A. Hemker, L. F. Livingston, J. F. Schaffhausen, and R. W. Trullinger for an organizational meeting in New York City on January 11, 1943. His letter to these men said that "We are the contact committee with government and military agencies for any services that our Society . . . can contribute at this time." Before the meeting, Turner had written to Walker that he wanted to inform United States President Franklin D. Roosevelt about ASAE and its war-time activity with a prospectus which would "pave the way for the new War Activities Committee." The prospectus would also be sent to Secretary of Agriculture Claude Wickard; to Paul V. McNutt, head of the Manpower Commission; to Secretary of Labor Frances Perkins; WPB Head Donald Nelson; and to other luminaries. Raymond Olney wrote Turner that it (the prospectus) probably "wouldn't get much beyond a junior secretary."

The WAC had a relatively short life but an active one. One significant achievement was the application to agriculture of the Job Instructor Training

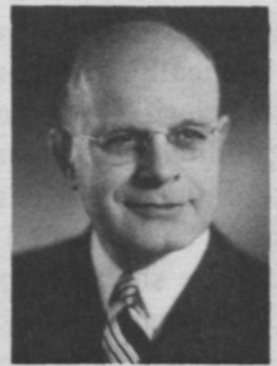

Arthur W. Turner

37th president, ASAE, 1943-44 
(JIT) principles. The flooding of inexerienced workers into agriculture made each farmer into a job instructor, for good or evil. The JIT program was used by the War Manpower Commission in the industrial sector; Leonard J. Fletcher led the way in adapting its simple principles for use by farmers (he was director of Training and Education for the Caterpillar Tractor Company).

His demonstrations of the system before the USDA Extension Service and the United States Office of Education spread the word rapidly. Turner did the same before a number of vo-ag groups and nine departments of agricultural engineering. Thousands of JIT cards, or reminder cards, were printed and distributed by ASAE. These were carried by the "instructors."

Turner and the WAC tried to influence Selective Service to class agricultural engineering students with other engineering students rather than with students of agriculture. The move was unsuccessful. A college department head wrote Turner about the basic problem:

"I think we are going to have some difficulty in getting agricultural engineers included in this list (of engineers) because of the tendency of many institutions to call students in agriculture who specialized in some line of farm mechanics, agricultural engineers. I see no way we can overcome this as long as the institutions continue to follow such classification, and it may be we will have to suffer with our own problems throughout this war. Certainly we have no clear ground to stand upon as long as this confusion exists, and until it is cleaned up it may be difficult to have agricultural engineering placed under scientific and specialized fields."
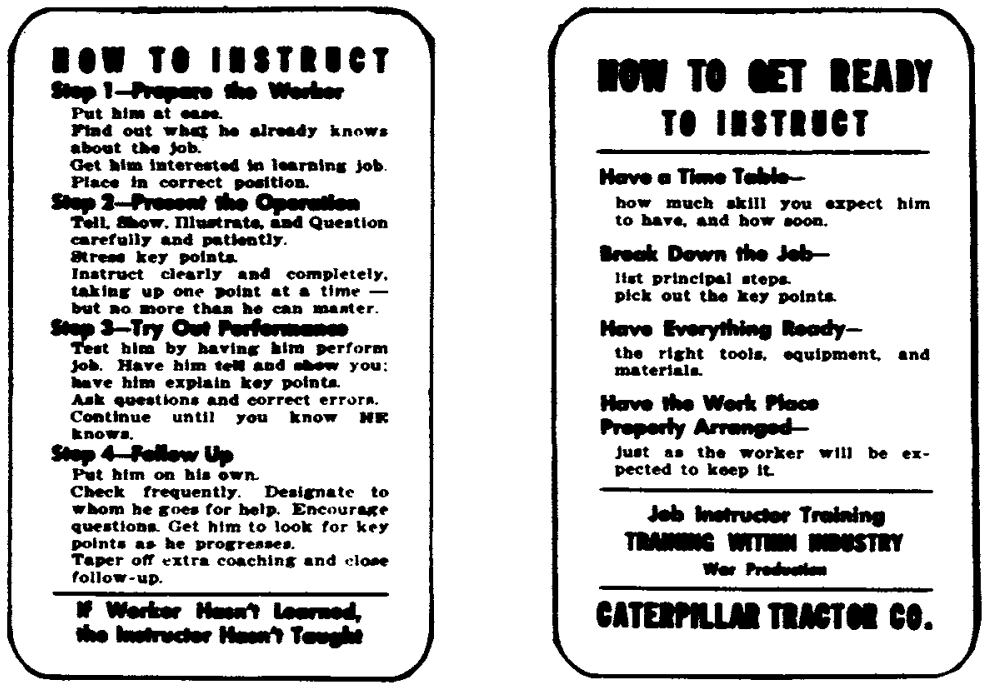
On the other hand, Turner contacted the director of the National Roster of Scientific and Specialized Personnel of the WMC "several times" and persuaded him to list agricultural engineering as a branch of engineering. Soon ASAE members would be asked to register with the NRSSP.

Turner became president at the June 1943 Annual Meeting but continued on as WAC chairman. The committee met in August. Its members agreed to cooperate with the War Food Administration in their national program to help farmers fully utilize their equipment, machinery, and structures in order to reach 1944 production goals. The USDA Office of Foreign Agricultural Relations was contacted about utilizing services of agricultural engineers outside the United States, to expand overseas food sources (ten federal agencies were working on this problem, without coordination).

Although the colleges were by now almost devoid of students, Olney raised an embarrassing question in September when he pointed out that since 1932 the Engineers Council for Professional Development had accredited 552 engineering curricula. Of these only three were in agricultural engineering: Iowa State, Kansas State, and the University of Nebraska. Olney said (and in the midst of a desperate national struggle) that this matter was one "of the really big questions confronting the ... profession," and it was high time to start finding the answer. Response to this plea ranged from

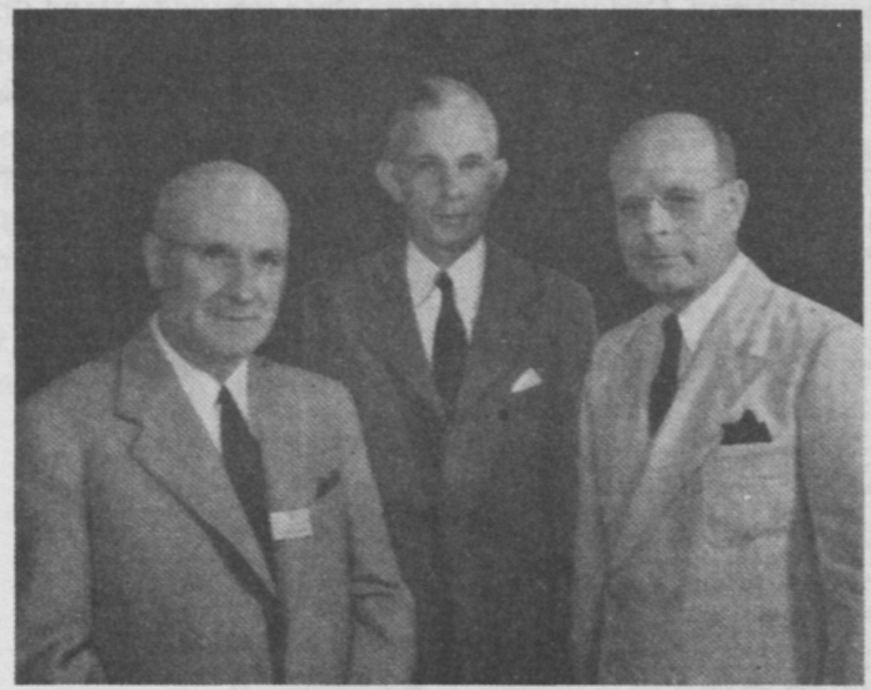

At left is Harry B. Walker, chairman of agricultural engineering, University of California, who completed his term as ASAE president at the 1943 Annual Meeting at Lafayette, Indiana. At right is new president Arthur W. Turner, educational advisor, International Harvester Company. In center is Raymond Olney, ASAE secretary-treasurer 
"ASAE should standardize a curriculum and an administrative pattern," to "We don't need (ECPD) accreditation anyhow."

President Turner (an indefatigable traveler) permitted himself a proud roundup of "The Fighting Agricultural Engineers" at the North Atlantic Section meeting in September.

Now over 230 ASAE members (out of about 1400) were in the armed forces; some had perished. A large group was in Washington serving wartime agencies such as WPB, WFA, and the Office of Price Administration (OPA). Many were in other government service, helping farmers meet increased production demands. Others were on the college and experiment station staffs, solving problems on the home front. Private industry had a corps of members producing war goods and training servicemen in the use of new weapons. Some were involved in helping to produce items formerly imported, such as edible fats and oils, paint and drying oils, soap fats, glycerine, rubber (from guayule, for example), hemp and other cordage fiber, tapioca and other tropical starches, sugar, tanning materials, and insecticides. The demand for agricultural engineers to help produce food in the overseas occupied areas and to aid in malaria control stimulated Headquarters to contact former members and other eligible persons.

At that North Atlantic Region meeting Frank J. Zink showed a chart of calories produced per hour of labor for all common items of food. The cereals were far ahead, particularly barley and wheat, because these crops were highly mechanized. Calories per hour of labor for meat and milk were comparatively low, but Zink noted that some 600 million acres of United States land could be made to yield only by livestock grazing; this had to be used, even though its energy yield per unit labor input was low. At that time the farm labor force was the same size as in 1941. Yet five million persons had left agriculture. The deficit was made up thus: 13 percent were under 14 years of age; 27 percent were female; 14 percent were over age 64 . Past history suggested that two million former farm workers would not return to the farms at the war's end; the work of those missing men would be done by women, youngsters, and old men. Therefore a great deal more labor-saving machinery would be needed soon.

Registration in NRSSP became quite important for draft-age agricultural engineers. The WMC announced that the Roster would be used by the drafting system for guidance in determining "qualifications and essentiality of professional workers," although local boards still handled deferments. The Engineering and Chemical Sciences List had agricultural engineering subdivided as follows:

Farm power and machinery-design and application.

Farm structures-design, materials, equipment. 
Soil erosion control, drainage, and irrigation.

Rural electrification.

Farm practices simplification.

Processing of agricultural products.

The end of 1943 brought Olney's usual expressions of optimism. The war was progressing so well it was time to think about "the problems of the postwar era, far greater and more troublesome than those of wartime." (It is a fact that most people expected a severe depression to follow the close of the war.) The December meeting at Chicago attracted 500 members (double that of 1942), in spite of pleas from the Office of Defense Transportation (ODT) that conventions not be held. ASAE membership and Journal advertising were both growing, although the latter could prove difficult because ASAE's paper supply had been limited to its 1941 consumption.

Back in April 1942 when A. W. Turner was in Washington on WAC business he met with Dr. E. C. Auchter, administrator of USDA's Agricultural Research Administration (ARA). Auchter informed Turner that he was interested in "rebuilding agricultural engineering to the status it rightfully deserves." (Turner's words), and that counsel from an ASAE committee would be welcomed. Turner jumped the gun on President Walker and appointed a "subcommittee" immediately because rumors were current that ARA's agricultural engineering appropriation was to be reduced; however. this group was a temporary measure.

Turner asked Harry Walker to accept chairmanship of the permanent ARA Advisory Committee. His letter, dated June 4, reveals his estimate of the committee's potential value in its closing line: "It seems to me that if we capitalize on the opportunity offered by Dr. Auchter that we will be in a position to influence him and his program the way it should be directed." Walker evidently agreed with Turner for he accepted the chairmanship. By then of course Turner had become ASAE president. The other members of the committee were L. J. Fletcher. L. F. Livingston, E. G. McKibben (now of Michigan State College), and R. H. Driftmier of the University of Georgia.

Late in August Turner visited Auchter and then wrote Walker, who had heard nothing from Auchter. Turner informed Walker that Auchter wanted a dual-capacity committee; it should be not only advisory but also legislative, a "lobbying group." Auchter wanted a meeting in October in which he would review activities, introduce the committee to Secretary Wickard, and possibly meet with the Budget Bureau. Then Turner stated that Auchter would try to attend the December ASAE meeting so that he could make contact with the "appropriations committee so as to stave off too much slashing of the budget . . . before it went before Congress."

Perhaps Walker smelled a rat at this point regarding Auchter's desire for 
an agricultural engineering "advisory" committee. For some reason, he tried to resign from the committee, but Turner bulldozed him into staying with it. The problem may have been only related to travel expenses. Driftmier also tried to resign but Turner wouldn't accept it.

The meeting with Auchter was finally held December 9 to 11 . Walker's report showed that his earlier doubts had evaporated and that he was now ready to not only "advise" the ARA but to back it in budget matters. Turner suggested the formation of a legislative committee, with its chairman in Washington and Driftmier as a member (he was now president-elect). Some kind of "interlock" with the War Activities Committee was worth consideration. However, Olney was against formation of a permanent committee. Even worse, Turner asked R. W. Carpenter, head of the department at the University of Maryland, to head such a committee. Carpenter declined. Such work should be done either by ASAE Headquarters or by a Society representative with a Washington office, according to Carpenter. However, when help was needed perhaps it would come from knowledgeable individuals rather than a standing committee.

Turner's interest in advising the ARA persisted beyond his presidential term. In August of 1944 he helped President Driftmier make up the committee. A meeting was held in Beltsville and Washington in September. Committee Chairman Turner drew up the lengthy report, which showed that a "30-minute appointment at the Bureau of the Budget was stretched to an hour." The analysis presented by Turner of the agricultural engineering research status and needs was masterly.

From the beginning, Turner probably hoped that ASAE would exercise strong but hidden influence upon ARA through working with Administrator Auchter. The end result was beneficial to agricultural engineering in the ARA, although perhaps not on the scale Turner hoped for. He at least got a new job out of it. Early in 1944 the search was on for a man to head the engineering research in the Bureau of Plant Industry, Soils and Agricultural Engineering (BPISAE). Turner zealously aided in this search; at one point L. J. Fletcher was a leading contender but he refused it. E. G. McKibben was mentioned. Then in July Turner was offered the job-to his surprise. In discussing the offer, Olney mentioned once again that ancient ASAE dream, the rebirth of the BAE. More to the point, he suggested that Turner put his trust in "divine guidance." Turner evidently did, for he became assistant chief of the BPISAE on December 1, 1944. Dr. Auchter stated in the news release that "the appointment foreshadows greater development of all phases of agricultural engineering in the program of the (ARA)." The ASAE advisory committee was mentioned in the news release.

For some reason, postwar planning started long before the war was over. 
Speaking at the December 1943 ASAE meeting, M. L. Nichols outlined the postwar plans for soil and water conservation. G. W. Kable, at that same meeting, spoke of the electrical equipment which would be needed on farms after the war's end. S. P. Lyle, speaking at the Southeast Section meeting in February 1944, listed the effects of wartime agriculture which would carry over into time of peace and cause concern for agricultural engineers. The Southeast Section also heard President Turner speak on "The Agricultural Engineer in the Postwar Period." He outlined very lucidly the areas of work which the engineers should tackle after victory arrived. He also commented that USDA's agricultural engineering research program was weak. Naturally he then was unaware that he would soon assume major responsibility for that program.

T. B. Chambers, chief of the engineering division, SCS, addressed the Southwest Section in March 1944 on "Postwar Opportunities." He cited a number of factors in the soil conservation area which would cause high demand for agricultural engineers. The Committee on Extension released a report containing suggestions for extension men which would focus attention on postwar planning.

But the war was far from over. The June 1944 Annual Meeting was again convened in Milwaukee because of an available hotel and good railroad connections (auto travel was out of the question). The great invasion of Europe had just commenced on June 6 and the real cost of victory was beginning to be understood. But attendance was highest of the war years, and all came away with a sense of satisfaction, dedication, and hope.

Leonard J. Fletcher received the McCormick Medal. C. E. Ramser, the SCS hydrologist, was honored with the Deere Medal. The membership on June 10 was 1360 , highest on record. Sections had been organized in Chicago and in Minneapolis-St. Paul. Arthur W. Turner reported that he had traveled 31,000 miles during his presidential term, by air, rail, and bus, a tremendous accomplishment in that time.

Turner's presidential address devoted much attention to how ASAE should help the nation prepare leadership for a peaceful world. Agricultural engineering technology would be uniquely helpful, he said, in maintaining peace because poverty is a root cause of war. He praised the services of agricultural engineers in support of the war effort and summoned them now to be thinking as citizens as well as technical men. It was possible to give so much for the country's welfare because, "We builded well during peacetime and we have withstood these war years." But now it is time, he said, to insure that those returning from battle, and ourselves will enjoy a peace containing both security and moral values.

The Milwaukee meeting yielded some quotes which characterize those 
agricultural engineers rather well:

"The individuals who make up your society are certainly of a very high type and they are interested in worth-while things rather than wasting their time as is so common at conventions." (From an applicant for membership.)

"The ASAE members were the quietest and most well-behaved of any group we have had for a long time." (From the hotel management.)

"The tightest, stingiest bunch I have seen in a long time." (From a bellhop.)

"It would be great if you could capture the personality and enthusiasm of the lobby conversationalists on the speaker's platform, also the news and ideas which they seem more willing to divulge in private conversation than in a formal paper." (From a visitor.)

Rudolph Driftmier, the new president, appointed Arnold B. Skromme to head a new College Division committee on "Placement of Discharged Service Men." This was stimulated by the news at Headquarters that a trickle of members back to civil life had begun. Yet those who remained in service wrote that their efforts had increased in scale; simultaneously, they expressed much concern over forthcoming problems of reconversion and readjustment.

ODT issued an urgent appeal on August 11 to all organizations to cancel planned meetings for the remainder of 1944 . The Council, therefore, voted to cancel the December Chicago meeting. ASAE found itself in company with 150 other national groups which also had to cancel fall meetings, including ASME and ASCE. However, meetings of the Council, Cabinet, Meetings Committee, and Jury of Awards could still be held because ODT hadn't suggested limiting travel of groups under 100 .

As a sidelight of the time, member Walter M. Carleton wrote Olney from the New Hebrides that he heard an ASAE report on mechanized farming of the future while listening to short wave radio from San Francisco.

While as of October 1, 1944, only 762 agricultural engineers had registered

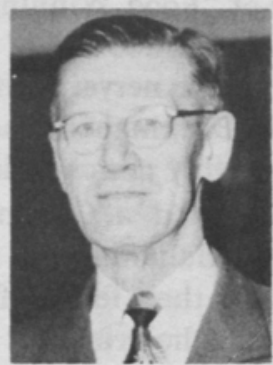

Rudolph H. Driftmier

38th president, ASAE, 1944-45 
with NRSSP, this was over half of ASAE's membership. Forty-three men were in armed services (none were women). Age distribution: 20 to 29, 179; 30 to 39,$293 ; 40$ to 49,$174 ; 50$ to 59,$82 ; 60$ and over, 34 . The median age was 36.9 years. Education attained was: Ph.D., 8; Master's degree, 147; Bachelor's degree, 513; 4 years of college (no degree), 21; others, 73.

ASAE's Cabinet held its first meeting on November 30, 1941. At that time it consisted of the Council, the Division Executive Committees (chairman, past chairman, and vice-chairman), and the chairman of the Meetings Committee. The Council in December 1944 authorized inclusion of chairmen and secretaries of regional, state, and local sections. The original purpose of the Cabinet was to improve communication between the Council and the Divisions, but formation of divisional steering committees caused them to assume a greater degree of independence from the Council. In later years the Cabinet became most important as an information focus for the geographic organizations.

Groups other than the Cabinet and Council, etc., which met that December 1944 in Chicago included: Committee on Hay Harvesting and Storage, Committee on Farm Structures Advancement, Committee on Curriculums, Committee on Cooperation with SPEE (Society for Promotion of Engineering Education), Committee on Farm Safety, and several others. Each of these committees had urgent problems and goals to discuss; evidently they believed that their work could not be adequately done by mail or telephone. Both had become unreliable; Olney commented that it took two weeks for mail to travel from St. Joseph to Philadelphia. The Council made plans for a June 1945 meeting in Milwaukee and for a December meeting in Chicago.

The year 1945 ushered in rumors that German V-Bombs could reach the East Coast of the United States. Suddenly the government banned meetings of more than 50 persons. Driftmier prepared an application to the War Committee on Conventions (WCC) for permission to hold the June Annual Meeting, but the importance of "Food Winning the War" had lost ground. Also recent WCC refusals had been 108 out of 110; ASAE's chances looked very slim. Sometimes it took a little nerve. Southeast Section Chairman Ray Crow told the ODT people in Birmingham that less than 50 would attend their meeting, but he was probably not counting the wives and kids.

Driftmier had meantime created a Committee on Postwar Objectives headed by Leslie E. Hazen of Oklahoma A. \& M. Hazen sent a letter to his committee members to ascertain their feeling for "postwar objectives." The letter pleased Olney so much that he printed it in the Journal along with two editorials praising Hazen's philosophy.

Hazen had written that "originally we espoused the idea of an engineered 
agriculture to beget welfare for farmers, abundant food and fiber for the populace, and friendly recognition for the membership ..." and he assumed there would be no change from this "initial intention." A significant point made in the letter was in line with long-term ASAE belief; some thought that agriculture was a "reserve bank from which to draw and retire industrial labor . . . a place to stay in safety against famine." This was contrary to Hazen's (and ASAE's) philosophy, in which the farm was to become a commercial unit so equipped with machinery that about 10 percent of the population could furnish food and fiber for the remaining 90 percent. "Farming as a way of life" had no place in ASAE doctrine. As Hazen put it: "Usually the folks advocating small-scale agriculture are making these recommendations for the other fellow ... "He ended with a list of processes, machines, and devices which he thought needed to be worked upon. Some of them were so advanced (or perhaps so unnecessary) that they have never appeared. The question of the professional curriculum was also raised by Hazen, who wondered how "economics, language, and decency" could be injected into it. This also received lavish editorial praise. The writer said:

"One of our postwar problems will be an academic generation of young people who are trained but not educated. They will be influential both by their youthful energy and by the respect they have earned as fighting men. It will be their right to have much to say about the rehabilitation of America and of the world. To do so wisely they should have some insight into the history of civilizations, the principles of economics, the ways of governments, the reactions of material and spiritual influences on men and nations."

But as usual it ended with the plaintive comment that there was no curricular room; the technical material had priority, so perhaps some of the humanities could be deferred to postgraduate study (a rather fatuous statement).

In February the Council bowed to necessity and cancelled the June 1945 meeting. It and the Cabinet would meet for one day in Chicago in June, with a dinner to permit Driftmier to give his address, award the medals, and confer the new paper awards. Attendance could not exceed 50 persons. This plus the cancellation of the previous December meeting had created a serious shortage of publishable Journal papers.

The new Paper Awards Committee, chaired by J. D. Long of the Douglas Fir Plywood Association, had been busy since the previous summer. Working solely by mail, they developed a rating procedure. The initial award papers were selected from those published in the five volumes of AGRICULTURAL ENGINEERING from 1940 through 1944. 
After learning of the Annual Meeting cancellation, a member suggested that the paper programming process continue unchanged except that their presentation and discussion occur at local unit meetings. This would keep the flow toward print uninterrupted. The idea received editorial approval because it would "maintain formulation and dissemination of our technology." The paper processing and programming could be done by mail if necessary.

There was by April a feeling that victory in Europe was near. But the members continued to focus on their goals. President Driftmier, C. E. Seitz, and R. W. Carpenter appeared before the Senate subcommittee on agricultural appropriations to protest House action which disallowed increases of $\$ 170,000$ for farm structures research and $\$ 25,000$ for rural electrification research requested by USDA for 1946 . The Senate subcommittee restored the increases. Member W. Forrest Smith of Shelby County, Kentucky, wrote John R. Carreker of SCS in Georgia about the damage one rain could cause to a Shelby County tobacco field. Smith wrote: "You will note the up-anddown-hill cultivation which is responsible for much of this destruction. There are just two things $I$ know of that will get the farmer away from 'square' cultivation. One is the coming of judgment; the other is the broad-base terrace. The former is indefinite and none of us are ready for it, so we are following through on the latter plan." (Carreker was in agreement with Smith; presumably, they weren't ready for judgment day in Georgia either!)

Then it was May and the news of unconditional surrender came from Germany. ASAE published its last honor roll. It contained about 300 names, plus six gold stars; the latter were all officers. Conversion to peacetime economy commenced immediately, a process accelerated by the Japanese surrender on August 14. The long ordeal was ended.

Raymond Olney's job required him to be a master of the soothing platitude and the encouraging phrase. His peals of joy over the war's termination were in his best tradition: " . . . in spite of the sand in the gears as humanity sets about the job of shifting to peacetime living and working, the grand victory over the hordes of evil must result in a better world for all men." He referred with satisfaction to the great opportunities now confronting the profession, when it "will be making its contribution toward bringing the world back to sanity and fruitful living and working. We will glory in that task ..."

Members now sought peacetime positions. The temporary Washington bureaucrats abandoned their positions of power. Some soldiers worried about whether their old jobs would still be there. One member wrote this to Olney, ending his letter with the phrase: "the case for patriotism doesn't seem too strong to me right now." Some who had left college for the service wondered, as they prepared to return, how they could tolerate association 
with undergraduates who had never worn the uniform.

Olney was right; it was a time of great change, of great opportunity. Those who had participated would forever remain marked by it.

Many agricultural engineers thought that their efforts to maintain food production during the war were significant. But $R$. W. Trullinger wrote in September 1945 that the victory was due largely to timely and effective research, none of which was performed by ASAE members! He believed that the profession would always be regarded as "second class" until significant research achievements became common and were widely known. The nuclear bomb was an example of the kind of research that conferred prestige, but no agricultural engineers had been connected with it.

Trullinger was off the mark because the "Manhattan Project" was farflung and intensely secret. Member D. E. Washburn wrote immediately that he and $\mathbf{O}$. C. French were involved in it. Trullinger replied that he "knew Washburn and French were mixed up in this atomic bomb business," although French himself had not known what he was working on. At any rate, this exchange led the members to speculate whether nuclear physics had anything of value to agricultural engineering beyond a bid for prestige.

President J. Dewey Long had been for some time concerned about the quality of professional education, a subject much related to the research concerns of Trullinger. Long headed a College Division subcommittee which worked from 1941 to 1945 on "Industry Requirements of Professional Agricultural Engineering Education." The report is an interesting milestone on the educational highway, noteworthy for such statements as, "A profession cannot rise above its educators," and "For most jobs in industry a thorough preparation in the fundamental sciences is to be preferred to a smattering of fundamentals and specialized knowledge." It presented a sample B.S. curriculum, however, which betrayed the shaky hands of non-educators: e.g., the agricultural engineering courses preceded their engineering science prerequisites and history was shown as an optional study. The report was sent to administrators at all the land-grant institutions.

Although Long was affiliated with industry, he had formerly been a faculty member at the University of California at Davis. His interest in quality of education while an ASAE president was exceptional and led to the big breakthrough in accreditation of agricultural engineering curricula by ECPD, an important event which will be detailed later.

It was announced in August that the Council had voted to cancel the December meeting, although the government had lifted the meeting limits from 50 to 150 . It was admitted that "rail travel conditions are probably worse now than at any time yet." But shortly after that the government lifted all restrictions. A one-day meeting was planned for December 7 at the Stevens 


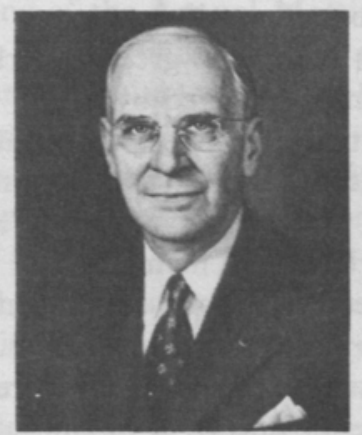

An end of an era was marked on July 11946 when J. B. Davidson retired. On the occasion ASAE Council elected him to the grade of Honorary Member of ASAE

Hotel, with theme speakers from all Divisions. A total of 250 registered for the meeting. Among items discussed in the corridors was the turnaround in the Personnel Service; for just about the first time since the United States entered the war there were more listings of "Positions Wanted" than of "Positions Open." Those Personnel Service listings were building a good reputation for bringing together potential employers and those seeking jobs; it tended to keep the recent graduates within the fold who might have drifted away.

The 1946 Annual Meeting was held in St. Louis. After the lean year of 1944-45 it was good to have a real meeting again, one lasting three full days. New technology was appearing. Barn hay drying, farm work simplification, airplane application of pesticides, negative radiation, and environmental control were a few of the newer problems being researched. J. D. Long's presidential address pulled no punches regarding the sorry state of agricultural engineering education and other factors, but he recited a nine-point "Agricultural Engineer's Creed" whose mastery would have made supermen of his listeners!

And to mark the end of an era, J. B. Davidson announced his retirement as of July 1 . The Council elected him to the grade of Honorary Member of ASAE, a very high honor. Hardly pausing to draw a breath, Davidson was planning to leave for China in August to spend a year as advisor to the government under a grant provided by International Harvester. The lengthy Journal citation regarding his honorary membership concluded:

"As though in return for his magnificent contribution, time and the world have dealt kindly with Dr. Davidson. He is one of the few privileged to live to see his influence and inspiration achieve the quality of immortality."

During Long's administration the total membership climbed to 1702 , divided as follows: Honorary, 3; Fellows, 77; Members, 888; Junior members, 364; Associates, 370 . The rate of increase was now greater than at 
any previous time. The Missouri and Virginia state sections were added and Council had just approved addition of the Pacific Northwest Section. ASAE now had 13 geographic units. The five regions were the North Atlantic, Southeast, Southwest, Pacific Coast, and Pacific Northwest. Six states had sections: Georgia, Minnesota, Missouri, Pennsylvania, Tennessee, and Virginia. Local chapters existed in Chicago and Washington, D.C.

The 1945 net monetary gain was $\$ 18,500$, compared to $\$ 110$ for 1941 . That increase was mostly due to wartime Journal advertising increases.

The human dynamo, A. W. Turner, alerted the membership in August 1946 to the passage of the Flannagan-Hope marketing research bill, although no money had yet been appropriated. A discussion of the bill attracted a capacity crowd at the 1946 Winter Meeting in Chicago. That crowd agreed that implementation of the act would involve agricultural engineering to a large extent. An unprecedented demand for researchtrained agricultural engineers would result from this. Unfortunately, the outlook for such men was not good; although numbers of graduates were increasing, industry was outbidding the public service for them. The colleges must begin to sell research (and advanced degrees) as a good career, or at least as a springboard to good industrial positions. Turner addressed the Southeast Region in January on the act, pointing out that when maximum funds came into being, federal grant money to the state experiment stations would be tripled, while the USDA research money would be doubled.

The act arose from wartime realization that "public funds spent in agricultural research pay rich dividends." Turner was sure that this new program was "the big challenge to agricultural engineering in 1947." But the enginers in the state stations would have to develop the projects and proposals, and Turner was afraid they were dragging their feet. Turner also feared that they were ill-prepared to compete with the better-trained agricultural scientists. A unique feature of the bill was Section 9-b-3 of Title I, which set up a Regional Research Fund in the Office of Experiment Stations to finance research on problems affecting groups of states.

The appropriations came in due time. Turner was right; the Research and Marketing Act of 1946 had a very significant effect on the development of research, and the associated educational thrust, in agricultural engineering.

The June 1947 Annual Meeting in Philadelphia found some developments to rejoice about. For example, 31 student branches were now activated, three more than the previous record; they had 1216 members enrolled, 50 percent higher than at any other time. The FEI award, withdrawn in 1943 because of the war, was reinstated; the winner was Oregon State College.

But, retiring president Mark L. Nichols addressed the members with some thoughtful words, which sounded rather gloomy: 
"It is very difficult to make an accurate review of the present situation. There are so many conflicting ideas of just what is happening in the world that it is impossible to feel positive as to what the real situation is. We are still technically at war, struggling to find the way out, and at the same time to set up some type of procedure or world organization which will remove . . the causes of war in the future. We do not know whether we can attain the philosophy of one world or whether the grim necessity of survival will force us into two opposing camps."

What meaning did this have for ASAE and its members? Nichols thought that power sources, transportation, communication, and production centers, all must now be dispersed, to permit "adequate defense." We must provide assistance to other democracies, to help them obtain a higher living standard. "If America is to continue to use food as a weapon, we in agricultural engineering have a great responsibility, because we must not only maintain our present productive efficiency but also increase it."

The "cold war" was becoming visible, with its battle for loyalty of allies, a battle waged partially with agricultural development. Reconstruction and rehabilitation of vast areas of the world were already under way, and included restoration of agricultural productive capacity. The words Nichols spoke were not really gloomy; in a sense, the agricultural engineers could perceive a golden age looming amid the bad news.

\section{B \\ Technical}

The initial move by ASAE toward organized concern for accident prevention had taken place when President Arnold Yerkes addressed the first National Farm Safety Conference. This was on October 15, 1937, at Kansas City as part of the National Safety Congress and Exposition. Yerkes spoke on "Farm Machinery Accidents and Their Prevention."

Late in 1938 a Journal editorial commented that farm equipment manufacturers were "taking active steps" to reduce machine hazards. The writer expressed the current philosophy quite well:

"Farm equipment can no more be made foolproof than a farmer can be made to keep his hands in his pockets. But safety can be made the farmer's own responsibility with warnings plainly stenciled near the dangerous parts of every farm machine ... It is gratifying to see that this is being done, and that agricultural engineers are cooperating in this activity." 
Shortly after, Wallace Ashby of the BAE addressed the National Safety Council on fire preventive construction on the farm.

Increasingly active safety interest resulted in the announcement in October 1940 that an ASAE Committee on Farm Safety was to be organized, with S. H. McCrory as chairman. This Committee did not do a great deal, probably because of war problems and McCrory's problems with the BAE. Probably the war had greatly inhibited safety progress. In $1944 \mathrm{~V}$. S. Peterson of the DuPont Co. became chairman of the committee; he and four other members were appointed as advisors on rural safety to the National Safety Council.

At the war's end, safety became a prime concern of agricultural engineers, with evidence of changing outlook toward responsibilities. Two papers on farm safety were published in the June 1946 Journal. Member C. L. Hamilton, assistant director of National Safety Council's Farm Division, noted that President Roosevelt had declared a "National Farm Safety Week" in July. His paper outlined how private industry led the way in engineering safety into machines and the environment. The farm problems could yield to similar approaches; some states had already hired full-time safety specialists, but the agricultural engineers were neglecting the field. Assistant Secretary Ralph Palmer published a paper which classified farm accident hazards on an engineering basis.

That same Journal contained an editorial by Frank Kranick of J. I. Case Co. who had been serving on the Farm Safety Committee. He stated that putting "caution" signs on machinery was futile. Devices must be designed into machinery to assure that careless people would not be injured. This was the responsibility of engineers; if they designed carefully, the added cost of safety would not be burdensome. Kranick's attitude was in striking contrast to that expressed in that 1938 Journal editorial.

As always, there was agreement and disagreement. A member wrote to Olney:

"I would like to hear somebody get up at our meetings and castigate some of our so-called agricultural engineers and manufacturers for not more rapidly putting into effect more practical designs for safeguarding machinery to reduce farm accidents ... About all we have had to date is such high-powered ideas as standardizing the kind of safety notices to be posted on machines. The efforts at eliminating accidents, for the present, so far as designs are concerned, seemed to consist mostly of running around in circles....'

Another member wrote that in servicing farm machinery he found power take-off shields removed, operators adjusting machinery while it was running, and owners complaining that "tractors would not travel fast enough 
in high gear." Something should be done to educate the operators.

V. S. Peterson, still chairman of the Farm Safety Committee, wrote that (in effect) manufacturers cannot be blamed because operators fail to utilize safety precautions. ASAE should not only promote safe design principles but also operator education. He claimed that the renowned Mayo Clinic had discovered that farm accidents were caused primarily by carelessness. At about that time (1946) farm accidents were responsible for 4500 deaths each year. Peterson and Kranick represented opposite poles of the problem.

So the decade commenced with relative indifference to the role that engineering might play in protecting people from themselves. It ended with ASAE awakened to the possibilities of that role, with a committee established, and with discussions commenced that would lead some day to industry-wide safety standards in machine design and operation.

The Second Agricultural Adjustment Act became law on February 19, 1938. It extended acreage and crop quotas financed from government revenue, authorized wheat crop insurance, and attempted to establish an "EverNormal Granary" by crop carryover in government storage to stabilize supplies and prices.

By 1936 agricultural engineers of the USDA-BAE and of the Kansas, Illinois, North Dakota and Maryland agricultural experiment stations were doing grain storage research. They sought to learn what types of storage structures would best preserve and improve the quality of wheat stored on the farm and what grades of wheat could be safely stored for long periods. They had already determined that wheat of more than 15 percent moisture content was generally unsafe for storage; however, the critical safe moisture content was yet unknown. Construction and ventilation of the bin were found to be important. Much of this work had been done on the farm, but C. F. Kelly of the BAE had in 1937 completed a set of experimental grain storage bins at Fargo, North Dakota, plus an experimental drier. Totalling 3000 bushels, those were filled and under long-term study within a year.

Other crops were also under study, particularly corn. The 1938 ASAE Annual Meeting at Pacific Grove, California, had a Farm Structures Division session which included reports on corn drying research by $\mathrm{H}$. J. Barre of lowa State College and F. E. Price of Oregon State College. Barre was concerned with the fundamental aspects of grain drying, the physics of the process; his paper on flow of water vapor explained some puzzling types of spoilage. The steel corncrib made its appearance at Ames about this time when BAE's J. R. McCalmont started tests on their stability. Barre was also in charge of a farm corn storage survey "financed by allotment from the 
Bankhead-Jones research fund" which was being made in Minnesota, Illinois, Indiana, and Iowa.

Kelly tested a continuous-type portable wheat drier in Virginia which had the capacity of 85 bushels per hour and could reduce average moisture content from 14.35 to 12.40 percent. He considered this performance as "good," but believed it could be made better.

Barre reported at the 1939 Winter Meeting on the corn storage surveys. The advent of hybrid corn and the need for storage criteria in connection with the loan provisions of the Agricultural Adjustment Act were creating a demand for better technology. It was found that farm storage practices in the Corn Belt were far from satisfactory, with much loss from spoilage and rodents. Structural design was so faulty that Barre felt compelled to conduct tests of pressures exerted by shelled corn (it was three times that of ear corn). Early machine picking (to avoid or reduce field losses) brought corn into storage at dangerously high moisture content. Many problems were uncovered for future research: ventilation practice; relation of weather to storage; pressures on bin walls and floors; control of insects and rodents; and possible loss in dry matter.

Barre and Kelly (both were now affiliated with the Bureau of Agricultural Chemistry and Engineering) brought ASAE up-to-date on grain storage at the 1941 Winter Meeting. The work had expanded greatly since 1939. More agencies were involved, including the Commodity Credit Corporation. For example, aided by the CCC, 340 steel test bins at Hutchinson, Kansas, were filled with 600,000 bushels of wheat for long-term studies of structure, ventilation, and management systems. Investigations of corn and grain sorghum storage problems were carried out at other sites, the latter in cooperation with F. C. Fenton of the Kansas experiment station.

The war had its effect on grain storage. When the Commodity Credit Corporation needed to purchase storage bins for more than 100 million bushels of wheat in the summer of 1942, steel bins were out of the picture. Barre helped the CCC obtain prefabricated units of wood or insulation board.

In October 1943, Deane G. Carter, agricultural engineer at the University of Illinois, became departmental project leader of "the most extensive soybean storage investigation in the U.S." Seventy bins were being built at Urbana; the CCC would lend 100,000 bushels of beans for the study. Engineering problems to be studied included comparisons of wood and steel bins; insect control; bin size; moisture migration; value of natural ventilation; artificial drying; bin strength design; effect of storage on germination, fat acidity, and market grade; and recommended designs for farm storage bins. Wallace Ashby, Leo E. Holman, and W. V. Hukill were scheduled to represent BPISAE on the project. 
By 1945 the technical groundwork needed to design structures for drying grain by air flow had been laid; fundamental data on resistance to air flow had been accumulated. The research on wheat had been done by C. F. Kelly; $S$. M. Henderson provided the data for shelled corn, soybeans, and oats; Claude K. Shedd did the same for ear corn. All of these engineers were with USDA.

The technology of the "Ever-Normal Granary" was researched, tested, and standardized by ASAE members, who were greatly aided by their technical society. It was a good example of cooperation between federal and state agencies working toward common goals. The impact of their efforts upon the economic and social life of the nation is beyond adequate measure. Those living today are still the active beneficiaries of it.

Technologically somewhat similar but with results more confined to the farm was the amazing surge of interest in barn hay curing that occurred at the end of the war. Traditional methods of curing hay in the field were risky because of weather; curing in the barn under controlled conditions reduced the risk. Availability of electricity and engines provided power for fans and controls; usually, unheated air was used because of fire hazard, although heated air was thoroughly investigated. Actually, the heat of respiration of partially cured hay is appreciable. Consider the papers published on this topic in AGRICULTURAL ENGINEERING during the decade: 1939-1; $1941-3 ; 1942-1 ; 1943-4 ; 1944-2 ; 1945-1 ; 1946-10 ; 1947-15$; 1948-3. This list does not include papers dealing only with airflow, equilibrium moisture content, field curing, handling, and similar matters not concerned directly with barn curing.

Probably the big push was given to barn hay-curing by a conference at Purdue University January 7-9, 1946. The conference was sponsored by ASAE's Committee on Hay Harvesting and Storage. All conference papers were published in the Journal. In March 1946 an editorial commented on the "Purdue Papers" thus:

"The swift progress of barn curing of hay has been almost breathtaking. From the first few faltering experiments to the present fund of quantitative data has taken little more than a decade, or perhaps twenty opportunities for observation (i.e., twenty ASAE meetings). No wonder there still remain many areas of ignorance, many conflicts of theory, clashes of opinion and economic questions.

"Ramifications of these problems and opportunities reflect anew the logical integrality of agricultural engineering. Obvious, of course, is the interlocking of farm structural design with rural electric practices. Just as real is the impact of barn curing on equipment for making, hauling and handling hay. Less obvious, but more profound, are the implica- 
tions of improved forage management in relation to soil conservation.

"Rivalry in good works will inspire better field curing and silage practices. All will make their contribution toward higher nutritional standards for the nation, as well as toward a higher estate for the farmer."

By the end of 1947 there seemed to be nothing much left to investigate except refinements. Techniques such as hay pelleting and wafering, hay crushing (which was called for by an Ohio farmer at the 1946 Purdue conference) and others were yet in the future, but at least part of the ageold hay-making problem had been solved.

The decade 1938-47 can be termed the "chemurgy decade" because the idea of chemurgy received the most attention and offered the greatest promise during that period. Chemurgy is defined in one modern dictionary as "The development of new industrial chemical products from organic raw materials, especially from those of agricultural origin." The agricultural surpluses that existed until America entered World War II stimulated much interest in industrial utilization of agricultural products. It is, however, surprising to discover that the hopes raised by chemurgy continued on through the war and did not begin to fade until around 1947. Today chemurgy is apparently forgotten; the "Agricultural Engineering Index, 1961-1970" of Carl W. Hall does not use "chemurgy" as a key word. Nor do we have a better word today for the processes and ideas once visualized as chemurgy by the agricultural engineers.

Opportunity glowed in chemurgy. For example, in 1937 the United States imported 150 million pounds of perilla seed from Japan. This was an oil seed used in paints and varnishes. Could perilla be grown at home if harvesting machinery could be invented? And consider the enormous volume of waste rejected from agriculture after the desired roots, tubers, bulbs, stems, leaves, flowers, fruit, seeds, or sap had been extracted. How could uses be found for those waste materials? The cotton seed was once regarded as waste but was rescued by engineering and chemistry. What processing of crops and "wastes" could be done by the farmer himself as a start toward chemurgic "vertical diversification?" (Distillation of corn would be a hazardous example of this!) Here appeared to be a genuine technical frontier.

A 1938 conference outlined the chemurgical challenges to agricultural engineers. The castor bean plant was coming on as a farm crop and needed a mechanical harvester. Importation of pharmaceuticals was becoming erratic and costly; with harvesting equipment much of this culture could move to the United States. Expanding industrial uses for cotton, grains and soybeans depended partially on lowered production costs. Cotton fabric was being tested as a road base. Farm fibers, regarded as waste, had a multitude of potential uses provided they could be delivered to industry in desirable con- 
dition, quantity, and cost. Alcohol as fuel was receiving widespread trial at the time, both in farm tractors and in automobiles (usually blended with gasoline). The soybean was found useful in non-food applications. Farm wastes were considered an inexhaustible source of chemicals such as sorbitol, mannitol, furfural, activated carbon, stearic acid, glycerin, and lignin.

A photo of baled straw in the 1938 Journal was titled "The Farmer's Cellulose Mountain," hinting that industry was going to create a valuable product out of this by-product.

Arnold P. Yerkes of the International Harvester Co. was ASAE president that year. An ardent chemurgist, his 1938 presidential address was concerned with the horizons opened by chemurgy to the agricultural engineer. Yerkes thought it was bad for nations to continue importation and exportation of cellulose, starch, sugar, and protein (he called these substances "moist air," being composed largely of air and water) to the great increase

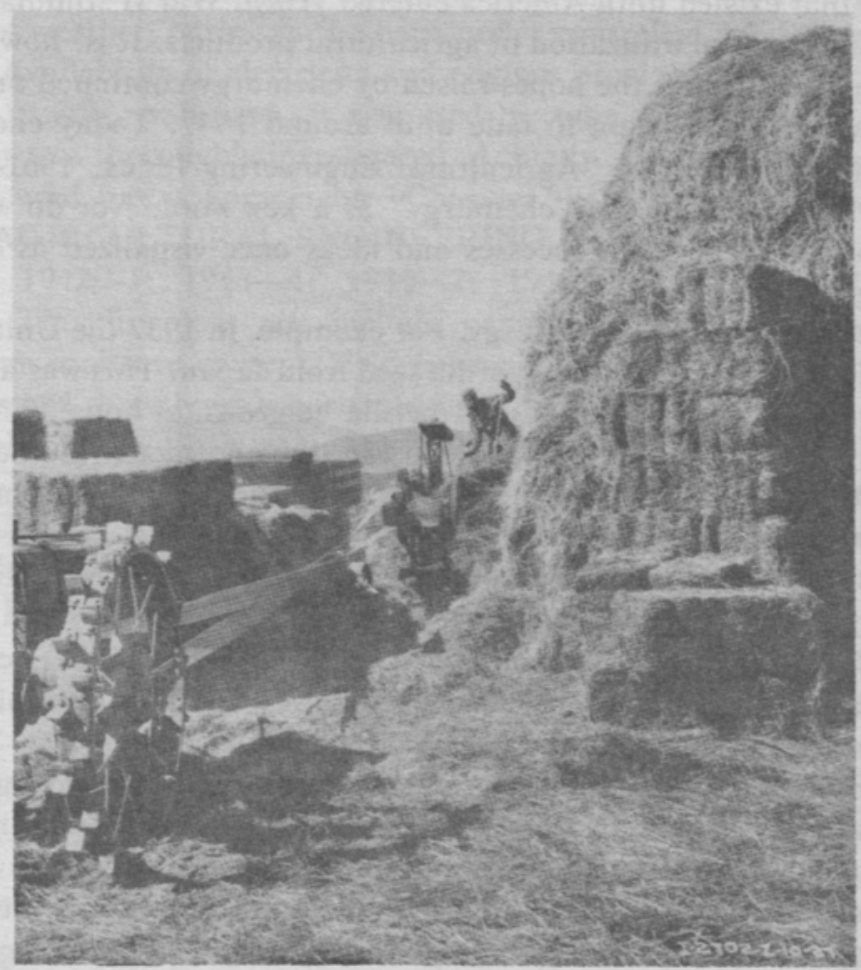

In September 1938 AGRICULTURAL ENGINEERING a full page was devoted to "The Farmer's Cellulose Mountain" which depicted baled by-product straw as a compressed packaged cellulose which grain farmers could deliver to factories 
in cost of such materials. If the practice should be stopped, agricultural engineers would be confronted with many new tasks and services. One indication of impending change was the section in the 1938 Agricultural Adjustment Act that established "four regional research laboratories . . to conduct researches into and to develop new scientific, chemical, and technical uses and new and extended markets and outlets for farm commodities and products and byproducts thereof." He pointed out how German imports of American cotton had dropped in recent years, partly because the Germans were starting to use wood cellulose to make textile fibers. Rayon was being considered for rubber tire manufacture. The Southern pine had become a leading source of paper pulp; this would reduce cotton acreage and call for forest mechanization. Wood waste was now being processed into objects resembling hard rubber or bakelite. Starch from the sweet potato, soap from corn or peanut oil, castor oil as replacement for imported tung oil-all were industrially possible but demanded new applications of agricultural engineering. Therefore, to Yerkes, chemurgy offered the chance to produce far more than just food and clothing from farm crops and ASAE should be giving "earnest consideration" to it.

A Journal editorial seized on that part of the Yerkes address which spoke of synthesizing, or modifying, organic materials at will. The writer opined this would give farmers "a wider choice of marketable crops and livestock ... best suited to any particular farm and its market, together with a market ... for commodities subject to chemical or physical modification." As to agricultural engineers, "it suggests a wider range of service, rich in opportunities..."

The establishment of the USDA regional laboratories for chemurgic research coincided with the reorganization which put the Bureau of Agricultural Engineering in with the Bureau of Chemistry and Soils. Although by 1938 the BAE had lost much personnel, it still seems strange to contemplate a union which was apparently based largely on chemurgic considerations. The government stated that the Bureaus were integrated "with the purpose of speeding up the federal government's attack on the problems of finding new and expanded uses for farm products and improving the machine processes in producing and refining them." That reads as if the whole resources of BAE were to be thrown into the chemurgy fray, but, although ASAE itself scented hope for enlarged prestige in the situation, future developments hardly justified the union.

The Bureau of Agricultural Chemistry and Engineering did not last long. Its head was Dr. Henry G. Knight, a man with much appreciation of engineering. He addressed the ASAE Annual Meeting in June 1939. He outlined an enormous field of cooperation between engineers and chemists, centering 
on the promise offered by utilizing America's surplus crops and farm wastes in industry. He cited many examples of how this could happen, particularly with four large laboratories now under construction to do the chemical research. Somehow, the competition from petroleum and mining was going to be met by agriculture in providing raw material. His talk was well received.

The Power and Machinery Division held a session on industrial use of farm products at the December meeting. E. C. Lathrop of the Northern Regional Research Laboratory spoke of the fantastic amount of fibrous waste produced by agriculture ( 200 million tons annually) of which half could become a source of farm profit. Straw, for example, made good paper but the wood pulp interests had solved their harvesting and transport problems much better than had the straw producers. The industry wanted clean straw, baled a certain way, with wire ties; the combine had almost eliminated straw stacks. Someone would have to add a baler to the combine. And who would buy it?

So in spite of warm enthusiasm, the agricultural engineers continued working on familiar problems. The chemurgy problems were complex, requiring parallel developments in chemistry, farm practice, industrial practice, and the market.

The Power and Machinery Division held another symposium on chemurgy in December 1940. Equipment, methods, and costs of collecting crop residues were discussed. A paper on power alcohol for tractors and farm engines was also delivered. The residues session resulted in much better information on industry requirements for straw intended for the strawboard mills and in a better understanding of the cost of collecting cornstalks (Iowa's J. B. Davidson contributed the latter). In a word, special machinery would be required.

Interest in chemurgy continued through the war years. Some of the warcreated shortages caused intense chemurgical development of substitute plants or culture of plants usually not widely grown in this country. Guayule for rubber was a famous substitute; flax, hemp, and castor bean are examples of "transplants." All of these required development of systems for planting, cultivation, harvesting, and possibly irrigation also. The record of these crops is perhaps valuable in giving at least partial insight to the chemurgy problem. Flax was to supply linseed oil and linen thread, but substitutes early appeared. Hemp was to provide fiber for cordage and cables, but substitutes could be used to some extent. Castor oil could be used as a first-class lubricant and also for paint; unfortunately, satisfactory harvesting systems did not arrive until after the war. Guayule was quickly forgotten when synthetic rubber, based on petroleum, made its appearance. It 
was difficult to persuade agricultural engineers to invest a lot of effort in a chemurgic crop when the chemists could wipe it out overnight.

Representatives of the Farm Equipment Institute met with representatives of the pulp and paper industry at the Northern Regional Research Laboratory, Peoria, in January 1947. Once again the agricultural engineers heard how wheat straw would make good strawboard for boxing and packaging; they heard how many tons of straw were available on Midwest farms; and they heard the specifications for straw bales required by the strawboard industry. To make a poor joke, the bale specs was probably the straw that broke the camel's back! The industry required (to spell it out) a bale $16 \times 18$ $x 42$ inches; it had to weigh 80 pounds; it had to have less that 5 percent chaff; after mowing, the height of stubble was to be 3 inches; bale ties were to be of wire; and the moisture content was not to exceed 18 percent. Although some had tried it, the hay baler did not produce a straw bale acceptable to the strawboard industry.

After this, the chemurgy movement seemed to sputter out as a significant ASAE thrust. Farmers preferred to produce what they had always produced and the major equipment companies felt justified in manufacturing machines for those purposes but not for chemurgy. Packaging straw and cornstalks with such care had to pay a decent profit-but the profit just wasn't to be had. Some experiment stations worked with cornstalks in the 1950s (Purdue, for example) as a building material under the Research and Marketing Act of 1946; sugar cane bagasse has long been used as an insulation board component. On the whole, however, the bright promise that chemurgy seemed to hold for agricultural engineering never was realized.

"Cotton growing is the least mechanized major division of agriculture. While to some extent modern machines are used in planting and cultivating cotton, yet this, our greatest crop and largest export item, is still harvested by hand. Every year in the South millions of human hands pick cotton in the same slow, tedious, backbreaking manner as was used thousands of years ago in the valley of the Nile when the Pharaohs reigned."

The speaker was Edward A. Johnston, vice-president in charge of engineering, International Harvester Co. The occasion was the 1938 ASAE Annual Meeting, at which Johnston received the Cyrus Hall McCormick Gold Medal. His address as medal recipient was titled "The Evolution of the Mechanical Cotton Harvester."

The requirements of a cotton-picking machine are dreadfully complicated. Since 1850 hundreds of patents had been issued on various devices intended to do the job but by 1938 the process had come to focus on the principles employed in International Harvester's picker and on the stripper 
machine developed in Texas.

Johnston had labored with picking mechanisms for 30 years. He had tried spiked drums, pneumatic pickers, and other collection methods without success. What did succeed was a set of rotating spindles that were tapered and equipped with numerous barbs to catch the lint. Such spindles, mounted on a revolving drum, would remove cotton without damage to it or to immature bolls. The drum carried the lint-filled spindles around to a rotating doffer system which removed the lint. The revolutions of the picker drum were synchronized with the speed of the tractor. They had tried a selfpropelled machine but by 1938 had settled on a single-row machine constructed to mount on a general-purpose tractor so that the picker spindles would enter and withdraw from the cotton plants without a raking action.

This harvester could harvest 1500 pounds of seed cotton in about 1 hour and 20 minutes. That amount of cotton when ginned would make a 500 pound bale. Based on this performance, Johnston believed that the machine would do the work of 75 hand pickers. After years of economic depression and cheap labor, he claimed that the day when pickers would work for 25 to 90 cents per hundred pounds was over. Furthermore, growers did not wish to rely on transient labor. The hand picking rate had risen to $\$ 1$ to $\$ 1.50$ per hundred, and it was time to weigh the costs very carefully.

But although a successful basic picker machine was now reality, much remained to be done. To Johnston, the cotton harvest was still a long way from being mechanized. He felt that "there is absolutely no likelihood of mechanical cotton harvesters being produced and sold in quantities sufficient to revolutionize agriculture in the cotton-growing areas in the near future."

W. Waterman of George R. Meyercord and Associates, who developed the "Gyracotn" harvester, said at that same meeting: "The problem may be compared to that of the automobile. In 1910 almost everyone conceded the mechanical success of the automobile, but very few people could use them."

Stripping cotton was a different process from picking. Stripping meant pulling off the entire cotton boll. H. P. Smith of the Texas experiment station wrote in 1938 that hand-snapping, or pulling, was extremely common in West Texas before World War II. The gins were equipped to handle pulled cotton. Therefore the Texas station started development of a stripper type cotton harvester.

Strippers were not new. Sled-type strippers, blacksmith-made, were used until World War II. This was a box equipped with fingers which, when drawn along the row, stripped off the bolls which in turn were raked back into the box by a man. Deere $\&$ Co. sold horsedrawn strippers until the depression stopped demand. In 1943, Deere came out with a two-row tractor- 
mounted stripper. International also had a stripper in the late 1920 s.

Smith and his co-workers had started work on their stripper in 1927. They tried the West Texas sled, the McCormick-Deering, and the Deere designs. Severe modification of the Deere experimental machine gave encouraging results. Rubber stripping rolls worked very well when one roll was movable under spring tension. The rolls moved upward on the plants to strip off the bolls; they were removed by a metal plate. While more modification was necessary, the rubber roll seemed to be satisfactory. These researchers even believed that stripping green plants might be successful by adding a cleaner to remove the green leaves.

But Smith soon found that stripper efficiency depended on characteristics of the cotton plant. Some varieties stripped well while others did not. In fact, the commonly grown varieties were not suitable for mechanical harvest.

Now began what is possibly the first example of an engineer making a machine and then telling the plant breeder the specifications of the plant (this was done years later when the California agricultural engineers designed the tomato harvester).

Smith told two obliging Texas experiment station plant breeders that he wanted "... a a plant with restricted vegetative growth, a determinate fruiting

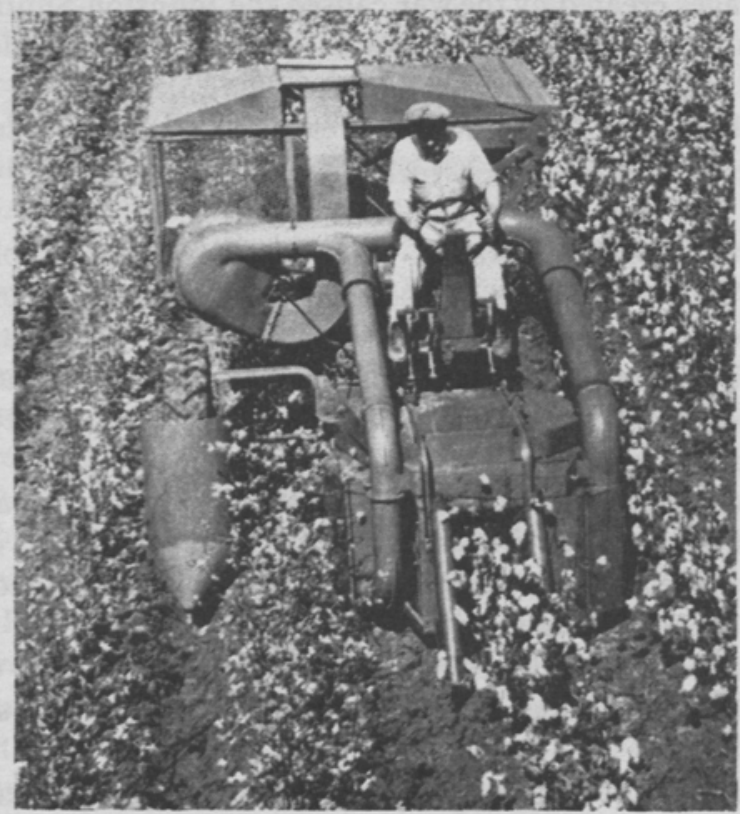

Small experimental cotton picker. Increased interest developed during World War II 
habit, relatively large stormproof bolls borne in semi-clusters but singly on long thin peduncles, and a small leaf or a deep-lobed leaf commonly called cut-leaf." And they produced it. Its design was held to be good not only for stripper harvesting but also picker and hand harvesting.

Smith believed that varietal characteristics and seasonal conditions explained failure of cotton harvesters and reluctance of growers to accept them. Wide use of high-yielding varieties suited to mechanical harvest would have to precede adoption of the machines. Other factors that tended to work against mechanization were small size of fields, slope, terraces, price of cotton, and availability of labor.

Integrating all these factors, Smith stated in 1938 that "I cannot visualize the mechanical cotton harvester taking the cotton belt by storm . . ."

Therefore Johnston and Smith, one a distinguished industry engineer and the other a young and dedicated researcher, both predicted in 1938 that mechanical cotton harvesting was in the far, dim future. Yet Smith wrote later, "In 1942, a few bales of cotton were harvested with experimental picking machines. In 1953, it is estimated that there were approximately 15,000 mechanical cotton pickers and 25,000 cotton strippers available. These machines harvested about 25 percent of the 26 million bales produced."

Labor shortages created by the war caused the Johnston-Smith predictions to be upset, although a steady stream of improvements in the technology played a vital role. Much of the labor force had been drawn into the war industries or the armed forces. At war's end many of these workers did not return to cotton culture. Much technology was lavished on the complex picker.

Doffing cotton from the spindles reliably was a major problem. Spindle design alone affected quality of the yield; also, the spindles had to be moistened on each drum rotation to prevent buildup of dirt, sap, and fiber. The drum height was critical, too, because of the need to accommodate masses of green foliage. International returned to the concept of a selfpropelled machine for large fields.

An early requirement was that the cotton picker should clean the cotton also. After some years of frustrating effort, the engineers decided that mechanically picked cotton should be dried and then cleaned at the gin, where the job could be done properly.

Development of the machines was slowed because the crop could not be stimulated and the machines could only be tested during the short picking season.

An entire package of cultural practices, including plants bred to order as in Texas, had to accompany the pickers and strippers. These included defoliation, insect control, soil management, and planting and tillage 
methods. Defoliation was a partial answer to the problem of green leaves which troubled the stripper developers; "green-leaf trash" caused the harvested cotton to sweat, heat, and mold before it reached the gin.

A final hurdle had to be jumped by machine-harvested cotton: its quality after being spun into yarn. Tests of this characteristic were made by $H$. P. Smith by comparing stripper cotton with hand-snapped and hand-picked cotton. The United States Cotton Ginning Laboratory at Stoneville, Mississippi, cleaned and ginned the cotton; the United States Cotton Spinning Laboratory at College Station, Texas, spun the cotton into yarn. The results showed that there was no difference in the spinning quality and yarn appearance. Smith's efforts were acknowledged in 1956 by award of the McCormick Medal.

One of International's first operational self-propelled pickers, known as "Old Red," reposes in the Smithsonian Institution's Museum of History and Technology.

\section{C \\ Education}

Although Iowa State, Kansas State, and Nebraska were accredited by ECPD in about 1937, Raymond Olney did not provoke public debate on the subject until late 1943. Perhaps he hoped that quiet missionary work might be effective; if so, it did not produce outstanding results. The problem had to be aired; ASAE had to take leadership.

Of course, the College Division had debated for many years the characteristics of an acceptable professional curriculum. Some wanted ASAE to "approve" or "disapprove" the curriculum at each college. But agreement upon a "standard" curriculum could not be secured because each college thought its approach was satisfactory. A set of general criteria for all engineering degrees was needed.

In 1932 ASCE, ASME, AIEE, and some other groups founded the Engineers Council for Professional Development to provide a forum for debate over the licensing of engineers. ECPD split over the licensing question. David B. Steinman, the famous bridge engineer, led a group out of ECPD to form in 1934 the National Society of Professional Engineers, which worked toward licensing by the various states. ECPD turned its attention to improvement of engineering education, including accreditation of undergraduate engineering curricula at the colleges.

Between 1934 and America's entry into World War II hundreds of engineering curricula were accredited. The acceptance of the process by engi- 
neers throughout the country gave ASAE's College Division the criteria needed plus a strong incentive to try to gain accreditation for agricultural engineering. Unless a majority of college departments achieved this recognition, hope for acceptance of agricultural engineering as a branch of engineering appeared dim. Many state boards of registration would license only those engineers who were graduates of accredited curricula.

War demands delayed action on these issues after 1941 to some extent; however, the College Division kept working. Its Committee on Curricula initiated and maintained contact with ECPD's Committee on Engineering Schools. It opposed the philosophy that ASAE ought to accredit its own curricula. A subcommittee on "industry requirements" was set up to obtain ideas from that sector on what the curriculum should consist of.

The break came in 1944. The year before, L. J. Fletcher was elected to the council of the Society for the Promotion of Engineering Education. He and President A. W. Turner arranged for SPEE to have two sessions on agricultural engineering at its June 1944 meeting in Cincinnati. The hope was that a number of engineering deans and ECPD representatives would attend and hear about agricultural engineering. Members of the College Division arranged their annual meeting program at Milwaukee to permit convenient travel to the SPEE meeting immediately after.

Olney worked hard to publicize the Cincinnati meeting, urging members to attend regardless of their affiliation with SPEE. A member wrote Olney that "We are standing between agriculture and engineering and could easily miss both boats unless we look out. I am of the opinion that much good can come from a thorough . . . discussion of the ECPD surveys and standards at the SPEE meeting ... " Another member wrote " . . . there is a possibility for good in it if high-class funerals occur among the proper folks."

The meeting was first addressed by J. B. Davidson, whose paper "Agricultural Engineering" was later published in "Journal of Engineering Education." Its opening sentences were as follows:

"It is the acknowledged purpose of this paper to enlist the interest and secure the moral support of a large group of members of the Society for the Promotion of Engineering Education in a new branch of the engineering profession. The development of agricultural engineering is worthy of their assistance and encouragement. Although the record for agricultural engineering is one of accomplishment, it is felt that progress has not been made as rapidly as the circumstances justify. It is very desired that engineering educators consider the possibilities in this branch of engineering and lend it support ...'

Davidson's paper effectively set the stage by defining the field of agricultural engineering, describing accomplishments and pointing out future 
trends. After discussion, a paper was presented by R. A. Seaton, dean of engineering at Kansas State College. Seaton reported on "Accrediting of Agricultural Engineering Curriculums," a subject which needed honest exposure.

Up to 1943 ECPD's Committee on Engineering Schools had examined 11 agricultural engineering curriculums. Three were accredited (as mentioned previously) and eight were not. In addition, one agricultural engineering option in an accredited mechanical engineering curriculum had been approved (at the University of California). Of course, numerous other curriculums had not been submitted for examination.

"This is not a situation that should be permitted to continue," Seaton stated. "It is unwholesome ..." "It is unfair to the graduates . . " And, "It tends . . . to bring agricultural engineering into disrepute as a branch of the engineering profession." Then he zeroed in on the difficulties:

"Obviously . . . agricultural engineering curriculums should be accredited by ECPD only if they are truly professional and are really curriculums in engineering. If they are not engineering curriculums, but are rather curriculums in mechanized agriculture, or if they are subprofessional in character . . . they should not be accredited as professional engineering curriculums, no matter how important their function may be or how high may be the standards and quality of instruction. The very name of agricultural engineering would in this case be inappropriate ...

"If the agricultural engineering curriculum, courses, staff, students, and budgets are administered solely or chiefly in the college or school or division of agriculture under a dean who knows little or nothing of engineering principles and of the engineering method, or if most of the departmental staff members are not themselves professional engineers, however competent they may be in other fields of endeavor, it is too much to expect that students in the curriculum will develop professional engineering competence."

In other words, teaching farm mechanics but calling it agricultural engineering, strong dominance by the deans of agriculture and poorly qualified staffs were pivotal reasons why the departments were losing their bids for accreditation.

Seaton probably made the ASAE men squirm by citing the specific deficiencies of three departments which had been turned down back in 1937. The deficiencies were so severe that one might marvel they had the nerve to apply for inspection. Still, although painful to hear, those present were probably left with no doubt in their minds about what ECPD inspectors did not like. Also, to be more positive, Seaton closed his paper with a detailed 
suggestion on an agricultural engineering curriculum that would make the grade.

Attending the conference were 12 department heads; engineering deans; agricultural engineers in industry; and Drs. H. T. Heald and D. B. Prentice, representing ECPD. Dr. Prentice, as chairman of the Committee on Engineering Schools, was to play a key role for ASAE later. He was president of Rose Polytechnic Institute. ASAE President Driftmier was also there.

After the sessions were over, Arthur Turner commented: "Consensus was that ag engineering should be recognized as another division of engineering and that we should seek to have as many departments accredited as possible. It's my impression we really cracked the engineering 'intelligentsia,' something we should have done long ago." Professor E. B. Doran of Louisiana State University was sure that the meeting laid a foundation for closer relationship "between our branch and other branches of engineering" and was "distinctly worthwhile."

This was the first organized effort to establish agricultural engineering as worthy of recognition as a branch of engineering. There were dissenters, however, from the ECPD thrust. Many department heads (perhaps fearing trouble with their deans of agriculture) wanted ASAE to set up its own independent curriculum accreditation procedures. F. C. Fenton of Kansas State, who was chairman of ASAE's Committee of Curriculum, saw no advantage to this. To him it would not be a valid accreditation. However, President Long asked Fenton to head a committee to investigate the topic and report on it to the Council at the 1945 Winter Meeting.

The exercise was made unnecessary by the arrival of an invitation from Prentice to ASAE to nominate representatives to the ECPD inspection committees. This was the payoff of the Cincinnati SPEE meeting, greatly aided by recent personal contacts made with Prentice by J. D. Long and others.

By March or April of 1946 the details of ASAE's representatives had been worked out. They were appointed to serve in pairs; each pair represented a

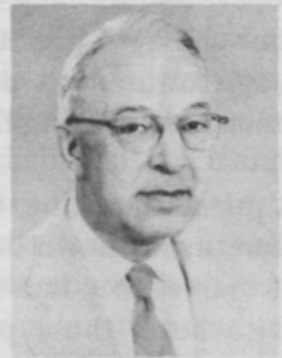

J. Dewey Long 39th president, ASAE, 1945.46

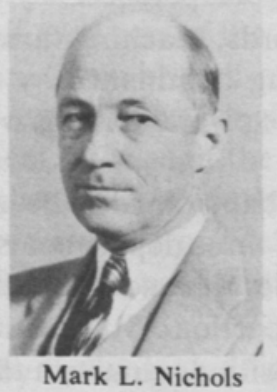

40th president, ASAE, 1946-47 
geographic region. The appointments were

C. I. Gunness and B. T. Virtue ............. New England

A. W. Turner and G. A. Rietz .............. North Atlantic

H. J. Barre and F. J. Zink ................. North Central

C. E. Seitz and R. H. Driftmier................ Southeast

F. C. Fenton and Howard Matson .............. South Central

I. D. Wood and G. D. Clyde .................. Southwest

C. J. Hurd and Hobart Beresford ............... Northwest

Long stated that the representatives would work with the ECPD Committee on Engineering Schools in reviewing criteria on which the curriculums and departments would be judged. These criteria included minimum standards for engineering subject matter, nature of advanced training, teacher qualifications, adequacy of facilities, requirements for admission and graduation, administrative issues.

Then a lull ensued while the agricultural engineers met with the ECPD committees and tried to assist in "reviewing criteria." As a result of the war, new schools of thought had arisen in engineering education and the ASAE men were to be exposed to them. Byron T. Virtue, then with the Torrington Co., recalled some of the hassles of the time:

"Several meetings were attended in New York City, one in Philadelphia, one in Washington, D.C., and finally one in Montreal jointly with Engineering Institute of Canada. The meetings were called by EJC and ECPD.

"The long and sometimes bitter discussions centered mostly on what constituted an acceptable and complete engineering educational program in view of the country's needs. In other words, curriculum and professional recognition.

"In those discussions there were those who fought savagely for a completely mathematical orientation as well as those who bitterly promoted strictly theoretical science programs while others supported science with practice and there were some who were hellbent on purely liberal arts base for bachelor degree programs. Then there were those who promoted five and six year programs for the bachelor's degree and conversely some argued strongly for a four year program leaving out all liberal arts subjects except English and one course in United States history. There were also lengthy and sometimes idiotic discussions on eliminating the bachelor and masters degrees and awarding only the doctoral degree after an eight year program ...

"The upshot of all this particularly after the Montreal meeting was that probably a program in which the first two years should be common 
for all engineers followed by Departmental Identification for the last two or three years...

"During the above meetings staff qualifications came in for a sound combing as well as physical plant...

"I do believe that a few were convinced that there was a need for agricultural engineering or at least an engineering area that should relate to the biological sphere...

"After all the arguments most succumbed to the idea that it was the engineer who should be responsible for integrating theory and science into useful and beneficial things for mankind."

Presumably the other ASAE men had similar experiences. At any rate, nothing concrete emerged from the ECPD-ASAE interaction until an announcement appeared in the 1949 Journal that the University of California (Davis) department of agricultural engineering had received accreditation as a "separate and distinct" curriculum from mechanical engineering. Then, early in 1950, came accreditation for the professional curriculum at Oregon State College.

By Sept. 30, 1950, ECPD's annual report showed that ASAE's work had indeed succeeded. After listing Iowa, Kansas, Nebraska, California, and Oregon, the following ten schools were also listed as having had their undergraduate degree programs accredited: University of Idaho, University of Illinois, Louisiana State University, Michigan State College, University of Minnesota, Oklahoma A. \& M. College, Purdue University, A. \& M. College of Texas, Utah State Agricultural College, and State College of Washington. With 15 accredited departments the move was now too powerful to be opposed by those who thought it was impolitic or who were discouraged by their superiors. Therefore, the 1950s was to become the decade when most of the professional curricula achieved recognition and when agricultural engineering secured its place as a branch of engineering.

It must not be thought that ASAE had become a member of ECPD in 1946; sending representatives to the accrediting committees did not entitle ASAE to such an exalted posture. That was to come later, but J. D. Long was thinking of it when he wrote a very detailed letter on "Policies and Program" to the ASAE representatives dated April 22, 1946. On that topic he wrote:

" . . . the main body of ECPD is composed of two members each from the four "Founder Societies," the SPEE, the National Bureau of Engineering Registration and the National Council of State Boards of Engineering Examiners. They do not anticipate enlarging this membership, preferring to maintain a small, closely knit working organization. Perhaps, in due time, we shall wish to challenge this arrangement." 


\section{"ANNIVERSARIES CALL FOR INVENTORIES:..

\author{
Roy Bainer
}

\section{A \\ General Progress}

In many respects Mark Nichols was correct when he forecast a time of uncertainty and conflict, but these very challenges increasingly brought American engineering and technology to the center of the global stage; agricultural engineering was a participant.

Paul M. Mulliken of the National Retail Farm Equipment Association testified at a U.S. Senate hearing on the Marshall Plan in 1948. He proposed that idle animal-drawn implements on American farms be reconditioned and sent to Europe. This would be much more suitable than exporting combines, tractors, pickup balers, etc., to areas where fuel and trained operators were nearly non-existent. He said that European agriculture could not be mechanized overnight, that it must be a progressive movement. After more than a third of a century, U. S. agriculture was not completely mechanized (Americans started using power farming methods before World War I) and it would be unwise to expect European peasants to move any faster.

The gathering momentum of technical aid to underdeveloped countries involved agricultural engineers in increasing numbers. Many had doubts of the value of such programs or questioned the methods employed. A thoughtful 1951 Journal editorial expressed some of those doubts:

"In the name of humanity we would not deny help where it can be given and utilized effectively. The question is where and how, and what types and concentrations of technical aid may be most effective? How can we make our help real rather than an expensive gesture with probable future repercussions?"

President Fred C. Fenton stated at the 1951 ASAE Annual Meeting that war and foreign aid were the main movements of the time, and that 
the latter offered agricultural engineers "their greatest opportunity." $\mathrm{He}$ called for a massive effort to train men for this kind of service, men with sympathy for other people who could transfer American technology with efficiency. With respect to Point IV of President Truman's foreign policy, the technical assistance program, Fenton justified the involvement of ASAE in it by saying:

"Compared to our billions for military preparations, the few millions expended for technical assistance are entirely inadequate. Yet in such cooperative programs for improving the standards of less fortunate people lies our greatest hope for peace."

At that time a large number of agencies were searching for qualified agricultural engineers to send abroad. The Departments of Agriculture, Army, Commerce, Interior, Labor, and State; the Economic Cooperation Administration; and the Federal Security Agency were among U. S. governmental subdivisions involved. The United Nations and the International Bank for Reconstruction and Development wanted agricultural engineers. Some foreign governments negotiated directly with individuals. Private consulting firms had entered the scene. Private industry maintained engineers abroad also. Religious and non-profit groups (foundations) needed agricultural engineers, particularly in underdeveloped countries.

The U. S. government recruiting of agricultural engineers was handled by the USDA's Office of Personnel. They were prepared to assign men to 19 countries in the Western Hemisphere, 12 in the Middle East, and 13 in the Far East. Agricultural engineering specialists in hydrology, irrigation, rural electrification, and farm machinery were particularly sought. Typical assignments on foreign duty were from two to five years.

The Point IV program was administered by the Technical Cooperative Administration (TCA). Agricultural engineers working with TCA might be required to perform technical assistance much broader than their specific specialty. In fact, they often were expected not only to help the host people

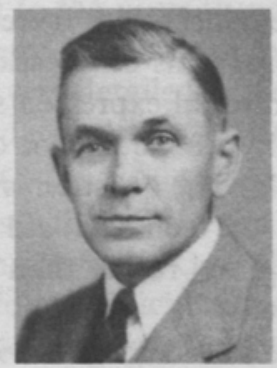

Fred C. Fenton 44th president, ASAE. 1950-51 
increase food production but also to assist them to find better opportunities for health and freedom.

Although governmental foreign technical assistance was organized after World War II principally as an adjunct to foreign policy, some agricultural engineers had labored abroad much earlier for genuine humanitarianism. Such a one was Mason Vaugh, who founded the Agricultural Engineering Department at the Allahabad Agricultural Institute in 1921, the first professional curriculum of its type in India. The first class with B.S.Ag.E. degrees graduated in 1944. Sponsored by a national religious organization, Vaugh presided over the organizational meeting of the Indian Society of Agricultural Engineers at Allahabad in 1952. Later he helped set up a factory to produce well engineered implements suited to Indian patterns of land tenure and cultivation. And all this was at no cost to the U.S. Vaugh, his graduates, and ISAE have probably done more for Indian agriculture than those many millions spent on ephemeral programs managed by "instant experts." At least, ASAE thought his work was a highly significant contribution because he was elected Honorary Member in 1960 .

Vaugh's experience was unusual in that he dedicated his entire professional life to agricultural engineering in India. More typically, many academic members started working on foreign assistance as part of their jobs. Universities increasingly became involved with a university in a foreign country. Exchange of personnel over a long period often led to mutual respect and understanding. Students came to the U.S. to study agricultural engineering; faculty came to take advanced degrees. Buildings were erected on the foreign campuses; teaching and research equipment was obtained and personnel trained in its use. Good agricultural engineering departments with some understanding of local problems sprang up rapidly in certain developing countries. Such foreign technical assistance had the potential of lasting value, although it tended to drain the Americans of scarce manpower (the 1950s was a decade of marked engineer shortage in all categories).

But the process had its negative points. Many foreign students preferred to stay in the U.S. after graduation, thus depriving their homelands of needed expertise. Professors who spent much time abroad tended to fall behind on American technical progress. Foreign governments complained that the research performed by their nationals in America usually had little relevance to home conditions.

The rise of foreign involvement was an important phase of the Fifth Decade. This was the commencement of an internationalization of American agricultural engineering. How effective this birth was is difficult to judge because of complexities associated with population pressures and other matters beyond engineering. It did much good for ASAE and its members, 
however. Many members had been abroad in the 1940s, but not as agricultural engineers. Now they were going out to deal with problems overseas that concerned their profession; that provided exciting new challenge.

But the outbreak of war in Korea had its effect on ASAE. With the memories of World War II quite fresh, the war was seen as another test of freedom and representative government, this time with communism as the predator. Editorially, the Journal stated in August 1950 that engineers have a perpetual job in helping each new generation to learn the value of freedom and productive work.

President Fenton appointed a temporary committee to consider what ASAE ought to do in support of the national war effort. F. P. Hanson, chairman, recommended to the Council in December that a Committee on Defense Activities be formed to carry out the defense work of the Society; the Council concurred.

At this time there was evidently complaint that ASAE was in danger of doing "too little, too late" because a chiding editorial was printed in January 1951 on "Mobilization Responsibilities." The writer cautioned that ASAE could only contribute to national defense in terms of its basic purposes and methods, which are definitely not in the political realm.

Problems of younger members in gaining consideration from draft boards caused ASAE to contact the U.S. Department of Labor. The Department stated that agricultural engineer was included on the Critical Occupations List under the general heading of "Engineer, Mechanical." Also under that heading were aeronautical, marine, and automotive engineer. Although otherwise distasteful, the ruling probably helped the draft board problem.

An April 1951 editorial counselled members that their best value to defense organization was to do work they were qualified to do and to avoid shifting to new work locations. In other words, the members could serve the country by doing agricultural engineering at the accustomed place.

In the confusion of the Korean crisis there were people who whispered that the American economy needed periodic war to keep it running at good speed. Such absurdity was submerged by the new demands laid upon productive capacity. In agriculture the "lid" was removed once again when USDA called for a 1951 production 3 percent higher than the previous record. And again the farm equipment industry was told that metal supplies were tight and their priorities were low. It was a replay of World War II with no lessons learned on the wisdom of stockpiling steel, aluminum, and copper for agricultural machine tools in time of emergency.

The Committee on Defense Activities proposed that ASAE offer its services to various national defense agencies. The Council approved the idea at its December 1951 meeting; President Stanley Madill of Deere and 


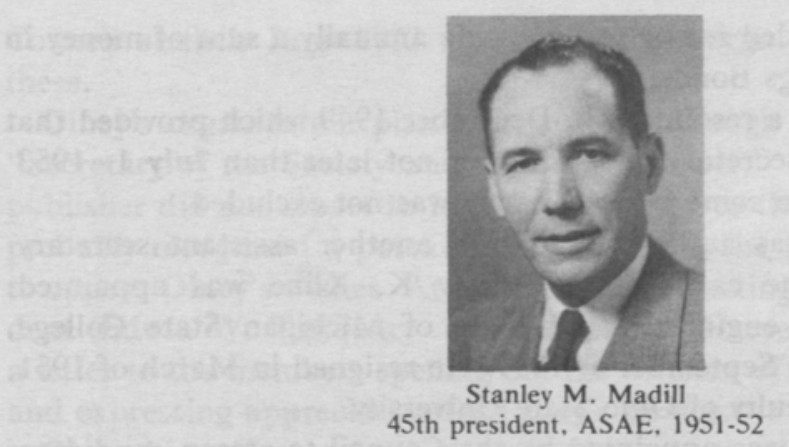

Company took the offer to Washington in person the following February. The committee's report showed among other things where several agricultural engineering specialties would qualify a person for assignments to work in special fields of engineering in military service. While it apparently made a good impression, it did not directly result in calls for action or service requiring further consideration. The Council minutes reflect no further activity of this type.

The Korean war dragged out its way from combat to conference. After the initial excitement it clearly was not destined to become World War III; its final impact on ASAE was not lasting. But one result was a better listing in the Department of Labor's Dictionary of Occupational Titles.

Listing of agricultural engineering as a sub-branch of mechanical engineering was incorrect. It caused difficulty in getting appropriate assignments in military service and reduced the recognition accorded as engineers. A committee headed by T. E. Hienton sent out a questionnaire in 1955 requesting qualifications and experience of members who had served in the Armed Forces during or since World War I. By November 1956 the Army had added agricultural engineering to its "Criteria for Selection of Scientific and Professional Personnel." Walter M. Carleton (USDA) was mainly responsible for the committee work which, through working with the Department of Labor Dictionary, achieved for agricultural engineering equal status with the major accredited branches of engineering.

Raymond Olney was aging. He had graduated from Cornell University (B.S.M.E.) in 1910. In 1947 he was almost 60. At the December Council meeting he reported that he had been refused a ten-year endowment life insurance policy which was intended to provide retirement income. This suggests that Olney planned to retire sometime around 1957. His retirement 
income was to be provided for by setting aside annually a sum of money in the form of U.S. Savings Bonds.

The Council adopted a resolution in December 1949 which provided that Olney would retire as secretary and treasurer not later than July 11953 although employment in some other capacity was not excluded.

Meanwhile, Olney was authorized to hire another assistant secretary. After interviewing some candidates, Cernyw K. Kline was appointed. Kline, an agricultural engineering graduate of Michigan State College, assumed his position on September 6, 1949. He resigned in March of 1951, however, to join the faculty of Ohio State University.

A special committee was appointed by the Council to screen candidates for the assistant secretary position. The chairman, Earl D. Anderson, presented three candidates who were interviewed separately by the Council. The position was offered to Frank B. Lanham.

A native of West Virginia, Lanham received his agricultural engineering degree at VPI in 1935 and the M.S.Ag.E. at Iowa State in 1936. After a research appointment at the University of Georgia, he served with distinction in the Army throughout World War II. After the war he engaged in private business, then returned to Iowa State and completed the Ph.D. degree. He took up his duties at ASAE Headquarters in April 1952.

The Council voted in December that as of July 1, 1953, Lanham would succeed Olney as Secretary of the Society. Olney would continue as treasurer and as editor and business manager of AGRICULTURAL ENGINEERING. Then followed an effort on Olney's part to define the duties of the key personnel. He presented an organization chart and set of job descriptions to the

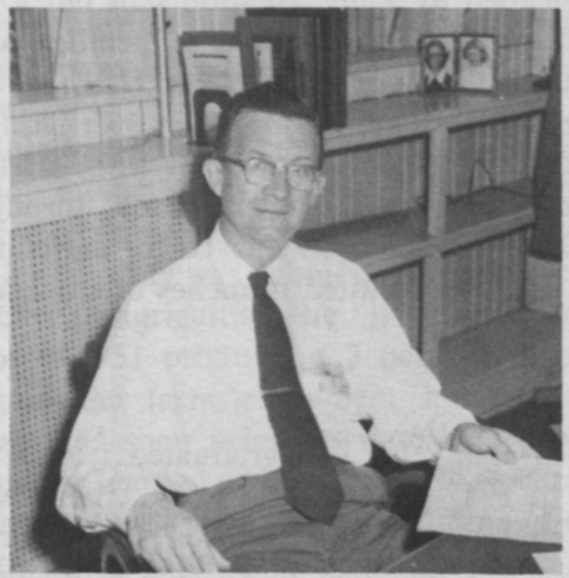

Frank B. Lanham became ASAE Secretary in April 1952 
Council at their June 1953 meeting in Pittsburgh. The Council accepted these.

Olney's organization plan was faulty. Although Lanham held the title "Secretary of the Society and Executive Officer," Olney as treasurer and publisher did not report to him directly, only to the Council. The Council probably recognized a potential for trouble in the alignment but hesitated to oppose Olney's wishes. At the December meeting it voted that the president (Edwin W. Tanquary of International Harvester Company) prepare a letter to the members spelling out the division of duties at Headquarters and expressing appreciation for Olney's service.

Olney himself may have thought the organizational scheme somewhat peculiar. His Publishers' Annual Report of 1953-54 claimed that the independence of the publisher from the ASAE secretary was based on reaffirmation of Council action taken back in 1921.

At the 1954 Winter Meeting President George B. Nutt of Clemson Agricultural College asked Vice-President L. H. Skromme to address the Council. Skromme told Lanham that he should organize the Headquarters staff into a "smooth, coordinated unit in the service of the Society." $\mathrm{He}$ introduced a resolution, which was voted, that enjoined Lanham to "more actively" carry out the provisions of Olney's organizational plan.

To add to the strain and difficulty, Headquarters was moved from the old 505 Building to the Masonic Temple at 420 Main Street. In the process of settling in at the new location, the Council gave Lanham orders to provide Olney with a suitable private office at the new location.

Thus Frank Lanham went to the 1955 Annual Meeting at Urbana saddled with a management problem: who was in charge at Headquarters? The organization chart the Council accepted from Olney was unworkable; nonprofessional staff loyalties at St. Joseph were divided.

The Council spent long hours at the Urbana meeting discussing the Headquarters problems. Finally President Nutt called for the Council to

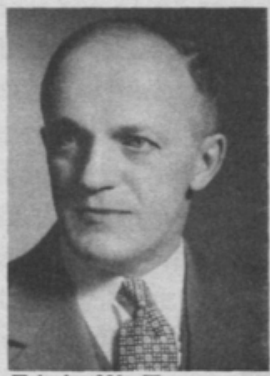

Edwin W. Tanquary 47th president, ASAE, 1953-54

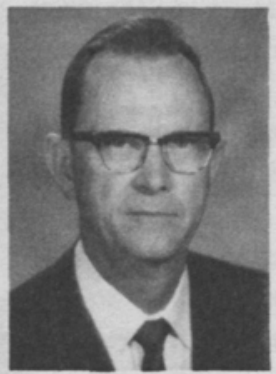

George B. Nutt 48th president, ASAE, 1954-55 
vote on who was to be in command; the vote was tied evenly-half for Olney and half for Lanham. This demanded that Nutt break the tie. He voted for Lanham, the duly elected secretary.

According to Lanham, Olney was extremely hurt by the decision. Evidently he found it difficult to yield the reins to a younger man. For this and other reasons, Lanham submitted his resignation, to be effective September 1,1955 . He was to become head of the agricultural engineering department at University of Illinois. Shortly after, Ralph Palmer was made acting secretary. President Wayne Worthington of Deere and Company plus PastPresidents Nutt and Tanquary formed a committee to screen candidates for the secretary's job.

The screening committee received 31 applications for the job. Five applicants were interviewed by the Council in Chicago in December 1955. As a result, Worthington was authorized to offer the position to Jimmy L. Butt of Alabama Polytechnic Institute.

Butt was hesitant; he had heard of the previous difficulties and did not wish to become involved in management squabbles. Worthington persuaded him to visit St. Joseph for an in-depth conference. After the visit Butt became convinced that he would be in complete charge if he accepted the secretaryship. Evidently Olney and the Council had learned a lesson from the experience with Lanham; a new organization chart was prepared which clearly set forth the chain of command. Based on these assurances Butt accepted the position and assumed office in late March 1956; on July 1 he became the executive officer with all personnel reporting to him.

Olney continued as treasurer until July 1 when Ralph Palmer assumed that office; Olney then carried the title "Counselor."

Jimmy Butt grew up in Tallahatchie County, Mississippi, and finished high school in Wetumpka, Alabama. He had an outstanding college career at Alabama Polytechnic Institute, where he took his agricultural engineering degree in 1943. Then followed a tour of duty as an artillery officer in

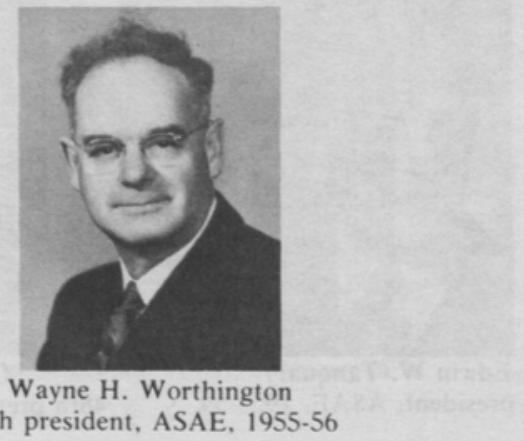




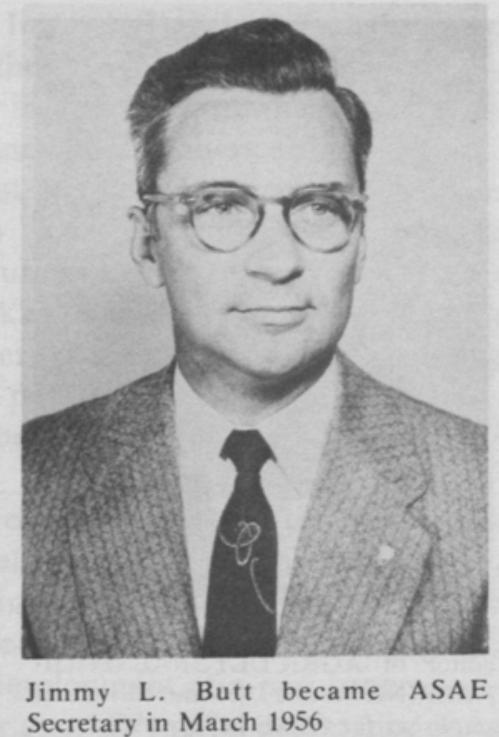

Mississippi, Oklahoma, and Germany. After the war Butt returned to API for an M.S. degree and remained there as research engineer until he joined ASAE.

The John Deere Medal was awarded Raymond Olney in 1954. In 1956 Max Eyth Gesellschaft, the German society of agricultural engineers, presented its Max Eyth Medal to Olney, the first American to be so honored.

Olney's dedication to ASAE began when he became a member in 1912 . After serving as president in 1919 he took over editing and publishing the Journal in January 1921. In November of that year he became secretary and in 1922 treasurer. After 1925 his employment by ASAE was fulltime. From then until 1953 the Society was his whole life. As he wrote to W. B. Jones in 1954:

"I am a member of no fraternal, business or social organization, and have no hobbies-ASAE and its publications have been both my avocation and vocation these past thirty odd years."

Olney was intensely conservative in fiscal outlook, which had helped ASAE through some very lean years. His publishing experience and ability developed the Journal into a respected organ. His devotion to agricultural engineering was an inspiration to most of his contemporaries. Although some presidents may have thought him old-fashioned in his later years, the files contain many letters of heartfelt thanks and appreciation written to him by them. The unfortunate case of Frank Lanham was actually an illustration of the deep respect held for Olney by the Council; another man probably 


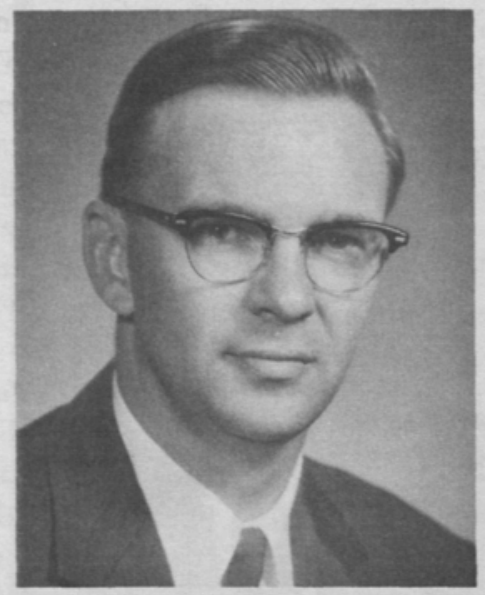

James A. Basselman became associate editor of AGRICULTURAL ENGINEERING in June 1955 and editor and publisher for ASAE in July 1956

would not have been permitted to retain power under such ambiguous circumstances.

But now Olney's day was past. As counselor he edited copy and handled advertising until June of 1959 , when he retired. Jimmy Butt wrote that he (Olney) tried to retain the old office manager when she reached age 65, having been with Headquarters many years, but this suggestion was vetoed.

Meanwhile, James A. Basselman, a 1952 agricultural engineering graduate from Michigan State College, had joined the staff in 1955 as associate Journal editor. Jim had gained considerable experience on the editorial staff of "Farm Implement News" and had also edited the "Tractor Field Book." As part of the July 1, 1956, changes, Basselman became editor and publisher.

\section{ena}

Interaction with other organizations became increasingly important during the decade. Some of it was negative. For example, ASAE received an invitation in June of 1949 to join a group headquartered in Zurich called CITA (Internation Confederation of Agricultural Engineers and Technicians). The Council asked Olney to check on this group and report back. $\mathrm{He}$ contacted C. H. Dencker, a respected German agricultural engineer and ASAE member. Dencker replied that CITA was a group of "graduated farmers" not interested in technical problems; the German Max Eyth Society 
was not a member. Instead, Dencker strongly urged that ASAE give full support to CIGR, the International Congress of Agricultural Engineers, which was definitely interested in technical problems of agriculture.

At the June 1951 meeting of American Society for Engineering Education a special agricultural engineering program was presented. Past-president Fred Wirt spoke on "The Role of Power Farming in National Defense." The dean of agriculture at Michigan State joined the dean of engineering at University of Nebraska in discussing "Objectives of Agricultural Engineering Curriculums." Other presentations concerned specifics of the college curriculums and the positions held by the graduates. The Journal editorialized on the broad-based teaching role Wirt played at the meeting and stated that:

"Defense requirements emphasize the importance of strong engineering leaders as well as sound technicians. Encouraging professional students to think in terms of the human environment and purposes, as well as the physical, to which agricultural engineering is applied, is a start toward the development of a new generation of leaders."

The following year another special conference on agricultural engineering highlighted the ASEE meeting. Two deans of engineering spoke on subjects related to agricultural engineering education; one of them was $L$. M. K. Boelter, University of California at Los Angeles, an ASAE member. E. G. McKibben presented a discussion of "Effects of Recent Research on Curriculum Requirements in Agricultural Engineering." McKibben had recently been named director of agricultural engineering research in the BPISAE at Beltsville, thus filling the vacancy left by Arthur Turner's death. Among items mentioned by McKibben as influencing curriculum requirements were: (1) use of new materials; (2) increasing importance of thermodynamic applications in agriculture; (3) greatly increased use of chemicals; (4) increasingly difficult instrumentation problems; (5) increasing importance of experimental design and statistical methods.

ASAE was elected to membership (associate level) in ASEE in 1954. The move was made on recomendation of the College Division and officers of ASEE's Agricultural Engineering Division. The membership helped to identify ASAE as an organization with a major interest in engineering education and gave the Society representation on the Engineering Colleges Research Council and the Engineering College Administrative Council.

ASAE had been an associate member of the American Association for the Advancement of Science for quite a few years. At the suggestion of the secretary of ASME and supported by the headquarters office of AAAS,

*Bureau of Plant Industry, Soils, and Agricultural Engineering. 
ASAE's Council voted at the December 1952 meeting to apply for transfer to affiliate status, which was a higher standing. The change would cost ASAE $\$ 50.00$ per year.

At Kansas City in June of 1952 Olney reported that the Council had authorized, on two previous occasions, the donation of $\$ 100$ per year to the National Council of State Boards of Engineering Examiners in appreciation of its efforts in working toward greater uniformity among the states in registration of engineers. The Council then voted to ask incoming President Ivan D. Wood to investigate the activities of NCSBEE, to attend its October meeting, and then to recommend whether to continue supporting it. The connection continued; T. E. Hienton attended the NCSBEE meeting during the 1955-56 Society year and recommended the affiliation be maintained.

In 1952 ASAE had representives working in cooperation with several organizations. These included: Engineers Council for Professional Development (ASAE was not a member then), National Fire Protection Association, National Fire Waste Council, American Society for Testing Materials, National Adequate Wiring Bureau, National Conference of Industrial Hydraulics, National Farm Electrification Conference, American Standards Association, National Joint Committee on Fertilizer Application, Joint Committee on Grassland Farming, and the Library Board of the Texas Natural Resources Foundation.

These cooperative activities promoted important mutual interests in several directions but (except for the ECPD interaction) did not necessarily raise ASAE's stature in the engineering community. Membership in ECPD would have helped but that was yet to come. The organization ASAE needed to enter was the Engineers Joint Council, which the founder societies had organized after World War II.

During the ASAE Council meeting in December 1953 Lanham was requested to contact EJC to determine what the requirements for affiliation

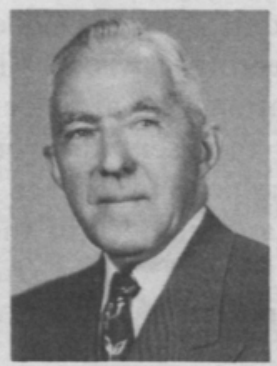

Ivan D. Wood 46th president, ASAE. 1952-53 
were. This request was later broadened to include investigation of other organizations involved in advancing the engineering profession.

Considerable time elapsed before action commenced. Vice-President Harold H. Beaty, who was with Edison Electric Institute in New York City, was asked to visit EJC headquarters there, attend meetings and find out what ASAE needed to do. In September 1954 he sent Lanham the EJC constitution, bylaws, and latest annual report. ASAE would be eligible for associate (not constituent) membership because it had less than 5000 members, not counting students. While the constitution stated that associate societies had no vote, Beaty suggested that proposed bylaw changes would permit them to vote. The wording of its constitution strongly suggested that EJC was organized to function strictly on behalf of the constituent societies. At that time these were the constituent societies (arranged in the order of their founding dates):

American Society of Civil Engineers

American Institute of Mining and Metallurgical Engineers

The American Society of Mechanical Engineers

American Water Works Association

American Institute of Electrical Engineers

The Society of Naval Architects and Marine Engineers

The American Society for Engineering Education

The American Society of Refrigerating Engineers

American Institute of Chemical Engineers

Only one associate society belonged to EJC at the time-The American Institute of Industrial Engineers.

Societies holding membership in EJC, whether constituent or associate, had two principal criteria to meet:

- The corporate or voting membership shall be confined to individual members.

- A majority of individual members shall be either engineering graduates of colleges of recognized standing or shall be licensed or registered by a state board of registration for professional engineers.

Because ASAE had only individual members that first criterion presented no problem. It had an appreciable number of members holding the grade of 'Affiliate'; these members could not be counted under the second criterion because by definition of the grade they were not engineers. However, the majority of ASAE members were qualified as engineers, which caused Beaty to optimistically view the prospects of being accepted by EJC. It was estimated that the cost to ASAE would amount to not less than $\$ 400$ per year.

Beaty's letter was discussed at the 1954 Winter Meeting by the Council. 
The uncertainties connected with the proposed changes in EJC's bylaws caused the Council to vote that Beaty and Lanham study the question further and report to the Council as soon as possible. Beaty was asked to attend the EJC General Assembly on January 211955 to learn more about the desirability of affiliation. Meanwhile, he commenced gathering information on agricultural engineering college enrollments, graduate placements, and similar statistics, with the aid of Ralph Palmer.

Lanham wrote the ASAE Council members on March 31 that affiliation with EJC was desirable "in the best interests of the Society."

Harold Beaty invited EJC Secretary E. Paul Lange to attend the 48th Annual ASAE Meeting at Urbana. Lanham confirmed the invitation on April 18 in the name of President Nutt. Lange was invited to appear before the ASAE Council and describe the activities of EJC. Lange promptly accepted and asked for ASAE's total dues income for the most recent fiscal year so that EJC's treasurer could calculate the cost of membership.

Lange duly appeared at the Council meeting (in fact, he stayed throughout the entire three days) and his efforts resulted in a vote that ASAE apply for "appropriate grade of membership in the Engineers Joint Council." The decision was communicated to Lange on September 7 by Ralph Palmer, now acting secretary, who requested "necessary forms and advice."

Secretary Lange sent Palmer a questionnaire prepared by the EJC Membership Committee which asked for the key information needed to determine ASAE's fitness to become a member. Lange wrote that the only difference between constituent and associate member societies (other factors being suitable) was the 5000 -member level. When an associate society's membership reached $\mathbf{5 0 0 0}$ it was subject to transfer to constituent grade.

Wasting no time, ASAE formally applied for membership in EJC on October 3, 1955. The required information was transmitted over the name of President Wayne H. Worthington. Two days later Palmer forwarded further details to Lange, including the fact that of 4660 ASAE members, 810 were non-voting affiliates. Another important point was that ASAE was exempt from income tax by the federal government, confirming that it was a learned or scientific association with objectives in harmony with the public welfare. Lange's acknowledgement stated that the application would be submitted to EJC's Board of Directors on January 25, 1956; if viewed favorably by the Board it would then go to each constituent society to be voted upon.

The EJC Board of Directors acted on ASAE's petition earlier than Lange indicated. On December 2 the Board voted to recommend favorable action to the constituent societies to admit ASAE as an associate member. This stimulated Palmer to ask Beaty, L. H. Skromme, and H. E. Besley to attend the EJC General Assembly in January as ASAE representatives; 
O. C. French joined them at the meeting. Beaty wrote Palmer on January 30,1956 , that apparently ASAE had been voted in and said that the question of accredited agricultural engineering curriculums had been raised.

Palmer then wrote Lange that ASAE listed 24 accredited curriculums, which he could verify by reference to the ECPD 1954 Annual Report.

Beaty notified Worthington on February 16 that Secretary Lange had informed him that ASAE would become affiliated with EJC at their next Executive Committee on February 24. Lange wanted ASAE to designate one observer and an alternate; these representatives should be officers or members of the Council. Worthington designated Beaty to be the observer and Jimmy Butt as the alternate. In his letter to Lange which gave him the names, Worthington said of ASAE's election to EJC: "We appreciate the obligations involved, and are resolved to continue to be worthy of the confidence accorded us."

Associate status did not carry with it a seat on the Board of Directors; the vote was restricted to constituent members. ASAE's observer was just that. ASAE advanced to constituent EJC membership in January 1961.

Admittance to EJC was a major step toward recognition as a distinct branch of engineering. EJC was the only unity organization of its kind (National Society of Professional Engineers had somewhat different goals and it did not take in member societies at that time). EJC was a forum where issues were discussed by the nation's leading engineers and where ASAE's leaders could absorb their opinions and profit thereby. The association with EJC could not fail to broaden ASAE's outlook and make the Society more aware of its place among similar societies. This development and the cooperation with ECPD that started the agricultural engineering curriculums toward accreditation were the two most important factors in gaining professional stature after World War II.

At the 1950 December Council meeting it was noted that ASAE had been invited to participate in the Centennial of Engineering celebration scheduled for 1952 in commemoration of the founding of ASCE, the first national engineering society. Participating societies would meet in Chicago for a two-day program devoted mainly to recounting the achievements of the various engineering branches. The invitation was accepted.

The Centennial adopted the slogan: "Human Well-Being Through Engineered Progress." Its chairman, Karl T. Compton of the Massachusetts Institute of Technology, said of that slogan:

"There is sureiy a close relationship between the work of engineers 
and the high standard of living ensuing from the high per capita production in the United States. Among our professions, that of engineering is outranked in numbers only by teaching and nursing. In no other country is this profession of such high standing. Furthermore, the demand for engineers continually exceeds the supply, and this is because our free-enterprise system gives limitless opportunity and very great incentive to make things new and to do things better."

Here was an era when all doubts concerning machines and their creators had vanished. That era commenced roughly when World War II started and it ran on without much of a hitch until 1962 when publication of Rachel Carson's "Silent Spring" created a nagging distrust of technology and business.

The 1952 Centennial was planned to assemble more than 40 technical societies in September. A "dynamic" exhibit at the Museum of Science and Industry was to remain in place for five years. Among other purposes, it was hoped that young men (no mention of young women) would be attracted to engineering. In 1954 some 17,000 engineering graduates were expected when 30,000 were critically needed.

The Secretary's Annual Report for 1951-52 gave much space to the Centennial as it applied to agricultural engineering, pointing out that "it is something of a paradox to think of the oldest and most basic of all industries as the last to give way to the engineering invasion." Olney went on to say that "the coming of the general-purpose farm tractor following the first world war was the first major contribution of engineering to agriculture, and gave our profession and our society its first real impulsion."

The ASAE contribution to the Centennial program was scheduled for September 8 and 9 at the LaSalle Hotel in Chicago. Each Technical Division was to present a one-half day session; a dinner program was also planned. Unfortunately the attendance was very small. A Journal editorial commented on the low attendance with an interesting statement: "The very absence of many engineers who might have attended was a tribute to the urgency of their current work, and their devotion to that work."

An exceptionally good set of papers resulted from the Centennial meeting. Six of them were published in the Journal. They were exceptional because of the stature of the authors and because they were broad-based and philosophical in viewpoint, tending to relate agricultural engineering technology to social and economic needs. They anticipated the quality and mood of the papers prepared for ASAE's Golden Anniversary meeting five years later. 
Most people expected economic depression would follow World War II. Instead, economic activity remained high and engineers were needed everywhere. It was both good and bad for ASAE's growth. From 1945 to 1950 ASAE more than doubled its membership, partly because agricultural engineers were returning to civil life from the armed services and partly because of growing appreciation of the importance of engineering in agriculture. By mid-1953, however, the growth rate had considerably slackened; fewer were being graduated and some graduates were accepting employment in other fields of engineering. Counting the number of members at any given time is difficult. However, without counting student members, the Annual Report of 1946-47 showed 2004; that of 1956-57 showed 4705. Thus the Fifth Decade produced a unique growth rate. Olney's last Annual Report as Secretary was for 1952-53. It must have given him much satisfaction to note that during his tenure the membership grew from less than $\mathbf{5 0 0}$ to more than 4000 . But the decreasing growth rate that commenced in 1953 gave rise to increasing concern.

The ASAE Student Branches were a principal source of members. After the war the number of branches increased and their membership reached an all-time high. But their admissions standards were somewhat loose. To correct this, the Committee on Student Branches recommended to the Council that beginning September 1, 1951, members admitted to authorized branches would be limited to undergraduate students enrolled in professional agricultural engineering curriculums; other students could be accepted only as "affiliates" without vote, without privilege to hold office, and without capacity to enroll as student members of ASAE. The proposal was submitted to agricultural engineering departments having authorized student branches for criticism and suggestions. The recommendations were adopted at the December 1950 Council meeting.

The 1951.52 Annual Report listed 41 student branches in the U.S. and four in Canada. But largely due to the change in admission standards the total branch membership had declined during that past year from 1520 to 1090. So ASAE's declining growth rate was partially created by itself.

For two or three years after the war the campuses were overrun by veterans supported by the "G.I. Bill." Still wearing fragments of uniforms embellished with famous insignia, they were mostly a hard-working (and harddrinking) lot who forced many a lazy prof to toe the mark. They gravitated strongly toward engineering, and agricultural engineering caught a share of them. At about the same time, larger-than-usual percentages of high school graduates enrolled as engineering freshmen. Consequently vocational guidance counselors by 1949 were advising high school seniors to avoid engineering. 
Yet the 50,000 engineers who graduated in 1950 were quickly absorbed and more were sought. Based on the 1950 enrollment forecast it looked like only 12,000 engineers would be graduated in 1954 . This was a serious shortfall from the 30,000 considered necessary each year to maintain the U.S. economy at its normal tempo, to say nothing of the demand about to be created by the Korean crisis. Excellent opportunities abounded for engineers after mid-1950, including agricultural engineers. The problem was to get young people into the colleges.

For about the first time ASAE leaders began to devote truly serious thinking to the problem of recruitment. The problem had confronted college leaders for many years but now it was a genuine national problem as well. There was much talk but not much action. Why, for example, did young people avoid engineering? Was it too difficult a study? But perhaps that was an advantage. As a Journal editorial put it:

"During 1952 a great deal will undoubtedly be done to interest high school seniors in preparing for careers in engineering and in the other sciences and professions.

"In this competition for brain power, there may be some temptation to paint too rosy a picture of engineering.

"The best way to attract prospective engineers may be to present engineering as a challenge; a life of measuring up to high demands; a man's work from the first day of freshman classes.

"Drawing its recruits mostly from farm boys who have learned early the meaning and satisfactions of a man's work, agricultural engineering should readily attract its share of the potential engineering material graduating from our high schools."

There was another aspect to the high school situation. All were agreed that some way ought to be found whereby parents, high school teachers, counselors, and students could be informed early of the demand for engineers and of the high school studies appropriate for potential engineering students. But as a 1953 Journal editorial admitted: “ . . . the precise role to be played by ... a professional engineering society in this long-range recruitment program has not, as yet, been made clear."

The June 1953 Council meeting minutes reflect the beginning of a concrete attempt to "sell" agricultural engineering. President Ivan D. Wood stated his view that the Society should develop a project resulting in a motion picture "to publicize the agricultural engineering profession." In the discussion it was brought out that the Committee on Public Relations was investigating the possibilities of such a project. It was agreed that the incoming president, E. W. Tanquary, would give the matter his special attention. 
A report was given to the Cabinet at the December 1954 meeting on this motion picture project. Past-president Tanquary was in Europe at the time, but a project had been set up. The 1954-55 Annual Report stated that:

"Problems incident to student recruitment will be solved not by defeatist attitudes but through hard work, sound factual approaches, and in general by a program having greater appeal than those presented by professions and vocations with which agricultural engineering is in competition for prospective students. The present motion picture program is a splendid example of effort properly directed to achieve this goal."

Tanquary reviewed the progress of the Motion Picture Operating Committee at the 1955 June meeting of the Council. A proposed story treatment had been developed by the producer (MPO Productions of New York City) and a plan developed for financing the project. The Council voted that the Committee be encouraged and commended with assurance of continued Council support. By December Tanquary wanted to publicize the project and invite contributions from the members; the principal problem was now money. The story treatment had been purchased by ASAE but production would not begin until funds were available.

At the 1956 Cabinet meeting in Roanoke, Tanquary reported that the Motion Picture Committee had been reorganized into a visual aids committee and three new subcommittees: operating, finance, and shooting. The project was later discussed at the December Council meeting. Jimmy Butt said the committee thought it could produce the picture for $\$ 10,000$ to $\$ 12,000$. It was agreed that the $\$ 3000$ already obligated by ASAE for the story treatment should not be refunded to the Society from money contributed for the motion picture. The Council also witnessed a special showing of films from other professions as background for the ASAE project.

At East Lansing during the 1957 Annual Meeting the Council again considered the motion picture. Lloyd Hurlbut stated that it would cost about $\$ 1000$ per minute of running time and that the USDA motion picture unit had been contacted for possible assistance. Later he reported that the committee favored a 131/2-minute movie; that the Divisions had representatives on the committee; and that the USDA film facilities might become available to ASAE.

The story of the motion picture stretched on into the Sixth Decade. Considerable difficulty attended the efforts to raise funds. Its format, even its name, underwent changes. It was impossible to include references to all technical activities of agricultural engineers. It was finally finished in 1960 under the title "Agricultural Engineering Profession with a Future." The premiere showing took place at the June 1960 Annual Meeting at Columbus, 
Ohio. Records indicate that 141 prints were produced and circulated. About 30,000 flyers describing the film and 50,000 folders describing agricultural engineering were distributed in connection with the film showings. The film won first place in the "Guidance Personal and Vocational" category at the Third American Film Festival of the Educational Film Library Association. For a time the story of agricultural engineering was indeed publicized as Ivan Wood desired. But there is no evidence in the ASAE archives to suggest that student enrollments were definitely affected by this supreme effort.

It is possible that ASAE, and probably many other engineering societies, were blinded by the unusual enrollment of veterans following World War II and expected to see those levels return to establish a new "normal" level in response to recruiting and heavy demand. If so, they were mistaken because the GI pool would not again become available without a repetition of the events that created it. A factual analysis of the problem was made by S. C. Hollister, dean of engineering at Cornell University. Hollister claimed in 1953 that the U.S. had already reached the limit of potential engineering manpower.

His figures were based on the Army General Classification Score records from the war, which provided the largest sample of U.S. population ever subjected to any single test. He estimated that of the $1,100,100$ males who reached age 18 each year, 17 percent would be above the intellectual level of 120 on the Army GCT score, which he considered the minimum requirement for engineering. Therefore, the annual basic pool was 187,000 prospects.

Of the basic pool, most would be attracted elsewhere, leaving the national engineering freshman class each year at a practical total of 44,000 young men. Only about half of these could be expected to graduate, or 22,000 per year, which was less than 12 percent of the maximum intellectual potential. But the national demand was for at least 30,000 per year and the 1953 backlog shortage amounted to 50,000 .

This dismal picture was a stimulus to the societies and the universities to recruit. They needed to work hard to keep their share of the basic pool. Also, the universities had to do some hard thinking about that 50 percent loss between enrollment as freshmen and graduation. And finally, industry and government needed to examine their usage of engineers to determine whether technicians could do some measure of the work classified as engineering.

This fact emerged from Hollister's analysis, assuming its validity: the days of graduating 50,000 engineers per year, as in 1950, would not return for a very long time. Without the GI's the potential simply wasn't there.

It is interesting to re-examine the problems of low enrollments. Some of 
the academic trouble was caused by the veterans. The agricultural engineering departments had expanded to take care of them but were overextended and in trouble when they were gone. It never occurred to anyone during the decade (based on the national ASAE publications and records) that young women might play a role in agricultural engineering. Many academic members expected ASAE to carry the entire burden of recruiting, but that was impractical and unrealistic. Some believed that the phenomenal ASAE growth rate of the seven years following the war ought to continue indefinitely; these persons tended to panic when a degree of "normality" returned, thinking that agricultural engineering was a dying profession.

ASAE did its best. It was found, for example, that only 50 percent of the students affiliated with ASAE upon graduation; therefore, an automatic, least-cost affiliation scheme was instituted. The universities were given all possible recruitment assistance. The ASAE Sections also began working on career guidance, with much aid from Headquarters. The College Division was the focus of a major share of this activity.

It was a golden age in many ways. With technology enthroned, with starting salaries high, with opportunities on every side, it was good to be a young agricultural engineer then. But the shortage had its painful aspects too. As George B. Nutt said in his 1955 presidential address:

"In the sense that scarcity of men has raised salaries, the present situation is healthy. But when all factors are considered the situation is not desirable. As an example, agronomists and civil engineers are being given assignments in the Soil Conservation Service which should logically be filled by agricultural engineers. Vocational-agriculture majors are being classified erroneously as farm machinery specialists by the Civil Service Administration in order to fill Point 4 positions which should be filled by agricultural engineers. Industry cannot wait for a new graduating class if their requirements are not met in a given year. They look to other professional groups. Most of our college departments are looking for men to teach, conduct research, or do extension work. They even find it necessary occasionally to seek men from other fields and often to their regret."

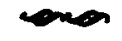

The last gasp of ASAE's attempts to restore the Bureau of Agricultural Engineering in the USDA occurred during this decade.

Chaired by R. H. Driftmier, ASAE had a Committee on Federal Relations in 1948 which was organized to function in an advisory capacity to the Divisions of Agricultural Engineering, BPISAE; the Research Division, 
SCS; Extension Service, USDA; and the Technical Standards Division, REA. Following conferences in November 1948 with the agencies concerned, it was reported that:

"a. The Committee feels that the best interests of engineering in agriculture will be served by the re-establishment of a Bureau of Agricultural Engineering. Such a Bureau should include all engineering research activities related to agriculture that are now being conducted under the direction of various federal agencies.

"b. Since the Department of Agriculture at times has stated that 85 percent of all agricultural research has engineering implications, the Committee feels that there should be an Agricultural Engineering Coordinator in the Agricultural Research Administration."

There was much more to the committee report, but those were the key items involving high policy and agricultural engineering.

A group of ASAE past-presidents and heads of agricultural engineering departments got together at the 1948 Winter Meeting and voted to endorse the proposal for re-establishment of the BAE and requested the Council to "take whatever steps are deemed appropriate toward realization of this objective."

The Council was informed of the action of the self-appointed group. It voted to request President A. J. Schwantes that "on his trip to Washington in the spring, he investigate the situation relative to the establishment of the bureau and consult with key individuals in the USDA, and also with the chairmen of the agricultural committees of the Senate and House of Representatives, to determine the most feasible course of procedure in further implementing the increased service of agricultural engineering in the USDA, and report back to the Council."

Presumably Schwantes made it to Washington but his visit was not given any publicity. His successor as president, Frank J. Zink, was passionately convinced that the BAE should be restored.

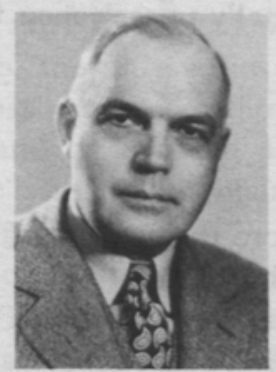

Arthur J. Schwantes 42nd president, ASAE, 1948-49

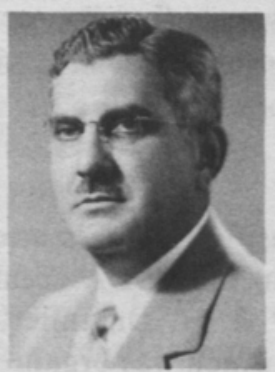

Frank J. Zink 43rd president, ASAE, 1949-50 
Zink called for re-establishment of the BAE in his presidential addresses. His appeal was based on a resolution passed by ASAE at the 1949 Annual Meeting; he was not acting on behalf of a few zealots. In the June 1950 Journal he published a three-column message entitled "Administrative Status of Agricultural Engineering in the USDA" in which he reviewed the background and present status of the problem.

Zink argued that in 1943 when the remnants of the BAE were placed in the Bureau of Plant Industry and Soils, it was done with the promise that engineering research would be re-established as a separate bureau. Furthermore, no objections to such a bureau were offered by the Hoover Commission task force that prepared a suggested re-organization outline for the Agricultural Research Administration following the war. Zink ended his message thus:

"The re-establishment of a Bureau of Agricultural Engineering is being urged by ASAE, not for the personal benefit of any individual, but because it means more efficient operation of a government agency, and because it is essential if our profession is to receive recognition as a major cooperator in agricultural technology and is to be placed where it can develop its full potential."

The Divisions of Agricultural Engineering were headquartered at Beltsville, a few miles north of Washington. Administered by A. W. Turner since 1944, research was conducted in four major branches of agricultural engineering, usually at field locations in cooperation with the state experiment stations. These were the technical branches:

Division of Farm Buildings and Rural Housing, headed by Wallace Ashby.

Division of Farm Machinery, headed by Roy B. Gray.

Division of Farm Electrification, headed by Dr. Truman E. Hienton.

Division of Mechanical Processing of Farm Products, headed by George R. Boyd.

Turner's title was assistant chief and director of engineering research of the BPISAE; the Bureau chief was Dr. R. M. Salter, an ASAE member, who succeeded Bennett as head of SCS in late 1951. In 1937 the BAE soil and water engineers had been transferred to the then-new SCS, which explains why Turner's group had no Division of Soil and Water.

Turner's untimely death came on November 17, 1951. Dr. E. G. McKibben, who had been in charge of the USDA Tillage Machinery Laboratory, was named to the position several months later by Dr. A. H. Moseman, the new chief of the Bureau.

In the fall of 1952 the Secretary of Agriculture placed responsibility for all research in water management related to crop production in the ARA. This caused such research being conducted by the SCS (which was outside 
the ARA) to be transferred to the BPISAE. This occasioned some alarm in ASAE. Soothing statements were issued by both Salter and Moseman early in 1953. However all the alarm and all the yearning for bureau status were about to be finally put to rest.

Within about 18 months USDA was reorganized. McKibben outlined the place of agricultural engineering in the new setup at a North Atlantic Section meeting on August 24, 1954. He pointed out that no one criterion, such as a scientific discipline, could be used to organize agricultural programs. The organization employed three criteria: scientific disciplines, commodities (such as wheat or corn), and functions (such as production, marketing, utilization).

Agricultural engineers appeared under two large administrative areas, the Agricultural Research Service (ARS) and the Agricultural Marketing Service (AMS). Within ARS agricultural engineers were in two Branches: the Soil and Water Conservation Branch and the Agricultural Engineering Research Branch. The further breakdown of the Branches indicated that AERB was essentially the former Division of Agricultural Engineering of the BPISAE. Within AMS agricultural engineers appeared in the Marketing Research Division, the Biological Sciences Branch, and the Transportation and Facilities Branch. Thus, they were pretty well scattered throughout USDA at points where their skills were needed ("carriers of water and hewers of wood" as one disgruntled USDA agricultural engineer put it).

ASAE was extremely disappointed at this development because it reduced the engineers to a service level and diminished the likelihood that scientific research in the discipline would be maintained. George Nutt devoted over half of his presidential address to a history of agricultural engineering in USDA and a commentary on the latest re-organization, which he characterized as "little short of disastrous" and an act of "political expediency." He hinted that there were "obviously forces responsible for the disintegration of agricultural engineering in the USDA" but did not identify them; they would, he believed, also affect ASAE and the college departments adversely.

Nutt's presidential blast deploring USDA's treatment of agricultural engineers was the best of them all; it was also the last. Lacking in numbers and political inflyence, ASAE had to accept reality and live with it as gracefully as possible.

ASAE came up with a rather graceful gesture about two years later. On May 28, 1957, Secretary of Agriculture Ezra Taft Benson, the man who had presided over the USDA re-organization, was made an Honorary Member of ASAE. This was part of ASAE's Golden Anniversary special activity (President Dwight Eisenhower was also made an Honorary Member). After Nutt's condemnation of USDA, it had a definite flavor of reconciliation. 


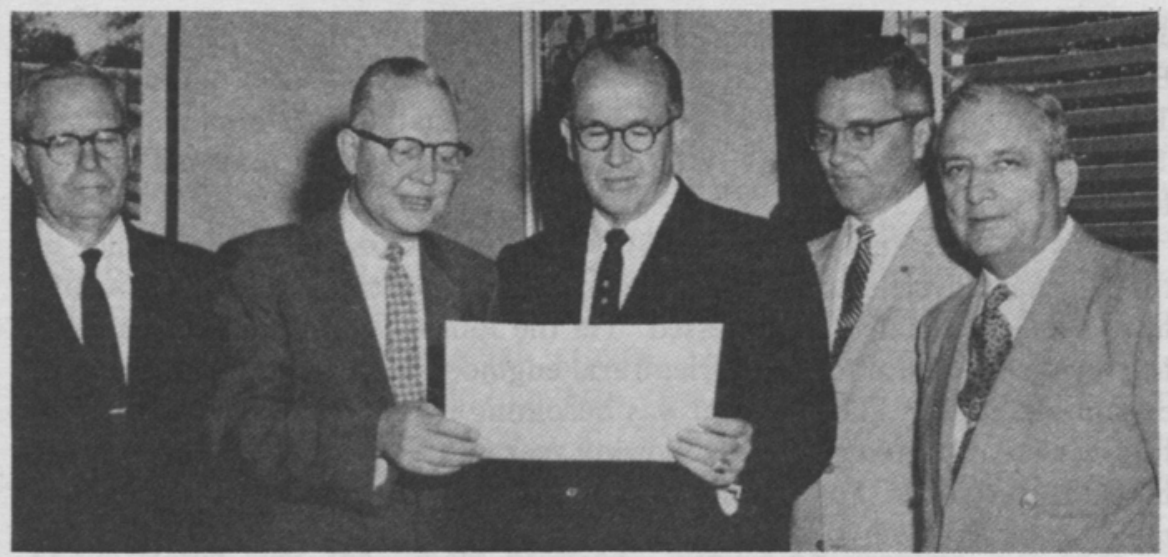

ASAE members welcomed Ezra Taft Benson, Secretary of Agriculture, to honorary membership in the Society. (Left to right) Wallace Ashby, head, farm buildings section, AERD, ARS, USDA; President-Elect Earl D. Anderson, director, agricultural extension, Stran-Steel Corp.; Secretary Benson; J. L. Butt, secretary of ASAE; E. G. McKibben, director of Agricultural Engineering Research Division, USDA

Benson's statement of thanks to ASAE was strongly in praise of agricultural engineering (Eisenhower's was merely a formal acknowledgement) and its great contributions; Benson concluded: "I shall cherish this membership in your Society and I pray God's blessing upon you and your work."

The importance of other activities may at times be debated but the publications of a technical society are at the heart of its services to the members and the public. ASAE served the public perhaps more than the members realized. Late in 1947, for example, the final printing of ASAE Bulletin No. 44 was contracted for in advance by major farm equipment manufacturers for distribution to their dealers and field sales organizations. Printed in three editions, 250,000 copies were issued. The Bulletin contained lists of equipment necessary to convert the various makes and models of tractors (both equipped and unequipped with power take-off) to ASAE standard dimensions for power take-off shaft, master shield, and drawbar hitch point. At about the same time, the circulation of AGRICULTURAL ENGINEERING was more than 2200 to members and 2200 to non-member subscribers.

After many years of argument and indecision ASAE finally issued what was hoped to be the first installment of a loose-leaf Agricultural Engineering Data Book. Titled "Engineering Data on Grain Storage” it was a 12-page, 
well-printed job optimistically subtitled A-E Data 1 . It was compiled by Benton M. Stahl of BPISAE and sponsored by an ASAE Committee on Technical Data chaired by W. V. Hukill. A-E Data No. 2 appeared later. These were intended to pave the way for a handbook, but that was quite a few years ahead.

In his Annual Report for 1950-51, Olney emphasized the importance of the Journal advertising as a source of revenue; without it, ASAE would have been financially hard-pressed. Yet the Journal was founded primarily to provide a medium for the agricultural engineering literature, and this was expanding rapidly. The Journal was becoming inadequate to provide space for the available material. The following year Olney raised the point again in his Annual Report. The volume of papers submitted for publication was too great to print them all. He hoped that program chairmen would offer guidance-the selection problem was more than his office could handle. He said:

"A theoretically easy and logical solution ... is a committee or picked group of specialists to be responsible for saying what papers and articles should and should not be published, but practically it has serious weaknesses. The most serious is that authors of papers are more often than not apt to be exceedingly particular in the matter of persons selected to pass judgment on their papers. The whole problem merits the most earnest consideration of the members."

The Society year 1952-53 was another record year for Journal advertising. The success of the Journal as an advertising medium was partly due to a promotion scheme which had been in use since the 1920s. This was the "Agricultural Engineering Bulletin," a mimeographed form mailed each month to over 800 persons influential in advertising. The "Bulletin" featured a review or commentary on an article in the current issue of AGRICULTURAL ENGINEERING; that article dramatized agricultural engineers and their influence on purchase of engineered products used in agriculture. The reviews were prepared by $W$. B. Jones at the Western Advertising Agency, whose president was ASAE member G. B. Gunlogson.

A publications landmark occurred in 1954 when the First Edition of the Agricultural Engineers Yearbook was issued. Partially financed by the advertising, the Yearbook, to be published annually, contained these features:

The roster of ASAE Officers, Council, Divisions, Sections and Committees The ASAE Constitution, By-Laws and Rules

ASAE-Approved Standards, Recommendations, Data and Codes

A Directory of Suppliers to Agricultural Engineers

The members received this valuable book each year, with the price included in the annual membership dues. 
Olney returned to the problem of selecting papers in his 1953-54 Publisher's Report. In his view, the professional divisions should serve as advisors to the editor on the suitability for publication of papers presented at the meetings. Each division could select a volunteer group of "recognized authorities" in their technical area to act as consultants in considering the merits of papers. Such a plan should be extended to the ASAE section meeting papers. Another problem was mentioned by him for the first time. Some papers were becoming quite technical, with interest in them limited to relatively small groups. Olney preferred to use AGRICULTURAL ENGINEERING for articles of less technical nature, of more general interest. He suggested that ASAE consider the usage of the "older engineering societies" who publish the more technical papers in a "transactions" type of publication, usually issued annually. However, Olney stated that the "most pressing" publishing problem was that of obtaining critical readership responsibility among the membership in order to maintain (and increase) the quality of the technology embodied in the Journal papers.

Convinced that ASAE needed more revenue, at the 1954 Winter Meeting Olney proposed that the dues be raised three dollars in each age bracket and that the Journal advertising rates be increased 18 percent. The advertising rate increase was accepted, but the Council was reluctant to increase membership dues. Then R. K. Frevert of Iowa State College moved that Secretary Lanham investigate charges made by journals comparable to AGRICULTURAL ENGINEERING for publishing technical articles and report his findings to the Council. The motion was amended to authorize a tentative schedule of charges for publishing technical papers based on that survey; the motion was passed unanimously. (Oddly, the same motion was made by L. H. Skromme at the 1955 Annual Meeting and passed also.) This was the beginning of the "page charge."

Acting Secretary Ralph Palmer reported to the Council on November 10 1955 on practices of other organizations in assessing page charges. Palmer found that of 14 replies, eight had no direct charge whatsoever. The other six charged authors in one way or another to try to recover costs of publication and reprints. No conclusions were drawn, but Palmer suggested that Olney prepare a proposal on charges.

An innovation appeared in the July 1956 Journal; it was a collection of 250-word technical paper abstracts. These were synopses of papers given at the Annual Meeting. Authors were to submit abstracts voluntarily for any papers they presented. Publication of an abstract did not affect possibility of subsequent use of the full manuscript in the Journal.

During October 1956 Henry Dreyfuss, the industrial designer, met with 
the ASAE Headquarters staff to review the Journal from cover to cover. Dreyfuss, a member of ASAE, was experienced in designing everything from farm tractors to ocean liners. His suggestions resulted in a new cover, a "Report to Readers," business-reply mailing cards, and a number of other significant improvements; these changes took place with publication of the January 1957 issue.

At the same time a system of "critical readers" to evaluate papers before publication was announced. Each ASAE division was asked to compile a long enough list of readers to permit at least two for each paper submitted. Authors were asked to submit papers in triplicate to the editor, who would select two or three readers from the appropriate subjectmatter list. Papers were sent to the critics for recommendations on their suitability for publication. A format was prepared for the critics to follow in their reviews. The critical readers were supposed to remain anonymous. Rejected papers could be abstracted in the Journal and mimeographed copies made available if the author so desired.

This system was a good move. A certain number of bad papers were being published; the critical readers tended to lower that number or at least cause some of their major faults to be corrected. It helped the college people because many disciplines held that publication in "non-refereed" journals was tantamount to no publication at all. The agricultural engineers were now publishing in a "refereed" journal.

But the problem of technical paper volume was acute by June of 1957 . President Bainer termed it the most pressing problem of the time. No matter how critical the readers were (not really severe) they could not stem the tide of papers that deserved publication and AGRICULTURAL ENGINEERING couldn't hold them all. Something had to be done. Consequently, the name "Transactions" was revived as the principal repository for ASAE technical literature. Volume 1, Number 1 of the new "Transactions," containing no advertising, was put in the mail in December 1958. This one issue was free to all members, but henceforth it was only to be sold.

The ASAE Technical Divisions had expanded considerably since their formation in the 1920s; they still functioned fairly comfortably as technical homes for the "classical" subdivisions of agricultural engineering. However some technical activities seemed to evade neat classification under one division. Hay drying was an example; Rural Electric, Farm Structures, and probably Power and Machinery Divisions could all claim a degree of interest in hay drying. This kind of activity in agriculture was called 
"processing" because it maintained or raised the quality of a farm product.

Processing could include cleaning and grading, freezing, canning and packing, or grinding and mixing. It need not be confined to the farm; its engineering unit operations often were integrated in a local plant or factory.

Early ASAE interest in processing centered partly on the dairy industry; in 1927 a Committee on Dairy Engineering was set up under the chairmanship of A. W. Farrall. Research results useful to dairy engineering were published in the Journal and the Committee promoted meetings and conferences. Those activities stimulated the suggestion from Olney that processing deserved to become a regular part of agricultural engineering. This was slow to come, partly because of the Depression and World War II and partly because processing advocates seemed to want to "leave the farm," an idea not universally accepted.

By 1949 a Committee on Agricultural Processing had been formed, with S. M. Henderson (University of California) as chairman. While the value of processing was recognized, its place in agricultural engineering was still under exploration. A 1949 editorial said "The full extent to which agricultural engineers might be helpful in farm processing progress remains to be outlined" and "some agricultural engineers may profitably be employed to study the technology and production economics of processing both on farms and in large-scale industries ...."

Actually, Henderson did not wish for processing to stray too far from the farm gate. On behalf of the Committee he wrote in 1950, in the Journal, that agricultural processing included "any processing which is or can be done on the farm or by local enterprises in which the farmer has an active interest."

W. M. Hurst was a member of the division of mechanical processing of farm products in BPISAE when he published a strong paper on "Industrial Applications of Agricultural Engineering" in the 1950 Journal. The paper was an admirable review of the total processing spectrum in agriculture and the need for research and application by agricultural engineering. Hurst called for an ASAE technical division devoted to processing, just as many college departments had sections for processing.

Hurst's paper drew an approving editorial which, however, felt constrained to say:

"Over a period of some twenty years or more, increasing numbers of agricultural engineers have come to recognize farm processing as a legitimate field of agricultural-engineering interest. A few have been directly employed in processing or in related research, and have become intensely interested in it. Most have been too preoccupied with immedi- 
ate duties and responsibilities in other fields of agricultural-engineering activity to give more than passing notice to processing."

Perhaps that was why ASAE did not rush forward with a new technical division. Although processing was receiving some favorable notice, its progress seemed slow. An August 1952 editorial commented on the reasons:

"The lag in farm processing is not due to a lack of incentive. It is not due to a lack of men with the spirit of free enterprise. It is not due to a lack of men with the required technical ability. It seems likely that it is due to a lack of well-defined starting points for the initiation of specific new enterprises or equipping farms for additional operations. If agricultural engineers can clarify some of those starting points, they will be rendering a major engineering service to agriculture."

Another point in favor of recognizing processing as part of agricultural engineering was the potential economic advantage. Prices paid to farmers for raw materials tended to fluctuate widely, while processing and marketing costs were relatively stable. Moreover, the proportion of total retail price received by the farmer for raw materials was usually quite small. Therefore it was argued that processing and marketing of raw products on the farm should be promoted as beneficial to the economic welfare of farmers.

A certain amount of instruction in processing was being given in the colleges. The instructors were aided by publication in 1955 of a professionallevel textbook in the Ferguson Foundation series* entitled "Agricultural Process Engineering" by S. M. Henderson and R. L. Perry.

Carl W. Hall and Jordan H. Levin gave a paper at the 1956 Annual Meeting on "Agricultural Product Preparation," a term they preferred to processing. New technological developments were discussed which ASAE should recognize "officially" in conduct of its meetings and alignment of its objectives. In summary, they said that "The Society should keep up with the changing times..."

Reaction of a kind occurred six months later at the December Council meeting. R. R. Mauney, chairman of the Rural Electric Division and its Steering Committee, presented a proposal that the Division name be changed to "Electric Power and Processing Division." He cited reasons for the change, including (1) increased interest within the Division in technical problems of farm electric power applications; (2) the increasing

\footnotetext{
*Harold E. Pinches, when employed by Harry Ferguson, Inc., stimulated the financing and production of the series; the publisher was John Wiley and Sons. Six books were published, first of which was "Farm Structures" by H. J. Barre and L. L. Sammet, 1950. The Foundation was dissolved in 1955: residual funds were donated to ASAE to be used for tinancing seminars for young agricultural engineering teachers.
} 
importance of farm product processing as a field of service for agricultural engineers; (3) the increasing extent to which electric power is a primary factor in processing operations; and (4) a belief that the members and potential members interested in processing will have a stronger community of interest with members engaged in rural electrification than with any other technical division of the Society.

Hall, of Michigan State College and chairman of the Committee on Agricultural Processing, was present. He supported Mauney's views and stated that the processing men would feel most at home in association with the rural electrification people. Evidently the Committee was willing to settle for the name "Processing" rather than "Product Preparation" and also for half a division, so to speak. As to the name, Mauney indicated that "more than a dozen" possibilities had been discussed but none was as satisfactory as the one proposed. The Council then voted the EPP Division into existence.

To the uninitiated the ASAE divisional nomenclature is probably baffling. For example, the Soil and Water Division is supposed to be concerned with soil and water. However, the Power and Machinery Division is vitally interested in soil also and in, for example, pumping water if it is pumped nonelectrically. If the water is moved electrically then Electric Power and Processing is in the picture. If the water is to be used in houses and farmsteads the Farm Structures Division has some kind of jurisdiction, and if water-carried waste disposal is a consideration, then one is returned to properties and characteristics of soil. Such overlapping scientific and technological interests have led to inter-divisional meetings, cooperation, and joint committees, which tend to keep the members acquainted with each others' problems. Whether a thoroughly rational divisional reorganization might be possible is an open question; it could perhaps cause more harm than good by disrupting the traditional areas of responsibility, not only in ASAE but in the colleges, where a system similar to ASAE's has governed the activities of the agricultural engineering departments for many years. Perhaps for this reason no serious attempt to rationalize the technical Divisions' names and spheres of interest has ever been made. On the other hand, rationalization itself may be impossible.

The Nominating Committee chose as 50th ASAE president Roy Bainer, chairman of the Department of Agricultural Engineering at University of California at Davis and assistant dean of engineering of all branches of the University. The choice was particularly appropriate because Bainer's father was ASAE Charter Member Harry M. Bainer. 


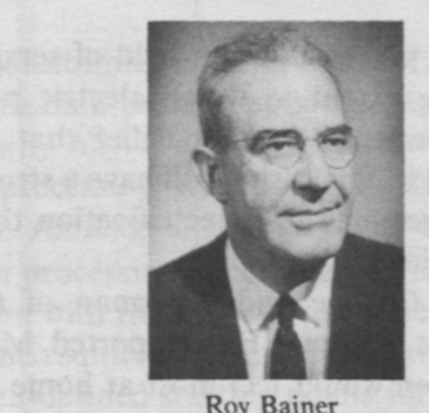

50th president, ASAE, 1956-57

Roy Bainer was an outstanding ASAE member. His work with rice, beans, and sugar beets gained world-wide attention and led to the Cyrus Hall McCormick Medal in 1948. Later honors included the University of Missouri Honor Award for Distinguished Service in Engineering (J. B. Davidson and L. J. Fletcher also received that award), the Vincent Bendix Medal of ASEE, and election to the National Academy of Engineering. An affable, outgoing personality made his public contacts as ASAE president reflect favorably upon the agricultural engineers.

The Council had earlier accepted an invitation to hold the Golden Anniversary meeting at East Lansing on the campus of Michigan State University (changed recently from College). At their June 1956 meeting, Dr. A. W. Farrall (head of the Agricultural Engineering Department) appeared on behalf of the University and the Michigan Section to discuss the plans of the local committee. Farrall wanted ASAE to use the Anniversary as an opportunity to obtain "extra recognition" throughout the nation, and outlined a program which would promote it. The Council then voted that the Golden Anniversary year was to be the calendar year 1957.

This information was conveyed to the membership via newsletter (these had been revived by Jimmy Butt) in July with many suggestions for special publicity plus the reminder that ASAE needed 5000 members to become a constituent member of EJC. The figure on June 1, 1956, was 4706; as Butt said, it was "frustratingly" close. A membership drive was launched in connection with the Golden Anniversary Year. Some members worked harder than others; Chairman Robert Alpers of the Michigan Section obtained 22 new membership applications in about two months, claiming that his group would surpass Iowa and California in ASAE members by June of 1957 .

Industries allied with agricultural engineering were planning to honor ASAE's 50th year in advertisements and mailings. A special Golden Anniversary Seal was under development and some corporations intended to use 

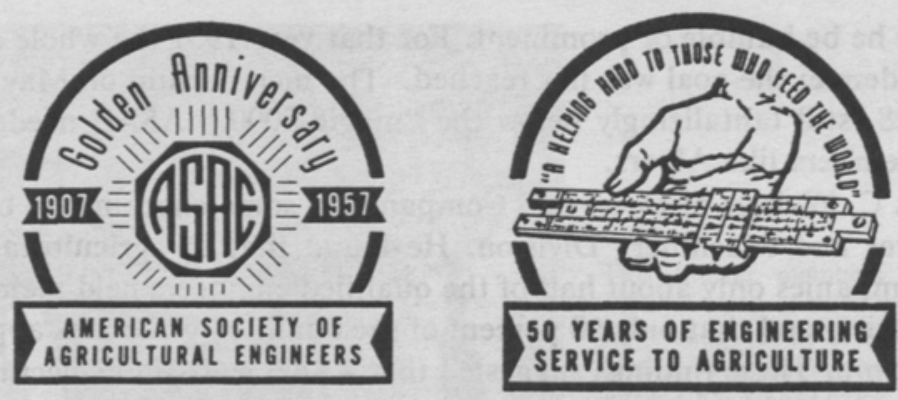

it on their letterheads. The Seal design was considered by the Council in December. It was decided to adopt a design based on the one submitted by the Michigan Section.

The Council also voted to request that a commemorative postage stamp be issued. Thus President Bainer wrote Senator William F. Knowland to ask him to support ASAE's request to the Postmaster General. Soon Bainer received word that the Postmaster General had 2600 such requests but normally issued only 12 to 15 commemorative stamps each year; with regret, ASAE could not be accommodated.

When Bainer became president he coined the slogan "50 hundred members in our 50th year." This goal was felt to be within reach during 1957. A squib in the January Journal analyzed the membership picture and predicted success by June. Tom Swearingen of the Masonite Corporation, who headed the Public Relations Committee, wanted to identify the 5000 th member when he came along and make much publicity of it. In fact, he wanted to assure that the 5000th member would provide maximum publicity value identifying the right kind of man, even if he wasn't quite No. 5000 . Secretary Benson would have been a good candidate but this idea was vetoed because Benson was not an engineer and might object to being fussed over as ASAE's 5000th member. By February it began to appear that the 5000 -member goal would not be reached by June; also, Swearingen's itch to juggle the numbers for better publicity made Bainer nervous. His counsel was to assign number 5000 to whomever turned up with that number,

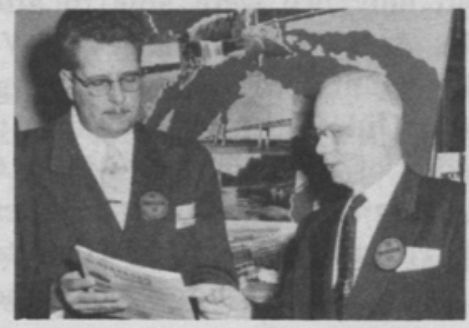

Robert Alpers, (left) chairman of Michigan Section, and A. W. Farrall. chairman of local arrangements group for the ASAE Golden Anniversary Meeting at Michigan State in 1957. posed before a display at 1956 Winter Meeting which invited all to "Come to Michigan in ' 57 "' 
whether he be humble or prominent. For that year 1957 the whole question was academic; the goal was not reached. The membership on May 1, 1958, was 4928, still tantalizingly below the "magic 5000." ASAE needed a few more members like Alpers.

Frank C. Walters of Deere and Company did some checking on behalf of the Power and Machinery Division. He found that in agricultural equipment companies only about half of the qualified engineers held membership in the Society and that only 60 percent of the qualified graduates applied for membership. These findings suggested that ASAE was still neglecting some prime sources of new members.

Early in 1957 the Golden Anniversary Seals became available. Academic departments and industrial concerns bought them and used them widely. Postage meter slugs were sold also, with a choice of two messages. A sevenpage basic news story was made available on request for use in local newspaper publicity; members could subtract or add to the basic story as appropriate to the local situation.

Farrall's group at East Lansing prepared for a banner turnout at that Annual Meeting. "Looking to the Future" was the slogan for the Golden Anniversary meeting. Outstanding speakers were lined up; the annual dinner promised to be a wondrous affair.

Farrall stimulated a survey of chief engineers in industry and heads of college agricultural engineering departments on the question: what was the most important professional development of ASAE's first $\mathbf{5 0}$ years? The answer: development and accrediting of the professional curriculum. The same group of engineers was also asked: what was the most important technical development? The consensus was: the development of the generalpurpose tractor (which agreed with Olney's judgment quoted earlier).

In the midst of these joyful preparations and anticipations, on May 8, 1957 J. Brownlee Davidson died in Denver, Colorado. All men must die but it was a pity that Davidson could not have been spared to attend the 50th annual meeting of "his" Society. The Council authorized a resolution of regret which was read at the annual business meeting in June by VicePresident Henry J. Barre. The old guard was now diminishing rapidly; a few charter members were left but only two were able to attend the Golden Anniversary meeting: Charles A. Ocock and Howard W. Riley. E. W. Hamilton (probably the Canadian Hamilton) wrote a touching tribute to Davidson which was published in the July Journal. He told of the time in 1911 when Davidson was chief judge of the Winnipeg Motor Contest. After analyzing the results and announcing them, Davidson discovered that he had made a decimal error. Highly chagrined, he asked Hamilton what he should do. Hamilton advised him to do as court judges do: stand on his 


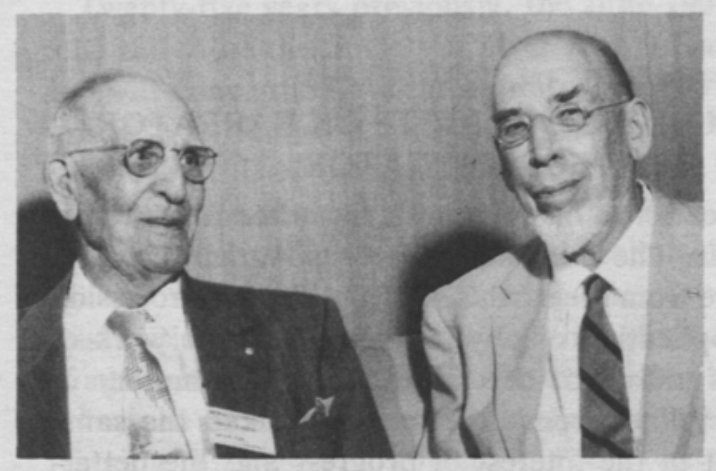

Two charter members of ASAE were on hand at the 50th Anniversary banquet held at Michigan State University in June 1957. At left is Charles A. Ocock. At right is Howard W. Riley who gave a brief report on the Society 50 years prior

decision and say nothing. Davidson was in agony, but evidently he took Hamilton's advice.

The meeting, aside from regret at Davidson's passing, was quite a success. Attendance was a record, with 1527 registered. President Roy Bainer's address was a good accounting of the "state of the union."

Production per farm worker had about doubled in the past 15 years, Bainer commented; one agricultural worker was producing food for 19 others. With 5 million tractors and farms 95 percent electrified, "the American farmer should lead the world ... . for years to come." The Ferguson Foundation textbook series and ECPD accreditation of 25 of the 44 agricultural engineering curriculums were mentioned as two of the greatest milestones in professional progress. Bainer warned his audience that engineers of other branches (electronics, heat and mass transfer, processing) could move into agriculture if agricultural engineers did not undergo advanced training in order to retain technical leadership. Opportunities abounded for engineering solutions to problems such as soil compaction, quality losses due to substitution of machinery for hand labor, improvement in farmstead labor efficiency, and materials handling. $\mathrm{He}$ ended by saying "Anniversaries call for inventories. Progress has been great. The problems ahead are even greater."

Since the time was a "golden age" of faith in technology we can assume the problems Bainer referred to were technical problems. In 1957 it was inconceivable that within a decade many technical problems would be resolved by protest marches and shouting matches, rather than by sound engineering.

The happy ticket-holders at the annual dinner, unaware that a way of life was passing slowly away, were treated to an "inventory" called "Fifty Candles to Light the Future." This was a dramatization of the history of ASAE prepared by MSU's Speech Department and Howard McColly of the Agricultural Engineering Department. Perhaps the flavor of this work of 
art should be suggested:

"HOUSE LIGHTS DIM - MUSIC IN.

AS HOUSE LIGHTS DIM BRING UP LIGHTS ON NARRATOR. MUSIC UP FULL, THEN FADE FOR NARRATOR.

"For several thousand years two of mankind's most honored professions walked separate paths. The first profession was Agriculture, the production of food and fibre from the earth's soil. The second profession was Engineering or the application of physical science to the work of mankind. As the centuries unfolded, necessity became the mother of invention and the two disciplines from time to time walked the same path. It was inevitable that in the interest of progress and the betterment of man's existence that these two professions would one day merge to create a new profession. And so it came to pass that Agricultural Engineering, as a profession, was born!"

This "dramatic story" in some respects was surprisingly accurate in its portrayal of the first half-century, although a degree of poetic license was to be expected under the circumstances. At any rate it was well received and followed by an enormous four-tiered cake decorated by 50 candles. Retiring President Roy Bainer cut the first piece with his usual aplomb.

After the facing of the more ephemeral aspects of the Anniversary there was left a valuable body of commemorative papers. The entire June issue of AGRICULTURAL ENGINEERING was dedicated to ASAE's history, with authorship representative of the Technical Divisions. Later issues of the Journal contained more papers written as contributions to the celebration.

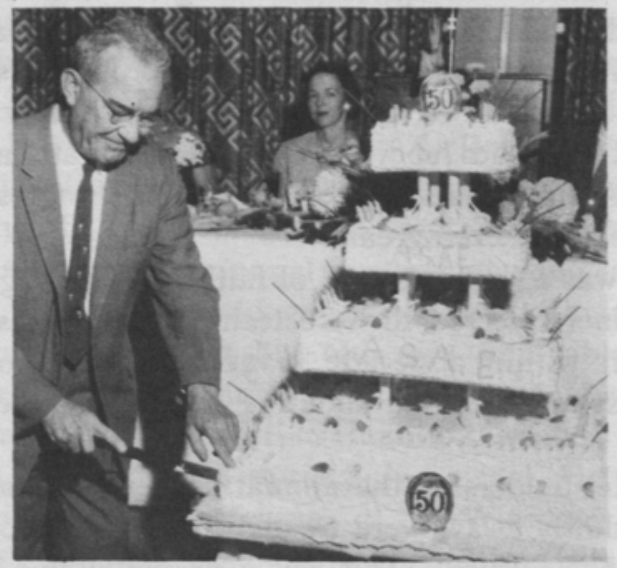

At the Golden Anniversary banquet outgoing ASAE President Roy Bainer cut Society's birthday cake 
Twenty-five years previously, the June 1931 Journal had been devoted to celebration of the Society's Silver Anniversary. The differences in outlook and self-conception are interesting. The 1931 president, $R$. W. Trullinger, wrote ". . . the work of agricultural engineers has just begun." Raymond Olney, J. B. Davidson, O. V. P. Stout, and Philip S. Rose presented short historical sketches which outlined the birth and development of ASAE. A large number of papers discussed technical history which was related to agricultural engineering. Generalization is risky but the sense of much of this writing is tentative. Some authors found it difficult to locate the place of agricultural engineering in the expanding body of agricultural technology; many advances were made by men entirely lacking in formal engineering training. Therefore, it appears that the technology of the 1907-1931 era was still of such comparatively simple dimensions that genuine engineering in agriculture was as yet not widely appreciated by the time of ASAE's Silver Anniversary. This was, of course, known to the members at the time but they did not wish to acknowledge that agricultural engineering had not played a major role.

By 1957 the agricultural engineers were able to present a better case. In all Technical Divisions, authors could point to solid advances made by agricultural engineers and to the sometimes decisive influence of ASAE on agricultural technology. The tentative atmosphere of 1931 had vanished. Further evidence of maturity was the willingness to admit that agriculture was helped by others besides agricultural engineers. For 'example, Roy Bainer said:

"Some of the increased production realized during the past halfcentury must be credited to advances in non-engineering phases of agricultural technology such as better crop varieties, more effective use of fertilizers, fungicides, herbicides and insecticides, and improved cultural practices."

Harold Pinches (now of the USDA) told the engineers that as part of their maturity, they should look to the economists, the agronomists, and the animal scientists for the characteristics of future agriculture. The economists were keeping score on the trend toward larger but fewer farms; these farms would demand more power and substitution of capital for costly labor. The agronomists were introducing new, high-producing crops which presented machinery problems. There was also the need for better tillage, more accurate fertilizer placement, and machines for changing the "microtopography" of fields. And the animal scientists were developing strains of livestock better adapted to climatic requirements of a given region, demanding changes in structural design and economy.

Pinches took note of the low birth rate of the 1930s which was now 
reflected in labor scarcity. High wages were attracting labor away from the farms, thus creating unusual opportunity for agricultural engineering. Unfortunately the declining number of farms was eroding the traditional recruiting base for agricultural engineering students. So there was good news and bad news in 1957.

Bainer had told the Council at East Lansing that the most pressing problem was to find space for publication of the rising number of technical papers. It is surprising that this was considered the most urgent problem because its solution required only money and some extra effort. Recruitment of new students into agricultural engineering in order to bolster the sagging graduation rate must have been a worse problem; money and extra effort could not necessarily solve it, yet failure to solve it would have far worse effects than the publication problem.

With the Golden Anniversary meeting the Fifth Decade ended. ASAE was now firmly established as a creator and disburser of agricultural technology. Its claims to recognition as a branch of engineering were now based on fact. It lost its battle with USDA for separate recognition of agricultural engineering, but its mode of warfare was honorable and dignified. It passed through a difficult change of secretaries with minimum disruption of service to the members. Its publications were strengthened and improved; its finances were in good order. Other improvements in its character had been made during the decade, not the least of which was the extensive work in emerging countries performed by many members. This helped change ASAE into the International organization it is today. "Fifty Candles to Light the Future" may have contained a touch of corn but it was an honest portrayal of a group who believed in American technology and its many blessings.

But the members were barely home from East Lansing when something occurred which was the foreshadowing of loss of confidence in technology. The July Journal "Report to Readers" quoted a news story that a chemical company was withdrawing from the manufacture and sale of insecticides. Why? " . . . because wide-scale use of insecticides is upsetting the balance of predator-parasite insects." A story from the International Harvester Company's "News About Farming" was also quoted in which the Canadian government was credited with support of research on biological insect control since 1948. In other words, the ASAE Journal (and others) were talking about ecology and integrated insect control at least five years before Rachel Carson published her book. In fact, the ASAE writer noted the "urgent need" for research on the subject.

Unfortunately, very few saw any urgency at the time. Meetings, research, and other modes of action would wait for an aroused (and mostly illinformed) public to stimulate ASAE into recognition that some technology 
may do harm rather than good.

\section{B \\ Technical}

By the middle of July 1947 unusual Corn Belt weather had delayed the crop by an average of two weeks. Even if good growing weather occurred during the remainder of the summer, much soft corn was expected to be harvested. Very little research data were available on the effects of early frost on soft corn. It was suspected that early frost would not only reduce quantity and quality of the crop but also reduce rate of field drying, creating a spoilage hazard in storage due to high moisture. However, USDA agricultural engineers at Ames had studied the effect of freezing on the drying rate of corn on the stalk in the fall of 1946; they found that frozen corn dried more rapidly than unfrozen. Therefore, losses in yield and quality from freezing might be offset by the faster drying rate and consequent safer storage from early harvesting.

The prospect of losing a major portion of the 1947 crop caused ASAE to call a conference on July 21 in cooperation with the BPISAE, the state experiment stations, and manufacturers. The meeting was held at the Congress Hotel in Chicago without advance publicity except to about 100 specialists and key persons. Nearly 200 attended.

Several formal papers were presented, including presentations by an agronomist, equipment manufacturers, and a corn processor. Engineering aspects were discussed by Wallace Ashby, D. G. Carter, Leo E. Holman, H. J. Barre, R. C. Miller, F. D. Yung, W. V. Hukill, and C. K. Shedd. These papers concentrated mainly on methods and equipment for drying corn. The conference was also addressed by the Under Secretary of Agriculture on the effect of the corn situation on world food needs.

Following the conference a committee of agricultural engineers appointed by ASAE President George A. Rietz spent the evening in drafting a set of recommendations for the mechanical conditioning of corn.

The recommendations first indicated the well-known practices for utilizing high-moisture corn; these practices included ensiling the crop, early feeding, delayed harvesting, and certain cribbing methods. The new factor was going to be use of forced-air ventilation, with or without heat; the engineers believed this would be required to save a large proportion of the crop and, being new, information about it would need to be rapidly and widely broadcast. 


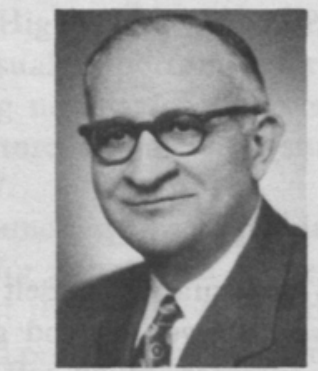

George A. Rietz

41st president, ASAE, $1947-48$

For mechanical ventilation without heat it was noted that the drying process would require long periods of time plus favorable weather. Use of heated air could shorten the time and permit drying to continue during unfavorable weather. Overheating the corn (particularly seed corn) could cause problems. Mixing of flue gas from an oil burner with the air was considered beneficial in terms of heat transfer. Certain precautions regarding fire were advisable. Fan and heater capacities, oil-burning, were tabulated with the approximate time necessary to dry 1000 bushels of ear corn with moisture content of 30 percent or more; the effect of weather on the process was pointed out. Instructions for adapting cribs to fan ventilation were included.

State extension agricultural engineers worked with county agents and manufacturers to get the information out where it was needed. Quick action was taken by the federal government to increase the effectiveness of the conference. The Secretary of Agriculture informed material manufacturers of the urgency of the situation and the desirability to make preferential allotments of materials and components to manufacturers of grain-drying equipment to expedite production of such equipment in the two or three months remaining before harvest. USDA called a meeting at Purdue University of its agricultural engineers familiar with grain-drying problems. The meeting was designed to give dryer manufacturers, farmers, and grain handlers all possible help. The help that resulted was a combination of engineering techniques and development of systems for obtaining maximum service from a limited number of dryers.

ASAE leadership was effective in uniting the efforts of government and private industry to avert a possible national disaster. It was a happy example of what a small technical society could do for the public welfare. A pleased Journal editorial in September said of ASAE's conference and the subsequent actions:

"It all adds up to a strong object lesson in timely, practical action to 
alleviate the shortage and accompanying inflationary prices of important public necessities.

"Agricultural engineers can take justifiable pride in their contribution to this program."

The soft corn emergency and the actions of ASAE in connection with it stimulated the establishment in October 1947 of the Committee on Crop Conditioning Equipment. Chaired by H. J. Barre, the Committee apparently had no divisional affiliation, but its members had participated in the soft corn emergency. As part of this they had discovered that many types of driers were being sold with no basis for rating their capacity. They felt that ASAE should formulate drier test procedures, develop a uniform capacity rating basis, specify drying conditions for the various crops, and assist Underwriters Laboratories with specifications for safety and control features of driers.

While the corn problem of 1947 soon ended, it had caused ASAE to attempt to influence permanent improvements in drying equipmentto the lasting benefit of the farmer.

Crop storage and conditioning were analyzed at the Farm Structures Conference sponsored by ASAE's Farm Structures Division and the University of Illinois in September 1947. The widespread use of hybrid corn and mechanized harvesting was not being accompanied by improvements in storage structures and drying equipment.-

These problems were recognized by the USDA Division of Farm Buildings and Rural Housing. That group started a cooperative project with the Grain Branch of the Production and Marketing Administration and the lowa and Indiana experiment stations to develop plans for better mass-produced farm grain storage bins. Specimen bins were to be obtained from manufacturers who were to supply bins for field tests and for adapting to mechanical drying. The investigations were to be financed under the Research and Marketing Act of 1946.

Interest of the farm structures specialists had been attracted to recent farm work simplification developments. These centered largely on the farmstead; they involved study of tasks such as milking and feeding dairy cows using methods similar to those used in industry. An ASAE Committee on Farm Work Simplification was formed in 1947 to cooperate with a similar committee of the American Farm Economics Association. ASAE's committee assisted Dr. L. M. Vaughan of the USDA Extension Service and Dr. L. S. Hardin, agricultural economist of Purdue University, in preparing a manual on farm work simplification. The book was intended to aid 
specialists in the layout of structures, integration of equipment, selection of work procedures, and identification of similar problems to optimize farmstead labor.

The committee also surveyed agricultural engineering departments to determine the amount of their cooperation in work simplification projects. Twelve colleges replied. These projects were mostly under the direction of farm management specialists, although agricultural engineers were contributing more than any other subject-matter specialists. The college people felt subordinated by the situation; they thought agricultural engineers should have charge, or at least have a major part, in such projects because their final outcome demanded considerable use of engineering techniques related to structures and equipment. Most departments mentioned lack of funds and scarcity of personnel as limiting factors.

By the end of World War II many U.S. farm structures were in bad shape. Because of war-time material and labor shortages few new service buildings had been erected. And the work of agricultural engineers on the functional requirements of livestock housing had also been interrupted. Consequently, during the war it was decided that fundamental research on the climatic needs of domestic animals should be undertaken on a major scale as soon as possible so that the rebuilding of the farm production buildings might be guided by sound research data.

A research laboratory for study of swine was established at Davis, California, and one for study of dairy cattle at Columbia, Missouri. The work was to be done cooperatively between BPISAE and the state experiment stations. A laboratory for study of poultry was set up at Beltsville under the control of BPISAE. The establishment of these research facilities appears to mark the first time that agricultural engineers participated in environmental research not only as engineers (maintaining and measuring environmental factors) but also as physiologists (instrumenting and interpreting measurements made directly on the animals). This was true although each group had its collaborating animal scientists.

The early engineering investigators on these projects were C. F. Kelly and T. E. Bond at Davis; H. J. Thompson, R. E. Stewart, and R. G. Yeck at Columbia; and Hajime Ota at Beltsville. They published a number of papers in AGRICULTURAL ENGINEERING concerning the effect of environment on heat and moisture dissipation and on production. Later some of the basic data were converted into forms useful for environmental control purposes. Also, Kelly and his group commenced field studies of beef cattle. Rising interest in using the new data for housing technology caused a summary of "Effect of thermal environment on production, heat and moisture loss, and feed and water consumption of livestock" to be printed in the 1956 


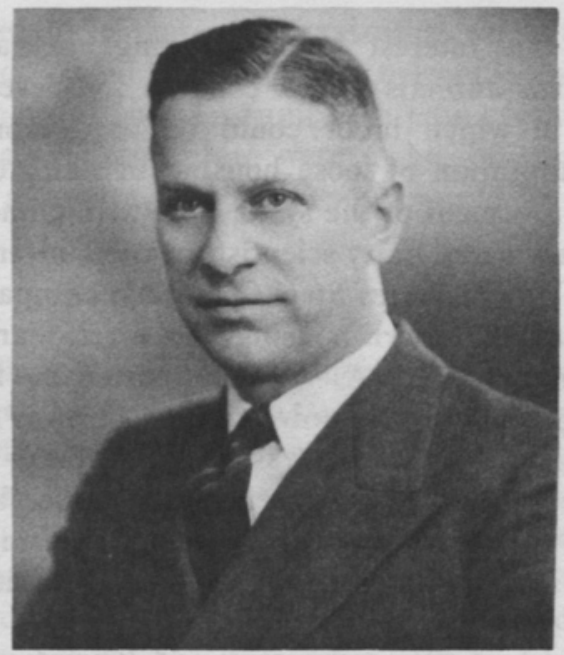

Professor Henry Giese of lowa State College originated the Midwest (Farm Building) Plan Service in 1929

Agricultural Engineers Yearbook for the first time.

The retooling of the agricultural physical plant after the war was greatly aided by the various plan services managed by agricultural engineers. Perhaps the best known was the Midwest Plan Service.

The original Midwest (Farm Building) Plan Service was initiated in about 1929 by agricultural engineers of the North Central Region working through and under the sponsorship of the ASAE Farm Structures Division. Its originator, Professor Henry Giese of Iowa State College, stated that "only a small group" was involved initially but by 1933 , when the first plans catalog was issued, about 15 land-grant colleges and USDA were participating. Later the idea spread to three other regions of the U.S. After the war the Midwest Plan Service was set up at Ames as an official activity of the experiment stations and extension services of the North Central Region states. Today its catalog is widely used and some of its other publications are used as teaching aids in the professional agricultural engineering structures and environment courses.

That urgent need for new designs for crop storage and conditioning structures was notably met in 1949 by the Midwest Plan Service. It produced in the space of one month a brand-new 16-page catalog of redesigned and up-to-date plans for these structures. However, as D. G. Carter commented, the feat could not have been performed without the cooperation of the USDA and without the long years of research that went before. 
Concurrent with this interest in determining accurate environmental requirements for farm animals was a concern for developing more economical structures in which labor could be used more efficiently. An example was the adaptation of loose housing of dairy cattle to northern regions and the improvement of the system in warm climates.

Agricultural engineers and dairy scientists at the University of Wisconsin, in cooperation with United States Steel Company, compared loose housing with conventional stanchion-barn housing over a ten-year period ending in 1951. The engineering leader, S. A. Witzel, reported the final results in the Journal. The findings were almost universally in favor of loose housing and the separate milking parlor. Labor was reduced, herd health was maintained, milk production and quality were equal under both systems, and a cold barn gave no trouble in winter (warm loose housing was found to be unsatisfactory). The disadvantage of loose housing was its greater requirement for bedding.

Dairy housing terminology was studied and "standardized" about this time by an ASAE committee because of the wide attention being given to that subject. For example, those terms "stanchion barn" and "milking parlor" were not approved by the committee; instead, the terms "stall barn" and "milking room" were recommended.

An example of the farm work simplification studies done by agricultural engineers after the war was the time-travel studies on dairy farms. These were performed by Thayer Cleaver of the BPISAE in cooperation with the Illinois experiment station. The project was started in 1946. Handling feeding and bedding, removing manure, and milking were studied on farms in Illinois, Indiana, and Wisconsin. Stall barns and loose housing systems were both examined. By 1952 Cleaver was able to recommend optimum combinations of men, animals, and machines which functioned at no sacrifice in sanitary standards. His work also produced criteria for improved design of new buildings.

Wallace Ashby reviewed 50 years in farm buildings for the Golden Anniversary. He concluded that the state of the art was lagging, that the modernization process was far from done. One improvement he called for was development of a building "package" to simplify purchase and erection of the building and to aid in selecting and installing its equipment. Partial packages had come into existence since the war, in a variety of sizes, all prefabricated. Made usually of metal, they were used widely in the grain storage program, for example.

D. G. Carter suggested trends in farm buildings in the Anniversary Journal. Structures were going to move toward pole frames, trussed roofs, prefabricated units, and contracted "package" buildings. Size of buildings 
was expected to generally increase. Mechanization would take over materials handling and livestock would be self-fed. Environmental control of dairy, swine, and poultry housing would assume greater importance. Loose housing and the elevated-stall milking room were to be the trends in dairy cattle housing. One-story structures for all purposes would be most common.

Senator Ralph Flanders was an engineer who believed that engineers should participate in public affairs. He also opposed governmental meddling with private enterprise. When it was proposed in 1951 that the government create industrial standards by decree, Flanders vigorously opposed the idea-ASAE applauded his views with equal vigor. Standards were too complicated a matter to leave to the government.

What do standards accomplish? The Journal reprinted a statement from “Mechanical Engineering" in September 1952, which claimed that standards have these distinct values:

(a) They educate by setting forth quality goals for the guidance of producers and consumers alike.

(b) They simplify by limiting the number of sizes, the variety of processes, the amount of stock, and the associated paper work-thus reducing the overhead costs of manufacturing and selling.

(c) They conserve by cutting down the losses, wastage, and unnecessary tooling that accompany odd-lot manufacture, thus promoting large-scale production of standard design.

(d) They certify by serving as hallmarks of quality and value.

In brief, standards make it possible to provide more goods at lower cost and enable buyers to determine and evaluate the goods that they require. But the mechanical engineers overlooked something else standards can do; they can promote safety.

It has been recounted how ASAE after much hesitation and some false starts entered into the business of standards. Over the years the procedures for adopting standards had been awkward, particularly because each corporate member was asked to vote by letter ballot on each proposed standard. At its June 1951 meeting the Council voted to adopt this more streamlined procedure:

(a) Any Society committee, after having formulated and approved a particular standardization proposal, should submit that proposal to the Steering Committee of the Division (or Divisions) involved.

(b) The Steering Committee, after reviewing and approving the proposed standard, shall submit it to the Council with its recommendations. 
(c) The Council shall thereupon either reject or approve the proposal. If the Council rejects, it shall refer the proposal back to the Steering Committee with appropriate recommendations. If the Council accepts, it shall instruct the Secretary to announce its adoption as an official ASAE standard and arrange for its publication.

In practice, proposals still were referred to the members but only as a formality. An example was baling wire. E. W. Tanquary, as chairman of the Advisory Engineering Committee of the Farm Equipment Institute, went before the Council in December 1951. He had a proposed standard for baling wire for automatic hay balers which had originated in the FEI and he requested ASAE to adopt it. The Council voted to accept the proposed standard on condition that it be approved by the Steering Committee of the Power and Machinery Division. This approval was presently forthcoming. The proposal was then printed as a proposed ASAE Standard in the April 1952 Journal with a note on its origin among manufacturers and the warning that "unless substantial objection . . . is raised within 30 days, it will be declared an official ASAE Standard by the Council of the Society."

As Olney noted in his 1951-52 Annual Report, standards activity "in order to attain maximum effectiveness must have the full sympathy and support of manufacturers whose interests are directly involved."

In that same report it was pointed out that (after all those years) the development of standards had thus far been limited to the Power and Machinery Division. Not that opportunities had been lacking, but aggressive response did not come about, perhaps partly due to faulty organization or none at all. For example, the Research Committee in 1947 criticized the Society for failure to adopt refrigeration standards which the American Society of Refrigerating Engineers had readily adopted. At the same meeting it was announced that the Safety Committee of the American Institute of Electrical Engineers had requested ASAE to set up standards for electric fencing based on the effect of electric shock on various farm animals. This request fell into a partial vacuum by being referred to the Agricultural Research Administration with the request that it "receive favorably any proposed research" on the subject.

The distinguished position of the Power and Machinery Division as the sole developer of standards was challenged finally by the Soil and Water Division. A divisional committee headed by $K$. $H$. Beauchamp prepared an ASAE Recommendation on "Design and Construction of Tile Drains in Humid Areas." It was published in the July 1953 Journal "to give ASAE members an opportunity to review and comment on it" before it was presented to the Council.

The Standards and Recommendations listed in August revealed that a 
Recommendation for design, installation, and performance of sprinkler irrigation equipment was in existence. The Council minutes and the Annual Reports are devoid of reference to this Recommendation nor was it printed in the Journal for member review.

Earlier it was indicated that a code for rating crop dryers did not exist in 1947. By June 1954 an official code had been prepared and adopted by the Crop Dryer Manufacturers Association; this was investigated and revised by an ASAE Committee on Crop Drying Equipment. A. M. Einerson, its chairman, caused the code to be printed in the Journal as a proposed ASAE Code.

The Power and Machinery Division reorganized its Steering Committee in 1955. The committee personnel had been mostly chief engineers of the various implement manufacturers and were concerned almost exclusively with standards. For this and other reasons the Steering Committee was redesignated as the Technical Committee and given responsibility for preparing and approving standards and recommendations. Because compliance with standards is voluntary, sometimes delicate negotiations may be required among companies; the Technical Committee's personnel can promote early agreement by knowing each other.

We have seen that standards can often originate outside the Society structure. Adoption can be greatly facilitated when the persons concerned belong both to ASAE and the "outside" group which originated a proposal. Standards relating to tractors and farm implements originated from FEI and Society of Automotive Engineers as well as ASAE. Many ASAE members were also affiliated with SAE or the FEI. Edwin Tanquary was active in FEI's Advisory Engineering Committee in the 1950 s. He wrote a Golden Anniversary paper on "Standardization of Farm Equipment." What follows is based on that paper.

Through a process of evolution the scope of activity of the three groups had by 1957 been narrowed down this way: SAE worked on standards related to farm tractors and components, such as tractor and implement tires; ASAE worked on standards related to farm implements and components; the AEC of the FEI was concerned with interchangeability between implements and tractors produced by different companies, with standards considered necessary to promote safer operation of farm implements and tractors, and with activities pertaining to the International Organization for Standardization (ISO).

Requests for standardization could come from practically any source. Farm organizations, USDA, and particularly the industry itself originated such requests. It was considered good practice to create standards before the introduction of equipment to the farmer. 
The Power and Machinery Division already had established a Technical Committee to handle standards. Other divisions did this later. Power and Machinery broadened its Technical Committee membership to represent public service as well as private industry. Although final responsibility lay with the ASAE Council, it delegated the technical program to the technical committees.

Membership on the FEI committee was held by appointment from the FEI member companies. Only chief engineers or executives were appointed; therefore, they could make decisions. In handling standardization proposals, the committee confined itself to standards which promoted interchangeability between tractors and trailing implements; the question of mounted equipment was left to the future.

The American Standards Association (ASA) was the American member of ISO, which was started by the United Nations in 1946. Through ASA, the FEI committee was active in two ISO technical committees-one was for tractor standards, the other for agricultural machinery. In the international work, the FEI group maintained the same concern for interchangeability as it did in domestic work.

This analysis of standardization procedures in the tractor and implement field suggests why ASAE's Power and Machinery Division was so active in standards. Through mutual membership in SAE and FEI and through concern with precision-manufactured items whose characteristics could be standardized, the processes could be more easily promoted, agreed-upon, and controlled than in the other Technical Divisions. The benefits of standardization, both to the public and to competing companies, were more readily apparent. And not least, in such a forum questions of safety could receive the attention they deserved. Furthermore, standards were not applied in a way that could diminish engineering creativity nor was the rationale behind their development held secret.

It is regrettable that the public is largely unaware of the benefits conferred upon society by technical societies and trade associations working together on standards.

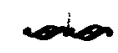

After World War II agricultural engineers attempted to utilize the new research techniques and equipment which the war had brought into being. The success of wartime research projects which involved the cooperation of many persons (such as the Manhattan Project) had been widely admired. Agricultural engineers had long been accustomed to cooperative research but not on such a generous scale of support. The wartime groups had 
been so successful, however, that Dr. F. A. Brooks of the California Experiment Station undertook to draw the lessons therefrom. As a contribution of the Committee on Research, Brooks delivered his classical paper "Research Procedures for Cooperative Projects with Limited Personnel" at the 1947 Annual Meeting.

Brooks acknowledged that "The essential difference . . between our customary cooperative research and war research is the almost unlimited manpower, money, and priorities willingly focussed on war research." Agricultural engineering shared another problem: it was in a transition stage between depending on crude observations of nature and depending more on scientific modification of nature. This called for a more thorough kind of research than had been customary. He noted that 15 or 20 experiment stations had been working on barn hay curing but without "satisfactory understanding" because they failed to cooperate. Another shortcoming was the general failure to cooperate with scientists in other disciplines.

Then followed a critical analysis and exposition of techniques for reaching valid findings, group arrangements to maximize the skills of each cooperator, and a scheme for attacking problems along multiple lines of approach. In the process, Brooks broke down engineering science into its components and re-synthesized it into the unit operations of agriculture. His paper has no flavor of obsolescence today; it should be required reading for every generation of researchers.

The ASAE Journal said of it:

"Certain mechanics of collaboration have been developed and proven effective in making the most of its advantages, while minimizing its acknowledged difficulties. They are points to be well learned, practiced, and taught to others by agricultural engineering research men and research administrators, in the interest of improved results."

And agricultural engineers were doing more research than ever before. One stimulus of course was the Research and Marketing Act of 1946. The emergency grain storage and conditioning research was one of the first projects under the Act. In 1949 the BPISAE launched a Southern Regional cotton mechanization research under the Act in cooperation with the state experiment stations and other BPISAE divisions. The project was to focus on equipment for producing and harvesting cotton on small farms (20 acres or less). As a conference at Stoneville, Mississippi, in August 1947 revealed, much top-quality cotton would be produced on small hill farms.

The Act funded projects at the Forest Products Laboratory on development of new uses for farm-grown timber and on methods for hydrolyzing wood to produce molasses and yeast for livestock feed. A chemical weed con- 
trol project was started at Beltsville, Ames, and Stoneville to evaluate herbicides, flaming, and cultivating by the engineers.

A Research and Marketing project started in 1948 in cooperation with the University of Georgia was concerned with improving facilities and equipment for rural plants processing farm products.

Insecticides and plant-disease research was partially funded by the Act, with major responsibility assumed by the USDA group at Toledo, Ohio, where Frank Irons was the agricultural engineer in charge. In 1947 the hazards of drift and toxicity to living organisms other than the target were clearly recognized. The group was equipped with a variety of airborne and groundbased spraying and dusting equipment which had been used against the corn borer for a number of years.

John G. Taylor, USDA engineer stationed at Purdue, found that the corn borer female moth was attracted to radiation in the near-ultraviolet region much more readily than to white, blue, green or bactericidal wavelengths. The insecticide manufacturers promoted installation of Taylor's light traps as an aid in timing spray applications.

In another area, in 1948 the Illinois Institute of Technology surveyed its faculty on the six major problems confronting the United States. In their opinion conservation of natural resources was second only to atomic energy in importance. Such a topic was of great importance to ASAE and drew Journal editorial comment suggesting that soil conservation research underlaid much beneficial practice and should be continued indefinitely. It was a field in which knowledge without limit was needed, partly because questions were just beginning to be raised of how much human life the planet could support and how well. As the agricultural engineer wrote:

"How much of the continuing wear and tear on our world and its capacity to support human life is due to physical forces of nature? How much is actually necessary to the support of the human population? And how much is sheer waste due to man's short-sighted pursuit of immediate objectives without thought of the future?

"To what extent and in what manner can the waste of resources by both natural forces and human activities be reduced? To what extent and in what manner can the rebuilding forces of nature be aided and accelerated? What available resources can be put to better uses? Can a state of biological unbalance favorable to man be maintained indefinitely? If so, how, and to what extent?"

Tough questions, and the research to answer them had not, in most cases, even commenced.

The agricultural engineers were not without friends when it came to research. ASEE's Engineering College Research Council published a booklet 
in 1949 which listed 12 case histories in which pure science research intended to improve the technical foundation of engineering had produced byproduct cash values which more than covered the research cost. Three of the 12 cases were selected from agricultural engineering: tractor testing, sugar beet mechanization, and flax handling machinery. The Nebraska Tractor Tests, cited as a "standard of the world," were given more space than any other example.

However, not all were so satisfied. An article appeared in the weekly journal "Science" in 1949 which claimed that agricultural research was moving too slowly. The reason, according to the author, was lack of knowledge of the fundamental biology of crop plants. A Journal editorial agreed, saying "one of the greatest and most commonly encountered obstacles to progress is the limited available knowledge of the biological subjects to which . . . engineering is applied." Perhaps that was why J. B. Davidson told his audience at an FEI dinner in December 1949 that "the golden age of agricultural engineering research is still ahead of us."

The old research expert, Robert Trullinger, addressed the June 1950 ASAE meeting on "Research for Tomorrow's Agriculture." Mass production was here to stay, he said; farm units were decreasing in numbers (one million less than in 1935); the need was for greater efficiency on the farms that remained. Science would be needed to offset the decreasing land area devoted to farming; resources had been strained and overworked. The war took a heavy toll of the land. Some advanced technologies had created problems. More basic research on factors such as photosynthesis would be only a beginning.

Trullinger noted that a lot of spraying was done to control plant disease and insects. "There is a large minus factor in these practices which some time in the future we cannot afford to accept," he said urging that alternatives be found. Because animal diseases could be transferred to humans, there were relationships between nutrition and disease for both which demanded research. Use of antibiotics had both good and bad features; more research was needed here. The same was said of hormone implants to stimulate growth in meat animals; the basic mechanism and its overall safety should be elucidated.

All agricultural scientists should be trained in mathematics, physics, chemistry, thermodynamics, etc. Engineers will need knowledge of advanced scientific instrumentation to solve future problems, according to Trullinger.

Trullinger died in 1955 shortly after he retired as chief, Office of Experiment Stations.

Most of the research was done by USDA and state agricultural engineers. The private sector did little research at that time. As the chief engineer 
of one company put it: "From my own observations, more than half the graduates seeking employment indicate they would like to get into research or testing work, which to them seems to have a certain glamour about it. Jobs in testing and field experimental work, in most companies, are in the minority."

Recognition of the importance of instrumentation occurred at a meeting of the new Committee on Instrumentation and Controls during the 1951 Annual Meeting. The chairman, Dr. W. H. Kliever, mentioned that returns were coming in from a Committee survey of instrumentation in about 140 agricultural engineering research activities. Publication of special material in the Journal was planned along with a new monthly feature to be called "Instrument News." The latter first appeared in August 1952, with an article by J. G. Taylor on thermistors. Karl Norris of USDA was then the editor for "Instrument News."

A kind of research the average agricultural engineer might not think of was discussed by A. J. Schwantes when he spoke to the National Safety Congress in 1951. Schwantes wanted research in farm safety performed in order to keep safety programs in progress and keep them correlated with new developments. At the local or county level he considered it essential that records of accidents, their causes and surrounding circumstances be kept. At

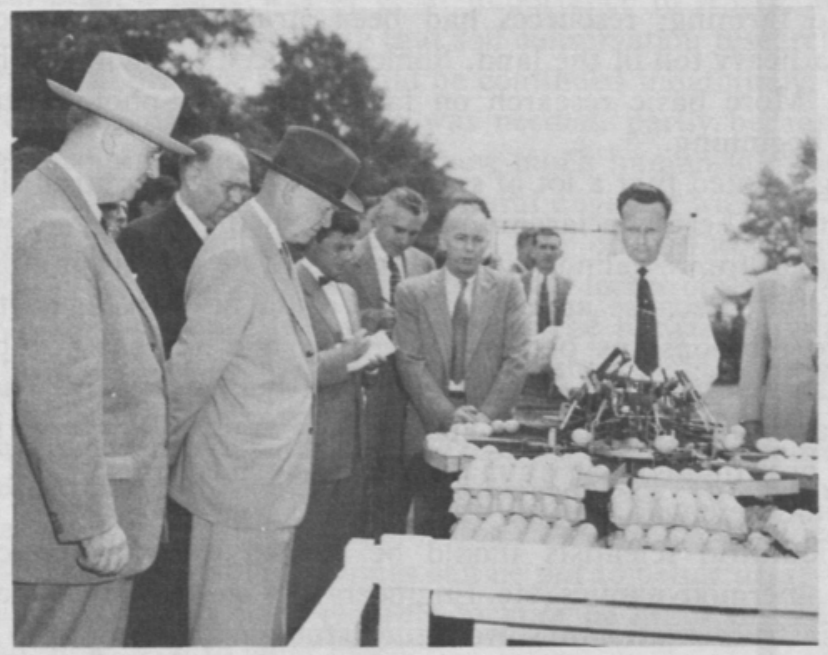

Karl H. Norris (member ASAE), agricultural engineer, Division of Farm Electrification, USDA, is shown demonstrating to President Eisenhower the shell-color egg grader. At extreme left is Secretary of Agriculture Ezra Taft Benson, an Honorary Member of ASAE 
his own University of Minnesota they were studying the exact cause of fatal tractor accidents with the help of an extension farm safety specialist. He thought that mechanical equipment needed safety improvement based on research and that FEI should be commended for its efforts along this line. A Journal editorial put it this way: "Research in farm safety can be a low-cost substitute for some high-cost learning in the hard school of experience."

Editorial notice was taken in 1953 of another research technique that flowered during the war, operations research. It was defined as the application of the methods of scientific research to operating problems of management, a means of providing additional quantitative evaluations on which to base decisions. Its purpose was to "reveal basic relationships underlying the operations studied. Theories of underlying mechanisms are sought which are consistent with facts brought out during operations or experimentations and which can be used to predict the effects of changes in procedure or environment." The concepts of operations research went beyond cost accounting, statistical analysis, quality control, market research, and certain phases of industrial engineering, but used these as part of the evaluation process. The Journal estimated that agriculture could be "served more effectively by engineers" when operations research removed more of the uncertainty surrounding new products and practices. It was implied that agricultural engineers should learn operations research and how to apply it.

The ASAE Farm Electrification Research Conference Committee served as advisors to the USDA Division of Farm Electrification. A meeting was held at Beltsville in October of 1953, after which the committee issued a report commending the Division's research progress and cooperation with the land-grant colleges and commercial organizations. It was noted that 91 percent of American farms were electrified; the farmers had invested billions in electrical equipment. The committee urged that major attention be given to those projects "that show the greatest promise of benefiting the largest possible number of farm people."

To implement this. the committee asked that increased emphasis be placed on these projects:

1. Use of radio-frequency energy to condition farm crops and to destroy insects.

2. Effect of radiant and electromagnetic radiation and fissionable materials on plants and animals.

3. Effect of environmental conditions on animals.

4. Mechanical refrigeration for storing perishable products on the farm.

5. Use of electric energy for controlling or exterminating insects that damage crops. 
6. Use of the heat pump to condition feed and forage.

7. Exploration of the processes of photosynthesis as they relate to the most efficient production of food and fiber.

The list (which is incomplete) is interesting in the way the projects seem to range in character from extremely basic research (like No. 7) to development (like No. 6). Not many ASAE leaders had attempted to develop a philosophy of agricultural engineering research in terms of desirable balance among basic, applied, and development, although Trullinger in his time had called for "fundamental" research on many occasions. However, Harry B. Walker, who died in 1957, published a Journal paper that was a judicious attempt to "balance" agricultural engineering research. His paper was taken from the address he gave at the FEI dinner on December 8, 1953. Research, he said, is usually divided into fundamental and applied. For his purposes it was divided into pure, basic, applied, development, and consumer.

- Pure research. An area where rare individuals without specific objectives conceive and discover new relationships.

- Basic research. Having greater objectivity than pure research, basic research broadens knowledge and builds it into more specific forms for usefulness. Pure plus basic research together constitute fundamental research. In engineering, basic research bridges the gap between pure science and its application.

- Applied research. An area where new scientific knowledge is tested. "The nature of agriculture is such that a lot of pioneering effort in experiment stations is required to introduce and establish a new crop or a new method of handling or processing established crops. Often such research must take place before industry can be induced to serve the farmer with new types of equipment or facilities."

- Development research. Applied research is translated into successful practices. "A sound economic practice or service once established requires a lot of development to make it more efficient and useful. Thus development is a primary function of industry."

- Consumer research. "This area provides a measuring stick for determining the practical acceptance of an innovation." It is used by all manufacturing industries for product improvement and also by non-profit institutions as a preliminary to investigations "of a more profound nature."

Walker examined the research picture of agricultural engineering as it appeared in 1926-28 and compared it to 1952-53. The earlier case showed 40 percent consumer, 25 percent development and applied, and 10 percent basic. He said of it ". . . our efforts were relatively juvenile and our workers inexperienced. It was natural that much time should be spent on surveys and 
the application of machines to tasks, such as were required to change farming operations from animal to mechanical power." Very few researchers "had a clear concept of their research responsibilities."

By 1952-53 the consumer percentage had dropped to 20 percent, development remained at 25 percent, applied had risen to 40 percent, and basic had risen to 15 percent. The amount of pure research was still zero. Walker acknowledged the small shift toward basic work but was not happy with the remaining strong bias toward application and development. In his view, the non-profit institutions were neglecting basic research, failing to generate sufficient new knowledge to sustain future technological growth. Why?

First, agricultural engineering progress to date had been attained mainly by the labor-saving route. Research had been concentrated on equipment development; it was now time to give attention to studies related to product quality, reduction of waste, dynamics of machines, fluid mechanics, unit operations, and similar issues rather than to direct machine development and labor saving.

Second, it was easier intellectually and financially to carry on applied and development research.

Third (Walker probably hated to say this), the non-profit institutions have not had agricultural engineering personnel with the superior ability and advanced training required for basic research. Industry and sincerity were not enough.

Fourth, too much time was wasted through duplication of research effort by the various states.

Fifth, the non-profit institutions were neglecting the research potential of private industry. The latter could be doing much of the applied and development research, leaving the former more free time to pursue the basic research. "It is a sin for these institutions to do research which industry can do as well or better for itself."

To serve future needs of agriculture and its related industries, Walker told his audience that agricultural engineering research in non-profit institutions should be balanced as follows:

Area of research Percentage of funds

$\begin{array}{cr}\text { Pure } & 5.0 \\ \text { Basic } & 30.0 \\ \text { Applied } & 35.0 \\ \text { Development } & 20.0 \\ \text { Consumer } & 10.0\end{array}$


It was his intention to limit the "pure" category largely to "academic research conducted by men qualifying for a doctorate."

Walker ended by saying.

"Certainly we will not be criticized for improving our research program, but most surely criticism will come if a search for new knowledge is not attempted. Let us organize now to obtain this new knowledge, and may we have a greatly expanded liaison service between research and industry in order to make our efforts most effective."

At the time he spoke, the colleges (some, at least) were beginning to produce Ph.D.'s in appreciable numbers. Some of their doctoral research was far from "pure" according to Walker's definition. Where they did attempt to create new knowledge it was often in forms unusable to industry (if not incomprehensible), giving rise to an increasing demand from that sector for more "application," a demand that still persists. Perhaps the missing element is the "liaison service," meaning a better sharing of information between the two groups, better forms of cooperation and mutual understanding.

The 1955 Journal listed all the active projects in agricultural engineering at the various state institutions. Ostensibly, this represents a unique opportunity to follow up Walker's $1952-53$ analysis because such a list rarely has appeared in the Journal. Actually, one cannot easily identify whether the research is basic, applied, or development by mere examination of the project titles. A title such as "Grain and Seed Moisture Studies," for example, could denote a project in which all types of research might be carried on.

Walker's suggested balance of research categories was checked against 50 papers published in the 1957 Journal (not including historical papers and similar items), with the following results:

$\begin{array}{cc}\text { Area of research } & \text { Percentage } \\ \text { Pure } & 0.0 \\ \text { Basic } & 24.0 \\ \text { Applied } & 42.0 \\ \text { Development } & 34.0 \\ \text { Consumer } & 0.0\end{array}$

The principal deviations were paucity of research at the "basic" end of the spectrum and over-emphasis on development. The absence of "consumer" research is not surprising; by 1957 people usually didn't publish work of that kind. The explanation for the deviations from Walker's ideal is that the papers in the sample originated from industry as well as non-profit institutions; the ideal was intended to guide the latter group only, so the 
bias toward development is understandable.

Also, it would be unwise to consider the Journal to be a completely adequate sample of agricultural engineering literature. The USDA and the state experiment stations employed several types of publications as research report outlets. Many of these allowed the authors to report their findings in a much more comprehensive fashion than was possible in the Journal. Some agricultural engineers published research results in journals and transactions of other technical or scientific societies. Many papers presented at ASAE meetings were never published. Industry engineers often utilized internal reporting methods. Therefore, an accurate estimate of the "Walker ideal percentages" is probably unattainable. His proposal may have found its best utility as a guide for administration.

Meanwhile, as part of the aid to research ASAE can give, the Soil and Water Division released these committee reports in 1957:

Evapotranspiration Committee, Hydrology Group-John R. Davis, chairman-completed an 87-page summary of "Evaporation and EvapoTranspiration Research in the United States and Other Countries."

Committee on Sprinkler Irrigation-E. H. Kidder, chairman-prepared a 102-page report on "Irrigation Research in the United States and Canada."

Committee on Drainage Research-Jan van Schilfgaarde, chairmanprepared a 25-page report on "Drainage Research Outside the United States and Canada."

Such activity by the Soil and Water Division was no doubt accompanied by an awareness that 1957 was one of several low rainfall years in succession in the Southwest. However, by April of that year it began to look like rain was coming back to the Southwest in normal amounts again. The Journal commented that by the law of averages the rain should return, but that students of weather cycles were also hopeful. One of these was a meteorologist at the Massachusetts Institute of Technology, who predicted (by use of sun-spot rhythms and other methods) the advent of another wet cycle. In his judgment, the next drouth period would occur somewhere around 1975 to 1980 .

C

\section{Professional Development}

ASAE had a Committee on Professional Registration in 1947. It consisted of S. M. Henderson, chairman, and R. K. Frevert. In September the committee reported on professional registration as it affected ASAE 
members. Their principal contact had been with the National Council of State Boards of Engineering Examiners. This group had sponsored the "Model Law for Registration of Professional Engineers" in 1929, which was supported by a majority of the engineering societies.

The Committee sent a survey form to all the state registration boards. The form asked: (1) Are your state registration laws based on the "Model Law"? (2) How many agricultural engineers are registered in your state as professional engineers?

Forty states returned the questionnaire. It was found that 55 agricultural engineers were registered as agricultural engineers in the 40 states. It was then estimated that a total of 66 agricultural engineers were registered, or about 3 percent of ASAE. Of all U.S. engineers, 39 percent were registered at that time.

Two-thirds of the states had registration laws based on the Model Law. According to the Model Law a graduate from an ECPD-accredited school with requisite experience could register without examination. Regardless of education. registration could be secured by passing an examination; therefore, an agricultural engineer could register in any state in which agricultural engineering was recognized as a branch of professional engineering. even if he was not graduated from an accredited curriculum.

Some of the states did not recognize agricultural engineering as a distinct branch of engineering. However, others did not specify any branch of engineering when registering.

The Committee recommended that ASAE be represented at the next NCSBEE meeting and that "a formal attempt be made to evaluate the need and desirability of registration, the results of which should be brought to the attention of Society members."

One year later Henderson was quoted in the ASAE Newsletter: "Our concern over acceptance of agricultural engineering by the various state boards of engineering examiners appears now to have been unfounded." $\mathrm{He}$ had attended a meeting of the NCSBEE in August 1948, where he found that most of the state boards had recognized agricultural engineering but that they needed examination questions. Henderson advised ASAE to push accreditation of agricultural engineering curriculums and to tighten requirements for all membership levels in the Society; these moves were suggested by the trend of thinking at the meeting.

In September 1948, Henderson and Frevert published another report in AGRICULTURAL ENGINEERING. They had conducted a postcard survey of all ASAE members on their registration status. It was found that 10.4 percent of the members were registered. Of those, 3.2 percent were registered as agricultural engineers, 3.0 percent as civil engineers, 1.5 percent 
as mechanical engineers, and the rest were of miscellaneous classification. Ohio had 25 members registered, with nine as agricultural engineers; Illinois had 25 and 5; Iowa, 15 and 7; Texas, 13 and 7; California, 15 and 1; Nebraska, 10 and 5; Pennsylvania, 10 and 1; Georgia, 9 and 5. Twenty-eight members were registered in two or more professional classifications, such as agricultural engineering combined with civil engineering.

The Committee again pointed out that where agricultural engineering was not recognized, as in some states, how important a large number of accredited curriculums was in swaying the state boards toward recognition.

ASAE's registration posture was far below the national average. Perhaps a trifle on the defensive, Raymond Olney tacked an "Editor's Note" to the report which was supposed to explain the small percentage of professional engineers in ASAE. Let us analyze his remarks by the comments in brackets:

1. About 20 percent (Olney wrote) of the membership were Junior Members, most of whom were still in the process of professional development toward qualification for registration. [Why were not an appreciable number registered as EIT's? That was the first step after graduation, and they would have been counted as actually "in the process." ]

2. More that $\mathbf{1 8}$ percent of the total members were Associates (i.e. affiliates) who make no claim to being technically qualified for registration. [In other words, almost one-fifth of a society that claimed to be composed of engineers was not engineers and probably never would be.]

3. Some 3 percent were so far advanced in professional development and of such established reputation and position that their registration would have been . . a a matter of form of little direct value either to them or to persons employing their services. [These were the very ones who should have registered to provide a good example to the younger members and to give prestige to agricultural engineering at the state boards.]

4. Many members had established their status in the engineering profession by the alternative method of obtaining a rating in the federal Civil Service which had long recognized the professional status of agricultural engineers. [Strictly speaking, possession of a Civil Service rating did not qualify as state registration; however, most states exempted federal engineers from registration while practicing within their borders. Thus the Civil Service people had no incentive to register.]

5. Many members eligible for registration have had limited incentive to apply for it because they are employed in industry. [This suggests that the design of machines, structures, and processes for agriculture by industry did not affect the public safety and welfare to such an extent as to demand supervision of "professional" engineers. Also, see later comment on this topic.] 
Olney said nothing about the college professors, yet most states recognized the teaching of engineering as a practice of engineering; therefore, the professors should have been seeking registration also.

Later in 1948 Henderson and Frevert published a discussion of the background of engineering registration along with the essential elements of the Model Law. They indicated that, although registration was intended as protection for the public, it had valuable effects on the profession itself: (1) It tended to create unification and raise standards; (2) it elevated the quality of college instruction: (3) it identified employees as a part of management and permitted them to collectively bargain as a separate unit.

Carl L. Svensen, secretary of the Texas State Board of Registration, had been an ASAE member for 20 years. He wrote the Committee on Professional Registration an encouraging letter in 1948. Svensen believed the time would come when "an agricultural engineer will find it impossible to designate himself as such unless he is registered, because it would be against the law to do so." One key issue was the scarcity of ECPD-accredited curriculums in agricultural engineering. Another was the necessity to insure that the "basic education and training of ag engineers should be identical with that of any other branch of engineering." However, Svensen was convinced that ASAE was proceeding "in a very wise manner."

At that time, 1948, the position of agricultural engineering education was at the bottom with respect to accreditation. Fourteen percent of the curriculums had been accredited. Industrial engineering was also at fourteen percent. By contrast, civil and mechanical engineering had 91 percent accredited, mining was 89 percent, electrical was 90 percent, and chemical was 50 percent. This situation was not only a disadvantage to individuals seeking registration; it diminished the chances of recognition of agricultural engineering in those states where it was not recognized.

The vital position of agricultural engineering education with respect to professional development and recognition had suffered at many institutions because the departmental objectives and status were not clear. This situation was given a substantial, if not crucial, clarification by a resolution adopted during a meeting in November 1948 of the Association of Land-Grant Colleges and Universities.

The resolution originated in the Agricultural and Engineering Divisions of the ALGCU. At the suggestion of A. A. Potter, dean of engineering at Purdue University, a special committee (H. J. Barre was its secretary) prepared a statement of principles to serve as background for the resolution. After review of the background statement, the deans of agriculture and engineering adopted this resolution as their expression of policy:

"RESOLVED that the principles approved by the Resident Instruc- 
tion Sections of the Divisions of Agriculture and Engineering at their joint conference on Tuesday, November 9,1948 , be used as a guide in formulating curricula leading to degrees of Bachelor of Science in Agricultural Engineering and to Bachelor of Science in Agriculture with a major in Mechanized Agriculture, and that land-grant institutions which have sound programs of study leading to the B.S. degree in Agricultural Engineering apply promptly to the Engineers' Council for Professional Development for inspection and accreditation."

The principles alluded to in the resolution were those drawn up by the special committee. These are of extreme interest. First it was stated that "Agricultural engineering is unique in the degree to which it combines the need for work of a technical character, as in research . . . and in industries serving agriculture, and work of a less technical character such as agricultural extension . . . and farm management." This being true, two distinct curriculums were recognized:

"1. A Curriculum Leading to a B.S. Degree in Agricultural Engineering. The objectives of this curriculum are to prepare the student for engineering service in rural communities; for teaching, research, and extension work with colleges, experiment stations and governmental agencies . . . ; for positions in the manufacture and sale of farm machinery and farm power equipment ...

"The courses comprising this curriculum should emphasize the fundamentals of engineering and agriculture . . Briefly this requires mathematics through calculus, physics given to students in all engineering curricula, chemistry, mechanics, thermodynamics . . . ; biology, soils, field crops ... ; general studies including humanistic and social sciences . . . ; and agricultural engineering subjects devoted to the engineering applications in agriculture which utilize the ... courses in engineering and agriculture ...

"2. A Curriculum leading to a B.S. Degree in Agriculture, with a Major in 'Mechanized Agriculture' (farm equipment, farm buildings, farm water management, or rural electrification). This plan of study is for agricultural students who are interested in the production and primary processing of crops and livestock; in county agricultural agent ... work; in soil conservation work; and in sales and other work that deals directly with farm people ... The courses should . . . be presented from the viewpoint of the user and consumer of farm equipment and not from that of engineering design."

After recognition of the need for two distinct undergraduate curricula, the desirability of sound graduate programs was pointed out. And finally, the special committee recommended that Mechanized Agriculture programs be administered by the agricultural dean, but that the Agricultural Engineering programs be jointly administered by the engineering and agricultural 
deans.

The debate that preceded adoption of the resolution brought out several important viewpoints and facts regarding the place of agricultural engineering in the academic scene.

For example, it was argued that agricultural engineering was not unique in its claim to a combination of technical work with service work. Some other branches of engineering and agriculture could say the same with equal justice. Nevertheless, the need for training of a vocational character was well-established.

There were questions about the dual curriculum concept. Some said that agricultural engineering was already handicapped by a lack of standards in its curriculums. To offer two curriculums of different technical levels would retard professional development even more by confusing prospective employers. However, both curriculums need not be offered at a given school; the important point was that a curriculum be clearly and completely in one category or the other. A point of significance to agriculture was the understanding that "service" courses would not be displaced by the introduction of a curriculum in Mechanized Agriculture.

The resolution of the ALGCU could not be enforced, but it had the prestige and power of the deans behind it. The two sets of deans were committed to the policy of accreditation; the concept of a "mechanized agriculture" curriculum was made respectable; and the need for joint cooperation in management of the agricultural engineering curriculum was underlined and agreed upon.

A report of the resolutions, written by L. L. Sammet, appeared in the April 1949 Journal. An example of its persuasive powers quickly followed. W. J. Promersberger, chairman of the Agricultural Engineering Department at North Dakota Agricultural College, announced in May that their curriculum which provided for a "major in agricultural engineering" would henceforth be known as the "major in mechanized agriculture." It would be administered by the dean of agriculture. Their five-year professional curriculum was in the college of engineering and was jointly administered by the deans of agriculture and engineering; no change was called for in this case.

At this same time ASAE turned to consideration of another important aspect of professional development: adoption of a code of ethics.

The history of ethical codes is an illustration of the difficulty engineering has always had in defining and regulating itself as a profession. Although the major societies were founded in the nineteenth century it was not until 1914 that they established written codes. At that time the civils, electricals, and mechanicals each adopted a different code. Behavior acceptable to one 
group was sometimes unacceptable to another. Even worse, the engineers could not agree precisely upon the question of who were engineers and who were not. The problem of writing and adopting a code of ethics for the entire profession seemed insurmountable.

However, in 1947 ECPD adopted a "Canons of Ethics for Engineers" which it recommended to the engineering societies for adoption as their own codes. This would create a standard set of codes throughout the profession and reduce some of the confusion. It was widely accepted by the societies, at least initially, and in April 1949 it was printed in AGRICULTURAL ENGINEERING for the information of the members. There was no intention of balloting on ECPD's Canons; however, members having "serious objections" were invited to have their say.

The ECPD Canons had 28 sections. These were organized under principal headings: "Professional Life," "Relations With the Public," "Relations With Clients and Employers," and "Relations with Engineers." One of its defects for ASAE was that its provisions applied largely to self-employed engineers, a small minority in agricultural engineering.

The "Canons of Ethics" were adopted as the "sole code of ethics for the Society" by the Council at its meeting on June 19, 1949. They remained in effect until 1967, when a revised ECPD Canons was placed in the ASAE Yearbook.

The Committee on Professional Registration evidently stirred up some interest in the subject. A survey was again made in 1949 which disclosed that 310 members were registered, with 120 of them registered as agricultural engineers. Compared to those September 1948 figures the number had increased by nearly 100 while the percentage had raised slightly from 10.4 to 11 , with the agricultural engineering percentage raised from 3.2 to 4 . It was also noted that 12 "younger" members were registered as "engineer-in-training."

Member B. F. Muirheid wrote to the Journal in 1950 that "you may find it increasingly difficult, as time goes by, to convince the public that you are a "professional engineer" unless you are duly registered." He went on to say that the requirements were not unreasonable and that those qualified had no argument against it. He indicated that the "public is cognizant of professional engineering and expects all engineers to be registered," particularly the younger engineers.

NCSBEE decided in 1950 to obtain some feedback on how employers of engineers felt about registration. Their Committee on Effects of Registra- 
tion studied 100 companies which employed large numbers of engineers. The representatives who furnished information to the committee were not, in most cases, engineers. The majority opinion was that "registration is advantageous to the public, to the engineering profession, and to employers of engineers." Most employers encouraged the registration of engineers in their organizations but they did not require it or favor those registered when employing engineers (this was a basic weakness in the registration scenario as it applied to industry; a registered engineer had no competitive advantage).

Meanwhile ASAE's Committee on Professional Registration had started working with sets of examination questions. It reported in 1951 that sample copies of questions and answers would be supplied as a guide to those preparing for examination. Also, concentration on seniors and recent graduates was considered to be highly essential; colleges were reminded of the publications available from ECPD and NSPE which offered guidance to young engineers seeking registration. ASAE members were encouraged to participate in activities of their state society of professional engineers. The Committee recommended that ASAE give its support to strengthening the "engineer in training" program for preliminary registration of recent graduates in the various states (at that time not all states had this program).

A difficulty encountered with the examinations was the increasing degree of specialization in agricultural engineering. Although the four technical divisions of ASAE had much in common, they utilized different backgrounds of engineering science; their fields of practice became more divergent as the decade advanced. The tendency was somewhat encouraged by the colleges, many of which demanded that the students select a field of specialization while still undergraduates. The situation was hardly critical (in 1958 ASME had 27 technical divisions) yet it created concern. An editorial in the 1952 Journal titled "Professional Unity" attempted to show that agricultural engineers were, after all, more alike than different.

A member had pointed out that "the time is long past when the man who designs barns will be called upon to design field machinery." This caused the writer to ask his readers, "wherein then is the essential professional unity among agricultural engineers?"

He claimed that their strongest common bond was a unity of purpose in service to agriculture. In technology there was the unity of basic training, viewpoint, and interest in applications of physical science which denote the engineer. There were bonds of related interest between any two branches of agricultural engineering. Those who preferred a high degree of technical specialization could make great contributions, provided the specialization be based on appreciation of "the common interest links holding agri- 
cultural engineers together as one distinct branch of the engineering profession devoted to serving agriculture."

The decade was witness to several examples of important trends in professional development. The registration movement received its initial impetus at that time, as we have seen, and its pace quickened as time went on. ASAE obtained membership in EJC and ASEE, moves which brought recognition of agricultural engineering as an engineering profession. ASAE adopted the Canons of Ethics for Engineers, in common with most other technical societies. ASAE participated vigorously in the Centennial of Engineering, which celebrated the founding of the American Society of Civil Engineers in 1852. Such participation was a mark of solidarity with the engineering profession. ALGCU clarified the position of agricultural engineering in the colleges. The crucial matter of curriculum accreditation by ECPD was strongly pursued by the academic sector, greatly aided by ASAE. We have seen that the number accredited grew during the decade from three to 25 (out of 44). The importance of this achievement cannot be overemphasized: in the end, all other aspects of professional development are rooted in the quality of the educational base.

One other aspect of agricultural engineering education had gained momentum during the period and strengthened the professional stance of agricultural engineering-graduate-level instruction.

For many years Earl White possessed the only earned doctor's degree in ASAE; he received his Ph.D. in agricultural engineering from Cornell. Later, Davidson's department at Iowa State College produced some Ph.D.'s (probably in cooperation with other science or engineering departments). E. G. McKibben and H. J. Barre were doctoral graduates of Iowa State. At least two Ph.D.'s in physics found their way into agricultural engineering: one was F. A. Brooks, a graduate of M.I.T., the other was Andrew Hustrulid, who graduated from the University of Minnesota. Hustrulid spent his working career with the agricultural engineering department at Minnesota. There may have been one or two others prior to World War II; E. W. Schroeder of Oklahoma A. and M. College wrote in 1956 that prior to 1950 only eight doctor's degrees were granted in agricultural engineering. The NRSSP of 1944 listed eight members holding the Ph.D.

At any rate, very few agricultural engineers possessed the highest academic degree until after 1950. The handicap this imposed on the profession in terms of research and educational development can well be imagined.

But the tide turned after 1950. According to Schroeder, between 1950 and 1956, 43 Ph.D. degrees were granted. Although several colleges and universities were involved in the thrust, Michigan State and Iowa State were the leading producers. As Roy Bainer said in his 1957 address," . . . the 
trend toward more and more graduate work is doing much to raise the level of professional training in the field."

This was true. The complexity and abstraction of the research undertaken by doctoral candidates offered some hope of attaining to the "pure" ideal advanced by Harry Walker, although some debated the desirability of it. Perhaps more valuable, the candidates tended to immerse themselves deeply in collateral fields such as biology, soil physics, or some branch of engineering science. This broadened them intellectually and gave them a discriminating approach to agricultural engineering problems, an attitude which was transmitted to their students. Also, the basic scientific training inherent in the doctorate programs, including critical use of the scientific method, was needed in agricultural engineering. In 1957 F. J. Hassler of North Carolina State College said this to the Southeast Section ASAE:

"Agricultural engineering should be more demanding in its reliance on the fundamentals of science than other professions because of the complexity of its problems and of the dispersion of its activities. All forms of energy, forces and materials must be taken into account if alternatives are to be considered fully. Also, most of our activities must accommodate the sensitivity of biological systems. In comparison agricultural engineers work under circumstances that require greater selfreliance if they are to be productive; therefore, for him to maintain a conscious awareness of scientific knowledge he must rely on the few underlying generalizations rather than the many facts and causal relationships."

It would not be perhaps too wide of the mark to state that the Fifth Decade was not only the one of most rapid growth of ASAE but also the one in which professional development and recognition of agricultural engineering attained their most marked progress. 


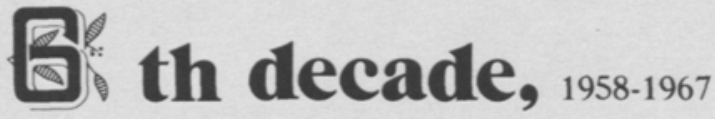

\section{"AGRICULTURAL ENGINEERING IS UNIQUE*..}

A. W. Farrall

\section{A}

\section{General Progress}

The first Soviet Sputnik (rocket-powered artificial earth satellite) went into orbit October 4, 1957. A second, carrying a dog, was orbited a month later. The U.S. awakened from its golden age of technological mastery to find itself menaced by a new master. As Walter Lippman saw it:

"In short, the fact that we have lost the race to launch the satellite means that we are losing the race to produce ballistic missiles. This in turn means that the United States and the Western World may be falling behind in the progress of science and technology.

"This is a grim business.

"It is a grim business because a society cannot stand still. If it loses the momentum of its own progress, it will deteriorate and decline, lacking purpose and losing confidence in itself."

Not all Americans were disheartened by the Russian space achievements. ASAE President Earl D. Anderson of the Stran-Steel Corp. perceived the basic weakness of the Russian economy. Five days after the "Muttnik" went

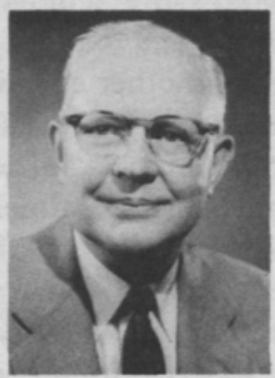

Earl D. Anderson 51st president, ASAE, 1957-58 
aloft he challenged Premier Khrushchev to an agricultural showdown.

Speaking before the ASAE Washington, D.C., Section, Anderson said the "Concentration of engineering and scientific talent on missiles at the expense of consumer goods production has left Russia's agriculture still in a primitive state." He asked how many Russian farms were electrified; 95 percent of U.S. farms enjoyed the blessings of electricity. He asked how many manhours were required to produce Russian wheat; in the U.S. such labor had been reduced from 57.7 to 1.82 man-hours per acre. Finally, he asked what percent of the Russian population was required to feed and clothe their people; the Americans did it with 13 percent living on farms.

These and other home truths were prepared as a news release, with copies to the Voice of America for possible broadcast behind the Iron Curtain. As a note of cheer in a time of gloom, Anderson's words should have enjoyed wide currency but the record is unclear. The Americans were prone to take agricultural production efficiency for granted; as for the Russians, if they heard Anderson's words they probably assumed he was telling capitalist lies.

The same theme - food vs. space - erupted again at the June 1961 meeting in a speech prepared by Secretary of Agriculture Orville Freeman. The recent manned space flights prompted him to say:

"I am sure the Communist nations with their food shortages realize far better today that to people who are really hungry, bread and milk at hand are more important than a star in the sky. To millions of men and women throughout this world the higher standards of living that can be achieved if we properly use our capacity to produce are of more direct and personal concern than the discovery of other worlds."

American agricultural technology did not lose prestige and esteem, therefore, because of Russia's initial lead in space. It was the environmental movement that put food production and "quality of life" into conflict. Rachel Carson published her book "Silent Spring" in 1962. In a way, it gave an impetus to the environmental movement as important as "Uncle Tom's Cabin" did to the abolition movement.

Doubts regarding pesticides and other chemicals had been raised earlier, as was noted in the previous decade, but most ASAE members were fairly well committed to the chemical technology. The public reaction to pesticide chemicals aroused by Carson's book was almost incomprehensible at first. Later, when the aversion to chemicals was extended to fertilizers, such attitudes seemed almost insane.

Response to the situation came early in 1963. Professor C. M. Hansen of Michigan State University was chairman of ASAE's Committee on Agricultural Chemical Application. He called a meeting of a number of interested organizations in Chicago, where they formed a temporary Council 
on Pesticide Application. Hansen was elected chairman of the group, and ASAE member John Wessman of FEI was made secretary. The purpose of the Council was "information exchange, liaison, nomenclature standardization, and coordination among organizations concerned with pesticide application." The next step was to obtain Board approval of the various organizations involved. In addition to ASAE, these included the Farm Equipment Institute, Farm Equipment Manufacturers Association, National Agricultural Chemical Association, American Phytopathological Society, Entomological Society of America, American Society for Horticultural Science, Weed Society of America, National Conference for Farm Safety, American Medical Association, and the Pesticides Regulation Division of the USDA. A number of other important societies expressed interest in the Council.

Hansen published a short rebuttal to Carson's book in the ASAE Journal in April 1963 which portrayed the puzzled bafflement of the contemporary technologist:

"From the standpoint of the agricultural engineer, the publication of one popular and sometimes sensational book censoring the use of pesticides does not establish a case. The agricultural engineer knows the worth of chemicals. They have been his defense against the malariabearing mosquito, the economic catastrophes produced by the boll weevil, termites, and the corn borer.

"Now, the agricultural engineer is forced to watch as that same John Q. Public who panicked when one spider wandered into his house suddenly becomes the protector of all that crawls, flies, or stings, whether good or bad."

The article, entitled "Noisy Summer?" was embellished by a large cartoon showing a dejected farmer leaning against a worm-eaten fruit tree. His dog is scratching busily; his crop is under attack; his cow is swarming with thies while rats play merrily around her feet. The farmer's eyes are glued to an open newspaper on the ground which says "Read 'Silent Spring,' A Best Seller!"

When the Board of Directors met in June at Miami Beach it considered a letter from Professor Hansen which invited ASAE to join the Council on Pesticide Application. It was voted that ASAE join the Council (the cost was only $\$ 25$ per year). Further discussion brought forth opinions that ASAE ought to "take a firm position in the current controversy concerning application of chemicals." However, it was finally agreed that such action had too much flavor of politics and might be risky.

A Pesticide Application Seminar was held one day preceding the 1963 Winter Meeting. "Pesticides, a Tool of Man" was selected as the seminar 
theme, which was planned on behalf of the Council on Pesticide Application. Its purpose was "to bring into clear focus the important role played by agricultural chemicals in the production of the food, feed. fiber and animal protein necessary for the existence and continued well-being of all peoples." Although ASAE published a 32-page proceedings of the seminar, the main points were summarized by Norman B. Akesson (University of California at Davis) in the February 1964 Journal. Aside from discussing technical needs and advances, the speakers called repeatedly for ways to enlighten the public as to the benefits of pesticides.

Wesley W. Gunkel of Cornell University published a Journal article in 1966 on "How Agricultural Chemicals can Boost Production." He mentioned another group of chemicals for the public to worry about along with fertilizers and pesticides - the plant growth regulators.

These rather mild responses by ASAE to the public panic created by Carson's book probably had little impact except to make the agricultural engineers feel slightly better. The effect on the public was probably very small in spite of certain "public relations" efforts. The engineers were extremely unwilling to appear at public hearings and in similar situations, particularly as spokesmen for ASAE. Thus they remained silent while hundreds of self-anointed "ecological experts" paraded their ignorance in public at every opportunity. Worse, the environmental movement articulated to a degree with opposition to the Vietnam war and with extremist shades of political opinion, until no room was left for reasonable discussion of technical alternatives.

The agricultural engineers thought, for example, they had accomplished much in soil conservation. But the environmentalists wanted the streams and rivers to run crystal-clear, as they did before the white man came (a good example of that type of ignorance). Therefore, the ponds and terraces and soilsaving practices that worked so well before were now ignored or misunderstood. The environmentalists thought one could pass laws and make the streams run silt-free. As to chemicals, large numbers of people went 'organic,' convinced that they were being poisoned or given cancer by fertilizers and pesticides. Legislation, some of it hasty and ill-advised, began to appear. Some individual members of ASAE worked hard with environmentalist groups, trying to help them keep a degree of sanity in their well-intentioned endeavors. But ASAE itself kept clear of controversy even though a part of its hard-won technology was now downgraded. Agricultural engineering was on the defensive again for the first time since the 1930s.

However, agricultural engineers started creating new technology in the area of agricultural waste disposal and management. This movement may have been in response to the rising public concern for environment or it may 
have been independent recognition that the new age was becoming intolerant of certain farming techniques.

Three ASAE members at Iowa State University, E. P. Taiganides, T. E. Hazen, and E. R. Baumann, started research in 1960 on an animal-waste disposal study financed by the U.S. Public Health Service. They hoped to bring the farmer some income from treated wastes and also to reduce the chances of water pollution.

In concert with the Poultry Science Association, ASAE sponsored a Symposium on Poultry Industry Waste Management in May 1963 at the University of Nebraska. The sessions covered manure processing, fly control, odors and air pollution, and water pollution.

Meanwhile, a special committee on Rural Waste Disposal had been appointed. Comprising 11 members, its chairman was $R$. E. Choate of the University of Florida. An initial task undertaken by this committee was an attempt to standardize terminology.

In 1964 the Farm Structures Division Committee on Research Needs and Statistics developed this resolution:

"Whereas farmers are building manure lagoons, holding tanks, septic tanks, manure dehydrators and processing plants without sufficient knowledge of requirements; and, whereas some of these devices constitute a threat to the public image of agriculture.

"Resolved that the American Society of Agricultural Engineers strongly recommend to the various agricultural research agencies of the State and Federal governments to intensify investigations into the means of cleaning livestock yards and buildings, conveying the manure and disposing of it with due regard to its value as fertilizer, fuel, etc., and to its danger as a source of contamination, insects and odor. The Society recommends further that the investigation be a broad effort backed by various other appropriate scientific disciplines and organizations as, for instance, the North Central Regional Committee on Farm Waste Disposal."

The resolution was sent by President Price Hobgood to 51 directors of the agricultural experiment stations, along with a personal letter. Several of them returned cordial replies, indicating extreme interest in waste disposal research and the development of projects.

Concerned ASAE committees held a session on waste disposal research at the 1964 Winter Meeting in New Orleans. S. A. Hart (U.C. - Davis), Taiganides, and $H$. J. Eby (USDA) summarized the problems as the "PreEminent Challenge to Agricultural Engineers." The state of the art was revealed as embryonic although under vigorous attack. Outstanding problems included: (1) The need for adequate criteria to measure pollution poten- 


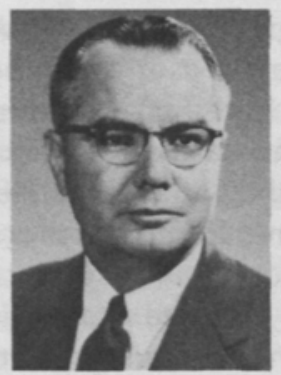

Price Hobgood

58th president, ASAE, 1964-65

tial of animal wastes; (2) design and construction methods for lagoons and similar devices; (3) disposal of other wastes such as cannery discharges, crop residues, and chemical contaminants; and (4) methods to render wastes useful, such as feeding them, producing algae for fish food from manure oxidation ponds, developing fuel sources, etc.

During that same Winter Meeting the Board of Directors approved the proposal of the Rural Waste Disposal Committee that it sponsor a National Symposium on Farm Animal Waste Management. The initial planning committee was headed by P. E. Schleusener of the USDA.

The symposium took place in May 1966 at Michigan State University. In addition to ASAE, it was co-sponsored by USDA, ASCE, the 13 agricultural experiment stations of the North Central Region, and Michigan State's Con-

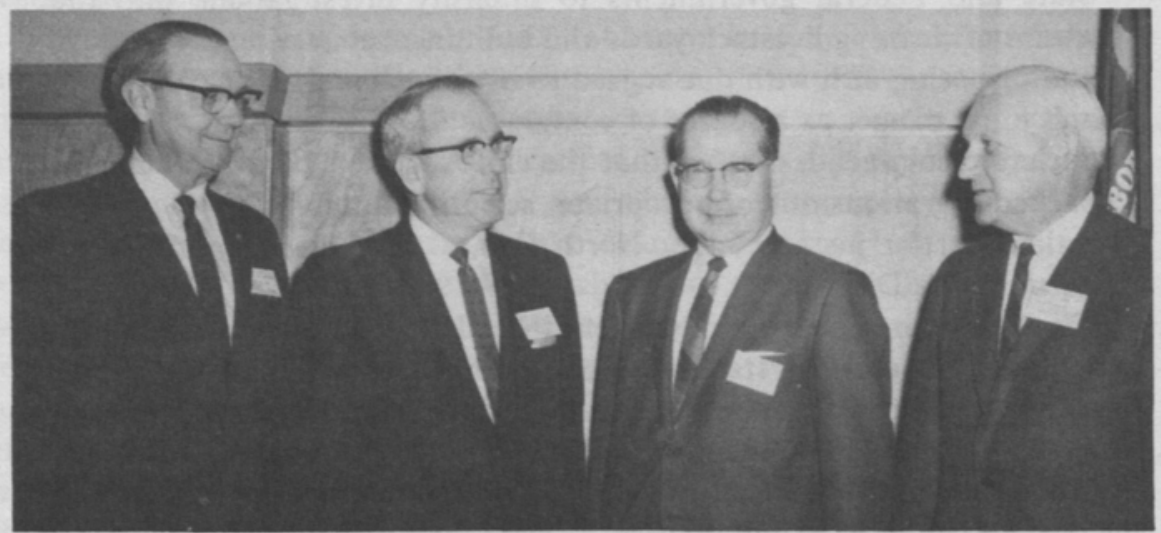

A National Symposium on Animal Waste Management was held at Michigan State University in May 1966. Officers representing sponsors or cooperators of the symposium opened the conference by outlining problems facing their respective organizations. Left to right are G. S. Hobbs, president, American Society of Animal Science; C. S. Morrison, president of ASAE; L. T. Cheney, director, American Society of Civil Engineers; and A. J. Maw, president, Poultry Science Association 
tinuing Education Service. Other cooperating organizations were American Society of Animal Science, American Dairy Science Association, American Society for Microbiology, and the Poultry Science Association. The symposium was supported by a grant from the Office of Solid Wastes, U.S. Public Health Service.

The conference attracted over 300, including several experts from Europe. It may be regarded as a landmark event, after which the study of manure disposal became not only quite respectable but well-financed. Urban expansion, confinement production utilizing increasing animal numbers, and the widespread desire for clean air and water had created a "national problem." Agricultural engineers took the lead in trying to solve the problem and this was at least a partial response to the outcries about "environmental degradation."

But the overall environmental concerns involved, it seemed, almost the totality of agricultural engineering technology. Soil erosion alone, for example, was bad enough, but water-borne silt carried nitrogen and phosphorus which ruined lakes and rivers. It carried pesticide chemicals which would not biodegrade and which killed wildlife. The attack on these problems required not only use of time-honored methods but fast development of new ones. ASAE's two largest divisions - Soil and Water and Power and Machinery were obviously involved. Search for non-chemical control of insects brought in Electric Power and Processing. Farm Structures was already somewhat committed to the waste-management thrust. Likewise, the Food Engineers had to think of the effluent from their processing plants.

The new dimension was complex. At first, Rachel Carson was viewed as an alarmist. The answer to her book was to be just a little more careful with pesticides. But an aroused public, whether informed or not, could prevail in a country where food surpluses were quite common, to cause some drastic changes. Even though food prices might rise, the public wanted a cleaner and safer environment. So government mechanisms were created to satisfy the demand. In the process, agricultural engineers started to work on problems created by the chemicals. They were perhaps inspired by the example of the manure-management engineers, who had been (in the words of E. P. Taiganides) "fighting the battle of the forgotten end."

It was earlier noted that back in 1938 some small efforts were made to define agricultural engineering as a kind of biological engineering. These efforts resulted in no remarkable changes; the idea submerged for over two decades, then emerged again. This time it received much more attention, not 
only from ASAE but from most of the engineering societies.

Wilson B. Bell, associate director of the Virginia Agricultural Experiment Station, gave a talk at the ASAE Southeast Region meeting in February 1960 which should have awakened the engineers to neglected opportunities. $\mathrm{He}$ told his listeners that "Your sphere of activity is more closely intertwined with the life sciences than is that of the other branches of engineering." He said that:

"Agricultural engineering in a broad sense includes those phases and features of the science and practice of engineering identified with and related to agriculture. The intricate relationships of soil fertility, water, and crop production under modern farming conditions involve many phases of engineering. You cannot escape, even if you wished, the world of living things."

According to Bell, there was no area of agricultural engineering free from involvement with biological materials. Because of this, these engineers had "an unlimited opportunity for the development of fundamental, as well as practical, knowledge." In soil management, for example, irrigation, tillage, and other engineering techniques have direct bearing on soil environment and ecological relationships. The engineer must take account of these relationships in design of machines and systems. Hay pelleting machines demand knowledge of the nutritive value of the pellets. Sound information on the effects of environment on plants and animals should guide design of structures intended to house those organisms.

Bell concluded by calling for intimate collaboration between life scientists and agricultural engineers; it was clear to him that both would serve the public much better as a result.

Although Bell's talk was published in the Journal, its impact was somewhat limited, perhaps because he was not a member and because the printed address was rather long. However, it may have inspired G. W. Giles in his speech to the FEI dinner guests at the Memphis Winter Meeting of 1960. Head of the Agricultural Engineering Department at North Carolina State College, Giles created a sensation with his address, which was titled "Goals for Agricultural Engineering Research."

Giles was concerned that synthetics were competing successfully with some agricultural products. To portray the problem, he noted how rayon fibers manufactured in a chemical plant from cellulose acetate and acetone were similar to cotton fibers manufactured in a biological plant from water, nutrients, $\mathrm{CO}_{2}$ and solar energy. The question was: Which is the more efficient factory? The agricultural engineers should work to make the "biological factory" more competitive by giving more attention to "the internal mechanism of biological production and to the external operations and 
environment that influence this mechanism." And this was a tremendous frontier, the opening of which will "attract the attention and capture the imagination of our younger generation." (The perennial low enrollment problem was troubling ASAE and the colleges; the magic of that last sentence can be imagined.)

The goals envisioned by Giles were these. First, to increase the efficiency of the producing system; both biological and operational efficiency were in his mind. With respect to the former he said: "Our professional contribution towards achieving an increase in the biological efficiency must be in the modification of the environment and the effective utilization of energy. .." Second, to develop more powerful agricultural operations. Third, to insure a dependable quality and supply so that industry will not be forced to use more synthetic products. More control in planting and environment were called for. Fourth, program and coordinate the operations, which again boiled down to environmental control.

Giles then developed research policies which he believed would help agricultural engineering research reach the goals. But in articulating the policies he broadened his argument to include not only research policy but a concept that tended to unify the hitherto rather fragmented field known as agricultural engineering:

"Some may say that the science of biological processes should be left to the pure scientist and that agricultural engineering should confine its activities strictly to engineering practices. Regardless of whether it is called pure science or not, the fact remains that the mathematical relationships of the physical to the biological processes are basic to developing superior engineering systems. Our profession needs some fundamental law on which to base our judgments and guide our direction and pattern of growth for engineering the biological system. The core of our profession should be built on engineering laws governing the intricate complex processes of plants and animals. This is the thing that distinguishes agricultural engineering from other engineering professions."

The ideas expressed by Giles were received with great interest by many in the colleges. They had coped for years with the concept that agricultural engineering was "the application of civil, electrical and mechanical engineering to the problems of agriculture." As C. O. Reed had commented years ago, such a concept did not lend much status or distinction, nor did it aid in the battle for students. But the Giles conception had an element of distinction about it, with just enough truth in it that it could be "sold" without blushing too deeply. Maybe agricultural engineering was a kind of biological engineering. Of course, the scenario was not universally admired; the 
biological approach was viewed with reservations by a large percentage of the members in private industry.

For a couple of years much discussion took place regarding biological engineering. Then, during the presidency of A. W. Farrall, the topic was introduced at a December 1962 Board of Directors meeting by E. H. Kidder of Michigan State, an ASAE director.

Kidder stated that modern agricuitural engineering was essentially biological engineering; that "many" new biological engineering departments were being established at various institutions; and that perhaps ASAE ought to consider "broadening its base to include all aspects of biological engineering." There was even a hint that ASAE might change its name to "American Society of Biological Engineers," which will suggest the degree of interest the topic had achieved by then.

Kidder's comments were well-received. The Board agreed that it was time to let all and sundry know that "agricultural engineers are actively concerned with engineering related to energy, structural and environmental factors of plant, animal, and human development and performance efficiency" and that ASAE should look for opportunities to "be of increased service in various phases of bio-engineering."

It was then voted to authorize President Farrall to appoint a special threeman committee to look into the possibilities of more active affiliation with biological engineering and develop a position statement for consideration. (Farrall appointed C. F. Kelly, F. J. Hassler, and R. E. Stewart, chairman.)

A. W. Farrall was not a man to neglect anything that held promise for improvement of ASAE and the profession. He liked the "biological" thrust and pushed it forward when he could. In planning a trip to Washington for February 1963 he wrote W. M. Carleton about the possibility of calling upon Dr. Newman Hall, Commissioner of Engineering Education. He wanted to "convince Dr. Hall that agricultural engineering is a leading profession and that, with this new angle of bio-engineering, it is something he should

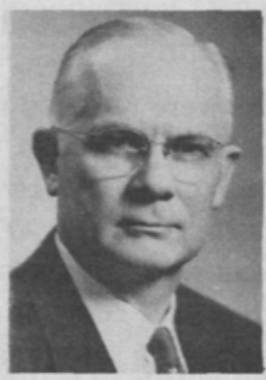

Arthur W. Farrall

56th president, ASAE, 1962-63 
become familiar with."

Jimmy Butt mentioned "bio-engineering" in his February 1963 "Check Points." He noted that EJC was devoting attention to it, along with ASME, and pointed out how agricultural engineering had always been involved with plant and animal environment. However, the attention of the other societies, biologically speaking, was turned more to medical and human aspects.

At the June 1963 Board of Directors meeting, H. H. Nuernberger, ASAE's representative to EJC (ASAE became a constituent, or voting, member in January of 1961), reported that a Committee on Engineering Interactions in Biology and Medicine was to be formed in order to evaluate the role of engineering in the biological sciences. An ASAE member was requested for consideration as chairman of the committee. The name of $R$. E. Stewart was later submitted to EJC; he became the first agricultural engineer to head a major EJC committee.*

Director Carl W. Hall reported to the Board on how the Agricultural Engineering Department faculty at Michigan State University emphasized biological engineering in talks to high school students. He commented that this was an excellent means of attracting urban boys and girls to the curriculum offered in the Department of Agricultural Engineering. At this point Director R. R. Raney of the New Idea Company observed that emphasis on biology suggested a scientific rather than an engineering orientation for agricultural engineering. He commented that industry might regard biological engineering as a "scientific" discipline and wondered if such emphasis was desirable.

Later in the meeting President Farrall again called for discussion of biological engineering; he pointed out that if ASAE was to be identified with it, "early action" was necessary. Director E. T. Swink (of VPI) said that agricultural engineers needed to "identify themselves in some unique manner" and that "this seems to be a good opportunity." Then R. E. Stewart, chairman of the ASAE Committee on Relationship of Biological Engineering to Agricultural Engineering, was called upon for an interim report.

Stewart (who was now at Ohio State) first expressed concern over a recommendation aired at the Cabinet meeting that ASAE change its name to include biological engineering. Such a move would be a great mistake because

\footnotetext{
* The committee was organized with representation from most of EJC's member societies. After flourishing for a time it was disbanded because EJC did not wish to encourage the committee's desire to obtain a grant from the National Science Foundation for support of objectives. Perhaps the only tangible remnant is a book published under auspices of the committee entitled "Advances in Bioengineering and Instrumentation." The book was edited by Dr. Fred Alt, who represented the Instrument Society of America on the committee; ISA published the book in 1966.
} 
ASAE had little to offer those interested in biomechanics or biomedicine. He felt that the unique character of agricultural engineering was the "proper combination of mathematics, physics, engineering, and biology." The path to biological engineering was through development of college curriculums and a strong biological program in ASAE, not by changing the name of the Society.

President A. W. Farrall's annual address at the meeting was titled "The Sixth Decade." The sixth decade was to him the biological age, a time when agricultural engineering urgently needed redirection. He expressed his views this way:

"The question might be asked what is the difference between agricultural engineering and the other principal disciplines of engineering. The answer might be: 'Agricultural engineering is unique in that it involves specifically biological and environmental factors, since it deals with engineering applied to biological matter - food, feed, natural fiber, animals and humans.' Note that the unique feature, the one we have which is different from any other, is the emphasis on the biological factor."

He presented examples of how agricultural engineering design constraints were largely biological in character. Increasing recognition of that situation was being paced by curriculum changes, including greater emphasis on the biological component; in fact, some universities were reshaping their entire professional degree courses to take advantage of the new understanding.

Farrall regarded the "ability to combine the knowledge of biology with engineering" as offering the "greatest opportunity that has happened to our profession in years."

There were many who agreed, as has been noted. Shortly before the 1963 Annual Meeting, E. T. Swink spoke to a rural electrification conference in Virginia about "environmental control." He pointed out that optimum environments were desired now routinely by humans of all classes and that sophisticated environmental control was highly essential for astronauts. The agricultural engineers were daily discovering the economic value of environmental control for domestic animals. This was a new and thriving field of teaching and practice, based largely on research collaboration with animal and medical scientists.

M. L. Esmay of Michigan State wrote from Taiwan suggesting that "a new name (for ASAE) should be seriously considered." He thought that the biological engineering movement would help the public to understand that agricultural engineering was concerned with far more than agricultural production. Further, if "many new biological engineering departments are being established" without relation to agricultural engineering then "it is later than 
we think."

Was ASAE really missing the boat or was the biological furor mostly a search for identity and status? Was it a genuine unifying concept or was it only a public relations and recruitment gimmick?

President J. W. Borden (Eversman Manufacturing Co.) called for Stewart's committee to deliver its final report at the 1963 Winter Meeting. The committee report was verbose but in essence sought to establish these ideas:

1. ASAE would be a doubtful nucleus for a "Society of Biological Engineers," principally because the biomedical engineers, the sanitary engineers, and other groups of engineers were interested in biological subject matter that did not closely coincide with that of agricultural engineering (soils, plants and animals). Under no circumstances should ASAE change its name.

2. The academic sector of agricultural engineering was obliged to define the field because it had to teach it and to bear the main burdens of recruiting. If the central activity of agricultural engineering were to be defined as "engineering the biological systems of agriculture" and if the curriculums actually reflected that activity, good students ought to be challenged because by that definition agricultural engineering was unique, not just applying "engineering to agriculture."

3. ASAE, it was suggested, should discontinue its technical divisional names such as "Soil and Water," "Farm Structures," etc., in favor of designations which described the functional aspects of engineering the biological systems of agriculture, along the lines of the Giles argument. The colleges should minimize applied agriculture instruction and strengthen the requirements in biological science. Courses in agricultural engineering should be restructured toward use of biological parameters as leading elements in engineering design.

The reception of the report was lukewarm; however, members were not

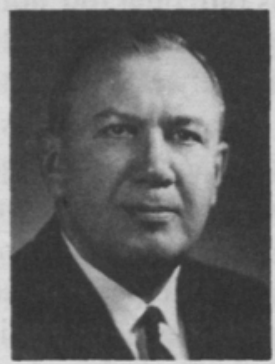

John W. Borden

57th president, ASAE, 1963-64 
ready to change the name of ASAE, so that part of the report was acceptable. The enthusiasm for biological engineering centered largely in the colleges; industry and government stayed somewhat aloof from the movement. College curriculums changed to some extent, and, to some extent, recruiting efforts were aided by the new approach, but no revolution came about. To make a genuine change toward biological engineering in a four-year curriculum demanded more than most faculties were willing to give. As for the suggestion that ASAE change its divisional names, it was received in silence by the Board of Directors.

Many industrial members were opposed to the biological conception. It clashed with the tradition that the farm equipment industry liked to hire mechanical engineers with farm background and call them agricultural engineers. It seemed to offer no scope or place for engineers interested solely in power plants, gear trains, metallurgy and such matters. Yet these engineers made great contributions to the design of agricultural machinery and their membership in ASAE was most welcome. Therefore, the industrial members were reluctant to encourage the idea that all agricultural engineers were some kind of bioengineers or that ASAE was composed only of bioengineers.

An example of this attitude surfaced at the 1966 Annual Meeting at Amherst when the reorganization plan was under study by the technical divisions. Undaunted by the relative failure of his committee report in 1963, Stewart (now chairman of the Forward Planning Committee) had inserted a "Bioengineering Division" in the ASAE reorganization proposal. The Power and Machinery Division expressed approval of all aspects of the proposal except the "Bioengineering Division" segment.

This rather negative attitude discouraged the Board of Directors and finally resulted in establishment of a Bioengineering Committee in the Education and Research Division. After all the talk was over, nothing but a committee remained which could be directly identified with the term "bioengineering."

To speculate somewhat, this outcome did not necessarily signify rejection of biology as a major component of agricultural engineering practice. Developments of the 1960s definitely embraced the biological dimension and used it with increasing skill. Examples of this can easily be cited - the biological aspects of the environmental quality thrust and the recognition that irrigation and drainage were elements of crop ecology, as were various mechanical soil management practices. Quality control in food engineering and processing demanded microbiological expertise. Control of animal environments required a strong background in physiology. With these developments can be cited the efforts in education to teach a brand of agricultural engineering that took in the properties of its living subject mat- 
ter as elements worthy of engineering analysis.

Thus, it may be said that while the agricultural engineers moved closer to being bioengineers during the sixth decade, they did not want to be called bioengineers or to be limited completely to the practice of bioengineering. In the process they gained something of the uniqueness Farrall (and many others) desired to set them apart from other engineers. But the "greatest opportunities" predicted by such visionaries, such as wide recognition by other branches of engineering, students flocking to the banner, etc., did not come to pass. These changes probably did not materialize because there was a basically false aspect to the "bio" argument: most agricultural engineers were not willing (or able) to truly "engineer the biological system" in the profound Gilesian sense. The system is too complex for easy understanding and the products are not valuable enough to justify the effort. Contrast the design of an agricultural machine to that of a cardiac pacemaker. Both are bioengineering, but the engineering of the latter machine better fits the meaning expressed by G. W. Giles in 1960 . The agricultural machine, unfortunately for ASAE's dream of greatness, can be designed by engineers with little or no biological knowledge. The pacemaker, of course, is less costly a device than the agricultural machine but its product (so to speak) is a human being, thus more worthy of intensive effort at understanding.

If C. O. Reed and the "Horse Feathers Club" left a permanent visible mark upon agricultural engineering (aside from the Bioengineering Committee of ASAE) it may be found in some universities. In 1965 F. J. Hassler, who inherited Giles' position as head of the Agricultural Engineering Department at North Carolina State University, announced its name had been changed to the Biological and Agricultural Engineering Department. Among other reasons for the change he mentioned the desire "to improve our position for solicitation of grants in keeping with capabilities, and to attract the attention of appropriate public and private enterprises for support of our programs. .."At later dates similar changes were made at Mississippi State University and Rutgers University.

In November 1956 Past-President Wayne $\mathrm{H}$. Worthington wrote to the ASAE Council that "The present method of selecting our officers and council members has a number of serious disadvantages. . ."

He proposed, among others, that five vice-presidents be elected, one from each of the divisions. Those officers would be members of the Council and also chairmen of their respective divisions. The idea was briefly discussed at the 1956 Winter Meeting but no action was taken. However, it revealed one 
weakness of the system - lack of divisional representation on the Council and undoubtedly stimulated events that followed.

Efforts during 1957 resulted in constitutional changes presented in January 1958 to the membership. The amendments provided for election of the president one year earlier than was the previous custom and for the election of one councilor for each authorized ASAE division. The change in presidential selection would permit him to sit for a year on the Council prior to assumption of office; the councilor change was in harmony with Worthington's suggestion in terms of giving the divisions a responsible voice on the Council. Also, the nominating committee was now to have a representative from each division.

A transition plan was adopted which by 1961 would put on the ballot the president-elect, a vice-president, and three councilors for 2-year terms. This would create an 11-member Council consisting of the president, pastpresident, president-elect, three vice-presidents, and five councilors. The councilors in succeeding years were to be elected three in one year and two during alternate years. Note that there were four technical divisions and the Education and Research Division (formerly College Division) to be represented. Voting was to be done by corporate members for all divisional candidates of their choice, not just for their own division. On completion of the transition the presidents and vice-presidents would serve terms of three years on the Council.

At the June 1958 Annual Meeting there was discussion of the roles played by the vice-presidents; actually, they had no particular roles and it was proposed that they be assigned definite responsibilities. Incoming President Eugene G. McKibben responded favorably to these assignments on a trial basis:

Senior Vice-President - General supervision of division activities and chairman of the ASAE Meetings Committee.

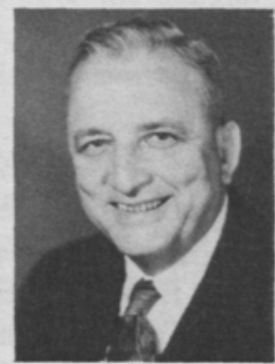

Eugene G. McKibben

52nd president, ASAE, 1958-59 
Second Vice-President - Section activities and programs for Cabinet meetings.

\section{Junior Vice-President - Public Relations.}

The policy was discussed again at the Winter Meeting and confirmed on a "test basis for a few years" before being adopted permanently.

There was also discussion of the defects apparent in the geographic organization of ASAE. Some states were not part of a regional unit, which made geographic representation in certain matters difficult. Also, regional, state and local sections were all called "sections." President McKibben finally appointed a small committee to investigate the matter further.

The scheme to put the vice-presidents to work did not prove to be entirely successful. Near the end of McKibben's term of office Jimmy Butt wrote him to the effect that the assignments made a year ago had not been acted upon. Perhaps the scheme was too much of a change; also, McKibben blamed himself to some extent for not pushing things along.

Meanwhile, Ralph Palmer prepared a code designation for the Society committees which was adopted at the 1959 Winter Meeting:

\section{Primary Committee Identification:}

Cooperative activities ................ C

Standing committees.................

Special committees................. X

Power and Machinery $\ldots \ldots \ldots \ldots \ldots \ldots$ PM

Soil and Water..................... SW

Electric Power and Processing ...........EPP

Farm Structures ....................

Education and Research ................ER

Palmer's code provided for nine points of information, but only two classifications were adopted.

A year later Vice-President J. W. Borden reported to the Council on behalf of the vice-presidents that they felt those officers should continue to be elected by the full membership rather than be elected to represent a specific region of the United States. He went on to say that the Society ought to make better use of the vice-presidents than it had been doing.

Borden's remarks pointed out another developing weakness in ASAE's structure-lack of geographic unit administrative strength and coherence. The Cabinet brought together the sectional officers, division officers and the Council twice a year, but only to hear announcements and speeches. Decisions were not made with direct geographic unit input at Cabinet meetings.

The Cabinet meetings were often informative and enjoyable occasions. Memorable was the Cabinet meeting at Chicago's Palmer House in 1962 when Roy Bainer strode in and dramatically asked if there were any reporters 
in the house. There being none, he proceeded to relate his experiences as chief negotiator with Premier Fidel Castro in Havana when he, J. B. Liljedahl, and C. M. Hansen attempted to trade tractors for the Cubans taken prisoner at the Bay of Pigs disaster. However, not all the meetings were quite that interesting.

Wally Borden also remarked in December 1960 that the Forward Planning Committee (a new creation) was working on a section reorganization plan and would report in June. As a temporary expedient he suggested that perhaps the councilors should serve as direct liaison between the Council and the geographic units.

The Forward Planning Committee delegated the sectional problems to a subcommittee headed by R. W. Kleis of the University of Massachusetts. The subcommittee presented a report in June 1961 as promised. It was found that ASAE's geographic structure evolved without any particular planning and now had "sections" with memberships ranging from 19 to 800 , with areas from a city to 13 states and four provinces of Canada. It was recommended that the "Regional Sections" be called "Sections" and that "State and Local Sections" be called "Chapters." Kleis also produced a map which subdivided all of the United States and Canada into broad ASAE geographic areas.

The subcommittee confirmed Borden's recommendation that vicepresidents not be elected to represent geographic areas. They argued that national officers should be national. Furthermore, the regional membership distribution was too uneven for fair representation in such a procedure. But they offered no alternate suggestions that would provide a reasonable voice for the geographic units in national decision-making.

Thus far we have considered problems related to composition and duties of the Council, or Board of Directors, and the weakness of the geographic structure. While these problems were emerging there were questions raised also about the divisional structure. Like the geographic units, the divisions had evolved without a great amount of planning. Attention was attracted earlier to the overlapping character of their functioning and the confusion (to the stranger) of their nomenclature. With reorganization in the wind, the divisions needed a share of scrutiny.

An early act of President Byron T. Virtue was to set the new Forward Planning Committee to studying the divisional structure. He wrote the chairman, E. W. Schroeder, to undertake a review of the divisional structure as one of their "major problems for thorough study and recommendation." His letter. dated July 26, 1961, counselled Schroeder to move slowly (perhaps to avoid undue excitement and rumors). He suggested that some sectors of ASAE were in need of unification, also that ASAE was composed of fragments 


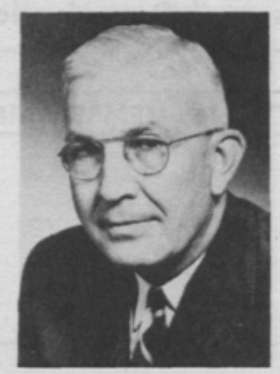

Byron T. Virtue

55th president, ASAE, 1961-62

unaware of each other's technical progress. He also suggested that some areas might need redirection to bring them more into general coordination.

Schroeder reported to the Board at the June 1962 meeting. The Forward Planning Committee presented a long-range plan to ASAE which included all aspects of needful action. In particular, however, the plan called for "reorganization of name and subject matter content of the divisions. . .taking into account the application of engineering in agriculture."

The Board then voted to establish a committee to work on the divisional structure; R. W. Kleis was made chairman of this committee also.

A year later (June 1963) Kleis reported the concept that, after considerable haggling and modification, became the basis for total ASAE reorganization. The committee had conceived the idea that ASAE be subdivided into three main parts: A geographic area, a technical (or divisional) area, and a professional area. Kleis called this the "three-prong approach.” Its logic appealed greatly to the Board; Kleis was encouraged to proceed and his divisional review committee was made a subcommittee of the Forward Planning Committee. The committee on sections which he formerly headed was to develop the geographic "prong," while a new committee was authorized to work on the professional "prong."

The "three-prong" organizational structure was presented for comments and suggestions in Jimmy Butt's "Check Points" in October. The proposal showed only "Administrative Structure" above the three prongs; the latter were portrayed as a Technical Board, a Geographic Cabinet, and a Professional Board. The Education and Research Division (called commission) was placed under the Professional Board; this Board would also be strengthened by other vital activities such as extension, registration and student affairs. The technical divisions had no names, nor was the mode of representation of each Board or the Geographic Cabinet suggested. Also, use of "Board" in this context was confusing since ASAE already had a Board of Directors. Even so, the crude outline was an adequate framework for future develop- 
Proposed "Three-Prong" Organization Structure for ASAE

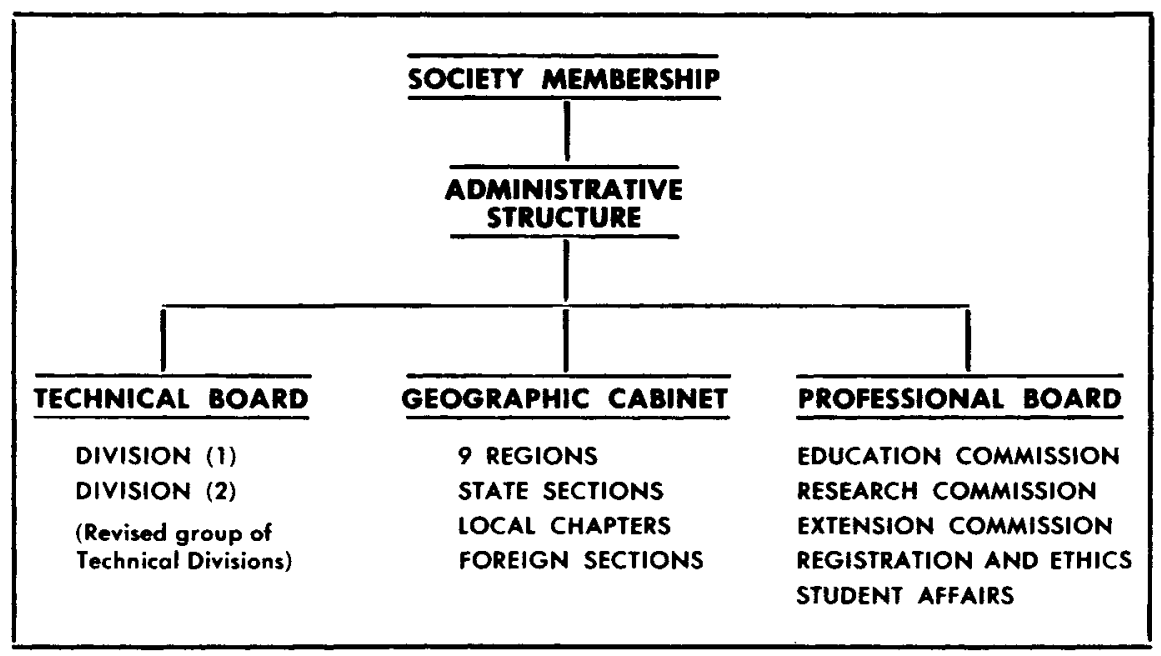

ment.

Things moved a little slowly for a time. A report given to the Board of Directors in December 1964 suggested this reorganization for the technical divisions: (1) Land and Water Resources, (2) Power and Field Machines, (3) Structures and Utilities, and (4) Processing and Marketing.

These plans received considerable attention from the divisions and some were eager to proceed with reorganization along these lines. Although the three-branch system was not yet perfected (on paper), President Price Hobgood (this was in June 1965) told the eager ones to go ahead with preliminary planning, particularly the FS and EPP Divisions, which had expressed some interest in a merger.

Delay in setting up a proposed "Professional Council" (as it was now called) had been caused by the untimely death on January 7, 1965, of PastPresident L. W. Hurlbut. Hurlbut had been chairman of the subcommittee which was studying the administration and coordination of ASAE's Professional aspects. So Hobgood turned the unfinished job over to incoming President C. S. Morrison of Deere \& Company.

Morrison informed the chairman of the Forward Planning Committee that he expected a complete report on reorganization by the December meeting.

Before the meeting, Morrison's correspondence indicates troubles awaiting those planning changes in the names of the technical divisions. H.J. Hansen, EPP director, forwarded letters to Morrison which suggested that the proposed merger of Farm Structures and Electric Power and Processing Divisions would be vigorously opposed if the resultant group name did not 


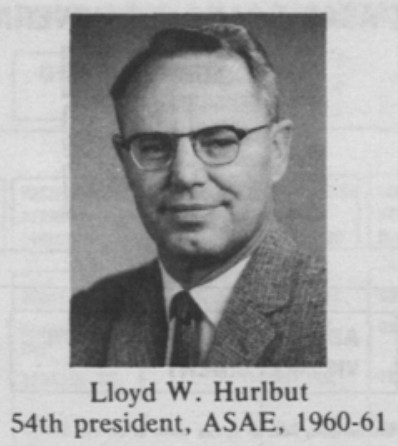

contain the words "electric power." K. L. McFate at the University of Missouri wrote Morrison essentially the same opinion.

Jimmy Butt wrote Morrison in September with a lengthy analysis of the vice-presidential duties, one of the sticky reorganization problems. These had changed since 1958; the assignments were now:

Senior Vice-President - Cabinet.

Middle Vice-President - Chairman of Meetings Committee.

Junior Vice-President - In change of $\mathrm{C}, \mathrm{X}$ and $\mathrm{L}$ Committees.

The arrangement had disadvantages. The vice-presidents, lacking genuine responsibility, had little prestige except as members of the Board of Directors. Butt mulled over several possible improvements for their job descriptions but all seemed awkward. Then he struck the right note (perhaps just thinking aloud as he dictated): "Since there will be three 'prongs,' an ASAE Vice-President might logically be assigned to serve as chairman of each of the 'Boards' or 'Cabinets.' "' That idea somehow diffused into the Forward Planning Committee and appeared in the ultimate form of the reorganization. As chairmen of the three Councils (to give the "prongs" their final designation), the vice-presidents gained great responsibility. As members of an Executive Committee which consisted of them plus the three presidents and the Secretary, they provided much-needed links between all sectors of Society action and decision. But this is anticipating the outcome just a bit.

At the 1965 Winter Meeting the Board reviewed progress on the reorganization. The Geographic Council was accepted in principle. The Technical Council was accepted in principle but many details (such as divisional realignment and renaming) were unsettled. The Professional Council was as yet unevaluated by key members. Morrison urged faster progress on reorganization. He hoped that most questions could be settled by the end of the 1966 Annual Meeting.

At that meeting considerable progress was made. The status of the geographic units was strengthened; the FS-EPP merger was postponed; 
FIG. 1

THE ASAE BOARD OF GOVERNORS

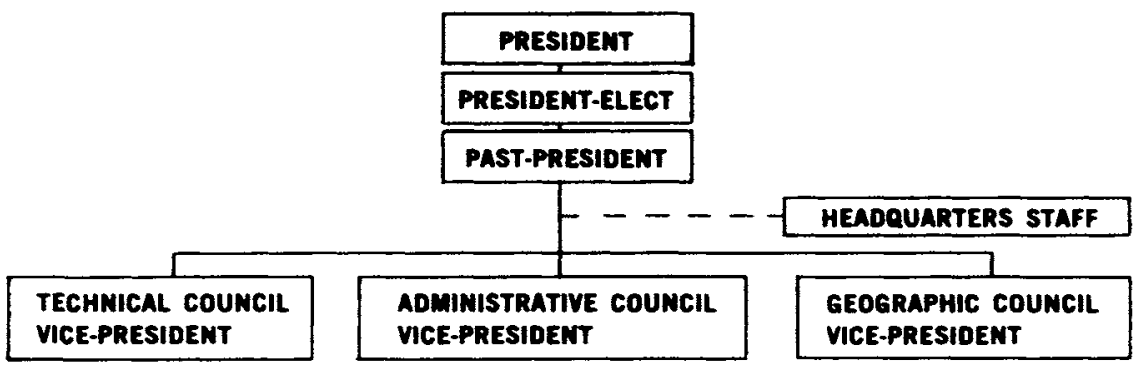

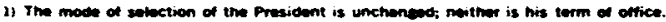

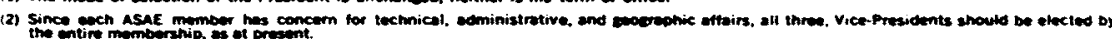

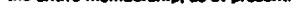

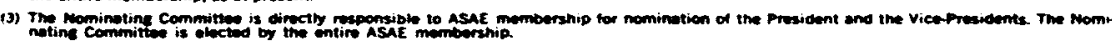

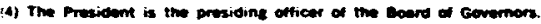

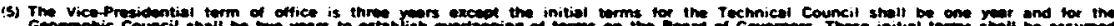

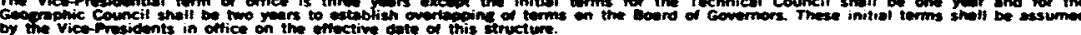

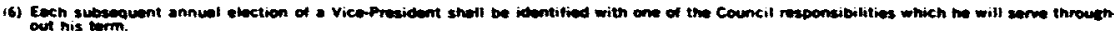

Power and Machinery liked everything but the proposed "Bioengineering Division," as previously noted. It was decided that the plan should be printed in the Journal prior to the forthcoming Winter Meeting. R. W. Kleis took over the Forward Planning Committee and prepared a complete summary of the proposed reorganization which was published in September.

The proposal showed the vice-presidents as heads of the three Councils and also as members of a Board of Governors (which became the Executive Committee). The Professional Council was re-named Administrative Council. Each Council had several directors to head up the various entities which composed the Council. For example, the Geographic Council had a director for each group of state sections, now called "regions." The new technical division names still appeared in the Technical Council. The old Cabinet was eliminated.

Under the plan the new Board of Directors would be composed of president, past-president, president-elect, the Secretary and his staff, the three vice-presidents (these would be the Executive Committee), plus all the directors of the three Councils. At first glance the Board seemed unwieldy; however, it was intended that the small Executive Committee would handle the big decisions, meet more often, and convene the entire Board only enough to ratify decisions and keep all communications open. The vicepresidents and the steering committees would deal with much detail formerly managed by the Board. Most members were probably unaware of the work which was overwhelming the Board under the current administrative configuration (the minutes of the June 1966 Board meeting contain 77 items of business and 13 appendices). 


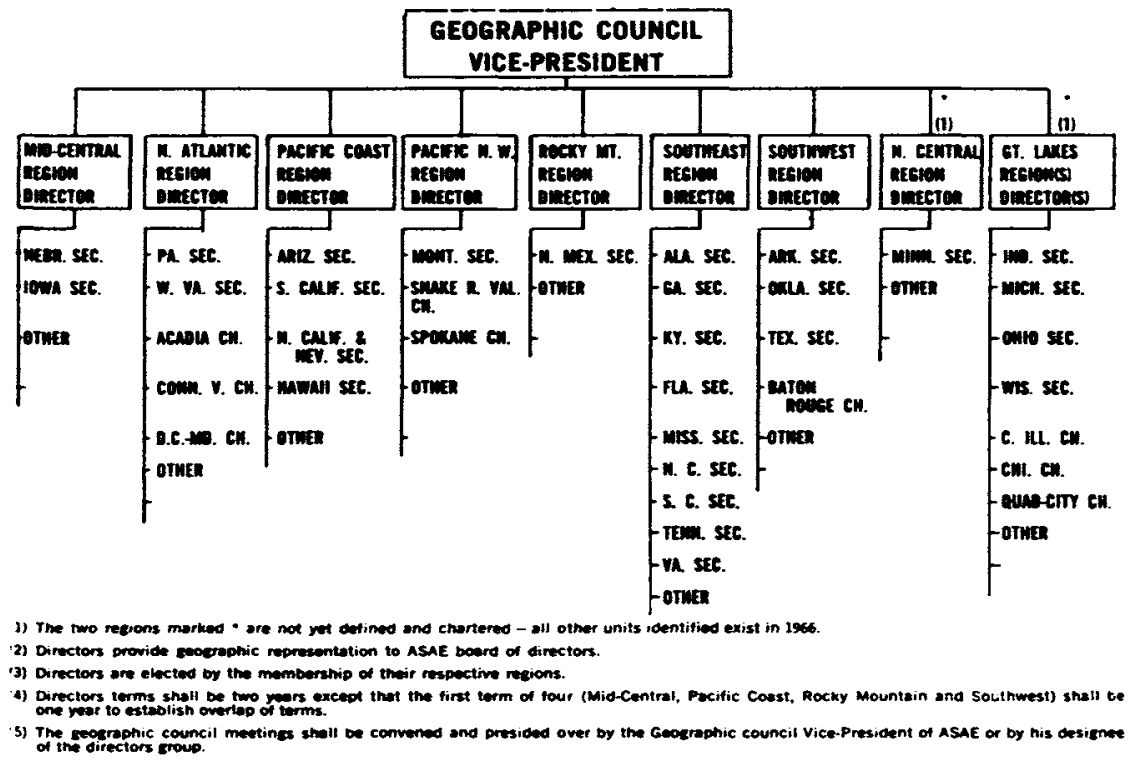

Jimmy Butt reported to the Board in December that he had received "strong objections" to the plan. Kleis, however, found that most objections boiled down to the proposed new names and realignments of the technical divisions. His Forward Planning Committee gave them up, therefore, and advised the Board to retain the old names; otherwise, the whole plan could fail. That suggestion was accepted. It was then agreed to publish a final version of the plan in time to present the necessary constitutional amendments at the June 1967 business meeting. Only Farm Structures Division officers petitioned at the time for a change in name to Structural and Environmental Division.

The final version of the reorganization plan was published in the April 1967 AGRICULTURAL ENGINEERING with an endorsement on behalf of the Board by President $O$. C. French. The new configuration became official in June 1968.

After two or three years the system settled into a smooth-running arrangement. The new Executive Committee had time for leisurely consideration of important questions. It met several times each year, sometimes at St. Joseph or in connection with a geographic unit meeting, as well as during national meetings. At the latter there was time to mingle with the members and attend a few sessions - rarely possible under the old regime.

As for the technical divisions, it seemed that when the chips were down the 
FIG. 3

TECHNICAL BRANCH ORGANIZATION

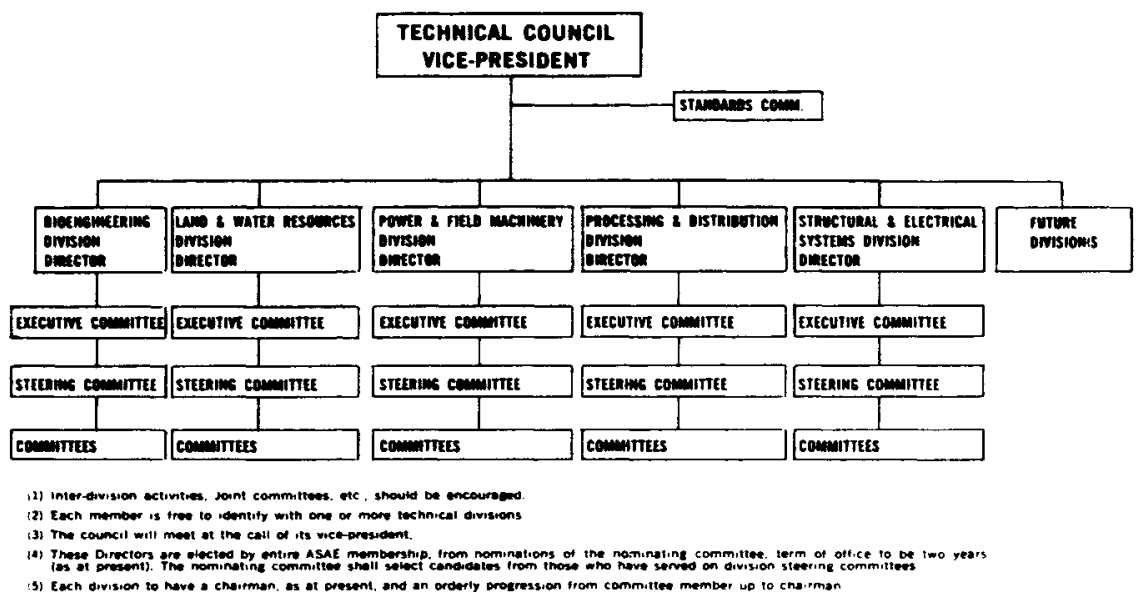

members allowed their basic conservatism to prevail. Probably no great harm was done because no matter how agricultural engineering is subdivided no really tidy subdivisions seem to emerge. After all, the members felt comfortable with the old names and the new ones just weren't much better.

At this time (1967), however, a group of members with interests somewhat different from the others formed a new technical division - Food Engineering.

Early beginnings in this area included the teaching and research of $A$. W. Farrall at U.C.-Davis in the field of dairy engineering in the 1920s. J. B. Davidson is believed to have initiated a similar course at Iowa State at the same time. When Davidson edited the Wiley Agricultural Engineering Series, one book was "Dairy Engineering," by John T. Bowen.

When Farrall went to Michigan State as head of the Agricultural Engineering Department, he started a series of Dairy Engineering Conferences and was responsible for establishing a Department of Food Sciences there in 1960.

When ASAE held its first session on food engineering it was therefore not surprising that Farrall gave the first paper on the program. This was at the Ames meeting in June 1961. Shortly after, a Food Engineering Committee was established with H. L. Mitten and C. W. Hall as co-chairmen; Mitten worked for the Creamery Package Manufacturing Co. The Committee was placed in the EPP Division in 1964.

Food engineering, according to D. R. Heldman of Michigan State, "requires the identification of a different type of industry than normally associated with agricultural engineering." This is the food industry, which is 
FIG. 4

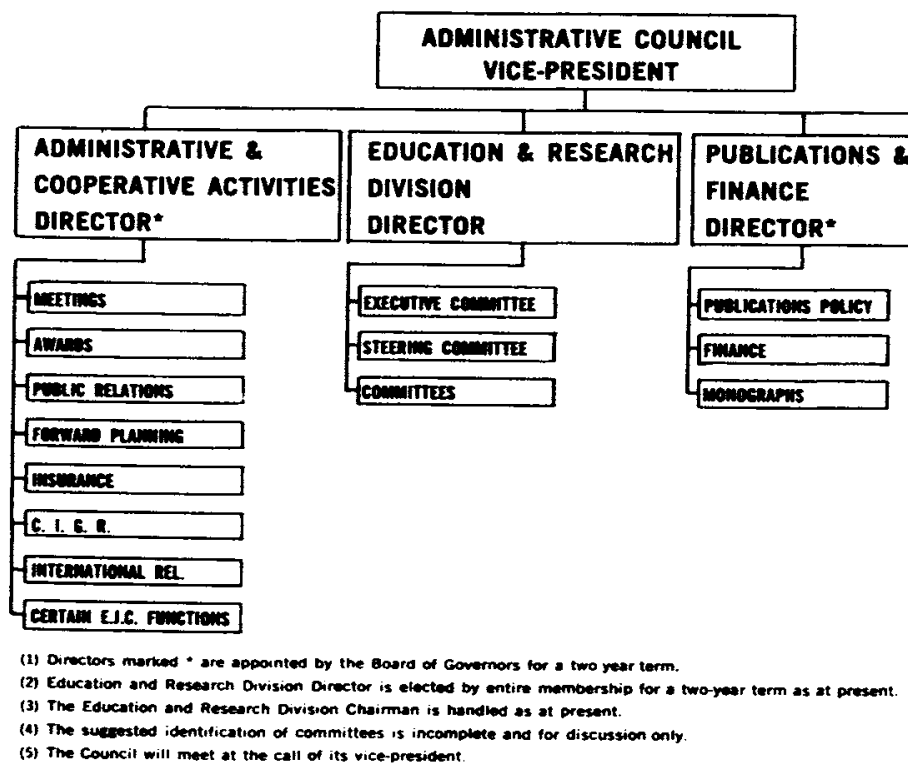

FIG. 5

\section{THE ASAE BOARD OF DIRECTORS}

\begin{tabular}{|c|c|c|c|}
\hline & \multicolumn{2}{|c|}{ PRESIDENT } & \multirow[b]{2}{*}{ H.Q. STAFF } \\
\hline & & & \\
\hline \multicolumn{2}{|c|}{ PAST-PRESIDENT } & PRESIDENT-ELECT & T-ELECT \\
\hline $\begin{array}{l}\text { VICE-PRESIDENT } \\
\text { TECHNICAL COUNCIL }\end{array}$ & \multicolumn{2}{|c|}{$\begin{array}{c}\text { VICE-PRESIDENT } \\
\text { ADMIMISTRATIVE COUNCIL }\end{array}$} & $\begin{array}{l}\text { VICE-PRESIDENT } \\
\text { GEOGRAPHIC COUNCIL }\end{array}$ \\
\hline $\begin{array}{l}\text { FIVE DIRECTORS } \\
\text { REPRESENTING } \\
\text { TECHNICAL } \\
\text { DIVISIONS }\end{array}$ & & & $\begin{array}{l}\text { NINE DIRECTORS } \\
\text { REPRESENTING } \\
\text { GEOGRAPHIC } \\
\text { REGIONS } \\
\end{array}$ \\
\hline
\end{tabular}

(1) The oreanization provides representation of technical, expraphic and functional interests.

(2) Of the rwabty Feur members; Twowe would be elected by the entire membership. nine would be elected by rezional memberships and three would be aposinted.

(3) Six serve throe year terms as officers and eighteen Directors serve staggered two your terms.

(4) Functions and duties of Directors would be executed peimenty through a councit and report through its Chairman, a vice-president, to the Boand of Conmors. (5) The President or his designe would preside at any joint meeting of the three Councils as a composite Board of Directors for apprapriate 
a large one and which employs about 20,000 engineers. The needs of this industry call for engineering services defined as follows: "Food engineering is the application of the principles of engineering and science to food processing and handling operations for physical, chemical or biological changes which occur during procurement, processing and distribution of foods primarily for human consumption."

An important aspect of these engineering activities is that they occur off the farm. The "Processing" phases considered by the EPP Division, for example, were not of this type. Consequently, the food engineers probably did not feel comfortable as a part of that division; they began working actively toward formation of their own division. The petition to the Board of Directors for formation of the Food Engineering Division was approved by letter ballot on February 13, 1967. At the June 1967 Annual Meeting at Saskatoon, C. W. Hall was appointed interim division director for one year until a director could be elected.

At the same Board of Directors meeting the first Food Engineering Division Chairman, R. A. Keppeler of Penn State, reported in the absence of a prior-elected director. He requested authority to send out a quarterly newsletter to interested individuals to let those outside of ASAE know about the new focus on food. Authority was granted for two years, although it is still being issued. Most appropriately, A. W. Farrall was the first editor of the ASAE-financed newsletter.

The Food Engineering Division has shown steady growth, mostly through attracting new member into ASAE. It has stimulated publication of new textbooks and technical papers, promoted conferences, and helped to establish food engineering degree options in some of the colleges.

These developments - establishment of a responsive and efficient power structure, confirmation of the traditional technical divisions, and a strong thrust into a new technical area - marked the beginning of a new style ASAE. Future growth could now proceed in a more orderly fashion, guided less by politics and more by logic. Unfortunately, one of those who pushed the reorganization to completion, Charles S. Morrison, did not live to see it succeed. Morrison died July 7, 1967, shortly after receiving the distinction of being made Honorary Member of ASAE.

The staff at ASAE Headquarters underwent growth and change. The Council authorized Jimmy Butt to assume the title "Executive Secretary" early in 1958 under its authority to amend Society By-Laws.

Raymond Olney was notified in December 1958 that he would be expected to retire on June 30,1959. Concurrent with Olney's expected departure Butt was authorized to employ a "public relations and advertising manager." This resulted in the employment of Harmon Mulbar. 


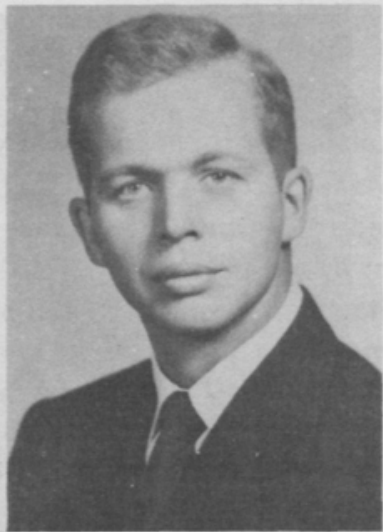

Harmon Mulbar

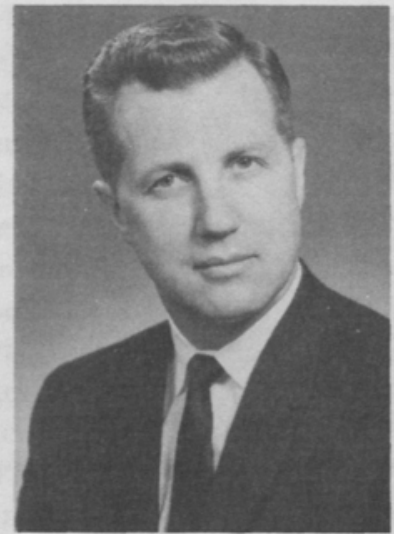

Page L. Bell inger

At the June Council meeting President E. G. McKibben presented Mr. Olney a desk set containing a clock and two pens. It was inscribed "In appreciation - to Raymond Olney - the ASAE Council of 1958-59." After a few remarks of appreciation for the thoughtful gesture Olney quietly left the room, thus closing a long chapter of service to ASAE.

The Board of Directors (a constitutional vote in 1960 led to changing the name of "Council" to "Board of Directors") authorized the Executive Secretary in June 1961 to employ a "technical coordinator."

The technical coordinator was needed to monitor committee affairs, maintain better contact with other technical groups, disseminate incoming technical data, collect and classify information, and assume a major role in handling the ASAE Yearbook and ASAE standards.

Page L. Bellinger assumed the job on October 30,1961. He came to ASAE from "Successful Farming" where he had been associate editor. A native of Michigan, Bellinger held two degrees in agricultural engineering from Michigan State University.

Jimmy Butt reported to the Board at their December 1964 meeting on the long-range personnel needs of the Headquarters office. First priority was given to employment of a TRANSACTIONS editor because that publication had expanded into a sizeable publication with no staff addition. Also, the changes in the Journal such as information retrieval and concise interpretive articles were demanding much more editorial effort. Other needs foreseen included an office manager and an assistant secretary to work directly with the sections (geographic units) on public relations, career guidance, and membership development.

Marianna Pratt of St. Joseph had done part-time editing for ASAE since 1958. On June 21, 1965, she was employed as associate editor of ASAE 


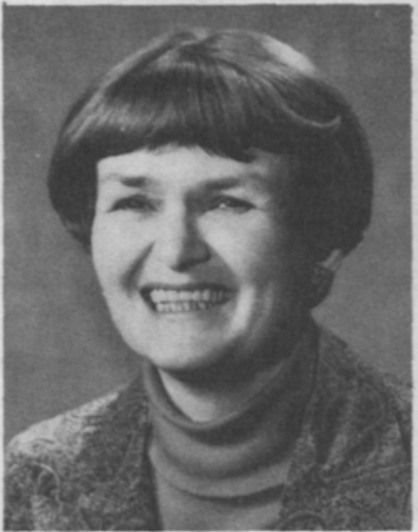

Marianna Pratt

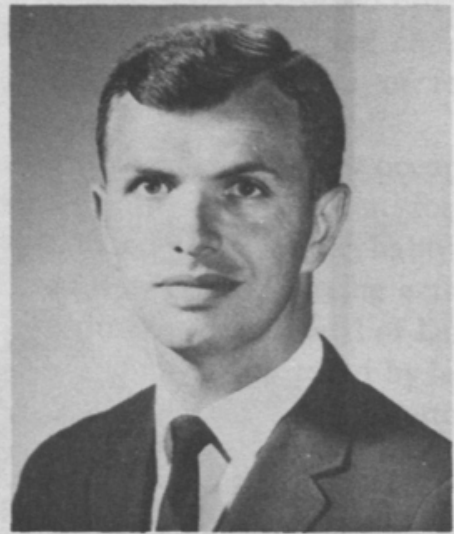

Russell H. Hahn, Jr.

publications. An Iowa native, Mrs. Pratt had a number of years of experience in various fields of writing and editorial work. A backlog of technical papers had accumulated between 1957 and 1963; a gift of $\$ 4000$ from Deere \& Company to underwrite some of the cost of publishing these papers encouraged the employment of Mrs. Pratt. Her first duties were to concentrate on a special edition of TRANSACTIONS devoted to the backlog. Subsequent gifts, including an additional $\$ 4000$ from Tractor and Implement Operations, Ford Motor Company, brought the total amount contributed toward publication of the backlog to nearly $\$ 12,000$.

Page Bellinger left the employ of ASAE in 1967. He was succeeded as technical coordinator by Russell $\mathrm{H}$. Hahn, Jr., a project engineer with $\mathrm{O}$. M. Scott and Sons of Marysville, Ohio. Hahn was an agricultural engineering graduate of Ohio State University.

Shortly after Byron Virtue became president in June 1961 he had a talk with G. B. Gunlogson*, former head of the Western Advertising Agency. Gunlogson believed that ASAE and agricultural engineering were not properly serving the farmer and agriculture in general. Lack of engineering planning in agriculture and low status of agricultural engineers were part of the problem. In later correspondence Gunlogson called for a "reappraisal of the place and purpose of agricultural engineering," starting with creation of an ASAE research director to do the job. He thought the position could be financed by "some established foundation," but he offered to contribute $\$ 5000$ initially to get the program started.

Past-president Wayne H. Worthington was offered the post of research 
director, which he accepted. The public announcement (in June 1962) quoted Gunlogson as saying that ". . . we have now entered an era when production is no longer a pressing problem. Rather the problem lies in translating this growing production potential into human gains - for farm people and the public." The research director was assigned objectives by a three-man Advisory Committee, objectives of a broad and general nature apparently difficult to interpret and implement.

The June Board of Directors meeting brought forth objections that the Advisory Committee did not represent divisional interests, plus considerable dislike for that title of "Research Director."

Worthington held a special conference in order to develop better understanding of the Research Director Program. However, at the December 1962 Board Meeting the title was again questioned. The main idea that emerged from the conference, according to Byron Virtue, was the need for obtaining a "better voice for agricultural engineering in Washington," which didn't sound like what Gunlogson wanted.

By early 1963 Worthington's health was creating problems, to say nothing of the difficulties attending the research director position. He therefore resigned the position.

Meanwhile, C. S. Morrison, chairman of the Advisory Committee, and President A. W. Farrall had agreed that the "most worthwhile accomplishment" would consist in having some articles published on topics which Morrison had thought up. Farrall's conception of the Gunlogson grant purpose was "to acquaint people ... with what Agricultural Engineers are doing and what they can do for agriculture and the general public." Gunlogson's "reappraisal" idea seemed to be taking second place to some public relations work intended to justify the status quo.

Another past-president, Earl D. Anderson, took on the job in October. The title had meanwhile been changed to Professional Planning Director. Morrison commented to the Board of Directors in December that Anderson's role might be expanded to include student recruitment activities.

Gunlogson's overriding concern with American life was the depopulation of rural areas because of urban industrialization and the consolidation of farms. Perhaps he hoped that his grant to ASAE might cause similar concern in the Society.

Anderson's work as Professional Planning Director resulted in publication of nine major articles in AGRICULTURAL ENGINEERING in a series titled "Engineering Planning in Agriculture." The series, published in 1966, was preceded by an article prepared by Anderson himself on the subject "Engineering Planning for a Rebirth of the Countryside." He also put together a recruiting brochure called "Agricultural Engineers and 
Agriculture." The Chicago Chapter donated \$500 toward that project.

The Gunlogson grant was used up by January 1966. Although Anderson recommended that a Professional Planning Director be included in the regular budget, this was not done. Nor did Gunlogson advance more money. Other money sources were discussed but none was forthcoming.

Anderson felt that the article series he had caused to be written were of value to the members. His final report to the Board of Directors stated that:

"It is evident that these carefully selected authors, in general, did not have a broad concept of engineering planning and had difficulty in citing examples of engineering planning in their field of work. This suggests that there was need for this series to stimulate broader thinking on the part of the Society members."

With an expanding Headquarters staff came also the need for more space. The Finance Committee, after careful study in 1962 of conditions at Headquarters, recommended that a permanent site in St. Joseph be obtained. As a temporary measure a portion of the second floor of the Masonic temple was rented in 1964 to augment existing Headquarters offices on the ground floor of that building.

President Hobgood appointed a subcommittee to work on the problem. Their report at the June 1965 Board meeting suggested that the Society should build its own Headquarters, financed principally by membership dues and contributions. A possible target date for moving in was set at February 1, 1970 . About $\$ 30,000$ would be required in each of the years 1967,1968 , and 1969 for investment in the building and its furnishings. Some $\$ 40,000$ per year should be obtained by dues increases commencing in the calendar year 1967. New staff additions were planned.

The Board of Directors was sympathetic to these proposals. Incoming President Morrison was anxious to get on with the job of "selling the

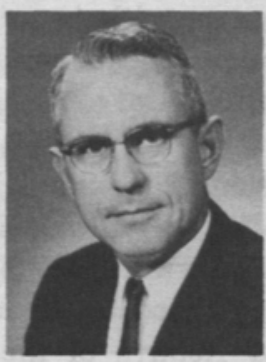

Charles S. Morrison

59th president, ASAE, 1965-66 
members on the new building." For ammunition, he asked Jimmy Butt in September for 15 slides showing the present cramped Headquarters facilities. In addition, he used slides illustrating ASAE growth, its committee structure, papers published and papers presented at national meeting. As a starting date he chose 1955 , with projections to 1970 . Morrison was anxious about the effect of the proposed dues increase on members in private industry. While checking on these, he found about 25 percent of ASAE members had their dues paid by their employers.

In December 1965, before going to Chicago, the Board met at St. Joseph to view the current facilities. ASAE had outgrown the first and second floors of the Masonic temple, without a doubt. Future services to members would be adversely affected by the cramped, undignified, and inefficient conditions.

On arrival at the Sherman House in Chicago the Board adopted the suggested dues increase along with the $\$ 30,000$ per year reserve for the building fund. Later, Morrison appointed a Building Facilities Committee headed by Norval Curry, who was in private practice at Ames. Then President Morrison asked Past-President Hobgood for his statement on financing the building for the Board members to use to answer questions on the building project. Since the statement did not specifically mention a dues increase, the latter was rescinded by Board action, pending firmer knowledge of building costs.

At this time no definite commitment to building in the St. Joseph-Benton Harbor area had been made, the Finance Committee's suggestion notwithstanding. Some thought space in the United Engineering Center in New York City ought to be considered, but costs were beyond reason. Morrison received a letter from Governor Rhodes of Ohio inviting ASAE to locate at Wooster, the agricultural experiment station headquarters. This invitation was not seriously conisidered because of Secretary Butt's opposition to it, based mainly on replacing a large number of office staff plus lack of certain facilities at Wooster.

Curry's Committee published a two-page spread in the March 1966 Journal outlining the growth and expanded services of ASAE. The facts presented were impressive. Another report appeared in April. This report analyzed staff growth, Headquarters space, income sources, expenses, and ASAE's net worth. The report ended with the promise that recommendations would likely be presented to the Board by the Committee during the 1966 Annual Meeting.

At that meeting Curry sat with the Board of Directors for a long time. Morrison's contact with the sections was very encouraging; when the members understood the need they wanted to go ahead and build. It was agreed that it would be better to stay in St. Joseph. Hobgood pointed out that the entire program of construction and financing should be presented as a 
single package to the members; there was the question of how to present it. Finally, the dues increase, the three-year $\$ 30,000$ per year reserve, a supplementary money donation scheme, and authorization for Curry to look for a piece of land were voted. The dues increase was to take effect on January 1, 1967. This package was presented at the Society business meeting, with generally favorable reaction.

At the December 1966 Board meeting Butt said that an option had been taken on a two-acre building site, which would be inspected by the Headquarters Facilities Committee during the meeting. A Building Fund was established. Price Hobgood, now chairman of the Committee, reported that the two-acre site was not appropriate and that investigation of other sites was proceeding. Subcommittees had been set up to select an architect and to raise gift funds. The ASAE Finance Committee had been requested to handle and supervise the investment of the building funds.

At the 1967 June meeting at Saskatoon, Jimmy Butt told the Board of Directors that a 2.5 -acre tract, owned by four people, was under an "agreement to purchase" subject to rezoning from residential to business. An architect had been selected by the appropriate subcommittee for recommendation to the Board.

At this time Secretary Butt presented each Board member with a copy of the 1966-67 Headquarters Annual Report. In it he stated that the most "significant single development" of the Society year was the decision made at Amherst a year ago to build a new Headquarters.

The new facility was dedicated in April 1970. A succession of presidents gave leadership to this development. These were Price Hobgood (1964-65), C. S. Morrison (1965-66), O. C. French (1966-67), R. R. Poynor (1967-68), T. W. Edminster (1968-69), and N. H. Curry (1969-70). It was fitting that Curry presided over the dedication ceremonies because of his early association with the planning. A large number of other members gave freely of their time in accomplishing the objective. The raising of funds, for example, yielded $\$ 76,435$ from 107 business organizations and $\$ 78,550$ from individual ASAE members, student branches, and geographic units. In addition, the

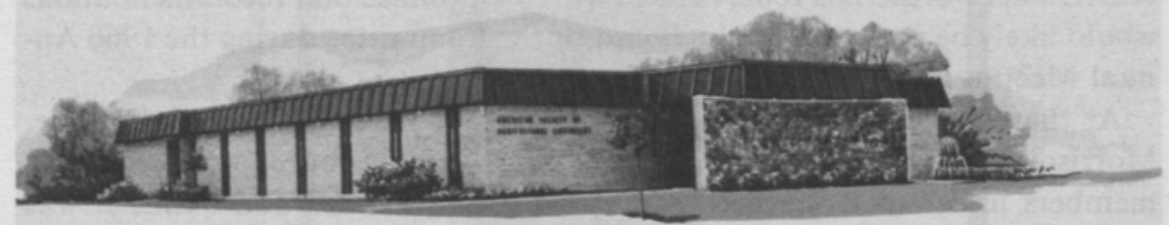

ASAE's new headquarters building occupied in November 1969 and dedicated in April 1970 
dues increase and operating surplus reserve policy put $\$ 99,000$ into the building fund. The need for a new Headquarters was underscored dramatically during the fund-raising campaign when a section of the ceiling fell on the desks at the old office just before time to start the day's work.

At the Santa Barbara meeting in June 1958 the Annual Report showed addition of four new ASAE Sections: South Carolina, Central Illinois, Baton Rouge, and Kentucky. This gave the Society seven regional, 15 state, and six local geographic units. Strong and enthusiastic geographic units were essential in maintaining ASAE local service and interest because most members did not attend the national meetings.

Questions raised by the geographic units sometimes reached the Council or the Board of Directors. In 1958 a section officer queried Headquarters as to whether non-members might be considered members of ASAE Sections. Jimmy Butt informed the Council that this question was not unusual and that the standard reply was to suggest that Sections invite non-members to their meetings but inform them that they must be members of the national organization in order to be members of the geographic unit. The Council saw no need to modify this recommendation.

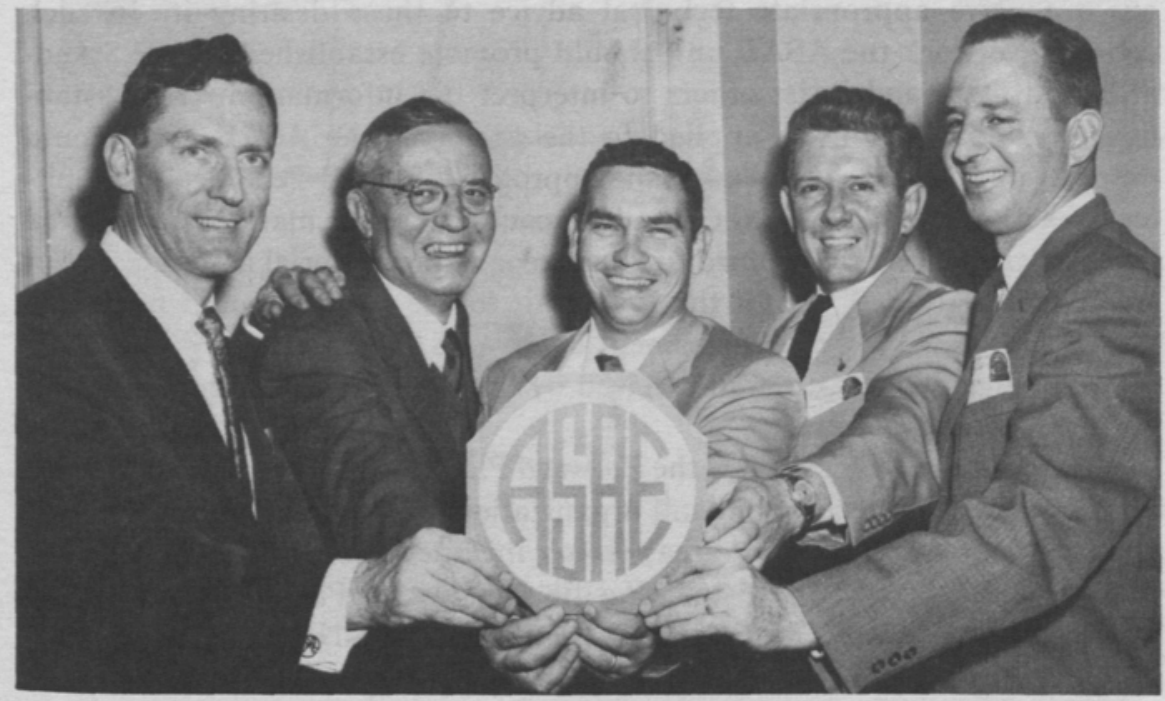

Officers of Tennessee Section of ASAE display the Society's emblem at a Section meeting. (Left to right) J. L. Montague, Jr., past chairman; R. L. Lester, program chairman; D. H. Luttrell, vice-chairman; W. J. Liddell, vice-chairman; and J. K. (Farmer) Jones, chairman 
A more subtle kind of problem surfaced at Miami Beach in June 1963. It was reported to the Board that the Georgia Section (which claimed to be the oldest state Section) was planning to develop and promote, within the state, a safety code. Concern was expressed as to how far a geographic unit should go in making technical recommendations on a local basis. The Board agreed that no ASAE unit should promote ASAE standards, recommendations, or data except those approved through established Society procedure. It was therefore voted that the Georgia Section should be complimented for its interest in safety but that any proposed standardization item must be submitted to appropriate divisional committees in accordance with regular procedure.

Later in the meeting other instances of similar activity came to light which created much Board discussion. A special committee was appointed to study the issue.

Merlin Hansen of the John Deere Tractor Research and Engineering Center was chairman of the Committee on Standards. Logically enough, he was asked to examine the question of standards created by geographic units. He reported to the Board at the December 1963 Winter Meeting (it is perhaps noteworthy that his five-man special committee included a member from Georgia - R. H. Brown of the University of Georgia).

The report of Hansen's Committee recognized that local ASAE groups ought to give appropriate technical advice to those desiring it. In such cooperative work the ASAE unit should promote established ASAE Standards and Data and assist others to interpret the information. If no established Standard or Data applied to the problem, the ASAE unit should prepare a proposal for referral to the appropriate ASAE Technical Committee for action. The Technical Committee could cause the material to be voted through as a national standard; it could regard the material as sound but of local value only and permit the local unit to use it; or it could reject the material as unworthy of endorsement by any ASAE unit.

These suggestions were well-received by the Board of Directors and voted into existence as policy.

It was hinted previously how the Forward Planning Committee cut its teeth on the problem of geographic unit organization. By 1963 the term "Region" applied to units comprising areas which included more than one state or province. Seven regions existed: Pacific Northwest, Pacific Coast, Rocky Mountain, Southwest, Mid-Central, Southeast, and North Atlantic. Two more regions were proposed at that time: "Great Lakes," including the five states bordering the Great Lakes, and "North Plains," including the Dakotas, Minnesota, Saskatchewan, and Manitoba.

The term "Section" was intended to designate geographic areas of exactly 


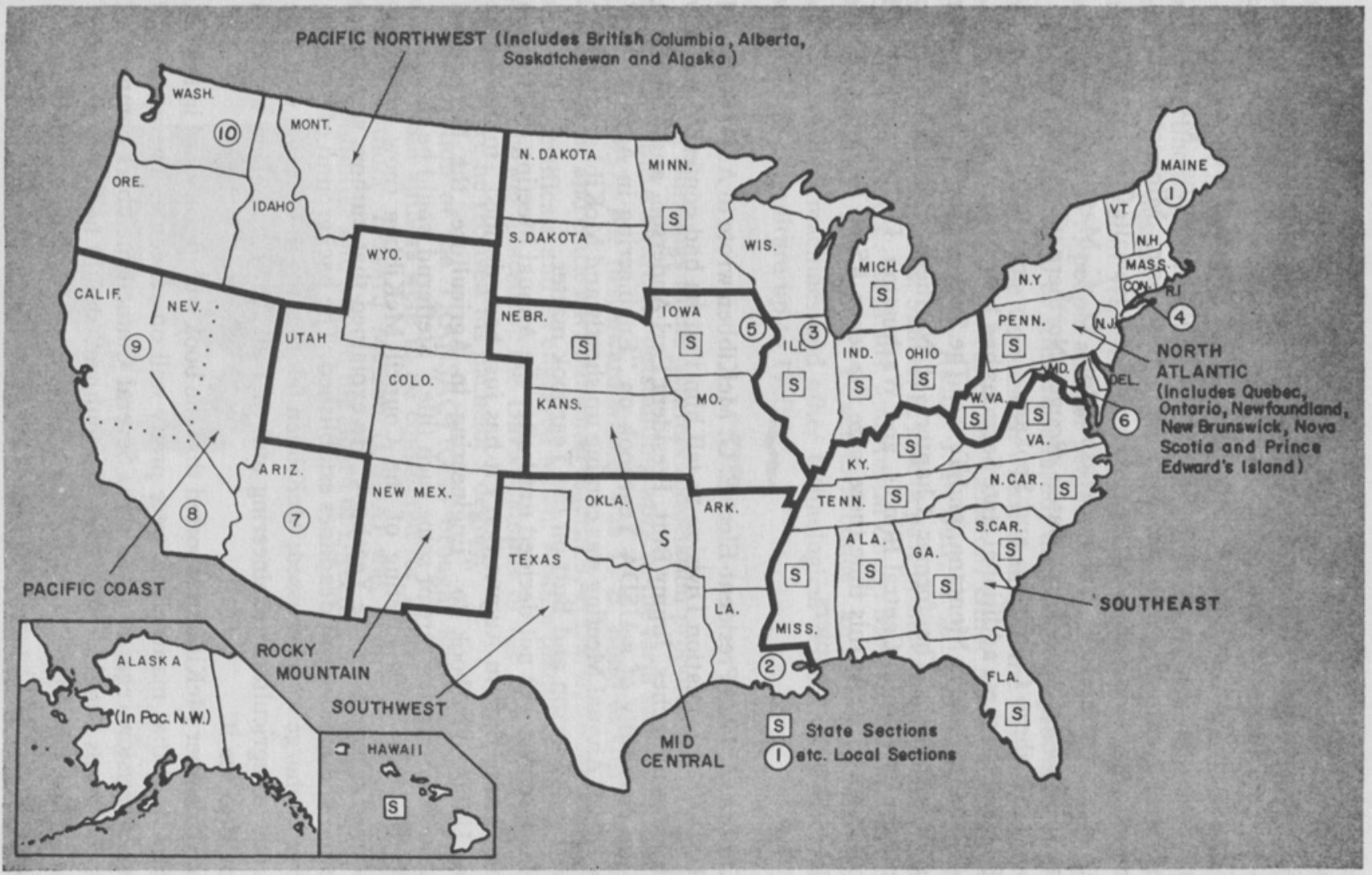

Regions, Sections and Chapters as established in 1963 
one state. A "Chapter" was a unit intended to serve members in areas smaller than Regions, but which could cover parts of a single state, parts of two or more states, or parts of all of two or more states.

Sections in 1963 included Pennsylvania, West Virginia, Ohio, Virginia, North Carolina, South Carolina, Georgia, Florida, Alabama, Mississippi, Tennessee, Kentucky, Indiana, Michigan, Wisconsin, Minnesota, Iowa, Nebraska, Oklahoma, New Mexico, Arizona, and Hawaii. Chapters included Acadia, Connecticut Valley, Washington, D. C.-Maryland, Chicago, Central Illinois, Quad City, Baton Rouge, Northern California-Western Nevada, Southern California, and Spokane.

By late 1967 these additional state Sections had been organized: Arkansas, Louisiana, Missouri, Montana, and Texas. The Snake River Valley Chapter was in existence. The former Chapters of Northern California-Nevada, Southern California, Central Illinois, and Washington, D.C.-Maryland had become Sections. At this time there were the seven ASAE Regions, $31 \mathrm{Sec}-$ tions, and seven Chapters.

On June 3, 1958 President-Elect E. G. McKibben wrote to A. D. Stefferud of USDA's Information Division to tell him that he had conferred recently with Harold Pinches, Jimmy Butt, President Earl Anderson, and McKibben on the possibility of a USDA Yearbook on "Engineering in Agriculture." The ASAE Annual Meeting was coming up shortly and McKibben wished to report to Anderson and Butt on the Yearbook matter.

The question was not decided until after the Annual Meeting. McKibben wrote Jimmy Butt in August that "it has just been decided" to devote the 1960 USDA Yearbook to "Engineering in Agriculture, the Mechanical Revolution in Agriculture or some such title." Stefferud would be the editor.

At the June 1959 meeting of the Council McKibben (now president) described progress on the Yearbook. He explained that authors were being selected and manuscript deadlines established. The background of the committee in charge was discussed; McKibben felt that the publication would be a credit to agricultural engineering and that all ASAE members would be pleased to see it.

In December McKibben reported that the book would come out in the fall of 1960 and that manuscripts were pretty well on schedule. There was still some indecision regarding the title. Several Council members commented that the words "engineering" and "agriculture" should be in the title; they stressed the fact that "no other combinations of words adequately or accurately described the contents of the yearbook." 
They were disappointed, however. The 1960 Yearbook of Agriculture was named "Power to Produce." Its broad headings were unified by the power concept: "Power in the Past," "Power in the Present," and "Power in the Future.”

Secretary of Agriculture Benson thought well of the book and its message of how technology had brought plenty to the American people. "But," he said, "the mere possession of tools, gadgets, machines, packages, things is not enough. Wisdom requires an understanding of what the march of technology can do to people and for people."

Under the editorship of Alfred Stefferud, the book was produced mainly by ASAE members. The Committee which managed the book through to completion was headed by Walter M. Carleton. Other ASAE members on the Committee were Wallace Ashby, J. L. Butt, E. M. Dieffenbach, T. W. Edminster, C. J. Francis, Samuel P. Lyle (a past-president of ASAE), Harold E. Pinches, Barton C. Reynolds, and Austin Zingg. Most of the authors were ASAE members. They made "Power to Produce" an extremely interesting overview of how machines and other technological devices were developed and used in agriculture up to 1960 .

The Metal Buildings Manufacturers Association proposed to the Council an ASAE-MBMA award for outstanding work in the farm structures field in December 1957. The first award winner was T. E. Bond of USDA for his work on swine and cattle environmental reactions, at Davis, California. Bond received a certificate and an engraved watch. Also, a plaque recognizing his achievements was placed at the Davis Campus of the University of California, where he received his bachelor's degree.

Inauguration of the TRANSACTIONS brought about the question of whether those authors were to be considered for Paper Awards along with Journal authors. Howard Matson (USDA) was chairman of the Paper Awards Committee and also on the Board of Directors in June 1961 when he

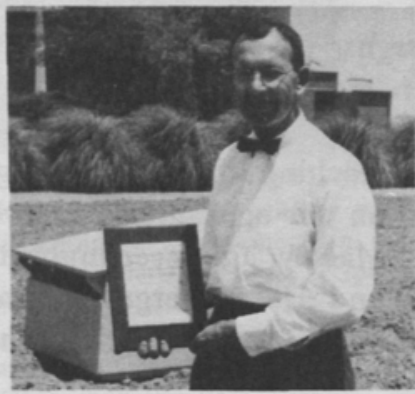

T.E. Bond was first recipient of MBMA Award in June 1959. Metal Building Manufacturers Assocation established the award for recognition of "distinguished work in advancing the knowledge and science of farm buildings" 
raised the question. A subcommittee of Board members worked on the problem. It was recommended that selections for Paper Awards shall be made from AGRICULTURAL ENGINEERING, TRANSACTIONS, and other ASAE publications of which ASAE members were sole or principal authors. Papers eligible could be prepared expressly for AGRICULTURAL ENGINEERING or could be presented before any Society meeting prior to publication.

Readers (older ones, anyway) will recall that one part of a Paper Award since 1944 was a one-year free membership in ASAE. At the June 1965 Board of Directors meeting Jimmy Butt stated that among current winning papers was one which had eight coauthors - most of them ASAE members. He went on to say that the five current winning papers had 16 authors and 13 of them were members. The Paper Awards, therefore, cost ASAE \$300 in addition to the cost of certificates, letters, and administration. This seemed excessive to the Board so they voted to discontinue the year's free membership. From then on the authors had to work for the honor of the Paper Award rather than its monetary value.

When A. W. Farrall was president of ASAE it occurred to him that no award for educators was in existence. He therefore wrote in February 1963 to Albert A. Thornbrough, President of Massey-Ferguson Limited in Toronto, with a proposal that his company underwrite such an award. Farrall suggested that the award consist of a medal and a cash sum. Since MasseyFerguson had supported the Ferguson series of agricultural engineering textbooks, Farrall believed that the company would have continued interest in educational matters.

Farrall's proposal received sympathetic consideration. Much of the work in connection with it was done by B. J. Lamp, an ASAE member with the Company. Farrall presented Lamp and E. L. Barger to the Board of Directors at their December 1963 meeting to comment on the Massey-Ferguson view of Farrall's proposal. The Board accepted the report with appreciation and hope that the details could be concluded in time to make the first presentation in June 1965.

The announcement of the Massey-Ferguson Educational Award was made at the 1964 Annual Meeting. The Award was to consist of a gold medal and $\$ 500$ in cash. It was to have a twofold purpose: "(1) To honor those whose dedication to the spirit of learning and teaching in the field of agricultural engineering has advanced with distinction our agricultural knowledge and practice . . . and (2) A tribute to Daniel Massey, a pioneer-innovator and an agricultural machinery manufacturer, and Harry Ferguson, an inventor whose unique educational approaches made a lasting contribution to worldwide agricultural mechanization." 
The first Massey-Ferguson Award was given to R.H. Driftmier, who had served for 35 years as head of the University of Georgia agricultural engineering department. The presentation occurred during the 58th Annual Meeting in June 1965 at Athens, Georgia.

Another award was first mentioned at the December 1964 Board meeting when B. A. Jones, on behalf of the Soil and Water Division, presented a proposal for a "Drainage Award" to be sponsored by the Hancock Brick \& Tile Co. of Findlay, Ohio. The first recipient was William W. Donnan of USDA; the presentation took place at the June 1966 meeting.

In 1963 the Committee on Engineering Registration compared ASAE member grades with those of other societies. In June 1964 the Committee proposed that the Board of Directors establish the grade of Senior Member. Committee Chairman J. H. Lillard published the proposal in the September Journal to allow the membership to react and comment.

The Committee felt that ASAE needed "incentive for the continuing professional and technical development of the members" and a greater parity with the other societies. The new grade of Senior Member would call for five years in the grade of member plus practice (or teaching) of engineering for at least 15 years, with "distinction" over a period of five years in publication of original work or in technical direction of others. Applicants for Senior Member would be required to possess engineering registration unless exempted by the Board of Directors.

The registration requirement created dissent as well as approbation. R. W. Irwin of Ontario Agricultural College wrote to the Journal that the registration requirement "should not be relaxed." But E. L. Hansen (U. of
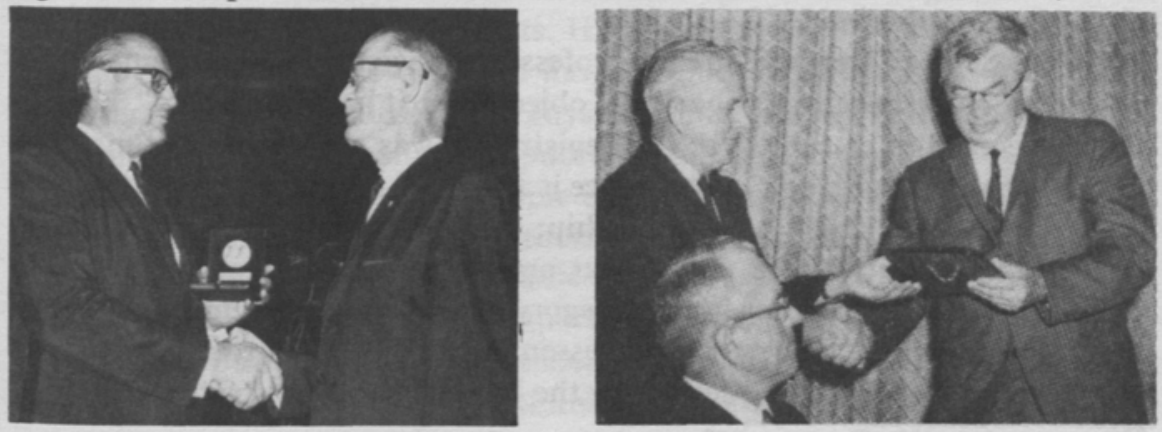

Above left-R. H. Driftmier (right), was first recipient of the Massey-Ferguson Educational Award in June 1965. J. G. Staiger, MF president, Detroit, made the presentation which recognizes "distinguished achievement in the field of agricultural education" - above right-W. W. Donnan (left), was first recipient in June 1966 of the Hancock Brick and Tile Drainage Engineering Award granted for "noteworthy contributions to the advancement of drainage engineering in teaching, research, planning, design, construction, management, or methods and materials". James L. Child, Jr., secretary-treasurer of the Hancock Brick and Tile Co., Findlay, Ohio, made the presentation 
Illinois) wrote "this requirement would have a bad effect on the future of the Society." His department head, Frank Lanham, wrote "it would be a mistake to include in membership qualifications the matter of professional registration." Jan van Schilfgaarde (USDA) also opposed the registration requirement: "The Society should base its evaluation on professional competence in the true sense rather than in the distorted trade lingo of the licensing boards."

M. J. Happe (New Holland Machine Co.), the new chairman of the Engineering Registration Committee, reviewed the professional registration issue with the Board at their December 1964 meeting. Some Board members had doubts about the proviso; therefore, President Hobgood was authorized to appoint a Board subcommittee to work with Happe's Committee on the question. These two groups were also requested to consider the feasibility of an "Executive Affiliate" grade.

Meanwhile, more letters appeared in AGRICULTURAL ENGINEERING. J. B. Rodgers of Oregon State University and R. W. Kleis of U. of Massachusetts favored the registration requirement for Senior Member. Robert B. Hickok and L. Donald Meyer of USDA and E. S. Shepardson at Cornell opposed the requirement. R. T. Lorenzen, also at Cornell, strongly favored registration because requiring it would "put the production of food into the area of legal concern for public health, in which an engineering practice requirement for design of facilities would be professional registration."

The necessary constitutional changes to establish the grades of Senior Member and Executive Affiliate and to strengthen the qualifications for Member were voted on in 1966. The necessary two-thirds in favor of those changes were obtained.

On the Senior Member issue the professional registration requirement had been eliminated because "substantial objection to it had developed." The objection seemed to be threefold: (1) Registration was not required of many (if not most) agricultural engineers, hence it appeared pointless to require it as a condition for any grade of membership; (2) registration did not pertain to outstanding qualities of a person but only to minimum requirements; (3) some states did not register in the category of agricultural engineer. The new grade was adopted, however, with essentially the other provisions for attainments and competence desired by the Engineering Registration Committee.

The new grade of Executive Affiliate did not require the applicant to be an engineer but he must have "attained a position of policy-making authority and recognized leadership in some pursuit related to engineering." This was a non-corporate grade.

The applicant for Member was required to be a graduate of an ECPD- 
accredited professional agricultural engineering curriculum (or its engineering equivalent) with no less than six years of practice or teaching. Professional registration could be substituted for three years of practice or teaching.

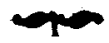

The sixth decade was no exception with respect to concern for professional identity and status. E. G. McKibben's annual address in 1959 expressed the perennial yearning of the agricultural engineer for recognition. Where most presidents tended to brag a little and then point to the need for further progress, McKibben tried to educate the engineers of other professional branches who were so uninformed as to believe that the term "agricultural engineer" was "incongruous, unsuitable, unreasonable, or . . inappropriate."

During his term as ASAE president McKibben had attended several functions where he came into contact with presidents of other engineering societies. Often he was forced to "explain, if not actually, to justify, the term 'agricultural engineering." " Evidently the experience deeply pained him, because his annual address was a masterly analysis of engineering in agriculture (indeed, that was the title of it) to aid agricultural engineers to explain just what their profession was all about.

When President Wally Borden delivered his annual address in 1964 the recognition problem claimed his attention also. He said "I feel that we are a meek, quiet group dedicated to technical excellence . . . but nobody knows we are in town!" Borden wanted ASAE and agricultural engineers to start taking credit for their achievements. His comment was "You should be tired of going into a hotel elevator and having someone comment: 'Agricultural engineers, huh? You must be the guys that milk the cows.' This is my fault and yours, for not informing the public about agricultural engineering."

Borden's ruminations on the topic of public indifference to the merits of agricultural engineering led him to suggest that ASAE and its geographic units should mount a sustained public relations effort. The main goals of the effort were to increase ASAE membership and to recruit more students into the colleges. But nearly all the presidents after him complained of a low rate of growth in membership and declining enrollments in the colleges.

Identity was a problem for most engineers. When A. B. Kinzel was president of the Engineers Joint Council he addressed an ASAE general session at the 1960 Winter Meeting. Kinzel stated that there was no voice which spoke for the engineer. In fact, there was no accepted definition of an engineer except through registration and Kinzel was dubious of its value because so many engineers were exempted from registration. Although fragmented, the 
technical societies did much good. They had formed the ECPD and the EJC. ECPD was influencing the improvement of engineering education, while EJC was able to bring its constituent societies together for consideration of mutual technological problems. The National Society of Professional Engineers was the only group, however, in position to perform legislative lobbying, a process which could benefit not only engineers but also the public. But, as Kinzel pointed out, NSPE membership was limited to registered engineers.

"The public usually thinks of an engineer as someone who can run a locomotive or a crane," Kinzel said. The press used "science" to include both science and engineering. The problem was to graduate an engineer specialized enough to do a job but with enough breadth to understand the relation of his job to the total picture. To achieve this, Kinzel suggested that every engineer should visit his local high school to insure that math, physics, and chemistry were being taught. He thought this would start the student off right; after that, ECPD and EJC would make sure that the college curriculum was specialized and broad enough.

Identity problems of the 1960 s were, of course, partially associated with recruiting difficulties. But some felt that agricultural engineering needed redefinition for its own sake because of changing concepts and new applications. When A. W. Farrall was president $(1962-63)$ he had a committee working on this new definition:

"Agricultural engineering is a field of engineering and science in which both physical and biological sciences are specifically utilized. It involves power, machines, structures, electronics, land development and soil and water management in connection with the production, processing, handling, and storage of food, feed and natural fiber."

This effort had the disadvantage of trying to list everything but still overlooking some aspects, thus invalidating the whole definition. The real questions however, were: "Why define?" and "For whom?"

Past-President Hurlbut in a letter in the August 1963 Journal cautioned those who hungered for definitions. He pointed out that one definition was needed to distinguish the undergraduate program from the others but an entirely different approach was needed to define the engineering services which ASAE members were qualified to offer to the public. If these professional activities were mixed, confusion would result.

The identity search took a different turn when Jimmy Butt announced that the Public Relations Committee wanted members to develop a slogan to describe the Society's function. Slogans selected would be worth a free lapel button to their authors. Butt suggested several as starters. One of them was "Dedicated to Dignity for the Man with the Hoe." 
A few slogans came in but most had a self-laudatory flavor that probably sounded a bit unprofessional. One was sent in by a non-member, a proofreader at the company which printed AGRICULTURAL ENGINEERING. Her slogan was about as good as any of them: "Agricultural Systems Affectively Engineered." The slogan business quietly died.

From identity to social responsibility is but a small step because the professionalism that grows with identity and status must sooner or later lead to concern for the public welfare. Paul H. Robbins, NSPE executive director, called the agricultural engineers to account for their neglect of public affairs when he spoke at the 1963 Winter Meeting.

Robbins pointed out that policy decisions on air and water pollution, transportation, and the world food shortage were being made by industrial and government executives in the absence of organized assistance from ASAE and its members. To Robbins it was not enough for agricultural (and other) engineers to assume that their responsibility ended when an "adequate technical job" was done. Involvement in public affairs should be considered a professional obligation.

When Price Hobgood delivered his annual address in June 1965 he endorsed an EJC meeting at which participants were told by government leaders that engineering advice was needed in political and civic affairs.

However, such calls for involvement were rare. The presidents were more likely to point to technical challenges or express concern about membership growth and student enrollments (which, of course, were very important).

The environment movement, a movement which contained the seeds of both disrespect and opportunity for agricultural engineering technology, did not produce much presidential reaction.

Such neglect of contemporary issues may have been based on hope that the environmentalists would tire or "go away." Or perhaps ASAE leaders did not perceive the movement as a threat but as an opportunity. The movement may have stimulated creation of agricultural systems less damaging to environmental quality. In addition, agricultural engineers were working with renewable resources, generally speaking, although the vital elements of petroleum and fertilizers tended to put agriculture in the same boat as any other industry.

Meanwhile, however, legislative activity was also stimulated by environmentalists, much of it in technical areas covered by ASAE. Concern for public welfare might suggest preparation of opinions and similar aids to the lawmakers by ASAE, but this was not done. It was believed that such work might jeopardize the tax-exempt status. Also, standards, recommendations, and data were available to all. The safe course apparently was to generate technical materials but make little or no effort to interpret the materials to 
non-technical people in government who might need it. This was contrary to the policy adopted in the case of Georgia Section.

The decade was one of considerable advances in ASAE's capacity to serve its members. Reorganization, new Headquarters construction, new staff additions - these are examples of that improved capacity.

Externally, somehow the story seemed different. Earl Anderson's challenge of Soviet food-producing technology at the time of American humiliation in space technology was a fine gesture at the decade's beginning. But at its end ASAE was on the defensive with respect to the environment, searching for new ways to solve old problems, and lacking an efficient mechanism for putting its technical arsenal into the hands of public servants.

B

\section{Technical}

During the previous decade the process of establishing standards had been considerably improved. The sixth decade was witness to important advances in the standards area and some new concerns.

Jimmy Butt wrote President L. H. Skromme just prior to the December 1959 meeting of actions regarding standardization procedures directed by the Council. The new president was to appoint a committee representative of all divisions to prepare a policy on standards for Council adoption. The committee was to consider the procedures employed by the Power and Machinery Division in making its recommendations.

Skromme duly formed the special committee, which labored for two years. Its final report was rendered in December 1961 to the Board of Directors, which adopted it and approved it for publication in the 1962 Yearbook.

The special committee (under the chairmanship of C. S. Morrison) had developed a mode of procedure entitled "Standardization in the American Society of Agricultural Engineers." The document contained a preamble

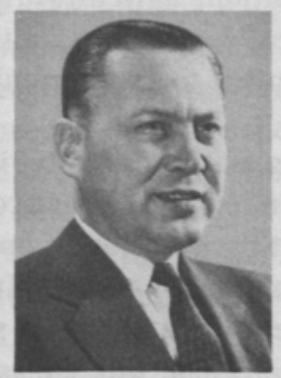

Lawrence H. Skromme 53rd president, ASAE, 1959-60 
which disclaimed ASAE responsibility for results attributable to the application of its standards. Definitions, procedural steps, administrative details, and provision for a permanent Committee on Standards were the highlights of the document. Some of its language and methods are still in use today.

Aside from regularizing the process, Morrison's committee had eliminated some legal problems to which the old standardization procedure had exposed ASAE, although some questions regarding the preamble arose in 1965.

Later the Board established the policy that ASAE Technical Committees should avoid recommending material for standardization unless the material was developed by ASAE or by a joint effort with ASAE.

In 1963 the Committee on Standards rendered a report on use of the metric system in ASAE Standards, Recommendations, and Data. Considerable concern had arisen on this matter; in fact, EJC had requested its member societies to express their attitudes toward adoption of the metric system and the request had been referred to the Committee on Standards.

The Committee noted that the cost to the U.S. public of changing to metric measure had been estimated to "exceed 20 to 30 billion dollars" and would "severely tax the economy of industry and consumers." Also, it was thought doubtful if good compliance would follow if ASAE shifted its standards to metric. However, the Technical Committees were encouraged to individually judge whether to use both British and metric, and to "decimalize" the British units. In other words, ASAE should proceed with caution on this touchy matter but recognize that the metric system was here to stay.

As American machines moved in greater numbers into foreign countries the metric system was only one of the problems. Almost all the developed countries had different standards which affected, for example, the tractor engineer. F. C. Walters of John Deere Waterloo Tractor Works published an ASAE paper in early 1964 on international standards.

In the case of materials there was no uniform way of specifying steels in different countries. Maximum speed varied from 16 kilometers per hour in Holland to $\mathbf{4 0}$ in Italy. Lights and brakes were subject to different regulations. Tractor noise level requirements and mode of measurement were variable. Drawbar details, PTO shaft and speeds, driver visibility, and wheel tread were unstandardized. Tractor testing was done in widely different ways, although some countries accepted the SAE-ASAE test code or the Nebraska test. Safety requirements were variable. Walters mentioned many more items of similar nature. Fortunately, the International Standards Organization (ISO) was working on the situation; unfortunately, no ISO standards had been completed in the agricultural power machinery field.

At the June 1965 meeting President-Elect Morrison distributed a proposal to the Board of Directors titled "ASAE Standardization." It outlined the 
growing importance of standards to ASAE and the national economy. It stated that ASAE standardization activities should no longer be financed by member dues; industry should begin to financially cooperate. Morrison believed that $\$ 10,000$ to $\$ 20,000$ per year would be needed to finance ASAE standardization activity at an appropriate level.

The proposal was received with interest in further development. Later in the meeting, when Morrison had assumed the presidency, he appointed this committee to study the financing of the Society's standards program: A. B. Skromme (chairman), H. J. Hansen (representing the Board of Directors), H. J. Barre (chairman, Standards Committee), P. W. Manson (University of Minnesota), R. E. Heston (Grinnell Mutual Reinsurance Co.), L. H. Hodges (J I Case Co.), and J. H. Zich (Ford Motor Co.). Skromme was also on the Board; Manson, Heston, and Hodges were members of the Standards Committee.

At that same meeting Skromme later reported to the Board that his committee suggested a plan be developed to obtain support of not less than $\$ 10,000$ per year from industry and trade associations for the ASAE standards efforts. The committee also recommended that ASAE become a member of the American Standards Association, or its successor body, when funds become available.

These suggestions were favorably received. Skromme was encouraged to proceed in developing the plan details for consideration at the December 1965 meeting, including legal review and approval of procedures plus specific recommendations on financing the program.

While on the subject, Earl Swink noted that the Standards Committee had expressed concern about the legal implications of the current preamble to the standardization procedures. Therefore, Morrison appointed H. J. Hansen (chairman), A. B. Skromme, and H. J. Barre, to review changes in the new preamble proposed by the Standards Committee.

Skromme's committee reported at the December meeting. The "Cooperative Standardization Program" (CSP) had been matured to a considerable degree. Lists of potential supporters had been developed, with a suggested contribution level for each organization. After discussing all aspects of the program the Board voted to set it into motion, including solicitation of financial support for the 1966 budget year.

Skromme's committee had budgeted \$23,015 for the 1966 program. Contributions from 157 manufacturers and other organizations amounted to $\$ 15,480$, about 67 percent. In addition to supporting a large proportion of the CSP, the funds allowed ASAE to join the United States of America Standards Institute, successor to the American Standards Association. Morrison was designated as ASAE's representative on the USASI Standards 
Council, with D. E. Kuska of the Oliver Corporation as alternate.

In cooperation with the FIEI a conference called "Standards - A Vital Tool in Engineered Agriculture" was held in December 1965. The main speaker was a past-president of ASA, Frank Roby. Roby forecast the change of ASA into USASI. The change would "make provision for government participation in standards activites with a degree of government support yet still continue the voluntary program sponsored and largely directed by industry." Thus U.S. industry could avoid some of the evils found in foreign countries where standards were often solely written by governmental agencies. Roby urged his industrial listeners to not only give financial support to standards writing, but also to help spread the idea of standards benefits among manufacturers and consumers. Other speakers delivered papers on specific areas of the problem, with special attention to the agricultural equipment industry.

Skromme reported on the CSP activity to the Board in June 1967. A total of $\$ 21,510$ had been received. The number of contributing companies had

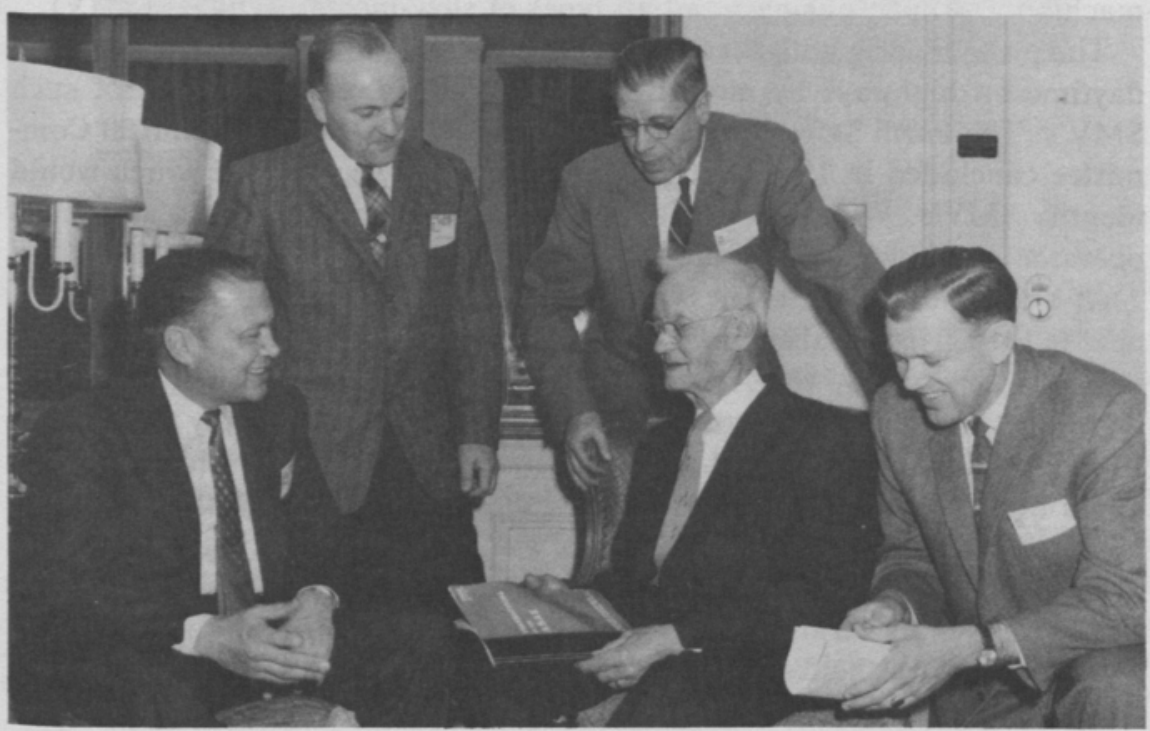

An agricultural engineering family held a reunion during the 1959 ASAE Winter Meeting. Austin Skromme (then 81), retired farmer of Huxley, IA, met his three sons and a son-in-law there. Standing (left to right) are Robert Skromme, J.I. Case Co., Bettendorf, IA, and Harold Beaty, (son-in-law), University of Illinois. Seated, (left to right) Lawrence H. Skromme, New Holland Machine Division of Sperry Rand Corp., and Arnold B. Skromme, John Deere Spreader Works. A fourth son, Austin Skromme, Jr., was with Caterpillar Tractor Co., Glasgow, Scotland 
grown to 274 . This represented a 36-percent dollar increase and a 72 -percent increase in companies over the 1966 figures. The money received exceeded the $\$ 17,000$ budgeted for the program year. Steps were being taken to better publicize new standards among interested possible users.

The activity had been remarkable for its vigorous execution and good reception. The stimulus given to ASAE's standards efforts was decisive (the 1966 Yearbook contained 22 pages of new ASAE standards). Arnold Skromme, a member of a family noted for its size and devotion to agricultural engineering, having moved the program into high gear, turned it over to Howard K. Johnson of the A. O. Smith Corporation. Since 1911 the Society had recognized the value of standardization and had groped toward some kind of regular approach to such public service. The dreams of the founders were now a reality.

While one particular ASAE standard is very familiar to the average American, he is probably unaware of ASAE's connection with it. This is the red-orange triangle marker seen in all parts of the country on tractors, road machinery, Amish buggies, and all types of slow-moving vehicles (SMV).

The problem originally was that agricultural vehicles were being struck in daytime on highways by motorists who misjudged the slow speed of such SMV's. The Farm Safety Committee and the P\&M Division Technical Committee concluded in 1962 that a standard symbol was needed which would identify SMV's. Wide acceptance of such a symbol would cause all vehicle operators to respond with caution.

At that time K. A. Harkness was testing a variety of symbols for the purpose in the agricultural engineering department at Ohio State University in a project sponsored by the Automotive Safety Foundation. Under simulated highway conditions, using students as subjects, Harkness finally arrived at a 14-inch high triangle. It had a reflective red border for night identification and a fluorescent orange center for daytime warning. The symbol was to be mounted base downward on the rear of the SMV at a minimum height.

The Harkness SMV emblem was subjected to considerable scrutiny during 1963 and 1964 by various ASAE and FIEI committees. An in-depth seminar on the subject was held at Ohio State in February 1963. Its advantages led to a series of field evaluation tests in 1964 by the National Conference for Farm Safety of the National Safety Council. ASAE's Chicago Chapter sponsored a symposium on the topic in May 1964. The speakers were C. L. Zink of Deere $\&$ Co. and L. J. Urben and T. D. McFarland of the National Safety Council. They indicated that the emblem was already being used in several states and was being sold by ASAE student branches and 4-H and FFA groups. This suggested the rising interest in the device even though it was not standardized by ASAE and its endorsement by the National Safety Council was on a 




Kenneth A. Harkness, instructor in the agricultural engineering department, Ohio State University, designed and developed the SMV (slow-moving vehicle) emblem to serve as a warning to motorists

qualified basis at the time.

In cooperation with ASAE's Farm Safety Committee, the Farm Conference Studies and Research Committee of the National Safety Council prepared a standard description of the SMV emblem. The standard was approved by the Power and Machinery Division Technical Committee and adopted by ASAE at the 1964 Winter Meeting as Recommendation ASAE R276. (It was later adopted by the Society of Automotive Engineers.) R276 was printed in the 1965 ASAE Yearbook. It contained a detailed description of the emblem, properties of the surfaces, construction materials, and mounting details. The emblem was intended to identify vehicles moving at 25 $\mathrm{mph}$ or less on public roads.

On April 5, 1965, Nebraska enacted a law requiring that equipment designed to travel less than $25 \mathrm{mph}$ must display the SMV emblem described in ASAE Recommendation R276. Ohio followed shortly with similar legislation. The Ohio act provided that "The standards and specifications for SMV emblems ... shall correlate with and ... conform with those approved by the American Society of Agricultural Engineers."

T. D. McFarland reported in 1965 results of a nationwide survey of SMV lighting and marking regulations. Forty-eight of the 50 states responded to the survey. The findings showed great variation among the states in these 


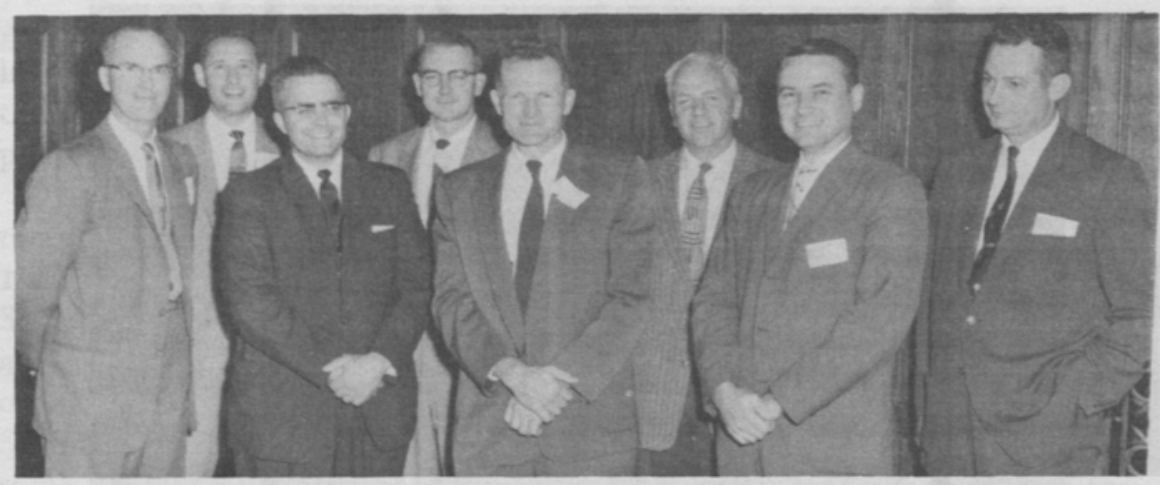

ASAE Committee for Conference on Materials Handling, held in September 1958 are (left to right) Marvin Nabben, D. F. Shimon, M. W. Forth (vice-chairman), R. W. Kleis, F. W. Andrew, C. K. Otis, S. S. DeForest (chairman) and N. H. Curry (chairman of local arrangements committee)

regulations. Because of the variation, wide adoption of the ASAE-Harkness SMV emblem was held to be a vital step forward in highway safety.

The Board of Directors of the National Safety Council approved a policy statement in April 1966 which supported promotion and use of the emblem. The statement emphasized how the requirements varied among the states through lack of standardization, pointing out that the SMV emblem met the need for identification of SMV's and that its design was standardized.

Meanwhile, K. A. Harkness received a citation from the Ohio legislature for his direction of the research from which the emblem design resulted.

Recommendation R276 became ASAE Standard S276.1 in 1966. At that time laws related to use of the emblem had been enacted in seven states and were under consideration in eight more.

Development of standards is usually a slow, painstaking process. The individuals involved rarely are known or their work much appreciated outside the specific technical world where standards have real meaning. The SMV emblems, however, should cause pride in all agricultural engineers because their millions, universally known, have served well in saving life as well as property.

As always, technical problems and advances, and new research approaches and needs, engaged the closest attention of the agricultural engineers.

Recognition of a neglected problem area led ASAE to sponsor a Farm Materials Handling Conference in September 1958 at Iowa State College. All papers presented during the conference were published in the 
September issue of AGRICULTURAL ENGINEERING plus a directory of suppliers, a bibliography on feed handling (1946-1958), and an analysis of current research on feed handling in the U.S. and Canada.

Harold E. Pinches called materials handling a "farm production integrator." He believed that increasing size of farms and increasing commodity specialization would justify much larger capital inputs into handling equipment. This would tend to reduce restrictions on size of enterprise or capacity. However, the optimal condition must integrate methods and equipment to facilitate the farm functions.

Materials handling, then, demanded creation of systems. S. S. DeForest, conference chairman, pointed this out in his articles in "Successful Farming." It was a time of systems awareness, due partly to the rise of operations research as a viable tool for guidance of complicated endeavors. $L$. $L$. Sammet of the University of California at Berkeley introduced the term "Systems Engineering in Agriculture" in a Journal editorial in 1959. Sammet called for greater attention to systems as a "basic orientation in agricultural engineering." The 1965 meetings of the American Association for the Advancement of Science at Berkeley included a program on "Systems Engineering in Agriculture" arranged by an ASAE committee. The growing availability of electronic digital computers offered enormous advantages in allowing analysts to simulate systems as part of their problem-solving techniques.

Exploration of the key factor in the system-man-machine interface gave rise to a session on "Ergonomics in Farm Equipment Operation" at the 1957 Winter Meeting. The term "ergonomics" (based on the Greek ergon, work) is no longer used; however, its meaning was evidently similar to what is now called "human factors" engineering.

Heinrich Dupuis (a non-member) of the Max Planck Institute for Farm Work and Agricultural Engineering in West Germany, contributed a paper on the "Effect of Tractor Operation on Human Stress." His detailed studies showed that: (1) The type of tractor influenced operator energy output; (2) the type of task influenced energy output. With respect to (2), using the same tractor, Dupuis found that manure loading, plowing, transporting, and harrowing demanded a gradation of energy input from highest to lowest in the order listed. Manure loading was equal to log cutting in energy demand, while harrowing was about like driving a passenger car, although accompanied by greater nervous stress. Examination of tractor controls and seating arrangements revealed some serious deficiencies. Improvements in controls and seating arrangements markedly reduced operator energy expenditure. Dupuis had noted that in manure loading, in one hour the operator shifted gears and moved the clutch 230 times, operated the brake 
100 times, and the hydraulic control of the front-mounted loader 250 times; thus controls and seats better proportioned to human geometry could save much energy.

A paper on "Engineering Psychology in Farm Equipment Design" was delivered by Ernest J. McCormick of Purdue University, also a non-member. Evidently McCormick believed that the design of work equipment and environments should be called "human engineering" and should involve engineers, physiologists, anthropologists, physicians, and psychologists like himself. However, they had not as yet contributed much to design of farm equipment. He discussed the contributions which human engineering could make to farm equipment based on work in other fields such as aircraft cockpit and truck cab design. For example, the common aircraft altimeter was the cause of many accidents because pilots had difficulty interpreting its meaning. In fact, it would be difficult to design an instrument more tricky to read, yet its configuration had been in use many years. McCormick mentioned how the arrangement of brake control, steering wheel, and gearshift lever in some truck cabs was an open invitation to accident. Such methods of human analysis were discussed as motion pictures to study the operator's eye and head movements and reaction time.

Also from Purdue, J. B. Liljedahl and two of his students in their paper on "Steering-Force Requirements of Wheel Tractors" pointed out that tractor steering systems would need improvement because these machines were increasing in size, speed, weight of implements, and need for more accurate steering, as in cultivation. They tested the effect of external forces on the steering system and the effect of devices to improve the steering. Certain mechanical devices proving effective in reducing steering-wheel shock and torque were the Kosch steering aid, power steering, and the roll-o-matic front end, available on the John Deere 70.

Since ancient times man has practiced human engineering in the design of tools, weapons, clothing, structures, etc. That the process had much room for improvement in agricultural applications was revealed by the Ergonomics Conference. In the case of tractors, evidently much pioneering work was done by the Germans in the early 1950s. The Americans picked it up in the middle 1950s. For example, Harlan Van Gerpen of John Deere Waterloo Tractor Works gave a paper at the June 1956 meeting on "Instrumentation for Evaluating Seating Comfort on Farm Tractors." Research on human heat stresses in tractor operation was reported to ASAE by the Purdue group in 1957. W. E. Splinter and C. W. Suggs of North Carolina State College reported development in 1956 of methods for measuring time and energy expenditure of humans engaged in agricultural tasks. M. L. Esmay used the term "human engineering" when discussing farmstead 
chores in a 1957 paper. Other work followed rapidly. Much of it was influential in making life physically easier and safer for the farmer.

Byron T. Shaw, administrator of the USDA Agricultural Research Service, perhaps described the modern agricultural engineer in an address at the Society's 1959 Annual Meeting.. After setting forth some of the contemporary challenges as he viewed them, Shaw then commented:

"Today's agricultural engineer no longer fits the definition, given in 1904, by a group of educators, as one who lays out farms, designs and constructs farm buildings and works, and makes and uses farm implements. A better definition today would describe the agricultural engineer as one who establishes new fundamental principles and basic requirements, and from these determines the techniques and specifications for particular applications of engineering to agriculture."

There was some truth in Shaw's picture. Not only human engineering but a number of other technical innovations came on the scene. Some of them, however, appeared to be ahead of their time, or just didn't fly.

E. V. Collins at Iowa State and W. F. Buchele at Michigan State worked out a scheme whereby two tractors were hooked together and controlled from the rear tractor. Called a tandem tractor, it provided a four-wheel drive machine for heavy loads, plus two two-wheel drive machines for lighter loads. The idea received much attention in 1957-59. The tandem was considered likely to fill the horsepower gap between about 50 and the much higher level where track-type tractors took over. But this did not occur, probably due to the large physical size and general engineering disadvantage of the tandem, such as two engines. Instead, the manufacturers started building rubbertired tractors to fill the gap. Many were four-wheel drive yet in a more compact design.

C. B. Richey of the Ford Motor Co. thought that the advent of power steering for tractors opened the way to automatic guidance of the machine while plowing, cultivating, or mowing. He published a Journal paper in 1959 which outlined some of his tests of guidance devices based on sensing of crop rows or plow furrow walls. Although his test devices functioned successfully, the technique was not adopted by the industry, perhaps because of the complications added by guidance mechanisms. However, Richey may yet be vindicated because interest in automatic guidance has increased considerably since about 1970 . It is interesting to note in this connection that J. B. Davidson and his students tested a "manless plow" back in 1924 at Ames; they were surely in advance of their time!

Tractors were powered by heat engines fueled either by gasoline or diesel oil. By Carnot's law the available energy of a heat engine is linked to the difference in temperature between combustion and exhaust. Because of this, 
their efficiency at best was limited to about 40 percent in a good diesel engine. But the fuel cell, not governed by Carnot's law, could be much more efficient. Known in principle for many years, the fuel cell was fed with fuel gas and oxidant at two electrodes; they react in an electrolyte with the aid of a catalyst. With very little heat given off, the chemical reaction energy could be converted into direct current to drive a motor. Allis-Chalmers installed 1008 fuel cells on a regular AC D-12 chassis. Commercial bottled oxygen was used with a mixture of gases to operate a 20 -hp electric motor. The tractor was unveiled in 1959. A paper discussing it created much excitement at the 1959 Winter Meeting. Although equipped with ordinary drive shaft and differential, no gearshift was required because control was entirely electrical. Its operation was so quiet that the driver could easily hear a radio while plowing. On the drawbar the machine developed $3000 \mathrm{lb}$ of pull. The fuel cell tractor seemed to be a great leap forward.

But nothing more was heard of it in agriculture. The space program used fuel cells to provide power for Gemini 6, 7, and 8. Models were being tested in 1967 for powering moon vehicles. But the tractor industry ignored the fuel cell. The problem was partly cost of materials. Then the large size of "engine" compared to its power output was unfavorable. The power output was affected by ambient temperature. Common fuels like gasoline, kerosene, or diesel fuel could not be readily used. It would take from 15 minutes to 1 hour to reach operating temperature if propane gas were used. And the system was exceedingly complex. It is not surprising that industry did not take up the fuel cell power plant. The fact that it is still not in use on tractors today suggests that the disadvantages have yet to be overcome.

International Harvester Co. announced in 1961 a research tractor equipped with gas turbine engine and hydrostatic drive. The engine was an 80-hp model, extremely small, which weighed only $90 \mathrm{lb}$ with reduction gears. It would operate on virtually any kind of liquid fuel. The transmission, minus gears or shafts, used high-pressure oil to actuate the pistons of a hydraulic motor installed in each driving wheel. The tractor looked very sleek; its fiberglass body suggested the lines of a racing vehicle. However, the innovation did not reach commercial production.

Hay wafering was an innovation whose time had come. A report was presented at the 1960 Winter Meeting by V. J. Lundell of the Lundell Manufacturing Co. and D. O. Hull of lowa State University on the first commercial hay wafering machine, which was designed by Lundell. The process of baling or chopping hay wasn't mechanized at the feeding stage. Wafering or cubing provided a form of hay which could be mechanized from field swath to feed bunk.

Interest in wafering went back to at least 1932 when Hobart Beresford 
demonstrated in Idaho that wafers could be made. H. D. Bruhn (University of Wisconsin) created a diversion at a 1954 Winter Meeting session when he interrupted his discussion on the possibility of pelletizing forages by reaching into his pocket and throwing well-made experimental hay cubes into the audience. John Dobie of U.C.-Davis pioneered studies of moisture content required for successful field wafering.

Others also aided Lundell in designing his successful machine. That machine picked up conditioned, cured hay from the windrow, cut it further with knives, then sent it to the wafering mechanism, with a dose of moisturizing agent applied en route. In the wafering chambers the hay was subjected to pressure which the operator could vary from 100 to 1000 psi. As the wafer column was extruded from the die it was broken into wafers of desired size. These were then elevated into a trailing wagon. The machine could eject a $2 \times 2$-inch or $1 \times 2$-inch wafer. Wafer density was controlled automatically. Machine capacity was 5 to 6 tons per hour. The Lundell machine is still in commercial production.

To illustrate the keen interest in wafering at that time, 50 ASAE papers and M.S. theses on the subject are listed in Hall's 1961-1970 "Agricultural Engineering Index."

L. H. Skromme (a part-time cattleman himself) illustrated the need for processes leading to mechanized feeding such as hay wafering in his introduction to a series of 1963 Journal reports on "Controls in Farmstead Mechanization." He wrote that for 1959-60 the sale of livestock and their products amounted to 56.1 percent of total farm receipts. Livestock feeding and handling had become the most important economic sector of the average farm enterprise; therefore, these deserved increasing mechanization inputs. As Skromme put it:

"Field crop mechanization has shown outstanding progress during the past 50 years. Output of crop products per man-hour of labor increased at a compound annual rate of 7.0 percent since 1945 . The production of livestock and livestock products has not yet been mechanized to the same degree. In the 1920-1944 period, output of livestock products per man-hour increased at a compound rate of only about 1 percent annually. Since 1945, when farmstead mechanization began to take effect, the rate has increased to about 3.6 percent."

Another aspect of livestock farming was discussed at the June 1962 Annual Meeting by Frank A. Todd of the USDA-ARS. Todd in his paper on "Nuclear Fallout and Livestock Survival" suggested that domestic animals are quite vulnerable to nuclear radiation. Unsheltered cattle, for example, could die after exposure to 650 roentgens for 24 hours; swine, sheep, and poultry could tolerate larger doses. An effective fallout shelter was the 
basement-type barn with loft full of hay. However, there was also the hazard of isotopes entering the food chain. Strontium 90 and iodine 131 might be the most hazardous; the former has a long half-life and accumulates in bone, while the latter is secreted in the milk of dairy animals. Todd listed elaborate precautions necessary to protect feed and water after fallout. The state extension agricultural engineers offered construction plans for barn and family fallout shelter. But people had lost interest in fallout protection, probably because the government seemed less concerned with civil defense.

A new horizon was suggested to those who attended the 1964 Winter Meeting and heard Victor L. Loosanoff (a non-member) speak of "mariculture." Loosanoff, with the U.S. Bureau of Commercial Fisheries, predicted that human population was fast outstripping the food-producing capacity of land; therefore, man must turn to the ocean.

Many think the oceans are an inexhaustible source of food. Not so, according to Loosanoff. The supply of fin-fish could be quickly depleted by the efficient methods employed in modern times. And ocean fishing is costly. Moreover, the production of oceanic fish (such as tuna) cannot be increased by any known technology. Loosanoff's answer was to raise other forms of aquatic life in the estuaries, harbors, bays, and sounds. Here algae, mollusks, and crustaceans can be raised under controlled conditions and harvested - a process called mariculture, or sea farming. Such processes were carried on by ancient peoples and by many people today.

Algae ranging from giant seaweed to unicellular Chlorella could be intensively cultivated to provide good protein for man and beast. Molluscans such as oysters and clams are admirably suited for farming. Crustaceans (lobsters, crabs, and shrimps) are amenable to artificial propagation, although Loosanoff mentioned some knotty problems yet unsolved.

In sum, he stressed that mariculture, to be commercially successful, would require precision engineering. And he seemed to prefer "engineers having experience in agriculture." The agricultural engineers in the Corn Belt and similar areas probably paid little heed to Loosanoff's message. But there were those near the seacoasts who scented opportunity; these engineers started cultivating oysters and designing machinery to deprive them of their shells.

Although Loosanoff emphasized that agricultural engineers might contribute to controlled production of inshore marine organisms, there were attractive opportunities for engineering in harvesting the open sea. Milner B. Schaefer, a non-member who directed the Institute of Marine Resources of the University of California, called ASAE's attention to these oppportunities in an article in the 1965 AGRICULTURAL ENGINEERING.

He wrote that offshore food production had recently exceeded the rate of 
growth of the world's human population. In 1962 the harvest reached 40 million metric tons. The growth rate was made possible by technological innovations developed by the leading fishery nations (like Japan and Russia). Examples were the factory ship, fish locator systems, and new catching equipment. From estimates of unused stocks of harvestable fish and appraisal of the food chain potential, Schaefer believed that the harvest could be increased two to four times with safety.

The essential engineering needs for the U.S. related mainly to: (1) Meeting the challenge of the Japanese and Russian factory ships by an "optimum combination of techniques at sea and shore."; and (2) development of new food commodities by utilizing species presently considered undesirable for human consumption.

As a result of considerable research by agricultural engineers in the $1950 \mathrm{~s}$, the concept of minimum tillage for corn gained some degree of acceptance. Prominent among the workers were Wendell Bowers, H. P. Bateman, A. A. Swamy Rao, and R. C. Hay at the University of Illinois; W. H. Johnson at Ohio State University; and George R. Free (USDA-ARS), R. B. Musgrave (a non-member) and P. J. Zwerman at Cornell. Stubble-mulch tillage, a practice well known in drier areas for controlling wind and water erosion, included such elements of minimum tillage as planting through trash. R. R. Poynor of International Harvester Co. reported in 1949 on an experimental mulch planter which could plant corn in an alfalfa-brome sod in a once-over operation, thus reducing time, power input, and traffic. Minimum tillage could produce corn (and other crops) with less labor, less petroleum, less soil loss from erosion, and less soil compaction.

Many farmers believed that more tillage insured a better seedbed. Bowers noted that some Illinois corn growers might complete ten or twelve trips over a field before tillage was considered adequate. He and his associates started working in 1952 to determine if all those trips were really necessary.

The Illinois studies compared conventional planting with these four basic minimum-tillage treatments:

Plow and plant, one operation with planter mounted on the plow.

Plow - then plant with no intermediate tillage.

Plow - then plant in press-wheel or tractor-wheel tracks.

Plow and pull a light tillage tool, such as a clodbuster, harrow, or rotaryhoe section - then plant.

Previous crops were clover, alfalfa, soybeans, and corn. In all cases, the 
plant populations were less than with conventional tillage while the yields were equal to or slightly greater than with conventional. Those high corn yields were due both to more ears per plant and larger ear size. Roots invariably developed better under minimum tillage; this was believed responsible for good growth later in the season. Yields and populations were high in clay loams when adequate moisture was available at planting. Minimum tillage was more successful after corn than after alfalfa or red clover. This also reduced the weed problem; most minimum-tillage plots required only one cultivation

Johnson and his associates worked on the glacial lakebed soils of Ohio. Chronically wet in the spring, these fine-textured soils might require twice as much tillage as coarse-textured soils. They found that these soils did not respond markedly to minimum tillage. Crop response was improved with minimum seedbed preparation, but obtaining consistent and adequate stands was difficult in such heavy soils. The practice of fall plowing was beneficial (if erosion could be avoided); spring-plowed land was benefited by tilling the furrow slice when plowing. Use of press wheels and similar devices yielded contradictory results. Plow-plant and wheel-track-plant gave fair crop responses but low stands. Thus, it appeared that minimum tillage was better suited to coarse and medium-textured soils than to those with a high clay content. This was confirmed by Swamy Rao in Illinois.

George Free reported on minimum tillage investigations carried on in New York since 1946. Corn yields were as good as those with conventional tillage and the reduced compaction aided moisture conservation. Free noted that yields of 70 to 100 bushels of corn were obtained without any tillage (except for a slit for the seed). Chemicals destroyed vegetation prior to planting. Herbicides were also used in place of cultivation but at some sacrifice in yield because of surface crusting. Overall, the reduction in time and cost was appreciable.

Those findings, which were supported by much work done elsewhere, appeared in ASAE literature in 1960. In 1965 Wendell Bowers wrote a short comment in the Journal on minimum tillage progress. A cultural practice committee had been formed in ASAE to focus the knowledge of tillage practices and disseminate it more widely. The college people were working through extension to teach farmers how to apply minimum tillage to their own situation. This was being done through field days and demonstrations, with the industry engineers cooperating fully. Bowers regarded this as an outstanding example of ASAE fostering the spread of uniform recommendations for a technological process. Unfortunately, research had not yet shown that minimum tillage could increase yields; therefore, acceptance was slow 
although suitable equipment was readily available. Bowers concluded by calling for more research "to find ways to reduce power and labor inputs for crop production."

Today, confronted by the increasing cost and scarcity of petroleum, minimum tillage has become a very important tool in the farmer's hands. Its time has arrived; the technology was available to the country when it was needed. This is also partially true of power alcohol, although many seem to think it is a brand-new idea.

In 1967 Ray I. Throckmorton, Jr. and R. R. Poynor (both of International Harvester) stuck their necks out and predicted what tillage would be like in 1975. First, they acknowledged that some tillage was probably necessary and that soil compaction problems would not be completely solved with tillage equipment requiring drawbar pull. Then, by 1975, they predicted: Drawbar pull will still power primary tillage; energy requirements per unit volume of soil tilled will decrease because of minimum tillage acceptance; deep plowing (10-12 inches) will be the norm; only the row zone will be tilled; deeper, faster tillage will be common, along with plow-plant machines and other once-over techniques.

One cannot fault their educated guesses. These practices probably would have become popular because of their real advantages to the farmer had the oil crisis not occurred.

With the growing availability of the digital computer it was inevitable that its usefulness would be recognized by agricultural engineers. The first ASAE computer paper, by Harlan Van Gerpen, was published on page one of TRANSACTIONS Volume 1, Number 1, 1958. Deere and Co. had an IBM 650 computer at Moline which Van Gerpen and his colleagues at Waterloo started using in 1956. It first was used to design spur gears; the process worked so well that it was extended to helical gears. The computer could in five minutes calculate a gear design problem which took one week of manual calculation and checking.

Numerous other problems had been programmed and debugged by the Waterloo group - prediction of tractor field performance, helical spring design, deflections of non-uniform shaft, Fourier analysis of complex wave forms, statistical analysis, and involute spline calculations. They anticipated further applications in the near future.

Van Gerpen illustrated his paper with a flow chart for gear design calcula- 
tion, the desired specifications, and the output answers. Also discussed was the iterative process of predicting field performance of farm tractors. The necessity for converting the flow chart into machine language was mentioned; however, the name of the language was not revealed. The FORTRAN compiler was first developed for the IBM 704 in 1956; it is therefore possible that the Waterloo group used some other language.

This pioneering paper called for an end to "cut and try" procedures and cited the need for investigation "from a theoretical standpoint." A noble call to arms it was; however, certain stalwart researchers had put forth the same doctrine many years before, and even practiced it, prior to the computer age.

But now it was time for agricultural engineers and computers to get acquainted. A spate of papers involving their use came in the 1960s. The digital computer took over in such problems as analysis of plow bottom shapes, soil compaction, tractor performance, complex drainage and runoff predictions, weather data, land-forming calculations, sprinkler irrigation distribution patterns, systems analysis, and a variety of machine design procedures.

Simultaneously the virtues of the analog computer were also being discovered. It was well adapted to study of many engineering problems because it could readily solve the simultaneous differential equations that so often characterize these problems.

Computers advanced from practically zero usage in the late 1950s to dominance as major tools ten years later. This was particularly true of the digitals, probably because their capacity grew markedly during that period. Availability of those powerful tools opened a new dimension to agricultural engineers, a dimension whose horizon is still widening.

\section{C \\ Education}

President L. H. Skromme was invited to address the Tennessee Section at that group's annual banquet in October 1959. Two Section members asked Jimmy Butt to make clear to Skromme that his presence would aid Clarence Bockhop, head of the Agricultural Engineering Department at the University of Tennessee, in his struggle for recognition by the School of Engineering.

President Skromme's missionary work was effective; in a letter to him dated March 31, 1960, Butt said the Tennesseans were "still bragging over the good you did . . ." Also as ASAE President Skromme was invited to attend a presidential inauguration at the University, an unusual development.

Among other stimuli to education sponsored by ASAE was a Winter 
Meeting talk in 1959 by L. E. Grinter of the University of Florida, the wellknown spokesman for quality in engineering education. He entered a strong plea for strengthening the science component and reducing the art in the education of the undergraduate engineer. In his view, perhaps 25 percent of the students should be prepared to serve as "engineering scientists."

Grinter was firmly convinced that the best teaching came from those who also researched. Such teachers could appreciate science and mathematics; they could move easily into curricula "emphasizing applications of theory and modern scientific experiment to practical problems." These curricula would attract able students.

Agricultural engineers, Grinter said, should have high standards in mathematics and physical sciences. Being more diversified in practice than most other engineers, they should emphasize engineering science but give less emphasis to specialized design or practice courses. His reasoning was this:

"The concept of a strong background in the engineering sciences with limited and concentrated experience in analysis and design, in a single field of interest to the student, probably represents the strongest achievable undergraduate engineering preparation for agricultural engineers. This background is highly transferable to any engineering work that may be involved in later practice. Inclusion of many unrelated practical engineering courses in the undergraduate curriculum would result in a low transferability of knowledge. Also those unrelated courses must necessarily be taught at such an elementary level as to be of little actual value in practice. As to humanistic studies, it is worth considering that agricultural engineers may have even greater need than more specialized engineers for use of written and spoken language along with an understanding of human nature."

Grinter's ideas were not universally admired, either in ASAE or the other societies. Nevertheless, upgrading of the agricultural engineering departments had been proceeding on similar lines for many years. Thirty of these had been accredited by June 1960 and there was a brisk demand for instructors holding doctoral degrees. Although undergraduate enrollment was a matter of much concern, the graduate level enrollment was flourishing in a climate of "applied science."

The number of accredited agricultural engineering departments was respectable, all things considered. Yet it galled some members, including Secretary Butt, that ASAE was not a member of the accrediting body, ECPD. When J. Dewey Long was president he wrote in April 1946 that ASAE should "in due time" attempt to become a member of ECPD. Jimmy 
Butt felt perhaps that "due time" had arrived in 1964 when he opened correspondence with $\mathrm{L}$. $\mathrm{K}$. Wheelock of EJC regarding ASAE's eligibility to join ECPD.

This action was reported to the Board by President Hobgood at the 1964 Winter Meeting. Although no reply from Wheelock had been received, it was voted that ASAE "take steps" to join ECPD "if eligible."

Hobgood wrote to EJC Executive Secretary Carl Frey in January 1965 to open the main question regarding the rules of membership. ECPD required its member societies to have a minimum membership of 5000 in full member grade. ASAE did not have that many full members but because its associate members are graduates of accredited departments, Hobgood thought they should be counted.

Frey was probably happy to turn the ASAE problem over to W. Scott Hill, president of ECPD. Hobgood and Hill engaged in correspondence which boiled down to the 5000 "full" member issue. At that time, February 1965, ASAE had 2436 full members and 2832 associate members. If ECPD stuck to its position, ASAE had little hope of getting in.

Hill, in early March, referred the matter to Ralph A. Morgen of Stevens Institute of Technology. Morgen was chairman of ECPD's Admission Committee. He promptly informed Hobgood that ECPD was planning "a special class of membership for those societies . . . who do not qualify for full membership."

Hobgood was not happy at this hint of "second-class" membership, as he described it to Butt. The latter reacted by counselling Hobgood to accept only a "class of membership . . . which recognizes fully that agricultural engineering is a bona fide separate branch of the engineering profession." Thus encouraged, Hobgood wrote Morgen that the special class of membership was of interest but only it if recognized that "our profession is a unique segment of engineering . . rather than a fraction of one of the older disciplines."

Matters were at this juncture in June when C. S. Morrison became president. He found that ECPD had not defined the meaning of "full member" since 1949 nor had they included a definition in their Rules of Procedure. If ASAE could not qualify under the " 5000 in full member" proviso, then the newly created "affiliate" grade would be its fate. This would relegate the Society to an observer role without even hope for committee memberships. Morrison wrote Jimmy Butt that he was "inclined to favor a delay until we can negotiate a better deal."

Seeking a better deal, Morrison wrote Morgen in August to stress the professional stature of ASAE, its more than $\mathbf{5 0 0 0}$ corporate members, its consti- 
tuent membership in EJC, and similar items. It ended by stating that the Society should "participate fully." Morgen replied that ASAE could not count its associate members as "members" for qualification as a Participating Body (as ECPD called their voting constituent societies).

After this seeming impasse, Morrison wrote to W. Scott Hill, enclosing the correspondence with Morgen. Morrison drew attention to ASAE's slow but consistent growth, although its rate precluded reaching the ECPD criterion within the near future. Then he commented:

"The ASAE actively participates in EJC, ASEE, and NCSBEE. I am truthfully unable to give our membership a logical explanation of the limitation which precludes similar ASAE participation in ECPD. The new ECPD Affiliate classification seems to be purely an observer status and may or may not be acceptable to our membership. The Board of Directors and membership must make this decision."

A lengthy period of gestation on the part of ECPD then took place. Carl Frey (always an ASAE friend and supporter) wrote Morrison twice in December 1965 with encouraging comments; Frey thought that "favorable" action would occur in early 1966.

However, when the Board of Directors convened in June no action had taken place. Morrison was optimistic when he reviewed the situation, saying that the ECPD Membership Committee (sic) had given "full support" to ASAE's application as Participating Body. The cost of the membership was estimated at $\$ 1200$ per year. Then a Board member asked what advantages ASAE would gain from membership in ECPD. Morrison (probably disgusted) merely replied that it was a Board decision made "several years ago."

Prospects looked bright when it was announced in the September Journal that ASAE's application would receive further consideration at a meeting of ECPD's Board of Directors in October. A change in the "Rules of Procedure" was hinted.

In December President Orval French announced ASAE's admittance as a Participating Body. John R. Davis, dean of engineering at the University of Nebraska, was to represent ASAE on the ECPD Executive Committee; Frank Lanham and Carl Hall were appointed to the Board of Directors. ASAE members were named to serve on all of ECPD's committees.

There was an exchange of correspondence between French and Butt prior to the public announcement. On first learning that ECPD had decided to allow ASAE to come in, French wrote "Now we must fish or cut bait. I see no alternative except to accept membership."

Later, Butt informed French that the ECPD membership would cost $\$ 2000$ 


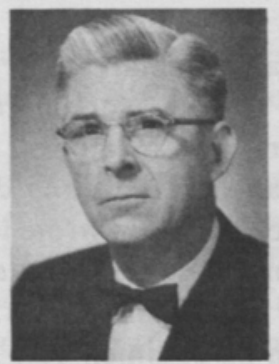

Orval C. French

60th president, ASAE, 1966-67

in 1967. Since a dues increase had just been established, Butt thought French should point out that such costs were part of ASAE's "expanding sphere of operations" in his forthcoming report to the Cabinet. Butt also suggested that French tell the Cabinet how important it was for ASAE to be a voting member. In fact, it might be appropriate, according to Butt, for French to comment on how ECPD modified its membership rules in order to admit ASAE in a non-humiliating grade.

French's remarks on ECPD at the December 1966 Cabinet meeting have vanished. He probably mentioned the prestige gained by agricultural engineers in having their technical society accepted on an equal basis by the civils, mechanicals, electricals, chemicals, etc. But that was a vague concept, probably not genuinely appreciated by many of his listeners. Morrison failed to list any real advantages of ECPD membership when asked by a certain Board member (it was R. E. Stewart), probably because the main advantage was available already without becoming a member: participation in the accreditation process. This battle had been won years ago in the time of J. Dewey Long.

Thus the principal advantage might be reduced to the intangible value of that tacit recognition conferred by being a Participating Body of ECPD. It recognized ASAE's claim to equal standing as representing a qualified and viable branch of engineering. On this basis ASAE was better off in ECPD than out; Morrison's determination to obtain a "better deal" was good for ASAE.

An argument advanced by Hobgood and Morrison to prove ASAE's capacity for membership in ECPD was that ASAE had discontinued its curriculum recognition program "in favor of full reliance on ECPD accreditation." Actually, ASAE was very glad to withdraw from the business of curriculum recognition. 
Readers will recall that in 1946 when ASAE started its accreditation thrust, it was very close to a policy of officially recognizing qualified professional agricultural engineering curriculums.

In 1958 the Curriculum and Course Content Committee wanted to apply ECPD criteria in ASAE recognition. The Council demurred from such a definite policy and asked that standards be developed that would produce engineers "qualified for direct admission into ASAE in the grade of Associate Member." Those departments producing such graduates would be worthy of recognition by ASAE, if not accreditation.

After some time and a considerable amount of wrangling, a new curriculum policy was announced in July 1961. Developed by the Committee on Curriculum and Course Content, approved by the Education and Research Division Steering Committee, and adopted by the Council, the new policy stated:

“A. Agricultural engineering departments accredited by ECPD will be listed as having recognized curriculums of ASAE . .

"B. Other departments offering curriculums which have been recognized by ASAE within five years prior to January 1, 1964, will be listed as having recognized curricula in the Society's records published during the calendar year 1964. Thereafter, no department will be considered to have a recognized curriculum unless its curriculum has either (1) been accredited by ECPD within the preceding five-year period or (2) has been recognized by ASAE within the same five-year period."

It was pointed out that "ASAE considers it a responsibility of the Society to establish requirements for approval." The Committee on Curriculum and Course Content had the job of reviewing the department.

Emphasis was placed on the penalties of non-recognition in the 1962-63 Annual Report when Jimmy Butt pointed out that "Those departments not recognized by the Society will not be authorized to have student branches of ASAE, nor will graduates of those departments be eligible upon graduation for admission to membership in the Society as Associate Members."

This was strong medicine. The Board of Directors listened to Butt in December 1963 as he called attention to the January 1 deadline for ASAE recognition of the departmental curricula. He commented that "some curriculums would probably be dropped from the ASAE-recognized list for the first time in memory and . . Board members be prepared to expect some repercussions."

Then appeared R. W. Kleis, chairman of the Curriculum and Course Content Committee. He read a committee report which listed those departments which his committee recommended should receive, or not receive, recogni- 
tion. The unlucky few not recommended were the Universities of Vermont, Connecticut, and Wisconsin, and Montana State College. The Board voted to accept the recommendations and to implement them. After some discussion it was agreed that President-Elect Hobgood write the departments whose request for ASAE recognition was refused. It was also agreed that the student branches of the institutions in question would not receive the usual Society notices in the fall of 1964.

There was unfavorable reaction to the Board's affirmation of the committee recommendations. The outcry from the Wisconsin department was particularly bitter and outspoken. (After all, that department sheltered the birth of the organization which was now condemning it!) The issue at Wisconsin was the practice of granting degrees in agriculture and in mechanical or civil engineering after five or more years of study. The Committee on Curriculum and Course Content argued that Wisconsin did not grant a B.S. in Agricultural Engineering; therefore, the department did not have a curriculum to be reviewed or recognized. This was perhaps literally true, but Wisconsin had pursued their policy for a number of years and had graduated many men who had made outstanding contributions to agricultural engineering. These men were now outraged by the apparently arbitrary behavior of the Society they had so loyally supported.

The action was disturbing to others also. President J. W. Borden presided when the Board decision was made. He conveyed expressions of doubt regarding the decision to Price Hobgood. Hobgood keenly felt that a mistake had been made. He wrote Borden in May 1964 approving Borden's "open approach" (Borden had appointed a Board subcommittee to work on the problem; the appointees were Farrall, Hobgood, and Morrison) and looked forward to an equitable solution. Hobgood stated that:

". . . there is room for some reconsideration of our real objectives and the possibility of developing some leniency in deciding whether people are agricultural engineers or not. It seems to me that there are two problems in the recognition and accreditation operation. The first one is concerned with our Society as such, encouraging the various groups throughout the country who are attempting to build and support an agricultural engineering program that we believe to be rendering a service in the area in which we have responsibility. In a number of cases these programs will not be ECPD accredited under present thinking. Nevertheless, this does not mean that they are not doing a creditable piece of work and meeting their responsibility to the State and Na- 
tion.

"The second thing that it seems that we can do is to describe the limits of agricultural engineering and what it may encompass in such manner that those members representing our Society on the ECPD Accreditation Teams will represent this thinking and thus give us a stronger position than the one which we have had for a number of years of running along and saying "me, too". I personally believe our Society can make real progress if we can do these two things and at the same time we will have improved our image with many people as well as the engineering accrediting groups."

Hobgood's department at the A. \& M. College of Texas had been accredited by ECPD some years prior to these events.

The uproar over the non-recognition decision weighed heavily on Wally Borden. Although an "industry man" he appreciated the difficulties ASAE had brought upon the "delinquent" educational institutions. He wrote Jimmy Butt that he hoped for "some overall general compromise" which the Board of Directors could approve. He was strongly convinced that the role of the Curriculum and Course Content Committee should be changed from "regulatory" to "helping and assistance." In his opinion, ECPD should do all the "accrediting and recognizing and everything else."

Thus matters stood when the Board convened at Fort Collins in June 1964. Shortly after Borden called the meeting to order he read a proposed new recognition policy. This policy resulted from meetings of the Board subcommittee with representatives of the Curriculum and Course Content Committee and the Steering Committee of the Education and Research Division. After a lengthy discussion and many changes, Borden suggested the matter be dropped until the evening session to allow the members time for reflection. At the evening session a revised procedure was developed; it was forwarded to the Committee on Student Branches, the Committee on Curriculum and Course Content, and the Steering Committee of the E\&R Division. These committees returned helpful comments later.

Finally, the latest revision was reviewed and voted upon one sentence at a time. This resulted in a new policy. The Board felt that the new policy was important enough to be published verbatim in AGRICULTURAL ENGINEERING; it appeared in October 1964 with a rationale for the changes.

The new Board policy abandoned "recognition" of curricula; ASAE would henceforth depend on ECPD and the Canadian Council of Professional Engineers for all accrediting in the U.S. and Canada. Graduates of accredited curricula and those still holding current ASAE "recognition" were 


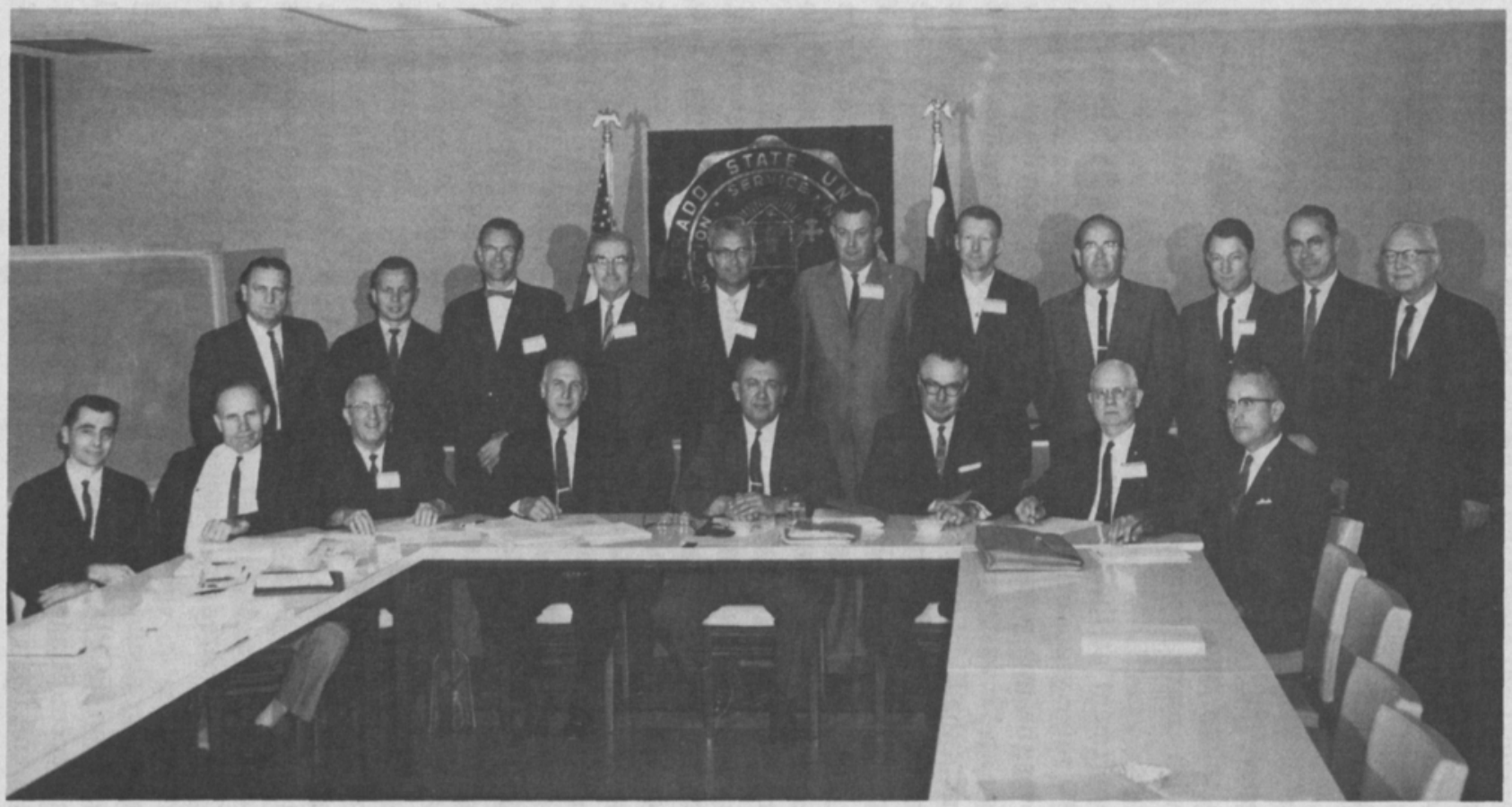

The ASAE Board of Directors at 1964 meeting at Colorado State University. Seated left to right are C. W. Hall, Michigan State University (EPP director); W. M. Carleton, AERD, ARS, USDA; Howard Matson, SCS, USDA, (vice-president); C. F. Kelly, University of California Agricultural Experiment Station (vice-president elect); J. W. Borden, Eversman Mfg., Co.. (president); Price Hobgood, Texas A\&M University (president-elect); A. W. Farrall, Michigan State University (past-president); C. S. Morrison, Deere and Co., (vice-president). Standing from left to right are E. T. Swink, Virginia Polytechnic Institute (vice-president); Harmon Mulbar, J. A. Basselman, R. A. Palmer, J. L. Butt, ASAE: N. H. Curry, Ames, lowa (FS director): H. J. Hansen, Electricity on the Farm magazine (EPP director-elect); E. H. Kidder. Michigan State University (SW director); J. W. Wolfe, Oregon State University (SW director-elect); R. R. Raney, New Idea Farm Equipment Co.. (PM director); and E. D. Anderson, Grosse Ile, MI (professional planning director) 
eligible to enter ASAE as associate members. Other institutions offering a program of resident instruction, research, or extension in agricultural engineering, if so certified by the deans of both agriculture and engineering, would be separately listed in the Yearbook. While the latter institutions were authorized to have ASAE Student Branches, their graduates were eligible only for affiliate member grade; however, individual graduates might qualify for associate member.

The Board explained that ASAE recognition of curricula had been very important when only a few were accredited. Now, with 34 out of 45 accredited in the U.S. by ECPD, ASAE recognition activity was not deemed necessary.

The policy was a triumph of diplomacy by the Board and the committees involved. It removed ASAE from what Jimmy Butt called the "sticky business" of recognition. This was worth doing because one or two further affairs like the Wisconsin one could have seriously damaged the Society. The Student Branches remained where they were, which was important to ASAE's growth. The question of membership grade was nicely solved for graduates of, for example, the Wisconsin department. Because they had degrees in some other engineering curriculum, presumably accredited, they therefore were eligible for associate member. The non-accredited departments were "penalized" by separate listing in the Yearbook so they weren't quite members of the club.

However, later a problem developed around the clause pertaining to certification of instruction, research and extension programs of non-accredited departments by the deans of agriculture and engineering. The dean of engineering at the University of Connecticut refused to certify the research and extension programs of the agricultural engineering department because he had no control over them. The question then was how to list that institution in the Yearbook. Jimmy Butt commented that "we still don't have an effective means of measuring eligibility of curriculums for listing." This was true when the teaching, research, and extension programs were listed separately. This was circumvented in the 1965 Yearbook by listing the names of the institutions but not the separate programs.

What would have happened under the 1961 policy if the University of Wisconsin adherents (mainly H. D. Bruhn, the department chairman) had not objected so strongly? Loss of their Student Branches and other disadvantages, such as downgraded ASAE membership status, might have stimulated the administration of some of the weaker institutions to strengthen their agricultural engineering departments, thus aiding them to make a better showing. Wisconsin might have abandoned its dual degree pattern long before it did. On the other hand these nebulous gains would probably not 
have offset the potential trouble that strict enforcement of the policy would undoubtedly have caused ASAE. Therefore Borden, Hobgood, and the other Board members were right in seeking a dignified compromise. The meaning and prestige of ECPD accreditation were known thoughout the engineering community; it was wise to relinquish the recognition burden to that agency.

The present decade brought more anxiety over student enrollment in agricultural engineering. Although opportunities for employment were plentiful, there were never enough graduates. ASAE placed much hope, and money, on the movie "Agricultural Engineering - Profession with a Future," whose conception in 1960 was described in the previous chapter.

A five-step plan for explaining agricultural engineering to the public and particularly to high school students was also unveiled at the 1960 Annual Meeting. The plan included promotional literature and follow-up information from local colleges along with the motion picture. However, the 1960-61 Annual Report stressed that the members were not utilizing the motion picture to the fullest extent. Jimmy Butt's "Checkpoints" of January 1962 told of an enrollment survey made of the recognized departments just prior to issuance of the movie to obtain a base for judgment of its effect. The undergraduate enrollment was still trending somewhat downward although graduate numbers were sharply advanced. So far, the career movie had not had measurable effect on the undergraduate situation. And the increase in graduate students was due mostly to growing numbers of foreign nationals, a trend independent of the movie.

At its June 1962 meeting at the Mayflower Hotel in Washington, the Board discussed the enrollment problems. Questions were raised regarding who was responsible for promoting activities to increase enrollment. How much responsibility belonged to ASAE and how much to the colleges? The upshot was a motion that the E\&R Division be encouraged to develop a "strong student guidance activity within the Society."

A. W. Farrall assumed the presidency at this meeting. He told the Board of Directors that student recruitment was among the activities which should be stressed.

Farrall worked hard at the problem. For example, it was noted at the December 1962 Board meeting that companies were failing to interview agricultural engineering seniors on the college campuses. The E\& R Division Steering committee felt that ASAE was at fault for not "doing a good job of telling various companies about agricultural engineering." The Board asked Ralph Palmer to write all of the agricultural engineering departments for a list of employers who should have interviewed their seniors. President Farrall would then write the companies, enclosing a list of recognized departments, and suggest that they interview agricultural engineers. Farrall signed more 
than 680 letters to individual companies which interviewed on campuses.

Meanwhile, the ASAE movie was getting some national exposure. In August 1962 the USDA Motion Picture Service's TV Semiannual Distribution Report claimed that "Agricultural Engineering - Profession With a Future" had been seen by more than two million television viewers. Later announcements claimed a record number of television viewers of this kind of movie, over 13,000,000. Through December 1963 the film was shown 4,920 times to a total live audience of 187,717 persons.

ASAE leaders and members had pinned much faith on the movie, perhaps too much; enrollment was not noticeably affected. Some wondered if the movie was so bad that it turned young people away from agricultural engineering. Farrall wrote Butt in December 1962 that the movie was out of date because it made no mention of "processing, handling and storage." However, an untutored viewer would probably not have noted the absence of those items.

The recruiting situation was perceived by President J. W. Borden as being the "greatest problem" for ASAE. He wrote Jimmy Butt in March 1964 that the department heads were concerned about "survival" because their administrators "can only make future judgements and decisions on the basis of how many students they have enrolled." The E\&R Division and the Career Guidance committee were doing little good because "no one seems to listen to them." He concluded by saying that "I am convinced that this problem can be solved only by determined and aggressive action on the part of each of our 6,000 individual members along with greater participation and assistance from industry ..." Borden had no faith in the power of committees to solve the problem.

Borden prepared a letter to send the presidents of companies which had contributed financially to the ASAE motion picture fund. In it he claimed that the "nationwide enrollment in agricultural engineering has about held steady" while enrollment in other engineering branches declined. This was about the best that could be said.

Borden's alarm over the situation was increased at the 1964 Annual Meeting. A unique resolution from the National Council of Student Branches was handed to the Board of Directors by Council President Billy Deen. NCSB presented recommendations "which we believe will help alleviate this problem." The basic thrust of their ideas may be listed:

1. The proper recruiting target is students in the early years of high school.

2. Reach these students through their guidance counselors and the vo-ag instructors.

3. ASAE sections should provide speakers at state FFA and 4-H conven- 
tions.

While these practical suggestions were appreciated, they did give the impression of profound unrest in the student ranks, a feeling that the students were losing faith in the ability of ASAE and agricultural engineering to attract new blood.

That and other inputs regarding enrollment at the Board Meeting put Borden in a state of near panic. He felt that the ASAE Foundation Trustees should raise funds to support a "career promotion effort" and that perhaps a "Director of Career Guidance" should be employed by ASAE. But was "public relations" by ASAE the answer?

Farrall said that the department heads needed to do a better job. Walter Carleton also emphasized that point, stating that the "principal effort in a given state must come from within the state." ASAE's job boiled down to furnishing the states with good quality, uniformly designed ammunition. However Carl Hall later suggested they stop referring to enrollment as the "No. 1 problem" because that was creating a flavor of hysteria; he claimed that enrollment in the ECPD-accredited departments was actually up.

Hall proved this in a letter carried in the August AGRICULTURAL ENGINEERING. From 1959 through 1962 the total agricultural engineering enrollment in the accredited departments rose from 2,002 to 2,265. However, the number of departments also rose from 45 to 48 in the same period, while the number of B.S. degrees fell from 443 to 368. In 1959, 256 were enrolled for advanced degrees; in 1962 this had risen to 367 . The change was from 13 to 16 percent of the total; on the graduate level things were not so bad. The disturbing factor was the decline in baccalaureate degrees.

ASAE leadership remained to some degree fixed on the idea that public relations was a prime key to solving the problem. The 1963-64 Annual Report contained a list of career guidance and PR aids prepared by various committees. In December 1964 the Board voted that the Career Guidance Committee should study the feasibility of updating the career motion picture. The 1964-65 Annual Report noted that over 3100 requests for ASAE career literature had been processed during the period.

President Morrison, convening the Board at Chicago in December 1965, reported on visits to five ASAE geographic units where he had been impressed by their "enthusiasm and dedication." The North Atlantic Region had held a successful student rally; the Pacific Northwest Region had mounted a "strong student program." Several department heads had reported enrollment upturns to him while he was on the road. A special conference on enrollment was to be held by the Career Guidance Committee, at the suggestion of the Board. But not all were happy. Past-President Hobgood had to relay to the Board a feeling on the part of some department heads that 
the Society "had not kept faith on the matter of emphasizing career guidance."

Although the recruitment of student engineers was faltering in almost all branches, Morrison believed that agricultural engineering had its special problems. Dresser Industries of Dallas, Texas, put an excellent advertisement in the Fort Worth Star-Telegram (in July 1965) asking high school students "with aptitude in math and science" to consider careers in engineering. The ad listed every conceivable branch of engineering, including agricultural. Vice-President Howard Matson clipped the ad and sent it to Morrison, who was stimulated to write a letter of congratulation to Dresser Industries. In it he commented that "In serving the broad field of agriculture, our Society has unique problems [of enrollment] due to a general public reaction influenced by crop surpluses, subsidies and a declining number of farms."

Morrison, as did Borden, regarded enrollment in agricultural engineering as a very serious issue. By April 1966 he informed President-Elect French that his travels during his presidential year had led him to believe "we have made only a modest gain in AE enrollment this year and it remains the No. 1 problem in our profession." So his initial optimism had nearly evaporated.

Meanwhile a new brochure was produced by ASAE for career guidance. A four-color, 12-page job entitled "Agricultural Engineering - Serving the World's Largest Industry," it was produced by a group headed by James Beeman of the University of Florida. ASAE sold it to members for 25 cents a copy.

Perspective on the relation of agricultural engineering degree production compared to that of mechanical, chemical, civil, and electrical engineering for the decade 1955-65 was furnished by S. M. Henderson (U.C.-Davis) at the 1965 Winter Meeting. The B.S. Ag.E. production peaked in 1959, then steadily declined until 1963 , when it began a gentle increase. The pattern was quite similar to the total of all other engineering B.S. degrees combined. The post-1959 decline was blamed on Sputnik, which aroused interest in scientific studies at the expense of engineering, plus the economic recession of 1957.

Henderson's diagrams indicated the rising importance of advanced degrees. He showed that the number of M.S. degrees per 100 B.S. degrees had gained sharply since 1957, with agricultural engineering second only to civil engineering. Ph.D. degrees per 100 B.S. degrees had come up strongly since 1958, with agricultural engineering second only to chemical engineering.

On these bases of comparison agricultural engineering had little to be ashamed of; it had been gripped by the same forces (not to mention the 
"unique" problems cited by Morrison) as the major branches of engineering and had performed about the same. But the bad effects of low absolute numbers could not be concealed by percentages and ratios.

The Board listened to Billy B. Bryan (University of Arkansas) report in June 1966 on behalf of the Career Guidance Committee. There was great need, according to Bryan, that someone at ASAE headquarters be designated to coordinate the Society's career guidance efforts, with about 20 percent of his time being devoted to such activity. The Board decided to sit on this suggestion for awhile. Bryan also brought up the question of a new motion picture. After considerable debate a motion was passed which authorized the Career Guidance Committee to "proceed with the preparation of a new movie." Funds were available for this purpose.

At the 1966 Winter Meeting the Board had second thoughts about producing another career motion picture. Jimmy Butt, after contacting the USDA Motion Picture Service following the June meeting, found that a new script would cost much more than before and that USDA was not anxious to conclude another film script agreement with ASAE. President French did not favor another movie because of the widespread dissatisfaction with the current one; he thought that "professional producers" might do a better job but ASAE couldn't afford the cost. Thus the Board voted to rescind the decision to make another movie. Instead, an ad hoc committee was formed representing the Public Relations and Career Guidance Committees. The new committee was charged to review career guidance proposals and develop a plan of activity; $\$ 7,000$ was committed for this use from the Motion Picture Fund. The leadership was beginning to believe that in the long run agricultural engineering might benefit more by having a person responsible for student recruitment at ASAE headquarters than by any other single action.

Critics of the motion picture argued that it was amateurish, stodgy, and overemphasized technical matters incomprehensible to the young. It failed to make the point that "agricultural engineers are unique." It suffered from a diffusion of its message because all technical divisions clamored to get their own specialties included (yet Farrall wanted to diffuse it even more). It did not picture young people interacting successfully with other young people to create a better world; many of the agricultural engineers depicted must have looked like tired old men to young viewers.

But let us reverse the coin. The ASAE movie brought the words "agricultural engineering" into literally millions of American households. This in itself was probably worth the cost. Additionally, by the laws of probability, the movie must have influenced at least some students to sign up. It was far from being a total loss.

The issue confronting the leaders was whether ASAE's money might better 
be spent on other modes of career guidance activity. They were probably right in deciding against another movie. Unless made with consummate skill, movies can have adverse effects. Also, for best impact, they should be shown by a "recruiter" on the spot who can relate the movie ideas to the local educational institution. Not many ASAE members have the time or the requisite personality to operate successfully in such a role.

Student recruitment is best carried on by the state universities, for they must receive and educate the future agricultural engineers. They can be greatly aided by ASAE, particularly by state sections, but only the universities can contact the right people, put on the "career days," and answer the questions - if they are willing to do it. The job cannot be turned over to ASAE entirely, as some apparently had thought in the 1960s. As to "public relations," the same point may also apply to some extent with respect to career guidance materials. The image of the local university probably carries more weight than that of ASAE in terms of impressing high school students.

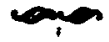

Having established curriculums in professional agricultural engineering, many departments retained parallel degree instruction in "agricultural engineering technology" or "mechanized agriculture." These programs varied with location but were typified by strong study units of agriculture, strong business and economics, and non-professional courses in agricultural engineering. The graduates were ostensibly prepared for technical employment or for work in business enterprises connected with agriculture. Many agricultual engineers viewed the "ag-mechs," or "mech-ags," as filling a major role in support of, or supplementary to, professional agricultural engineering practice. Thus sooner or later ASAE would have to ponder the status of mech-ag students and graduates.

President Lloyd Hurlbut commented at the December 1960 Council meeting that the enrollment of mech-ag students was increasing rapidly and that ASAE should concern itself. The Council recommended "that the Forward Planning Committee consider the mechanized agriculture situation as it might affect or influence the Society in the near future and that the Education and Research Division concern itself with problems relating to curriculums in mechanized agriculture."

Nothing was done until 1964 by these agencies, perhaps because Forward Planning was involved in the early phases of reorganization while E\&R was deep in the problems of enrollment and curriculum recognition.

G. E. Henderson of the University of Georgia published a guest editorial on the topic in the Journal early in 1965 . He pointed out that development of 
professional agricultural engineering had been "partly at the expense of the technical levels." The technology phase demanded attention equally with professional engineering; here was an opportunity for ASAE to "clarify the place of engineering technology as related to professional engineering."

A panel discussion had been sponsored by the E\&R Division on the topic at the June 1964 meeting. One of the panelists was R. E. Stewart, who told why the mech-ag curriculum was dropped at Ohio State. The main reasons advanced were: (1) The graduates were not finding the kind of employment they thought they were trained for; (2) no departmental advanced degree was available in mech-ag; (3) confusion existed in the public mind between students and graduates of the mech-ag and the professional curriculums; (4) mech-ag students had a dubious status in the Student Branch of ASAE; (5) mech-ag graduates were being confused with technicians having only two years of training; and (6), the department felt that agricultural engineering technology could be better promoted through improved service courses for agricultural students and short courses for technicians.

Donnell Hunt of the University of Illinois took the opposite view. He contended that mech-ag graduates were needed in sales and service areas of farm mechanization and that agricultural engineering departments should not hesitate to provide their training. Service courses were not enough; two-year programs were not enough. A definite four-year curriculum, faculty advisers, and student clubs were all necessary to produce the right kind of graduate. However, Hunt did not believe that graduate work in mech-ag was desirable.

Summaries of the viewpoints advanced by panelists Stewart and Hunt were published as editorials in AGRICULTURAL ENGINEERING during 1965. It quickly developed that Stewart's negative views were unpopular. Several letters were printed in the Journal which offered reasons why the agricultural engineering departments should carry on parallel programs in mech-ag and agricultural engineering. One writer was Carl W. Hall of Michigan State. His argument focussed on the complementarity of the two curriculums:

"The agricultural mechanization program provides education and training in the application of mechanical principles to agricultural production, processing, and business. Its focus is on the service aspects of the mechanization. As such, the mechanization specialist can provide an extra arm for agricultural engineers, to provide services often not covered by the engineer, and usually not of interest to him. Because of the continuing increase in mathematical rigor and scientific coverage in engineering, most engineers are not interested in the less technical aspects. This leaves a wide gap between the skilled worker and the engineer which was not present a few years ago. Mechanization majors are specifically trained and educated to bridge this gap, and so, one 
program complements the other."

In fact, Hall thought that a properly mounted mech-ag program would actually strengthen the professional agricultural engineering program in a department. It would add to the overall student numbers, certainly, and that was a strong consideration for many departments.

The mech-ag movement was proceeding essentially without national uniformity or guidance. Not all departments had such programs but those that did showed much variation in approach. And a satisfactory name for the curriculum had yet to be invented. Standards of instruction, the question of student clubs, and perhaps even recognition were issues which ASAE was expected to face.

Concerned members continued to call for action. President Hobgood finally told the Board of Directors at the June 1965 Annual Meeting that it (the Board) must soon answer these questions on agricultural engineering technology: (1) Is it time for action? (2) What action do we take? (3) Can we afford to wait until interest dies, or develops elsewhere? Guidance was requested from the E\&R Division, which gave the Board a report from its Committee on Agricultural Engineering Technology (ER-35).

The report stated that there was a demand for "trainees in applied engineering" in many areas such as junior college instructors, technical assistants, off-campus instructors, rural service advisers with power companies, and extension personnel. Money was available from the federal government to support such training. Full development of this neglected area represented a large potential for growth of agricultural engineering.

The Committee called for studies of the technology, or mech-ag, field in order to gain a basis for better college training, to "broaden the usefulness of agricultural engineering," and to make possible the establishment of standards parallel to those of ECPD. Finally, it was recommended that ASAE formulate a proposal to the U.S. Office of Education for financing a "broad study" of the problems perceived as existing in the gap between craftsman and professional engineer. It was hoped that completion of such a study would go far toward defining a leadership role for the Society.

Correspondence of C. S. Morrison indicates that the U.S. Department of Health, Education and Welfare (HEW) was working on a curriculum in mech-ag in the summer of 1965. One of their officials was on the 1965 Annual Meeting program; during the meeting he discovered ASAE's interest in the subject. HEW was quick to invite the cooperation of ASAE through placement of agricultural engineers on the committee involved in the project. This would make available to HEW the vast experience of ASAE on the subject. In turn, HEW could spend money to study the question with the possible outcome, as Jimmy Butt phrased it, of devising a "recommended cur- 
riculum which might serve as a basis for the development of further agricultural mechanization programs." Thus the desire for further study in cooperation with the government was realized much more rapidly than the E\&R Division could reasonably have expected.

In line with a recommendation of the ER-35 report of last June, President Morrison requested Drayton Kinard (University of Florida), chairman of the E\&R Division, to appoint a special committee to work on the mech-ag problem.

Frank W. Peikert of Pennsylvania State University headed the special committee. Its report was presented to the Board of Directors during the 1966 Annual Meeting.

The report submitted by Peikert's committee was thorough and wellwritten. Its preamble noted that "educational work in the broad field of applied agricultural engineering is currently underway . . . in agricultural engineering departments, in junior colleges and community colleges." ASAE was regarded as the "bridge" between all these educational agencies and in a "key position to provide guidance."

Responsibility must be assumed, according to the report, by the universities for training two-year technicians and four-year mech-ags, and even for providing graduate degrees for the mech-ags. Further, the agricultural engineering departments must improve their service course offerings. Suggested courses of study were offered for the two-year and the four-year categories.

ASAE was asked to vigorously support the mech-ag movement in several specific ways:

1. By promoting and guiding activites concerned with "applied agricultural engineering."

2. By making a forecast of potential Society membership likely to arise in the "next several years" from the mech-ag group; if a "substantial number" appeared likely, then ASAE should provide a "separate grade of membership." (Presumably, this was to be a voting grade of membership.)

3. Standards should be established for mech-ag clubs at the universities.

4. With acceptance of responsibility, someone at the central office staff should be delegated to spend time on activities related to applied agricultural engineering.

The Peikert report aroused key issues. Particularly important were the special membership grade and the additional staff member at ASAE Headquarters. No decisions were made.

These questions were taken up again at the 1966 Winter Meeting. First the Board discussed a motion that a member or a new member of the Headquarters staff be assigned to coordinate and promote activities in the area of 
applied agricultural engineering. The motion failed by a unanimous vote.

Later, Frank Peikert and Clarence Bockhop (he was now E\&R Division chairman) joined the Board for discussion of the Peikert report. These men made a strong plea for adoption of the report, if not in its entirety, then at least to allow the mech-ags some kind of voting status in the Society. (Affiliates could not vote, and this was the membership grade usually held by those not possessing degrees in engineering.)

The voting question was in many respects the most controversial aspect of the report. Peikert was asked how voting membership for mech-ag graduates could be achieved without affecting ASAE's status as an engineering society; he indicated the question had not been discussed in his committee. C. S. Morrison stated flatly that in his opinion mech-ag graduates could be admitted only in a nonvoting category of membership; President French said the same. Arnold Skromme, a Board member, stated that agricultural engineers were "currently subject to criticism as being nonengineers and have been fighting to improve this status for a number of years." He was therefore opposing any action that would lower the admission standards.

Frank Lanham, another Board member, expressed concern that if ASAE became involved with the "applied agricultural engineering" area it would be identified as "engineering," an undesirable development in his opinion. Morrison was more concerned whether or not ASAE became involved at all.

Peikert and Bockhop at length were ushered out, probably with the impression that the work of E\&R Division was not appreciated by the Board of Directors.

French, realizing that something positive ought to result from so much work and discussion, appointed a Board subcommittee consisting of R. G. Yeck, B. A. Jones, and Morrison. Their task was to prepare a statement concerning the agricultural mechanization question for Board consideration. After due deliberation Yeck reported back with a statement which was adopted by the Board as follows.

The Yeck subcomittee report stated that the Board "recognized responsibility for guiding development of education and other activities in areas closely related to the agricultural engineering profession." The E\& R Division was encouraged to take the leadership; guidelines were to be suggested by the Board. Any activities should not detract from the "professional standing of agricultural engineering"; the Affiliate grade should remain available to mech-ag (i.e., no voting memberships); the Board would consider sponsorship of student mech-ag clubs. These ideas were adopted from Peikert's committee recommendations.

While the mech-ag proponents did not win everything they desired, their feet were now in ASAE's door. President O. C. French had earlier expressed 
his conviction that "this subject is of vital concern to agricultural engineering." He concurred with Jimmy Butt's suggestion that copies of Peikert's report be sent to members of the Forward Planning Committee because of the "long-range implications ... for the Society incorporated in the report." In a letter to a mech-ag student at the University of Nebraska, French encouraged that student to think positively of "organized student activity in ASAE somewhat parallel to the Student Branch activities." That same letter reported overall mech-ag enrollment as of April 4, 1966, to be 1217 students; several Canadian universities were involved. The number, it should be noted, was of the same order as the enrollment in agricultural engineering. Most of the institutions involved were the land-grant universities at many states.

At the June 1967 Annual Meeting the Board of Directors authorized the "Agricultural mechanization question" to be referred to ER-35 with the request that this committee develop guidelines for curriculum and terminology in that area. The question as to mech-ag clubs and their place within the Society was referred to ER-41 (Student Branch Committee) for comment.

So ASAE entered into the mech-ag sector of education. With so many agricultural engineering departments committed to these programs, and more to come, the need for discussion of procedures, standards, and goals was obvious. ASAE could provide an excellent forum for these discussions.

Of course, many ASAE leaders found themselves fascinated by the growing numbers of mech-ag students. As a potential source of new members, here was something to think about. Unfortunately, these potential members didn't care for the only grade open to them upon graduation - that of Affiliate. With the passage of time the demand for some kind of voting status in the Society grew to be greater than could be conveniently ignored.

D

\section{Publications}

When the Council met in December 1957 at the Edgewater Beach Hotel in Chicago, a report was delivered by R. K. Frevert for the Publications Committee. It was recommended that ASAE commence charging for the papers distributed at meetings and that the price of reprints be doubled. These recommendations were accepted and voted upon favorably by the Council; it was left to Secretary Butt to determine appropriate charges for the papers. Frevert then announced that the Publications Committee was still considering the possibility of placing a "per-page charge" on "certain types of material for publication in the Journal." The Committee was working with 
Editor and Publisher Jim Basselman on the question. Basselman noted that ASAE had been publishing research articles free of charge, although "landgrant colleges and other institutions supporting research have funds available for publishing research results." These institutions could get more papers published by paying for part of the printing costs.

It was mentioned previously that the Journal had become inadequate to accommodate the rising number of technical papers. Raymond Olney had suggested revival of a "Transactions" kind of publication; its birth was noted in the last chapter. The Council decision on this matter was made on June 22, 1958, when George Eveleth (Kewanee Machinery Co.) moved that a "Transactions of the ASAE" be inaugurated, that the first edition be published in 1958 , and that all costs (of the first edition) be borne by the Society. The motion passed unanimously.

Further policies for TRANSACTIONS were also hammered out at this meeting. There was to be a slow transition of technical articles from AGRICULTURAL ENGINEERING to TRANSACTIONS; the latter was to be sold separately, and, if justified by demand, might evolve into a divisional organ. The charges for succeeding issues of TRANSACTIONS were to be so increased as to gradually reimburse the costs of the first issue.

In December, Jimmy Butt told the Council that additional TRANSACTIONS could be issued in the future under current arrangements, provided sufficient orders were received "to bring unit costs down to a reasonable figure." The first issue, Volume 1, No. 1, (which was given to all members) contained 96 pages. The second issue, Volume 2, No. 1 (1959), contained 128 pages; it was offered to ASAE members for $\$ 2.50$, and for $\$ 5.00$ to all others. The second issue was subscribed for by 1107 members, which was a good showing in order to pay the bills.

T. W. Edminster (USDA) appeared before the Council in December 1959 with a new publication idea. He proposed that a monograph series be started by ASAE, similar to that being published by the American Society of Agronomy, on subjects of interest to agricultural engineers. The monographs would be prepared by ASAE committees and turned over to a publishing firm for publication; therefore, the publisher would be responsible for promotion and other costs of publication and marketing. The idea was remanded to a special committee for study and a report at the June 1960 meeting.

Jim Basselman discussed the number and subject matter area of TRANSACTIONS for 1961 with the Council at the June 1960 meeting. It was concluded that one general issue and one power and machinery issue would be published, provided P\&M Division could guarantee enough sales to avoid financial loss; otherwise, two general editions would be published. The discussion was then broadened to include future considerations relative to 
TRANSACTIONS. It was decided that all facts pertaining to the publication should be assembled by Basselman and sent to the divisional Steering Committees prior to the Winter Meeting at Memphis and that these committees would be asked for recommendations regarding future issues of TRANSACTIONS. (Power and Machinery Division came through with enough sales for a special issue in 1961. It was not, however, the first one. Soil and Water Division had already published the first special TRANSACTIONS issue in 1960.) D. D. Smith of USDA offered a preliminary report on the monograph question; his special committee considered the idea with favor but asked for more time to prepare a written report. The Council suggested that Smith and his committee strive for early action and coordinate their efforts with Editor Basselman.

Gathered at the Peabody Hotel in Memphis, the Council heard Jimmy Butt's elaborate presentation entitled "A Program for Progress." Much of his analysis pertained to ASAE's publication posture. As part of recent "professional progress" he mentioned the launching of TRANSACTIONS, the "modern format" of AGRICULTURAL ENGINEERING, the growing number of meeting papers, and the fact that this year (1960) the Yearbook showed a surplus for the first time. Next, Butt said, among other areas, greater effort should be directed toward making additional, useful information available to members. To do this, another professional staff member (a "Technical Coordinator") would be needed to handle technical papers and cooperate with Editor Basselman in various important ways.

To make ASAE's publications meet all needs, the Secretary thought that AGRICULTURAL ENGINEERING should be "popularized" to the point where "leading farmers and agricultural workers" could also benefit from reading it. Expansion of TRANSACTIONS would be an important adjunct to such a move, to allow a higher percentage of the "better technical papers" to be published. Perhaps additional technical papers could be screened, indexed, published, and sold as proceedings. Monographs on special subjects would enhance the picture. Thus, people everywhere would "look to ASAE as the place to obtain the latest information on all phases of agricultural engineering."

The Council appreciated Secretary Butt's "Program for Progress." There were indications that some of the recommendations would be favorably acted upon.

Jim Basselman then submitted a proposal to the Council which picked up one of Butt's ideas. This was to prepare a "Proceedings" of papers presented at each national meeting, except those papers selected for publication in AGRICULTURAL ENGINEERING, TRANSACTIONS, or monographs. Papers of "less than permanent reference value" were also to 
be excluded. The "Proceedings" would be financed by a modest increase in meeting registration fee for those attending; after the meeting, members could buy it for $\$ 2.50$.

While the proposal received considerable interest, it was not acted upon because the future status of TRANSACTIONS bore an important relation to it. The division Steering Committees were studying a possible increase in dues to support the cost of enlarged TRANSACTIONS issues. Were this to be done, the need for a "Proceedings" would be diminished. (It should be noted here that mimeographed copies of individual papers presented at the meetings were available in 1960 ; meeting registrants were charged $\$ 1.00$ for ten of these papers.)

The Steering Committees acted as follows:

The Soil and Water Division recommended that TRANSACTIONS be financed by a general increase in dues, if necessary, and published by divisions, and that each member of the Society be permitted to select one divisional TRANSACTIONS each year.

The Power and Machinery Division recommended that no dues increase connected specifically to TRANSACTIONS be voted.

The Farm Structures Division recommended that there be no increase of dues for the purpose of expanding TRANSACTIONS.

The Education and Research Division recommended that dues be raised to support TRANSACTIONS.

The Electric Power and Processing Division recommended that dues be increased to finance TRANSACTIONS costs and that general (rather than divisional) issues be published.

These results left the situation where it was before; individual purchase of TRANSACTIONS as desired was retained as policy, while Basselman's "Proceedings" proposal never was implemented, presumably on the supposition it was not vitally needed.

An important development took place during the June 1961 Board meeting at Ames. Carl Hall had completed and published a subject index to a number of agricultural engineering publications. He offered ASAE the opportunity of distributing the INDEX 1907-1960 to ASAE members at a discount. The Board was happy to accept Hall's proposal. Such a book had been sorely needed for many years*. Hall indexed subject matter from the following publications: AGRICULTURAL ENGINEERING (1920-1960); ASAE Papers (mimeo series 1956-1960); TRANSACTIONS (old series

\footnotetext{
*Another long-awaited book was published in 1961: the "Agricultural Engineers' Handbook." With C. B. Richey as Editor-in-Chief, it was published by McGraw-Hill Book Company. Richey was associated with the Ford Motor Company at the time.
} 
1907-1935, new series 1958-1960); ASAE Yearbook (1954-1960); Canadian Agricultural Engineer (1959-1960); Journal of Agricultural Engineering Research (1956-1960); Landtechnische Forschung (1951-1960); Journal and Proceedings of the Institution of Agricultural Engineers (1949-1960) and its Yearbook (1960-1961). His book is a unique record of early agricultural engineering achievement, not only in the technical sense but also in the historical and philosophical realms. For example, all of the editorials published in AGRICULTURAL ENGINEERING from 1921 through 1952 are indexed by title. These editorials and the presidential addresses embody the best and most forward-looking nontechnical thought arising from ASAE during that time. Yet many technical indexers would have omitted the editorials as having no permanent value.

During 1961 a new Publications Policies and Finances Committee was formed with M. L. Burgener as chairman; he was with the Portland Cement Association. The Committee had five members plus a technical adviser from each division. An initial task the Committee set for itself was to survey colleges, industry, and USDA to determine attitudes toward a page-charge to authors for publishing in TRANSACTIONS. Such a charge would permit publishing a higher percentage of acceptable papers. The Committee also planned to work with the divisions on setting up uniform paper-screening procedures.

Burgener reported to the Board in December. The Publications Policies and Finances Committee recommended that AGRICULTURAL ENGINEERING should be edited for readers rather than writers; that

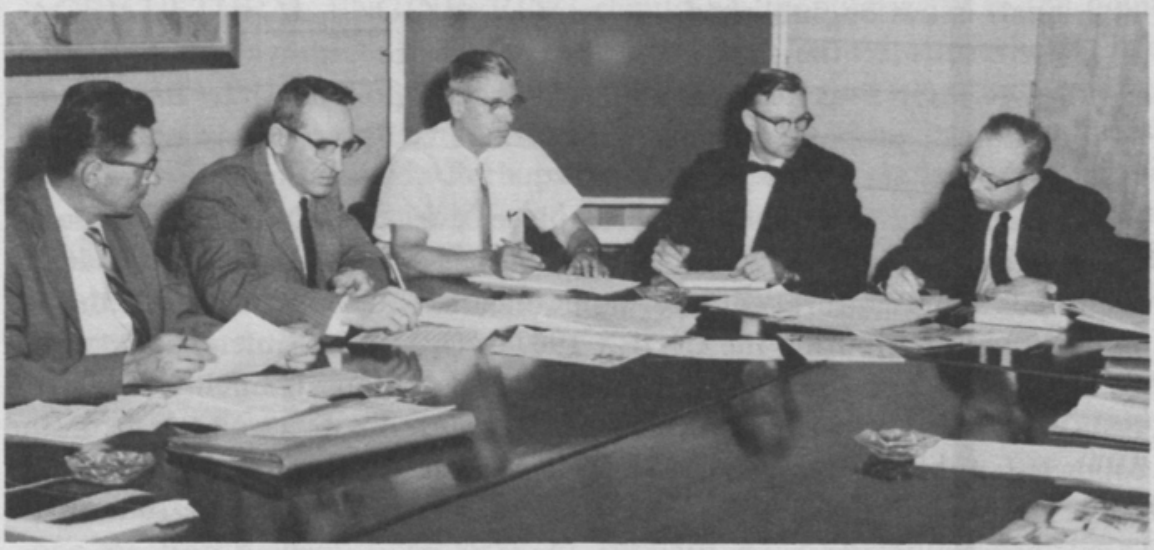

ASAE Publication Policies and Finances Committee met July 1962 in the Portland Cement Association Building in Chicago, to draft plans to meet future publication needs of the Society. Left to right are: R. R. Poynor, International Harvester Co.; W. F. Buchele, Michigan State University; H. H. Beaty, University of Illinois; J. A. Basselman, ASAE; and M. L. Burgener, Portland Cement Association 
TRANSACTIONS should be a writer's publication; and that a charge of $\$ 20.00$ per page should be made to the author of the articles for reproduction of a paper in TRANSACTIONS. This charge would include 300 reprints for the author. It was further recommended that the divisions set up a paper screening procedure (which included critical readers) which would speed up that process while assuring higher quality.

The Board adopted the paper screening procedures but did nothing (at that time) about the other recommendations.

Formation of the Publications Policies and Finances Committee was hailed as a major step forward in Society affairs in the January 1962 Journal. In a lengthy editorial about the committee, which gave ASAE members a rundown on the new screening procedures, it was said that the next project of the Committee was to determine the "current interest patterns of Society members in existing publications and to determine projected interest patterns and needs."

Jimmy Butt called attention in the April Journal to improvements in the 1962 Yearbook. These included a better index, a layout of Society officers, a map showing the boundaries of the geographic units, and a list of ASAE committees for 1962-63. This was the first time the members had the list available to them at the start of the Society year. Other improvements of the Yearbook were also mentioned; these were the result of Page Bellinger's work as Technical Coordinator.

Meanwhile, Jim Basselman had been advanced to the position of Director of Publications. He was to coordinate all Society publishing activities while still serving as editor of AGRICULTURAL ENGINEERING and TRANSACTIONS.

In May of 1962 the page charge issue was discussed at considerable length by Secretary Butt in his "Check Points." At that time, ASAE was publishing about half the papers that deserved publication. "New interest groups" would demand more future space, also. These needs could be met by charging the researcher (actually his sponsor) $\$ 25.00$ per page to publish in TRANSACTIONS; 200 reprints would be given to the author. This charge would cover type setting and engraving charges; the subscriber would support the cost of processing papers, paper and printing costs, bookkeeping and mailing costs, etc. The subscription prices would be adjusted so that ASAE would break even financially (being a non-profit organization).

Butt cited policies approved by the National Science Foundation and the Association of Land-Grant Colleges which showed that these prestigious entities were greatly in favor of the page charge. By this means ASAE should be able to publish "practically all" of the papers submitted for publication.

When the Board of Directors convened in June, Burgener reported for the 
PP\&F Committee. Its principal recommendation was to adopt the $\$ 25.00$ page charge. Evidently Butt's preparatory Journal article had aroused no particular concern regarding the charge; therefore, it was voted into policy (effective in 1965) by the Board. However, in estimating costs of a 350-page 1963 TRANSACTIONS it was found that even with the page charge the publication would require a certain amount of regular operating budget to finance it.

By that time (June 1962) the divisional paper screening committees had been established. The chairmen were: M. C. Ahrens (EPP); G. L. Nelson (FS); K. K. Barnes (PM); and J. T. Phelan (SW). These committees provided initial screening of divisional subject matter presented at national or geographic unit meetings or submitted expressly for publication. The papers were to be put into one of three categories: "recommended for publication," "questionable" (held for publication only if space becomes available), or "rejected." (Papers not recommended for publication were to be microfilmed and indexed.) Papers recommended for publication were to be sent to anonymous reviewers as in the past. The whole process was supposed to be accelerated, but many and loud were the complaints about how long it took to get a paper into print.

While those events were unfolding, the Engineers Joint Council entered into a major project on information retrieval which involved ASAE. During the early months of 1962 Jimmy Butt, Jim Basselman, Page Bellinger and some other ASAE members attended meetings and training sessions conducted by EJC on indexing and abstracting. EJC was also compiling an Engineering Thesaurus to which all the engineering societies were to contribute. Divisional representatives on the ASAE Thesaurus Committee were: $C$. W. Hall and R. W. Kleis (EPP); W. F. Buchele, W. W. Gunkel, and C. B. Richey (PM); E. H. Kidder and L. D. Meyer (SW); and Wallace Ashby (FS). This group met several times for instruction by Jim Basselman and compiled a total of 3,463 words as agricultural engineering input.

Transition of AGRICULTURAL ENGINEERING, meanwhile, from technical journal to "popular" monthly publication was to take place. It would carry one full-length, broad-interest technical article per issue; several concise-interpretive, condensed-technical and/or general-interest articles per issue; abstracts of selected Society materials;' and Society news, editorials, advertising, product information, and other timely information. Articles selected for AGRICULTURAL ENGINEERING were to be financed entirely by subscribers and ASAE members (i.e., no page charge to authors).

By the summer of 1963 these developments were well-established, including the adoption by ASAE of the EJC indexing and abstracting system for improved information storage and retrieval. ASAE TRANSACTIONS 


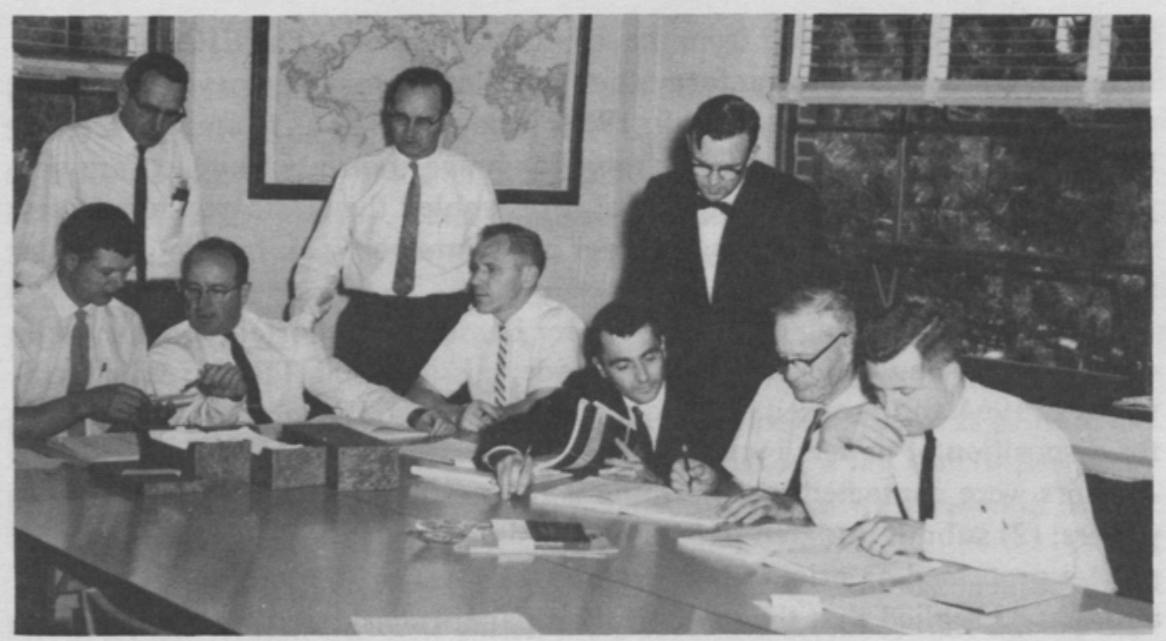

A special committee with representation from each division of ASAE, was appointed to obtain agricultural engineering terms to be included in the Engineers Joint Council Thesaurus as the first step in the EJC Information Retrieval program. The committee met in July 1962 at Michigan State University where a list of 3,463 words and subwords was compiled. Seated left to right are: L. D. Meyer, ARS, USDA; E. H. Kidder, Michigan State University; W. W. Gunkel, Cornell University; C. W. Hall, Michigan State University; Wallace Ashby (retired), Port Republic, $\mathrm{MD}$; and P. L. Bellinger, ASAE. Standing left to right are: W. F. Buchele, Michigan State University; C. B. Richey, Ford Motor Co.; and J. A. Basselman, ASAE

had increased to quarterly publication; the $\$ 25$ page charge covered about 40 percent of publishing costs and subscription payments covered one-third. The remaining costs were borne by the Society's operating fund.

The EJC information retrieval plan was put into operation with the aid of an explanatory paper in the January 1964 Journal by Jim Basselman. The paper explained the mechanics of the system. In brief, each technical article in TRANSACTIONS or AGRICULTURAL ENGINEERING was to be accompanied by a catalog card containing keywords, abstract, bibliography, and manuscript number. A user would clip catalog cards of interest and file them; he would also have a keyword file, an alphabetical file of words with each card providing manuscript numbers related to the word on the card. The system depended upon transfer of manuscript numbers to the keyword cards each time a catalog card was filed. When information was needed, the user would first enter the keyword file. Refinement of a large filing system could be obtained by use of devices called "links" and "roles" which helped to reduce false retrievals. Also, it was believed that the Engineering Thesaurus mentioned previously would become an important adjunct to information retrieval, for example, in handling inter-society word usage.

Evidently the members did not use the catalog cards to a great extent. By 
1966 they had disappeared from the ASAE publications. The EJC had plans, however, for an elaborate information-handling system (for pay) which was expected to become operational in 1968 . This scheme was to employ certain kinds of technology (such as electronic language translation) which are not yet available in 1977; other aspects of it resembled the electronic data bases which are so widely used today. It never came into being for lack of adequate funds.

At the Board meeting of June $1964 \mathrm{Jim}$ Basselman reported that the page charge was being well-accepted. It made possible 400 TRANSACTIONS pages in 1964 and aroused hope for 500 pages in 1965. A plan was described for disposition of papers bypassed from 1957 through 1963 (the "backlog"). Authors were contacted to determine if they wished to: (1) Withdraw their papers; (2) submit updated papers for possible publication; or (3) have their papers processed as originally submitted. A total of 353 letters was sent to authors; 83 replied that they wished their papers considered for publication, either updated or otherwise.

Later in the meeting R. R. Poynor and John R. Carreker (USDA), representing the Publications Policies and Finances Committee, told the Board that the "most serious problem" was to find a means of publishing the backlog of technical papers in TRANSACTIONS.

The Board discussed the problem at some length and then voted the following motions: (1) That the page charge be increased to $\$ 30.00$ no later than January 1, 1965; (2) that the Finance Committee be asked to locate financial assistance for publishing the backlog, such as a grant of money or the use of ASAE's restricted reserve; and (3) that the Headquarters office proceed with screening and plans to publish the backlog.

The Director of Publications reported in December that the $\$ 5.00$ increase in the page charge met with no objections and would allow an expansion of TRANSACTIONS to 500 pages in 1964, with 600 planned for 1965 . Basselman felt that 600 pages would approach a "respectable" percentage if one considered only those papers presented at the national meetings. However, he estimated that 750 pages would be required as an adequate percentage of the total "publication responsibility."

Contact had been made with National Science Foundation regarding a possible grant to finance the paper backlog. Walter Carleton and Karl Norris presented a draft proposal to NSF; ASAE was invited to submit a final proposal containing 10 percent of the titles of the papers and supporting letters from "scientists in the field." There was some pessimism about the fate of the proposal because so few of the papers could be regarded as basic research reports.

The pessimism was justified because NSF rejected ASAE's proposal. 
However, a new development changed the picture: Deere \& Company offered $\$ 4000$ to ASAE to help publish the backlog. As mentioned previously, this stimulated the employment of Marianna Pratt in June 1965 to get the backlog of papers moving. Later contributions for the same purpose included $\$ 4000$ from the Ford Motor Company, $\$ 1000$ from Allis-Chalmers, and $\$ 500$ from the ASAE Chicago Chapter; about 25 donors altogether were involved in this generous action.

The backlog was published in four numbers of 150 pages each; two were published in 1966 and two in 1967. The first backlog number was printed as Vol. 9, No. 2, of the TRANSACTIONS. It contained a tag which listed the financial contributors but was not otherwise identified as a backlog issue. The total TRANSACTIONS pages for 1966 ran to 900 .

Also printed in 1966 were the proceedings of four ASAE-sponsored conferences. Basselman was able to tell the Board in December that during the year ASAE had published a total of 1948 pages and 499 articles. The conference proceedings were to be indexed with the other publications.

As a technical society the quality and volume of ASAE's printed output must be regarded as one of its most important activities. In this respect the sixth decade was the most important of the seven since 1907. The outstanding events are worthy of repetition: (1) Growth of the Yearbook into an indispensable tool of practice and administration; (2) establishment of TRANSACTIONS as the principal technical repository and its growth to six numbers per annum embracing over 900 pages; (3) the shift of AGRICULTURAL ENGINEERING from technical repository to broadly based general readership; (4) establishment of meaningful paper screening and critical review procedures; and (5) broadening the publication base to include proceedings of important conferences. It is a record which the Headquarters staff and the members can look back upon with much pride. 


\section{2 th decade, $1968-1977$}

\section{"FOR THE BENEFIT OF MAN:.. \\ N. H. Curry}

\section{A \\ General Progress}

The 1970 Annual Meeting was held in July for the first time, at Minneapolis. It was preceded by a two-day Symposium on Graduate Education in Agricultural Engineering which was supported by a grant from the National Science Foundation. Both Annual Meeting and Symposium were wellattended and much appreciated.

Consulting engineer Norval Curry, as retiring ASAE president, delivered his address at the annual business meeting. The mounting concerns of American society, as expressed in the news media, were "concentrated heavily on problems of rapidly expanding world population and world food supply, of the urbanization of both our national and world population, of all types of product and equipment safety, of environmental pollution and resource conservation." These concerns, Curry argued, were not new to ASAE, since "we have been concerned with these problems for a long time." The new aspect was the belated recognition of these problems by various professions and organizations, by industries, government agencies, news media,

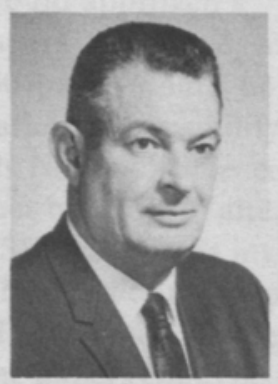

Norval H. Curry

63rd president, ASAE, 1969-70 
and the general public ..." which created a "feeling of urgency."

Finding technological solutions to these problems offered opportunity to engineers, Curry said. He defined engineering as "the art . . . of utilizing the materials and forces of nature for the benefit of man." The opportunity lay in showing the public that the engineering profession was working "for the benefit of man" when it worked on the problems he outlined, the great technical problems of the 1970s: Population, food, safety, pollution, resources. Each of these had dimensions which agricultural engineering could attack with reasonable hope of doing something "for the benefit of man."*

Unfortunately, the problems were not solely technical; they did not possess plain technological solutions in the sense of Curry's meaning, even before the news media got excited about them. Now they infiltrated all levels of national consciousness and government. Problems that seemed technical were now unveiling socio-political aspects which had formerly been unsuspected. This meant that engineering accomplishments were "for the benefit of man" or maybe not, depending on the viewpoints of those involved. Engineers themselves were no longer the sole arbiters of the value of their work, nor were the institutions they served.

The muttiple stimuli of the environmental movement, consumer advocacy (Naderism), and a spreading distrust of technology and business gave unprecedented powers both to government and to ad hoc organizations of concerned citizens. In the end, the government wielded decisive power, partly through its politically conscious Congress and other legislatures and partly through an enormous bureaucracy of regulation. In the end, the problems mentioned in Norval Curry's speech were placed under priority by government; it was the government that wrote the blueprints for their solution, with or without engineering aid. Hence the unveiling of the political aspects.

The Seventh Decade was an Age of Government, an age when government ranged itself against industry to curb its excesses and teach it social responsibility. Each side had its engineers. No one voice spoke for American engineers, as usual. Because most ASAE members work for government or for private industry, the decade might have created bad feeling within the Society. This did not occur, probably because the majority of government members did research, practiced engineering, or were in the universities and therefore did not identify with the mushrooming regulatory agencies.

Engineers were aware that the government was in control; therefore, they constantly advised each other to move into government and become involved

*Note: When Russell R. Poynor was president in 1967-68 he delivered an address entitled "For the Benefit of Man" to several ASAE geographic units; the address was never published. 
so that governmental decision makers might profit from sound engineering advice and counsel. How? Acting as individuals was no problem, but many were the voices which called for concerted action by technical societies. But advice could not be forced upon the lawmakers; this kind of activity risked the loss of tax-exempt status. However, where requested, ASAE could respond with specific statements or recommendations. But was it responsible for these in an official sense?

This question was addressed in 1971 by the Technical Council under VicePresident B. J. Lamp of the Ford Motor Co. The Agricultural Safety Committee requested guidance on ASAE's role in "social-political" issues. Lamp prepared a set of guidelines on how ASAE should react to "governmental and non-governmental actions and proposals which seek to protect or to improve quality of life." One must acknowledge that the phrase "quality of life" embraced all the great problems recognized as important to agricultural engineering by President Curry.

Lamp's guidelines were approved by the Board of Directors and published in AGRICULTURAL ENGINEERING in October 1971; they have since been published in each ASAE Yearbook. They contain the following essentials:

1. ASAE develops, publishes and distributes engineering information, including technical papers, standards and practice data. ASAE promotes and encourages the use of all such information.

2. When invited, and when the subject is appropriate, ASAE may develop statements on proposed actions or problems. Statements are limited to technological-economical feasibility and practicality of proposed actions. All statements will be presented as the judgment of those who formulated the statement and will not be presented as an official statement of ASAE.

3. ASAE will not seek governmental regulations which dictate that ASAE information will be used.

4. ASAE assumes no responsibility for results attributable to the application of its information.

The policy leaves unavailable the opportunity (some would say obligation) of ASAE to interact with government on pertinent issues when uninvited. A principal objection has been fear of identification as a "lobby," with possible tax status reclassification. With respect to ASAE's tax-exempt status, President Hugh Hansen asked in 1972 if such status was worth ASAE's failure to "get involved in the socio-political-economic arena."

The government, let us say the Congress, has some powerful agencies to assist its legislative processes related to engineering. Among these are the Office of Technology Assessment, the National Academy of Engineering, and the Congressional Research Service. Unfortunately, these respond only to re- 


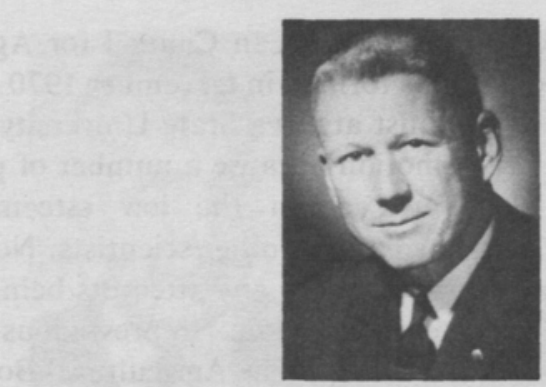

Hugh J. Hansen

65 th president, ASAE, 1971-72

quest. If a special study is required it may take a year to get the answer. It has been pointed out* that Congress, being almost totally composed of lawyers, would be delighted to accept assistance from technical societies and that this could be done without lobbying. Technical societies have credibility because of their objectivity and high professional standards; they have expertise and are recognized as trustworthy sources of information; and they have established organizations which reflect the collective impact of a large number of respected individuals. Therefore, input from societies like ASAE would probably be accepted readily and would perhaps be helpful in aiding to solve the great problems, granting that the political dimensions of problem-solving must remain untouched in order to retain credibility. This course of action seems fairly safe. It is attractive as contributing to human welfare. Yet ASAE never chose to adopt it. Instead, ASAE chose to shift such burdens to organizations such as the National Society of Professional Engineers, Engineers Joint Council, and the Council for Agricultural Science and Technology (CAST).

There were reasons other than the tax-exempt status which led ASAE to avoid the effort of influencing legislation on technical issues. Most prominent among these were the probable high money costs of such activity and the undeniable fact that on many broad issues the members themselves would probably not agree as to official technical policy. Also, the work involved in legislative action would likely make unreasonable demands on members who could not even expect to have their expenses reimbursed.

Considerations like these caused ASAE to look carefully at CAST when it first was proposed.

\footnotetext{
*Gilbert W. Keyes, Staff Director, Senate Committee on Aeronautical and Space Sciences. Can Engineering Societies Effectively Influence Legislature at the Federal Level? Engineers Joint Council Conference Proceedings on The Role of the Engineering Community in the Public Decision-Making Process. October 21-22, 1976.
} 
CAST commenced existence as the "American Council for Agricultural Science." Its organizing committee was formed in December 1970 under Dr. C. A. Black, a distinguished agronomist at Iowa State University.

Dr. Black's committee was set in motion because a number of prominent agricultural scientists were concerned about the low esteem felt for agriculture by the public, the news media, and other scientists. Nothing was being done to correct this impression, nor were any attempts being made to furnish the government with accurate information. No prestigious organization existed in Washington to do these things. The Agricultural Board of the National Academy of Sciences-National Research Council was rather far down in the hierarchy and could advise the government only upon request. These facts dictated creation of a Council whose principal function would involve communication with the Congress, a process termed "education" rather than lobbying.

ASAE was invited to join the Council in March 1971. At that time it was suggested that member societies pay dues at the rate of $\$ 1.00$ per member. ASAE had about 6000 members then and was in somewhat restricted financial posture because of inflation and the new Headquarters building; therefore, the Executive Committee was not inclined to view the invitation with extreme interest.

The Executive Committee held a regular meeting in Chicago during November 1971. On invitation, Dr. Black appeared to discuss the Council, which had meantime become CAST. The principal task of the organization would lie in working with Congress to furnish factual information on proposed legislation, according to Black. Action was postponed to the December 1971 meeting, at which time it was concluded to poll the membership as to whether ASAE should participate in CAST. Although the members voted in favor, the Executive Committee decided to postpone action.

For years, perhaps in recent times since Hobgood in 1965, the ASAE presidents had been calling for more involvement, more interaction with society as it struggled with technology vs. quality of life. However, President C. F. Kelly said in June 1973 that "ASAE's greatest service to the country and to its membership will be through our remaining basically a technical society." Social problems were too complex for ASAE to confront. Besides, ASAE had become affiliated with the National Society of Professional Engineers' Engineering Liaison Societies Activity (to be treated later) and that gave ASAE a contact with a Washington lobbying effort without having to become a lobbying organization and lose its tax-exempt status. But was that enough? Was membership in EJC, with its concern for technology assessment, enough?

There was a growing sentiment that ASAE was involved in some problems 


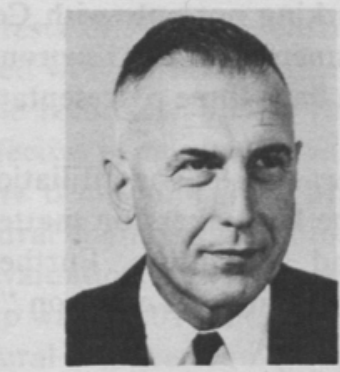

Clarence F. Kelly, 66th president, ASAE, 1972-73

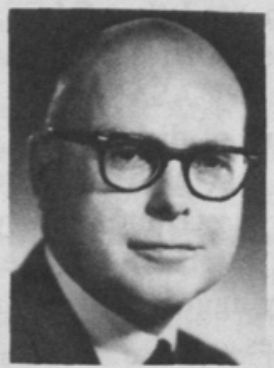

Lawrence $\mathrm{H}$. Hodges

67th president, ASAE, 1973-74

that NSPE and EJC did not address: that is, problems of agricultural significance did not interest these organizations. Perhaps CAST had something to offer.

Jimmy Butt wrote in the May 1974 AGRICULTURAL ENGINEERING that some board members now believed ASAE ought to become a member of CAST. A vote was scheduled in June. The cost would be $\$ 5000$, and a $\$ 1$ dues increase would be necessary. Butt noted that reports for Congress had been prepared by CAST committees on reclamation of mine lands, pesticides, feedlot effluents, and on energy. CAST officials claimed they could recognize the language of their reports in legislative amendments issued after reports were submitted. There was a distinct feeling that CAST was acting effectively on behalf of the agricultural community.

At the June meeting at Oklahoma State University, outgoing ASAE President L. H. Hodges of the J. I. Case Co. put the case for involvement this way:

"Having technology controlled by those untrained in technology could reduce our great country to mediocrity. Our society improves its productivity, its standard of living, and economic status through innovation. Overregulation of science and technology will surely curtail innovation just as inevitably as the passage of time leads to old age."

The Board of Directors voted unanimously that ASAE join CAST on January 1, 1975; however, no dues increase was levied. The cost of belonging to CAST was higher than any other organizational membership.

The affiliation of ASAE with CAST was announced in the November Journal by a lengthy interview with Dr. Black, who had become CAST Executive Vice-President. He emphatically denied that CAST was a lobbying organization; rather, it was strictly educational in purpose, "created to increase the effectiveness of agricultural scientists as sources of information for the government and the public..." CAST to date had prepared 33 reports on a wide range of controversial subjects. It comprised 13 professional societies and 42 business firms and trade associations, including FIEI. 
Black commented that CAST had been working not only with Congress but also the new Office of Technology Assessment and the Environmental Protection Agency. ASAE would be entitled to have three representatives on the CAST board of directors.

It appeared that ASAE's move into CAST was wise. The affiliation gave ASAE a fairly direct opportunity to inform the lawmakers on matters pertaining to the intersection of engineering and agriculture. Furthermore, CAST was very aggressive, very alert for opportunities to carry on "educational" activities.

Those who hoped for similar behavior by EJC were usually disappointed, although EJC tried hard to meet the changing times. It had a program on technology assessment and committees working on the social implications of technology, but it couldn't come up with an effective program for legislative action. This may have been due to vacillating leadership by the constituent societies. At any rate, EJC's floundering prompted ASAE member M. E. Singley of Rutgers University to recommend in 1976 that it follow the example of CAST in influencing the Congress. That is, EJC should assemble knowledgeable committees from its constituent societies to deal with specific issues with hard-hitting, factual, succinct reports.

Was a better performance to be expected from NSPE? Engineers could hold individual membership in NSPE, although the requirement (before 1970 ) that they be registered limited NSPE's size. NSPE devoted principal attention to non-technical areas of engineering such as economic status and employment conditions; of greater interest here is the fact that NSPE had an extensive organization for governmental and legislative contacts and activities and was "chartered" as a lobbying group. Not surprisingly, NSPE's headquarters was located in Washington, DC; it had state societies in every U.S. state and territory.

The ASAE Board of Directors voted that ASAE become a liaison member of NSPE in June 1972. This would demand ASAE membership on several NSPE committees, in addition to an increased burden of duty for Jimmy Butt.

By the liaison agreement, ASAE members were eligible to participate in NSPE activities ranging from full membership to receipt of national services only. Thus, an opportunity was provided whereby ASAE members could be informed of, and have a voice in, professional affairs both at national and state levels. And that included political concerns aiso. The opportunity was available for a fee payable to NSPE, of course.

It is probably fair to say that much of the effort exerted by NSPE in the legislative sphere has been effective and of considerable public benefit. But very little of the effort has been directly influenced by ASAE, partly because 
the interests of NSPE's constituents have not been directed toward issues concerned with agriculture.

On the record it appears that ASAE's work with CAST has been much more effective in causing agricultural engineering technology to play a role in legislative decisionmaking. Many of the CAST reports were prepared by agricultural engineers; presumably, these had credibility at least equal to an ASAE evaluation, although we have no way of knowing. At any rate, CAST ended up with a 501 (c) (3) tax exempt classification. And, presumably, the agricultural engineering inputs to CAST have been "for the benefit of man."

As to the role of the government vs. the obligation of engineers to be moral and ethical protectors of the public, perhaps a practicing engineer named Florman* wrote something of interest:

"Voluntary good works are to be admired wherever they occur. But in the world of industry, compulsory good works, ordered by legislation, provide much better protection for society, and for men of conscience within industry as well. It is toward sensible workable controls that we should all be exerting our efforts, rather than relying on a corporate virtue that is not likely to appear until the day of judgment. Government controls depend to some extent on morality, of course. But they stem more from common sense than they do from conscience.

They are esentially a consequence of enlightened self-interest."

Florman suggests that engineering partnership with the government will serve society much better than agonizing over "social responsibility" or feeling guilt about the adverse effects of technology. This is probably true, within sane limits, but granting that total "unification" will not occur in the near future, then how is such a partnership to be brought about? The technical societies have segmented industry to a degree that their recommendations on broad technical issues could be diametrically opposed. ASAE's liaison relationship with NSPE has probably caused it to lend at least nominal support to policies contrary to its own interest on some issues. If engineers could agree on "sensible and workable controls," and if legislative and executive agencies would accept their counsel, the beginnings of a partnership could emerge,but the Seventh Decade seemed to produce so much unguided governmental regulation that the total impact of engineering must have been minor. Perhaps the government, although constantly on record as desirous of engineering counsel, grew weary of conflicting counsel when the engineers spoke for the interests of their various industries and clientele.

Final action taken regarding interaction with government was encouraged

*Samuel C. Florman, The Existential Pleasures of Engineering. New York: St. Martin's Press. 1976. 


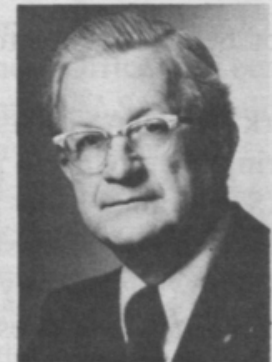

Frank B. Lanham 70th president, ASAE, 1976-77

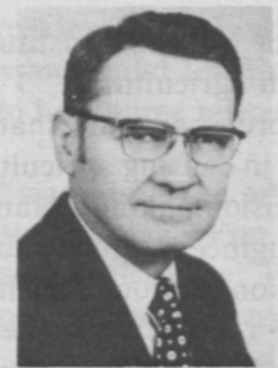

Sherwood S. DeForest 69th president, ASAE, 1975-76

by the Board of Directors at the December 1976 meeting. President Frank B. Lanham was authorized to appoint a Government Affairs Committee "to evaluate for two years the potential for making permanent an ASAE program for contributing to the legislative decision-making process."

Jerome P. Harper of the Argonne National Laboratory was appointed chairman of the Committee which held its first session at the 1977 Annual Meeting at Raleigh, NC. Harper had served as a Congressional Fellow under the auspices of the American Association for the Advancement of Science.

The objectives developed at the Raleigh meeting were as follows: (1) To provide avenues for involvement by Society membership in the legislative and governmental arena; (2) to initiate studies on current food and agricultural issues and provide views to appropriate governmental groups; (3) to encourage participation of the members in all aspects of public affairs, including public office; and (4) to fund a Congressional Fellowship program. It was proposed to implement these objectives in various ways, such as special meetings, use of existing ties with CAST and the others, and special awards for achievement in public affairs. Members were to be encouraged to take stands on issues, to communicate their views to legislators.

Perhaps by June 1977 ASAE was doing about all it could to interact with government. Further significant activity would probably be carried out by individual members acting for themselves alone through contacting Congressmen and other lawmakers. For those who try, this can be an unhappy experience. S. S. DeForest tried to inform two Congressmen regarding three bills. After wrestling with them and their staffs he concluded the experience was "a waste of time, disillusioning and frustrating." He found that "participating in the legislative process isn't very simple if one really wants to get something across to the fellow that does the voting." Yet he felt that the members could have impact by writing their Congressmen, provided that ASAE (perhaps through the Government Affairs Committee) furnished early commentary regarding bills of vital interest. This would leave untouched the 


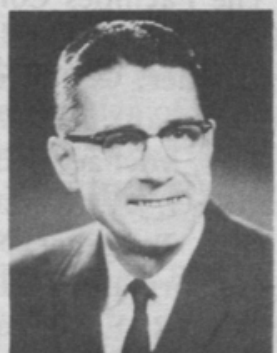

Russell R. Poynor 61st president, ASAE, 1967-68

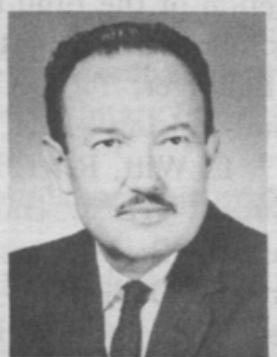

Talcott W. Edminster 62nd president, ASAE, 1968-69

administrative processes of agencies like OSHA and EPA, which propose rules in the Federal Register and the rules become law without debate unless objections are filed within a specific time limit.

Big, all-powerful government was here to stay. Since the 1930s Americans had turned to government for solution of big problems, and no change in this tendency was on the horizon. ASAE would have to live with a large and powerful government in the foreseeable future and do what it could to help make the government's technological measures as sane as possible while hoping that its actions were "for the benefit of man."

In the previous chapter brief mention was made of the dedication of ASAE's new Headquarters in April 1970. The dedication ceremonies were on April 17 at the Hilton Inn in Benton Harbor. This was followed by a joint meeting of the Illinois-Wisconsin and Tri-State (Ohio, Indiana, Michigan) Regions. On April 18 and 19 the building was open to the public; about 500 visitors toured the Headquarters at that time. The April and May issues of AGRICULTURAL ENGINEERING carried articles describing how the building was planned and financed.

As set forth earlier, the program of obtaining the Headquarters building was executed during the presidential terms of Price Hobgood, C. S. Morrison, O. C. French, R. R. Poynor, T. W. Edminster, and N. H. Curry. Many members assisted in getting the job done. Curry, Hobgood, and Morrison worked out details in 1964 and 1965 on location, finance, and timetable. They were aided by Howard Matson and R. R. Raney and, later, by Poynor, Edminster, J. W. Martin, M. L. Burgener, C. E. Ball, J. K. Jones, J. E. Dixon, Michael O'Brien, B. A. Jones, Jr., R. G. Yeck, and R. H. Brown. In 1968 the Headquarters Facilities Committee was reorganized under General Chairman R. H. Tweedy, and Past-President Earl Anderson 
assumed direction of the fund-raising drive. The Facilities Committee was subdivided as follows: Information and Publicity $-K$. L. Pfundstein (chairman), P. L. Bellinger, T. E. Clague, W. J. Fletcher, C. J. Kuska, W. F. Overman; Fund-Raising-J. H. Ebbinghaus (chairman), A. W. Farrall, L. H. Hodges, W. E. Witt, R. H. Brown, W. R. Fox, Michael O'Brien, E. W. Tanquary; Budget - H. J. Hansen (chairman), G. A. Karstens, R. E. Heston; Architect-B. A. Jones (chairman), M. L. Burgener, N. H. Curry, R. R. Poynor; and Dedication-Dexter Jones (chairman), P. L. Bellinger, W. J. Fletcher, K. L. Pfundstein, G. A. Karstens, R. E. Heston.

Tweedy (Allis-Chalmers Corp.) presided over the dedication ceremonies, which commenced with a luncheon. The luncheon tables were graced by tall bottles of red wine, a sight that would have cheered J. B. Davidson and Bascom Clarke. A gold-plated plaque was presented from Headquarters Facilities Committee to the ASAE headquarters staff for extraordinary personal and professional services, thereby acknowledging extra effort on the part of Jimmy Butt and his staff J. A. Basselman, R. H. Hahn, T. D. McFarland, H. A. Mulbar, M. B. Pratt, L. A. Straw and R. A. Palmer (retired) as a major contribution to the successful completion of the new building.

The program was opened by W. J. Harris, president of EJC, with "Greetings from the Engineering Family." Harris complained of the bad press engineers were receiving those days for their sins against the ecology but asserted that agricultural engineers were above such blame because they had learned to provide for humanity without destroying natural resources. He was followed by S. W. White, FIEI chairman, with "Greetings from the Agricultural Family." White called for more attention to the depopulation of rural areas created by modern farming and for more emphasis on the human aspects of industrial development as engineering creates jobs. "Greetings from the Local Community" were delivered by State Senator Charles O. Zollar, who pointed out that because Berrien County was half manufacturing and half agricultural, only through engineering could these two groups continue to exist together. B. A. Jones, Jr. of the University of Illinois, chairman of the Architect's Committee, commented that the new building would serve as ". . . a reminder of our ability to meet new and greater challenges in the future."

President Curry richly deserved the honor of delivering the dedication speech because of his vital and effective services throughout the period of land acquisition and building construction. He first noted the importance of agriculture in human life and the related engineering responsibilities which ASAE had assumed. The new building was "erected in anticipation of the enormous expansion of the agricultural engineering profession as these 
responsibilities multiplied." Curry outlined the activities which ASAE carried on-publishing, standards, conferences-and emphasized that processing and dissemination of information was the "primary function" of ASAE. He ended by dedicating the building as follows:

"TO OUR PREDECESSORS-by whose labors this profession was established,

"TO OUR CHARTER MEMBERS"-from whose vision this Society was created,

"TO OUR MEMBERS AND SUPPORTERS-through whose generosity this project was completed,

"BUT MOST OF ALL TO THE CITIZENS OF THIS PLANET

EARTH-for whose service this building is intended,

"TO ALL OF THESE, THIS BUILDING IS DEDICATED."

Past-President T. W. Edminster displayed an American flag which had been presented to ASAE for the occasion by Clifford M. Hardin, Secretary of Agriculture. The flag had been flown from the staff in front of USDA's Washington Administration Building. Hardin sent a letter to Curry along with the flag to congratulate ASAE on its accomplishments and leadership which had been "so valuable to the progress of American agriculture."

The ceremonies were attended by a group of 200 prominent ASAE members; dignitaries representing organizations who worked with ASAE, such as SAE, ASHRAE, ASTM, ECPD, ASME, CSAE, ASA, and many others, also were in evidence. As Jimmy Butt expressed it later, "It was a great day!"

That night President Brooks McCormick of the International Harvester Company addressed a banquet sponsored by the two ASAE Regions. His words were a sobering analysis of the effect of agricultural technology on quality of life and a challenge to his listeners to assume the burden of accountability for their actions. Quantity was no longer enough; abundance was no longer enough. Once again the message was delivered: Engineers, live up to your pledge of placing human welfare above all else. Outside, the illuminated Hilton Inn sign read, "Welcome, Brooks McCormick." Inside, the noonday wine and roses suddenly seemed a long time ago.

The April 1970 issue of AGRICULTURAL ENGINEERING was a festschrift in honor of the new Headquarters. The articles were mostly predictions of the future. Arnold B. Skromme of Deere and Company wrote the first article, which related the growth of ASAE to that of the farm equip-

*The last living charter member, Howard W. Riley of Cornell University, died August 19, 1971, aged 92. He was fifth president of ASAE in 1912; he is one of the two men for whom Riley-Robb Hall, the agricultural engineering building at Cornell, is named. 


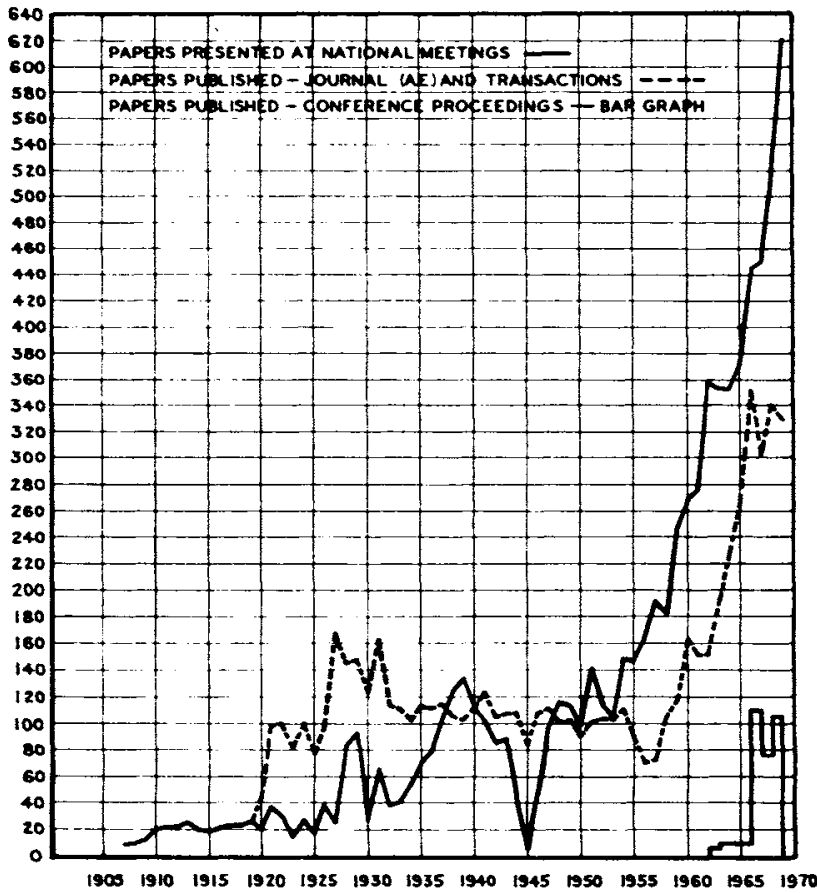

Solid line represents papers presented at ASAE national meetings; broken line those published by ASAE. Bar graph at the lower right represents papers published from special-subject conference proceedings

ment industry from 1907 to 1970 . Skromme found that ASAE had published 7294 papers during that period. The publication rate per year reached a peak in about 1927 that was not exceeded again until around 1963. In his "Farm Equipment Milestones" he traced the interaction of ASAE papers and meeting discussions (or the lack thereof) with developments in farm equipment; highlights in developing standards also received attention.

"Agri-Business in the Year 2000" was projected by U.S. Steel Corporation's S. S. DeForest. The author had a vision of people living in kitchenless homes, their meals furnished in advance by a distributor via radio-controlled vehicle; the distributor would also handle garbage and dish disposal, converting them into useful substances. The distributor would obtain his raw materials from a producer-processor, where crops would be grown in multistory structures under complete environmental control. The crops would also be processed here into food "elements" and then sent to the distributors.

Carl W. Hall of Washington State University predicted that the "family 
farm" would require from $\$ 500,000$ to $\$ 1$ million in capital, would be computerized, and mechanized by radio-controlled tractors. Efficiency of crops and livestock would increase. The operator would be a practicing engineer in many respects.

T. W. Edminster saw a future where research would continue to develop a mechanized agriculture. Teams of researchers, with agricultural engineers in the principal roles, would work on problems of tillage and soil compaction, plant growth factors, pest control, environmental physiology of plants and animals, and improved harvesting machines for fresh fruits and vegetables.

Walter Carleton, in his article on "Engineering Research Concepts for the Year 2000," opted strongly for nuclear energy. He predicted that tractors would be powered by nuclear reactors by 2000 if not sooner.

A group of members contributed predictions about various aspects of agricultural engineering in the year 2020, 50 years after ASAE dedicated its new building. These short prognostications were appropriately identified by a sketch of a crystal ball.

ASAE gained much favorable attention and publicity when it dedicated its new Headquarters building. Many were the good wishes from sister societies, both engineering and agricultural, that poured in. Also, a large number of local businesses joined in the congratulations to the agricultural engineers. ASAE staff enjoyed the community's plaudits very much, but within a year had to risk its enmity in order to secure ASAE's status as a tax-exempt institution through the courts.

Deep and thorough analysis of ASAE by an educated "outsider" has been made only once during the first 70 years. It was rendered by Judge Chester J. Byrns of the Berrien County, Michigan, circuit court.

On February 9, 1971, ASAE filed suit in the Berrien circuit court to obtain return of its 1970 real and personal property taxes and a court order barring future collections. ASAE named as defendants St. Joseph township, the County of Berrien, Lake Michigan College district, Berrien school district, and the county building authority. The Society claimed it was tax-exempt under Michigan law as a nonprofit educational and scientific institution, and sought recovery of about $\$ 8300$ paid under protest. The following year ASAE paid about $\$ 8900$ additional taxes under protest.

The suit was tried in June of 1972. Judge Byrns found that ASAE was taxexempt under law as claimed and ordered its money returned in an opinion dated December 6, 1972. The defendants appealed but the decision of the circuit court was upheld on April 30,1974 by the Michigan Court of Appeals. 
The taxing authorities appeared to believe that since ASAE Headquarters had no classrooms or teachers in evidence it could not be an educational and scientific institution. After a searching examination of the building, of ASAE's exhibits at the trial, and the witnesses, Judge Byrns found otherwise in a lengthy opinion. His conclusions should be of extreme interest and value to all ASAE members:

"The ASAE performs a vital function in the field of agriculture. The primary beneficiary of its work is the public which as a result enjoys better conservation and use of its natural resources and ultimately better quality and more food which is a prime essential to all life. The ASAE fills a void in the field of agriculture which, were it not doing it, government and public-supported schools would. In allowing for exemptions the legislature recognized that the private sector not only could save government expenses, but could do certain scientific and educational work more effectively than government. A tax exemption is the reciprocal of the public service it does. The facts in evidence show the public receives more than a quid pro quo for the tax exemption the ASAE seeks.

"The government . . . directly benefits from the work done by the ASAE, and for the essential work that it does, the government reaps great savings from the expenses of attempting to duplicate it.

"The work of the ASAE is of an educational nature and of an educational value within the terms of the tax exemption since it forms the foundation and the guide for much of the work being done by agricultural schools and institutions both in the field and with their students, thus benefiting, without cost to the public, agricultural education in Michigan and elsewhere in the United States.

"While its real and personal property in St. Joseph Township is technically neither a school nor a research laboratory in the strict traditional sense, it is the clearing house or the center of the communications system which triggers study, discussion, analysis and research using the brains, skills, experiences and contributions of its national membership and then funnels out the results throughout the nation and world for the benefit of government and agricultural people, educators, students, farmers, etc. Without this contribution, such results would not be realized or would be of great cost to the tax-payer to replace.

"The ASAE is neither primarily or substantially a social organization and it functions not for the benefit of its members or a particular industry; but, rather, the general public (all of it, since food is used by every human) is the beneficiary. 
"The ASAE is also a scientific organization for it uses its scientist members to develop and report research and exchange between teachers, scientists, students, universities, government, industry and the public and thereby creates, develops and publishes primary research which the uncontested evidence clearly shows contributes to the knowledge and improvement of agriculture from the farmer through the processor to the consumer. This scientific work is relied on by the government as well as educational facilities who admittedly have been saved the cost of doing the same."

The tax case revealed ASAE in a rather new light. The revelation that the Society relieved government of some of its burden was strange to some, but nevertheless reasonable according to legal viewpoints. Strange it was because the welcome opinion came at a time when government was assuming an adversary posture to the view of many ASAE members.

The Board of Directors voted its thanks in June 1972 to witnesses who acted on behalf of ASAE in the case. Named in the resolution were J. L. Butt, A. W. Cooper, M. L. Esmay, L. H. Hodges, J. B. Liljedahl, Morris McMurray, and Claire Musgrove. Another resolution of thanks was rendered on behalf of Attorney James B. McQuillan, who handled ASAE's case, but it was not transmitted to him until the appeal was concluded favorably in 1974 .

On conclusion of the litigation McQuillan wrote a letter praising Jimmy Butt's assistance in the case to President L. H. Hodges for transmission to the membership at the June 1974 meeting. Among other admiring opinions, McQuillan stated that

“. . . . in my twenty years' experience as a trial lawyer, $I$ have never met a gentleman who was so pleasant to work with and so helpful in preparing a major lawsuit. Although we had numerous other witnesses of the highest caliber available to testify at the trial for ASAE, in all honesty, I am certain we could not have prevailed without the assistance of Mr. Butt, both in preparation of the case and in his testimony given at the trial. Since the trial, many of the court personnel, including Trial Judge Byrns, commented that they had never seen a witness in court who was as articulate and lucid as Mr. Butt in explaining, in a concise and understandable form, the nature and organization of a very complex Society."

After receiving its money from the taxing authorities, ASAE made a substantial contribution back to them in recognition of services received such as police and fire protection. The leadership hoped to preserve the good feeling and respect of the community. 
The conflict in Vietnam dominated, or at least influenced, major aspects of American life from 1964 to 1973. During the latter five years internal dissension about the conflict reached civil war proportions. Mistrust of the Asian policy was in evidence everywhere.

Unlike during previous wars, ASAE made no special effort to aid the government with its conflict in Vietnam. It would be difficult to determine from ASAE's archives that the conflict ever occurred except for its effect upon members and students.

An appreciable number of members served in the armed forces, but no lists of names were published as during World War II. In fact, the only indication available in AGRICULTURAL ENGINEERING was a brief remark in 1968 (J. L. Butt's "Check Points") which quoted statistics gathered by the Engineering Manpower Commission of the EJC. These figures showed that as of December 1967 there was a total of 352 agricultural engineers serving as commissioned officers in the Army, Air Force, and Navy. One cannot assume that all of these were ASAE members but it is probably that most of them were. No data were made available on enlisted men with engineering degrees.

The Selective Service System handed the graduate schools a savage blow in 1968 when it suspended occupational draft deferment based on specific college training, including engineers and scientists, between ages 19 and 26. About 7500 doctoral candidates were placed in class I-A; 112,000 full-time graduate students were likewise reclassified; and the 1968 graduates $(200,000)$ also, to a total of 320,000 subject to induction ahead of any younger men. The policy was to draft the older men first; therefore, those completing advanced degrees, and many of their instructors, were now to be trained as buck privates.

The effect of this policy on agricultural engineering education was suggested by a survey of 80 percent of the college departments conducted in 1969. Forty-one percent of the graduate students were non-citizens of the U.S. while 30 percent of the U.S. citizen students were in draft-liable status. There was no increase in enrollment between 1967 and 1968. Other fields of engineering reported similarly. This situation created a serious problem for undergraduate teaching-whether or not to use foreign graduate students as teaching assistants. Jimmy Butt commented that the basic problem was the same one which had plagued the profession for years-the need for increased undergraduate enrollment.

The student branch membership declined markedly from 1967 to 1969; in the same period the number of branches dropped from 45 to 42 . This decline continued through 1971; in January of that year 15 branches had no duespaying members. Branch membership reached its nadir in 1972, then started back up in 1973. It is difficult to connect this decline in (primarily) 
undergraduate strength with the Vietnam war, although the upturn roughly coincided with the cease-fire agreement and ending of the draft.* It would be illogical to assume that the 19-year-olds were volunteering in great numbers during 1968-1973 when the draft deferments of the 19-26 age-group college students were abolished. At any rate the branch membership grew almost exponentially from 1973 to 1977 , when it set the record.

Among other hazards the drafted engineering graduate of the time had to face was the distinct possibility that he would be forced to serve in a capacity unrelated to his technical training. In 1969 the military needed about 7000 enlisted men in technical specialties. While 4600 engineering graduates were available, the man had been matched to the job in only 1016 cases. Engineers were assigned as medical and dental specialists, clerks, and supply handlers. The EJC's Engineering Manpower Commission tried to alleviate the condition through recommendations leading to better utilization of this valuable resource.

Campus disruptions of the time were centered principally against the war and its handmaidens such as the ROTC and "military-industrial complex." Students protested research done for military purposes and demanded greater voice in the "governance" of their universities.

It was good to know, however, that students of engineering were rarely involved in disruptive tactics. Their elders assumed that they were "too busy" for such extra-curricular activity. It is more likely that they were quite aware that their careers would be intimately associated with the Establishment; therefore, it would be rather foolish to behave like a radical while preparing for a life of conservatism. However, a student group calling itself the "Engineering Coalition" asked EJC in 1970 to undertake a study of engineering reform. Their arguments for reform of the engineering societies, education, and the profession, are interesting enough to deserve space here, although it is doubtful if any agricultural enginering student was involved.

In May of 1970 the Engineering Coalitiont asked EJC to finance and supervise a study of problems which were considered to have been caused by failure of engineers to protect the public welfare. The problems were posed as: (1) Neglect of environment, transportation, medicine, education, infor-

*The cease-fire agreement was signed in Paris on January 27, 1973.

tComposed of students at City College of New York, Columbia University, Cooper Union, Fairleigh Dickinson, New York University, Newark College of Engineering, Polytechnic Institute of Brooklyn, Pratt Institute, S.U.N.Y. at Stony Brook, and Stevens Institute of Technology. 
mation systems, and energy conversion; (2) the moral dilemma of engineers engaged in military work; and (3) economic deterioration of essential industries (shipping, steel, railroads) caused by engineering indifference to allocation of resources. The Coalition's view was that the professional societies had failed to enforce the precepts of the Canons of Ethics, thus causing the U.S. standard of living to decline and the stature of individual engineers to be diminished. In addition, this "blindness" to the needs of society would turn youth away from careers in engineering.

The students wanted EJC to remedy the situation through study and development of programs such as: (1) Occupational retraining to put engineers into new fields, particularly non-military, where society needed them the most; (2) guidance of new graduates into "morally acceptable" employment; (3) elimination of rigid divisions between engineering disciplines in the colleges and establishment of courses concerned with the social effects of technology; (4) refusal of accreditation to engineering colleges which fail to require study of social implications and moral responsibility of engineering; and (5) encouragement of the professional societies to devote more conference time to ethical and social issues for which present knowledge is inadequate.

The document presented to EJC by the Engineering Coalition was wellwritten, complete with references; a key reference was one of EJC's own publications. The Engineering Manpower Commission considered it at a meeting in July 1970 with considerable interest, according to Walter Carleton who represented ASAE at that time. Nothing concrete was done in response, however.

This student "protest" was actually a nagging restatement of the way many engineers felt and believed at the time. It was another demand for attention to the "benefit of man" theme whose historical roots were planted long before the members of the Engineering Coalition were born. But this present time was made more difficult by a conflict which technology couldn't seem to win, despite enormous engineering input. In effect, it was a defeat, tending to turn men's thoughts to the good that technology ought to perform. So the philosophy of the Engineering Coalition was rather well on target, but its youthful idealism asked for too much.

After the reluctant Board of Directors commitment to "recognition" of the existence of mech-ag programs and graduates in December 1966, the process of recognition slowly began to take shape. The developing mech-ag programs in the universities undoubtedly spurred ASAE to hasten its pace toward a 
resolution of the difficulties outlined in the preceding chapter.

The next major move came from the Universities of Nebraska, Kansas State, and Missouri, whose mech-ag students petitioned the Board in May 1968 that ASAE recognize and support Agricultural Mechanization Clubs in a similar manner to the support it gave to the ASAE Student Branches. Roger Meyer, a Nebraska mech-ag student, accompanied by Professor John Sulek of that university, appeared by invitation before the Board in June to present the petition. The report was accepted and transmitted to the Administrative Council for action and recommendation; the Council recommended approval of ASAE support of Agricultural Mechanization Clubs and appointment of an Agricultural Mechanization Club Committee.

After the passage of about a year, the Administrative Council received four petitions for club recognition. At the 1969 Winter Meeting one of these was approved, that of Michigan State University, which therefore established the first official ASAE-recognized Agricultural Mechanization Club. The following July eight more were officially authorized.

These events settled one of the questions about mech-ag status. As students they could take pride in their own organization. Also, in $1970 \mathrm{a} \mathrm{Na}$ tional Council of Affiliated Student Clubs was formed, in parallel to the structure and activities of the National Council of Student Branches. Later, competition for an FIEI trophy was made available to the Student Clubs. By June 1974, 18 universities had recognized Affiliate Clubs and 11 planned to participate in the FIEI competition.

Handling the question of student status was not too difficult once it was started. A more thorny issue was the status of mech-ag graduates in ASAE, some of whom had chafed under the Affiliate grade of membership assigned to them (because they were non-engineers), regarding it as "second-class citizenship" since it did not allow them to vote or hold office on the national level. Readers will recall that the Peikert Report of 1966 requested an improved grade of membership for Affiliates but the Board of Directors chose not to pursue the subject.

It was a difficult topic to approach and handle. Not only ASAE but also many other engineering societies were wrestling with similar problems. President Stewart wrote Jimmy Butt regarding this on September 1, 1970:

"The whole question of these technology programs was aired at length at the Joint Societies Forum. Great difficulty is being experienced in differentiating between graduates of 4-year technology curricula. None of the presidents had a good answer. I commented that the ag mech curricula are in similar relationship with us, and that I believe we should work with them, work toward accreditation, and even change our grade of membership for them, all for the sake of keeping 
their affiliation and loyalty to agricultural engineering intact. This seems wise in order to better serve the industry; however, it certainly raises questions of professional identity, and would enhance the risk of confusion in the public mind."

No action occurred until President C. F. Kelly was authorized by the Board to set up a Task Force on Affiliates.

Carl W. Hall, dean of engineering at Washington State University and ASAE president-elect, was asked to head the new Task Force. The committee members were R. M. Lien (Purdue University), Carlton Johnson (Ohio State University), G. W. Isaacs (Purdue University), K. K. Barnes (University of Arizona), W. M. Carleton (USDA), and R. C. Evans (Bacon Bin, Inc.). All of these individuals had been active either in the Affiliate movement or held high office. Isaacs was Professional Development Director; Barnes was Technical Vice-President; Carleton was Administrative Vice-President; and Evans was Regional Vice-President. Lien and Johnson had worked for many years on issues related to Affiliates; Johnson was chairman of A-214 Instruction in Agricultural Mechanization Committee while Lien was past-chairman of A-218 Student Affiliate Clubs Committee.

Hall convened his Task Force for the first time at a brief organization session on June 18, 1973, at the Lexington, KY, Annual Meeting. It was revealed that ASAE had about 800 Affiliate members, some of whom were mech-ag graduates; there were 31 universities with mech-ag programs, and 17 Affiliated Clubs. It was decided that the issue of corporate (i.e., voting) membership for present and future "Affiliates" (or mech-ags) was to be pursued. This raised two crucial questions: (1) Would ASAE's status in EJC, NSPE, and ECPD be affected? (2) how would the present corporate membership accept changes in membership grades and the constitution?

After a great amount of labor, the Task Force developed suggested changes in the ASAE Constitution which the members could vote upon. The proposed changes appeared in the November 1974 AGRICULTURAL

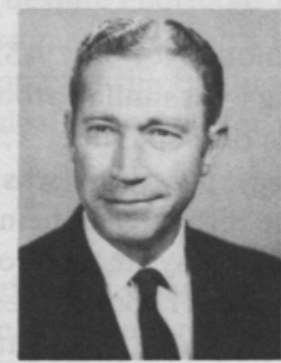

Robert E. Stewart 64th president, ASAE. 1970-71

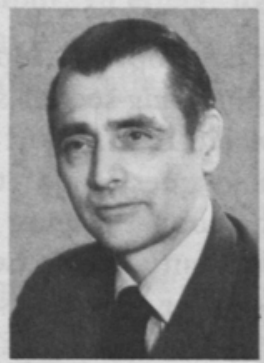

Carl W. Hall

68th president, ASAE, 1974-75 


\section{ENGINEERING.}

To the corporate membership were to be added Mechanization Members and Mechanization Associate Members. Student Mechanization Members were to be added to the non-voting list. The qualifications for the new grades specified "graduate of an ASAE-approved agricultural mechanization curriculum [or its equivalent]", but a certain number of years' experience could be substituted for the degree requirement. Thus ASAE was to be put back into the business of recognizing curriculums. Furthermore, the "experience" criteria would need to be established.

The Task Force gave much publicity to its proposals and sought counsel widely during the period of its deliberations. The announcement of the proposed constitutional changes which appeared in AGRICULTURAL ENGINEERING stated that a "special forum" was planned for the 1974 December Winter Meeting "to provide members with more background on the reasons for those changes in corporate membership structure." But the move had its opponents. S. O. Nelson (USDA), chairman of the Constitution and Bylaws Committee, authored a letter in that same November 1974 issue of AGRICULTURAL ENGINEERING urging members to reject the proposal.

When the vote was revealed at the 1975 Business Meeting the degree of opposition was apparent. There were 1860 votes cast for the change and 560 votes against. A two-thirds majority of the votes cast was required to make the change official; this proposed change secured a three-fourths majority, sufficient to pass, but it was a much lower percentage of "yes". votes than was usual in amending the ASAE Constitution.

By June of 1978 ASAE had acquired 29 Mechanization Members and 178 Mechanization Associate Members; the Affiliate members had dropped to 652.

Judging by these numbers, the work of the Task Force was hardly worth the effort when measured against the disappointment of those who voted against the change in such large quantity. Many of them could recall the humiliating time when ASAE was trying to become a voting member of ECPD; that organization did not wish to count even the Associate Members as qualifying. To these members it was crucial that ASAE maintain its posture as a society of engineers. They remembered that it took ASAE from 1907 to about 1950 to convince other engineering groups that ASAE was not a society of mech-ags.

Were they right? ASAE's position in the umbrella organizations is wellestablished; the old campus problems surrounding mech-ag vs. ag engineering have been fairly well resolved; and most employers today are not likely to confuse graduates from the two curriculums. Therefore, as chief clearing- 
house and focus of agricultural engineering technology, perhaps ASAE ought to give the mech-ags a home and some dignity; perhaps it was time to change.

While the dedication of ASAE's new Headquarters in 1970 stimulated some speculation about the future, the nation's Bicentennial year of 1976 created an occasion for more imaginative glances at the future as well as pride in the past.

ASAE's observance of the Bicentennial, according to President Frank Lanham, originated at the May 1975 meeting of the Meetings Committee. There it was decided that the two national meetings in 1976 should have a single theme related to the Bicentennial. Later ASAE's public relations counsel suggested to Jimmy Butt that Heritage and Horizons was a suitable theme. At its October meeting, the Meetings Committee developed a format for the 1976 Annual Meeting at the University of Nebraska where the Heritage of each Technical Division would be reviewed. Also, for the 1976 Winter Meeting, a "Horizons Extravaganza" was planned. This was to be a 40-50-minute audiovisual presentation showing future Technical Division thrusts and programs in the year 2000 and beyond. A written description of the Technical Divisions' projections was to be made available and printed in AGRICULTURAL ENGINEERING, because the audiovisual presentation could not show all of the ideas advanced by the Divisions.

The ASAE staff was called upon to locate the hundreds of pictures to consolidate the division reports and to oversee the preparation of some 1400 slides to complement the narrative for the audiovisual presentation. Roger Castenson, a Texas A\&M graduate who had joined the staff in June of 1973, and Will Cook, a Kansas State University alumnus and past president of the ASAE National Council of Student Branches, played major roles in this acquisition process, in cooperation with Steve Reed, ASAE public relations counsel.

President S. S. DeForest launched the Bicentennial observances with some thoughtful statements in the June AGRICULTURAL ENGINEERING entitled "Stepping Across the Threshold." Although pride in past achievements was worth display, he believed ASAE ought to pay more attention to "the crucial years ahead" where a "new era" beckoned to agricultural engineering. These factors appeared to shape that new era: 


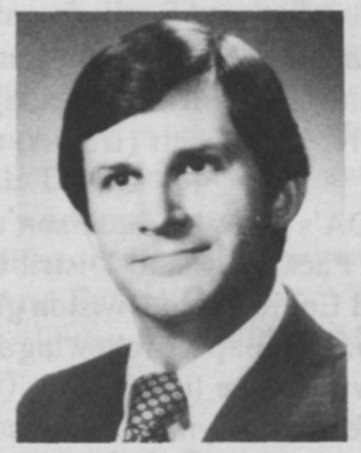

Roger Castenson

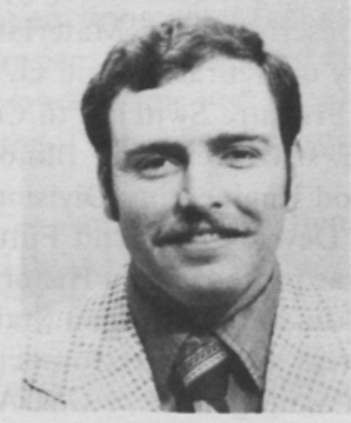

Will Cook

Food surpluses were gone;

Populations of the developing countries were still growing;

Interdependence of all nations was increasing;

Natural resources were limited;

The U.S. cannot alone feed the world;

Governmental legislative and/or regulatory controls would increase;

Environmental protection was to receive the highest priority.

DeForest thought that ASAE had at least one overall response to the new era: Help to increase agricultural productivity. This response had many complex aspects related to machines, people, automation, resources, regulations, and responsibility; many questions had to be answered, but it was time to start.

At Lincoln (ASAE's 69th Annual Meeting) the Bicentennial Heritage theme sessions were kicked off by a General Session keynote address by Carl W. Hall on "Electric Power and Processing: A History of Contributions-Challenges of the Future." The session was held, appropriately, in the Centennial Room of the Student Union, which was jammed with listeners for this and the ensuing Heritage sessions.

Hall's keynote address was followed by a Heritage session of the EPP Division. The papers that were delivered at this session were titled and authored as follows:

"Energy-Not a New Field for Electric Power and Processing." L. B. Altman (USDA).

"Electric Power-Electrification-Then and Now." K. L. McFate (Farm Electrification Council) and E. F. Olver (University of Illinois).

"Materials Handling-Is the Challenge of 60s Over?" B. A. McKenzie (Purdue University) and R. L. Maddex (Michigan State University). 
"Grain Drying-Reflections and Perspectives." G. H. Foster (USDA) and R. M. Peart (Purdue University).

"The Description of Materials-Only a Beginning." T. L. Thompson (University of Nebraska) and G. L. Zachariah (University of Florida).

"From Pressure Switches to Computers." H. B. Puckett (USDA) and F. W. Andrews (University of Illinois).

The Food Engineering Division heard USDA's Dale L. Anderson discuss "History, Development and Future of Meat Packaging and Distribution." His talk was preceded by a History of the Food Engineering Division given by D. R. Heldman of Michigan State University. The papers following Anderson's address were not retrospective and so will not be listed.

Jan van Schilfgaarde of USDA gave the Heritage keynote address on the following day for the Soil and Water Division. His address "A Challenge in Soil and Water Engineering" paid tribute to agricultural engineering contributions but noted that there exists "example after example where we continue to use our scarce and valuable water resources ineffectively even though the technology exists for drastic improvement."

The keynote was followed by a group of Soil and Water Engineering Heritage and Horizons Papers:

"Progress and Future of Soil and Water Education." G. O. Schwab (Ohio State University).

"Progress and Future of Soil and Water Research." W. E. Splinter (University of Nebraska).

"Progress and Future of Soil and Water Engineering Practice." F. J. Humenik (N.C. State University).

"Progress and Future of Industry in Soil and Water." D. R. Sisson (L. R. Nelson Corporation).

General Session Heritage keynoters on the last day of the Annual Meeting were Norval Curry and L. H. Skromme.

Curry stated that very few ASAE members of the Structures and Environ-

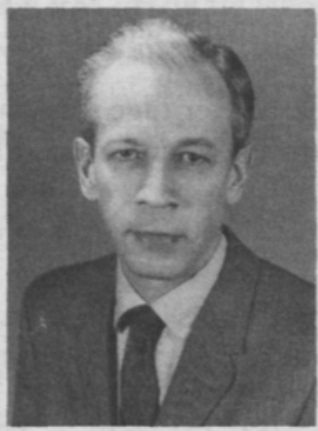

J. van Schilfgaarde of USDA gave Bicentennial "Heritage" keynote address for ASAE Soil and Water Division at 1976 Annual Meeting at University of Nebras- 
ment Division were concerned with structural developments or design of building shells. The challenges in farm structures related largely to compliance with regulations, such as control of environmental factors like odors and disposition of animal wastes. Considerations of energy and environment were now the principal problems that demanded time and effort.

S\&E Division speakers and topics at the Theme Session subsequent to Curry's address were:

"Milestones in Environmental Control of Animal Production Structures ... And Future Outlook." T. E. Bond (USDA).

"Designing for the Plant Microclimate." J. N. Walker (University of Kentucky).

"Past, Present and Prospectus in Farm Structural Design." L. W. Neubauer (U.C.-Davis).

"Engineered Management in Designing Building Systems." R. G. Light (University of Massachusetts).

"Animal Waste Management: Should Manure Be a Waste or a Resource?" R. Smith (Iowa State University).

L. H. Skromme of the New Holland Division of Sperry Rand gave his keynote Heritage address on "From the Past-Food for the Future," sponsored by the Power and Machinery Division. He reviewed the history of plows, reapers, binders, threshers, steam traction engines and internal combustion engine tractors. These implements had not only freed farmers from drudgery but had released many millions from farm labor and permitted them "to make our dramatic progress in science, engineering, education, other professions, and the arts."

The Power and Machinery Theme Session came on after Skromme's General Session. These papers were presented to mark the occasion:

"Engineering Education Trends." H. L. Wakeland (University of Illinois).

"Changes in Farm Machinery Resources to Meet Food Production Demands." W. G. Lovely (USDA).

"The Role of Technology in Food Production." G. H. Millar (Deere \& Co.).

The Heritage aspect of the Lincoln meeting was actually more extensive than has been indicated. Some of the committees reviewed past achievements in their areas of expertise; some held sessions looking toward new horizons of achievement.

The Horizons aspect of the 1976 Winter Meeting was centered on an "Overview of the Next 200 Years." This audiovisual presentation was structured by a public relations firm from materials provided by the Technical Divisions; it was supposed to ask "thought-provoking questions that will stimulate viewers to achieve extra insight into agriculture's future." 


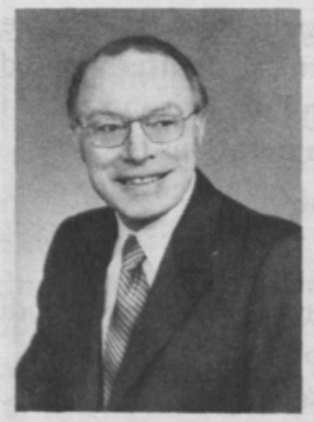

G. H. Millar, Deere \& Co., presented "The Role of Technology in Food Production" during the "Heritage" portion of the ASAE Bicentennial program at 1976 Annual Meeting at University of Nebraska

With Frank Lanham presiding, the 45-minute multi-projector "Horizons in Agricultural Engineering" was presented at the first General Session of the Winter Meeting. The show was exciting and very entertaining, of high quality and sophisticated technique. It portrayed an essentially manless agriculture in the future populated with wizard machines that fulfilled the needs of a hungry world with effortless ease. It suggested that engineers, given the capital, could overcome all the barriers that in 1976 prevented much of the world's people from obtaining an adequate diet.

Roger Castenson, who had replaced T. David McFarland as ASAE staff person responsible for membership development, public relations, student branches and clubs, career guidance, personnel service, and geographic units later coordinated the development of the basic audiovisual story into 15 minute public relations and career guidance films, featuring several of the futuristic concepts portrayed in the 45-minute presentation.

The future of agricultural engineering found a degree of favor with the news media. In particular, the Chicago Tribune gave it a first page treatment under the headline "Tomorrow's farms to go beyond Buck Rogers," although the headline was far smaller than one pertaining to President Jimmy Carter's selection of two cabinet members.

The following day another General Session was held at which Don

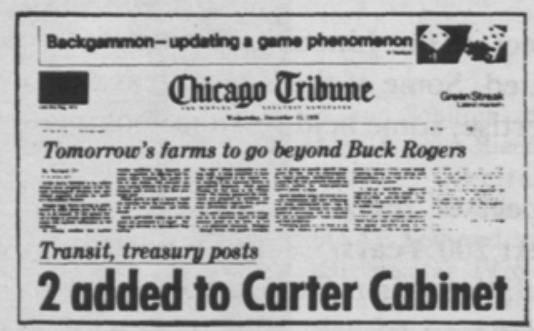


Paarlberg, noted USDA economist, spoke on "The Next 200 Years."

Paarlberg, apparently not a devotee of Buck Rogers, predicted that unquestioned acceptance of technology was already on its way out, along with the plow. What he believed would come: Population control; better food distribution systems; long-range weather prediction; decreasing use of chemicals for fertilizer and for harmful insect control; desalination of sea water; soil-management techniques to permit farming tropical rain forests. The family farm, he believed, would disappear as a commercial unit. Viable production units would require farms so large that a single person could not provide all the land, capital, and management required. Part-time farming would rise in importance, coupled with redevelopment of the rural areas. Land use policy would be a major issue in the years ahead.

His views were, he said, primarily optimistic. He hinted that the first 200 years had been the worst. Although problems would "be on the agenda during the years ahead," they would be of comparatively modest proportions. Unlike the engineers, whose future world contained nothing but more machines, he guessed that "We will make better use of our technological competence in the years ahead and strike a better balance between things material and things of the heart, the mind, and the spirit."

Following Paarlberg's speech the Awards and Recognition Luncheon sponsored by the Council of Past-Presidents was convened. This was a new function which was started at the 1975 Winter Meeting by the newly formed Council. At the 1976 Luncheon the following awards were presented: Student Agricultural Engineer of the Year; Countryside Engineering Award; Engineering Concept of the Year; Young Designer Award; Young Educator Award; Young Researcher Award; Young Extension Man Award; the biennial Food Engineering Award; and the FIEI Engineering Award. In addition, the Past-Presidents Award (an attractive plaque) was given to: Lilliston Corporation; University of Georgia; National Safety Council; MasseyFerguson; and Ford Tractor Operations. In a surprise gesture, the PastPresidents gave Executive Vice-President J. L. Butt a plaque and a cash award in honor of his 20 years service as ASAE's chief administrative ofticer, about which he wrote "thank you for your patience, your support, your dedication to our profession, and especially for your friendship."

The speakers' table was then vacated and the members witnessed a multiprojector, multi-screen Bicentennial presentation on "America-and the American Farmer" which was presented by Allis-Chalmers and narrated by their Ginny Habermann, who was aided by Terry Meeuwsen, Miss America of 1973. The subject was Heritage-the meaning of the past-and it was extremely nostalgic and appealing to the hundreds of country boys in the audience; whether it was the exact truth did not matter-the heritage was 


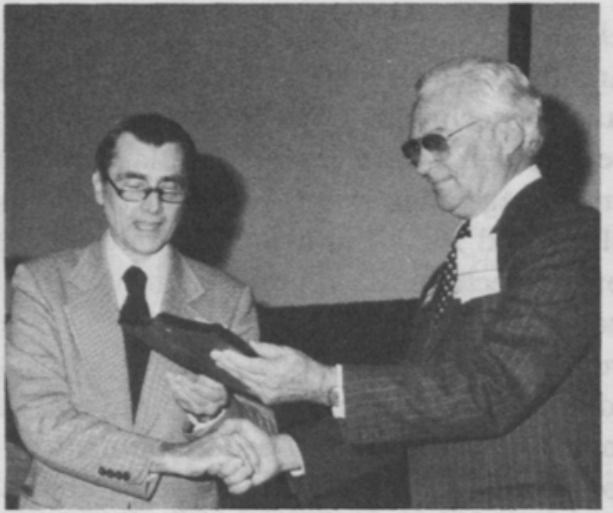

J. L. Butt, ASAE Executive Vice-President, was honored for 20 years of inspired leadership as ASAE's top full-time administrative officer. Presentation was made at 1976 ASAE Winter Meeting

shown as it ought to have been. On its conclusion the applause was thunderous and some members exited with moisture in their eyes and lumps in their throats. It seemed a good ending to the Bicentennial year because it touched some of the deep beliefs and inspiration of agricultural engineers: Their love of the land and its independent people; their belief in human progress; and their desire to see America as always a place of challenge and fulfillment for those who dream and labor to make dreams real.

The old question of agricultural machines and progress vs. people came up again during the Seventh Decade. Attention was drawn earlier to the address delivered at the Headquarters dedication in 1970 by President Brooks McCormick of International Harvester Co. One would have expected friendly platitudes from McCormick but he used the occasion to set forth a major indictment of the agricultural engineer, ASAE, and the farm equipment industry.

McCormick noted how different things might have been if the earlier members of ASAE (including members of his company) had foreseen the problems which their accomplishments were to create. There would have been no dust bowl, no battle over chemicals, and no urban problem. But that did not come to pass; therefore, the present and the future are to be considered. The challenge of the past-to provide abundance, or quantity-has been met completely. As he said:

"The new challenge is to provide a significant increase in the quality of life." 
Here followed a detailed analysis of agricultural engineering achievements, together with the undesirable side effects spawned by each. Of greater interest here is the statement regarding mechanization:

"We have made it possible for one man successfully to work an everexpanding acreage. But we are still contributing to the human exodus from the countryside, bankrupting scores of rural communities, creating difficult problems of human adjustment, expanding the urban ghetto and magnifying the dependence of citizens on public assistance."

Now, McCormick said, satisfaction with quantity must be enjoyed in an environment of quality. We now stand ready to define the problem, to understand the true facts:

"Out of this experience must come that wisdom which. apparentiy, we have lacked. It is simply that we cannot wall in human endeavor. We cannot treat agriculture, for example, as a world apart. We cannot solve its problems, increase its efficiency, multiply its output and assume that all other life will continue unaffected and undisturbed-or that "someone else" will mop up what may spill over into the outside world."

McCormick suggested that perhaps freedom to specialize allowed the U.S. economy to grow so fast, but "no one is ever really free until he assumes responsibility for all his own actions as they may affect society at large."

So, to tit the capstone on his argument, he ended by saying:

"If we are now to provide the quality of life as abundantly as we have provided its quantity, we will begin with the clear conviction that we cannot subdivide our responsibility to society, selecting these parts for which we will be accountable, but that it is of one cloth to be worn intact if our system and our society are to survive."

In those troubled times, when all forms of technology were under suspicion, (many of these attitudes originated with "Silent Spring" in 1962), ASAE members listened to voices like McCormick's, but could not seem to imagine or propose a socially responsive role. Most of the members visualized ASAE as primarily technical in purpose. Without denying the social changes wrought by their technology, they saw no way to change without disrupting or diminishing the technical thrust-or perhaps even dissolving ASAE as it had existed in principle since 1907. As professional engineers the Canons of Ethics enjoined the members to set the public welfare above other considerations, yet much of their activity had (as Brooks McCormick reminded them) worked in some areas to the detriment of the public welfare. Recognition of this surfaced back in the 1930 s with the thought that some optimum social limit may exist in the process of replacing men with machines. Therefore, the 
strong resurgence of the problem in the 1970s was a double dilemma for ASAE members: It caused concern for the public welfare since no optimum social limit had been devised, and it could not merely be turned over to CAST (or some similar group).

Concern for loss of manpower from agriculture was not typical of ASAE members; some, however, did express concern. David C. Lewis of the U.S. Corps of Engineers and Douglas W. Williams of the University of California at Davis published a paper on the topic in AGRICULTURAL ENGINEERING in 1970. They noted that agricultural engineering feasibility studies of mechanization usually omitted consideration of the fate of displaced workers. They argued that total mechanization of harvesting is not always the best solution. Partial mechanization could at times be done cheaper while training workers for better jobs. Incentives should be provided for growers to stabilize a local labor force along with reducing peak season labor demand. Lewis and Williams cautioned engineers skilled in systems analysis that the total system reached beyond immediate needs of the usual cost-benefit analysis; the people displaced from jobs by automation must be taken care of in some way. What role could engineers play? They believed that the agricultural engineers should "advocate a re-evaluation of the ultimate demise of U.S. rural life because the impact of ag engineering technology on the quality of rural life has immediate effects."

Thoughtful agricultural engineers of the 1970s looked at the decaying small towns, rotting farmsteads, and weed-choked schoolyards with something less than pride. Caught up in a complex system which yielded these consequences, they wanted to shift responsibility for them on to the system. As country boys it was difficult because they could remember that life was once worth living there; now they were obligated to boast about how few were left and what a good thing that was. But something old-fashioned deep within them wondered at the loss to American values.

Then there were the cities. W. J. Hennessy, dean of engineering at Columbia University, claimed in the 1970 AGRICULTURAL ENGINEERING that "The technological revolution on the farms has led directly to the gargantuan problems of our major cities, has led directly to the slums, the urban riots, and the need for massive changes in our society in order to accommodate the casualties of the revolution." The migration, he asserted, was growing each year, partly due to engineering skill in development of harvesting machines. About 23,000 farm youths were needed as replacements each year on commercial farms, but 225,000 farm boys reached age 19 annually. Less than one-sixth of hired farm workers were employed year round.

Hennessy suggested a massive nationwide program to encourage industry to locate in areas of surplus farm labor plus a program of retraining for 
surplus farm labor with readjustment pay until permanent employment could be secured. He thought this should slow down if not reverse the migration, while giving time for solving urban problems. He wrote: "This nation is being tested unlike it has been tested before. What are the implications for engineers?" He implied that engineers (presumably agricultural engineers) should care about the crisis of the cities as well as the loss of vitality from the countryside.

Walter Carleton and his USDA colleague Glen Vanden Berg replied to Dean Hennessy's thesis by noting that the peak migration from farms occurred in 1940-1945; although it still continued, its net amount will be smaller because of the reduced farm population. Also, they pointed out that most population increases occurred in smaller towns and cities, sized from 2500 to 50,000 . Mechanization was not the sole cause of migration but if it were, that would not justify discontinuance of mechanization. They recalled how crisis situations brought significant advances in mechanization: The Civil War and the reaper; World War I and the tractor; World War II and the cotton picker and the combine; and how the imminent loss of foreign migrant labor in California gave birth to the tomato harvester. These advances did not result from a frivolous desire to promote and capitalize upon mechanization.

Carleton and Vanden Berg presented a view of mechanization as it appeared to ASAE, the USDA, and the land-grant universities. Dean Hennessy, however, believed that "those who seize upon any signs of a lessening of the revolution on the farm are running the risk of greatly underestimating the incredible thrust of our technological genius." Replying to the agricultural engineers, he envisioned a future agricultural economy based on:

1. Rainfall on demand through a process of silver iodide cloud seeding.

2. Huge corporate farm holdings with the capital for completely computerized operations.

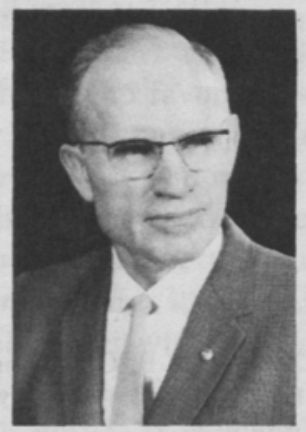

Walter M. Carleton took a stand against an implication that agricultural engineers were responsible for problems in the cities 
3. Livestock housed throughout life in automatically controlled environments.

4. Orbital satellites equipped with remote sensing instruments that will feed into computers vital information on soil characteristics, soil moisture, crop disease, vigor, and rate of maturation. Such advances would, in Hennessy's opinion, cause the "dislocation of people to go on unabated."

It is interesting to observe that the ASAE's "Horizons Extravaganza" of 1976 contained forecasts of agricultural technology that caused Dean Hennessy's to pale in comparison.

G. B. Gunlogson, ASAE member since 1913, recognized early that agricultural engineering could do something for rural areas besides remove people from them. He saw the country towns dry up and the cities overgrow, and he saw how inadequate were the governmental efforts to stem the tide of city poverty. Writing in 1970 , he stated:

"Neither technology nor industrial enterprise need threaten our future. The threat has been lack of public foresight, and it has been lack of initiative in a new area of engineering. The function of engineering is to make things work. The engineers' classic concept of efficiency must be revised to include many new factors. The challenge now is to make technology work more efficiently for the welfare of man."

Through his Countryside Development Foundation, Gunlogson sponsored agricultural engineering studies of rural industrial development. He believed that ASAE had an important part to play in helping industry move to the country and thereby bring new economic and social life to it. Problems involving water supply, waste management, housing, community structures, electrification, and many others could be involved. Also, integration of parttime farming with country industry could create demand for small machines. The whole process called for agricultural engineering.

In 1975 Gunlogson established the G. B. Gunlogson Countryside Engineering Award. The award, a plaque, was to be given annually to the

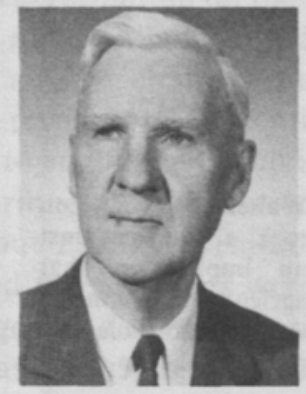

In 1975 G. B. Gunlogson established the G. B. Gunlogson Countryside Engineering Award 
ASAE member whose engineering contributions resulted in significant progress in rural development. The first winner of the award was Junius L. Kendrick of the Alabama Power Co. Gunlogson and Hennessy both advocated the same remedy for the side effects of agricultural technology - attraction of industry to the countryside. The difference between them was that Gunlogson himself tried to do something about it while Hennessy apparently expected the government to take care of it.

Indirectly, the USDA had been working to attract industry to the countryside for a number of years through its rural development programs. Funding of principal USDA rural development programs in 1972 was $\$ 3.5$ million, more than six times that of fiscal 1961 and twice that of fiscal 1970. Farmers Home housing assistance, with emphasis on low and moderate income families, tripled between 1969 and 1971 . Funding for community sewer and water facilities in 1972 was eight times greater than in 1970. SCS flood prevention and watershed work was expanded during that time. The Rural Electrification Administration-financed systems provided the largest threeyear growth in 1969-1972 since the 1950s. Extension Service community development activities in 1972 attracted $\$ 13.7$ million, an increase of $\$ 4.7$ million over 1969. These activities were laying the foundation for a revitalized country population. With inspired local leadership and commitment from the private sector, Americans in rural areas might hope for equal opportunity in health care, education, housing, and public services as well as employment. But the government could not possibly bear the full burden.

Nor could ASAE. The question for ASAE was whether any portion of the mechanization vs. people burden ought to be assumed. In 1972 a Committee for Social Action was founded which addressed controversial issues at the meetings. At a Winter Meeting session on manpower implications of mechanization, several members of the audience heatedly asserted that ASAE should not discuss such matters and that ASAE had no responsibility for workers displaced by agricultural machines.

Attitudes toward mechanization vs. people were also polarized back in the 1930s when ASAE's leaders took positions for and against some kind of social concern. Those who favored social concern offered no concrete proposals for action. Those opposed believed ASAE's technical posture would suffer if socially responsive action was adopted. H. B. Walker said in 1936: ". . . we invite disaster to good professional service when we try to design social justice into production machinery." When is a machine "for the benefit of man" and when is it not? Also, what is social justice? How is it to be defined and allocated with respect to machines and people in a free economy?

Roger E. Garrett and T. H. Burkhardt of U.C.-Davis pondered these vex- 
ing questions in the 1974 AGRICULTURAL ENGINEERING in an article, "The Engineer's Responsibility in Mechanizing Agriculture." They believed that opposition to mechanization of field operations was "becoming more vocal." They noted that mechanization was increasing, and that cities were filled with "the unemployed who once worked on farms." Those opposed to mechanization claimed that agricultural engineers were not aware of workers' problems. Those favoring mechanization thought that displaced people were no concern of agricultural engineers. The authors stated that "Perhaps these (farm) workers do have problems ag engineers are not aware of."

To feed and clothe the world's people, wrote Garrett and Burkhardt, is the responsibility of the agricultural engineer and one he must meet. Even if he may not fully appreciate the problems of farmworkers, he moves ahead with mechanization when labor is unavailable, too costly, or unskilled. If skilled labor is available, "the economics must overwhelmingly favor a mechanical production system before it will be adopted."

The effect of not mechanizing may be a labor shortage which leads to crop and yield losses or to a shift to crops with lower labor requirements. The workers involved would be "just as unemployed as if they had been displaced by a mechanical harvester." Also, loss of crops leads to higher prices, thus lowering demand and eliminating jobs. In a more humane sense, not mechanizing means perpetuation of menial, arduous, stupefying jobs, a system unworthy of modern times in the U.S.

Thus, according to Garrett and Burkhardt, the "Agricultural Engineer faces a dilemma." The natural course of engineering is to increase human productivity through mechanical systems, but the process may relieve farmworkers of their jobs. If the engineer does not develop the mechanical systems, the farmworker will either lose his job as the cost of his produce exceeds its market value or he will continue working under conditions of virtual slavery.

Social justice might have been better served if agricultural engineers had had the extraordinary foresight to anticipate adverse effects. But they had no more foresight than any other group with comparable intelligence and education. Indeed, had they possessed the foresight, they would have probably been powerless to aid the thousands who were adversely affected by the building of a more powerful agriculture. However, this does not excuse a tendency to regard mechanization as an unquestioned blessing; mechanization has done more social good than harm-but it has not been totally "for the beñefit of man."

A minor counter-revolution has possibly occurred in connection with the countryside and rural area development movement which calls for machines 
adapted to small farms. ASAE has not responded to this potentially beneficial movement in any truly significant way. ASAE's view of agriculture's future was expressed in the 1976 "Horizons Extravaganza" which painted 21 st Century farming as an empty landscape peopled by monstrous mechanisms almost as intelligent as their creators and requiring little human guidance to accomplish enormous tasks. It was 1970s agriculture pushed to its logical conclusion: Nearly total elimination of the human factor. There seemed to be no question but that this "Buck Rogers" scenario was agriculture's future according to ASAE, whether it made economic or social sense was apparently not considered. ASAE's Bicentennial celebration consisted to some extent in predicting that agriculture held no future for people.

Melvin Kranzberg, distinguished historian of technology, addressed the Winter Meeting of 1971. He noted how "agricultural engineers have put most of our farmers out of business," then said:

"Yet ag engineers are not sinister monsters aiming to force the small farmer to the wall. Ag engineers were merely doing their thing. Technological trends led them to follow paths which have increased the cost advantages of the larger farmers with capital and managerial expertise. But it is conceivable to think of alternate lines of technological development which might have been pursued to make the small farm again economically viable."

Kranzberg admitted that the work of agricultural engineers was viewed as "beneficial or harmful to mankind" depending on perspective. They work toward solution of narrow technical problems and disclaim responsibility for consequences of their activities. Yet their work is sometimes misused-who is to blame?

"Perhaps the blame rests not on individual men or groups of men but on the human institutions we have developed for control and use of our technology. One characteristic of institutions is that they are created and run by people. Consequently they tend to serve the interest of their owners or managers rather than that of their constituency."

Modern technology, Kranzberg continued, is so pervasive that all parts of the population should have access to it and a voice in its control. Engineers must redefine the concept of efficiency to include social costs and benefits, or be held accountable by the public for social consequences of their actions. Decisions regarding applications of science and technology must be made democratically rather than by special interest groups, a process involving Technology Assessment.

This process, in Kranzberg's view, is an idea whose time has come;

"We know now that technological developments have a broad and 
accelerating social impact. We know also that we have technological capabilities to perform different tasks in many different ways, so we need not settle for a technique which might have possible harmful longrange effects. We have the knowledge, wealth, and opportunity to apply technology for the benefit of mankind. * What really counts is our willingness to apply that knowledge in practice. The decision is up to each of us-and to all of us-as to whether we make human or inhuman use of our technology."

These are brave words. They were applauded and then forgotten by the audience that day in the Sherman House, but they offer much hope to ASAE as it ponders the central dilemma of the American late 20th century: How to maintain technological momentum and economic growth with minimal environmental damage, governmental regulation, and social cost.

Many Americans have learned to distrust business and technology, but ASAE (indeed, engineering itself) is dedicated to these aspects of human endeavor; therefore, ASAE should devote more time to learning why they are losing respect. From this may emerge a new philosophy for guidance in the future, based not on defensive reaction but on understanding of how people feel about their country.

As a corollary to the above: Some ASAE members have long advocated farming large holdings with big machines. Yet many who do this cannot get a decent monetary return. The reasons for this are extremely complex, but it may be time for ASAE to stimulate significant thinking about alternative systems of food production.

Other facets of the dilemma include the unacceptable loss of soil from American crop lands and the question of chemicals. ASAE's posture is basically complacent on these issues and the time has long since arrived for a more vigorous policy in terms of public benefits. In view of the growing suspicion that professions are not as public-spirited as they claim, ASAE ought to lead in the critical debate of such issues and thus give evidence of concern for public welfare. Older members, at least, should remember the "Golden Years" of 1941-1962 when engineering could do no wrong, and realize that such times will not likely return except in case of world war.

So the Seventh Decade of ASAE's existence brought new dimensions to the practice of agricultural engineering. The nation seemed to falter on the question of what price to pay for continued economic growth and the consumption of finite resources. "Engineering for the benefit of man" became loaded with humanistic puzzles and political constraints. No credible leadership emerged in government or in technology, which could inspire the faith

*Italics supplied by R.E.S. 
necessary to move the nation in a direction where new greatness might be achieved. All sectors of society wanted what they wanted without sacrifice.

In the course of 70 years ASAE has grown from a dream to a wellorganized, responsible group of 8000 with many notable accomplishments on the way. Many agonizing problems were solved; many benefits were brought to the consuming public. Today's problems may seem worse in some respects, but every generation has to face its own issues. ASAE has always applied technology in terms of contemporary constraints; there is every prospect that it will continue, even though the new constraints are indeed multifarious and baffling. This in fact makes the challenge-making human use of its technology - yet more profound and exciting.

As J. B. Davidson said in 1907, ". . . let us devote ourselves . . . to benefit the world to the greatest degree."

\section{B \\ Technical}

In 1967 International Harvester introduced a tractor with hydrostatic transmission. The engine operated a hydraulic pump to produce pressurized oil flow which was used to drive the wheels. By adjusting the pump output, the operator could regulate ground speed without changing engine speed. Thus machines driven by the PTO could operate independently of ground speed. The new tractor transmission exemplified the developing technology of fluid power which had grown to importance over the past ten years. Improvements in controls, fluids, filters, conductors, and other components led the way. Intense interest was growing in the new field of fluidics, where large fluid flows are controlled by small fluid flows. F. W. Howard, of Caterpillar Tractor Co., researched a fluidic control system for hydrostatic tractor transmissions while a student at Kansas State University. Such a system potentially could maintain rated load of the tractor engine automatically, thus improving efficiency of the hydrostatic transmission. Fluidics control devices were also forecast for automation of irrigation, waste water handling, and other water management systems.

The ASAE Tractor Committee PM-47 sponsored a conference on "Field Modifications of Tractors" in December 1967, preceding the Detroit Winter Meeting. The conference was intended to assist extension personnel in answering inquiries on tractor life resulting from various power modifications. The general conference chairman was J. T. Kulhavy of J. I. Case Co. The Conference Proceedings formed a valuable reference for the attendees. They discussed how power increases could be obtained from diesel engines by 
increasing the fuel pump delivery rate or by increasing the fuel pump delivery rate in combination with increased air supply by adding a turbocharger. These changes are accompanied by problems related to cooling, parts failure, and lubricant contamination. The increased power must result in higher speed operation if the tractor weight remains unchanged, which causes transmission problems. Another issue concerned the proper usage of dynamometers commonly used by tractor dealers to measure performance. Discussions were presented of injecting LP gas into the intake air of a diesel engine to utilize some of the excess air available. This process gives additional power but also higher temperatures and possibly increased exhaust smoke density. Nine technical papers were presented.

Former ASAE staff member Page Bellinger, a product safety engineer with Deere \& Co., entered a plea for the human side of machine design in the 1969 AGRICULTURAL ENGINEERING. Farmers can do more work with modern machines but poor man-machine compatibility leads to undue mental demand and risk of error. Proper application of human factors principles will create safer, more comfortable, and more efficient machines. Engineers, according to Bellinger, often design equipment poorly because they can't visualize how people will use the equipment in ways unforeseen by them.

Human factors principles and their application represent an aspect of bioengineering. The tlirtation of agricultural engineering with bioengineering in previous years has been recounted. It is perhaps true that many agricultural engineers, although deeply involved with designing systems to interact with living entities, would not wish to be defined as bioengineers. Yet the usage of biological principles and parameters is so widespread and significant, and occupies so much research time, that good agricultural engineering design probably would suffer without that dimension. M. W. Forth and W. M. Roll of Deere \& Company surveyed 18 chief engineers of major farm machinery companies regarding the amount of bioengineering training needed by the farm equipment industry. They published the survey results in 1969.

Forth and Roll found that most engineers ( 80 percent) were hired to do machine design work. College studies considered most important were drafting, chemistry, metallurgy, stress analysis, and computers. Also desirable was training in human engineering factors, safety, physical properties of agricultural products, systems analysis, and design of agricultural production systems. The latter group, especially human factors, has bioengineering implications. However, the respondents assigned little value to study of botany, animal science, and soil fertility as background for bioengineering because of the descriptive way they were taught. A course in quantitative biology would be a much better foundation for bioengineering involvement. 
The authors concluded that bioengineering knowledge was of some value to the design engineer in planning specifications. Such knowledge was of more value to the product planner in relating machine requirements in production systems. But engineers in research had the greatest need for bioengineering knowledge and data; however, these were the smallest number in the industry, only 2.8 percent. Of course, those in research would likely obtain further knowledge through an advanced degree. The machine designers could not obtain adequate bioengineering training as undergraduates without sacrificing essential design courses. Thus they would be equipped only to recognize and discuss bioengineering problems and to seek specialist assistance when necessary. Evidently the Forth and Roll respondents viewed the bioengineering dimension as of minor significance in the farm equipment industry.

In 1971 the Bioengineering Committee T-4 published results of an attempt to learn the attitudes of ASAE members toward significance of bioengineering in agricultural engineering. The Committee obtained its data by surveying a broad spectrum of ASAE membership. The results suggested that: (1) The least amount of bioengineering work was centered in the P\&M Division; (2) agricultural engineering was not adequately defined as bioengineering; (3) ASAE's structure was adequate to meet the bioengineering interests of the members; and (4) ASAE ought to work diligently toward a more complete development of its bioengineering component.

This 1971 survey confirmed the marginal position of bioengineering in ASAE and in agricultural engineering. It helped to explain the lukewarm feeling for bioengineering revealed by the Forth and Roll machine design respondents. The positive note of item (4) was probably just a vote for doing something as opposed to not doing something. However, the Bioengineering Committee continued its efforts to identify and nurture the bioengineering component. N. R. Scott of Cornell University summarized a group of papers on "Bioengineering for the $\mathrm{Ag}$ Engineer," which was published in AGRICULTURAL ENGINEERING in 1976. The papers were presented during a panel discussion at the 1975 Annual Meeting on the question: "Is There a Need for Bioengineering Instruction in Agricultural Engineering Programs?" sponsored by the Committee.

In his introduction, Scott wrote ". . . it is clear that ASAE, as probably the first bioengineering society, must spotlight the tremendous opportunities that exist in bioengineering for agricultural engineers." These opportunities, stated or implied, apparently consisted in creating a better kind of agricultural engineering practice and in defining a unique aspect for agricultural engineering which would set it apart from other disciplines and attract young people. 
The papers emphasized these points: (1) More data on plants, animals, soils, biomaterials, environmental relationships, etc., were needed in formats useful for instruction; (2) the farm equipment industry still had little use for bioengineering instruction; (3) the federal government would employ more bioengineers in the future; (4) some students wanted a strong bioengineering emphasis in the curriculum; (5) many agricultural engineering departments were teaching material defined as bioengineering, such as physical properties of biological materials and production environment; and (6) courses in animal and crop physiology for engineers were called bioengineering courses.

This effort by the Bioengineering Committee was valuable in keeping ASAE members and others aware of a significant technical issue underlying agricultural engineering education and practice: The design subject matter was (and is) biological. Therefore, reasonable knowledge of the subject matter (soils, plants, animals) ought to promote better design. Where this knowledge is scanty, research should fill the gap. But the tools of design-such as mathematics, statics and dynamics, mechanics of materials, thermodynamics, etc. - are not unique but universal and are so extensive and essential that their mastery leaves little time for "bioengineering" studies per se to the undergraduate. Thus if bioengineering is to be studied it must be done in appropriate agricultural engineering design courses. Uniqueness, however, could be demonstrated by applying the universal tools of design to a unique subject matter. If this principle is valid then the bioengineering component of agricultural engineering might be defined as "engineering design for agricultural and food production where the design parameters and constraints are biological as well as economical." Scott and A. T. Johnson (University of Maryland) have proposed the term "agri-bioengineering" to identify this component, but have not emphasized design in their definitions, which may have caused some members to downgrade the concept.

The year 1968 saw the 1000th official test at the University of Nebraska Tractor Testing Lab, and 1970 was the 50th year of its operations. The story of ASAE's influence on the establishment of the Lab in 1920, and on the mode of testing, was outlined in an earlier chapter.

The Nebraska Test Number One was made on a John Deere Waterloo Boy (probably designed without benefit of human factors engineering) which can be seen today in the Lab Museum. The 1000th tractor tested was a Ford 5000 Diesel.

Carlton Zink was engineer-in-charge at the Lab from 1930 to 1942. Lester F. Larsen took over from Zink and was engineer-in-charge at the 50th an- 


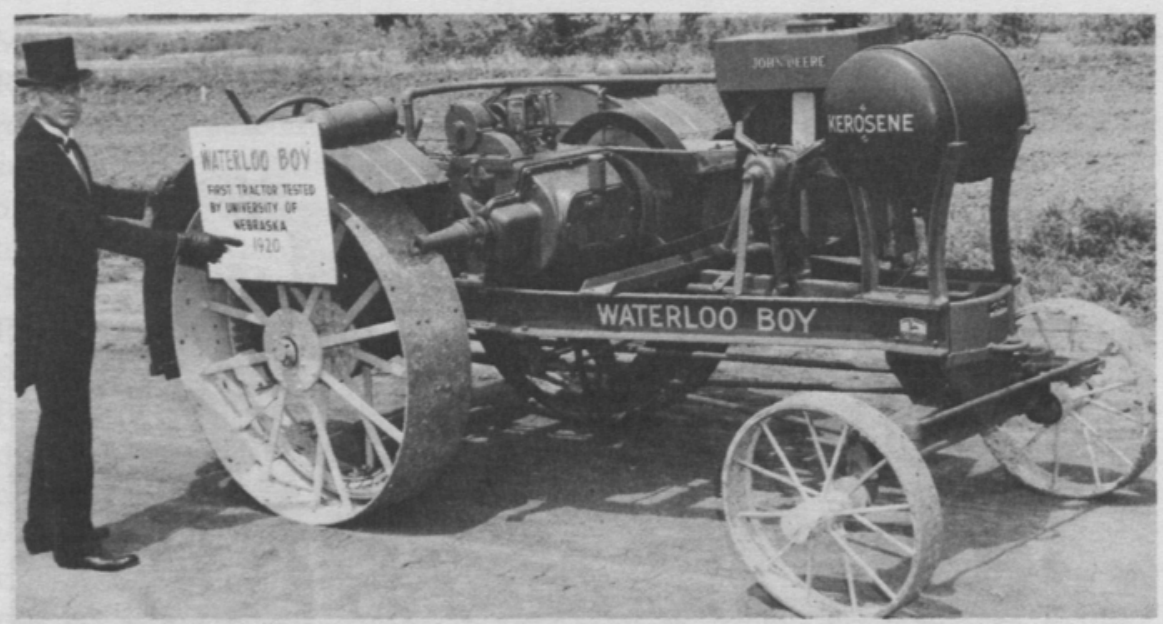

In 1920: John Deere's Waterloo Boy was the first tractor to complete the testing under Nebraska's new Test Law. In 1970, during a 50-year observance, Chauncey W. Smith, long-time Tractor Test Board member shows off that first tractor

niversary. George Steinbruegge was head of the Test Board and William Splinter was head of the Agricultural Engineering Department at that time. Previous department heads were Elmer E. Brackett and Lloyd W. Hurlbut, both ASAE past-presidents, who did much to develop the Testing Lab.

The history of tractor technological change and improvement is reflected in the Lab Test records. Many milestones were recorded in the September 1970 AGRICULTURAL ENGINEERING. Some of these are worth recording here.

YEAR

1922 First crawler tractor

1922 Articulated four-wheel drive with hydraulic power steering

1925 Successful all-purpose row crop tractor

1930 Imported tractor (from Ireland)

1934 Pneumatic tires on a tractor

1935 Diesel engine in wheel-type tractor

1940 Three-point hitch and hydraulic draft control
MAKE \& MODEL

Cletrac "W" 12-10

Rogers Four Wheel Drive

McCormick-Deering

"Farmall"

Fordson " $F$ "

Allis-Chalmers "WC"

McCormick-Deering

"WD-40"

Ford-Ferguson System 9N 


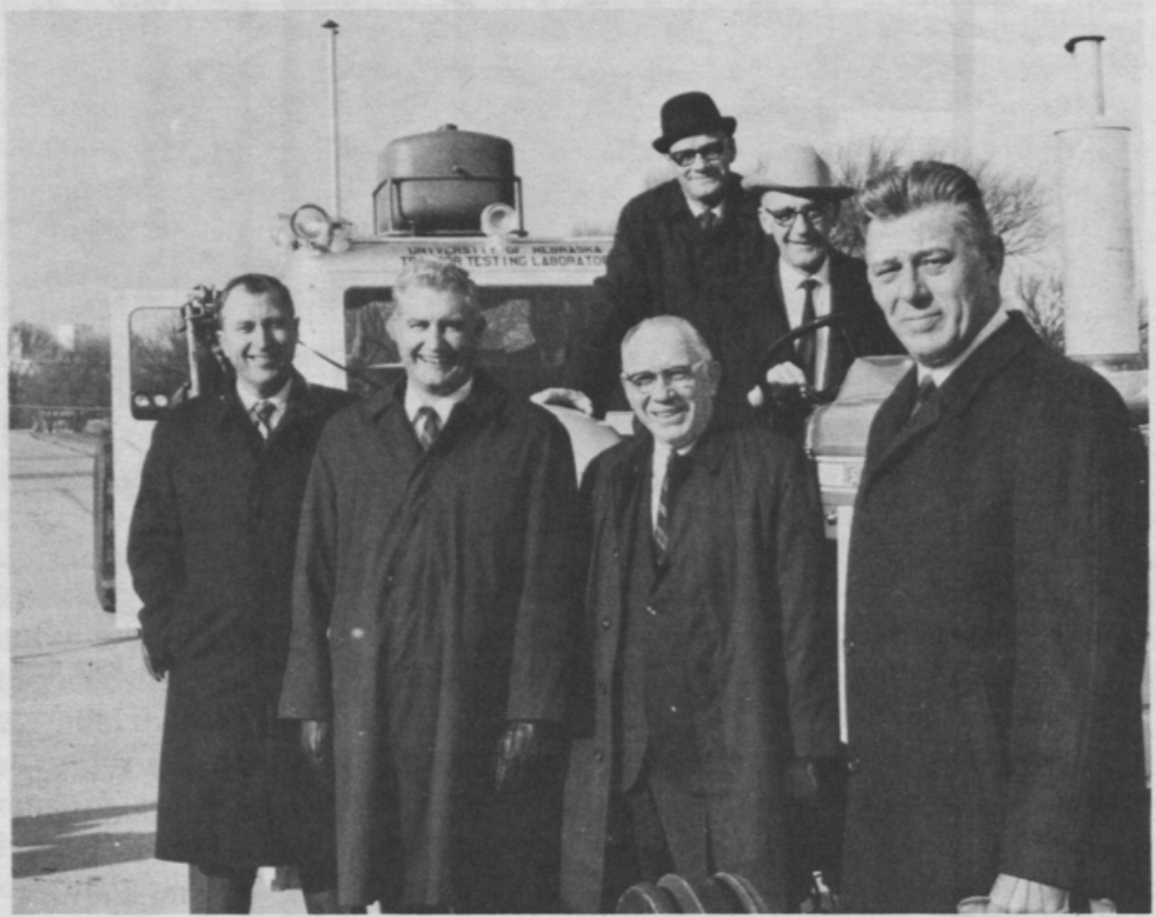

The 1000th tractor tested by the Nebraska Tractor Test Board was a Ford 5000 Diesel in 1969. At the wheel is Elmer Schlaphoff of the Nebraska Department of Agriculture. ASAE members left to right are: W. E. Splinter, head, Agricultural Engineering Department; Howard Wittmuss, agricultural engineer: Carlton Zink, former engineer at the test lab and George Steinbruegge, who heads the Test Board. Delbert Lane, extension agricultural engineer, is on tractor behind Schlaphoff

1947 Independent PTO

1956 Record fuel economy (10 hr run)

1962 Largest wheel tractor tested (crab steering)

1966 Roll guard protection for operator

1970 Official sound testing
Cockshutt 30 Gasoline

John Deere 520 LPG

John Deere 720 Diesel

John Deere 620 Gas

International 4300

John Deere 4020 S.R. LPG Case 970 Diesel

The tractor continued to be the prime mover of agriculture and therefore the subject of much technical and engineering attention. Some will remember J. B. Davidson's "manless plow" of 1924. Since then the idea of automating the tractor has emerged several times. C. B. Richey of Ford 
Motor Company published a paper on automatic tractor steering in 1959. Richey's system was based on a set of feelers which sensed a crop row or furrow wall and caused microswitches to guide the tractor by varying the current supplied to an electric motor connected to the steering mechanism. The operator watched events and made the turns at the ends, centering the tractor on the row after the turn. L. A. Liljedahl designed a hydraulic control for tractor steering at the Minnesota Agricultural Experiment Station. J. D. Pichon (University of Nebraska) published a paper in 1961 on a radio-control system which steered, shifted gears, and operated the implement-lift system. Pichon commented that "The primary obstacle to field operations with driverless tractors is the lack of a reliable automatic method for providing control stimuli." Later, in 1965, Pichon and G. W. Steinbruegge investigated the idea that the magnetic field emitted by a buried, currentcarrying wire might be used for guidance of unmanned self-propelled machines. Their studies with conductors buried 24 inches in silty clay loam soil showed that the propagated magnetic fields would be suitable for automatic guidance systems.

M. A. Grovum and G. C. Zoerb at the University of Saskatchewan analyzed the state of the art in 1969. Rejecting other guidance systems they developed a design for a marker-follower subsystem which was successfully tested. The full system consisted of a buried leader cable to turn the tractor at the headlands, a logic and memory device to operate the cycle, and the devices included in the marker-follower subsystem.

L. N. Shukla, C. E. Goering, and C. L. Day at the University of Missouri presented an analysis of the effect of tractor parameters on automatic steering in 1969. Parameters modeled were wheel base, wheel tread, type of steering, sensor length, type of drive travel speed, and type of path. The model was verified by means of an experimental vehicle. Results indicated (among others) that for minimum tracking error: (1) Minimum wheel base was best; (2) front and rear tread width should be equal; and (3) for stable operation, at least one sensor had to be near or ahead of the front axle.

Meanwhile, a non-member, Karl Rushing at Mississippi Delta Junior College, presented a paper on the topic at the 1968 Winter Meeting which was summarized in the 1971 AGRICULTURAL ENGINEERING. Rushing's system was based on buried wires excited by an electric generator. Such wires provided steering guidance as well as headland turning guidance. Appropriate sensors, linkages, and servos operated the steering, clutch, throttle, and implement controls of a 4020 John Deere. Sequential control operated the tractor and its attachments through the turns. It was estimated that the cost of tield preparation (\$15 per acre) would be offset by reduced costs of chemicals and by crop savings due to more accurate steering. Equip- 
ment cost, about $\$ 3000$ per tractor, would be offset by reduced labor cost. However, savings would be greatest when several automated tractors are operated by one man; Rushing believed that one man could supervise at least five, either from a control point or riding one of the tractors.

Writing in 1972, C. E. Goering, M. M. Blaine, and J. C. Frisby (University of Missouri) concluded that the leader cable system was most promising. With a ten-year cable life, the breakeven acreage for automation was estimated to be 355 on a multicrop farm, and profitable for farms greater than 770 acres. Profitable crops were considered to be corn, soybeans, and sorghum, but not small grain, silage, or hay.

After that, the ASAE indexes contain no further reference to papers on automation of tractor operations. Although the basic technology was fairly well established during the late 1960s and early 1970s, it was not followed by commercial development and marketing. High installation cost, possible maintenance problems, and difficulties in adapting to land use and cropping patterns may have been the cause.

In 1971 a group of prominent ASAE machinery experts speculated on the nature of power for the future of agriculture. USDA's Walter Carleton believed that the steam engine would be resurrected, but R. R. Poynor of International and J. B. Liljedahl of Purdue disagreed. Use of buried cable was discussed, but no great optimism was expressed for widespread adoption. Liljedahl thought that more automatic control devices would monitor tractor performance, however. The internal combustion engine, both gas and diesel, and the electric motor, will provide agricultural power in the foreseeable future. The turbine and the rotary engine will probably play a role some day, but the internal combustion engine will be the principal source of mobile power for a long time.

In fact, the diesel engine will be the major tractor power plant for a long time, wrote R. M. Doll of Massey-Ferguson in the 1974 AGRICULTURAL ENGINEERING. Design improvements were allowing diesels to accept fuels with lower cetane values and to use a wide range of burner fuels. Smoke, noise, and odor pollution were being reduced. An English company, Perkins Engines Ltd., was in the forefront of developing a combustion chamber which would reduce noise level by half and meet stringent gaseous emission standards. The new combustion chamber, called the Perkins Squish Lip, produced those advantages at no significant power or fuel consumption penalties. In addition, the Squish Lip did not require excessive and complex fuel injection equipment; it had low sensitivity to fuel quality; and it permitted lighter engine structure.

Roy E. Young of Auburn University and R. L. Schafer of the National Tillage Machinery Laboratory called attention in a 1977 report to the advan- 
tages of automating the tractor's tractive efficiency. They argued that the human operator is too slow in responding to traction status, so they developed some alternatives based on automatic control. First, as reference input, they considered a soil characteristic sensor, or measurement of tire deflection or sinkage. Drawbar pull or travel reduction could also be used as reference. Final control could be had through modification of the tire-soil contact area or wheel sinkage; slip could be controlled by changing weight on the drive wheels. A more innovative device considered was the Lockheed major-minor wheels concept. The controller component could be made of available microcomputer elements which "could easily implement any traction control algorithms conceived by man." The result was called "Autotraction."

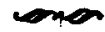

The decade witnessed an explosion of computer usage; although the first usage was reported in 1958, the full power and convenience of computers were probably not realized in agricultural engineering until the seventh decade. Also, during that decade the hand calculator was introduced (in the early 1970s); this device quickly reduced the sliderule to museum status. As to computer usage, only a few examples can be mentioned.

Harlan W. Van Gerpen (Deere \& Co.), who published the first computer paper in TRANSACTIONS of the ASAE, published an article in 1968 in AGRICULTURAL ENGINEERING on "Using Digital Computers in Farm Equipment Design." Van Gerpen thought engineers were reluctant to take full advantage of these relatively new tools. He analyzed the question of whether or not to use the computer, with the aid of a flow diagram. Use of a computer program, or writing one if necessary, made possible accuracy and cost savings in equipment design not before available. Moreover, the computer permits rapid trials of design variations and optimum combination of parameters.

Computer applications developed by the members began to appear in a special AGRICULTURAL ENGINEERING feature called "Computers in AE." In 1970, R. C. Strohman, L. F. Huggins, and C. G. Haugh of Purdue University showed how to connect a gas chromatograph to an analog computer. The results of gas chromatography were usually recorded on a strip chart, inconvenient for computer processing. The authors worked out a method of automatic recording of peak heights or integrals. A gas chromatograph was connected to a remote analog-hybrid computer which provided signal conditioning and automatic analysis capacity. Voltages corresponding to the integral and the peak height associated with each gas com- 
Engineering Systems for Cotton Production

Regional Research Project S-69

\section{।}

\section{TECHNICAL COMMITTEE}

W. T. Dumas Auburn University

Auburn, Ala.

H. N. Stapleton University of Arizona Tucson, Ariz.

E. J. Matthews University of Arkansas

Fayetteville, Ark.

D, G. Batchelder Oklahoma State University Stillwater, Okla.

North Carolina State University

Raleigh. N. C

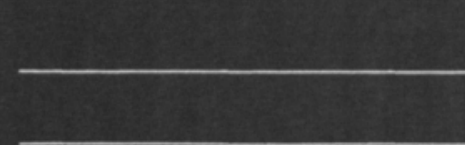

Experiment Station Director Representative J. H. Anderson, Miss.

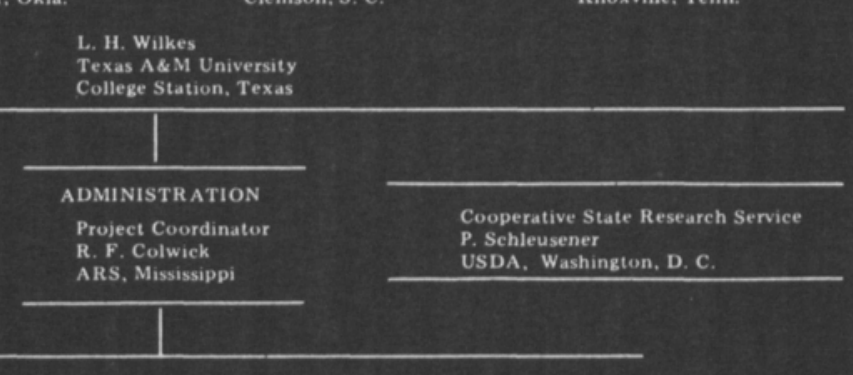

COMMITTEE ASSOCIATES

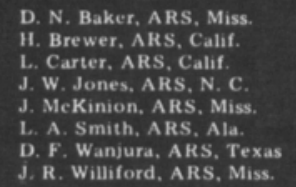

D. N, Baker, ARS, Miss

i. Brewer, Aks, Calif.

J. W. Jones, ARS, N. C.

. MieKinion, ARs, Miss.

D. F. Wanjura, AkS. Texas

J. R. Williford, ARS, Miss.

\section{R. W. Whitney Louisiana State University Baton Rouge, La.}

\begin{abstract}
J. Witz, ARS, Texas
O. B. Wooten, ARS, Miss.

F. Fulgham, ARS, Miss.

K. Luekett, ARS, Miss.

E. Hudspeth, ARS, Texas

J. Friesen, ARS, Texas

A. Brashears, ARS, Texas

G. Barker, ARS, Miss.
\end{abstract}

E. B. Williamson

ARS, USDA

Mississippi State University

Mississippi State, Miss.

J. A. Mullins

(itins

nessee

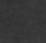

R. Parrish, Ark.

A group of agricultural engineers who had been researching cotton mechanization developed a Regional Project S-69 to control crop prediction by computer simulation. Each state in this regional project had one official representative to the Technical Committee 
ponent were converted to digital and sent to a teletype adjacent to the chromatograph.

Also in 1970 M. Y. Hamdy and R. B. Curry, of Ohio State University, offered a discussion of "Simulating Flood Routing Through a Reservoir." Reservoir design is complicated by non-analytic inflow and storage, and by non-linear discharge; also, if the spillway outlet is submerged, the hydraulic head requires another non-analytic and non-linear model. The analog computer is convenient for this type problem; variations in parameters are easily made and results visualized. With the spillway outlet not submerged, an algorithm was constructed with discharge fed back to the inflow such that their difference formed the time derivative of the reservoir storage. The inflow hydrograph, initial storage, and spillway physical characteristics were assumed. With appropriate time scaling, the simulation was run with results displayed on the X-Y plotter. Effect of changes in the spillway pipe size, elevation, or the storage capacity could be easily investigated.

K. C. Das and L. F. Huggins of Purdue University reported in 1971 a laboratory device for determining overland flow. A rainfall generator deposited raindrops on a catchment equipped to measure mass runoff,

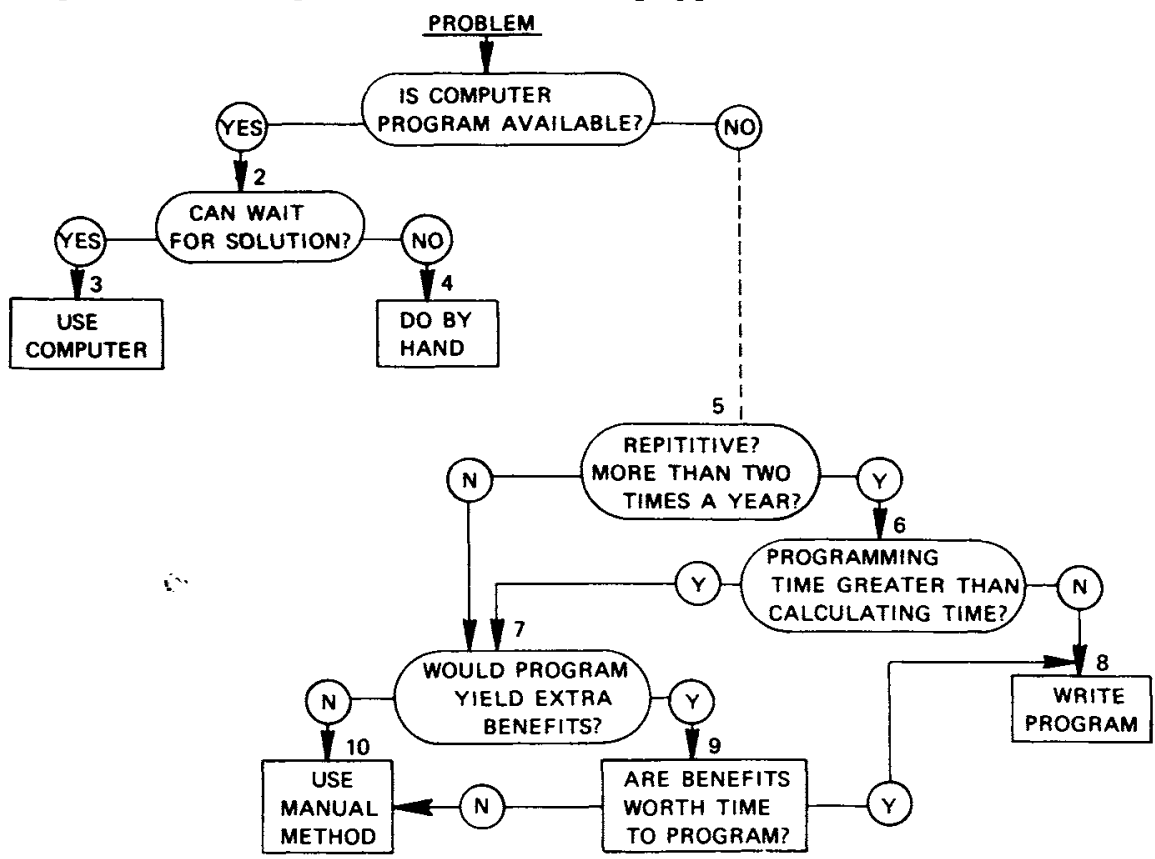

H. W. Van Gerpen (Deere \& Co.) used this tlow diagram in his article "Using Digital Computers in Farm Equipment Design" in the July 1968 issue of AGRICULTURAL ENGINEERING 
runoff rate, and forces on the bed. An analog/hybrid computer summed the output data and recorded it on tape.

An extensive and important "giant step" in control of crop prediction was announced in 1973 by Henry D. Bowen of North Carolina State University, Rex F. Colwick of the USDA, and David G. Batchelder of Oklahoma State University. During the summer a cotton crop was produced from planting through harvest by computer simulation. This resulted from many years of cooperative effort by a large group, Regional Research Project S-69. The pioneering work was initiated by H. N. Stapleton at the University of Arizona in the 1960s.

Crop simulation offers three benefits: (1) Research guidance; (2) the ability to test interactions of weather and cultural practices on the computer, thus reducing costs of applied research; and (3) a method of optimizing crop management systems.

The cotton simulation developed from federal-state cooperation. Improvements in cultural practices and mechanical equipment had been devised over a period of time, but these were not optimized under specific conditions. There was no quantitative description of the cotton plant as influenced by daily interaction with environment, until Stapleton and others showed the way. Two plant models emerged: one for the irrigated west, and one for the humid south.

The simulation sequence feeding the plant model consisted, in turn, of a soil moisture profile model and an emergence model. The production model was completed by a harvest-ginning model which was provided with yield values and opening curves by the cotton plant model. At the time of the report, submodels were under development to simulate root development, boll weevil and bollworm attack, nematode and disease attack, weeds, drainage, plant populations, and soil-machine interactions.

Verification had been extended to each component of the production model. The soil moisture profile model was verified only for one soil type at one location, primarily for lack of necessary soil parameters; these were to be available in 1974 for 20 soils covering about 80 percent of U.S. côtton land. The emergence model was tested in five states for two or more years; it was found satisfactory to excellent in years where the temperature increases as the season advances. The plant models were verified at several locations; under usual conditions there was excellent correspondence between observed and simulated plant development and yield. A single-field model was tested for two years at one location with good results.

The value of crop production by computer was emphasized with respect to research and extension personnel, teachers, equipment manufacturers, and producers. The computer cost to grow a complete crop of cotton using the 
computer simulation from planting through the harvested bale was $\$ 3$ when the program was stored on a disk.

J. R. Lambert of Clemson University called attention in 1974 to CSMP, Continuous System Modeling Program. He pointed out that many engineering systems are continuous functions of time. Simulation of these systems by analog computer had been customary with relatively simple systems; however, more complex systems and the need for more accuracy and flexibility led to the use of digital computers.

CSMP utilized a problem-oriented language. Unlike FORTRAN, its statements could be written according to computational logic with centralized numerical integration at the end of each time interval. All analog computer functions were available. Input and output were simplified by means of user-oriented output control statements providing data output at selected time increments. Output included tabular printing, print-plotting, or analog plotting on either a video screen or an X-Y plotter.

Another problem-oriented language of interest to agricultural engineers was the Electronic Circuit Analysis Program (ECAP). Developed initially for computer-aided design and analysis of electronic circuits, it could be applied also to analysis and design of other systems possessing electrical network analogs. B. K. Huang of N.C. State University illustrated in the 1974 AGRICULTURAL ENGINEERING how ECAP was used to determine frequency response of a trailer dynamic system with two degrees of freedom.

In contrast to CSMP and ECAP, GPSS was a language in which fixed time intervals were unsuitable. Stochastic, rather than deterministic models, were best handled by GPSS, which was developed for scheduling and queuing problems. These are frequently encountered in agricultural systems. A time and motion study was necessary to provide a distribution function basis for the input requirements. D. R. Price of Cornell University described in 1974 how GPSS was used to simulate flow of cows through a milking parlor.

Computer usage in agricultural engineering continued its rapid growth in application throughout the decade. TRANSACTIONS papers with computer applications multiplied. Undergraduates were required to learn programming, while graduate students planned research around the computer. Much was being done that was virtually impossible before. This kind of progress was taking place in all sectors of American life; ASAE and agricultural engineering, always conservative, may have boarded the computer bandwagon later than some, but once aboard they took full advantage of the new technology.

To round out this review, a few more examples of adaptation to agricultural engineering problems can be mentioned. These are from AGRICULTURAL ENGINEERING. 
Simulation of tractor side overturn motion, to teach operators defensive countermeasures. Denny C. Davis, Cornell University, 1973.

TELPLAN, a telephone-access extension program at Michigan State University with available engineering models. F. W. Bakker-Arkema, 1975.

Discrete system simulation of "traffic" type systems using SIMSCRIPT. J. R. Lambert, 1975.

SYMAP, a computer cartographic program, useful for crop or rainfall inventories. D. L. Roberts and P. B. Larimore, Louisiana State University, 1975.

SYMVU, a program for three-dimensional plotting of data generated by the SYMAP program. T. L. Thompson and A. L. Stark, University of Nebraska, 1976.

Modeling of combined discrete and continuous systems using a set of FORTRAN subroutines called GASP IV. G. E. Miles, Clemson University, 1976.

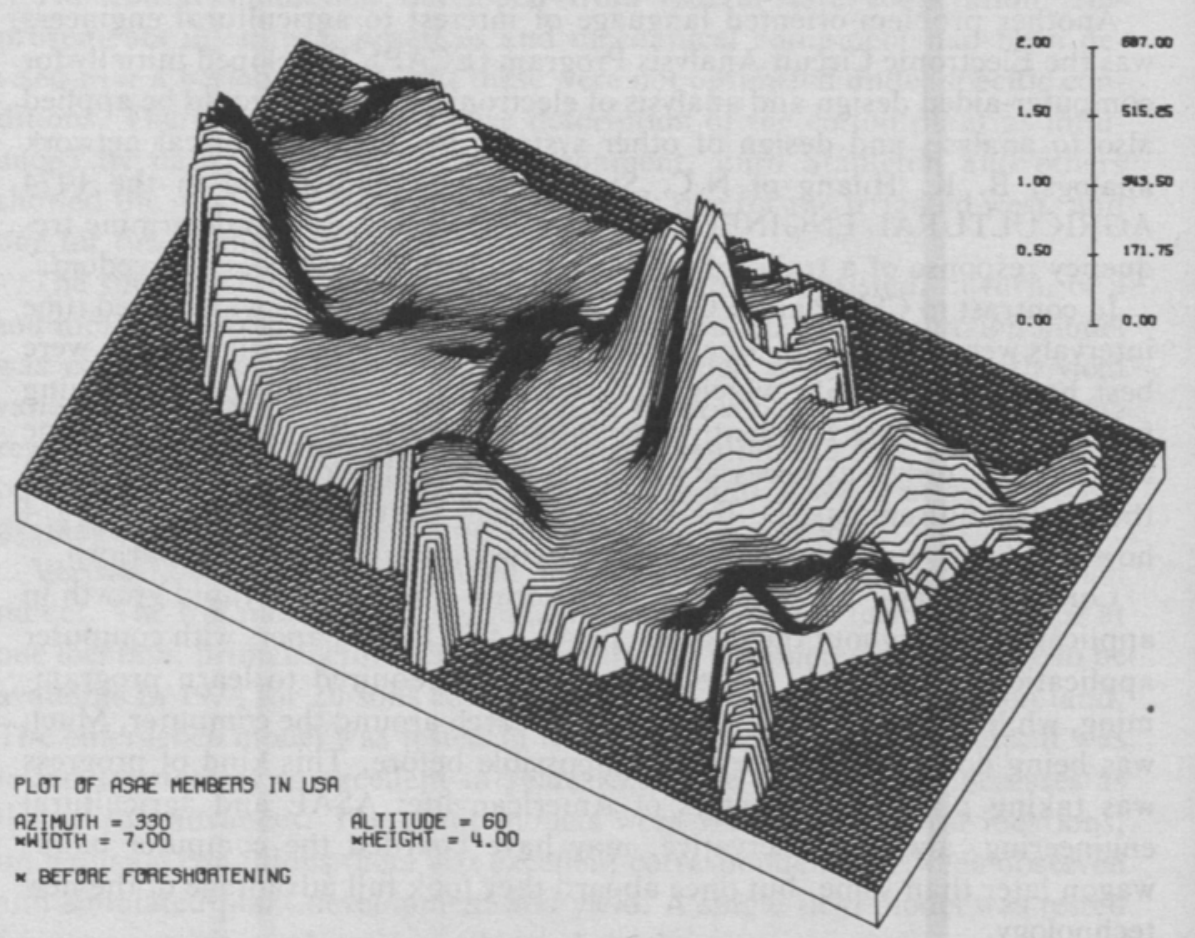

ASAE members in the continental US are graphically represented in this plot-the peaks represent areas of greatest member concentration. Thomas L. Thompson and Alfred L. Stark used this diagram in a "Computer News" article in March 1976 
Suggestions on how microcomputers could be used in agriculture. Glenn Kranzler, Washington State University, and R. C. Camp, Iowa State University, 1976.

DYNAMO II as a simulation language for handling problems modeled by System Dynamics. O. J. Loewer, University of Kentucky, 1977.

The ASAE Computers Committee (T-5) stimulated an exchange service of computer programs. Starting in January 1977 available programs were listed in a Computer Registry in AGRICULTURAL ENGINEERING; in that month eight programs were listed. By the end of 1977 the program list had increased to 15. For the sum of $\$ 1.20$ members could obtain from ASAE Headquarters a complete description of a program and details on how to obtain it from its originator. Entries in the Computer Registry looked like this:

COM-0106

\section{Equilibrium Moisture Content of Peanuts}

Provides a subroutine which will return the equilibrium moisture content of peanut kernels, hulls, and whole pods when temperature and relative humidity are specified.

\section{C \\ Energy}

In 1972 the U.S. consumed 30 percent of the world total petroleum production. In that same year U.S. production fell to 18 percent of the world total. The difference was made up by oil imported mainly from Venezuela and the Middle East. Dependence on foreign oil commenced long before 1972 , but its rate was increasing. Connected with this trend was the move in the 1960s toward replacing coal with natural gas for generation of electricity, thus driving up the cost of gas. Likewise the cost of oil was rising, and the search for it was expanding into some very remote places. There was talk of an "energy crisis."

The energy problem worsened in 1973, particularly in Western Europe and Japan. The U.S. experienced similar problems early in the year and into the summer. In October the Arab oil-producing countries agreed to reduce their production 5 percent per month to force the U.S. to change its Middle East policy; a few days later, they announced an embargo of U.S.-bound oil.

In April 1973 President Nixon proposed legislation authorizing increased offshore oil drilling and removed limitations on oil imports. In June he reduced government energy usage by 7 percent. In September he urged states and cities to relax their air pollution regulations. He tried to speed up the licensing procedure for nuclear power plants. Meanwhile, supplies of pro- 
pane and diesel fuel were very short in the agricultural sector. After the embargo, supplies of gasoline and heating oil were reduced. Gas stations closed on Sunday and lighted displays were curtailed. In January 1974 the nation went on daylight saving for two years to save electricity. In December 1973 Congress legislated the maximum speed limit to $55 \mathrm{mph}$ in the states under threat of losing their federal highway funds.

Many critics in the U.S. believed that the energy crisis had been deliberately contrived by the large oil companies in the interest of greater profits. The firms denied the charge, but late in 1973 the government planned an investigation. It was a fact that during the year the Persian Gulf producer nations raised the cost of a barrel of crude oil by 470 percent to over $\$ 11$ and other oil countries followed suit; U.S. gasoline prices increased to 45-55 cents per gallon by year's end.

Agricultural engineers talked of the crisis at the 1973 Annual Meeting of ASAE at Lexington, KY. A special session on energy, led by R. E. Patterson of USDA Extension, discussed shortages of LP gas, petroleum, and anhydrous ammonia. An Ad Hoc Task Force on Energy in Agriculture was set up and approved by the Technical Council with W. L. Harris (University of Maryland) as chairman. An immediate function of the Task Force was to assist in a survey of state energy needs for agriculture being conducted by Patterson. In the corridors members compared notes on difficulty of obtaining gasoline in traveling to Lexington.

In the July 1973 AGRICULTURAL ENGINEERING Bruce McKenzie and Otto Doering (an economist), both of Purdue, stated that the LP gas supply for crop drying was critical. They earlier recommended to Secretary of Agriculture Earl Butz that to avoid disaster in the fall an early allocation of LP gas to Indiana and other Corn Belt states should be made.

At the North Atlantic Region meeting in August, David Pimentel, insect ecologist of Cornell University, spoke on "Food and the Energy Crisis." Pimentel's principal point was centered on the energy cost of producing corn. Mean U.S. corn yields increased about 2.4-fold from 1945 to 1970 while mechanization reduced labor per acre over 60 percent. During that period mean inputs of energy in fuel and fertilizer increased 3.1-fold. Thus the yield in corn calories declined from $3.7 \mathrm{kcal}$ per $\mathrm{kcal}$ input in 1945 to a yield of about $2.8 \mathrm{kcal}$ by 1970 , a 24 -percent decline. No value was assigned to the human energy saved by mechanization nor to the absolute increase in average corn yield from 34 bu to 81 bu. He went on to recommend "increased labor input for some farm tasks, thus reducing some energy inputs." More palatable suggestions included use of manure and rotation of legumes with corn to reduce dependence on chemical fertilizer; raise corn in regions where irrigation is seldom necessary; and increase the number of acres 
handled per tractor and other machinery. Pimentel claimed that such alternatives would reduce energy inputs by half and still maintain 1970 corn yields. No suggestion was offered regarding the source of the increased "labor input."

Jimmy Butt, always the optimist, wrote in the January 1974 AGRICULTURAL ENGINEERING how rural America might help solve the energy crisis. His suggestions included: Use of livestock waste for energy (produce methane gas, feed to livestock, use it as fertilizer); change emphasis from "maximum output per man-hour" to "maximum output per unit of energy"; harness the wind; use solar energy; grow high-energy crops (how about wood for fuel?); salvage waste heat from power plants; and distill power alcohol from grain. Most of these items will be subject to comment later; however, the maximum output per unit of energy input attracted much attention in those days from armchair agriculturists. Like Pimentel, they held human energy as valueless. Serious proposals were aired that the U.S. should become a nation of subsistence farmers divided into self-sufficient villages, as in the Middle Ages, cultivating corn with hoes and killing insects with fly-swatters-and thus be independent of the Arabs. These thinkers seemed ashamed that the U.S. consumed so much of the world's energy, overlooking the nation's enormous total output, particularly of agricultural products.*

A group of 150 association executive officers attended a White House energy meeting on January 25. Executive Secretary Jimmy Butt attended and reported the highlights to ASAE members. The conference was assured that the energy shortage was real, but that immediate conservation measures would avert a crisis. The objective of the Nixon administration was to achieve energy self-sufficiency and to avoid future "economic blackmail." Current government thrusts to achieve self-sufficiency included: The Trans-Alaska pipeline; tripling offshore exploration leases; utilizing oil shale reserves; exploring geothermal potential; increasing coal utilization; developing more hydroelectric facilities; expanding nuclear capability; and developing solar sources. Butt commented that he left the meeting with the impression that "highly competent people are in command and that solutions will be found."

Meanwhile CAST had been requested by Senator Walter D. Huddleston, chairman of a Senate subcommittee on agricultural production, to prepare a special report on energy in agriculture. Although ASAE was not yet a member of CAST, Technical Vice-President K. K. Barnes chaired the report Task Force and was aided by five other ASAE members in addition to seven

*Although by 1972 the U.S. output per hour of manufacturing was the lowest of the large industrialized nations on a basis indexed at 100 in 1963. 
specialists from other fields. The report was printed in several 1974 issues of AGRICULTURAL ENGINEERING.

The CAST report indicated that a breakdown of total energy to put food on the U.S. table shows:

\begin{tabular}{lc}
\multicolumn{1}{c}{ FUNCTION } & $\begin{array}{c}\text { PERCENT } \\
\text { OF TOTAL }\end{array}$ \\
\cline { 2 - 2 } Agriculture & 18 \\
Food Processing & 33 \\
Transportation & 3 \\
$\begin{array}{l}\text { Wholesale \& Retail } \\
\text { Trade }\end{array}$ & 16 \\
$\begin{array}{l}\text { Household } \\
\text { Preparation }\end{array}$ & 30 \\
& \\
& 100
\end{tabular}

The report was concerned only with agriculture; that is, with production and production-related activities until the material lost its identity as a farm product. Of the energy used by agriculture, it was found that less than onehalf was consumed directly on farms by tractors, pumps, crop dryers, etc. The remainder was consumed indirectly in producing and delivering to farms the production inputs such as fertilizers, chemicals, and machines.

The total U.S. energy use in 1970 was the equivalent of 46.3 million barrels of crude oil per day. The energy was supplied by hydropower, nuclear, natural gas and coal as well as oil. Of the total U.S. energy, the total food system used 12 to 15 percent. Direct agriculture used 1 to 1.5 and indirect input to agriculture used 1 to 1.5 percent. For the first time, agricultural engineers became aware of how small a share agriculture takes of the nation's energy supply, energy-intensive as it is. Thus a reduction in agricultural energy which would seriously disrupt that vital activity would have had little influence on alleviating the total U.S. energy shortage.

The report discussed how at that time it was fashionable to compare the energy contained in the edible portion of a plant with the energy required from fossil fuel and other sources in producing the edible material. This value varied widely. Artificially dried corn in storage has 2.82 times the energy input up to that point. Grain-fed meat on the table has only 0.10 of total energy input required to get it there. In 1974 (and the foreseeable future) it was futile to worry about such things. The Americans don't eat for energy except incidentally; they eat for pleasure and nutrition. The goal of 
the U.S. food system was (and is) maximization of consumer convenience and satisfaction.

Authors of the report estimated that agriculture could suffer a 15-percent curtailment in its energy supply and still produce at about the same level through forced increases in efficiency and management. In the long-run, agriculture might benefit from new energy technology stimulated by the times. Solar energy, energy from wind and from wastes, could be applied in moving farm production toward self-sufficient units-self-sufticient not as in animal-power days but with a quality of life acceptable to a 1983 standard.

In the meantime there were changes in management and new technologies which could be very helpful in increasing efficient use of energy. In field operations, timely planting and harvest; engine tune-ups and operating equipment near their rated outputs; minimum tillage; change to the more efficient diesel engine- these and factors which increase per-acre yields would brighten the energy picture.

In 1972-73, agriculture used 8,339,000 tons of nitrogen fertilizer. Most of it was derived from ammonia compounds using natural gas as a source of hydrogen. Thus while natural gas was a vital source of nitrogen fertilizer, only 2 percent of total natural gas used was to produce ammonia for fertilizer. The CAST report indicated that this small proportion of natural gas ought to be reserved for U.S. farm production so that per-acre yields would not drop. Alternative manufacture of hydrogen by hydrolysis of water required large amounts of electrical energy. The rising costs of fertilizer were stimulating measures of conservation or substitution of manure, sludge, or other organic wastes. Energy requirements of organic wastes, and economic problems, left many questions unanswered about them. As to nitrogen, rotation with legumes was a source of nitrogen but at the cost of greatly reduced production for a given land area.

The CAST report noted that the U.S. had $387,000,000$ acres of cropland at that time. Irrigated land was about 10 percent of the cropland, and this percentage was growing. Irrigation is a high user of energy. Where 5 acrefeet of water per acre is lifted 250 feet, the energy required to supply water to the crop will be 20 times that required for field operations in that crop. Electricity, gas, and LP fuels were all used for pumping. The pump lifts were increasing, so cost per acre was rising. Specific suggestions for improving the energy efficiency of crop production per unit of irrigation water were lacking.

Artificial drying of grain and forage had become common by 1973, largely because of favorable economics. Electricity, LP and natural gas, and fuel oil were the energy sources for fans and heated air. A change to non-heated air would save fuel cost but require larger air circulation. Drying and storage facilities would require redesign. A change to harvest based on natural dry- 
ing would be serious. For corn, a change from field shelling to ear-corn harvesting equipment would be demanded; several years would be needed to produce enough ear-corn harvesters to handle the entire crop. Yield would be reduced because of loss in harvest timeliness. Storage volume would have to be doubled for the same amount of grain. The long-run picture might be improved by use of coal, organic wastes, or wind and sun as drying energy sources.

Barnes and his committee were dubious about the energy cost of animal production. Environmental control, including heating, cooling, and ventilating structures, has allowed more efficient use of feed energy; however, the energy used for environmental control should be compared to the feed energy of delivered feed and the feed saved by environmental control. Reduction of energy supplied to animal agriculture would, in general, reduce available products and raise their cost. In the long run a return to consumption of more forage and less high energy-input feed might be adopted, but that also would reduce not only quantity but also quality of products. With respect to the beef industry, there are no low energy options for producing beef in the quantities approaching those consumed in this country.*

The CAST committee observed that transportation is essential to agriculture. Different needs of transportation had very different energy requirements as of 1973:

\begin{tabular}{cc}
$\begin{array}{c}\text { MODE OF } \\
\text { TRANSPORTATION }\end{array}$ & \\
\cline { 1 - 2 } PTU & \\
Pipeline & TON-MILE \\
Rail & 450 \\
Barge & 670 \\
Truck & 680 \\
Air & 3,800 \\
& 42,000
\end{tabular}

Agriculture had placed much reliance on rail shipment in the past but the deterioration of equipment and roadbeds forced increased use of less energyefficient trucks. Energy cost of transportation could be lowered by: (1) Reduction of the ton-mile requirement, and (2) by increasing the energy efficiency of the transportation system. Use of navigable rivers deserves reevaluation. Rail transport ought to play a much greater role; for example, in moving grain, rail transport would be preferred if better service could be obtained.

*G. M. Ward, P. L. Knox. and B. W. Hobson, "Beef Production Options and Requirements for Fossil Fuel," Science 198:265-271. 1977. 
The CAST report concluded that agriculture uses a very small portion of the total U.S. energy supply; therefore, agriculture offered little opportunity for large savings to help solve the energy shortage. However, long-run opportunities included adoption of new energy sources and land-use policies favoring improved energy efficiency. Questions which faced agriculture were identified as:

1. Will the U.S. be forced to establish priorities for fuel involving choices among food production, recreation, and convenience? For example, to what extent should food processing for consumer convenience compete for energy with food production if energy supplies are critical?

2. To what extent should the U.S. let freely established price equate supply and demand for energy?

3. What would be the consequences of limiting U.S. exports? Exports of food and all products are exports of energy. What are the potential consequences of equating agricultural exports in a dollar balance versus an energy balance?

On March 18, 1974, most of the Arab oil exporting nations agreed to lift the embargo on oil shipments to the U.S. Shortly before that welcome event, ASAE announced the theme of the summer meeting at Oklahoma State University in June: "The Agricultural Engineer in the Energy Equation."

J. J. McKetta, a distinguished University of Texas chemical engineer, spoke at one of the June General Sessions on "The Energy Problem Lingers On." Chairman of the National Energy Policy Committee in 1970, McKetta said that there was no "oil conspiracy." The companies and the Federal Energy Administration had long urged the government to be aware of trouble ahead. But now President Nixon was telling the public to drive on Sunday, so the public thought the crisis was over.

McKetta's view of the future U.S. energy posture was pessimistic. Federal laws and regulations plus environmentalist obstruction will continue to hamper attempts to achieve energy independence. He saw no hope for the U.S. to meet the expected energy demand in 1985 by using its own resources, even with an assumed zero percentage growth in the gross national product.

Another General Session speaker at the 1974 Annual Meeting was Director S. H. Wittwer of the Michigan Agricultural Experiment Station. Wittwer observed that agriculture did not receive credit as a major source of energy production, nor did people notice how engineering was improving the productivity of land and releasing land for other uses. The U.S. was exporting energy at an enormous rate in the form of agricultural commodities; for example, a bushel of corn will produce three to four gallons of alcohol.

Wittwer proposed that a 50 -percent increase in agricultural productivity be established as a national goal in the next five years, to enlarge the nation's 
energy stockpile. This, he claimed, would help the balance of payments, revalue the dollar, and help the hungry nations. A change in philosophy would be stimulated: It is important to live in harmony with food-producing systems as well as to live in harmony with nature, and the two are not incom. patible. Meeting such a goal would demand the rebuilding of technology reserves and the release of technology now in an experimental stage. Agricultural engineers could assume leadership in this effort and take charge of much emerging science.

But Wittwer, like McKetta, had nothing good to say for the government:

"Today we are a nation with no effective leadership. This begins with the Chief Executive and includes Congress, the Food and Drug Administration, the Environmental Protection Agency, National Science Foundation, USDA, and similar groups. Canada, Britain, France and West Germany are in equal difficulty. The U.S. has no land use policy, no food use policy. The Board of the National Science Foundation, the great repository for science funding at the federal level, currently has no agricultural representation and little, if any, from biology. Food production is not even among the 21 national priorities for additional research and development published in 1973 by the National Science Foundation Board under the title 'Science in Indicators'."

ASAE members L. F. Nelson and W. C. Burrows of Deere \& Company presented a paper at the 1974 Annual Meeting on "The U.S. Agricultural Energy Picture," in which it was shown that reducing the highway speed limit to $55 \mathrm{mph}$ would save more motor fuel than was used for all off-highway agricultural purposes. The authors noted that the total fossil fuel energy input for providing material, growing agricultural produce, and delivering it to the marketplace required only $2 \frac{1}{2}$ percent of the U.S. total energy consumption. They showed that this requirement could be reduced, but dangerous food shortage should not be risked. For example, conversion from gasoline to diesel fuel would achieve a 50-percent increase in horsepower-hours per gallon. In corn culture, no-till versus conventional tillage would save about 4 gallons of diesel fuel per acre. However, low fertilizer application rate combined with any cultural practice would not produce enough corn to meet U.S. domestic needs; lowering the fertilizer application rate would be a disastrous method of saving energy. The generous return made by corn to energy invested was brought out: Regardless of cultural practice, the energy content of the grain harvested is about six times greater than the fossil fuel energy input to grow the crop. On a whole plant basis, the energy return is about 12 times the investment. The estimate was based on production of about two bushels of corn per gallon of diesel fuel equivalent.

Lifting of the embargo in March 1974 caused many to relax and stop wor- 
rying. A sense of urgency departed from the public mind. This caused ASAE Special Project Editor Sam Rosenberg to write in the April AGRICULTURAL ENGINEERING that the word "crisis" had been replaced by "problem." This, he argued, was a bad mistake by the general public. The drive toward energy self-sufficiency would not be completed by Washington but through involvement of all, and this required agreement that a "crisis" existed.

The agricultural engineers generally agreed with Rosenberg. Many years of hard data, available to all, indicated that McKetta was right: The days of cheap energy were past; the oil companies were not engaged in conspiracy; environmental gains were not going to be sacrificed; and the government could not create instant energy self-sufficiency. Therefore, the profession began to look at some "new" technologies related to agriculture.

Solar energy, whose capture in photosynthesis forms the basic agricultural process, offered much potential for heat energy; also, wind, the partner of solar energy, offered energy potential. Use of wastes for solid fuel, methane gas, and for fertilizer offered energy sources. Growth of crops for fuel or for industrial products usually requiring petroleum would help the energy picture; examples are wood, jojoba for oil, and guayule for rubber. Distillation of grain or organic byproducts would yield power alcohol to be used as motor fuel when mixed.with gasoline. These processes were not new, but they could be analyzed, improved by modern engineering, and perhaps make a contribution toward relief of the energy crisis.

Consider fuel from livestock wastes. W. C. Fairbank, of U.C.-Riverside, published an economic analysis of this process in the 1974 AGRICULTURAL ENGINEERING.

Production of methane gas by digesting manure anaerobically is interesting. Along with $\mathrm{CH}_{4}$, the product will contain a high percent of $\mathrm{CO}_{2}$ and some other gases. Gas scrubbing is possible but impractical under farm conditions. Liquefaction also is impractical, thus prohibiting vehicle use. Digester payback ratio of $\$ 1$ of gas per year per $\$ 20$ capitalized suggested that it could not be justified on the basis of fuel production. According to Fairbank, a digester using the waste from 60,000 cows might make economic sense, but he saw no future for the process on farms.

Fairbank next considered the ancient process of pyrolysis, or anaerobic dissociation of dry manure with heat, to produce a gas, a pyrolyzate, and a char. The heat value of the gas is about 20-30 percent of the fuel value of the dry manure. The pyrolyzate is considered without value. The process would be economically feasible only in an arid climate where a continuous supply of dry manure is available. Again, this is not a farm process.

Combination of waste with $\mathrm{CO}$ and $\mathrm{H}_{2} \mathrm{O}$ under high temperature and 
pressure with catalysts can yield oil and water (dung oil process). A plant costing over $\$ 25$ million and designed to take in 690,000 pounds per hour of manure was designed by the Bureau of Mines and based on this process. Its operating costs, and the selling price of the oil, were based on the assumption that cattle producers would pay to have the plant take their manure.

Compared to bio-gas and dung oil, Fairbank believed that substituting manure for commercial fertilizer when practical would conserve a primary fuel - natural gas - and would be economic and much safer. The capital and technical resources needed for real exploitation of the energy-recovery processes were beyond the typical agricultural enterprise.

The scale of methane production visualized as actually profitable by Fairbank was later realized by Thermonetics, Inc. at Guymon, Oklahoma. Their Calorific Recovery Anaerobic Process plant converts 500 tons of manure per day into 1.6 million cubic feet of methane. After removal of impurities, the gas is sent to Chicago by pipeline. Economic feasibility of the plant is contingent upon the sale of feedstuffs recovered from the manure slurry to furnish approximately half the gross revenue; 26 percent protein filter cake is recovered from the digested slurry by centrifugation. Feedlot operators are paid $\$ 1$ per ton for the manure.*

In March of 1975, Jimmy Butt (now Executive Vice President) urged the members to assume that the petroleum supply would diminish and that its price would steadily increase. Therefore, agricultural engineers ought to: (1) Create an efficient agriculture with energy utilization as the prime consideration; (2) begin to study alternative ways of getting the same jobs done with different or reprocessed materials; and (3) redouble efforts to preserve basic resources and environment. Research and education, as in the past, would carry the profession to the new heights of achievement demanded by the times.

President Carl Hall commented that same month on the charge that food production demands more energy than is gained from the products. By the time the product is consumed, eight to nine calories of hydrocarbon energy have been consumed to produce each calorie of food energy; therefore, the charge is correct. However, no industry can be expected to obtain more energy from a process than is put into that process. The calories in food are not as valuable as the protein, vitamins, and minerals without which people would die. As with Jimmy Butt, Hall asked the members to look toward an agriculture designed for energy efficiency, but within limits. The most energy-efficient agriculture is a system in which each person grows and proc-

*John M. Sweeten, "Methane Production from Livestock Waste." Texas Agricultural Progress/Summer 1978. 
esses his own food - a system obviously unsuited for an urbanized industrial society like ours. Agricultural engineers, then, must develop new technologies to increase production while lowering energy input; also, they must seek more energy from renewable resources.

Older members by this time were remembering the days of World War II. Gasoline rationing, 35-mph speed limit, meat and sugar rationing, disappearance of natural rubber, "Victory" gardens, and similar constraints made petroleum shortages of the 1970 s look like a picnic. It irked the oldtimers as they viewed the half-measures and vacillations of the national leadership, who lack the political courage to ask for sacrifice and to enforce self-denial. When Jimmy Carter entered the White House in 1977 he called for an attack on the energy crisis on such a plane as "the moral equivalent of war." But Carter's equivalent of war soon dissolved in the usual political selfishness and cowardice (Congress was as spineless), leaving citizens still convinced that the oil companies contrived the crisis. And the oldtimers, who know what war was really like, were ashamed for their country, whose policy was now being dictated by a group of less developed nations, many of whch enjoyed aid from the U.S.

In 1975 the U.S. Senate requested CAST for a report on the "Potential for Energy Conservation in Agricultural Production." Now ASAE was a CAST member, and one of its members, D. M. Price of Cornell University, was appointed chairman of the Task Force. Other ASAE members on the Task Force included V. Cervinka, California Dept. of Food and Agriculture; B. A. McKenzie, Purdue University; M. L. Miller, Deere \& Co; H. C. Olson, Butler Manufacturing $\mathrm{Co}$; and Harmon Towne, Superior Equipment Manufacturing Co.

The report (No. 40) discussed ways to save energy in agriculture.

Nearly 80 percent of all new tractors and combines sold in the U.S. were diesel powered. A complete changeover to diesel power would effect a potential energy saving equivalent to 643 million gallons of gasoline.

About 300 million pounds of insecticides were applied on routine schedule. If these were applied instead only when necessary, treatments could have been reduced by about 35 percent.

Using only 0.5 percent less irrigation water would save the equivalent of 5.5 million gallons of gas per year. Drip irrigation could save about 50 percent in water and energy used in irrigation. Using drip irrigation on 5 percent of the land then under irrigation would have saved about 27 million gallons of gas per year.

Efficiencies of various crop drying techniques were brought forth; no data were yet available for solar heat drying systems. The enormous disruption that would accompany a return to natural air drying of ear corn, and the 
probability that corn would be in short supply as a result, was discussed. Field losses in corn harvested at high moisture content are minimal; delaying harvest until natural drying has reduced moisture content increases field losses significantly and may delay fall tillage.

The framers of CAST Report No. 40 were criticized by member Paul Jensen, director of product engineering research for $\mathrm{A}$. $\mathrm{O}$. Smith Harvestore Products, for overlooking the energy-saving technique of storing and feeding high-moisture grains to livestock. This technique allows early harvest and avoids drying cost, according to Jensen. The grain must be stored under oxygen-free conditions.

In April 1975 ASAE sponsored an International Symposium on Livestock Wastes at the University of Illinois. Here it was again emphasized that the economics of farm generation of methane from waste was unfavorable and would probably remain so for the next $15-25$ years. Controlled refeeding of waste and the time-honored use of it as fertilizer emerged as the best choices.

The theme for ASAE's 1975 Annual Meeting at U.C.-Davis was "The Productivity/Resources/Environment Interface," an idea developed by S. S. DeForest when he was president-elect. Much wisdom on the American energy dilemma was uttered by a number of outstanding speakers. For example, Athelstan Spilhaus, distinguished administrator of the National Oceanic and Atmospheric Administration and father of the Sea Grant program, spoke at one of the General Sessions. His topic was "Striking a Balance" among the three factors of the meeting's theme. He said, "Even if we find excellent ways to increase the amount of available energy, unless we reduce the rate of population growth to below the rate of increase of energy growth, we're in bad trouble."

Members W. J. Chancellor and J. R. Goss (U.C.-Davis) agreed with that view in their presentation on "Balancing Energy and Food Production: 1975-2000." They observed that the key elements in achieving food/energy balance are zero population growth, limited per capita resource consumption, and zero increase in energy consumption. Using solar energy captured through photosynthesis as the only energy source and assuming an end to world population growth at 8 billion in the year 2050 , the authors modeled a stable balance thereafter with high levels of food and industrial output per capita. But, they warned, the steps necessary to achieve the balance would have to be initiated in the year 1975.

Many of the papers presented at the 1975 Annual Meeting and at the Winter Meeting which related to the energy dilemma were assembled into an attractive booklet published by ASAE in 1976 under the title "An American Success Story, Increasing Agricultural Productivity."

As the energy crisis wore on, there were suggestions that reversion to 
animal power might be wise. Deere \& Co's L. F. Nelson and W. C. Burrows, with a colleague, F. C. Stickler, considered this alternative to mechanized agriculture at the 1975 Winter Meeting. In 1915, 26.5 million horses and mules powered U.S. agriculture; about 100 million acres (one-third of the total cropland) were required to feed these animals. Starting in 1975 and breeding all workstock, it would take eight years to raise only 2 million head of work animals - but at least 20 million would be needed. Their feed requirement would leave barely enough food for the U.S. population, with nothing left for export. These authors pointed out that 27 million horses and mules would require $520 \times 10^{12} \mathrm{kcal}$ of biological energy, in contrast to the $158 \times 10^{12} \mathrm{kcal}$ of fossil energy used in 1975 by tractors, combines, and other farm machinery. The authors did not mention the enormous energy cost of changing from mechanized implements to animal-powered implements nor the production losses that would be suffered during the years a generation of farmers learned how to handle horses and mules.

Assessment of blame for the deepening chaos was a symptom of the time. Kenneth E. Curtis, Amoco Oil Co. executive, wrote in the 1977 AGRICULTURAL ENGINEERING that farmers were totally dependent on crude oil and natural gas. The dependency was increasing while U.S. supplies were diminishing and the federal government was "effectively turning aside efforts by private industry to help dislodge the nation from this mess." According to Curtis, a principal federal sin lay in maintaining price controls on domestic crude oil and natural gas. That policy encouraged consumption and discouraged production; U.S. crude oil prices averaged about half those of imported crude. The solution to the energy problem, then, would be to release petroleum and natural gas from price control, thus permitting competition to provide adequate supplies of these resources. Here, then, was the oil company view of what the government should do.

The short-run prospect for agriculture in the complex energy picture is difficult to forecast. Conservation, plus use of solar, wind, and biomass energy will play a role, but an irreducible minimum of crude oil and natural gas must be allocated to food production if this vital activity is to continue unimpaired. Much more significant energy conservation could be effected in processing, packaging, distribution, and home preparation of food than in producing it. Considering the long run, the Chancellor-Goss solar-powered world by 2050 requires sacrifice of resources by some nations; these nations probably will not do it. McKetta said in 1974 that the U.S. will never again produce an adequate supply of energy from its own resources; perhaps the oil companies are wrong in supposing that competition is the answer. The nuclear option is violently opposed by environmentalists, as is the coal option, although both of these could stretch the oil and gas supply. Therefore, 
somewhere in the future may lie an agriculture increasingly deprived of diesel fuel, gasoline, LP gas, chemical fertilizer, and a variety of pesticides. Of course, all other sectors would be proportionally deprived also; hence the net effect, barring anarchy (which wouldn't help), would be the gradual decline of the U.S. into a labor-intensive economy. The horses and mules may once again be the prime-movers of agriculture and ASAE will have arrived where it started!

\section{D}

\section{Publications}

The Seventh Decade brought considerable progress in ASAE's publications. Quantity of publication increased dramatically, and many innovations were launched.

AGRICULTURAL ENGINEERING (no longer known as the Journal) evolved by 1971 into the "Society's primary news magazine carrying material of broad scope and interest as opposed to detailed items of interest to a more limited specialty area." New features appeared, such as "AE in Action,: "New for the Design Engineer," "Continuing Education Opportunities," "In Government," "Computers in AE," and "NIAE Translations." The cover designs became increasingly artistic and attractive.

During the Society year 1970-71 an editorial board was appointed to counsel and assist the ASAE editorial staff. Chairman of the first editorial board was Frank E. Buckingham of Massey-Ferguson. Members were Earl D. Anderson (private consultant), S. S. DeForest (U.S. Steel), J. H. Ebbinghaus (Republic Paint Co.), G. A. Karstens (American Feed Manufacturers Assoc.), and E. D. Wilborn (The Progressive Farmer).
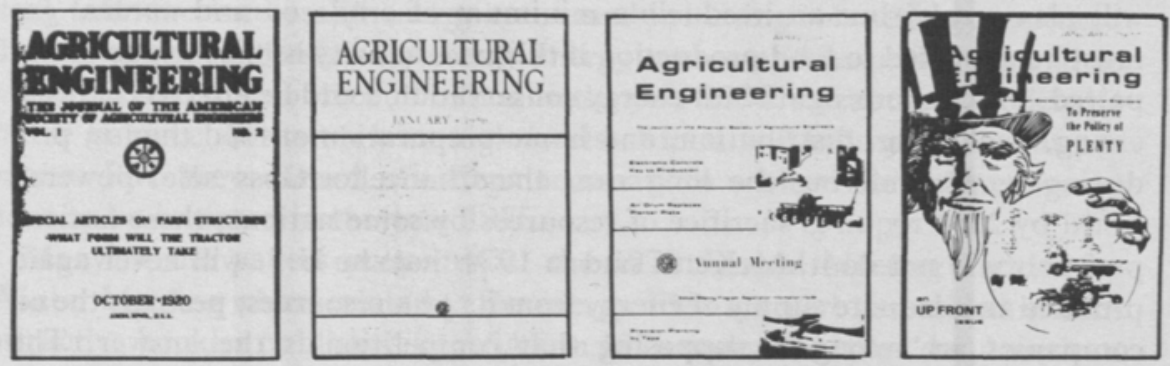

Various changes in cover design and format evolved in the Society's monthly publication as its role changed from a journal to a primary news magazine 
In December 1972 the Board of Directors authorized expenditure of $\$ 7000$ to develop and test a special "Demographic Supplement" for executives of the farm equipment industry. Jimmy Butt reported results to the Executive Committee at its May 7, 1973 meeting. It was determined that the supplement ought to be sent to entire AGRICULTURAL ENGINEERING mailing list and that its feasibility and format were satisfactory. "UP FRONT in Agricultural Machinery" was chosen as the supplement's name. UP FRONT first appeared as part of AGRICULTURAL ENGINEERING with publication of the October 1973 issue. After that it appeared regularly in the January, April, July, and October issues. Those issues were sent to a special mailing list as well as the regular list, and improved advertising sales resulted. Sam Rosenberg joined the staff in January 1974 as UP FRONT editor and Production Manager; in July Marianna Pratt was named Managing Editor of AGRICULTURAL ENGINEERING. Jim Basselman was Publications Manager. By June 1976 UP FRONT added 16 to 24 pages to the issue in which it appeared; the magazine usually filled at least 40 pages without UP FRONT. The supplement, aimed strictly at the agricultural machinery industry, was now being received by over 1500 executive engineers, corporate management officers, and plant managers. The upward trend in AGRICULTURAL ENGINEERING advertising sales commenced in 1974 continued through 1976, due partly to the influence of UP FRONT.

Technical publications progressed markedly in quantity and quality. TRANSACTIONS of the ASAE moved from six issues with 892 pages in 1968 to six issues with 1200 pages in 1970 . The Technical Division editor and critical reader system assured publication of high-quality papers. A new for-

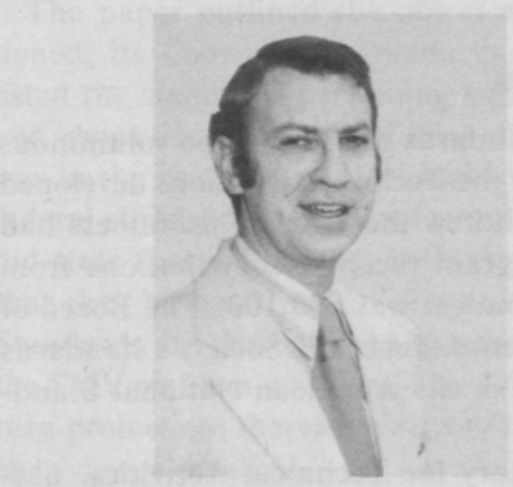

Sam Rosenberg

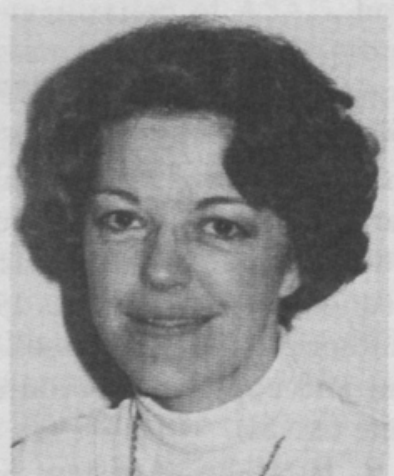

Joan Baxter 
mat was adopted in 1975 to permit publication of a special edition for each of the ASAE Divisions. Each regular issue was sectionalized by subject matter. At year's end special editions were compiled by selecting from the six issues and binding into one publication only those articles pertaining to one Division. In 1976 a total of 670 copies was sold.

Conference proceedings and other technical items formed a major part of the publications load. Proceedings published in 1968 were: Evapotranspiration and Its Role in Water Resources Management; Economy Housing Seminar; Field Modification of Tractors; and Tillage for Greater Crop Production. In 1969, proceedings published were: Second Water Quality Control Conference; Forest Engineering Conference; and Computers in Farm Machinery Management. In 1970 ASAE published Agricultural Engineering Curricula for the Seventies. For 1971 the Graduate Education Seminar Proceedings and the International Symposium on Livestock Wastes Proceedings were printed. The latter was the first publication in which type was set entirely in ASAE Headquarters. The first ASAE Monograph, "The Compaction of Agricultural Soils," was published in 1971. In the following year the National Drainage Symposium Proceedings came out; the Agricultural Engineering Index, 1961-70 by Glenn and Carl Hall, a supplement to the original index for 1907-1960, was published; and a new comprehensive index to all publications was issued. This kind of activity proceeded unabated. During 1976 over 4000 pages of technical and non-technical material were published, which more than doubled production of 1970 . About 70 percent of ASAE's budget was now devoted to publications. Also in 1976 Joan Baxter was employed to serve as managing editor of that most valuable compendium, the AGRICULTURAL ENGINEERS YEARBOOK.

\section{$\mathbf{E}$ \\ Standards}

The ever-expanding story of ASAE's standards program is too voluminous for more than a cursory glance. Each year the Technical Divisions developed new standards, revised old ones, and withdrew those whose usefulness had expired. The Cooperative Standards Program received contributions from 253 organizations in 1976 , and its 1977 budget was $\$ 83,100$. The Board of Directors authorized the staff to seek accreditation of the Society's standards development and approval procedures from the American National Standards Institute (ANSI).

In 1975 R. H. Hahn, Assistant Secretary for Technical Activities, participated in a three-week visit to the Soviet Union with members J. H. Born- 
zin, L. H. Hodges, and W. M. Roll. The trip was organized under the USUSSR Agricultural Agreement to further discussions on compatibility of standards for agricultural equipment. Discussions were centered on terminology and definitions, tractor and implement hitching, operator safety, and testing methods.

In 1970 the U.S. Congress directed the Department of Transportation (DOT) to conduct a study of agricultural tractor accidents and to provide a report setting forth the magnitude of the problem, primary causes, and recommendations for corrective measures. "Because of the long interest of (ASAE) in improving the safety of those who work with farm equipment ..." ASAE was invited to prepare a paper for DOT. Particular interest was expressed in the subject of standards for agricultural tractors, whether or not federal tractor safety standards were required, and how the retrofit problem should be handled. A deadline of September 30 was specified for submission of the paper.

On August 25 ASAE Headquarters sent a questionnaire to all members of the Agricultural Safety Committee, Committee on Standards, the Power and Machinery Division Standards Committee, and the Tractor Committee. The questionnaire asked for opinions on the points raised in the DOT invitation to submit data and comments.

This task group was organized: B. J. Lamp, Technical Vice-President; L. H. Hodges, P\&M Division Director; R. E. Heston, Vice-Chairman, Committee on Standards; P. L. Bellinger, Chairman, Agricultural Safety Committee; G. P. Barrington, Chairman, P\&M Division Standards Committee; and E. J. Zeglen, Chairman, Tractor Committee. The group met with Russ Hahn in Chicago on September 10 to review questionnaires and draft a report. Page Bellinger served as chairman and agreed to prepare the draft. The final draft of the paper was ready for DOT on September 28.

The paper outlined the object and organization of ASAE, how it functioned, its Cooperative Standards Program, and standards procedures. It listed the standards pertaining to agricultural tractor safety (there were 22) and showed an example of how effective the cooperative standards process was in the case of the SMV emblem. The task group declined to state that federal standards should be formulated to improve tractor safety. The group did state that if Congress authorized such regulations it would be desirable that they be based upon "the technology and expertise from which ASAE Standards are derived." As to retrofit, this could be simple, as in the case of the SMV emblem, or it could be difficult or hazardous, as in the case of overturn protection; therefore, retrofit feasibility "must be carefully evaluated for each device involved."

The possibility of unneeded federal standards for tractor safety was 
averted by ASAE's timely and effective input. Hahn informed the members in the March 1971 AGRICULTURAL ENGINEERING that DOT Secretary John A. Volpe recommended to Congress that Federal standards were not necessary at this time. However, after the passage of two to five years another evaluation would be made to determine if voluntary standards efforts were still producing desired results. This suggested that ASAE should intensify its standards activities.

When the Occupational Safety and Health Act (OSHA) of 1970 became law on December 29, 1970, Russ Hahn was concerned about its impact on agriculture and whether or not it could be enforced. The Act applied to all businesses "engaged in interstate commerce except for the mining and railroad industries." It gave authority to the Secretary of Labor to promulgate occupational safety standards such as those developed by organizations such as ASAE.

OSHA appointed a Standards Advisory Committee for Agriculture in 1972 to "assist in setting new standards and updating existing standards to protect agricultural employees from hazards to their safety and health." ASAE members J. G. Erisman (Illinois State University) and R. D. Schnieder (University of Nebraska) were appointed to the committee and Schnieder was named chairman. Advisory Committee priorities included two areas of ex. treme interest to ASAE: agricultural tractor rollover protection and shielding of agricultural machines.

The Federal Register of February 4, 1974, contained rules proposed by OSHA that would require rollover protective structures (ROPS) on new agricultural tractors above 20 engine horsepower manufactured after August 31,1974 . The proposed rules were recommended by the Standards Advisory Committee on Agriculture. The rules provided that protective frames and enclosures were to meet specified performance standards adopted from ASAE. Also proposed on February 8 were rules for the guarding of field equipment, farmstead equipment, and cotton gins. Many, but not all, of the guarding requirements were based on ASAE standards and recommendations.

Final regulations as published by OSHA on April 25, 1975, required that ROPS be labeled that they were tested in accordance with OSHA regulations. And the test procedures and performance requirements specified in the OSHA regulations conformed to ASAE and SAE voluntary standards.

At about that time the AFL-CIO complained to Congress that OSHA was failing to inspect agricultural work places adequately. Such inspections took place only after a job fatality or serious injury. Since OSHA was not collecting accident data from farm workers, the AFL-CIO trade union claimed that no reliable accident injury data were being accumulated in the agricultural 
industries.

On March 9, 1976, OSHA regulations for guarding of farm field equipment, farmstead equipment, and cotton gins were published in the Federal Register. Most of the provisions were based on ASAE standards. Russ Hahn wrote that "The existence of such voluntary standards no doubt helped make the OSHA regulations more reasonable and acceptable than they might have otherwise been."

Also in 1976 OSHA's Standards Advisory Committee on Agriculture drew up a tentative standard on noise level exposure in agricultural work places. This was a complex field, lacking in reliable measurements; ASAE, for example, had no standards or recommendations pertaining to noise of machinery. The Advisory Committee recommended adoption of the noise standard but advised OSHA not to write the standard until testing could determine noise levels of farm and farmstead equipment.

Because the interaction with OSHA had again demonstrated the valuable role of the private sector voluntary standards system, ASAE was shocked when Senator J. G. Abourezk (South Dakota) introduced his 1976 bill S.3555 to regulate the procedures of all voluntary standards organizations in the U.S. The Senator commented that "Such vast, unregulated power-tantamount to lawmaking-has caused numerous documented charges of anticompetitive activity against standards developers and certifiers. Such power has, until now, gone largely unchallenged because of the time and costly nature of antitrust suits. Yet, voluntary standards and certifications, in their present form, must be challenged, because they are a basic component of industry attempts to restrain trade by price-fixing, boycotting, controlling supply, and foreclosing new technology from the marketplace."

ASAE could not view its standards program so negatively; rather, its standards program helped to promote safety and to reduce consumer costs. ASAE staff and officers provided input to the American National Standards Institute for preparation of testimony before the Subcommittee on Antitrust and Monopoly of the Committee on the Judiciary, which had scheduled hearings on S.3555 for July 22. The hearings were cancelled at the last minute and were not rescheduled.

The following year, 1977, a rewritten Senate Bill (S.825) was introduced by Senators Abourezk, Birch Bayh, and Edward Kennedy which would eliminate ANSI and bring the voluntary standards system under regulation by the Department of Commerce. The Senate Antitrust and Monopoly Subcommittee held hearings on the bill in May. ASAE requested to be heard on two separate occasions but received no acknowledgement of its letters. Senator Abourezk this time characterized the voluntary standards system as one of "today's most convenient modes for restraining trade and deceiving 
consumers."

Russ Hahn pointed out in his Progress Report column in July 1977 AGRICULTURAL ENGINEERING that prior to introduction of S.825 ANSI established a program to develop a National Standards Policy acceptable to all segments of society. ASAE member K. L. McFate was a member of the program Advisory Committee. Hahn thought the Congress ought to await results of this voluntary program, which could provide needed policy and services at little expense to the government, before legislating the whole voluntary system out of existence.

S.825 quietly disappeared also. L. H. Hodges (J. I. Case Co.), 1973-74 ASAE president, probably worked more closely with the standards effort than any president of the decade; in addition, he was closely associated with the standards program throughout the decade. It was his opinion that the federal agencies began to realize that standards development without the aid of the private sector organizations was beyond their capacity and their ability.

In effect, the Senate bills attacked the credibility of the engineering societies involved in standards development. ASAE received financial donations from a large number of business companies in support of its Cooperative Standards Program (CSP). Did this allow or encourage ASAE to "restrain trade" or "deceive consumers" through operation of the CSP? The standards developed under the CSP provided industry and consumers the following: Interchangeability; reduction in variety of components; improved personal safety; performance criteria; a common basis for testing, describing, or informing; increased efficiency; design data; and a sound basis for codes, legislation, and education. The CSP was carried on in full public view; any person or entity could propose a standard but it had to be needed to become a standard. Most of the contributors to CSP were in competition with each other. Above all, the members of ASAE involved in writing standards were professional engineers, responsive to the Code of Ethics that formed a part of ASAE's constitution. They came from public service positions and universities as well as farm industry. They know farm people and farm machinery. The language employed by Senator Abourezk was to them an irresponsible slap delivered under Congressional immunity.

The fruitful interaction with OSHA in rollover protection structures and rules for guarding field equipment showed how the private sector could work with, and for, government on behalf of consumers. Other examples could be cited, such as the SMV emblem, where ASAE's standardization work has benefited the general public rather than just agricultural consumers. It is no surprise that President S. S. DeForest said in June of 1976 that "ASAE Voluntary Standards, along with ASAE publications, are our greatest contributions to mankind." 


\section{$\mathbf{F}$ \\ Professional Development}

James H. Lillard of Virginia Polytechnic Institute was ASAE representative to the National Council of Engineering Examiners (NCEE) in 1969. He reported in the 1970 AGRICULTURAL ENGINEERING on progress in professional engineering registration. As of 1969 U.S. ASAE members were 42 percent registered; Canadian members were 59 percent registered. In both countries, members in the education sector held the highest number of registrations while the industry members held the lowest. The total registration of ASAE technical members was well above the national average for the total engineering profession.

Lillard discussed recent proposals made by NCEE and the National Society of Professional Engineers (NSPE), which would assure that registration would continue to protect the public, and find a supplementary device (in addition to registration) for identifying the professional engineer. NSPE suggested elimination of the EIT (Engineer-in-Training); upgrading of the educational requirements; and provision for a uniform 16-hr examination at graduation. NCEE recognized the growing concern that registration alone would not insure full recognition for the profession, particularly when so few engineers were required by law to be registered.

Briefly stated, NCEE visualized two possible paths to full professional recognition. One way would, by registration (licensing), provide legal recognition qualifying for practice; the procedure would follow essentially the NSPE recommendations. The other way envisioned "accreditation" by peers, probably through the engineering societies. This route would not qualify for public practice; licensure by the state boards would still be required for public practice.

Lillard emphasized that a current problem for agricultural engineers was the lack of examinations specific to that discipline in the principles and practice examinations administered by the state boards. Although he had repeatedly informed NCEE of ASAE's willingness to furnish appropriate questions and answers, he was pessimistic because of the high cost-percandidate ratio. However, his pessimism was unjustified because in a relatively short time ASAE commenced furnishing NCEE with examination questions for agricultural engineers taking the principles and practice exam.

At a Joint Societies Forum held in August 1971 those in attendance requested the Engineers Joint Council (EJC) to assume leadership in convening a task force on accreditation of engineers. Accreditation, it was expected, would “provide professional recognition by a man's peers in his own engineering society at a level at least as high as that provided by registration procedures." $O$. C. French, ASAE's representative on the EJC Board, in- 
formed Jimmy Butt in September that he had just attended a Board meeting whose members preferred the term "certification" rather that accreditation. He went on to say that EJC President R. J. Raudebaugh had requested the member societies to name representatives to the task force.

In the February 1972 AGRICULTURAL ENGINEERING Jimmy Butt introduced the members to the thought that accreditation of engineers was to be a major professional issue in the 1970s. He pointed out the shortcomings of the existing registration procedures: New branches of engineering were not included; registration was not national in scope; and many areas of employment did not require registration. The proponents felt that national accreditation by the engineering societies would be more effective in identifying all U.S. engineers of a certain competence level as evaluated by uniform standards. He asked the members to be prepared to express opinions on this important subject.

In December 1973 Butt again tried to inform the members of the potential impact certification could have on their professional careers. He stated that under such a program ASAE would administer qualifying examinations and periodic re-examinations in the various specialty areas of agricultural engineering. As to registration, certification would complement rather than compete with it. The decision to adopt certification would be made by the Board of Directors, but the members ought to help in the decision. Involvement would require funds and the time of individual members.

EJC's 1971 Task Force on Engineering Certification recommended creation of a National Commission for Accreditation of Engineer Certification Programs. The Commission was to be established in November of 1974. Its members were to be those engineering societies which had a certification program in effect or which intended to start one within a three-year period. ASAE membership was informed of this development through a comprehensive article in the May 1974 AGRICULTURAL ENGINEERING.

NSPE held a conference on certification which was attended by $G$. W. Isaacs, ASAE Director of Professional Development and head of Purdue University's Agricultural Engineering Department. Isaacs reported in the August 1974 AGRICULTURAL ENGINEERING that engineering societies having the most registered professional engineers as members were most reluctant to adopt certification and vice versa. It was agreed that a certification program would add enormously to ASAE's continuing education offerings (a major part of certification) at no little cost. Unanswered were the questions: Must an engineer be both registered and certified? Is the certified but unregistered engineer qualified for identification as an engineer?

Meanwhile, at the June 1973 ASAE Board of Directors meeting, President C. F. Kelly had called for consideration of the problem with action in 
December. Information was to be furnished to the Board by Ted Stivers. ASAE representative to NCEE. Past-President Hugh Hansen spoke in favor of certification. The question was referred to the Professional Development Department. But at the December meeting no decision was as yet required of ASAE, so the Board decided to continue gathering data.

The confusion of attitudes toward certification was a reflection of the diversity of engineering organizations and orientation. The discipline societies, such as ASCE, ASME, and ASAE, derived recognition from state licensing; they were opposed to certification which would create another bureaucracy to contend with. Suggestions for relicensing calling for rigid annual requirements of professional development activities contravened their codes of ethics (which obligated the members to continued professional development) and ignored the continuing education opportunities of their societies and their local universities.

Specialty societies such as SME (Society of Manufacturing Engineers) and ASQC (American Society of Quality Control) represent groups of engineers whose areas of practice tend not to be included as specialties within the discipline societies. Usually they have no recognition through the state licensing laws. To gain recognition, these societies had, or were establishing, certification programs.

Stronger relicensing requirements were in the wind for all professions. For engineering, the state engineering societies were working with the state registration boards on this issue. There was indication (as of 1974) that strengthening of relicensing was under consideration in some states, In Iowa the state engineering society actually recommended that the law be changed to require 40 hours annually of reported professional development. The certification proponents, of course, were critical of registration because no further proof of competence was required after the license was secured.

NCEE was working with the state boards on relicensing requirements that might be acceptable to the engineering societies. It was also willing to facilitate certification programs in the same way it worked with the licensing state boards. NSPE had sponsored two intersociety meetings on certifications; one was previously mentioned. However, EJC was perhaps in the strongest position to promote certification. At least, the record indicates that EJC was moving aggressively toward organizing and unifying such a program.*

President Carl W. Hall was asked by EJC in January 1975 to declare the

*This and the preceding three paragraphs are from an unpublished analysis: "Response of Engineering Societies to Certitication and Relicensing Requirements," by James T. Cobb. Jr. Department of Chemical and Petroleum Engineering. University of Pittsburgh. Circulated by EJC. 
position of ASAE relative to certification. If ASAE had, or intended to have within three years, a certification program then ASAE would have a seat on the Commission on Certification. Hall delayed reply while he searched the Board and Council minutes for a statement of policy. There was no statement of ASAE policy on the issue. Hall wrote Jimmy Butt that his recollection was ASAE should "remain on the sidelines and watch the development of the certification program but try to avoid getting our feet wet by investing dollars and making long range commitments." Butt wrote Hall on about the same date that ASAE's loss of charter member status in the commission would not be of great consequence. The only future problem he could foresee was that another society might begin to certify engineers in some area of ASAE's expertise. Consequently, EJC was informed that ASAE "neither has a certification program in effect nor plans to have one in effect for the next three years."

Fourteen societies joined the EJC Commission as regular members. The better known of this group included AIIE, ASHRAE, and IEEE. Of those fourteen societies, only the industrial and electrical engineering societies represented disciplines with college curricula identified with the field. Nine other societies, including ASAE, chose to maintain contact with the Commission only as "observers." Several prominent societies (ASCE, AIChE, AIME) had made no decision as of August 1975.

ASAE, it seemed, did not want to be in the vanguard of a movement that had potential for increasing the already high state of confusion in the public mind regarding who is and who is not an engineer. In March 1971 Lawrence Skromme attended a meeting in Washington, DC, of the National Research Council. There he listened to an address by Clarence $\mathrm{H}$. Linder, president of the National Academy of Engineering, on "The Structure of the Engineering Community." Skromme reported that Linder characterized the agricultural engineers as being "conservative, right wing members of the engineering community."

Texans are that way also. Texas law provides that only registered professional engineers can use the term "engineer." The Society of Manufacturing Engineers (SME) and the National Association of Corrosion Engineers both had certification programs. In 1975 they asked the Texas attorney general if the law prohibited an individual (non-registered engineer) from displaying or making public his membership in or accreditation by an association of engineers. The attorney general held that an individual who is not a registered engineer may not display or use memberhsip or certification by an association using the term 'engineer' in its name in his professional or business activity.

SME took the case to the Texas Supreme Court, which upheld the Texas 
Engineering Practices Act. Presumably, therefore, a certified but nonregistered engineer, or any non-registered engineer, may not even display a certificate of membership in a recognized engineering society in his office.*

Although the decision caused considerable furor, it stopped many abuses of the term "engineer." Some claim that increased respect and professional status have resulted for those bearing the title "engineer." Other states have considered enactment of laws similar to the Texas Statute. This statute forced the concept of certification to be linked with registration in attaining professional recognition.

Statutory professional discrimination against agricultural engineers in Louisiana was called to ASAE's attention by Merritt E. McDonald in August of 1970. McDonald, a registered P.E., was a consulting agricultural engineer with offices at Baton Rouge. In a letter to AGRICULTURAL ENGINEERING he observed that "Legislation is being promoted in this state by the Louisiana Engineering Society in their professional policy and has been enacted in many local building codes that accepts only E.E. stamps on electrical drawings, M.E. stamps on mechanical drawings and C.E. stamps on structural drawings." This resulted in a large number of multi-million-dollar agricultural facilities being designed by engineers other than agricultural engineers. In brief, McDonald wanted to know what ASAE could do to assist the Louisiana ASAE members confronted by this problem.

As was logical, the ASAE Louisiana Section entered the conflict first. After considerable discussion and investigation it was determined that legal action was called for. At that point contact with Jimmy Butt was made during November 1971 and ASAE was asked to financially support a legal action against certain governmental agencies. In a December 6, 1971 letter to Billy B. Bryan, Director of the Southwest Region, the Louisiana Section implied that ASAE Headquarters was reluctant to give them the support they wanted and asked Bryan to take their problems to the Board of Directors.

The Louisiana members were probably ill-informed as to the mechanics of how ASAE leadership action was accomplished. Their problems were discussed at the December meeting of the Executive Committee. Headquarters was authorized to cooperate with the Louisiana Section and to ex-

*In Texas, teachers of engineering are held to be engaged in practice of engineering. If they bear a title such as "Professor of Engineering," they must be registered. Young instructors and assistant professors are allowed a reasonable time to accomplish the experience requirements of registration. 
pend funds to keep the ASAE attorney informed of the actions taken by the Section's attorney. But ASAE Headquarters could not authorize financial assistance in a court action without approval of the Board of Directors.

The Executive Committee met on May 1, 1972 and reviewed all correspondence. Professional Development Director J. R. Davis was asked to schedule a meeting with representatives of the Louisiana Section at the June Annual Meeting at Hot Springs. It was hoped that a plan of action might emerge that would solve the problem without need for going to court.

The case was discussed at some length during the Board of Directors meeting at Hot Springs. The Louisiana members now desired to obtain a legal opinion from the newly elected attorney general on the right of agricultural engineers to practice in that state. It was voted that ASAE support the Louisiana Section with up to $\$ 500$ in its effort to obtain the opinion, and that the opinion could be sought in the name of ASAE if no legal impediment existed. Further, the Professional Development Department and the Professional Registration Committee were directed to determine if similar situations existed in other states and to recommend remedial action if necessary.

All ASAE members were informed of Louisiana problems by a comprehensive article published by Ted Nissing and Wiley Poole in the September 1972 AGRICULTURAL ENGINEERING. Nissing and Poole were affiliated with Louisiana State University; Poole was chairman of ASAE's Committee A-414 on Engineering Registration. In brief, an act of 1950 provided for registration by certain branches of engineering, including agricultural. The State Board of Registration did not define the scope of work falling within each branch. The cities and parishes (counties) of Louisiana had amended their building codes so that only architects or civil engineers could prepare plans and specifications for buildings and structures. This excluded agricultural engineers from design of auction barns, agricultural processing plants, livestock production systems, agricultural warehouses, refrigerated food storage structures, and similar installations. Also, such facilities might be designed by unqualified persons.

Nissing and Poole called upon agricultural engineers to become registered as a basic prerequisite of professionalism. They charged agricultural engineers to "vigilantly spotlight discriminatory employment practices created by the older established engineering disciplines," noting that discrimination existed in other states as well as Louisiana. They did not mention how Louisiana Section and ASAE were attempting to break down the discrimination in Louisiana.

When the Board of Directors convened in December 1972 J. R. Davis, Professional Development Director, reported that apparently only two states had 
right-to-practice problems: Louisiana and New Mexico. He commented that this kind of problem was less likely to occur in states where engineers are not registered by branch; Nissing and Poole noted this also.

The attack upon Louisiana discrimination took the form of a memorandum from the Louisiana Section to the state's Attorney General requesting an opinion on these key issues:

1. If in Louisiana a fire marshal can automatically reject plans for construction of public or private utilities, structures, machines, equipment, processes, works and products not drawn up by a licensed architect or civil engineer, and

2. If the agricultural engineer in Louisiana can legally plan, design, and supervise construction of public or private utilities, structures, machines, equipment, processes, works or projects when these require the application of engineering principles and interpretation of engineering data.

A 1970 Louisiana Attorney General opinion held that the fire marshal was empowered to decide what is engineering and what is architecture, and to reject plans not drawn up by an architect or a "civil" engineer. The Louisiana Section memorandum contended that the fire marshal is not qualified to decide such questions. It further contended that the form "civil engineer" may have meant to include all professional engineers; if it did, then agricultural engineers registered in Louisiana should be accepted as qualified for appropriate design work. If "civil engineer" meant only a specific engineering specialty, then qualified agricultural engineers were illegally discriminated against in the practice of their profession.

The results of the attack upon Louisiana's status quo were announced in the October 1973 AGRICULTURAL ENGINEERING. The Attorney General ruled that "agricultural engineers can plan, design and supervise the construction of public or private works so long as the work contemplated requires the application of engineering principles and the interpretation of engineering data." Also, the Attorney General wrote a letter to the state fire marshal informing him that any professional engineer can plan, design, and supervise the construction of various engineering projects. In particular, the fire marshal should not automatically reject construction plans unless drawn by a licensed architect or civil engineer; the activity subsumed under "civil engineering" deals with the entire field of professional engineers. In conclusion, he informed the fire marshal that the opinion of 1970 was reversed.

Therefore, ASAE, by establishing this legal precedent, achieved a major professional advancement for agricultural engineers, not only in Louisiana but in any state where such discrimination might be practiced or attempted. As Nissing and Poole wrote in 1972, "Agricultural Engineers must be allowed to fill their rightful roles within the engineering profession-with their 
successes limited only by their own abilities."

Professional development has demanded a struggle for appropriate education, identification, and status for the agricultural engineer since 1907. Status has been achieved to a major extent through cooperative and individual effort, dedication to the world's most important industry, and a fair amount of ethical behavior. Engineering is a joyful pursuit; agricultural engineering is especially so because it provides people with the most basic necessities. How joyful it has been for members of ASAE to see their professional status gradually expand over a period of 70 years and finally to take their place as members of a profession ranked second only to medicine for honesty and ethical standards.* The possession of status and public trust confers opportunity to serve as never before possible. President Cornelius Wandmacher of ASEE (American Society for Engineering Education) told ASAE members at the 1974 Winter meeting that "Recent technological developments now give us the greatest opportunity ever to plan ahead for food, clothing, shelter, personal services, and utilization of natural resources all on a one-world basis and for the benefit of all mankind."

How joyful it is to be a trusted professional in command of a technology so crucial, but how humbling the obligation and responsibility.

* Results of a 1976 Gallup poll ranking the medical profession first and engineering a close second as perceived by the public according to honesty and ethical standards. Of 11 professions so ranked, Congressmen were at the bottom. 


\section{Epilogue}

ASAE and agricultural engineering have moved forward a long way from 1907 to 1977. The technology developed by agricultural engineers and codified by ASAE has profoundly influenced the patterns of life in the United States and large areas of the world.

What lies in the future?

In December 1975 the Board of Directors adopted a set of long-range goals for ASAE. The overriding goal of this program is "To lead in developing and implementing engineering-technology-for-agriculture that will optimally serve human needs and aspirations both now and in the future."

Technology in optimal service of mankind offers a worthy future indeed for agricultural engineering. But to achieve it will demand continual reassessment of the economic, social, and political realities. For example, the manless, totally automated agriculture predicted during ASAE's celebration of the U.S. Bicentennial may be not only socially undesirable but impossible in a future depleted of fossil fuels.

Through ASAE, agricultural engineering can best influence and respond to the future. When the panicky uninformed will perceive non-problems and divert resources to their solution; ASAE can offer wise and reasoned guidance through (as always) sound new research techniques, standards, and education. When old and important problems will be ignored or downgraded, ASAE can draw upon its rich storehouse of knowledge for old technology to be fitted to a new age. And, through its unique organization, ASAE will have the capacity to discern emerging problems and respond with proposals for their solution.

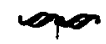

By the end of June 1977, ASAE and agricultural engineering had left the American landscape and society forever changed. If past is prologue, the profession will continue to effect change. May the changes optimally serve human needs and aspirations. 
Harry M. Bainer

William Boss

Leon W. Chase

Bascom B. Clarke

Fred R. Crane

J. Brownlee Davidson

\section{CHARTER MEMBERS}

Robert M. Dolve

John Evans

Christian I. Gunness

Elmer W. Hamilton

Everett W. Hamilton

Matthew L. King
William M. Nye Charles A. Ocock Howard W. Riley Philip S. Rose Earl A. White John G. Wynn

\section{PRESIDENTS OF THE ASAE}

*J. Brownlee Davidson ....... 1908

*John G. Wynn ........ 1909

*Philip S. Rose ......... 1910

*Charles A. Ocock ....... 1911

*Howard W. Riley ....... 1912

*Leon W. Chase .......... 1913

*Wallace F. MacGregor . . . . . . 1914

*Harry H. Musselman ...... 1915

*Frank M. White ......... 1916

*Edmund B. McCormick .... 1917

*Daniel Scoates ........ 1918

Raymond Olney ....... 1919

* Frank N. G. Kranick . . . . . . 1920

*Earl A. White ........ 1921

*Arthur J. R. Curtis . . . . . 1922

*Emil W. Lehmann . . . . . . . . 1923

* Samuel H. McCrory . . . 1923-24

*Frederick W. Ives ...... 1924-25

*Frederick A. Wirt . . . . . 1925-26

* Oscar W. Sjogren ... . 1926-27

* Oliver B. Zimmerman . . . 1927-28

*William Boss ...... 1928-29

*William G. Kaiser . . . . . 1929-30

* Robert W. Trullinger ... 1930-31

Leonard J. Fletcher ... . 1931-32

* Charles E. Seitz . . . . . 1932-33

* Arthur Hunitington ..... 1933-34

* Glen W. McCuen ..... 1934-35

* Lawrence F. Livingston . . 1935-36

*Ralph U. Blasingame . . . . 1936-37

*Arnold P. Yerkes . . . . . 1937-38

Samuel P. Lyle . . . . . . 1938.39

* Karl J. T. Ekblaw . . . . . 1939-40

* Elmer E. Brackett . . . . . 1940-41

* George W. Kable . . . . . 1941.42

*Harry B. Walker ...... 1942.43
* Arthur W. Turner ..... . 1943-44

Rudolph H. Driftmier . . . 1944-45

J. Dewey Long . . . . . . . 1945-46

*Mark L. Nichols . . . . . 1946-47

*George A. Rietz . . . . . 1947.48

Arthur J. Schwantes . . . 1948-49

Frank J. Zink . . . . . . 1949-50

Frederick C. Fenton .... 1950-51

Stanley M. Madill . . . . . 1951-52

Ivan D. Wood ....... $1952-53$

Edwin W. Tanquary .... 1953-54

George B. Nutt . . . . . . 1954-55

Wayne H. Worthington . . 1955-56

Roy Bainer ........ 1956-57

Earl D. Anderson ..... 1957-58

*Eugene G. McKibben . . . . 1958-59

Lawrence H. Skromme .. . 1959-60

*Lloyd W. Hurlbut ... . . . 1960-61

Byron T. Virtue ..... 1961-62

Arthur W. Farrall ..... 1962-63

John W. Borden ..... 1963-64

Price Hobgood ........ 1964-65

*Charles S. Morrison .... 1965-66

Orval C. French ..... 1966-67

Russell R. Poynor . . . . . 1967-68

Talcott W. Edminster ... 1968-69

Norval H. Curry . . . . 1969-70

Robert E. Stewart . . . . 1970-71

Hugh J. Hansen. . . . . . . 1971-72

*Clarence F. Kelly . . . . . 1972-73

Lawrence H. Hodges . . . . 1973-74

Carl W. Hall ....... 1974-75

Sherwood S. DeForest . . . . 1975-76

* Frank B. Lanham . . . . 1976-77

William G. Moore . . . 1977-78 


\section{HONORARY MEMBERS}

${ }^{*}$ Arthur O. Fox (1908) ${ }^{\dagger}$

${ }^{*}$ Franklin H. King (1908)

* Bascom B. Clarke (1911)

* John B. Bartholomew (1921)

*Joseph D. Oliver (1921)

*William Louden (1921)

*Willard A. Van Brunt (1922)

*Elwood Mead (1923)

* Samuel Fortier (1923)

*Oscar Van Pelt Stout (1928)

*John J. Glessner (1929)

*William N. Rumely (1933)

* Oliver B. Zimmerman (1937)

*Claude R. Wickard (1945)

*Walter W. McLaughlin (1946)
*J. Brownlee Davidson (1946)

*G. E. P. Smith (1955)

Leonard J. Fletcher (1956)

*Harry B. Walker (1957)

*Dwight D. Eisenhower (1957)

Ezra Taft Benson (1957)

*Charles Edward Seitz (1959)

Wallace Ashby (1960)

Mason Vaugh (1960)

*William G. Kaiser (1961)

*George D. Clyde (1963)

*Charles S. Morrison (1967)

Andrey A. Potter (1969)

Roy Bainer (1977)

* Decensed

+Year elected 


\section{ASAE Medalists and} Award Winners

\section{The Cyrus Hall McCormick Medal}

Presented annually since 1932 "For Exceptional and Meritorious Engineering Achievement in Agriculture."

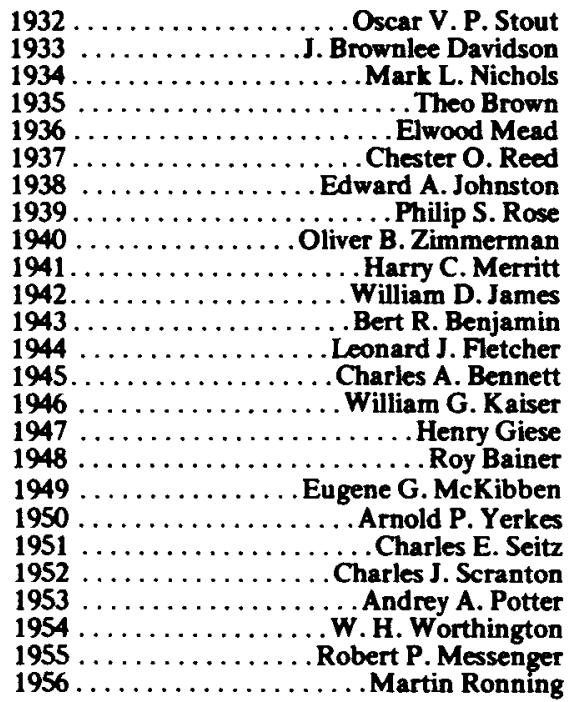

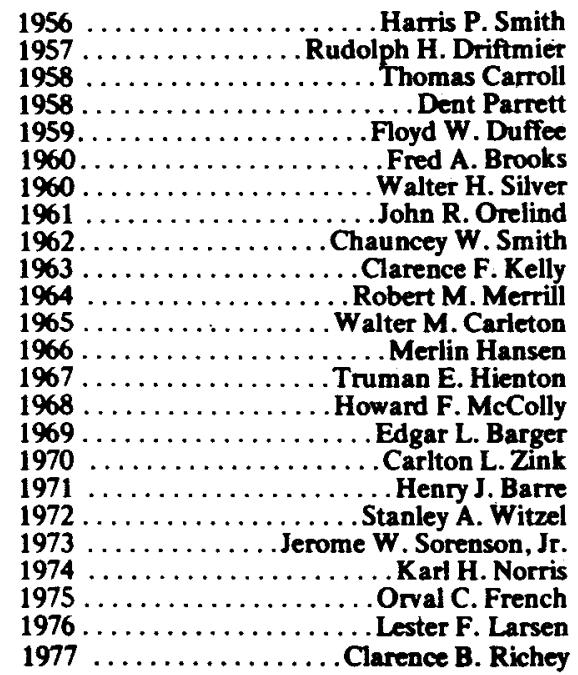

$1956 \ldots \ldots \ldots \ldots \ldots \ldots \ldots \ldots \ldots \ldots \ldots$ Harris P.Smith 1958 ................. Thomas Carroll $1958 \ldots \ldots \ldots \ldots \ldots \ldots \ldots$. Dent Parrett $1959 \ldots \ldots \ldots \ldots \ldots \ldots$. . . . . . . . . . . Duffee $1960 \ldots \ldots \ldots \ldots \ldots \ldots \ldots$. . . . . . Bred A. Brooks $1960 \ldots \ldots \ldots \ldots \ldots \ldots$ Walter H. Silver $1961 \ldots \ldots \ldots \ldots \ldots \ldots$ John R. Orelind $1962 \ldots \ldots \ldots \ldots \ldots$ Chauncey $W$. Smith $1963 \ldots \ldots \ldots \ldots \ldots \ldots$ Clarence F. Kelly $1964 \ldots \ldots \ldots \ldots \ldots$. . . . . . . Mert M. Merrill $1965 \ldots \ldots \ldots \ldots \ldots \ldots$ Walter M. Carleton $1966 \ldots \ldots \ldots \ldots \ldots \ldots$. . . . . . . . . . . . . . . $197 \ldots \ldots \ldots \ldots \ldots$ Truman E. Hienton $1968 \ldots \ldots \ldots \ldots \ldots$. . . . . . . Mard F. Melly $1969 \ldots \ldots \ldots \ldots \ldots \ldots$. . . Edgar L. Barger $1970 \ldots \ldots \ldots \ldots \ldots \ldots$ Carlton $L$. Zink 1971 . . . . . . . . . . . . . Henry J. Barre $1972 \ldots \ldots \ldots \ldots \ldots \ldots$. Stanley A. Witzel 1973 ........... Jerome W. Sorenson, Jr. $1975 \ldots \ldots \ldots \ldots \ldots \ldots \ldots$ Orval C. French $1977 \ldots \ldots \ldots \ldots \ldots \ldots$ Clarence B. Richey 


\section{The John Deere Medal}

Presented annually since 1938 for "Distinguished Achievement in the Application of Science and Art to the Soil."

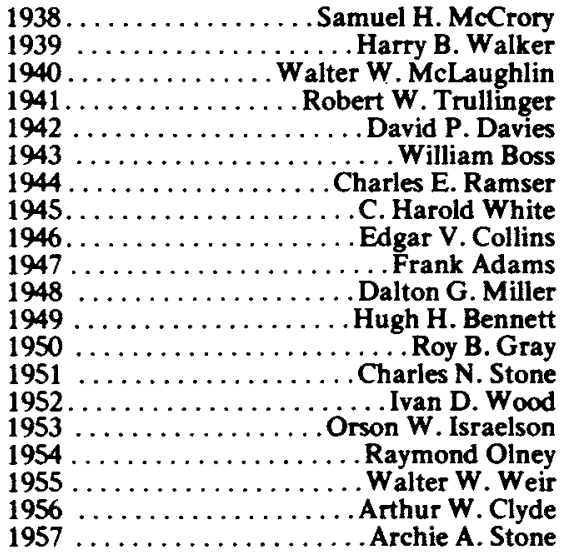

\begin{tabular}{|c|c|}
\hline $\begin{array}{l}1958 . \\
1959 \\
1960 \\
1961 . \\
1962 . \\
1963 \\
1964 . \\
1965 . \\
1966 \\
1967 . \\
1968 \\
1969 . \\
1970 \\
1971 \\
1972 \\
1973 . \\
1974 \\
1975 . \\
1976 . \\
1977 .\end{array}$ & 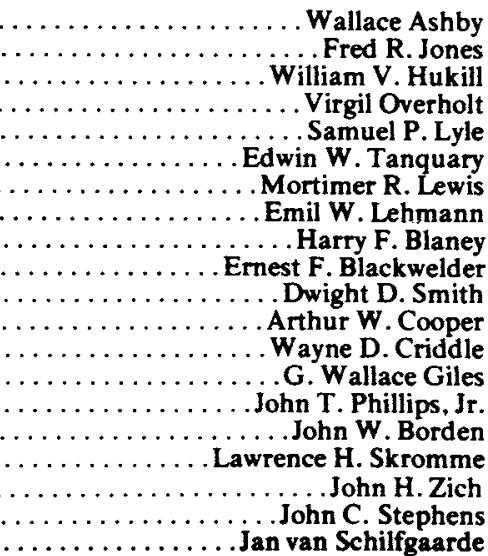 \\
\hline
\end{tabular}

\section{Metal Building Manufacturers Association (MBMA) Award}

Inaugurated in 1959 to be presented annually to ASAE members whose activities lie in the farm structures field "For distinguished work in advancing the knowledge and science of farm buildings."

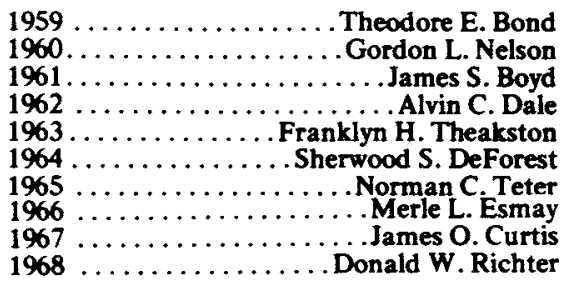

$1969 \ldots \ldots \ldots \ldots \ldots \ldots$ Landis L. Boyd $1970 \ldots \ldots \ldots \ldots$......... Howard K. Johnson $1971 \ldots \ldots \ldots \ldots \ldots \ldots$ Thamon E. Hazen 1972 . . . . . . . . . . . . Robert R. Rowe $1973 \ldots \ldots \ldots \ldots \ldots \ldots$ Bruce A. McKenzie $1974 \ldots \ldots \ldots \ldots \ldots \ldots \ldots$ John $\mathbf{N}$. Walker 1975 . . . . . . . . . . . . Warren L. Roller $1976 \ldots \ldots \ldots \ldots \ldots \ldots$. G. LeRoy Hahn $1977 \ldots \ldots \ldots \ldots \ldots \ldots$. . Frank Wiersma 


\section{The Massey-Ferguson Medal}

Inaugurated in 1964 to be presented annually "To honor those whose dedication to the spirit of learning and teaching in the field of agricultural engineering has advanced our agricultural knowledge and practice, and whose efforts serve as an inspiration to others."

1965

1967

1968

1969

1970

1971
Rudolph H. Driftmier Mack M. Jones Price Hobgood Frederick C. Fenton Ervin W. Schroeder . No Recipient Arthur W. Farrall
1972

1973

1974

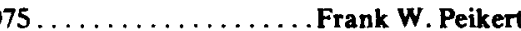

$1976 \ldots \ldots \ldots \ldots \ldots \ldots \ldots$ Carl $\mathbf{W}$. Hall $1977 \ldots \ldots \ldots \ldots \ldots$. . S. Milton Henderson

\section{The Hancor Soil and Water Engineering Award}

Presented annually "For noteworthy contributions to the advancement of soil and water engineering in teaching, research, planning, design, construction or management, or methods and materials."

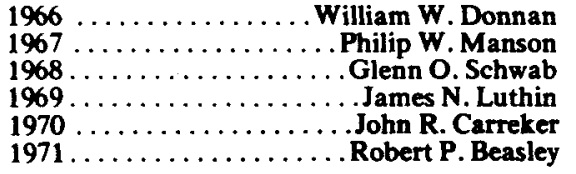

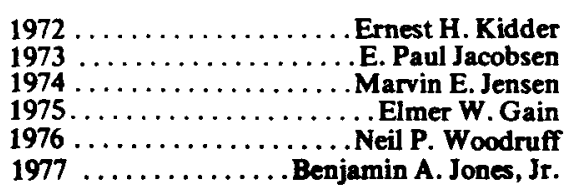

$1972 \ldots \ldots \ldots \ldots \ldots \ldots$ Ernest H. Kidder

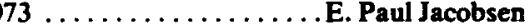
1975 1976 . . . . . . . . . . . . . Neil P. Woodruff $1977 \ldots \ldots \ldots \ldots$. . Benjamin A. Jones, Jr.

\section{The George W. Kable Electrification Award}

Presented annually to honor individual agricultural engineers "For outstanding personal and professional contributions in applying electrical energy to the advancement of agriculture through agricultural engineering."

$1 \% 9$

1970

1971

1972

1973.
Everette C. Easter

H. Seymour Pringle

Morris H. Lloyd .... Nolan Mitchell William E. McCune
1974

Kenneth L. McFate $1975 \ldots \ldots \ldots \ldots \ldots \ldots$. Frank W. Andrew $1976 \ldots \ldots \ldots \ldots \ldots \ldots \ldots$. . . . . . . . Winn $1977 \ldots \ldots \ldots \ldots \ldots \ldots$. Clesson N. Turner 


\section{The DFISA-ASAE Food Engineering Award}

Presented biennially to "Honor those who have made original contributions in research, development, or design . . or in the management of food processing equipment or techniques of significant economic value to the food industry and the consumer." Walter M. Urbain

\section{Engineering Achievement Awards}

Presented annually, "To honor members of ASAE under forty years of age for outstanding contributions to the advancement of the profession and to stimulate professional achievement in the fields indicated."

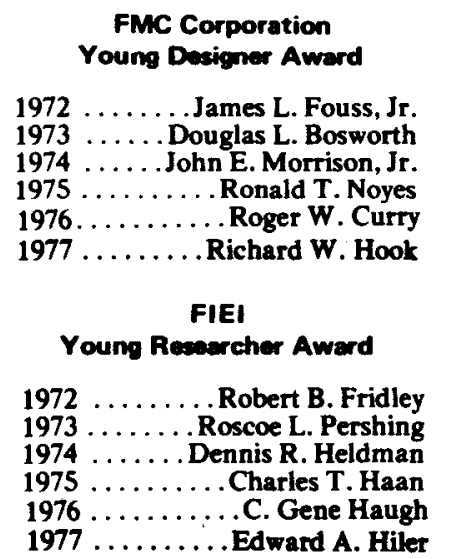

\section{A. $\boldsymbol{W}$. Farrall \\ Young Educator Award}
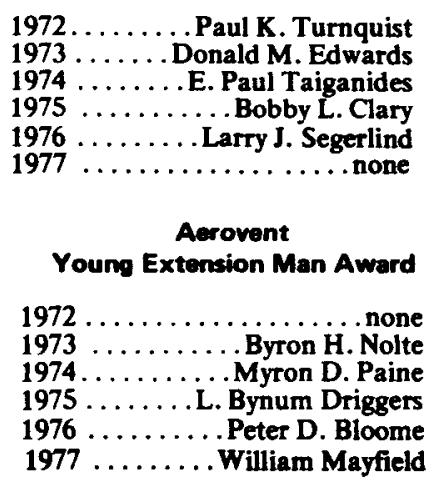

\section{Doerfer Engineering Concept of the Year Award}

Presented annually, "To the engineer or engineers making the most outstanding contributions in the development or advancement of a new engineering concept." One person, representing the team, receives the plaque. 


\section{The John G. Sutton Memorial Award}

Presented annually "To the outstanding junior student in one of the agricultural engineering departments in the United States."
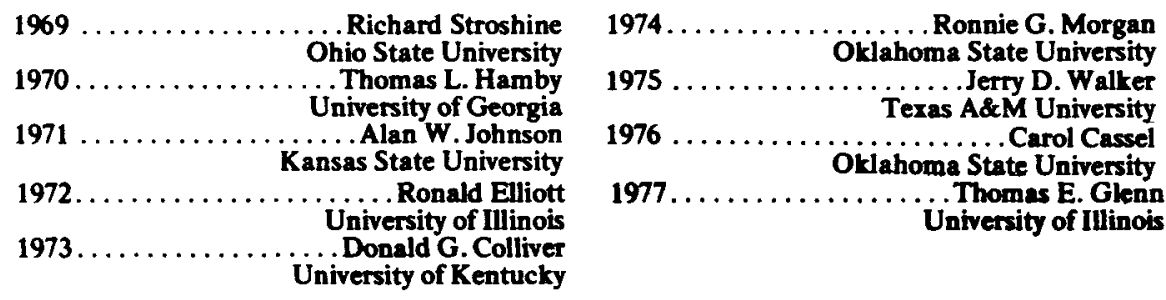

\section{The G. B. Gunlogson Countryside Engineering Award}

Presented annually "To honor outstanding engineering contributions to the healthy climate of the American countryside and to a viable economy for its small towns." 


\section{ASAE Student Paper Award Winners}

Student Paper Awards are presented annually to encourage undergraduate students in the preparation of better papers. ASAE records do not list Student Paper Award winners prior to 1953. Documentation of earlier winners would be appreciated by ASAE.

1953 . . . . . (Graduate Class) G. E. Williams University of Nebraska (Undergraduate Class) Robert PalmerOklahoma State University $1954 \ldots \ldots \ldots \ldots$ E. E. Nelson .......... Ohio State University $1955 \ldots . . . \ldots$. . . Gerald Zachariah . . . Kansas State University $1956 \ldots \ldots \ldots$. . . . Daniel Van Duyne ....... Pennsylvania State University $1957 \ldots \ldots$. . . . . Irvin Eickmeyer . . . . . . University of Illinois 1958 . . . . . . . . Robert Mensch . . . . . . Iow a State University $1959 \ldots \ldots \ldots$. . . . . Roland Gehman. Pennsylvania State University $1960 \ldots \ldots \ldots$. . . . . . . . . . . . . Ohio State University

$1961 \ldots \ldots \ldots \ldots$ John Cannon . . . . . . . . Utah State University $1962 \ldots \ldots \ldots$ J . . . . . Smes $\ldots \ldots \ldots$ University of Illinois

$1963 \ldots \ldots \ldots \ldots$. Neil Webster . . . . . . . . University of Maine

$1964 \ldots \ldots \ldots$. . . . John Hummel . . . . . University of Maryland 1965 . . . . . . . . James Burkholder . . . . . Virginia Polytechnic Institute and State University

$1966 \ldots \ldots \ldots$. . . . David Thompson........ Purdue University

$1967 \ldots \ldots \ldots$. . . Will Hamilton .... Oklahoma State University

1968 . . . . . . . . Larry Kluesner . . . . . . University of Missouri

$1968 \ldots \ldots$. . . . . James Steichen ... . Oklahoma State University $1970 \ldots \ldots$. . . . . R. A. Ridout . . . Virginis Polytechnic Instituie Thomas Kudson .... West Virginin University $1972 \ldots \ldots$. . . . Larry Bilien . . . . . OkJahoma State University $1973 \ldots . . \ldots \ldots$. . . . . . . . Oknie Morgan ... Otate University 1974 . . . . . . . . . Jacob LaRue ... North Dakota State University 1975 . . . . . . . . Ronnie Morgan ... Oklahoma State University $1976 \ldots . . \ldots \ldots$. . . Dirk Peterson ....... . University of Nebraska $1977 \ldots \ldots \ldots$. . . Rick Marshall . . . . . . . . Cornell University 


\section{ASAE Past Presidents Award}

The ASAE Council of Past Presidents recognizes outstanding support of Society activities by companies, agencies, organizations or groups. The recognition consists of a Past Presidents Award plaque presented at the Winter Meeting to the chief ofticer of the group being honored.

\section{5}

Sperry New Holland H. G. McCarty Vice President and General Manager International Harvester . . . . . . . . . . . . . . . . . . J. President, Agricultural Equipment Division

Deere \& Company . . . . . . . . . . . . . . . . . . . Gordon H. Vice President Engineering

The University of Wisconsin Glenn $\$$. Pound

Dean of Agriculture

J I Case Morris W. Reid

Chairman

Jowa State University Lee R. Kolmer Dean of Agriculture

Farm and Industrial Equipment Institute ......... H. H. Rawson President

United States Department of Agriculture T. W. Edminster Administrator, ARS

\section{6}

The University of Georgia $\ldots \ldots \ldots \ldots \ldots \ldots \ldots$ Fred C. Davison President

Lilliston Corporation . . . . . . . . . . . John T. Phillips, Jr.

Ford Tractor Operations, Ford Motor Company ......... L. R. Ross

Vice President and General Manager Massey-Ferguson Limited . . . . . . . . . . . . Albert A. Thornbrough

President

National Safety Council Vincent L. Tofany President

1977

A. O. Smith Harvestore Products, Inc. ......... John H. Brinker

Chairman National Tillage Machinery Laboratory, USDA ...... William R. Gill

Director

Chain Division, FMC Corporation J. M. Gordon Manager Allis-Chalmers Roy W. Uelner Erecutive Vice President The University of Nebraska $\ldots \ldots \ldots \ldots \ldots \ldots \ldots \ldots$ Roy Young 


\section{Sources of Historical Information}

To avoid distracting the reader, footnotes were kept to a minimum. In many cases internal documentation is used in the text.

Principal sources of information and bibliographic aids were as follows.

a. Transactions, American Society of Agricultural Engineers, with Business Records. 1907-1935.

b. TRANSACTIONS of the ASAE. 1958-1977.

c. AGRICULTURAL ENGINEERING. 1920-1977.

d. Agricultural Engineering Index 1907-1960, by Carl W. Hall.

e. Agricultural Engineering Index 1961-1970, by Glenn E. Hall and Carl W. Hall.

f. American Society of Agricultural Engineering Bulletins: July 1, 1914; January 1, 1915; April 1, 1915; June 1, 1915; August 1, 1915; September 1, 1915; November 1, 1915.

g. Newsletter, ASAE, issued monthly from January 1916 to August 1920.

h. Secretary's Letter, issued irregularly to the members in mimeo from March 1, 1923 to August 31, 1944.

i. News Letter, issued monthly to the members in mimeo from September 1944 to December 1946.

j. In the 1960s A. W. Farrall collected ASAE historical information on a number of topics from Howard Matson, Ralph Palmer*, T. E. Hienton*, Page Bellinger*, E. W. Schroeder, C. W. Hall*, Walter Carleton*, E. G. McKibben*, R. H. Driftmier*, G. L. Nelson, J. L. Butt*, C. B. Richey, B. T. Virtue, Chauncey Smith, Virgil Overholt, E. H. Kidder, Ralph Hay, Ben Jones, J. E. Harmond, Clyde Walker, Lloyd Hurlbut*, and Arnold Skromme*. Materials compiled by those whose names are starred were used in this book. The collection also contained a copy of the memorial presented by the ASAE leaders to President Coolidge in 1927 and news clippings regarding this event.

k. Secretary's Annual Reports, 1908-1977.

1. Secretary's Correspondence Files, 1909-1977.

m. Minutes of the Council, Board of Directors, Executive Committee, Technical Council, Administrative Council, Regional Council, starting in 1924 and running through the reorganization of 1968 to 1977.

n. AGRICULTURAL ENGINEERS YEARBOOK, 1954-1977.

o. Private correspondence and conversation with ASAE past-presidents and others, including Frank Lanham, H. P. Smith, C. F. Kelly, L. H. Hodges, Price Hobgood, Carl W. Hall, George Nutt, Roy Bainer, C. M. Hansen, Norval Curry, Hugh Hansen, Edwin Tanquary, Byron $T$. Virtue, A. W. Farrall, S. S. DeForest, L. J. Fletcher, T. W. Edminster, Samuel P. Lyle, J. Dewey Long, Earl D. Anderson, E. G. McKibben, 
Lawrence Skromme, Arnold Skromme, J. W. Borden, O. C. French, R. R. Poynor, James Ebbinghaus, G. W. Steinbruegge, Andrew Hustrulid, H. J. Barre, E. W. Schroeder, and J. L. Butt.

p. Roy Bainer, The Engineering of Abundance. Oral History Program, University of California, Davis, 1975.

q. Edwin T. Layton, Jr., The Revolt of the Engineers. Case Western Reserve University Press, 1971.

r. Miscellaneous ASAE archival materials, including some early correspondence of J. B. Davidson.

s. William E. Akin, Technocracy and the American Dream. University of California Press, 1977.

t. Webster's Guide to American History, G. \& C. Merriam Company, 1971.

u. 1974 Britannica Book of the Year, Events of 1973. Encyclopaedia Britannica, Inc. 1974.

v. R. B. Gray, Development of the Agricultural Tractor in the United States. Part I. USDA-ARS Information Series No. 107, 1956.

w. Power to Produce, The Yearbook of Agriculture, USDA, 1960.

$x$. J. R. Kluger, Elwood Mead: Irrigation Engineer and Social Planner. Ph.D. Dissertation, University of Arizona. 1970.

y. F. H. Buelow, Chairman, Agricultural Engineering Department, University of Wisconsin, for locating picture of ASAE second president.

z. Engineering Dean's Office, Kansas State University, for picture of ASAE tenth president.

\section{Author's Acknowledgements}

ASAE's Executive Vice-President Jimmy L. Butt for many years of encouragement and valuable suggestions.

ASAE's retired Treasurer Ralph Palmer for crucial assistance with ASAE archives, for valuable suggestions, and for personal recollections.

ASAE's James Basselman and Marianna Pratt, Director of Publications and Managing Editor, respectively, for editorial assistance and valuable suggestions.

Edward A. Hiler, Head, Texas A\&M Department of Agricultural Engineering, for encouragement and interest.

Price Hobgood, ASAE Past-President and former Head, Texas A\&M Department of Agricultural Engineering, for encouragement and interest.

Mrs. Gladys Taylor, secretary, Texas A\&M Department of Agricultural Engineering, for typing the entire manuscript.

Mrs. Bonnie Stewart, assistant editor, Texas Agricultural Experiment Station, for assistance with writing and proofreading and for valuable suggestions. 


\section{Index}

\section{A}

Abourezk, J. G., 399,400

Accreditation, 133, 305, 307

Accreditation of Engineer Certification, National Commission for 402

Ad Hoc Task Force on Energy in Agriculture, 382

Advance-Rumely Company, 22

Advertising, 200

AFL-CIO, 398

Agri-bicengineering, 370

"Agri-Business in the Year 2000" 342

Agricultural Adjustment Act (1933), 119

Agricultural Adjustment Administration (AAA), 116, 118

Agricultural chemicals, 244, 246

Agricultural engineet, 180

AGRICULTURAL ENGINEER. ING, $6,32,36,38,326,327$, $329,393.395$

Agricultural Engineering Bulketin, 200

Agricultural Engineering Company, 35

Agricultural engineering coordinator, 196

Agricultural Engineers Creed, 154

Agricultural Engineering Data Book, 199

Agricultural engineering definition, 408

Agricultural engineering education, 49

Agricultural Engineering Index, 161

Agricultural Engineering Research Branch, 198

Agricultural Engineering Student's Conference, 10

Agricultural engineering technology. 315

Agricultural engineering texts, 56

Agricultural Engineers Yearbook. 200,217

Agricultural mechanization clubs (see ASAE Committees)

Agricultural mechanization chubs, 349

Agricultural mechanization, 131

Agricultural wastes, 245

Ahrens, M. C., 326

Akesson, Norman B., 244

Alabama Polytechnic Institute, 60 70,182

Alabame Power Company, 107, 363

Alcom County, Mississippi, 112

Alexander, C. O., 12

ALGCU, 239

Allahabad Agricultural Institute, 177

Allis-Chaimers Company, 28, 294, 329, 340, 357
Allis-Chalmers, "WC", 371

All purpose trector, 78

Alpers, Robert, 206, 208

Altman, L. B., 353

Alt, Fred, 251

Amarillo, Texas, 94

America and the American Farmer, 357

American Association for the Advancement of Science, 185, 338

American Dairy Science Association, 247

American Engineering Council, (AEC) $43,49,60,83,110,111$, $118,120,121,129,130,135$. 136

American Farm Bureau Federation, 40

American Farm Economics Association, 215

American Feed Manufacturers Association, 394

American Film Festival, 194

American Institute of Chemical Engineers (AIChE), 404

American Institute of Electrical Engineers (AIEE), 135, 136, 169 $187,220,404$

American Institute of Industrial Engineers. The, 187

American Medical Association, 243

American Phytopathological Society, 243

American Radiator Company, 17

American Seeding Company, 22

American Society of Agricultural Engineers (ASAE), 76, 77

ASA E Board of Directors, 259, 260 . $261,264,267,348,349,350$ Administrative Council, 259, 260. 349

Technical Board, 259. 260 Geographic Cabinet, 259, 260. 261

Professional Boerd, 259, 260, 261 Geographic Council, 261, 263

Technical Council, 261, 263 Professional Council, 261, 264

ASAE Bulletin No. 44, 199

ASAE Cabinet, 258

ASAE Committees

Agricultural Chemical Application, 242

Agricultural Engineering Technol. $\infty 8,317$

Agricultural Mechanization Club, 349

Agricultural Processing, 203, 205

Agricultural Safety, 331

Animal Motors, 40, 44, 66

Architect, 340

Belt Machinery, 40

Bioengineering, 369, 370

Building Facilities, 271

Career Guidance, 312, 314
College, 7, 38

Colonization, 38

Computers, 381

Constitution and Bylaws, 35!

Cooperation, 150

Cooperative Relations, 53, 55

Crop Conditioning Equipment. 215

Crop Drying Equipment, 221

Curriculum and Course Content. $150,170,305,307$

Dairy Engineering. 203

Defense Activities, 178

Disc Harrow Investigation, 40

Divisional Structure, 259

Drainage, 7, 37, 38

Drainage Research, 231

Education, 49

Effects of Registration, 237

Engineering Registration, 279. 280

Evapotranspiration, 231

Farm Building, 7

Farm Building Design, 39

Farm Building Ventilation, 68

Farm Lighting, 40

Farm Machinery, 7

Farm Power Machinery, 26

Farm Safety, 150, 157, 158, 288, 289

Farm Structures Advancement, 150

Farm Work Simplification, 215

Federal Relations, 195

Finance, 270, 328

Food Engineering, 265

Foreign, 7

Forward Planning, 258, 259, 260 ,

$261,262,274$

Government Affairs, 338

Grain Handling Equipment, 40

Hay Harvesting and Storage, 150, 160

Headquarters Facilities, 340

Highway. 7

Horse Drawn Field Machinery, 40 Instruction in Agricultural Mechanization, 350

Instruction in Agriculture, 9

Instrumentation and Controls, 225

Irrigation, 7, 38

Land Clearing, 38

Left Hand Plow Investigation, 40

Meetings, 352

Membership, 7

Motion Picture, 193

Motor Contest, 23

Motor Fuels, 40

Paper Awards. 151

Patent, 7

Postwar Objectives, 150

Power Farming. 40

Professional Registration, 231.

239, 406

Public Relations, 192, 207, 282, 314 
ASAE Comenitues (ceathaned)

Publications, 7. 320

Publications Policies and Fi-

nances, 324, 325, 326

Relations of Electricity to Agticulture, 41

Relations With the Federal Power Commission. 110

Relationship of Biological Engineeting to Agricultural Engineering, 251, 255

Research, $50,60,63,64,65$,

$66,72,73,74,220,223$

Research Needs and Statistics. 245

Rural Wste Disposel, 245, 246

Senitation, 39

Social Action, 363

Soil Erosion, 38

Soil Preparation and Tillage, 102

Sprinkler Irrigation, 231

Standards, 8, 26, 27, 76, 77, 284. 285

Standards for Farm Machinery. 24

Stationary Gas Engines. 40

Student Affiliate Clubs, 350

Student Branches, 191, 320

Student Organizations, 11

Technical, 274

Thesaurus, 326

Tractor, 367

Tractor Demonstrations, 22

Tractor Field Machinery, 40

Tractor Testing and Rating. 40

Ventilation. 39

Wartime Allocation of Farm Ma-

chines, 141

Wheel Equipment, 126

ASAE Committee identification, 257

ASAE Constitution, 350

ASAE Council reorganization. 256

ASAE Dhilwe. 36, 41

"Biological Engineering". 254, 262

College, $36,37,42,50,52,53$,

$57,58,149,153,169,170,195$.

256

Consulting Engineers, 47

Education and Research, 42, 169 , $256,257,259,310,311,315-319$, 323

Electric Power and Processing.

204, 205, 247, 257, 260, 323, 353

Farm Buildings, 39

Farm Power and Equipment. 40. 77

Farm Power and Machinety. 44.

Farm Structures, 42, 45, 46, 158, 202, 205, 215, 217, 245, 247, 253, $257,260,323$

Food Engineering, 42, 323, 354

Power and Machinery, 21, 94.

$117,122,124,126-128,164,202$,

$247,254,257,262,283,323,355$, 369

Reclamation, 37, 34, 79

Rural Electric, 40, 41, 42, 79,

105. 109. 111, 112, 202, 204

Soil and $W$ ater, 197, 205, 220
$231,247,253,257,279,323,354$ Structures and Environment, 355 ASAE emblem. 273 ASAE Geerraphic Uate

ASAE Refit, 275

"Great Lakes", 274

Mid-Central, 274

North Atlantic, 35, 70, 110, 145,

$155,274,312$

North Central, 48

"North Plains", 274

Pecific Coast. 35, 46, 80, 155, 274

Pacific Northwest, 155, 274, 312

Rocky Mountain, 274

Southern, 35, 91

Southeast, 150, 155, 248, 274

Southwest, $36,155,274$

ASAE Section, 258, 275

Alabama, 276

Arizona, 276

Atkansas, 276

Baton Rouge, 273

Northern California-Nevada, 276

Southern California, 276

Florida, 276

Georgia, 274, 276, 284

Hawaii, 276

Central Illinois, 273, 276

Indiana, 276

Iowa. 276

Kentucky, 273, 276

Louisiana, 276, 405, 406, 407

Michigan, 206, 276

Minneapolis-St. Paul, 148

Minnesota, 276

Mississippi, 276

Missouri, 276

Montana, 276

Nebraska, 276

New Mexico, 276

North Atlantic, 198

North Carolina, 276

Ohio. 276

Oklahome, 276

Pennsylvania, 276

South Carolina, 273, 276

Tennessee, 273, 276, 300

Texas, 276

Virginia. 276

Washington, DC-Maryland, 242.

276

West Virginia, 276

Wisconsin, 276

ASAE Chapun, 275, 276

Acadia, 276

Baton Rouge. 276

Northern California-Western

Nevada, 276

Southern California, 276

Chicago, 148, 276

Connecticut Valley, 276

Central Illinois, 276

Quad City. 276

Snake River, 276

Spokane, 276

Washington, DC, 276

ASAE's Golden Anniversary, 190.

206, 208, 212

ASAE growth, 14

ASAE Headquarters Building (see
ASAE Committees)

ASAE membership, 380

ASAE Student Branches, 349

ASAE Transactions, 8, 14, 16, 17, $32,34,62,66,75$

ASAE Vice-Presidents, 256, 261

American Society of Agronony, 321, 341

American Society of Animal Science, 246, 247

"American Society of Biological Engineers", 250

American Society of Civil Engineers (ASCE), 1, 6, 8, 42, 135, 136, $169,189,239,246,403,404$

American Society for Engineering Education (ASEE), 185, 239, 303. 40 :

ASEE's Engincering College Research Council, 224

American Society of Heating,

Refrigerating and Air-Conditioning Engineers (ASHRAE), 341 . 404

American Society for Horticultural Science, 243

American Society of Mechanical Engineers (ASME), 1, 6, 24, 28, $77,80,135,136,169,238,341$. 403

American Society for Microbiology, 247

American Institute of Mining Engineers (AIME), 1, 404

American Society of Quality Control (ASOC), 403

American Society of Refrigerating Engineers, 220

American Society for Testing Materials (ASTM), 186, 341

American Standards Association, 186, 222, 285, 286

American Steel and Wire Company.

American Thresherman, 3

Amoco Oil Co., 393

Anderson, Dale L.. 354

Anderson, Earl D., 180, 241, 242.

$269,276,284,308,339,394$

Andrew, F. W., 290, 354

Animal motors, (see ASAE Commit tees)

Animal power, 1

Annual Meeting, 40

Aquaculturt. 296

Architect's (see ASAE Committees)

Architectural Engineering, 131

Arentson, James, 12

Argonne National Laboratory, 338

Arizons, University of, 350

Artanses, University of, 45, 69, 314 378

Army, 121, 176, 180

Army General Classification Score, 19

Ashby, Wallace, 12, 157, 197, 213, $218,277,326,327$

Asian policy, 346

Ascociation of Land-Grant Colleges and Universities, 234, 321, 325 
Atlantic Ocean, 117

Auburn. Alabama, 35, 116, 126

Auburn University, 374, 380

Auchter, Dr. E. C., 146, 147

Automative Safety Foundation, 288

Autotraction, 375

Awerde, 131, 133, 155, 165

ASAE Past Presidents Award.

357, 418

Aerovent Young Extension Man

Award, 357, 415

DFSIA-ASAE Food Engineerit.g

Award, 357, 415

John Deere Medal, 413

Doerfer Engineering Concept of the Year Award, 357, 415

The Farm and Industrial Equipment Award (Student), 357, 415

The Farm and Industrial Equip-

ment Institute Young Researcher

Award, 357, 415

FMC Young Designer Award.

357,415

A. W. Fartall Young Educator

Award. 357,415

G. B. Gunlogson Countryside

Engineering Award, 357, 362, 416

Hancor Soil and Water Engineer-

ing Award, 414

George W. Kable Electrification

Award, 414

Massey-Ferguson Medal, 414

Cyrus Hall McCormick Medal,

412

Metal Building Manufacturers

Association Award. 413

Paper Awards. 417

John G. Sutton Memorial Award

(Student Agricultural Engineer

of the Year), 357, 416

Awards and Recognition Luncheon. 357

Avery Company, 8, 21. 24

Ayres, Q. C.. 38. 54

\section{B}

Bacon Bin, Inc., 350

Bainer, Harty M., 3, 9, 205

Bainer, Roy, 202, 205, 207, 209.

$210,211,212,239,257$

Bakker-Arkema, F. W.. 380

Ball, C. E.. 339

Bankhead-Jones Research Fund, 159

Barger, E. L., 124, 278

Barnes, K. K., 326, 350, 383, 386

Bart, H. T., 98, 124

Barre, H. J., 158, 173, 204, 208.

$213,215,234,239,286$

Barrows, H. H., 63

Barrington, G. P.. 397

Bartel, F. O., 115

Bartholomew, 1. B., 8, 21

Basin lister, 116, 118

Basseiman, James A., 184, 321-329,

308. 340. 395

Batcheldet, D. G., 378

Bateman, H. P., 297

Baumenn, E. R., 245

Baxter, Joen, 395, 396

Bayh, Birch, 399
Beaty, H. H., 287, 324

Beauchamp, K. H., 220

Behrends, 56

Bell. Wilson B., 248

Bellinger, Page L., 267, 268, 326, $327,340,368,397$

Belt machinery (see ASAE Commit tces)

Beltsville, MD, 147, 197

Benjamin, Bert, 77, 79

Bennett, H. H., 115, 118, 119, 120

Benson. Ezra Taft, 198, 199, 207. 277

Bentley, R., 115

Benton Harbor, MI, 89

Beresford, Hobart, 98, 124, 173. 294

Berlin, 98

Berrien County, MI, 340, 343

Besiey, H. E., 188

Bethany, MO, 116

Betts, M. C., 63

Bicentennial, 356-358, 365

Bicentennial year, 352

"Big Red", 169

Bioengineering, 250, 251, 254, 369

Bio-gas, 390

Biology, 132

Biological engineering. 249, 251. 254

Biological engineering (see ASAE Committees)

Biological factory, 248

Biological processes, 249

Biological Sciences Branch, 198

Black, C. A., 334-336

Black, R. H., 40

Blasingame, Ralph U., 36, 63, 99, 104, 105, 111, 121

Blaine, M. W., 374

Blauser, 1. P., 109

Bliss, H. B. 12

Block, Walter R., 3

Bockhop, Clarence, 300,319

Boeltet, L. M. K., 185

Bond, T. E., 216, 277, 355

Borden, J. W., 253, 257, 258, 281 306, 308, 309, 311, 313

Bornzin, J. H., 396

Boss, William, 1, 63, 82, 106

Boulder (Hoover) Dam, 97

Bowen, 56

Bowen, Henry D., 378

Bowen, J. T.. 265

Bowers, Wendell, 297

Boyd, George R., 197

Brackett, Elmer E., 75, 137, 138 , 371

Brandon, W. J., 18, 24

Bransky. O. L. E., 17

Brate, H. R., 27

Brigham Young University, 97

Brown, R. H., 274, 339, 340

Brown, Theo, 40

Brooks, 12

Brooks, F. A., 223, 239

Bruhn, H. D., 295, 309

Bryan, Billy B., 314, 405

Buchele, W. F., 293, 324, 326, 327

Buckingham, F. E., 394
Buelow, F. H. 420

Building facilities (see ASAE Committees)

Building package, 218

Buildings, Prefabricated, 218

Bureau of Agricultural Engineering (BAE) S0, 61, 83, 84-86, 88, 93, 93, 115, 116, 118-120, 122 .

$133-135,163,196,197$

Bureau of Agricultural Chemistry and Engineering. 159. 163

Bureau of Chemistry and Soils, 115. 118,163

Bureav of Plant Industry, Soils and Agricultural Engineering (BPISAE), 134, 147, 159

Bureau of Public Rosds, 85

Burgener, M. L.. 324, 325, 339, 340

Burkhardt, T. H., 36.3, 364

Burrows, W. C., 388, 393

Bulletin. 32

Butler Manufacturing Co., 391

Butt, Jimmy L., 182, 184, 189, 193 $206,259,261,267,271,272,276$ $277,282,300,301,303,304,308$ $309,314,320,321,325,326,340$ $341,345,346,349,352,357,358$, $383,390,395,402,404,405$

Butz, EarI, 382

Byrns, Chester J., 343, 344, 345

\section{C}

Cable, E. Y., 12

Cahow, 12

California Associated Concrete Pipe Manufacturers, 85

California Dept. of Food and Agriculture, 391

California's Imperial Valley, 97

California, 95, 105, 124, 167, 174 . 361

California, University of (Berkeley) 291

California, University of (Davis), 17. $40,56,72,74,185,203,244,245$. 265, 295, 355, 360, 363, 389, 392

Calorific Recovery Anaerobic Process, 390

Camp, R. E., 381

Campbell, Thomas D., 73, 94

Canada, 102

Canadian Agricultural Engineer, 324

Canadian Council of Professional Engineers, 307

Canadian Society of Agricultural Engineering (CSAE). 341

Canons of Ethics for Engineers. $237,239,348,359$

Capper's Weekly, 93

Career guidance, (see ASAE Committees)

Career Guidance, 311, 312

Carleton, Walter $M$., 149, 179. 250 $277,308,312,328,343,348,350$. 361,374

Carnegie Institute, 136

Carnot's Law, 293, 294

Carpenter, R. W., 142, 147, 152

Carreker, John R., 152, 328 
Carson, Rachel. 190. 242-244. 247

Carter, Deane G. 45, 56, 69, 159 . 213, 217, 218

Carter, Jimmy, 356, 391

J. I. Case Company. 45, 124, 157. 286. 287, 335. 367. 400

Case 970 Diesel. 372

J. I. Case Plow Works, 22

J. I. Case Threshing Machine Company, 14, 22, 54,58

Castenson. Roger, 352, 353, 356

Castro. Fidel. 258

Caterpiliar Tractor Company. 90.

98. 143, 287, 367

Cathcart. Chatles, 12

Cellulose Mountain, 162

Census Bureau, 112

Centennial of Engineering. 189. 190

Certification of engineering. 402 , 403

Cervinka, V., 391

Chancellor. W. J.. 392, 393

Chambers, T. B., 148

Chapters (see ASAE chapters)

Character, 104

Chase. L. W., 3, 13, 15, 20-23, 25.

$40,55,56,75,76,87,96$

Chase Plow Company. 55

Chase. Stuart. 117

Chemical Foundation, 95

Chemicals (see ASAE Committees)

Chemurgy, 95, 161, 164

Cheney, L. T., 240

Chicago, 30

Chicago Tribune. 356

Child, James L., Jr., 279

China. 154

Choate. R. E. . 245

Cincinnati, OH, 170

City College of New York, 347

Civilian Conservation Corps (CCC) 89. 93. 116-119, 122

Civil engineering. 81. 131

Civil Service Administration. 195

Civil Service Commission, 59

Civil War, 361

Clague. T. E., 340

Clarinda, 1A. 116

Clark. Hamilton, 12, 101

Clark, Bascom B.. 3, 96. 340

Classification, 143

Cleaver. Thayer, 218

Clemson Agricultural College, 54, 181

Clemson University. 379

Cletrac " $w ", 12-10,371$

Cleveland Tractor Company, 132

Clyde. A. W.. 65, 125, 127, 128 , 173

$\mathrm{CO}^{2}, 389$

Cobb, James T.. Jr., 403

Cockshutt 30 Gasoline Tractor, 372

College (see ASAE Committees)

College of Mechanics, 56

College Park, MD. 107

College Station, TX. 169

Collier's, 84

Collin, Henry, 100

Collins, E. V., 40, 64, 66. 118,128 293
Colonization (see ASAE Committees)

Colorado, 117

Columbia University, 347,340

Colwick, Rex F., 378

Comfort Engineering, 126

Commission Internationale du Genie Rutal (CIGR). 98

Committee on the Relation of Elec. tricity to Agriculture (CREA). 59. 66. 105-112

Commodity Credit Corporation. 159

"Common Sense and Wisdom". 104

Compton, Karl T., 189

Computers (see ASAE Committees)

Computers. 298, 299, 375-378

Computer Registry, $\mathbf{3 8 1}$

Confessor. The. 37

Congress, 83, 98, 111, 119, 120

Congressional Research Service, 332

Congressional Fellow, 338

Connecticut. University of. 306. 309

Conservation. 129, 330

Continuous System Modeling Program (CSMP). 379

Constitution and Bylaws (see ASAE Committees)

Constitution, ASAE, 187

1907,15

1913. 15

Conventional symbols. 25

Cook. Will, 352, 353

Cooke, Morris L.. 110, 120

Cooley, Mortimer E. 44

Coolidge. John Calvin, 45, 48, 8284. 106

Cooper, A. W., 345

Cooper Union, 347

Cooperative relations (see ASAE Committees)

Cooperative Standardization Program (CSP). 286, 287, 396. 397. 400

Corn Belt, 127

Comell University, 16, 70, 194. 239, 244, 280, 297, 327, 341 369, 379, 380, 382, 391

Cosgrove. P. C. 42

Costigan, G. L.. 12

Cotton, 163, 165, 378

Cotton mechanization, 376

Cotton picker. 167

Cotton Regional Project S-69. 376 . 378

Cotton stripper, 167

Council of Past-Presidents, 357

Council on Pesticide Application, 243

Country Gentlemen. The, 84

Countryside development, 269

Crane, F. R., 3

Creamery Package Manufacturing Co., 266

Criswell, J. W., 3

Criteria for Selection of Scientific and Professional Personnel, 179

Critical Oecupations List. 178

Critical readers, 202

Crop conditioning equipment (see ASAE Committees)
Crop Dryer Manufacturers Association, 221

Crop drying equipment (see ASAE Committees)

Crow, Ray, 150

Crozier. Wilmot F., 76

Cuba. 258

Curriculums (see ASAE Committees)

Curriculums, 50, 235, 252, 254, 301. 305-308, 317

Curry, R. B., 377

Curry, Norval H., 271, 272, 290. 308. 330-332. 339-341, 354

Curtis. A. J. R., 38

Curtis, K. E., 393

Council for Agricultural Sciences (CAST) 333-338, 360, 383, 384. 386. $387,391.392$

Dairy engineering (see ASAE Committees)

Dairy engineering. 56. 265

Dairy Engineering Conferences, 265

Dairy Housing Terminology, 218

Daley, 12

Dallas, TX, 114

Das, K. C., 377

Davenport. E.. 19

Davidson. J. Brownlee, 3, 5, 11, 12. 15. $17-20,23,24,30-32,40,44$, $50,53,56,60,61,63,73,82,87$. 88, 96-98, 118, 135, 139, 154. $164,170,206,208,209,211,225$. $239,265,293,340,367,372$

Davis, CA. 93

Davis, Chester C., 137

Davis, D. C.. 380

Davis, John R., 231, 303. 406

Davison, Eloise, 42

Day, C. L.. 373

DeBaufre. W. L.. 66

Deen. Billy, 311

Deere Medal, 133, 148, 183

Deere \& Company, 54, 122, 166 . 178. 208, 260. 268. 288. 298. 329. 341, 355, 356. 368, 375 388, 391, 393

John Deere Plow Company, 22 John Deere Spreader Works, 287 John Deere Tractor Research and Engineering Center. 274

John Deere Waterloo Boy, 370-37! John Deere Waterloo Tractor Works, 285, 292

John Deere 520 LPG, 372

John Deere 620 Gas. 372

John Deere 720 Diesel, 372

John Deere 4020 S.R. LPG, 372. 373

Defense activities (see ASAE Committees)

DeForest. S. S., 291, 338, 342, 352. $353,392,394,400$

de la Fuente, J., 84

Demaree, F. H., 18

Dencker, C. H.. 184

Depression, 130

Design. 81 
Dickerson, I. W., 40

Dickson, R. E., 114

Dieffenbach, E. M., 277

Dinsmore, Wayne, 44, 66

Disc harrow investigation (see ASAE Committees)

Disk harrow investigation, 64

Distinguished Service in Engineering Award, 206

Ditch, 81

Divisions, 6, 134

Divisional Structure (see ASAE

Commitrees)

Dixon, J. E., 339

Dobie, John, 295

Doering, Otto, 382

Doll, Paut, 101

Doll, R. M., 374

Dolve, R. M., 3

Donnan, W. W., 279

Doran, E. B.. 172

Dougles Fir Plywood Association, 151

Drainage (sec ASAE Committees)

Drainage, 46, 56, 80

Drainage Award (Hancock Brick \&

Tile Co.), 279

Drainage research (see ASAE Committers)

Drainage and Soil Erosion Control,

Divisin of (BAE), 116, 119

Dresser Industries, 313

Drew, I. M., 3

Dreyfuss, Henry, 201

Driftmier, R. H., 68, 146, 147, 149 ,

$150,152,172,173,195,279$

Dues, 14

Duffec, F. W., 65, 74, 124

Dunlap, 114

E. I. du Pont de Nemours and

Company, 95, 157

Dupuis, Henrich, 291

Dust Bow1, 92, 94, 116, 117

Dynamics, 72

DYNAMO II, 381

Dynamometer

Watson, 69

Hyatt recording hydraulic, 69

Eason, C. M., 18

Easter, E. C., 107

Ebbinghaus. J. H., 340, 394

Eby, H. J., 245

Economic Cooperation Administration, 176

Edgewater Beach Hotel, 320

Edison, Thomas A. 109

Edison Electric Institute (EEI), 109 112. 187

Edminister, T. W., 272, 277, 321, $339,341,343$

Education (see ASAE Committees)

Education, 55, 169, 299, 334

Educational Film Library Associa. tion, 194

Educational organization, 49, 344

Eggleston, L. W., 17

Ehrman, Edwin, 23
Einerson, A. M., 221

Eisenhower, Dwight, 198

Ekblaw, K. J. T., 45, 56, 137

Electronic Circuit Analysis Program (ECAP), 379

Electric Farm and Home Authority, 111

Electric tractor, 40

Electrical Engineers, American

Institute of (AFEE),

Electrical engineering. 81, 131

Electricity (see ASAE Committees)

Electricity, 40, 41

Electricity on the Farm, 108

Ellis, L. W., 23

Emblem, ASAE, 15

Emergency Conservation Work (ECW), 117, 118

Emergency Relief Administration, 92

Energetics, 132

Energy, 381-394

Energy crisis, 382

Energy report No. 40, 391

Engineer, mechanical, 178

Engineer shortage, 177

Engineer-in-Training (EIT), 40

Engineering, 331, 408

Engineering Aspects of Agriculture, 85

Engineering of biology, 133

Engineering Coalition, 347, 348

Engineering College Administrative Council, 185

Engineering Colleges Research Council, 185

Engineering Data on Grain Storage. 199

Engineering Institute of Canada, 173

Engineering Manpower Commission, 346-348

Engineering planning in agriculture. 269

Engineers Joint Council (EJC), 173. $186-188,239,251,281,282,285$ $302,303,326,327,333-336,340$, 346-348, 350, 404-404

Engincers Council for Professional Development (ECPD), 144, 153. 169. $171,173,174,186,189,209$. $232,237 \cdot 239,280,282,301-309$, $317,341,350,35$

Engines, 18, 20

England, 98

English, 100

Enrollment, 313

Entomological Society of America, 243

Environmental control, 39, 252

Environmental Protection Agency (EPA). 336, 339, 388

Environment movement, 283

Epilogue, 409

Ergonomics, 291, 292

Erisman, J. G., 398

Esmay, M. L.. 252. 292. 345

Estes Park, CO, 10

Europe, 98

Evans, John, 3
Evans, R. C., 350

Evapotranspiration (see ASAE Committees)

Eveleth, George, 321

Ever-Normal Granary, 94

Eversman Manufacturing Co., 253

Executive Affiliate Member Grade, 280

Exhibit, 33

Experiment Station Record, 102

Expositions, 20

Extension, 72

Extension agticultural engineers, 214

4-H Clubs, 288, 311

FFA Clubs, 288, 311

FEI Advisory Engineering Committee, 221

FEI Award, 155

Fairbank, W. C., 389, 390

Fairbanks, F, L., 125

Far East Soviet Republic, 97

Fargo, ND, 158

Farleigh Dickinson, 347

Farmall tractor, 73, 79

Farm Building (see ASAE Committees)

Farm buildings, 38, 56

Farm building ventilation (sce ASAE Committees)

Farm Bureau Federation, 41

Farm Chemurgy Council, 95

Farm Electrification Council, 353

Farm Electrification Research Conference, 227

"Farm Equipment", 156

Farm Equipment Institute (FEI),

$100,128,140,165,220-222,225$. $227,228,243,248,287,335,340$, 349

Farm Equipment Manufacturers Association (FEMA), 243

Farm home, 42

Farm Implement News, 184

Farm and Industrial Equipment Institute (FIEI), 100,128, 140 $165,220-222,225,227,228,243$, $248,287,335,340,349$

Farm lighting (see ASAE Committees)

Farm machinery, 17, 176

Farm machinery courses, $\mathbf{5 0}$

Farm Materials Handling Conference, 290

Farm mechanics, 6

Farm motors, 52

Farm operating equipment, 38

Farm power and equipment, 39

Farm power and machinery, (see ASAE Committees)

Farmstead mechanization, 295

Farm structures advancement (see ASAE Committees)

Farm Structures Conference, 215

Farm structures, 202

Farm work simplification (see ASAE Committees) 
Farrall, A. W., 74, 203, 206, 208. 250-252, 265, 266, 269, 278, 282. $306,308,310,311,340$

\section{Feay, 12}

Federal Power Commission (see ASAE Committees)

Federal Register, 339, 398, 399

Federal relations (see ASAE Committees)

Federal Security Agency, 176

Federated American Engineering Societies, 43, 44

Fenton, Fred C.. 42, 159, 172, 173 , 176, 178

Ferguson Foundation Series, 204 209,278

Ferguson, Harry, 122, 278

"Fifty Candles to Light the Future". 209

Filson, 12

Finance (see ASAE Committees)

Fire, 157

Firestone Tire and Rubber Company, 123,127

Fisherman, 82

Flag, 341

Flanders, Ralph, 219

Flannggan-Hope marketing research bill, 155

Fletcher, L. J., 42, 56, 63, 64, 68.

$78,79,82,90-94,97,109,129$,

$135,136,142,143,146,148,170$ 206,340

Fletcher, $W$. J., 340

Flood control, 80, 119, 120

Florida, University of, 245, 301 . 318, 354

Florman, Samuel C., 337

Food and Drug Administration. 388

Food Engineering (sec ASAE Committees)

Food Engincering, 266

Food Engineering Newletter, 266

Food for Freedom, 139

Food Science Department, 265

Food supply, 330

Food as weapon, 156

Ford, Henry, 95

Ford 5000 Diesel, 370, 372

Ford-Ferguson System 9N, 371

Ford Motor Co., Tractor and

Implement Operations, 268, 286,

$293,327,328,332,357,373$

Fordson "F", 371

Foreign (see ASAE Committees)

Foreign Aid, 175

Foreign Policy, 176, 177

Forest Products Laboratory, 223

Forestry, 121

Fort Benning, GA, 89

Forth, M. W., 290, 368, 369

Fortier, Samuel, 38, 58

FORTRAN, 379, 380

Fortune, 94

Forward planning, (see ASAE Com. mittees)

Foster, 56

Foster, G. H., 354

Foster. W. A., 39
Founding Societies, 1, 187

Fox, A. O., 3, 23

Fox, W. R. 340

France, 98

Francis, C. J., 277

Free, George R., 297

Freeman, Orville, 242

Fremont Demonstration, 22

French, O. C., 153, 189, 265, 272. $303,304,313,314,319,320$.

339, 401

Frevert, R. K., 201, 231, 232, 234, 320

Frey, Carl, 302, 303

Frisby, J. C., 374

Frost, K. R., 124

Fuel cells, 294

Fujii, Howatd, 101

G

G. I. Bill, 191

Gallup poll. 408

Gartett, Roger E., 363, 364

Gas engines (see ASAE Committees)

Gas Engine Association, 26, 27

Gasoline, 372

Gasoline rationing, 391

Gas turbine tractor, 294

Gavel, 138

Gemini. 6-8. 294

General Motors Research Corporation, 69

Geographic units (see ASAE Sections, ASAE Regions.

ASAE Chapters)

Geological Bureau, 12

Georgia Student Branch, 101

Georgia, University of, 101, 146

180. 274. 279. 315. 357

Germany, 98

Gesellschaft, Max Eyth, 183. 184

Giese, Henry, 65, 74, 217

Gilbert, A. H., 40

Gites. G. W.. 248. 249. 253, 255

Gilmore, W. J.. 52

Gittins. E. J.. 58

Gouls. 409

Goering, C. E., 373, 374

Golden Anniversary Seal. 206. 208

Goss, J. R. 392. 393

Government, 9

Government Affairs (see ASAE Committees)

Government, Age of, 33

Government testing. 27

"Graduate Education in Agricultural Engineering". 330

Grain Branch of the Production and Marketing Administration, 215

Grain handling equipment (see ASAE Committees)

Grain storage research, 158

Grand Detour Plow Company. 22

"Grapes of Wrath", 129

Grass Roots, 120

Gray, R. B., 63

Great Plains, 117

Grinnell Mutual Reinsurance Co. 286

Grinter. L. E.. 301
Gross. E. R.. 50.98

Grovum. M. A.. 373

Gunkel, W. W., 244, 326, 327

Gunlogson, G. B., 40, 200, 268 269. 270, 362. 363

Gunness, C. 1.. 173

Guthrie. Oklahoma, 116

Gyracotn cotton harvester, 166

\section{H}

Habermann, Ginny, 357

Hahn, R. H., 268, 340, 396-400

Hall, Carj W., 16i, 204, 205, 251.

265, 266, 295, 303, 308, 312, 316

323. 326. 327. 342. 350. 353. 390 . 396. 403. 404

Hall, Gienn E.. 3\%

Hall, Nęwman, Commissioner of

Engineering Education. 250

Hamdy. M. Y.. 377

Hamilton. C. L.. 157

Hamilton, Elmer w.. 3, 8, 20, 208 209

Hamilton. Everett W... 3, 8, 12

Hampe, 12

Hancock Brick \& Tile Co. (Hancor) Award, 279

Handbook, 15

Haney. J. W., 75

Hansen, C. M.. 242, 243. 258

Hansen, E. L., 279

Hansen, H. J., 200, 286, 308, 332 . $333,340,403$

Hansen. Merlin. 274

Hanson. Frank P. 31-34. 178

Happe, M. J., 280

Hardin. Clifford M. 341

Hardin, L. S.. 215

Hardy, E. A. 215

Harkness, K. A.. 288-290

Harper. Jerome P. 338

Harrington, W. C.. 98

Harris. W. J., 340

Harris, W. L., 382

Hart, S. A.. 245

Hassler. F. J.. 240. 250. 255

Haugh. C. G.. 375

Hawthorn, F. W., 124

Hay, R.C., 297

Hay, 160, 161, 202, 294

Hay harvesting and storage

(see ASAE Committees)

Hays, Kansas, 116

Hazen, Leslie E., 51, 150

Hazen, T. E., 245

Headquarters building. $89,270-273$. 339

Headquarters Building Fund. 272

Heald. H. T., 172

Heating and Ventilating Engineers. American Society of. 2

Heitshu. D. C.. 55

Heidman, D. R. . 266. 354

Hemker. A. 142

Henderson, G. E., 315

Henderson. S. M. 160, 203, 204.

231. $232,234,313$

Hennessy. W. J., 360-363

Heritage and Horizons, 352-356

Herring. W. E.. 111 
Heston, R. E., 286, 340, 397

Hickok, R. B., 280

Hienton. Truman E., 41, 110.179. 186. 196.197

Highway (see ASAE Committees)

Hill. W. Scott. 302

Hirshfield, C. F., 16

History of ASAE, 209

Hobbs. G. S., 246

Hobgood, Price. 245, 270-272, 280.

283. 302, 306-309, 312, 317, 334 . 339

Hobson, B. W. 386

Hodges, L. H., 286, 335. 340. 345 . 397, 400

Hodson, F. G., 12

Hoffman. A. H., 98

Hoff, C. R., 12

Holley, Alexander, 80

Hollister. S. C., 194

Holman. Leo E.. 159, 213

Hoover Commission, 197

Hoover, Herbert, 43-45, 85, 88, 93, 94, 105, 106

Hoover, Mrs. Herbert, 85

Horizons Extravaganza, 352, 362 . 365

Horse Association, 44

Horse drawn equipment (see

ASAE Committees)

"Horse Feathers Club", 132, 255

Horseless farming. 45

Horses, 33, 44

Horton. H. E.. 17

Houston, David, 58

Howard. F. W.. 367

Huang. B. K., 379

Huddleston, Walter D.. 383

Huggins, L. F., 375, 377

Hukill. W. V.. 159, 200, 213

Hull. D. O., 294

Human engineering. 292, 293

Humenik, F. J., 354

"Hundred Days", 90

Hunt. Donnell. 316

Huntington. Arthur. 41, 44, 82, 85 . 91,92

Hurd, C. J., 173

Hurlbut, Lloyd $w_{,}, 124,193,260$. 261, $282,315,371$

Hurst. W. M.. 203

Hustrulid. Andrew, 239

Hyatt Roller Bearing Company. 17

Hyde, Arthur, 85, 86, 114

Hydrostatic drives, 294

Hydrology. 176

[COR, 97

lckes, Harold, 97

Idaho, 124

Idaho, University of. 174. 295

Illinois, $99,112,124$

Illinois Institute of Technology, 224

Hlinois. University of, 4, 19, 34,

159, 174, 182, 215, 279, 287.

297, 316, 324, 353.355, 392

398

lliuminating Engineering Society, 2
Index, Hall's, 295, 323

Index of Publications. 326

India. 177

Indian. American, 94

Indian Society of Agricultural

Engineers (1SAE). 177

Indiana, 112, 124

Industrial

Applications of agricultural engineering. 203

Engineering. 132

Use of farm products, 164

Information retrieval, 327

Institution of Agricultural Engineers, 324

Institution of Civil Engineers of Great Britain, 80

Institute of Electrical and Electronics Engineers (IEEE). 404

Instruction in Agriculture (see

(ASAE Committees)

Instrumentation, 251

Instrumentation and Controls (see ASAE Committees)

Instrument News, 226

Instrument Society of America. 25

Instruments of warfare. 30

International Bank for Reconstruction and Development. 176

Interational Confederation of

Agricultural Engineers and Technicians, 184

International Congress of Agricultural Engineers (CIGR). 98, 185

International Harvester Company. $8,22,45,49,61,73,77,79,96$. $141,162,165,169,181,212,294$ $297,298,341,358,367,374$

International (Harvester) 4300. 372

Internationalization. 177

International Organization for Standardization, 221

International Standards Organization (ISO), 285

International Symposium on Livestoack Wastes. 392

Interstate Commerce Commission. 43

lowa, 83, 99, 124

lowa Electric Light \& Power Company. 41.91

lowa Railway and Light Co.. 83

lowa State University (College). $6,11,12,14,17,19,32,37,49$ $50,52,54,65,88,101,117,144$ $158,174,180,201,217,239,245$. 265. 290, 293. 294, 334. 355. 381 Irons. Frank. 224

Irrigation (see ASAE Committees)

Irrigation, 176

Irrigation, Division of (BAE), 120

Irwin, R. W. . 279

Isaacs, G. W.. 350. 402

Ithaca. New York, 36, 120

Ives. Frederick $W ., 17,31,35,36$, 42,43

Ives, Mary A., 35. 39

Iverson, George W.. 12, 18, 76. 78 .
Japan, 16

Jardine, W. M.. 60, 62, 82, 85

Jensen, Paul, 392

Job Instructor Training (JIT), 142 , 143

\section{Johnson, 297}

Johnson, A. T., 370

Johnson, Carlton, 350

Johnson, Howard K., 288

Johnson, W. H., (Ohio State), 297

Johnston, Edward A., 165, 166

Joint Committee on Grassland

Farming, 186

Joint Societies Forum, 349

Jones, B. A., 279, 319, 339, 340

Jones, Dexter, 340

Jones, E. R., 38, 121

Jones, F. R., 125

Jones, G. D., 132

Jones, J. K. (Farmer), 273, 339

Jones, L. A.. 63, 113, 115

Jones, M. M., 56

Jones, Walter B., 46, 102, 124, 125 ,

$128,139,183,200$

Josephson, H. B., 71, 98

Journal, 32, 34, 89, 93, 94, 102 ,

$108-110,116,118,119,124$ $124,126-128$

Journal of Agricultural Engineering Research, 324

Journal of the College Division, 37

Journal of Engineering Education. 170

$\mathbf{K}$

Kable, George W.. 74, 85, 107,109 $110,112,135,139,140,148$

Kaiser. William G., 12, 39, 85, 86, 98. 115

Kansas. 92. 99.117, 124,127

Kansas State Agricultural College. 17. $19,43,49$

Kansas State University, 34, 52. $68,144,171,174,349,352$ 367

Karstens, G. A., 340, 394

Kelly, C. F., 158-160, 216, 250, 308

334, 335, 350, 402

Kelley, J. B., 12, 68, 109

Kelley, M. A. R., 12, 39, 63, 64 68

Kendrick, Junius L.. 363

Kennedy, Edward M., 399

Kentucky, University of, $68,355$. 381

Keppeler. R. A., 266

Kewanee Machinery Co., 321

Keyes. Gilbert W.. 333

Khrushchev, Nikita, 242

Kidder, E. H., 231, 250, 308. 326. 327

Kinard. Drayton. 318

Kinematics. 73

King. F. H., 16.39

King. M. L., 3, 17, 18

Kinsman, C. D.. 63, 68

Kinzel, A. B., 281, 282 
Kleis. R. W.. 258. 259. 262. 280. 290. 305. 326

Kliever, W. H. 226

Kline, Cernyw K.. 180

Knight. Henry G. . 163

Knowland. William F., 207

Knox, P. L., 386

Korea, 178, 179

Kranich. Frank N. G., 17, 26. 31 59. 73, 124. 126. 157. 158

Kranzberg. Meivin. 365

Kranzler, Glenn, 381

Kulhavy, J. T.. 367

Kuska. C. J., 340

Kuska, D. E., 287

L.

Labor's dictionary of occupational titles. US Department of, 179

Lake Mead. 97

Lambert. J. R., 379. 380

Lamp. B. J.. 278, 332, 397

Land clearing. 50

Land clearing (see ASAE Committees)

Land grant colleges (universities). 87, 95, 107, 36I

Land Reclamation Division. 115, 119

Land use, 357

Landtechnische Forschung, 324

Lane. Delbert, 372

Lange. E. Paul. 188, 189

Lanham. Frank B., 180-183, 186 188, 201, 280, 303, 319. 338 . 352. 356

Lantz. E. G.. 74

Large scale farming. 93

Larimore, P. B.. 380

Larsen. Lester F., 370

Las Vegas, NV, 97

Lathrop. E. C. 164

Left hand plow investigation. 4

Lehmann. E. W.. 39. 42. 59. 99. 114

Lester, R. L., 273

Levin, Jordan H., 204

Lewis. David C.. 360

Lexington. KY. 350

Libberton, P. T., 17

Library Board of the Texas

National Resources Foundation, 186

Liddell, W. J.. 273

Liege. Belgium. 98

Lien, R. M., 350

Light. R. G., 355

Light traps. 224

Lights. 2

Liljedahl, J. B.. 258, 292, 345, 374

Liljedahs, L. A. 373

Lillard, James H.. 279, 401

Lilliston Corporation, 357

Lincoln. NE. 42

Linder, Clarence H.. 404

Lippman. Walter. 241

Liquefaction. 389

Livestock wastes. 392

Livingston. L. F.. 95, 135, 142, 146

Loewer, O. J., 381
Long. J. Dewey, IS1, 153, 154. 172. 174, 301, 304

Longnecker. A. D., 12

Loosanoff. Victor L.. $2 \%$

Lorenzen. R. T., 280

Louisiana. 118,124

Louisiana Engineering Society. 405

Louisiana State University. 172.

174. 380. 406

Lovely, W. G.. 355

Lundell Manufacturing Co.. 294

Lundell, V, 1, 294

Luttress. D. H. . 273

Lyle. Clayton. 101

Lyle, S. P.. 132, 138, 141, 148, 277

\section{$\mathbf{M}$}

M.1.T., 239

MacGregor. Wallace F. 13, 14, 24. 25. 26.45

Machinery, 40.56

Maddex. R. L.. 353

Madill, Stanley, 178

Madrid, 98

Mallet, Mr., 3

Mangum, 114. 116

Manhattan Project. 153

Manson. P. W.. 286

Mariculture. 2\%

Marshall Plan, 175

Marston. Anson. 19

Martin, 12

Martin, G. E., 115

Martin, J. W.. 339

Martin. T. E.. 124

Maryland, 107

Maryland, University of , 106, $\mathbf{3 7 0}$. 382

Masonite Corporation. 207

Massachusetts Institute of Technology, 189, 231

Massachusetts, University of, 258. 280. 355

Massey, Daniel. 278

Massey-Ferguson Educational Award. 278, 279

Massey-Ferguson Limited, 278. 357. 374, 394

Materials handling. 290. 291

Matson. Howard. 173, 277. 308 313, 339

Mauney. R. R., 204

Maw, A. J., 246

Max Planck Institute for Farm Work and Agricultural Engineering. 291

McAdams. A. J.. 56

McAlister, J. T. 54

McCalmont, J. R. 158

McColly. Howard. 209

McCormick. Brooks, 341, 358, 359

MeCormick. Cyrus Hall, 87

Cyrus Hall McCormick Medal. 77. 88. 97, 131. 148, 165. 169. 206

McCormick-Deering

"Farmall". 37!

"WD-40", 371

McCormick, Edmund B., 14, 18

19. 58

McCormick. E. J.. 292
McCrory, Samuel H., 36, $41 \cdot 43$. 45, 56, 59-63, 80, 86, 121, 133 134. 157

McCuen, Glen W., 40. 64. 68.73, 91. 98, 109, 123

McDermott. G. I.. 12

McDonald. J. O. 98

McDonald. Merritt E., 405

McFarland. T. David. 288. 289. 340. 356

McFate, K. L., 261, 353, 400

McGraw-Hill Book Co.. 56

McKelvie, S R, 82

McKenzie. B. A.. 353. 382, 391

McKetta. J, J., 387, 388, 393

McKibben, E. G., 72, 73, 98, 146. $147,185,197,198,239,256,267$. 276. 281

McLaughlin. W. W.. 120

McMillen. Wheeler. 94

McMurray, Morris, 345

McNutt. Paul V., 142

McPheters. W. H., 68. 121

McQuillan. James B.. Attorney. 345

Mead. Elwood. 6. 46. 58, \%, 97 . 115

Mechanical engineering. 81, 131

Mechanized agriculture (mech-ag). 171. 236. 315. 316. 318-320. 348. 350, 352

Medals. 133

Meetings (see ASAE Committees)

Meeuusen. Terry (Miss America of 1973), 357

Meier. Oscar. 112

Member grades. 11

Members

Mechanization. 351

Mechanization Asscriate, 35

Student Mechanization. 351

Membership. 31, 34, 143

drive. 31 grouth. 31

problems. 10

Membership (see ASAE Commintees)

Memphis, 35

Memphis Engineers Club. 35

Metal Buildings Manufacturers Association, 277

Award. 277

Methane production. 390

Mever. L. Donald. 280, 326, 327

Mever. Roger. 349

Michigan Agricultural Experiment Station. 387

Michigan Court of A ppeals. 343

Michigan State University. 19. 146. 174, 180, 184, 206, 242, 250-252 $265-267,293,316,324,327,349$ 353, 354, 380

Microtilm, 326

Midwest (Farm Building) Plan Service. 217

Miles, G. E., 380

Millar. G. H. 355. 356

Miller. M. L.. 391

Miller, R. C.. 109. 213

Miller, Wendell P.. 47

Milwaukee, 140, 148, 170

Minimum tillage. 297

Minneapolis Steel and Machinery Co. 77 
Minnesota, 84, 106, 124

Minnesota Agricultural Experiment Station. 373

Minnesota State Buard of Agriculture. 20

Minnesota. University of. 1, 52, 174. 227.239 .286

Mississippi, 114

Mississippi A\&M College. 30. 50

Mississippi Delta Junior College. 373

Mississippi State University. 255

Missouri. 101. 114.117.155

Missouri, University of. 34.49 .56 . 349, 373, 374

Mitten, H. L., 205

Model law for registration of protessional engineers. 232

Modeling. 379

Monograph, 396

Moningraph series. 321

Montague. J. L. Jr. 273

Montana. 94

Montana. University of. 51.306

Morgen, Ralph A.. 302

Morrison. C. S., 246, 260, 261, 266. $269-272,283.286,302-304,306$. 308. 312-314. 317.319. 339

Morse. S. F.. 54

Muscon, 97

Moseman. A. H.. 197

Moses, B. D., 42, 124

Motion picture. $310-312,314$

Motion picture (see ASAE Committees)

Motor contests, 10, 20

Motor Contests (see ASAE

Commitiees)

Motor fuels (see ASAE Committees)

M1. Clemens. M1. 34

MPO Pronductions. 193

Muirheid, B. F., 237

Mulbar. Harmon, 267, 308, 340

Muilen. B. R.. 12

Mulliken. Paul M., 175

Murdock. H. E.. 98

Muscle Shoals Bill. 105. 106

Museum of Science and Industry. 190

Musgrave, R. B., 297

Musgrove. Claire. 345

Musselman. H. H.. 14.63

Muttnik. 241

NRSSP, 145, 150, 239

Nabben. Marvin, 290

National Academy of Engineering, 206, 332, 404

National Academy of Sciences-

National Research Board, 334

National Adequate Wiring Bureau, 186

National Agricultural Chemical

Association. 243

National Association of Corrosion Engineers (NACE), 404

National Association of Farm Equipment Manufacturers (NAFEM), 42, 53, 58, 61, 72, 77 . 100
National Association of Tractor and Thresher Manufacturers, 27

National Bureau of Engineering Examiners, 174

National Conference for Farm Safety, 243

National Conference of Industrial Hydraulics, 186

National Council of Affiliated Student Clubs, 349

National Council of Engineering Ex miners (NCEE). 401، 403

National Council of State Boards of Engineering Examiners (NCSBEE). 174, 186, 232, 237. 303

National Council of Student Branches, 100, 101, 311, 349

National defense, 138

National Defense Commission, 137

National Drainage Congress, 40

National Electric Light Association, (NELA), 40, 55, 79, 107, 109

NELA Bulletin. 106

National Farm Electrification Conference, 186

National Farm News. 83

National Farm Homes Conference. 45

National Farm Safety Conference. 156

National Farm Safety Week, 157

National Fire Protection Association, 186

National Fire Waste Council, 186

National Implement and Vehicle Association, 20, 21, 24, 26

National Industrial Recovery Act, 109

National Joint Committee on Fertilizer Application. 186

National Oceanic and Atmospheric Administration, 392

National planning, 129

National Rural Electrification Project, 107

National Research Council. 404

National Retail Farm Equipment Assoc. 175

National Safety Congress and Exposition, 156, 226

National Safety Council, 157. 288. 289, 357

National Science Foundation, 251, 325, 328, 330, 388

National Society of Professional Engineers (NSPE), 169. 189. 238 , 282, 283, 350, 401, 333-337

National Stockman and Farmer. The, 46

National Symposium on Farm Animal Waste Management, 246

Naval Architects and Marine Engineers, Society of, 2

Nebraska Agricultural Experiment Station. 87

Nebraska Tractor Test Board 137, 372

Nebraska Tractor Testing Lab., 370 Nebraska Tractor Tests, 22. 23, 75 , 76. 225, 285
Nebraska, 75, 76, 82, 86, 88, 97. $99,116,124,127,128,174,371$

Nebraska, University of, 17, 19, 20 . $49,52,75,77,144,245,303$ $320,349.352,354,356,373$ 380. 398

Neff, Grover, 112

Neilson, 98

Nelson, G. L., 326

Nelson, L. F., 388, 393

L. R. Nelson Corporation, 354

Nelson. S. O. 35

Neubauer. L. W. . 355

Newark College of Engineering. 347

New Deal, 88, 90-94, 109.111. I16118, 122

New Holland Machine (Division Sperry Rand Corp.), 280, 287. 355

New Idea Company, 25]

Newsletter. 62, 206

New Mexico, 407

New York. 125

New York City. 97

New York Times. 83

New York University, 347

Nichols, Mark L.. 60, 67, 69.72. $109,116,134,148,155,156,175$ Nile, R. P., 9

Nessing. Ted. 406. 407

Nitrogen. 385

Nixon, Richard M.. 381

Noisy Summer. 243

Norman, C. A 12

Norris Act. 109

Norris, Karl, 226, 328

North Carolina. 114. 115

North Carolina State University. 34, 111. 239, 248, 255, 292, 354 . 378. 379

North Central Regional Committee on Farm Waste Disposal. 245

North Dakota. 33

North Dakota Agricultural College. 16. 236

Northern Regional Research Laboratory. 164

Nuclear fallout. 295

Nuernberger. H. H., 251

Nutt, George B.. I81. 182. 188. 195 198

Nye. W. M.. 3

$\mathbf{O}$

Obloochy. 97

O'Brien, Michaet, 339, 340

Occupational Safety and Health Act (OSHA), 339, 398, 399

Ocock. Charles A., 3. 11. 23. 96 . 208

Otfice of Defense Transportation. (ODT). 146

Otlice of Experiment Stations. (OES). to

Otfice of Price Administration. (OPA), 145

Otrice of Technology Assessment. 332. 336

Ohio. 88, 119. 120. 124 
Ohio State University, $17,31,35$, 42,$4 ;, 64,99,109,123,131,(40)$. $250,208,288,289,297,350,354$. 377

Oklahoma Siate University tOkla. homa Agricultural and Mechan ical College). $51,08.114 .115$. $11^{7}, 129,150,174,239,378$

Oiver Corporation. 287

Oines. Raymond. 3. 27. 31. 34. 36. $40,43,44,46,48,58,59,61$. 62. to. 75.7 . 84.85 .88 .94 \%. 9?. 102,113,119,137, 139. 144. 152. 169. 170.179-181. 183. 184. 191. 200. 201. 208. 211.220 223, $26^{\text {? }}$

Olson. H. C. . 391

Olver, E. F.. 153

Ontario Agriculture College. 279

Organization. 15

Oregun State University (Oregon Agricultural College), $52,74,100$. 101, 158, 174, 280

Oregon CRFA, $10^{7}$

Oregın Student Branch. 100

Ota. Hajime, 216

Otis. C. K.. 290

Overman. W, F. . 340

\section{P}

Paarlberg. Don. 356

Pacific Grove. CA. 158

Page charge, 201, 320, 325, 328

Paine, F. D., 42

Palmer, Ralph A., 47, 89, 102, 138 ,

182, 188. 189, 201, 257, 308, 310, 340

Panama Canal, 40

Panama-Pacific Exposition, 20. 23

Paper, 165

Paper Awards, 151, 277

Paper Awards (see ASAE Committees)

Parker. J. B.. 3

Parkinson, E. E., 3

Parlin \& Orendorff Plow Works. 22

Parshall Flume. 120

Parshall, R. L.. 120

Patch. Earl S.. 66. 67

Patent (see ASAE Committees)

Patitz, Max, 18

Patitz. J. F., 28

Patterson, R. E.. 382

Patty. Ralph L., 48, 54

Peabody Hotel. Memphis, 322

Pearl Harbor, 139

Peart, R. M 354

Peikert. Frank W.. 318-320

Peikert Report, 349

Pennsylvania. 98, 125

Pennsylvania State University

(College), 36, 71, 99, 100, 318

Perilla. 161

Perkins. Frances, 142

Perkins Engines Ltd., 374

Permanent Buildings Society, 17

Perty, R. L., 204

Personnel Service. 154
Pesticide Application Seminar, 243

"Pesticides, a Tool of Man'. 243

Peterson. V. S.. 157. 158

Pfundstein, K. L.. 340

Phelan, J. T., 326

Philadelphia, 155

Pichon. J. D., 373

Pilgram. E. W.. 42

Pimentel. David, 382. 383

Pinches. Harold E.. 129. 204, 211. 276. 277. 291

Pittsburgh. University of. 403

Plowing contests, 20

Plowing match, 33, 34

Plows, left hand (see ASAE Committees)

Podlesak, H. J., 24

Pollution. 330

Polytechnic Institute of Brooklyn. 347

Poole, Wiley, 406, 407

Portland Cement Association, 17. 38. 39. 98.324

Postwar objectives (see ASAE Committees)

Postwar problems. 151

Potter, A. A., 19, 234

Poultry Industry Waste Management Symposium, 245

Poultry Science Association. 245. 246. 247

Power. I

Power alcohol, 95

Power Farming. 27, 31, 34

Power farming (see ASAE Committees)

Power Farming Press, 34

Powers. 56

Power steering. 293

Power Take-Off, 199

Poynor, R. R., 272, 297, 298, 324.

328, 339, 340, 374

Prairic Farmer, 93

Pratt Institute, 347

Pratt. Marianna. 268. 329. 340. 395

Prentice, D. B.. 172

Price, D. M.. 391

Price, D. R., 379

Price, F. E., 158

Proceedings, 322, 323, 3\%

Processing. 197. 203, 204

Processing (see ASAE Committees)

Professional Development. 401-408

Professional Engineer, 237

Professional identity. 19

Professional Planning Director. 269

Professional registration (see ASAE Committees)

The Progressive Farmer, 394

Promersberger, W. 1., 236

Psychological testing. 104

Psychology, 292

Public affairs. 129

Publications (see ASAE Committees)

Publications, 32, 200. 277. 320-329. 394-396

Public relations (see ASAE Committees)

Public relations. 256, 312, 352

Puckett. H. B., 354
Pullman, WA, 116

Pulp. 165

Purdue University, 19, 100, 127.

$160,174,215,292,350,353,354$.

374, 375, 382, 391, 402

Purnell. Bill. 70.71

\section{$\mathbf{Q}$}

Quality of life. 334

ROTC. 347

Radio-frequency energy, 227

Radio talks, 56

Radiation, 224

Railraad, 43

Railroad Engineers' Association,

American, 2

Rainfall generator, 377

Ramser, C. E., 114, 115, 117. 118. 120,148

Ramsower, H. C., 17, 31

Randolph. J. W.. 70, 72, 74 , 126. 128

Raney, R. R., 251, 308, 339

Rapid City, SD, 82, 83

Raudebaugh, R. J., 402

Rayon, 163

Reciamation, 38, 80

Recommended practice, 25

Reconstruction Finance Corporation.

88

Recruitment, 176, 192, 195, 315

Red Wing, 41, 106

Reed. C. O.. 15. 17. 131. 132, 249. 255

Reed, I. F., 102

Reed, Steve, 352

Registration, 232, 279, 280, 402. 406. 407

Registration (see ASAE Committees)

Regulations, 331

Renner, D. L., 42

Report to Readers, 202

Republic Paint Co., 394

Research (see ASAE Committees)

Research. 17. 36. 37, 39. 41. 42. 45. $55,59,6466,72,194,223,225$. 227-230, 248, 294, 345

Pure, 228

Basic. 228

Applied, 228

Development, 228

Consumer, 228

Fundamental, 228

Research Director, 268

Research and Marketing Act of 1946, 155, 215

Research and Marketing Project, 224

Research methods, 67,69

Resolutions Committee, 114

Reynolds, Barton C. 277

Richey, C. B., 293, 326, 327, 372

Rietz, George A.. 173, 213

Riley, Howard W., 3, 11, 13, 15 . 17. 18, 21, 40, 208, 341

Robb, Byron B., 56 
Robbins, Paul H., 283

Roberts, D. L., 380

Roberts, J., 124

Roby, Frank, 287

Rodgers, J. B., 280

Roe. H. B., 84

Rogers Four Wheel Drive, 371

Rollover Protective Structures

(ROPS), 398

Roll, W. M., 368, 369, 397

Roosevelt, Franklin Delano, 88, 90 , $97,110,120,122,139,142$

Rosenberg, Sam, 389, 395

Rose, Philip S., 1, 3, 10, 13, 16. 27.29, 211

Rose Polytechnic Institute, 172

Rostov, 97

Rubber, 123

Rubber tires, 122, 124, 128

Rural engineering, 6

Rural electrification, 105, 176, 202

Rural Electrification Administration

(REA), 92, 110.112, 121, 363

Rushing, Karl, 373

Russia, 242

Russian, 102

Russian Jews, 97

Russell. H. L.. 3

Rutgers University, 98, 255, 336

Sabetier, J., 98

Safety, $74,219,221,226,330,397$

Safety (see ASAE Committees)

Safety-accidents, 156

Salter, R. M.. 197

Sammet, L. L., 204, 236, 291

Senitation (see ASAE Committees)

Saskatchewan, 125

Saskatchewan, University of, 46, 373

Schafer, R. L., 374

Schaffhausen. R. W., 142

Schlephoff, Elmer, 372

Schleusener, P. E., 246

Schnieder, R. D., 398

Schroeder, E. W., 239, 258

Schwab, G. O., 354

Schwantes, A. J., 125, 196, 226

Science, 225, 282

Scientific organization, 344,345

Scoutes, Daniel, 30, 37, 48, 56

Scott, N. R, 369, 370

O.M. Scott and Sons, 268

Scribner's, 84

Seaton, R. A., 171

Seats, 292

Secretary, 31-34

Secretary of Agriculture, 84, 93

Secretary's Letter (Olney), 84. 119. 138

Seitz, Charles E., $\$ 2,63,90,91$, $109,152,173$

Selective Service System, 346

Senate Stbeommittee on Agricultural Appropriations, 152

Senior Member Grade, 279, 280

Settlement. 30

Severson, 12

Shaw, B. T., 293
Shaw, R. S., 19

Shawl, R. I., 124

Shedd, C. K., 17, 75, 114, 118, 160

Shepardson, E. S., 280

Shicids, J. W., 123

Shimon, D. F., 290

Shukla, L. N.. 373

Siberia, 97

Silcox, F. A., 120

"Silent Spring", 190, 242, 243, 359

Silver Anniversary, 21

Silver, E. A., 124

SIMSCRIPT, 380

Simulation, 376, 378, 379

Singley, M. E., 336

Sisson, D. R., 354

Sjogren, O. W., 18, 40, 44, 46-48,

$53,56,62,64,75.77,82,87$

Skromme, Amold B., 122, 149, 285 . 287, 319, 341, 342

Skromme, Austin Jr., 287

Skromme, Austin Sr., 287

Skromme, Lawrence, 101, 181, 188 , $201,284,287,295,300,354,355$, 404

Skromme, Robert, 287

Slipher, J. O., 132

Slogan, 282

Slow Moving Vehicle Emblem (SMV), 288-290, 397, 400

A. O. Smith Corporation, 288

A. O. Smith Harvestore Products, 392

Smith, Chauncey $W ., 52,76,124$, 126, 371

Smith, D. D., 322

Smith, H. P., 166, 169

Smith-Hughes Act, $\mathbf{5 3}$

Smith, L. J., 18

Smith, R., 355

Smith, W. Forrest. 152

Snow Cover, 120

Snyder, S. D.. 12

Social action (see ASAE Committees)

Social intelligence, 105

Society for the Promotion of Engineering Education (SPEE), 42 54, $135,150,174$

Society goals, 3

Society of Aeronaut Engineers, 28

Society of Automobile Engineers, 2, 24, 28

Society of Automotive Engineers (SAE), 28, 76, 77, 128, 221, 222 . $285,289,341$

Society of Manufacturing Engineers (SME), 403, 404

Society structure, 5

Society, The, 5,6

Society of Tractor Engineers, 28

Socio-political aspects, 331, 332

Soil and water engincering, 354

Soil conservation, 113

Soil Conservation and Domestic Allotment Act, 119

Solar energy, 385

Soil dynamics, 72

Soil erosion (see ASAE Committees)

Soil preparation and tillage (see ASAE Committees)
South Dakota State University

(College), 48,54

Southern regional cotton mechaniza. tion research, 223

Soviet government, 97

Soybean plastics, 95

Spain. 98

Spilhaus, Athelstan, 392

Splinter, W. E., 292, 354, 371, 372

Sprinkler irrigation (see ASAE Committees)

Spur Substation, 115

Sputnik, 241, 313

St. Joseph, MI, 34, 88, 89

St. Lowis, 30, 154

Stafford, C. W., 12

Stahi, Benton M., 200

Standard Oil Company, 17

Standardization, 20, 24, 28, 284

Standardization of farm equipment,

Standards, $16,23,25,199,200$, $219-221,115,274,283-287,290$. $318,332,396-400$

"Standards-A Vital Tool in

Engineered Agriculture". 287

Standards and data, 274

Standards (see ASAE Committees)

Stapieton, H. N., 378

Stark, A. L., 380

State experiment stations, 107

State University of New York (SUNY), 347

Statesville, NC, 116

Steam engines, 20

Steam tractor, 8

Steering for tractors, 292, 293

Stefferud, A. D., 276, 277

Steigerwalt, S., 12

Steinbeck, John, 129

Steinbruegge, George, 371, 372, 373

Steinman David B., 169

Stengle, 83

Stere, James B.. 100, 102

Stevens Hotel, 153

Stevens Institute of Technology, 302. 347

Steward, J. F.. 8

Stewart, E. A., 42, 52, 106

Stewart. R. E., 216, 250, 251, 304 316,349

Stickler, F. C., 393

Stivers, Ted, 403

Stout, O. V. P., 19, 38, 65, 80, 86$88,97,211$

Stran-Steel Corp., 241

Straw, 165

Straw, Lee A., 340

Strawboard, 165

Strohman, R. C., 375

Structures, 59

Studebaket Corporation, 24

Student affiliate clubs (see ASAE Committees)

Student branches, 12, 14, 34, 46, $105,191,305,309,316,346$

Student branches (see ASAE Committees)

Student enroliments, 194, 248

Students, 10, 313, 315, 320 
Successful Farming Magazine, 291

Suggs, C. W., 292

Sulek, John, 349

Superior Equipment Manufacturing Co., 391

Surplus, 130

Sutton, John G., 120

Svensen, Cart L.. 234

Swamy Rao. A. A. 297

Swearingen. Tom, 207

Sweeten, John M., 390

Swenehart, John, 38

Swink. E. T. 251, 252. 308

Sylvester, D. W.. 12

SYMAP. 380

SYMVU, 380

Systems engineering, 291

\section{$\mathbf{T}$}

Taiganides. E. P.. 245, 247

Taiwan, 252

Tanquary, Edwin W., 181, 182. $192,193,220,340$

Task Force on Affitiates. 350

Task Force on Engineering Certification. 402

Tax court case, 343

Taylor, John G., 224, 226

Teaching methods. 36

Technical, 213-231, 283-299, 367 . 381

Technical (see ASAE Committees)

Technical assistance program. 176

Technical Cooperative Administration, 176

Technical coordinator, 322

Technical knowledge, 104

Technical papers, 16-18, 200. 202. 323. 332. 342

Technocrats, 92

Technology. 334

Teele, R. P., 3, 9. 58

Teeter, 56

TELPLAN. 380

Temple. TX, 116

Tennessee River, 106

Tennessee River Basin, 106

Tennessee. University of, $\mathbf{3 0 0}$

Tennessee Valley Authority (TVA). 92. 109. $110,112,121,122$

Texas, 114, 117, 125, 166, 404, 405

Texas A\&M University, 48, 51, 101 , 115, 174, 307, 352

Texas Agricultural Experiment Station, 115

Texas Engineering Practices Act. 405

Texas State Board of Registration. 234

Texas, University of, 387

Textbooks, 56, 277

Thatcher, R. W. 70

Thermal environment, 216

Thermonetics. Inc.. 390

Thesaurus of Engineering Terms. 326. 327

Thespurus (see ASAE Committees)

Thompson. H. J., 216

Thompson, T. L., 354, 380
Thornbrough, A. A., 278

Three-point hitch, 122

Three prong organizational structure. 259,260

Throckmorton. Ray I., Jr., 298

Tile drains, 220

Tillage. 297

Timken Roller Bearing Co.. 73

Tires, 163

Todd. Frank A., 295

Tokyo. 98

Tomato harvester, 167

Torch Press, 32

Torreon, Mexico, 84

Torrington Company. 173

Towne. Harmon. 391

Traction. 8

Tractor (see ASAE Committees)

Tractor, 18, 30, 44, 76, 130, 140

Tractor demonstrations (see

ASAE Committees)

Tractor field machinery (see

ASAE Committees)

Tractor testing and rating (see

ASAE committees)

Tractor testing law, 75

Tractor tires. 122

Tractor Field Book, 184

Tracy. William R., 142

TRANSACTIONS of the ASAE.

102. 201, 202, 267, 268, 277, 321329, 375, 395

Trullinger, R. W., 59, 62-69. 71. $75,89,136,142,153,211,225$. 228

Truman, President, 176

Tumer, Arthur W., 141, I42, 144 148. 155, $170,172,173,197$

Tweedy, R. H., 339, 340

Twin City tractor, 77

Tyler. TX. 116

Underdeveloped countries, 175

United Engineering Center, 271

United Nations, 176, 222

United States of America Standards Institute, (USASI), 286, 287

U.S. Bureau of Commercial Fisher. ies. $2 \%$

United States Chamber of Commerce, 94

United States commissioner of reciamation, 97

U.S. Corps of Engineers, 360

United States Cotton Ginning Laboratory, 169

U.S. Department of Agriculture. (USDA), 23, 36, 40, 54, 58, 62 , $64,68,83,86,102,106,109,113$ $116,118,121,128,176,198,199$ $213-215,217,221,225,245,246$, $276,277,279,280,293,295,350$, $351,353-355,357,361,382,388$

USDA Agricultural Engineering Division, 36, 56,60

USDA Agticultural Marketing Service, 198

USDA Agricultural Research Ad. ministration (ARA), 146, 147.
196-198, 220, 293, 297

USDA Bureau of Agricultural Engineering, 8, 9, 195, 196

USDA Bureau of Plant Industry. Soils, and Agricultural Engineering (BPISAE), 185, 195-198, $200,203,213,216,218,223$

USDA Burenu of Public Roads, 36 , 59-61

USDA Division of Farm Buildings and Rural Housing, 97, 215

USDA Division of Farm Electrification, 197, 227

USDA Division of Farm Machinery 197

USDA Division of Mechanical Processing of Farm Products, 197

USDA Division of Rural Engineeting, 26, 58

USDA Extension Service, 111, 138, 195, 363

USDA Farm Electrification Branch,

USDA Information Division, 276

USDA Motion Picture Service, 193, $314,321,322,327,328,374,378$

USDA National Tillage Machinery

Laboratory, 70, 126, 196, 374

USDA Office of Experiment Stations (OES), 59,64

USDA Office of Foreign Agricultural Relations, 144

USDA Office of Personnel, 176

USDA Office of Public Roads and

Rural Engineering. 27, 58

USDA Pesticides Regulation

Division, 243

USDA Rural Electrification Administration, 36.3

USDA Soil Conservation Service (SCS), 92, 118, 119, 122, 134, 148, 195, 197

USDA Soil and Water Conservation Branch, 198

USDA Soil and Water Conserva-

tion Division, 119

USDA Transportation and Facilities Branch, 198

USDA Yearbook "Power to Produce". 276, 277

U.S. Department of Commerce. $85,176,399$

U.S. Department of Health, Education and Welfare (HEW), 317

U.S. Department of Interior, 85 . 176

Soil Erosion Service, 117, 118

U.S. Department of Labor, 176-179

U.S. State of Department, 176

U.S. Department of Transportation (DOT), 397

U.S. Forest Service, 115, 118, 120

U. S. Public Health Service, 245. 247

U.S. Supreme Court, 119

U.S. Senate. 39 !

U.S. Senate Antitrust and Monopoly Subcommittee, 399

U.S. Sente Bill (S.825), 399, 400

United States Steel Cotp. . 218, 342, 394 
U.S. Weather Bureau, 121

UP FRONT (AGRICULTURAL ENGINEERING), 395

Upstream Engineering Conference, 120

Utben, L. J., 288

Utah Agricultural College, 49, 174

Valdez, Justin, 12

Vanden Berg, Glen, 361

Van Gerpen, Harjan W., 292, 298, 375

Van Meerten, E. J., 12

van Schilfgarde, Jan, 280, 354

Vaugh, Mason, 177

Vaughan, L. M., 215

Ventilation (see ASAE Committees)

University of Vermont, 306

Vietnam, 346, 347

Vincent Bendix Medal of ASEE, 206

Virginia, 90, 99, 155, 159

Virginia Agricultural Experiment Station, 248

Virginia Agricultural and Mechanical Colkge and Polytechnic Institute, 52

Virginia Polytechnic Institute, 55, 251, 401

Virtue, B. T., 173, 258, 259, 268, 269

Voice of America, 242

Volpe, John A.. 39

$\mathbf{W}$

Waggoner, J. E., 12

Wakeiand, H. L.. 355

Walker, J. N., 355

Walket, Harty B., 41, 43, 44, 53, $55,65,82,92,97,140,146,228$. 230, 239, 363

Wallace's Farmer, 93

Waliace, Henry A., 110, 120, 134

Watlece, Henry C., 36, 59

Wallace, L. W., 43

Wallis Tractor Company, 22

Walters, Frank C., 208, 285

Wandmacher, Cornelius, 408

Warburton, C. W., 129

Ward, G. M., 386

War, 30

War Activities Committee (WAC) 142, 144, 147

War Committee on Conventions (WCC), 150

War Manpower Commission (WMC), 141, 143, 144

War Production Bourd (WPB) $140,141,142,145$

Wartime allocation of farm machines (see ASAE Committees)

War veterans, 30

Washington, DC, 85, 116, 120, 153

Washington News Letter, 136

Washington State University, 174. 342, 350, 381

Waste in agriculture, 44
Waste disposal (see ASAE

Committees)

Waterman, W., 166

Water supply, 56,120

Weaver, D. S., 111

Weed Society of America, 243

Weeks, D. M., 24

Weeks, D. P., 37, 38

Weir, Walter W., 40

Welch, E. G., 12

Wessman, John, 243

Western Advertising Agency, 200, 268

Wheel equipment (sec ASAE Committees)

Wheelock, L. K., 302

White, Eari, 3, 8, 34, 38, 41, 44, $59,63,72,96,105,108,110$ 112. 131,239

White, Frank M., 14, 15, 27

White House, 85, 383

White, S. W., 340

Wickard, Claude, 142, 146

Wiggins, E. P., 18

Wiggins, E. R., 40

Wilborn, E. D., 394

Wileman, R. H., 124

Wiley Agricultural Engineering

Series textbooks, 265

Williams, Dougles W., 360

Winnipeg contests, 20, 21

Winnipeg Motor Contest, 200

Wirt, Fred A.. 17, 44.46, 72, 78, $79,82,85,87,138,185$

Wisconsin, 112, 124, 309

Wisconsin Power and Light

Company, 112

Wisconsin, University of, 16, 34,

$57,65,81,218,295,306,309$

Witt, W. E., 340

Wittmuss, Howard, 372

Wittwer, S. H., 387, 388

Witzel, S. A., 218

Woife, J. W., 308

Wood cellulose, 163

Wood, Ivan D., 116, 118, 173, 186 . 192, 194

Woods, A. F. (Dr.), 85

Wooley, J. C., 56, 117, 118

Wooster, OH, 27]

Works Progress Administration (WPA), 92

World War I, 84, 95, 106, 361

World War II, 92, 346, 361

World Engineering Congress, 97

World's Fair, 20, 23

Wormley, D. S., 12

Worthington, Wayne H., 182, 188 , 189, 255, 268, 269

Wyant Bill, The, 85

Wynn, John G., 3, 10

Wyoming, 105, 117

\section{$\mathbf{Y}$}

Yearbook of Agriculture " Power to Produce", 276, 277

Yeck, R. G., 216, 319, 339
Yerkes, Arnold P., 61, 96, 130 156, 162

Young. Roy E., 374

Yung, F. D., 213

2

Zachariah, G. L., 354

Zanesville, OH, 116

Zeglen, E. J., 397

Zelle Tractor Company, 77

Zelle, William C., 77, 79

Zimmerman, Oliver B., 45, 49,64,

$81-85,87,133$

Zich. J. H., 286

Zink, Carlton L., 288, 370, 372

Zink, Frank J., 124, 127, 140, 142. 173, 196, 197

Zings, Austin, 277

Zoerb, G. C., 373

Zollar, Charles O., 340

Zwerman, P. J., 297 


